\title{
A MONOGRAPH OF THE FERN GENUS PYRROSIA
}

\section{(Polypodiaceae)}

BY

\section{P. HOVENKAMP \\ Illustrations by $\mathrm{J}$. Wessendorp}

with a contribution by W. J. Ravensberg and E. Hennipman

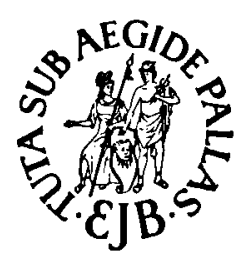

E. J. BRILL / LEIDEN UNIVERSITY PRESS

LEIDEN 1986 
This book can be cited as:

Hovenkamp, P. 1986. A monograph of the fern genus Pyrrosia (Polypodiaceae). E. J. Brill/Leiden University Press (Leiden Botanical Series, vol. 9), 280 pp., 37 figs, 6 plates.

Ravensberg, W. J. and E. Hennipman. 1986. The Pyrrosia species formerly referred to Drymoglossum and Saxiglossum (Filicales, Polypodiaceae). E. J. Brill/Leiden University Press (Leiden Botanical Series, vol. 9), 30 pp., 4 figs.

In the Leiden Botanical Series will be published papers of a monographic nature from the entire field of botany (including its history, bibliography, and biography) which by their length ( 100 printed pages or more) are unsuitable for publication in journals. Information can be obtained from the editors, Rijksherbarium, Schelpenkade 6, Leiden, The Netherlands.

World distributor for publications of the Universitaire Pers, Leiden: E. J. Brill, Postbus 9000, 2300 PA Leiden, The Netherlands.

Copyright 1986 by E. J. Brill, Leiden, The Netherlands

All rights reserved. No part of this book may be reproduced or translated in any form, by print, photoprint, microfilm, microfiche or any other means without written permission from the publisher

PRINTED IN THE NETHERLANDS BY E. J. BRILL 


\section{CONTENTS}

Acknowledgements................................................ XIII

\section{GENERAL PART}

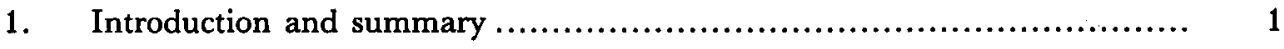

2. Material and methods

Methods and techniques

indument

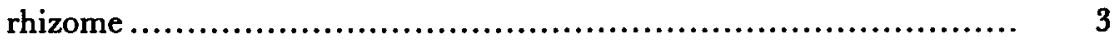

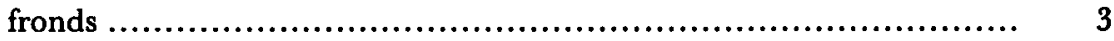

anatomy

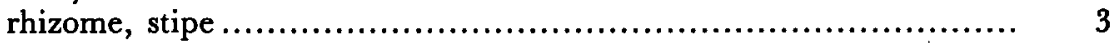

rhizome scales ..................................................... $\quad 3$

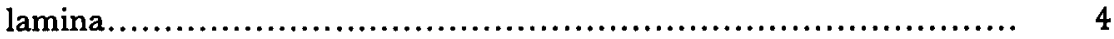

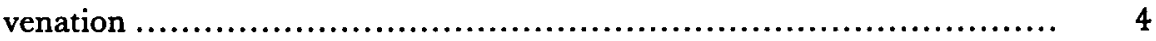

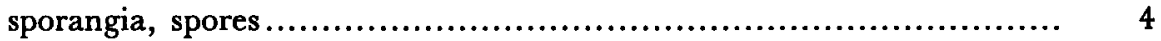

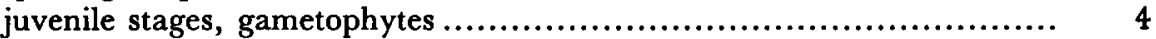

ontogeny................................................................ 5

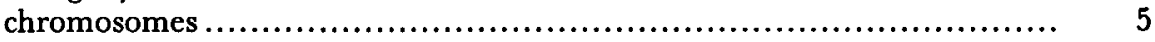

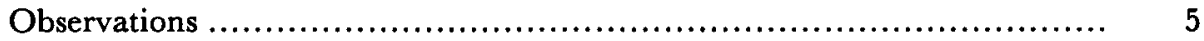

3. History and exploration

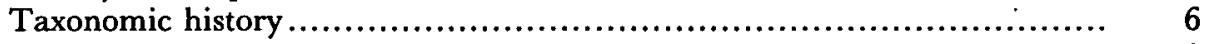

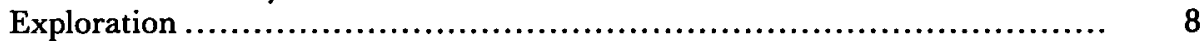

4. Subdivision of the genus ............................................ 11

5. Morphology

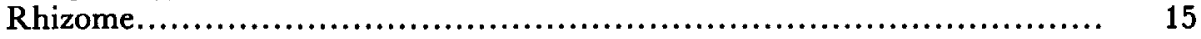

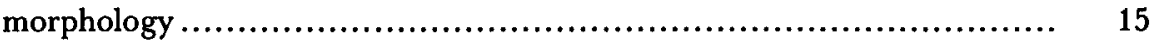

anatomy
vascular structure $\ldots \ldots \ldots \ldots \ldots \ldots \ldots \ldots \ldots \ldots \ldots \ldots \ldots \ldots \ldots \ldots \ldots \ldots \ldots \ldots . \ldots \ldots \ldots \ldots$

non-vascular structure............................................... 19

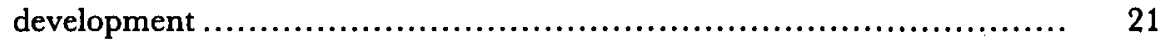

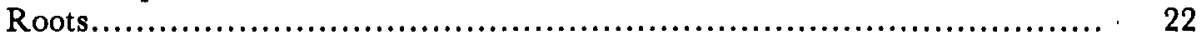

Rhizome scales ..................................................... 23

morphology

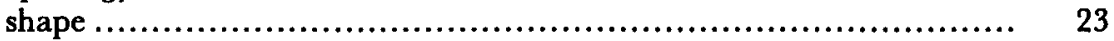

marginal indument.................................................. 24

superficial indument ................................................ 25

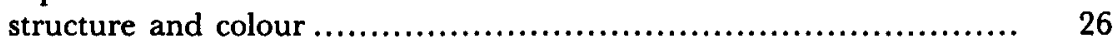

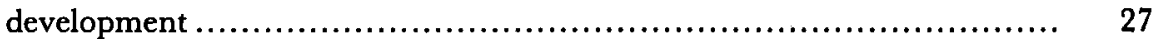




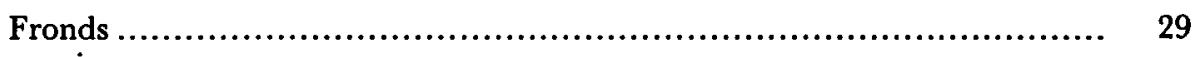

stipe

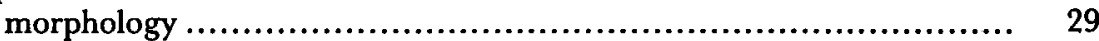

colour .................................................................. 39

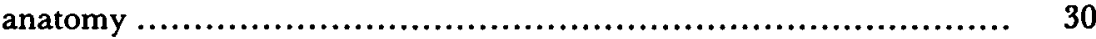

lamina

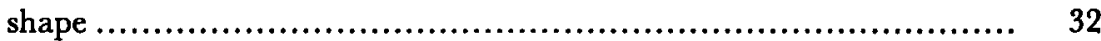

dimorphism ........................................................... 32

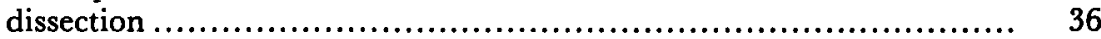

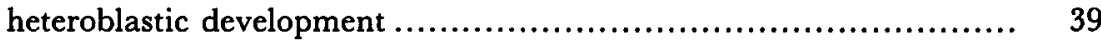

Lamina indument ........................................................... 40

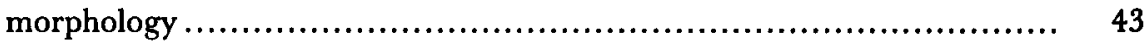

monomorphic.......................................................... 44

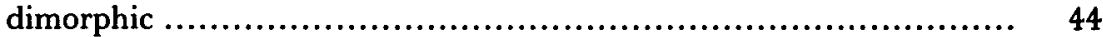

development

ontogeny............................................................... $\quad 45$

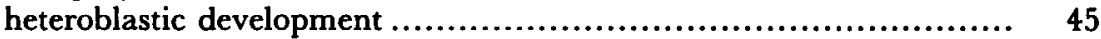

filaments............................................................... 46

Venation ..................................................................... 48

venation pattern

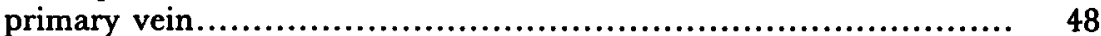

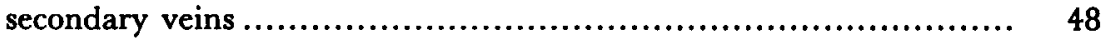

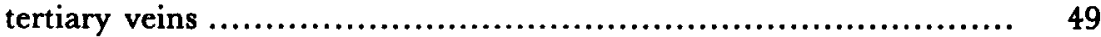

included veins .......................................................... 49

costal areoles ........................................................... 49

"costular" areoles..................................................... 49

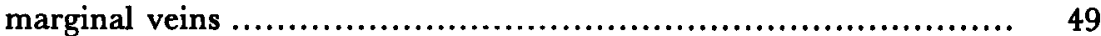

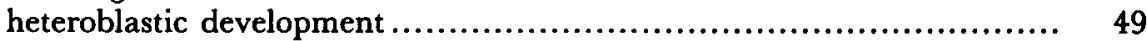

hydathodes .................................................................. 53

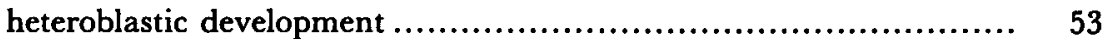

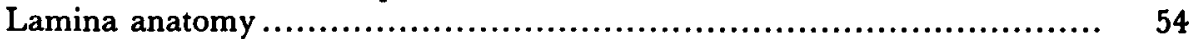

upper epidermis ......................................................... 54

mesophyll .................................................................... 54

lower epidermis.......................................................... 56

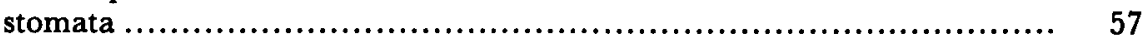

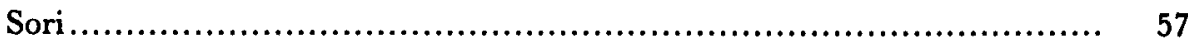

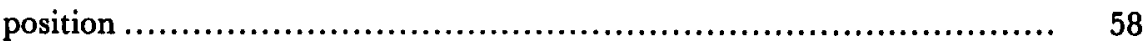

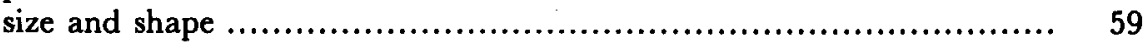

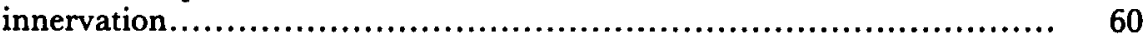

paraphyses ................................................................. 60

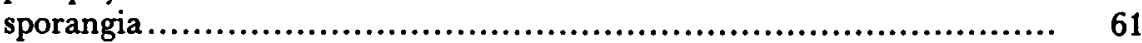

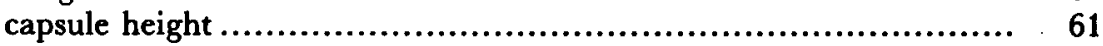

stalk length............................................................ 62

modifications .......................................................... $\quad 62$

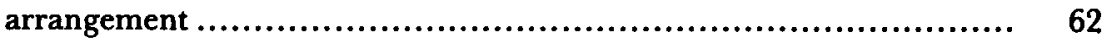

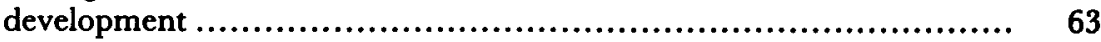

spore output ........................................................... 63

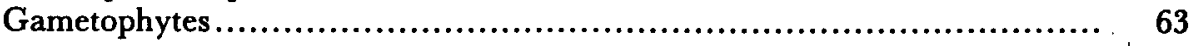


6. Karyology and hybridization

Karyology

results

discussion

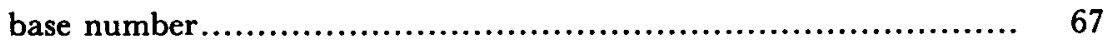

polyploidy ...................................................... 67

Hybridization

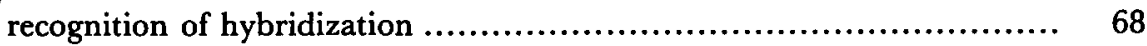

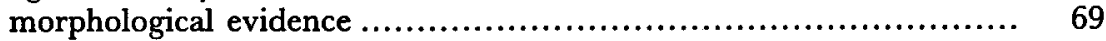

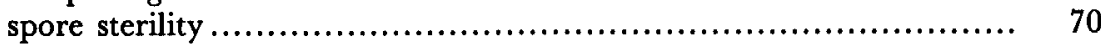

possible cases of hybridization $\ldots \ldots \ldots \ldots \ldots \ldots \ldots \ldots \ldots \ldots \ldots \ldots \ldots \ldots \ldots \ldots, \quad 73$

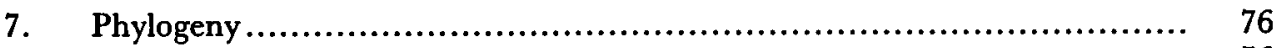

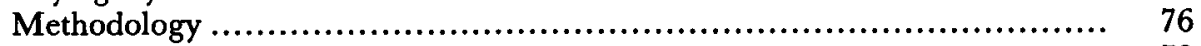

Construction of cladogram............................................... $\quad 79$

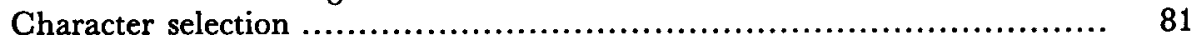

fragmentary data ................................................... 81

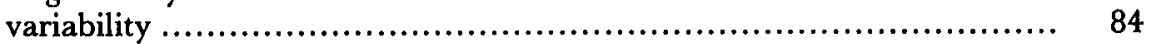

unknown transformations ........................................... 84

Proposed transformations
rhizome morphology.................................................... $\quad 85$

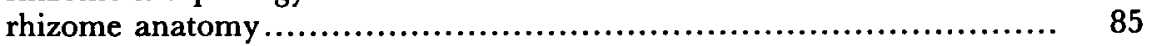

rhizome scales....................................................... 86

frond characters, stipe ............................................. 88

frond characters, lamina............................................ 88

lamina indument ................................................... 89

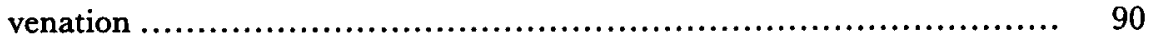

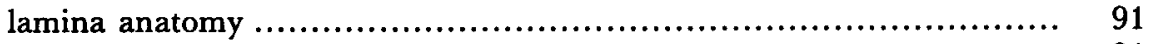

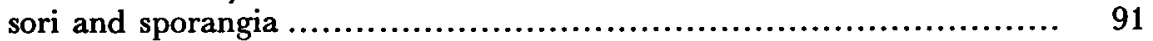

Are the groups monophyletic? ......................................... 93

Relationships within the genus ......................................... 94

Is Pyrrosia monophyletic? ............................................. 99

Relationships with other Polypodiaceae ................................ 100

Postscript........................................................... 102

8. Geography

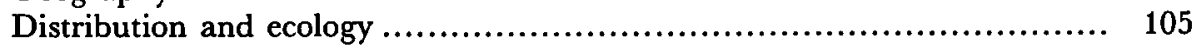

Historical geography

methodology .......................................................... 114

geographical analysis ................................................ 116

implications ...................................................... 122

9. References ......................................................... 123 


\section{TAXONOMIC PART}

1. Presentation of data

\begin{tabular}{|c|c|}
\hline 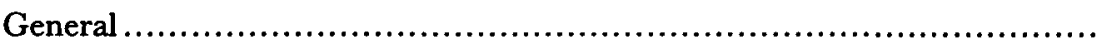 & 135 \\
\hline 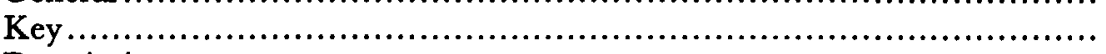 & 135 \\
\hline 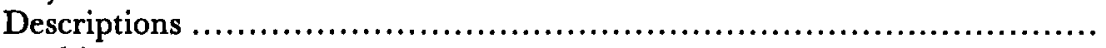 & 136 \\
\hline 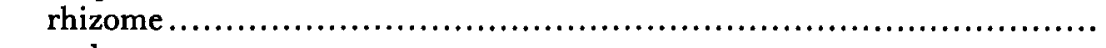 & 136 \\
\hline scales ..... & 136 \\
\hline stipe ... & 137 \\
\hline lamina & 137 \\
\hline sori & 137 \\
\hline dossary & 137 \\
\hline
\end{tabular}

2. Pyrrosia Mirbel........................................................ 139

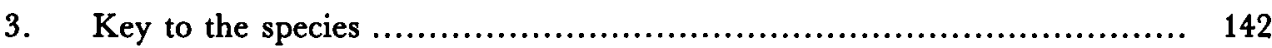

4. Descriptions

P. abbreviata ....................................................... 149

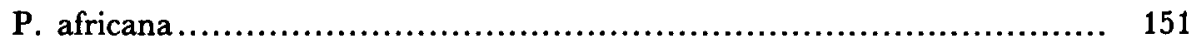

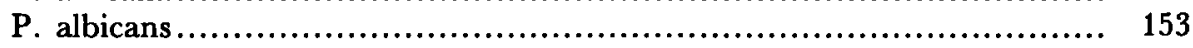

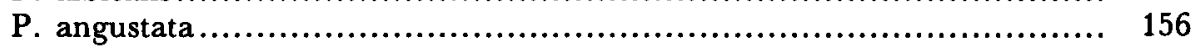

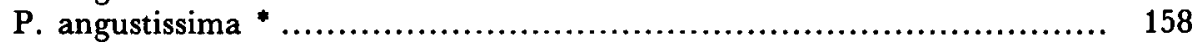

P. assimilis ................................................................. 158

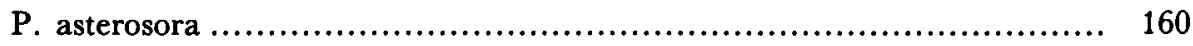

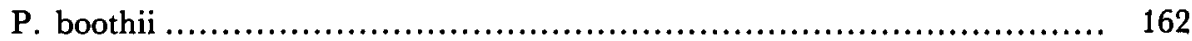

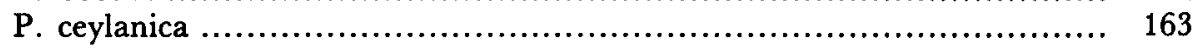

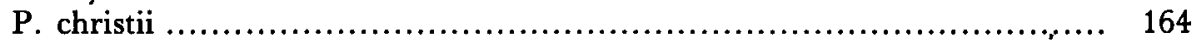

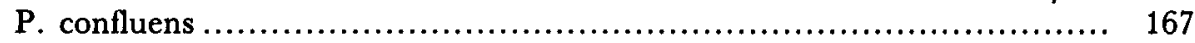

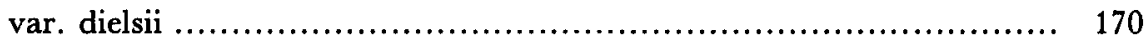

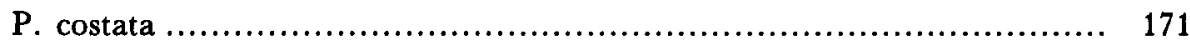

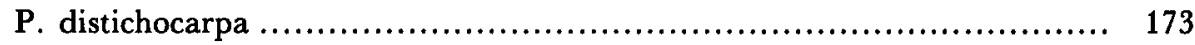

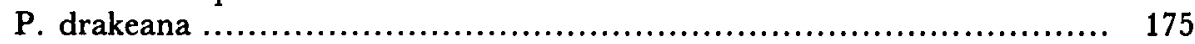

P. eleagnifolia ............................................................ 177

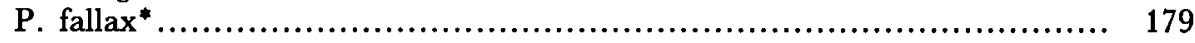

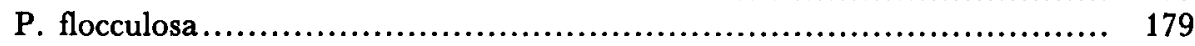

P. foveolata............................................................. 181

var. lauterbachii ..................................................... 183

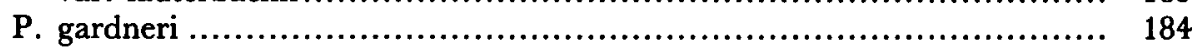

P. hastata .............................................................. 186

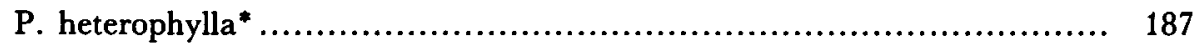

P. kinabaluensis .......................................................... 187

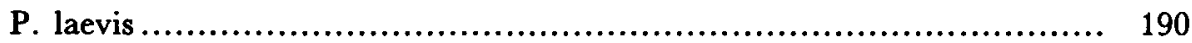

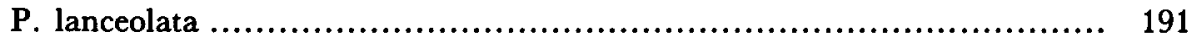

P. linearifolia................................................................ 201

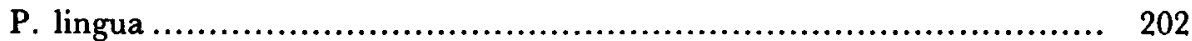

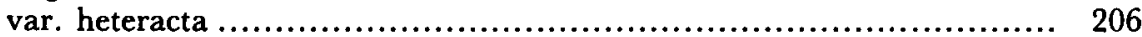

P. longifolia ............................................................... 208

P. mannii $\ldots \ldots \ldots \ldots \ldots \ldots \ldots \ldots \ldots \ldots \ldots \ldots \ldots \ldots \ldots \ldots \ldots \ldots \ldots \ldots \ldots \ldots \ldots \ldots \ldots \ldots \ldots \ldots \ldots, \quad 212$

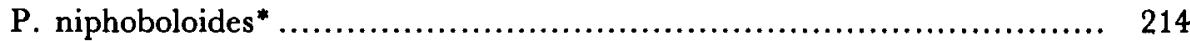




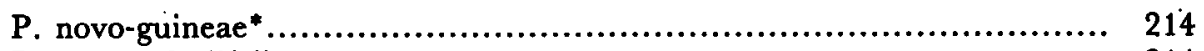

P. nummulariifolia........................................................ 214

P. pannosa................................................................ $\quad 217$

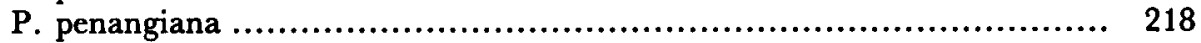

P. petiolosa .............................................................. $\quad 220$

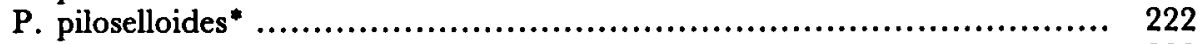

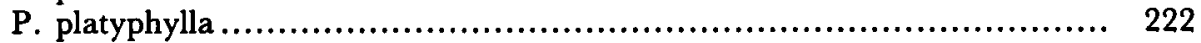

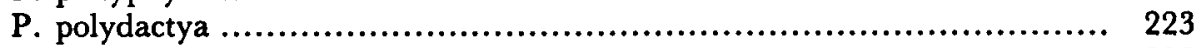

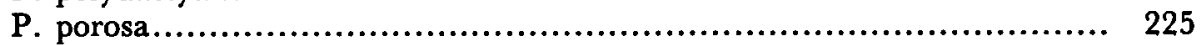

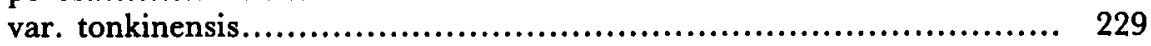

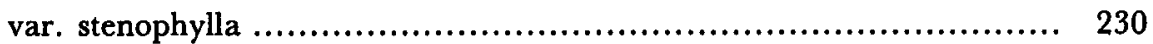

P. princeps .............................................................. 231

P. rasamalae ............................................................. 233

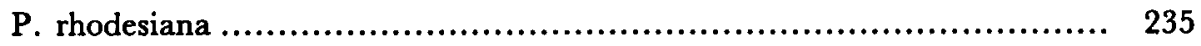

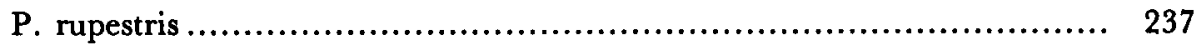

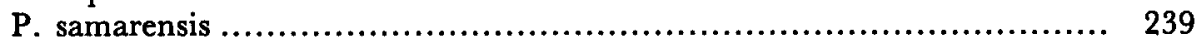

P. schimperiana ......................................................... 241

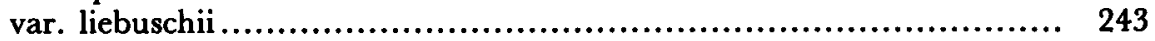

P. serpens............................................................... 244

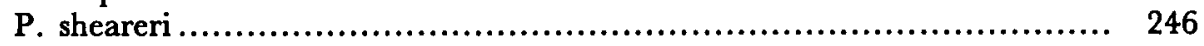

P. sphaerosticha .......................................................... $\quad 249$

P. splendens..................................................................... 251

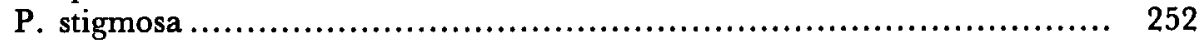

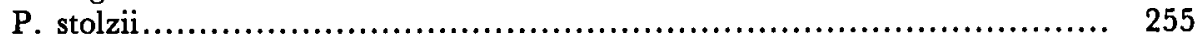

P. subfurfuracea ........................................................ 256

The species marked " are treated by Ravensberg and Hennipman (pp. 281-310)

5. Doubtful and excluded names or species

Species dubiae ........................................................... 258

Nomina dubia ........................................................... 260

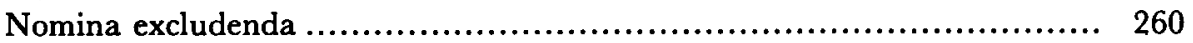




\section{ACKNOWLEDGMENTS}

My thanks are due to Mr. P. Baas (Leiden) and Mr. T. G. Walker (Newcastle) for reading and commenting upon parts of the manuscript. I am indebted to the directors of the institutes from which specimens were received on loan. I also want to thank all those who provided living specimens or spores from various localities: Mr. D. Darnaedi, Mr. G. J. de Joncheere and Dr. E. Hennipman during the 1979 Rijksherbarium-LIPI expedition to Celebes; Mr. N. A. P. Franken \& M. C. Roos from Sumatra, Dr. R. Geesink from Borneo, Prof. Dr. E. Hennipman from Atherton, Prof. Dr. K. U. Kramer from Taiwan, and Dr. J. F. Veldkamp from Sri Lanka. For the cultivation of these and many other plants I am indebted to the staff of the Leiden Botanical Garden.

A visit to the herbarium in Paris (P) was made possible by the support from CNRS (Centre National de la Recherche Scientifique) and ZWO (Nederlandse organisatie voor zuiver-wetenschappelijk onderzoek).

The manuscript was prepared using a DEC PDP-11 mini-computer. I am grateful to the dept. for Information Processing of the subfaculty Biology, Leiden University, for putting these facilities at my disposal and for their permanent assistance. 


\section{GENERAL PART}

\section{INTRODUCTION AND SUMMARY}

This monograph deals with the systematics and phylogeny of the genus Pyrrosia (Polypodiaceae). It is one of the results of the Polypodiaceae-project that is being carried out under the supervision of Prof. Dr. Hennipman (State University, Utrecht). With this treatment of Pyrrosia, the group of the Platycerioid ferns (sometimes regarded as a subfamily) will be completed. The total number of genera in this group is reduced to two: Platycerium and Pyrrosia. Other publications dealing with this group are Hennipman \& Roos (1982), dealing with Platycerium; and Ravensberg \& Hennipman (1986), dealing with the former genera Drymoglossum and Saxiglossum, now in Pyrrosia.

Together with Hennipman \& Ravensberg's account this forms the first complete account of Pyrrosia. The genus has been subject to revision on a world-wide scale only once before (Giesenhagen, 1901). In that work, however, several species were omitted and the genera Drymoglossum and Saxiglossum were not included. After Giesenhagen's monograph, Pyrrosia has been the subject of several regional studies, most notably Ching's (1935), which deals with the species from the mainland of Asia including Japan and Taiwan. The African species were revised by Schelpe (1952), the Australian ones by Tindale (1961). Nayar \& Chandra's (1965) account of the species from India emphasizes the morphology rather than the taxonomy of the species treated.

It was found that in the material at hand the criteria for the delimitation and discrimination of species that were used by Giesenhagen and Ching could not always be applied. In Giesenhagen's work, undue stress is placed on minute variations in lamina anatomy; in Ching's work a similar, and in my opinion unjustified, emphasis is put on details of the indument. Therefore, a morphological analysis was carried out, resulting in the recognition as important taxonomic characters of e.g. the distribution of sclerenchyma in the rhizome and the sculpture of the perispore. The range of the variation in Pyrrosia for both these characters appears to be unique in the Polypodiaceae. Details of the sculpture of the perispore are treated separately by Van Uffelen \& Hennipman (1985). Other characters that were found to be important are the morphology of the rhizome, of the rhizome scales, as well as the presence or absence of specialized paraphyses. 
Using these and other characters 51 species were recognized, two of which were new (Hovenkamp, 1984) and 6 other species were reduced to the level of variety. Evidence was sought for the occurrence of hybrids among in the genus, but no indications could be found that hybridization plays an important role in the development of new species in this genus. The available evidence from chromosomes indicated, however, that in several species polyploid complexes occur.

As a result of the morphological analysis hypotheses could be formulated about the probable course of evolution of several characters. With the aid of these hypotheses, and by using cladistic techniques, an explicit idea could be formulated regarding the phylogeny within the genus. This, in its turn, led to an elaboration of ideas concerning the historical geography of the genus. As a result, a hypothesis is formulated according to which the origin of the genus must be placed in what is now Africa, some time in the Jurassic. The present distributon of the genus was reached in two ways: one via 'rafting' on the Indian subcontinent, one via 'rafting' on Australia. 


\section{MATERIAL AND METHODS}

\section{Material}

This study is based on the material in the following herbaria (abbreviations follow the Index Herbariorum): A, B, BM, BO, BR, GH, K, L, M, P, SING, U, US, WAG, $Z$. Incidentally, specimens were also examined from the following herbaria: AAH, BISH, E, LWG, NA, W, UG.

In addition, living plants were studied from appr. 20 species cultivated in the Leiden Botanical Garden.

\section{Methods and techniques}

\section{Indument}

Rhizome. The scales of the rhizome were wetted with a strong solution of photographic detergent (KODAK Photo-Flo 200 : water - appr. 1:3), then lifted from the rhizome. In order to obtain whole scales it is sometimes necessary to dissect carefully as the scales break off easily above the point of insertion. The scales were then rinsed in water and semi-permanent preparations were made by embedding them in glycerin-jelly.

Fronds. The hairs on the stipe and lamina were treated in a similar way, but careful dissection is not necessary here.

\section{Anatomy}

Rhizome, stipe. For anatomical study pieces of rhizome or stipe were boiled in water, usually after adding a few drops of detergent (see above), for a few minutes, or until they sank when transferred to cold water. They were sectioned at $\pm 30 \mu \mathrm{m}$ with a Reichert slide microtome using a Gilette double-edged razorblade. The sections were embedded in glycerin jelly. No staining or other treatment of the sections was found to be necessary to study the distribution of the vascular strands and/or the sclerenchyma.

Rhizome scales. Cross-sections through the rhizome scales were often found to be included in cross-sections of the rhizome. Thinner sections were prepared 
by boiling the scales in water for several minutes and then sectioning the softened scales at 5-10 $\mu \mathrm{m}$ using a slide microtome with a double-edged razor blade and elder-pith. Sections of scales obtained in this way were found to be superior to sections obtained after embedding the scales following routine procedures.

Lamina. Cross-sections of the lamina were prepared in a similar way as those of the rhizome (see above) but were sectioned at 20-30 $\mu \mathrm{m}$. The sections were bleached in a commercial solution of hypochlorite, stained for a few minutes in Astra-blue, and embedded in glycerin jelly. To obtain epidermis peels, as a rule small pieces of lamina were bleached following a procedure slightly modified from that used for studying the venation (see below). They were simply boiled in a 5 $\%$ solution of $\mathrm{KOH}$, then bleached in hypochlorite. Either the lamina in its entire thickness was then embedded in glycerin-jelly, or the mesophyll was scraped away as much as possible. Staining with Astra-blue was sometimes applied. Due to the diversity in anatomical structure of the lamina the results thus obtained were highly variable in quality. More conventional methods of obtaining epidermis preparations by maceration were found to yield equally unsatisfactory results and are more laborious.

\section{Venation}

For study of the venation sufficiently large pieces of lamina were cleared following the procedure developed by O'Brien \& Von Teichmann (1974). This involves autoclaving the pieces in a $5 \%$ solution of $\mathrm{KOH}$ and then bleaching them in commercial hypochlorite. For Pyrrosia this was found to yield better results than bleaching with chloro-lactophenol according to Hennipman (1977). Unfortunately, after the treatment the tissue had become so brittle that remounting the pieces on the herbarium sheets was impracticable. The venation patterns were photographed following the method developed by Hennipman (1977).

\section{Sporangia, spores}

Sporangia and spores were treated in a similar way as the indument of the lamina.

\section{Juvenile stages, gametophytes}

To study the stages of the heteroblastic development, spores were sown on an Agar medium. In various stages of development gametophytes or juvenile sporophytes were fixed in FAPA. This was found to clear the tissue sufficiently in the course of a few days, so that details of venation, epidermis and indument could be observed without further treatment. For observation, specimens were transferred to water or observed in FAPA. 


\section{Ontogeny}

The development of hairs and scales was studied in a few species. Actively growing shoot- or frond-apices were macerated and stained in acetocarmine and squash-preparations were made in $45 \%$ acetic acid. No attempt was made to convert these preparations into permanent ones.

\section{Chromosomes}

For cytological study actively growing root-tips were fixed in Carnoy's fluid (alcohol:chloroform:acetic acid - 6:3:1) for one hour to several days at room temperature and stained and macerated by boiling for several minutes in acetocarmine. Squashes were made and photographed. No attempt towards more permanent preparations was made. Pretreatment with alpha-bromo-naphtalene was not found to produce visible results.

\section{Observations}

Light-microscopical observations were made with a Leitz Laborlux microscope with drawing-arm; for photography a Leitz Ortholux microscope was used.

For scanning-electron microscopy, rhizome scales were dissected as indicated above, air-dried, and then mounted on aluminium stubs using double-stick tape or silver-containing conducting glue. For study of the indument, small pieces of lamina were taken from herbarium-specimens and mounted (lower side up) as indicated above. In some cases fresh pieces of lamina were dehydrated in a graded acetone series and critical-point dried using $\mathrm{CO} 2$. All preparations were coated with gold (using a Polaron E 5100 series II sputter-coater) and observed with a JEOL JSM-35 scanning electron microscope. 


\title{
3. HISTORY AND EXPLORATION
}

\author{
Taxonomic history
}

The genus Pyrrosia was established by Mirbel in 1803 , but its history goes back at least one more century. A plant that is almost certainly a Pyrrosia (most likely P. heterophylla) was depicted by Rheede (1703, Hortus Malabaricus $12 \mathrm{Pl}$. 29).

Linnaeus (1753) placed two species in the genus Acrostichum that are now included in Pyrrosia. Under the second of these ( $A$. heterophyllum) he cited Rheede's (l. c.) plate 29; under the first he cited Rheede's plate no 33 (an error for 74). The plant depicted on this plate, however, is sterile and not identifiable as a Pyrrosia. In the second edition of the Species Plantarum Linnaeus (1763) placed a third species now assigned to Pyrrosia in the genus Pteris (Pteris piloselloides).

Subsequently, species now included in Pyrrosia were described in the Linnean genera Acrostichum (A. longifolium Burmann, 1768; $A$. hastatum Houttuyn, 1783; $A$. lingua Thunberg, 1784; $A$. bicolor Cavanilles, 1799) and Polypodium ( $P$. glabrum Burmann, 1768; $P$. acrostichoides and $P$. serpens, Forster, 1786; $P$. stigmosum Swartz, 1801).

In 1803 Mirbel (Hist. Nat. Vég. 5) established the genus Pyrrosia with $P$. chinensis (= Pyrrosia stigmosa) as the only species. In the same work he established the genus Candollea with 4 species, three of which are now included in Pyrrosia. C. heterophylla is probably a mixture: Mirbel cited Acrostichum heterophyllum L. ( = Pyrrosia heterophylla (L.) Price) but also included plants from Java, where $P$. heterophylla does not occur, and the description that he gave of $C$. heterophylla cannot be matched with any species now known from either India, Africa, or Java. The next two species, Candollea longifolia and the 'candolline lanceolée' (Mirbel did not make the combination $C$. lanceolata) probably represent Pyrrosia longifolia and $P$. lanceolata, respectively; the fourth species included in Candollea ( $C$. polypodioides) is not a Pyrrosia.

Swartz (1806), probably not knowing of Mirbels genera, transferred most of the Pyrrosia species then known to Polypodium, together with many other species now regarded as belonging to various genera. Desvaux (1811) accepted the genera established by Mirbel (1803) but changed Candollea to Cyclophorus, as in the meantime the name Candollea had been used by Labillardière (1806). At the same time he excluded Candollea polypodioides from Cyclophorus, transferring it to 
Polypodium as $P$. incanum. Later, Desvaux (1827) established the genus Pteropsis for a heterogeneous assembly of species, some of which are now included in Pyrrosia (see Pichi-Sermolli, 1953, for an extensive account of the history of Pteropsis).

Kaulfuss (1824), while accepting Cyclophorus in Desvaux' circumscription, renamed it Niphobolus, to avoid confusion with a genus of shells named Cyclophorus. Throughout the 19th century, most of the species of Pyrrosia were referred to Niphobolus by authors who considered the genus distinct from Polypodium (Blume, 1828, 1829; Presl, 1836; J. Smith, 1842; Hooker, 1842; Fée, 1853-4; J. Smith, 1875; Beddome, 1863, 1892; Giesenhagen, 1901); whereas the name Cyclophorus was largely neglected until it was brought up again by Underwood (1903). Other authors, among whom Mettenius (1856) and Hooker (1863) were the most influential, followed Swartz (1806) in considering Niphobolus as part of Polypodium.

Diels' account in Engler \& Prantl (1899), together with Giesenhagen's monograph (1901), were influential in restoring Niphobolus to almost universal use as a distinct genus. In 1906 Christensen (Index Filicum) followed Underwood (1903) and reinstated the older name Cyclophorus, making all necessary and some unnecessary new combinations. Neither Giesenhagen nor Christensen altered the circumscription of the genus, in which they have been followed by most modern authors.

In 1931 Farwell revived the by then completely forgotten name Pyrrosia, making several new combinations. A number of others were made by Ching (1935) in his revision of the species from China.

Several authors have attempted to divide the genus.

Presl recognized two groups in 1836; in 1851 he distinguished 8 genera. In this he has not been followed by other authors. Apart from that, in 1836 he transferred one species to the new genus Drymoglossum, where it was placed together with a species that is not a Pyrrosia. Subsequent authors expanded the concept of Drymoglossum into a heterogeneous assembly of species, many of which were removed to other genera by Christensen (1929). Drymoglossum in Christensen's ( $l$. c.) narrower circumscription has been accepted by many modern authors (Backer \& Posthumus, 1939; Copeland, 1947; Holttum, 1954; Nayar, 1957; Sledge, 1960). All species, however, were transferred to Pyrrosia by Price (1974), and subsequent investigations tend to confirm this view (Ravensberg \& Hennipman, 1986).

John Smith (1857) removed Pyrrosia angustata to the monotypic genus Niphopsis. In this he was not followed, but the name Niphopsis was taken up by Alderwerelt (1909) and Shing (1983) for a subgenus and a section within Pyrrosia, respectively, though with circumscriptions that differed widely from each other.

Nakai (1928) removed Pyrrosia linearifolia to the monotypic genus Neoniphopsis. This was also rejected by other authors. 
In 1933 Ching established the genus Saxiglossum to accomodate the aberrant Pyrrosia angustissima. This genus has been accepted in some recent floras (Nakaike, 1975; DeVol, 1975) and other taxonomic works (Pichi-Sermolli, 1977b).

Apart from the genera mentioned so far, species of Pyrrosia have been placed in the genera Craspedaria (Link, 1841); Antrophyum (Kunze, 1848); Drynaria (Brackenridge, 1854) and Taenitis (Moore, 1857; Luerssen, 1882).

In the present work, Pyrrosia is considered as including both Drymoglossum (in the circumscription of Christensen, 1929) and Saxiglossum, but the species formerly assigned to these two genera are treated in detail by Ravensberg \& Hennipman (1986).

\section{Exploration}

The total number of taxa accepted in the present work is 57. A historical review of the number of described taxa is given in Table 1, compared with the number of taxa accepted here.

TABLE 1

\begin{tabular}{lcc} 
period & $\begin{array}{c}\text { no of taxa } \\
\text { described }\end{array}$ & $\begin{array}{c}\text { no of taxa } \\
\text { now accepted }\end{array}$ \\
\hline before 1800 & 10 & 7 \\
\hline $1800-1824$ & 15 & 4 \\
\hline $1825-1849$ & 29 & 8 \\
\hline $1850-1874$ & 24 & 13 \\
\hline $1875-1899$ & 17 & 10 \\
\hline $1900-1924$ & 59 & 10 \\
\hline $1925-1949$ & 21 & 3 \\
\hline after 1950 & 10 & 2 \\
\hline
\end{tabular}

As shown by this table the highest number of taxa now accepted (second column) has been described during the 19th century, and the number dwindles rapidly in the 20th century. The effect is more pronounced if it is taken into account that relatively many species are only described a considerable time after the first specimens have been collected. These species have gone unnoticed for some time and are recognized only when a critical revision is made of a large number of species. Thus, Giesenhagen (1901) described three new species from material that 
had been known for some time (Niphobolus christii, N. ceylanicus and N. mannii); the present revision has resulted in the description of two new species, neither of which is based only on recently collected material.

A comparison with the total number of taxa described in each period (Table 1 , first column) shows that the diminishing number of accepted taxa is not the effect of diminishing efforts on the part of descriptive taxonomists. Almost the reverse seems to be the case: increasing numbers of taxa described do only occasionally result in increasing numbers of accepted taxa. Particularly in the 20th century the "law of diminishing returns" seems to be at work. If this general concept applies, it can be considered an indication that the total number of Pyrrosia species awaiting discovery and description is rapidly decreasing in relation to the number of taxa already described. Expectations that each large collection will yield at least a few new species seem to be unfounded, at least for Pyrrosia.

A closer examination of the history of the exploration of the genus tends to confirm this.

The earliest species known were all collected in the vicinity of trading posts in Ceylon (Herman), Japan (Thunberg), or Java (Thunberg, Burmann); or else they were found during the early exploration of the Pacific (Forster). Exploration of these relatively easily accessible places was sufficiently intense, so that when Blume enumerated the ferns of Java (1828), he included almost all species now known from that island (Hennipman, 1979). Many of the species of Pyrrosia occurring on the Malesian islands were collected relatively early during the exploration by, e.g., Cuming, Zollinger, and Korthals; and the intensive exploration during the 20th century (e.g., by Clemens, collectors from Buitenzorg, the Philippine Bureau of Science) did not result in the discovery of a proportionally large number of new species.

In New Guinea, all species now known had been collected already at least once before the exploration by the Archbold expeditions, and recent large collections by Croft and others in the LAE series have not yielded any new species. This is in striking contrast to the situation in some other genera, of which Grammitis (recently revised for New Guinea by Parris, 1983) may be taken as an example. In Parris' revision, out of a total number of 64 accepted species, some 30 are based on material collected by Brass or other collectors active since around 1925 . This is a large proportion compared to Pyrrosia, and the difference cannot only be due to a different species concept that may have been used in the present work.

In other areas a similar situation prevails.

In India and Ceylon, for instance, by far the largest number of species was already collected by Wallich, Griffith, Thomson, Hooker, Mann, and other collectors active in the 19th century.

In China the species were discovered mainly by the early explorers (Henry, David, Shearer), intensive exploration in the 20th century by Forrest, Wilson, 
Rock and Chinese collectors (C.W. Wang, W.T. Tsang and others) has not resulted in the discovery of new species accepted here.

Therefore, the conclusion must be that further exploration is not likely to lead to the discovery of a considerable number of new species. Further efforts in the field therefore might more profitably be directed towards more detailed investigation of some of the problems in the genus, e.g., the description and elucidation of possible mechanisms that may be concerned in maintaining or not maintaining the distinct entities found in $P$. lanceolata and $P$. porosa.

The reason for the relatively complete knowledge of the genus may be in the ecology of the species. Most species are either common species, widely distributed throughout the tropical lowlands, extending frequently into gardens, plantations, etc.; or else they are species with a distinct preference for the middle elevations in hilly areas, areas that have been favoured as summer resorts in many cases on account of the pleasurable climate in contrast to the hot, humid lowlands. None of the species is confined to the less accessible higher montane areas, and there are hardly any species that are both rare and restricted to the lowlands. 


\section{SUBDIVISION OF THE GENUS}

In this work I do not present a formal subdivision of the genus. Although several groups of species can be recognized that have distinctive characters, recognition of these groups would leave us with a considerable number of "species incertae seals" species tirai iack aii ciraracierisilcs necessary io assign tinem io any of the groups; or species that have combinations of characters that would make assignment difficult, arbitrary, or even impossible. Such a subdivision of the genus in my opinion is better not formalized.

Another reason is that, although several of the easily recognizable groups are so distinctive that they can safely be assumed to be monophyletic, at least some groups would be paraphyletic or polyphyletic. Recognition of paraphyletic groups is not desirable. It is defended sometimes with the argument that 'natural' groups do not necessarily have a synapomorphy (Geesink, 1984). The existence of a monophyletic group, however, is evidenced only by an autapomorphy, and in the absence of other knowledge about the course of the evolution, autapomorphies are the only arguments for the monophyletic character of a group. In some cases it may be necessary to recognize para- or polyphyletic groups to comply with the basic requirements of taxonomic practice. Complete avoidance of para- or polyphyletic groups would make classifications unwieldy with a very high number of groups of different ranks. The formal recognition of series, subgenera, etc., in the case of Pyrrosia, where a relatively small genus is involved, is not one of those cases where more would be gained than lost.

For the same reasons, the arrangement of the species in the Taxonomic Part is strictly alphabetical. To facilitate discussion, however, those groups that can easily be recognized are recognized informally. Throughout the discussion in the general chapters they are called by the name of one of their most characteristic, or most common, members; or by the number assigned to them here. A discussion of the monophyly of these groups is given on pp. 93-99.

The groups thus recognized are:

\section{The P. africana-group: $P$. africana, $P$. schimperiana.}

These species are similar in rhizome structure, rhizome scales, frond shape, venation, stomata, and spores. The rhizome is distinctly elongated between the phyllopodia; the lateral buds are close to the phyllopodia; the tissue is completely parenchymatous. The scales are pseudopeltate. The fronds are estipitate and 
often slightly falcate; with an irregular venation without distinct secondary veins. The stomata are polocytic. The spores have a very thin, tightly adhering perispore; the exospore is often strongly ornamented.

2. The P. costata-group: $P$. costata, $P$. stigmosa, $P$. princeps, $P$. platyphylla and $P$. splendens.

These species are similar in rhizome structure, rhizome scales, venation, sori and spores. The rhizome is generally rather thick and completely sclerified; the scales are basifix and not thickened. The venation of the lamina is characteristically complex, with very strongly developed secondary veins and an intricately anastomosing pattern of included veins. The sori have few sporangia each, and sporangium structure is peculiar (p. 62). The spores are smooth, with a thin, tightly adhering perispore.

3. The P. porosa-group: $P$. porosa, $P$. assimilis, $P$. linearifolia, $P$. stolzii, $P$. rhodesiana.

These species have few characters in common; they are nevertheless all rather similar in appearance: the rhizome is shortly elongated, with peltate scales. The fronds are estipitate, with a simple venation pattern with mainly simple, excurrent included veins.

4. The P. sheareri-group: $P$. sheareri, $P$. drakeana, $P$. hastata, $P$. polydactyla, $P$. sub furfuracea, $P$. boothii, $P$. flocculosa.

This group is characterized by the combination of a thick, short rhizome and distinctly stipitate fronds. $P$. flocculosa is in some ways aberrant: it has fewer sclerenchyma strands in the rhizome than the other species; it has dentate, instead of ciliate-dentate, rhizome scales; and the perispore is not as densely granulate as those of the other species.

5. The P. lingua-group: $P$. lingua, $P$. petiolosa, $P$. christii, $P$. sphaerosticha, $P$. ab breviata.

The typical combination of characters for this group is the long-creeping rizome with ciliate scales; the slightly to distinctly dimorphic, distinctly stipitate fronds; and the indument with appressed, boat-shaped rays.

The group, however, is markedly heterogeneous with regard to perispore morphology.

6. The P. albicans-group: $P$. albicans, $P$. asterosora, $P$. distichocarpa, $P$. num mulariifolia, $P$. kinabaluensis, $P$. rasamalae.

These species are similar with regard to certain aspects of rhizome structure, rhizome scales, frond, and spores. The rhizomes are all long-creeping; and the scales are peltate, with a uniformly coloured acumen (no distinct pale or hyaline margin present). The fronds are stipitate; usually they have a succulent lamina 
with a distinct water-tissue; hydathodes are absent. The perispore is characteristically ornamented.

7. The P. angustata-group: $P$. angustata, $P$. samarensis, $P$. novo-guineae.

The typical combination of characters for this group is the absence of hydathodes and the the contraction of the sori into a single row or into a coenosorus.

8. The P. confluens-group: $P$. serpens, $P$. confluens, $P$. rupestris, $P$. eleagnifolia.

This is a group of similar-looking species but with relatively few unique characters. The rhizome scales of many specimens from species in this group show annular figures as described on p. 27. The fronds are small, and dimorphic in various ways. There is a tendency for the hydathodes to be restricted to a single marginal row, and they are absent in $P$. eleagnifolia. The indument is uniformly monomorphic and appressed. The sori are relatively large, often more or less confluent, and usually contain many paraphyses with short, straight rays.

9. The P. lanceolata-group: $P$. lanceolata, $P$. ceylanica, $P$. longifolia, $P$. fallax.

This is a distinct group characterized by the deeply sunken sori with centrally situated paraphyses that are arranged in a bundle in most species, or in a central row in $P$. fallax. In many other characters this groups also is homogeneous.

10. The P. piloselloides-group: $P$. piloselloides, $P$. heterophylla, $P$. niphoboloides.

This is the group considered to be "true" Drymoglossum by Christensen (1929). It is characterized by the presence of coenosori, the characteristic venation with recurrent included veins, and the homogeneous lamina structure. Although some of the characters of this group (e.g. the peculiar venation) are unique in Pyrrosia, in other characters (spore morphology, rhizome structure, indument) it is similar to the $P$. confluens- or the $P$. lanceolata-group.

The following species are not included in any of the groups mentioned above: $P$. mannii, $P$. penangiana, $P$. pannosa, $P$. angustissima, $P$. gardneri, $P$. laevis, and $P$. foveolata.

$P$. mannii and $P$. penangiana are aberrant in having the combination of a short rhizome with pseudopeltate scales, estipitate fronds, and polocytic stomata. They differ from each other in indument and do not form an obvious group themselves.

$P$. angustissima shares many characters with the $P$. angustata-group (e.g. the absence of hydathodes, the presence of a coenosorus, the entire rhizome scales), but differs markedly in perispore sculpture. In this preliminary analysis $P$. angustissima is not incorporated in any group.

$P$. gardneri is more or less intermediate between the $P$. porosa-group and the $P$. lingua-group: the short-creeping rhizome and the hardly stipitate fronds indicate a connection with the $P$. porosa-group. The spores and the structure of the rhizome scales are similar to what is found in the $P$. lingua-group. 
$P$. pannosa has stipitate fronds like the $P$. lingua-group, but the scales are often pseudopeltate and more like those of $P$. schimperiana in structure.

$P$. laevis can be included in the $P$. lingua-group on the basis of indument and perispore sculpture, but is aberrant there on account of the absence of frond dimorphism.

$P$. foveolata has the deeply sunken sori that are characteristic of the $P$. lanceolatagroup, without any tendency to become confluent; it lacks the central position of the paraphyses in the sorus that is the other character used to delimit the $P$. lanceolata-group. 


\section{MORPHOLOGY}

\section{Rhizome}

The morphology and anatomy of the rhizome have been studied by Giesenhagen (1901, pp. 23-29) and by Nayar and collaborators (Nayar, 1957, 1961, Nayar \& Chandra, 1965, 1967). They chiefly paid attention to the vasculature of the rhizome, which was illustrated by these authors for both short- and long-creeping rhizomes (Giesenhagen, l. c. p. 23 fig 3, p. 27 fig. 4; Nayar, 1957, p. 170 fig. 3-5; 1961 fig. 19-21; Nayar \& Chandra, 1967, p. 616 fig. 1-3), and this character plays an important part in the phylogenetic considerations of Nayar \& Chandra (1967). These authors paid relatively little attention to the various ways in which the sclerenchyma may be distributed in the rhizome.

The comparative morphology of the rhizome has not been as intensively studied. John Smith (1842) used the gross morphology of the rhizome to distinguish two sections in the genus: the Repentes, and the Caespitosae.

\section{Morphology}

The rhizome of Pyrrosia is always horizontally creeping and varies from shortly so to long-creeping (fig. 1).

Dorsally, the rhizome bears two alternating rows of phyllopodia. The width of these generally differs not much from that of the rhizome, the height is variable but rarely exceeds $5 \mathrm{~mm}$. Only in $P$. gardneri the phyllopodia are distinctly higher (fig. 1 a) and here they are a conspicuous feature. The abscission pad on the phyllopodia is more or less concave. In short-creeping rhizomes (fig. $1 \mathrm{~b}$ ) the phyllopodia are very closely set, in long-creeping rhizomes (fig. $1 \mathrm{~d}$ ) the internodia may attain lengths of c. $9 \mathrm{~cm}$. Young plants (and plants that grow under rather adverse conditions can retain this juvenile morphology for several years), or newly-formed branches of older rhizomes usually have the phyllopodia more densely set than do fully mature plants; on the other hand, vigorously growing plants occasionally have the phyllopodia up to a few $\mathrm{cm}$ apart even if that is not the normal condition.

On each side the rhizome bears a row of lateral buds. These are regularly present even if they do not develop into branches, which they do more frequently in 


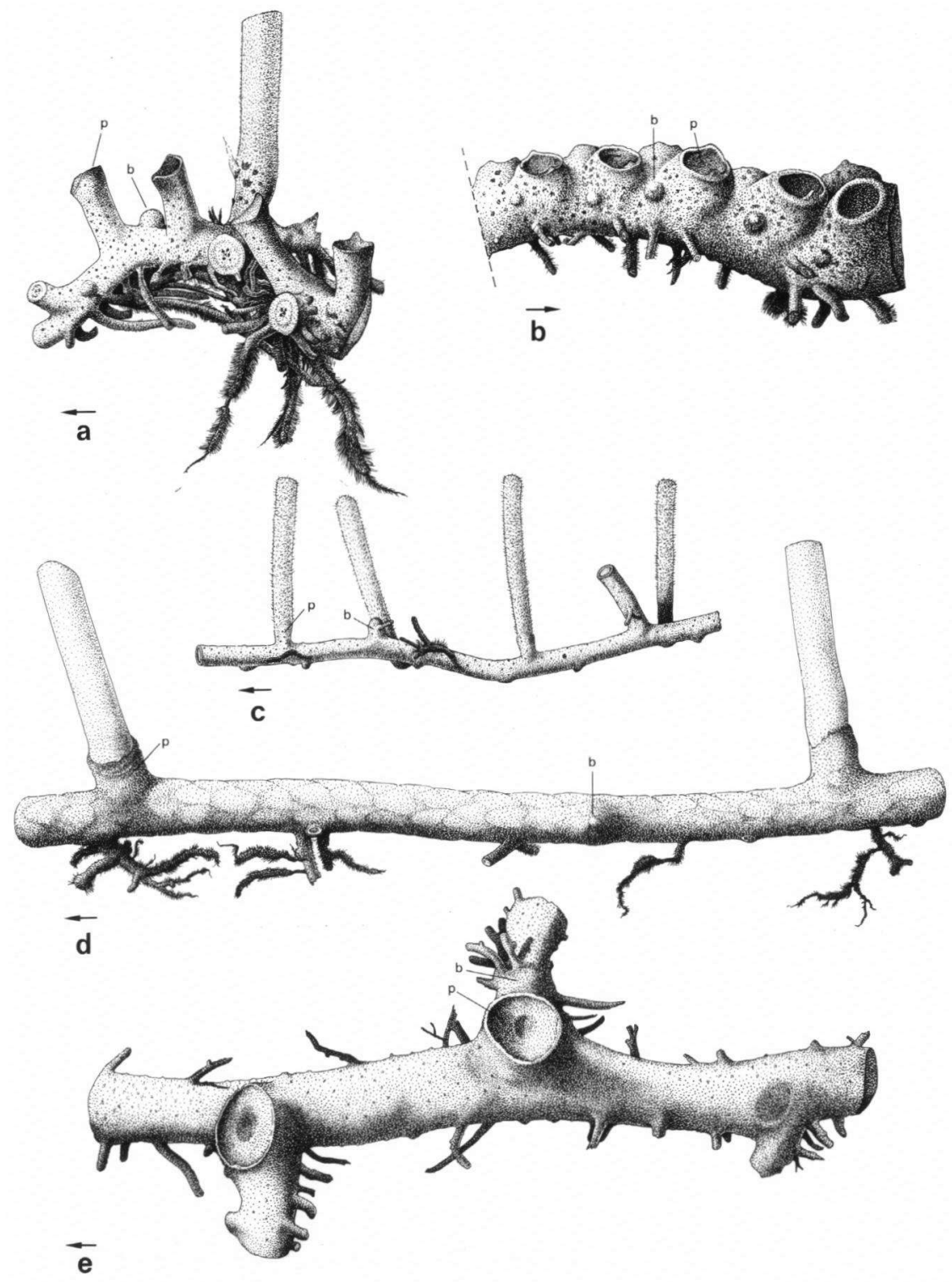

Fig. 1. Rhizome morphology. $x \pm 1.8$. a. $P$. gardneri; shortly elongated rhizome, buds \pm halfway down the internodia. - b. $P$. sheareri; short-creeping rhizome. - c. $P$. nummulariifolia; thin, longcreeping rhizome, buds more than halfway down the internodia. - d. $P$. abbreviata; long-creeping rhizome, buds \pm halfway down the internodia. - e. $P$. platyphylla; shortly elongated rhizome, buds not shifted. (a. cult. Leiden Bot. Garden, LEI 22359; - b. cult. Leiden Bot. Garden, LEI 21434; - c. cult. Leiden Bot. Garden, LEI 3606; - d. cult. Leiden Bot. Garden, LEI 23920; - e. Kostermans $13308, \mathrm{~L})$. Scales removed. p: phyllopodium, with b: associated bud or branch, $\rightarrow$ : direction of growth. 
some species than in others. As Nayar and Chandra remarked (1967, p.617), each bud is associated with a phyllopodium. In short-creeping rhizomes with closely set phyllopodia (fig. $1 \mathrm{~b}$ ) the buds are situated basally on the phyllopodia, in an abaxial-lateral position, but in species with more or less elongated rhizomes and longer internodia the position of the bud varies. In some species in which the phyllopodia are up to several $\mathrm{cm}$ apart (e.g., $P$. africana, $P$. platyphylla, tig. $1 \mathrm{e}$ ) the buds are placed very close to or on the phyllopodia, just as they are in species with short-creeping rhizomes. In other species the buds are shifted downwards to a position up to halfway down the internodia (e.g., $P$. rhodesiana, $P$. pannosa). In most species with long-creeping rhizomes (e.g., $P$. abbreviata, fig. 1 d) the buds are constantly situated from halfway to farther down the internodia, in some species (e.g., $P$. nummulariifolia, fig. 1 c, $P$. foveolata) they usually occupy a position opposite the phyllopodia and apparently are shifted downwards over the whole length of the internodium.

Other ferns with a vining habit have buds in the same position, e.g., Microgramma (Hirsch \& Kaplan, 1974). A detailed analysis of these cases might reveal a similar remote association of buds and phyllopodia, although Hirsch \& Kaplan $(l . c$.$) in their morphological analysis concluded that there is no relation$ between buds and fronds.

In cross-section the rhizome is often \pm rounded, but in very short rhizomes the dorsal side is often somewhat flattened due to the very closely set phyllopodia. In many long-creeping rhizomes, on the other hand, the ventral side is often more or less flattened or even distinctly furrowed. Often this is more distinct in dried specimens, but the frequent occurrence of rhizomes that are round in dried state indicates that the ventral groove is not an artifact of drying.

Branching of the rhizome is exclusively by means of development of the lateral buds. In many species the rhizome is always profusely branched, but in others the parts collected are often unbranched. This is particularly so in the species with short creeping rhizomes. In many cases where branches were present they have probably been distributed as duplicates, in other cases truly unbranched rhizomes may occur. Specimens of $P$. polydactyla and $P$. sheareri did not show any branching even after a long period of cultivation in the greenhouse .

Apical dichotomous branching occurs occasionally in galled rhizomes of $P$. eleagnifolia and $P$. confluens, both species with a long-creeping rhizome.

\section{Anatomy}

Vascular structure (plate 1; fig. 2). The stele of Pyrrosia has been called a "'highly dissected siphonostele"' by Nayar et al. $(1961 ; 1967)$ and a "perforated dictyostele" by Schmid (1982, p. 864).

In Schmid's elaborate classification there is no fundamental difference between a dictyostele and a solenostele. Steles are called dictyostelic if the leaf-gaps 

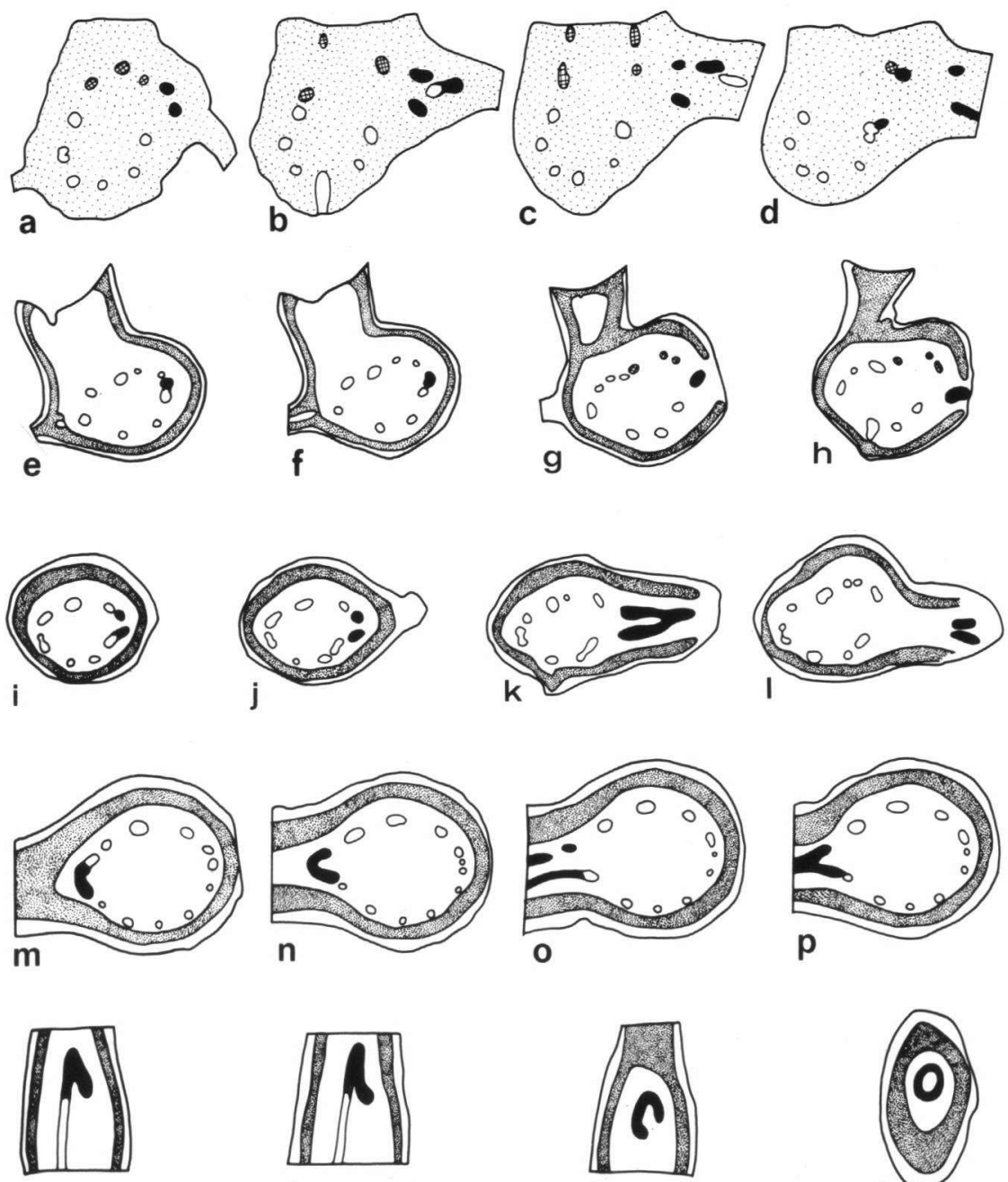

$q$

$r$

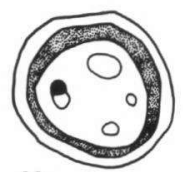

u
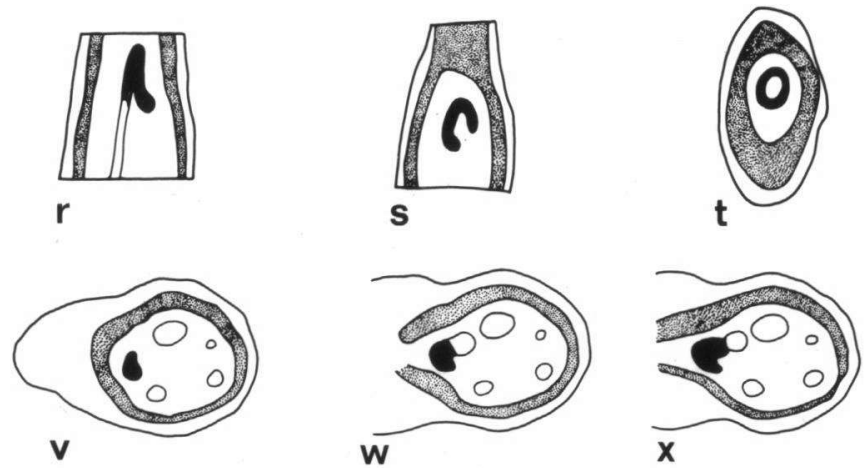

Fig. 2. Rhizome anatomy, vascular organization. All. $x \pm 6$ except $u-x \times \pm 12$ a-d. $P$. stigmosa; transverse sections through rhizome. - e-h. $P$. drakeana; id. - i-l. P. porosa; id. $-\mathrm{m}-\mathrm{p}$. $P$. albicans; id. - q-s. $P$. lingua; tangential sections through rhizome. $-\mathrm{t}$. $P$. lingua; transverse sections through base of branch. - u-x. P. niphoboloides; transverse sections through rhizome. (a-d. Geesink et al. 6944, L; - e-h. Tsai 57159, GH; - i-l. Tsai 60659, GH; - m-p. Jermy 7203, L; - q-s, t. cult. Leiden, LEI 20369; - u-x. cult. Leiden, LEI 20402). Scattered sclerenchyma strands omitted in e-t. cross-hatched: branch trace; black: frond trace; stippled: sclerenchyma. 
overlap, solenostelic if they do not, and the two types are considered as closely related, and difficult to distinguish in highly perforated steles (Schmid, l. c. p. 900). From the drawings of stelar structure given by Nayar \& Chandra (1967) it appears that in Pyrrosia the frond-gaps may overlap (their fig. 1) or not (their fig. 3 ), or only just a little (fig. 2), which confirms the fundamental unity of the two types postulated by Schmid.

In cross-sections 3 to $c .13$ vascular strands may be seen, the number of strands being roughly correlated with the thickness of the rhizome. In thin, long-creeping rhizomes (especially those of the $P$. lanceolata- and $P$. confluens- group) often five strands (pl. $1 \mathrm{f}$ ) are present in a fixed arrangement: two ventral strands, two lateral ones, and a relatively thick dorsal strand. In thicker rhizomes of these species a larger number of strands may be present, but this may be due to a larger number of anastomoses between the five main strands.

Branch traces are composed of one to several strands. Branch traces with several strands occur in the $P$. costata-group (e.g., $P$. stigmosa, fig. 2 a-d). Traces with a double strand occur in $P$. subfurfuracea and $P$. schimperiana, traces with either a double or a single strand in $P$. porosa (double strand: fig. $2 \mathrm{i}-1$ ) and $P$. penangiana. A double strand is also found in $P$. nummulariifolia and in $P$. piloselloides, but here the two strands quickly fuse to a single one entering the branch. In all other species that were investigated a single strand was found.

This single strand is often U-shaped but sometimes it is fully cylindrical for a short distance before splitting up into separate strands in the base of the branch (fig. $2 \mathrm{t}$ ). Due to the relative inaccessibility of this character (either laborious dissection is necessary or large series of consecutive sections must be made) no fully representative survey of the genus has been made, and results should be interpreted with caution.

Frond traces have 2-9 strands, the number depending mainly on the size of the frond. When more than 2 strands are present in the frond trace they are in a Ushaped configuration, with two prominent strands on the open side. This arrangement is similar to the vascular arrangement in the stipe, and is already distinct at a short distance from the rhizome bundles. In species where the phyllopodia are very closely associated with the lateral branches, some of the strands to the branch may originate from the frond trace instead of directly from the rhizome bundles (e.g., in $P$. stigmosa, $P$. princeps); in other cases branch trace and frond trace are completely separate.

Non-vascular tissue. In most species the non-vascular tissue is distinctly differentiated into parenchymatous ground tissue and sclerenchyma. Parenchyma cells have thin, uncoloured, walls; the sclerenchyma cells have more or less thickened walls and are often almost completely filled with brown or dark-brown wall-material (pl. $1 \mathrm{~h}$ ). Generally a distinct sheath of sclerenchyma is present situated peripherally to the vascular cylinder and several cell layers below the 
epidermis. In some species (e.g., $P$. rhodesiana, pl. 1 c, $P$. pannosa) this is less distinct but it is rarely completely absent $(P$. schimperiana, $P$. africana, pl. 1 b). In the latter case sometimes a very faint collenchymatous sheath may be found instead. When present, the sclerenchyma sheath is more distinctly demarcated from the peripheral parenchyma than from the inner, central parenchyma. In one aberrant specimen of $P$. penangiana (De Wilde \& De Wilde-Duyfjes 15653) the sclerenchyma sheath extends inwards to within the vascular cylinder, so that the vascular strands are embedded in sclerenchymatous tissue instead of in parenchymatous tissue.

Apart from the sclerenchyma sheath, sclerenchyma occurs in the form of longitudinal strands in the central parenchyma of the rhizome. In most species the number of strands varies considerably, but nevertheless the arrangement of the strands and their position in the parenchyma is a valuable taxonomic character.

The structure of the cell walls in these strands is similar to that of the walls in the sclerenchyma sheath, but the wall material is often distinctly darker. This is particularly evident in the specimen of $P$. penangiana mentioned above in which the sclerenchyma sheath extends unusually far inwards: not only the vascular strands are embedded in it, but also some of the many sclerenchyma strands, and these stand out distinctly from the surrounding material. Due to the strong coloration of the wall material I have not been able to assess by way of standard diagnostic staining to what extent lignification is involved in either or both types of wall-thickening in sclerenchyma cells.

In many species the sclerenchyma strands occur in large numbers, scattered in the inner parenchyma (e.g., $P$. penangiana, the $P$. subfurfuracea-group). In others, fewer strands are similarly scattered in the inner parenchyma (e.g., in $P$. mannii, $P$. porosa). Between these two states there is a gradual transition: within several species the number of strands varies considerably (e.g., from 0 to over 20 in $P$. albicans and $P$. distichocarpa, from 0 to c. 15 in $P$. stolzii).

In some cases the sclerenchyma strands are not scattered irregularly in the parenchyma but are restricted to a peripheral zone, and thus occur more or less in between the vascular strands (e.g., in $P$. angustata, pl. $1 \mathrm{~g}, P$. samarensis, $P$. $a b$ breviata). Several species (e.g., $P$. rasamalae, $P$. asterosora) have a variable but still lesser number of strands scattered in the parenchyma. Sometimes, the absence of strands seems to be fixed in geographical races $(P$. confluens, $P$. rasamalae). This can be considered as a step towards complete loss of the sclerenchyma strands, as has apparently occurred in, e. g., $P$. eleagnifolia, $P$. christii, $P$. rhodesiana.

A condition that seems to be strongly fixed in many species with relatively thin, long-creeping rhizomes is the presence of a single sclerenchyma strand, which is usually distinctly dorsiventrally flattened and occupies a central position. This is characteristic for most of the species with a strongly grooved rhizome (e.g., $P$. 
foveolata, $P$. lanceolata, pl. $1 \mathrm{f}, P$. ceylanica) with 5 vascular strands in a fixed arrangement (see above).

Exceptions to this correlation between rhizome morphology, vascular and nonvascular anatomy occur, however. Some specimens of $P$. lingua have a single central sclerenchyma strand but not the fixed arrangement of 5 vascular strands, and $P$. nummulariifolia sometimes has a central strand but less than 5 vascular strands owing to its very thin rhizomes. In other forms of $P$. lingua sclerenchyma strands are completely absent, or else there may be up to 10 scattered strands. Similarly, in some forms of $P$. nummulariifolia the sclerenchyma strand is absent. In $P$. confluens and $P$. rupestris the vascular strands usually show the fixed arrangement of 5 , but the central sclerenchyma strand is often absent or replaced by a small number of strands occupying the same position.

Species of the $P$. costata-group (pl. 1 a) have a distinctly different rhizome structure. The rhizome is not differentiated into sclerenchyma and parenchyma, but is almost entirely composed of sclerenchymatous tissue. Only a thin peripheral zone is more or less parenchymatous, possibly corresponding to the thin parenchymatous layer outside the sclerenchyma sheaths of other species. The cell walls of the sclerenchyma in this type of rhizome, however, are not as strongly thickened as they are in the distinctly differentiated sheaths of other species. In this they are comparable to the walls of the rather ill-defined sclerenchyma sheath of, e.g., $P$. rhodesiana, $P$. porosa, or $P$. flocculosa on the one hand; on the other to the walls of parenchyma cells.

The lack of differentiation in the rhizomes of the $P$. costata-group can be compared to that in the $P$. africana-group. The species of that group have fully parenchymatous rhizomes in which no or only very slight differentiation is visible. The abscission pad of the phyllopodia, however, is more or less sclerified in a way similar to that in the rhizomes of the $P$. costata-group.

In all other species, the structure of the phyllopodia is similar to that of the rhizome. They have a sclerenchyma sheath in direct continuation of the sheath of the rhizome, but lack the scattered strands of sclerenchyma in the central parenchyme.

\section{Development}

The development of the rhizome structure could be studied in some species by way of serial sections through the rhizomes of young sporelings grown in the Leiden Botanical Garden.

In $P$. lingua there is from very early on a more or less distinct sclerenchyma sheath; the stele at that stage is composed of only two vascular strands. As the rhizome increases in thickness the sclerenchyma sheath becomes gradually more distinct. The adult situation in $P$. lingua would be a very distinct sclerenchyma 
sheath with or without a number of scattered sclerenchyma strands, but this stage was not reached in the plant studied.

In $P$. angustata the mature situation is more or less similar to that in $P$. lingua, but sclerenchyma strands are more constantly present and usually very strongly developed. In the young sporeling a sclerenchyma sheath was present from about the same stage onwards as in $P$. lingua, though in a less distinct form, but the inner parenchyma was slightly sclerified as well. As the thickness of the rhizomes increases, the distinction between sheath and inner parenchyma becomes more clear. Sclerenchyma strands did not develop in the stages studied and may be supposed to develop in a later stage.

In $P$. princeps ( $P$. costata-group) the adult condition is a fully sclerified rhizome, and this is also found in the young sporeling. Only directly behind the apical meristem the structure is parenchymatous as in all other species studied. Directly behind this apex the sclerenchyma is restricted to a peripheral zone, thus indicating that sclerification develops first in the form of a sheath. The same has been observed in Platycerium-species with a fully sclerified rhizome; here also the sclerenchyma takes on the form of a sheath directly behind the apex of the rhizome.

\section{Roots}

Roots are scattered over the ventral side of the rhizome, either very densely set in short-creeping rhizomes, or more sparsely, often in distinct tufts, in longcreeping ones. The roots appear to be initiated continuously at the growing apex of the rhizome. A root, however, soon ceases growth if no contact is made with a suitable substrate. Apparently the ability to develop is then lost permanently: even if contact with a substrate is made afterwards, the new roots arise from new initials directly behind the apex of the rhizome or on new branches. In species with short-creeping rhizomes the rhizome is permanently in contact with the substrate so that all roots can grow out. All these roots thus form a dense, spongy mass around the rhizome. By retaining moisture this may again facilitate the growth of new roots. In species with a long-creeping rhizome the tufted occurrence of the roots is a reflection of the degree to which the rhizome apex has been intermittently in contact with a suitable substrate.

In those species that have a long-creeping rhizome with a distinct ventral furrow the roots arise in two distinct rows on the ridges on both sides of that groove (e.g., in the $P$. lanceolata-group). In some species the rhizome is less distinctly and more shallowly grooved (e.g., in $P$. abbreviata) and here the roots are again scattered over the surface of the rhizome. In thin, elongated and terete rhizomes it is not possible to assess whether the roots arise in two rows or not. 
Root-traces branch off from the vascular strands running ventrally through the rhizome at irregular distances. Whether the roots are irregularly scattered or arranged in two more or less distinct rows thus depends directly on the number of ventral vascular strands.

The structure of the roots is uniform throughout the genus and has been described by Nayar (1961, p. 166 fig. 23, p. 168). They have a distinct sclerenchyma sheath, which is structurally similar to and continuous with that of the rhizome. This sheath is also present in those cases in which the rhizome does not have a distinct sheath, and is then acquired by the root as it passes through the zone where in other species the sclerenchyma sheath is situated.

\section{Rhizome scales}

Rhizome as well as phyllopodia are densely covered with overlapping scales. Shape, colour, and indument of these scales are highly variable and provide many taxonomically useful characters. More or less extensive descriptions of the scales are given by most authors. Scales were described in some detail by Nayar (1961, p. 166 fig. 1-18).

\section{Morphology}

Shape. In the $P$. costata-group the scales are basally attached (basifix) to the rhizome by a more or less semicircular attachment strip (fig. $11 \mathrm{~g}$ ). The base is thus broadly cordate, with auricles that extend some way along the rhizome, but do not overlap each other below the point where the scale is attached. From this rather wide base the scales are abruptly to more or less gradually contracted into a long, narrow acumen, often with a long, needle-like apex. This apex, however, is often worn off and is usually found only on small scales that have been protected by the surrounding larger ones. The length of the intact scale can therefore often not be assessed.

In $P$. princeps the scales are conduplicately folded backwards along their length so that the attachment to the rhizome is $U$-shaped with the open end of the $U$ towards the base of the rhizome (fig. $37 \mathrm{~b}$ ). Within these folded scales several, increasingly smaller, scales are usually clasped. The large, folded scales can often not be flattened under a coverslip, whereas with scales of other species this is usually no problem.

Several other species have "pseudopeltate" scales. Scales of this type are also basally affixed, but have auricles that come together, in many cases overlapping widely, below the point of attachment of the scale (fig. $11 \mathrm{~h} ; \mathrm{pl} .2 \mathrm{e}$ ). The scales thus at a first glance look similar to fully peltate scales in which the point of attachment is situated some way above the base. A closer look will reveal the two auricles that together form the base of the scales, each with a free margin running 
to the point of attachment. Compared with the basifix scales described above, the strip forming the attachment is usually less wide. In some cases, though, it is strongly curved or describes an almost full circle, and leaves a distinct hole after dissection of the scale from the rhizome. Pseudopeltate scales occur in the $P$. subfurfuracea-groun, in the $P$. africana-group (fig. $30 \mathrm{c}$ ), and in $P$. mannii, $P$. pannosa, and $P$. penangiana.

All other species have truly peltate scales. The point of attachment is situated some way above the base, and is developed into a short, usually rather stout stalk (fig. $11 \mathrm{l}$, pl. $2 \mathrm{c}$ ). In most cases the point of attachment lies at $1 / 10-1 / 5$ of the total length of the scale, and the widest part of the scales lies at about the same height. Only rarely (in $P$. albicans and in $P$. distichocarpa, fig. 34 b; less distinctly in $P$. asterosora, fig. $32 \mathrm{c}$ ) the widest part of the scale is situated distinctly above the point of attachment. The base of the scale (the part below the point of attachment) is usually rounded or more or les truncate, the acumen (here defined as the part of the scale above the point of attachment) is gradually narrowed to the more or less narrow apex. As the scales are often very closely set on the rhizome the base often shows more or less deep incisions where the stalks of adjacent scales have obstructed lateral expansion.

In outline, pseudopeltate and peltate scales are mostly narrowly ovate to linearovate, with a length/width index of 5-10, notably higher or lower in a few species only. Smaller, shorter, scales are often present intermixed with the normal scales. In most aspects they are similar to the large scales but they have only a short acumen or sometimes completely lack one. These small scales are usually completely hidden under the larger ones, but in some forms of $P$. lanceolata small scales are relatively more numerous, and visible without removal of the larger ones.

Marginal indument. The margin of the scales may be entire or very slightly sinuose-denticulate, in other cases the margin is more distinctly dentate with fine teeth composed of the protruding cell ends of single marginal cells (as in $P$. eleagnifolia, $P$. assimilis, $P$. porosa p.p.) or with coarser teeth composed of the protruding cell ends of two adjacent marginal cells (as is often the case in $P$. africana, $P$. distichocarpa, pl. $2 \mathrm{~g}$ ). These two-celled teeth are often forked at their tips.

In many species the margin is set with long or short cilia. The short cilia (pl. $2 \mathrm{f}$ ) may not be very distinct from long unicellular teeth (as in some specimens of $P$. porosa, $P$. drakeana), but very long and curled cilia occur in other species (e.g., $P$. lingua, $P$. abbreviata, pl. $2 \mathrm{~h}$ ). In that case they are easily lost with age and often absent from older parts of the rhizome, but they are often distinct as a more or less dense web covering the apex of the rhizome. Most species have cilia that are intermediate between short teeth and these long, curly cilia. In all cases they are composed of a single cell with thickened walls. They are always unicellular and never obscurely uniseriate, as is often the case with the apparently unicellular cilia in other ferns (e.g., most Grammitidaceae). 
In some species entire and ciliate scales can be found in one collection. Partly this may be due to abrasion of the marginal indument as in the case mentioned above, but in other cases differences in relative development may be involved. This last explanation is indicated in $P$. foveolata (fig. $35 \mathrm{~d}$ ): in this species the thicker parts of the rhizome tend to have scales with more cilia than thinner parts. In var. lauterbachii (fig. 35 a), with thin rhizomes, cilia are always absent.

In peltate scales the marginal indument is usually confined to the acumen, and the base of the scales is more or less entire. Several species, however, have forms in which the base of the scale is also more or less deeply ciliate or lacerate $(P$. nummulariifolia, $P$. linearifolia, $P$. lanceolata, $P$. kinabaluensis), and the species of the $P$. piloselloides-group have deeply lacerate scale bases (Ravensberg \& Hennipman, 1986). In this last group, the long cilia all around the scales give a characteristic, "woolly" appearance to the rhizome. In P. sphaerosticha on the other hand, long cilia are absent from the apex and confined to the basal part of the acumen.

One or two sessile glands are often present near the apex of the scales (fig. 11 $\mathrm{f}, \mathrm{j}$ ). Either one or both of these may be replaced by a long, acicular hair which is usually quite distinct from the more or less sinuose marginal cilia below the apex (fig. $11 \mathrm{k}$ ). In many cases the absence or presence of these glands is difficult to ascertain, as the apex is abraded easily, and the gland itself may have collapsed, or be completely hidden by and inconspicuous among the long marginal cilia surrounding it. Probably the glands are present in all species. The acicular hairs sometimes found instead probably are structures in some way equivalent to the glands.

The apical glands or hairs are best observed on the relatively short scales that have been protected by the larger ones.

In several species glands are also present at the base of the scales. In the $P$. costata-group they can often be found on long, multicellular, apex-like extensions of the base of the scale. In $P$. schimperiana, $P$. eleagnifolia, and $P$. rupestris they are more or less regularly present, in number varying from $0-5$, at the margin of the scale or on short, uniseriate stalks.

Superficial indument. The abaxial surface of the scales is usually smooth or finely striate. Sometimes, however, papillae or cilia may be situated on it, similar to the teeth or cilia situated on the margin. The superficial indument is confined to the abaxial surface and usually to a marginal zone or to the apex of the scale. In most species it is not constantly present. In $P$. porosa (pl. $2 \mathrm{~g}$ ) forms occur either with or without abaxial papillae near the margin; the presence of similar papilla at the margin of the base of the scales is one of the very few characters distinguishing the Madagascar specimens of $P$. rhodesiana from those of the continent of Africa. The more frequent occurrence of cilia on the surface of the scales in $P$. lingua var. heteracta only weakly distinguishes this variety from the type variety.

Glands seem to be completely absent from the surface of the scales. 
Structure and colour. Structurally simplest are those scales that are composed of a single layer of cells with relatively thin walls (pl. 2 a). This simple structure occurs mostly in basifix or pseudopeltate scales, and the point of attachment generally does not show a more elaborate structure. Generally these scales are translucent, light brown, and the anticlinal cells do not stand out distinctly from the other walls, as in clathrate scales. For the structure of similar scales Pichi Sermolli (1972, p. 390-391) has introduced the term "isotoechous", as opposed to 'clathrate'. However, especially in the $P$. costata-group a few cells may be present, mostly at the margin of the scale, in which the periclinal walls are almost hyaline and the transverse walls more prominent, so that the clathrate state is approached.

A more complicated structure can be reached in two ways: multiplication of the number of cell layers constituting the scale; or thickening of the walls of the cells. Usually, but not always, both processes have been involved in the same scale. In a few species only the number of cell-layers has increased without an increase in thickness of the walls, resulting in scales with a more or less parenchymatous structure $(P$. pannosa, $P$. schimperiana).

The thickening of the cell walls is often confined to the abaxial side of the scale. In all cases at least the outer periclinal walls are thickened. The adaxial side of the cells may be thickened as well but usually less strongly. With regard to the thickness of the anticlinal walls, there seem to be two different patterns of cell wall thickening: one in which the anticlinal walls are thickened as well (pl. 2 b) and one in which they are not involved (pl. $2 \mathrm{c}$ ).

Thickened anticlinal walls occur, among the species investigated, in the scales of $P$. sheareri, $P$. polydactyla, and $P$. porosa (fig. 2 b). All of these three species have relatively dull, rather tough and flexible scales. Thickening of the outer periclinal walls only has been found in $P$. abbreviata, $P$. albicans, $P$. gardneri, $P$. angustata, and $P$. serpens, (fig. $2 \mathrm{c}$ ). The scales of these species are relatively shiny, and, if strongly thickened (as in $P$. abbreviata, $P$. gardneri), stiff and brittle. There is thus a clear indication that the type of wall-thickening determines the texture and stiffness of the scales. The brittleness of the last type of scales may be caused by the more continuous layer of wall material that is present in these scales, contrasting with the interrupted layer of material found in scales of the first type.

The colour of the scales varies with the thickness. They are light to dark brown in most species, but mostly blackish when they are strongly thickened. Usually the area around the attachment is most strongly thickened and accordingly darkest in colour, in transmitted light it is often completely opaque. The margins, being relatively thin, are generally translucent and light brown or hyaline. In some species a large part of the acumen is also hyaline, in others the dark part around the base extends upwards far into the acumen as a wide, ill-defined, pseudocosta. 
The material with which the cell walls are thickened is yellowish-brown or blackish in most cases, and is distinctly different from the brown material that often fills up the lumina of the cells. In a number of species $(P$. confluens-group, also in $P$. lanceolata and incidentally in $P$. ceylanica) the scales, in transmitted light, may show a more or less distinct pattern of annular figures in the cells near the basis (pl. $2 \mathrm{~d}$ ). These figures usually lie in rows of 3-4 in the length of the scales, thus almost completely filling the lumina of some cells. They show up as lightcoloured rings (14-25 $\mu \mathrm{m}$ diameter) with darker centres. The different colours probably are the result of differences in thickness of the cell wall, the light ring representing a relatively thicker area in the wall and the central area representing a thicker section through the darker contents of the lumen.

The presence of these structures is rather erratic. In some specimens they are very distinct and abundant, in other specimens only a few, faint figures can be discerned, or annular figures are completely absent. Considering the variable occurrence of these structures it cannot be excluded that they might also have been found in other species than those indicated above if larger samples had been studied.

\section{Development}

The development of the rhizome scales of $P$. lanceolata has been illustrated by Nayar (1961, p. 166, fig. 7-15). I have investigated the development of the scales in $P$. nummulariifolia (fig. $3 \mathrm{a}-\mathrm{n}$ ) and in $P$. rupestris (fig. $3 \mathrm{o}-\mathrm{u}$ ). In all three species development seems to follow a similar course.

The first stage is a uniseriate hair with relatively undifferentiated cells. Transverse divisions result in a hair composed of 5-8 cells. In a later stage longitudinal divisions occur, resulting in a dilation at the base of the hair. Soon after that, the apical cell differentiates either into a swollen, glandular cell or into a long, acicular hair. Marginal hairs start to develop at the apical part of the scales, which in its development generally appears to be well ahead of the basal part. Thus, the soft meristematic apex of the rhizome is always well protected by a dense cover composed of well-differentiated apical parts of developing scales. A first indication of the formation of the glands at the base of the scales in $P$. rupestris is visible some time after the apical gland has developed (fig. $3 \mathrm{u}$ ).

At a distance of less than $5 \mathrm{~mm}$ from the apex of the rhizome, the outline of the scales is almost fully developed. At this stage of their development the scales are still tender and hyaline, but with further ageing they darken until they have reached the mature condition, usually at c. $2 \mathrm{~cm}$ behind the apex. The thinner parts of the scales (i.e., the apex and marginal zone), may be abraded on still older parts of the rhizome, where the scales may thus become totally unrecognizable. 

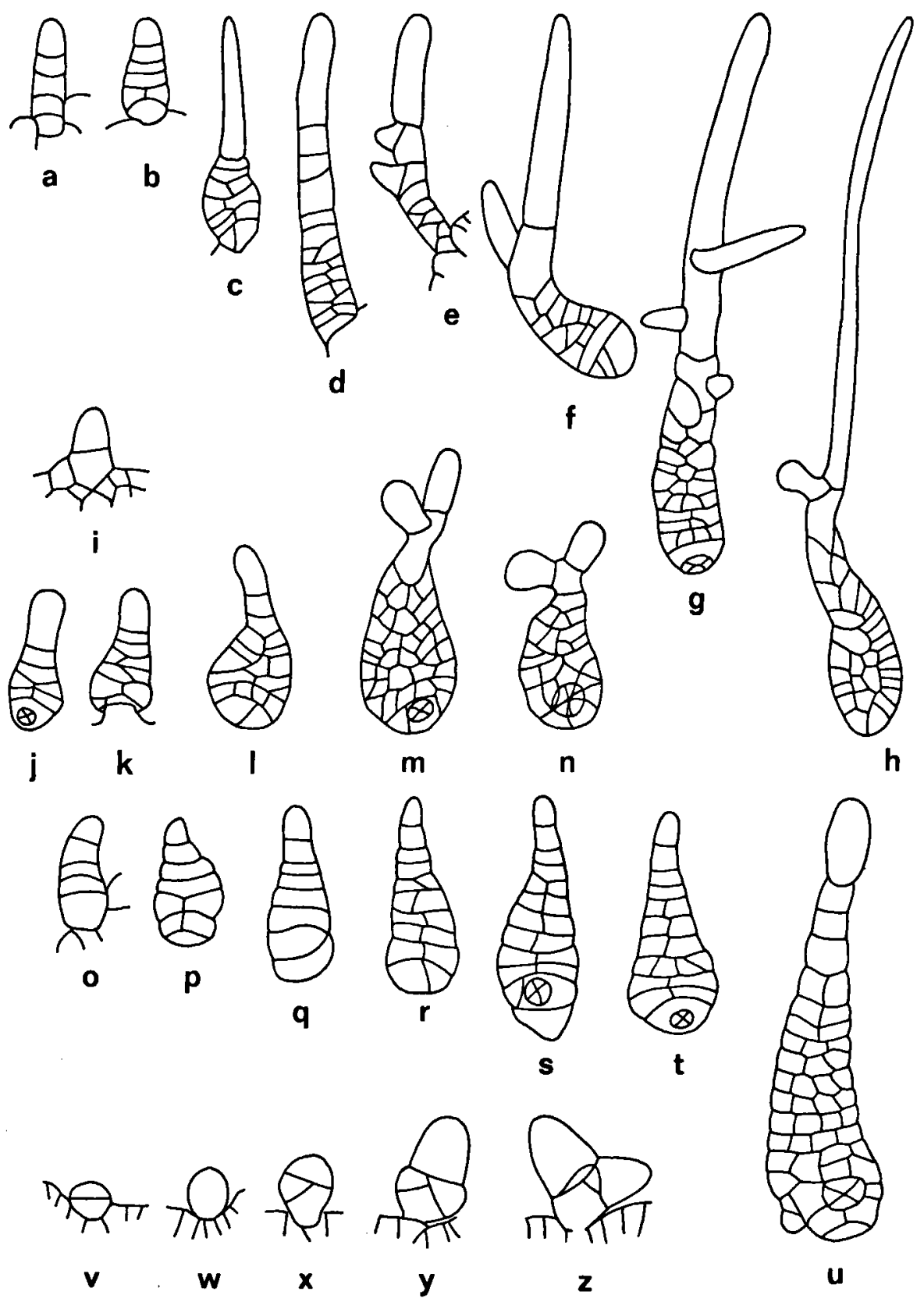

Fig. 3. Ontogeny of trichomes. $\times 175$. a-h. $P$. nummulariifolia; ontogeny of elongated scale. $\mathrm{j}-\mathrm{n}$. $P$. nummulariifolia; ontogeny of short-ovate scale. - o-u. $P$. rupestris; ontogeny of scale. $-\mathrm{v}-\mathrm{z}$. $P$. christii; ontogeny of stellate hair. (a-n. cult. Leiden Bot. Garden, LEI 21199; - o-u. cult. Leiden Bot. Garden, LEI 21151; - v-z. cult. Leiden Bot. Garden) 


\section{Fronds}

The fronds are articulated to the phyllopodia. In c. two thirds of the species the fronds are distinctly differentiated into a stipe and a lamina, in the other species a stipe is absent or indistinct. In a large minority of the species some form of fertile/sterile dimorphy occurs, which may show all degrees of differentiation. The range in dimorphy in Pyrrosia is cited by Wagner \& Wagner (1977) as an example of a gradual transition from uniform to strongly dimorphic fronds. Price (1974) uses this as an argument to unite the (almost) uniformly dimorphic genus Drymoglossum with Pyrrosia.

\section{Stipe}

Morphology. In the species in which the frond is not differentiated into stipe and lamina the fronds are gradually narrowed towards the attachment to the rhizome. Near the articulation point the lamina is usually reduced to two narrow, often indistinct, ridges, and at the very base a short part of the costa may be completely free of these ridges. In some fronds a stipe of 13-16 cm may be formed in this way. A stipe formed in this way, however, is not a constant feature in the species here considered, nor can the unridged part of the costa be distinguished clearly from the gradually narrowed lamina. Absence of a distinct stipe mostly goes together with a short, or shortly elongated, rhizome, as in, e.g., the $P$. porosagroup, most species of the $P$. costata-group, the $P$. africana-group, $P$. penangiana, $P$. mannii, $P$. rhodesiana, and $P$. stolzii.

The fronds are here considered as differentiated into stipe and lamina if a stipe is more distinct, or more constantly present. It is difficult to make a sharp distinction: in $P$. gardneri there is an indistinct stipe, but it is nevertheless almost constantly present, and accordingly $P$. gardneri is considered as stipitate. A stipe may also be indistinct or almost absent when the fronds are very small and the lamina gradually attenuated (as is often the case in, e.g., the $P$. lanceolata-group, the $P$. confluens-group, and the $P$. piloselloides-group). In some cases a stipe may be distinctly demarcated from the lamina but still be very short and inconspicuous below the cordate base (e.g., the sterile fonds of strongly dimorphic forms of $\boldsymbol{P}$. nummulariifolia, some forms of $P$. distichocarpa). In all these cases the stipitate character of the fronds may not be evident at once, but only after comparison with different forms of the same species.

In most of the stipitate species, however, a stipe is both distinct and constantly present. In length it varies from a few $\mathrm{mm}(P$. distichocarpa) to $40 \mathrm{~cm}(P . a b$ breviata). In comparison to the lamina it may be very short to about as long; only occasionally, in $P$. abbreviata, $P$. hastata, and $P$. polydactyla, the stipe may be distinctly longer than the lamina. 
In cross-section the stipe is abaxially usually rounded and adaxially slightly rounded, flat, or distinctly grooved. In continuation of the decurrent lamina there may be two narrow lateral ridges at the distal end.

Colour. In most species the stipe is straw-coloured to brown when dry, but it may be blackish in $P$. hastata and $P$. polydactyla.

Anatomy. Directly below the epidermis of the stipe there is a colourless collenchymatous sheath. Distally, this is often interrupted by two narrow, lateral parenchymatous bands, in continuation of the narrow wings decurrent from the lamina. These aerating bands do not run along the whole length of the stipe. Within the collenchymatous sheath the ground tissue is parenchymatous and only very rarely contains sclerenchymatous strands like those that occur frequently in the rhizome, but often there is a sclerenchyma-sheath enclosing, or partly enclosing, the vascular strands.

Centrally in the stipe in many species of the $P$. costata-group a thick bundle of collenchyma cells is present (fig. $4 \mathrm{e}$ ). Outside this group a similar bundle of collenchyma is found only sporadically.

The vascular structure of the stipe of Pyrrosia in general is comparable to the configuration described by Lin \& DeVol (1978) for Polypodiaceae, Davalliaceae, and Aspleniaceae. A varying number of vascular strands is present, arranged in an arc with the open end towards the adaxial side. The two strands on both ends of this arc are more strongly developed than the other strands, the number of which varies from 0 in stipes of small fronds to c. 8 in stipes of large fronds. The total number of strands in the central bundle (central strands) thus varies from 2 to c. 10. This number increases slightly from the point of articulation to c. $1 \mathrm{~cm}$ above the base of the stipe, and decreases gradually upwards from there. The two adaxial strands are usually separate for most of the length of the stipe and fuse at the base of the lamina. Only in $P$. hastata and $P$. polydactyla (fig. $4 \mathrm{~d}$ ) this fusion occurs lower down the stipe; in $P$. polydactyla a single adaxial strand runs through almost the entire length of the stipe. As this single strand enters the lamina it divides to form the midribs of the lamina lobes.

In the highly reduced stipes of small fronds of $P$. nummulariifolia (fig. $4 \mathrm{~b}$ ) the two strands are sometimes replaced by a single one.

Apart from these central strands most species have a varying number of lateral strands running along the adaxial side of the stipe. The number of lateral strands increases gradually from the base of the stipe upwards, and after entering the lamina they form the first lateral veins. Again, the number roughly depends on the size of the lamina, and lies between 1 and 5 in most species. These lateral strands, however, are conspicuously absent in the largest part of the stipe in species of the $P$. albicans-group. There they appear only rather high up the stipe, a short distance below the lamina. In contrast, in other species with stipitate 


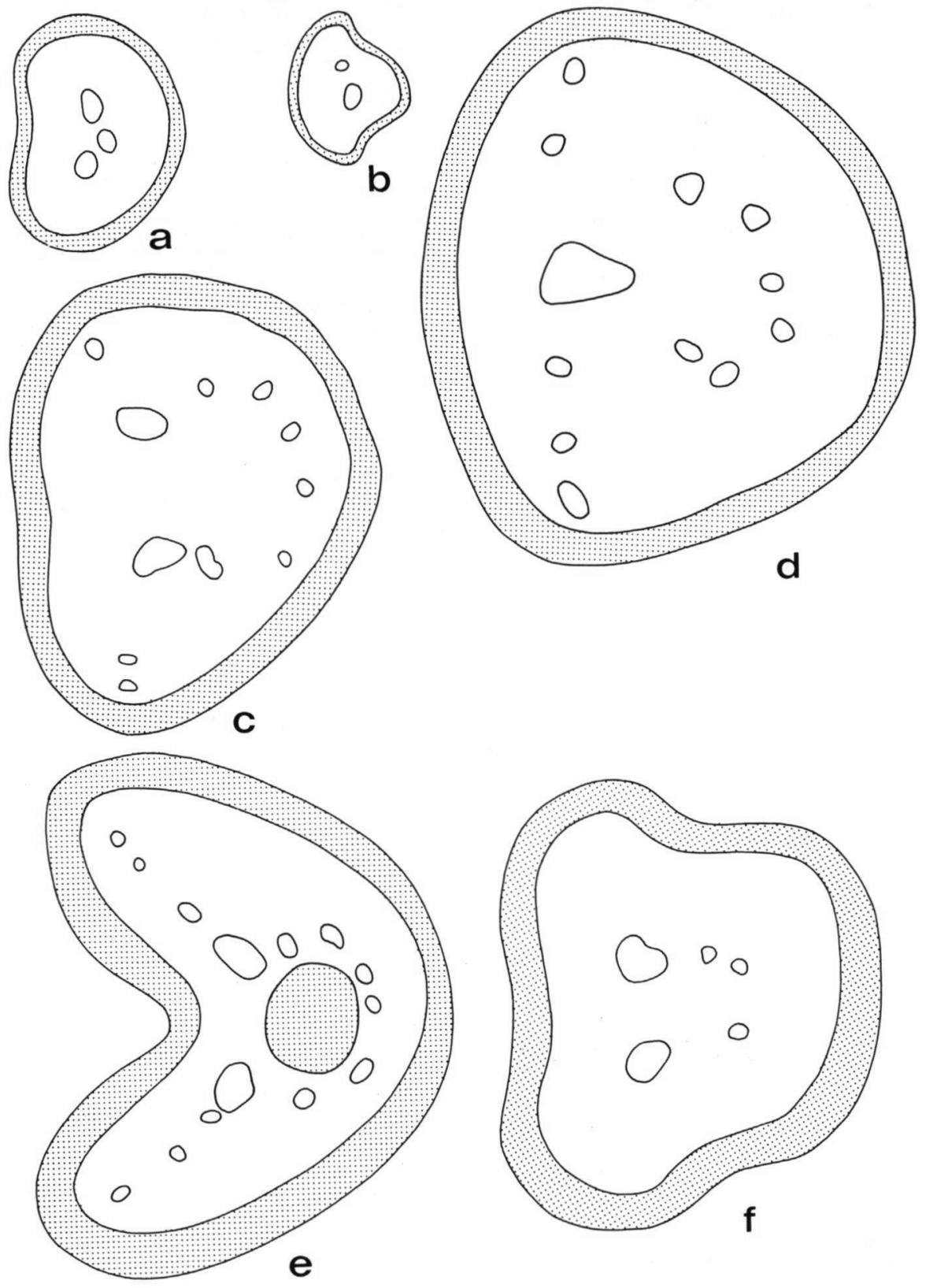

Fig. 4. Stipe anatomy. a. $P$. eleagnifolia; transverse section through stipe $\times 24 .-$ b. $P$. nummulariifolia; id., $\times 24 .-$ c. $P$. sheareri; id., $\times 28 .-$ d. $P$. polydactyla; id., $\times 22 .-$ e. $P$. stigmosa; id., $\times$ 26. - f. P. albicans; id., $\times 24$. (a. Lam 7125, L; - b. Bloembergen s.n., L; - c. Fan \& Li 433, L; - d. cult. Kew Bot. Gardens; - e. Van Balgooy 2226, L; - f. Van Steenis 3884, L). Stippled: collenchyma; open: vascular strands. 
fronds and a similarly sized lamina (e.g., the $P$. lingua-group) usually at least one lateral strand is present from the base of the stipe upwards.

\section{Lamina}

Shape. In species in which the fronds are not distinctly differentiated into a stipe and a lamina, the fronds are usually oblanceolate in shape, with an index of c. 5-20 or more. The largest width is situated in the upper half of the frond. When the fronds are differentiated into a stipe and a lamina, the latter is more variable in shape, varying from orbicular (in e.g. $P$. abbreviata, fig. 29 a; $P$. nummulariifolia) to very long and strap-shaped ( $P$. longifolia). The largest width in these cases usually is below or about the middle of the lamina. In both stipitate and estipitate species, however, very narrow, linear fronds may be found (e.g., in $P$. linearifolia, P. rasamalae).

At the base of the lamina there is a transition to the ridges running downwards along the stipe. This transition is gradual in species with an attenuate lamina base as well as in species with a truncate lamina base. In the latter case the lamina base is also often distinctly unequal, and sometimes there is a difference of $2 \mathrm{~cm}$ or more between both sides of the lamina-base.

The shape of the apex varies widely, from rounded to acute to distinctly acuminate. In some species ( $P$. lingua var. heteracta, $P$. abbreviata) this whole range can be found, but in most only part of the range is encountered.

The texture of the lamina in most species is coriaceous or thick-leathery. It may be thinner in specimens probably originating from sheltered situations. In living plants the lamina is usually more or less succulent, in extreme cases $(P$. nummulariifolia, $P$. confluens) it may be up to $2 \mathrm{~mm}$ thick. A strong reduction in thickness of course occurs in drying, and the width may be reduced by a factor of $1 / 3$.

Dimorphism (fig. 5). In most species there is no sterile/fertile frond dimorphism (fig. 5 a, b; fig. $30,31,32,34,37$ ). In these monomorphic species sterile fronds are usually present only in young plants or in plants growing under unfavourable circumstances. Once the plant has matured all fronds produced subsequently will be fertile. These fertile fronds are similar in shape to the earlier produced sterile ones, though often distinctly larger. The soriferous area is generally situated apically, extending downwards to a varying degree; sometimes the lamina is entirely covered with sori. Sterile fronds of these species are often absent from collections, and presumably were wanting at the time of collecting.

In principle, the formation of sterile fronds can be regulated by two possible mechanisms: either some internal mechanism may be active which is largely independent from the external circumstances, or the formation of either sterile or fertile fronds may be a more direct response to changes in the environment. Some indication for the presence of a mechanism of the second type is found in the 

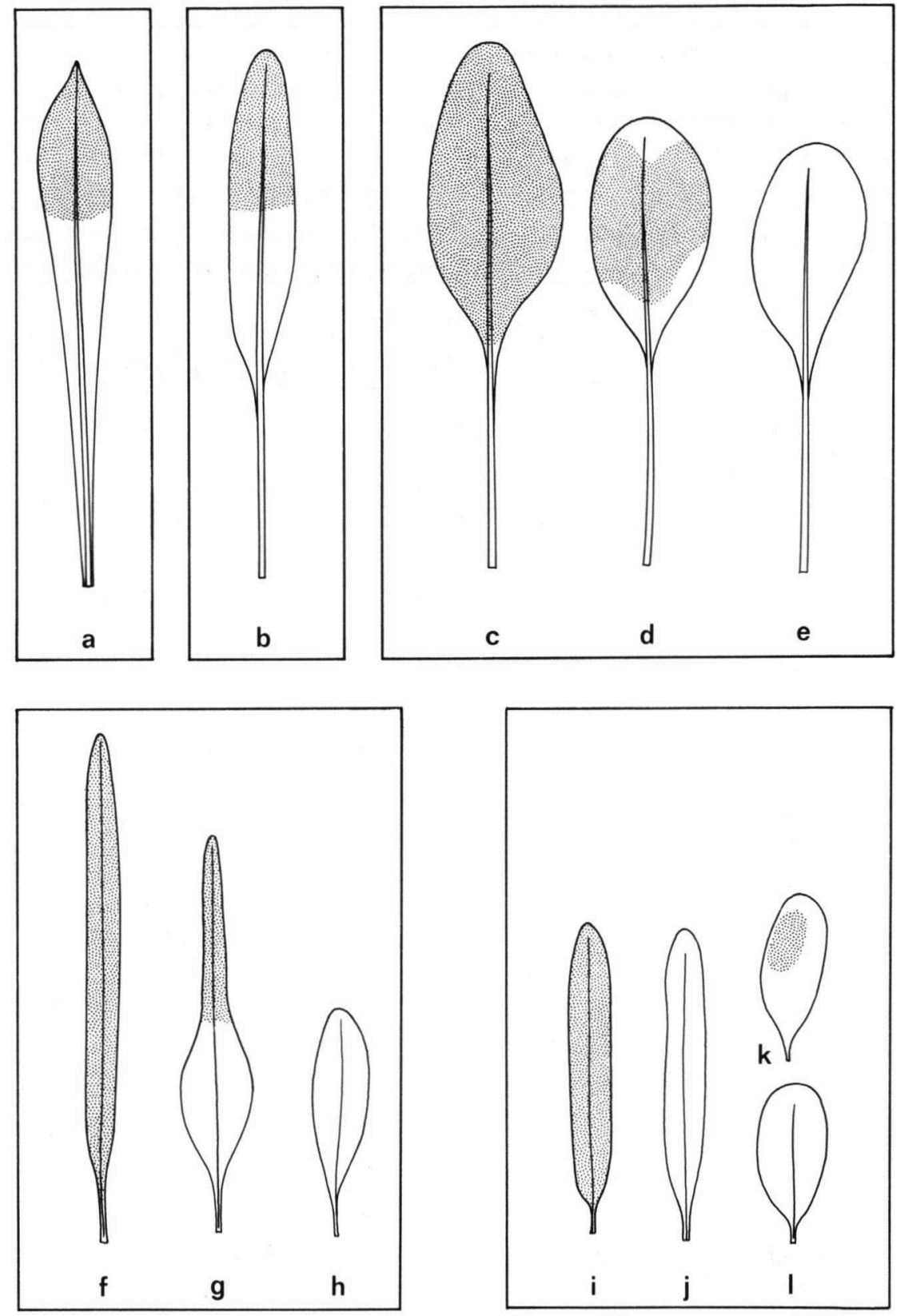

Fig. 5. Schematic representation of frond dimorphism in Pyrrosia. a, b. monomorphic fronds. c-e. dimorphic fronds as occurring in the $P$. lingua-group. $-f-h$. dimorphic fronds as occurring in the $P$. lanceolata-group. $-\mathrm{i}-1$. dimorphic fronds as occurring in $P$. nummulariifolia and the $P$. confluens-group. Stippled: soriferous parts. 
monomorphic species, which occasionally produce only sterile fronds. They often do so for long periods in the greenhouse, and it seems likely that this is due to unfavourable circumstances. On the other hand, most of the dimorphic species seem to produce sterile and fertile fronds in an irregular alternation. Many do so also in the greenhouse, where they may grow alongside monomorphic species that continue to form fronds of only one type, be it sterile or fertile. At first sight, therefore, it seems that two different mechanisms are active. However, both apparently different growth-forms may be explained by the same mechanism if it is considered that dimorphic species tend to be fast-growing plants with longcreeping rhizomes, on which many, quickly developing, fronds are produced. The monomorphic species are generally short-creeping, with fewer, more slowly developing fronds (fig. 6).

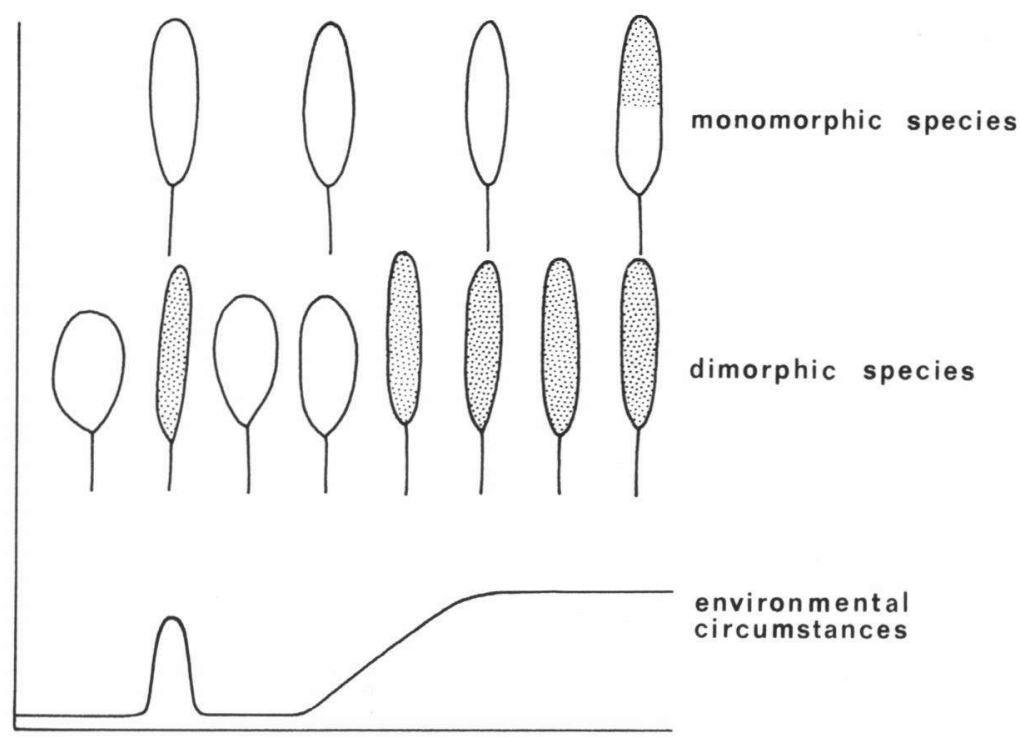

Fig. 6. Schematic representation of the (hypothetical) relation between environmental circumstances and the formation of fertile fronds.

If sterile or fertile fronds are produced in response to environmental changes, the dimorphic species may thus be able to react more quickly to a changing environment by the formation of sterile or fertile fronds. More drastic or longer-lasting changes are necessary to induce the "monomorphic" species to form another type of fronds. Dimorphic species therefore can adapt their mode of reproduction (vegetative or sexual) to slight or brief changes that pass by unnoticed by monomorphic species. Dimorphic species have then the double advantage of quick growth and a flexible reproductive strategy, and it is not surprising that 
some of the most widespread species of Pyrrosia ( $P$. lanceolata, $P$. piloselloides, $P$. nummulariifolia) have long, vining rhizomes with mostly dimorphic fronds.

Whatever mechanism is involved in the ability of plants to produce sterile or fertile fronds, only when sterile fronds occur regularly in mature plants alongside with fertile fronds a morphological dimorphism of the type encountered in Pyrrosia can develop. As is often the case with fertile/sterile frond dimorphy in Polypodiacaea (Wagner \& Wagner, 1977), the morphological differences between the two types of fronds seem to be related to specialization as either assimilating or spore-producing organs. In Pyrrosia, there is always at least a slight difference in size or shape between sterile and fertile fronds, and in some groups there is a pronounced difference. Only in $P$. pannosa no difference whatsoever between sterile and fertile fronds was found. This may be due to the small number of available collections, so that possibly a slight difference (as is present in, e.g., $P$. petiolosa) could not be discerned.

In the $P$. lingua-group (fig. $5 \mathrm{c}-\mathrm{e}$ ) the sterile fronds are only slightly wider and shorter than the fertile fronds. The length/width index shows a considerable overlap in, e.g., $P$. lingua, $P$. petiolosa, but less so in, e.g., $P$. abbreviata. Fertile fronds of the $P$. lingua-group are usually fertile all over the lamina, or else the sori are arranged in an irregularly shaped patch that is not always situated apically. Sterile fronds may have been formed in this group by suppression of the development of the sori without other changes in the morphogenesis of the fronds than those that produce the slight dimorphism.

In the $P$. lanceolata-group the fertile fronds are usually distinctly longer and narrower than the sterile ones (fig. $5 \mathrm{f}-\mathrm{h}$ ). The sori are often situated apically, in a more or less contracted part of the lamina. Often there is a distinctly wider, sterile part at the base of the lamina, similar in shape and size to the sterile fronds. Sterile fronds may thus be supposed to have developed from fertile ones through suppression of apical growth before the sori are initiated in the apical meristem. If so, that is a marked difference between this group and the $P$. lingua-group, in which only soral development seems to be suppressed and the development of the lamina is only weakly affected.

A similar mechanism seems to occur in the $P$. angustata-group. In $P$. angustata the situation prevails as described for the $P$. lanceolata-group, and a wide sterile area is often present at the base of fertile fronds. Fronds that are fully fertile and narrow throughout also occur. In $P$. samarensis a sterile widened basal area is present in all fertile fronds, and the fertile area is contracted to an apical spike, similar to the apical spikes occurring in the genus Belvisia. This condition can be described as "hemidimorphic" in the sense of Dickason (1946). In P. samarensis completely sterile fonds occur sometimes which are indistinguishable from fertile fronds before these develop an apical spike; they may be derived directly from fer- 
tile fronds through suppression of growth before the formation of sori. In $P$. novoguineae, the situation is at first sight different. In this species the sterile fronds are wide and relatively short, the fertile fronds are uniformly narrow and mostly longer than the sterile ones. This condition, holomorphic sensu Dickason $(l . c$.$) ,$ is connected to the hemidimorphic condition of $P$. samarensis through the intermediate situation in $P$. angustata.

Frond dimorphism in the $P$. confluens-group is more variable. Partly (in $P$. confluens and $P$. serpens) it follows the pattern of the $P$. lanceolata-group, partly (in $P$. eleagnifolia and $P$. rupestris) a somewhat different situation prevails. In these two species (and in $P$. nummulariifolia, from the $P$. albicans-group, as well) the fertile fronds distinctly differ in shape from the sterile ones. The fertile fronds are longer, narrower, and often erect, whereas the sterile fronds are usually more or less appressed to the substrate. However, intermediate fronds occur that are sterile but similar in shape to the fertile fronds; or similar to the sterile ones but (partly) fertile (fig. $5 \mathrm{j}, \mathrm{k}$ ). This appears to occur more often in cultivated plants than in material collected in the field. Some sort of dimorphism thus seems to have developed but to a certain degree it has become independent of the actual sterile/fertile dimorphism.

Dimorphism in the $P$. piloselloides-group is more pronounced than in most species from other groups (Ravensberg \& Hennipman, 1986). Similarly strongly dimorphic species, however, occur in the $P$. angustata-group $(P$. novo-guineae $)$ and in the $P$. lanceolata-group $(P$. fallax). This is an indication that this pronounced dimorphism may have been reached by different evolutionary pathways. The comparatively weak dimorphism in $P$. niphoboloides, if compared with the other species in this group, appears to be of a similar type as the dimorphism in $P$. angustata or the $P$. lanceolata-group.

Dissection. Normally developed fronds are simple and entire in all species except $P$. hastata and $P$. polydactyla. The fronds of these two species are pedately dissected to a varying degree, and the shape of the lamina has been compared to that of Dipteris and of Platycerium (Holttum, 1954; Jarrett, 1980,). The resemblance to Dipteris, however, is superficial only. In contrast to Dipteris, in Pyrrosia there is always a well-developed midrib in a well-developed middle lobe of the dissected lamina. This midrib is continuous with the stipe, and is obviously homologous with the costa of undivided fronds. In contrast to the situation in Platycerium, each lobe is provided with a distinct midrib and a regular venation that is directly comparable to that of the lamina of undivided species.

There is, moreover, a chain of intermediates linking the highly dissected lamina of $P$. polydactyla to the simple lamina of most Pyrrosia-species (fig. 7). This chain can be detected by comparing the closely related species $P$. drakeana, $P$. sheareri, and $P$. hastata. In $P$. sheareri the lamina often has a number of distinct 


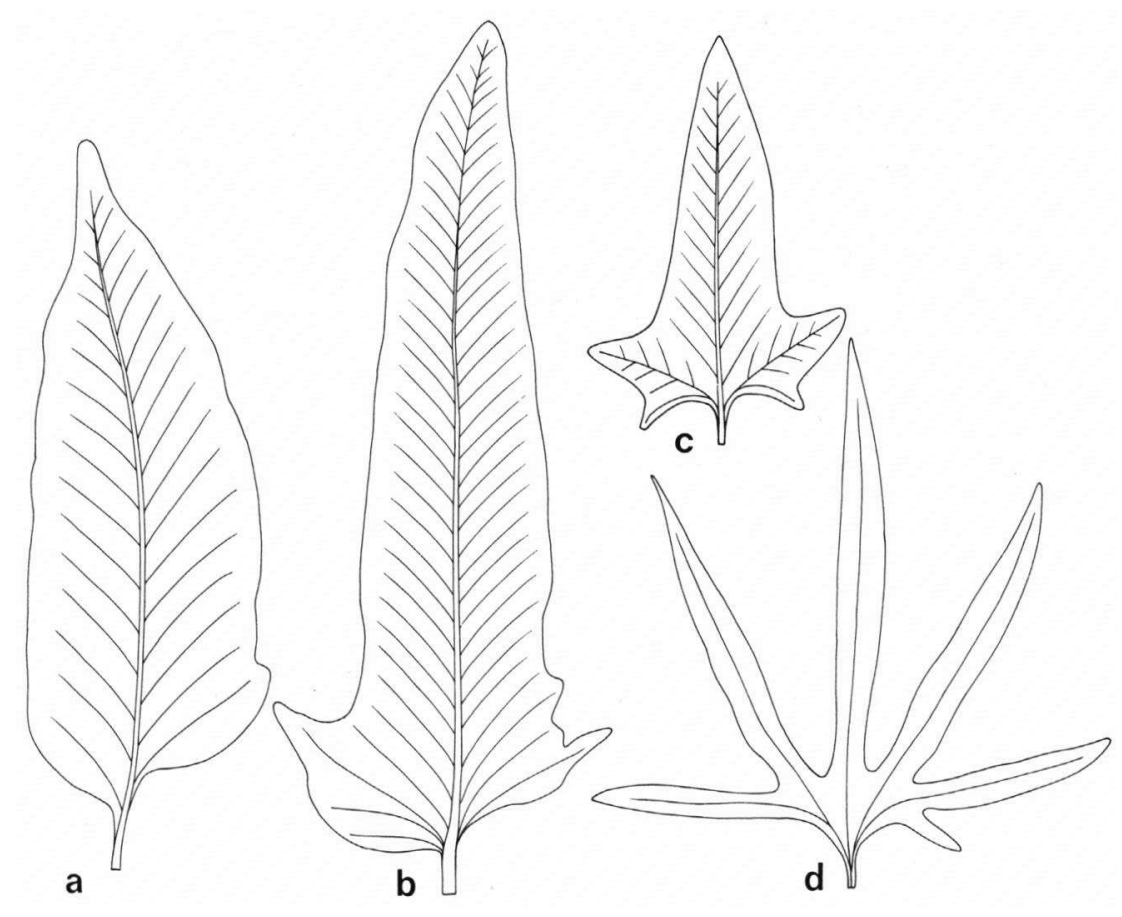

Fig. 7. Frond shapes in the $P$. sheareri-group. $\times 1 / 2$. a. $P$. drakeana; slightly lobed frond. - b. $P$. sheareri; distinctly lobed frond. - c. P. hastata. - d. P. polydactyla. (a. Purdom 97, US; - b. Fang 5840, GH; - c. Tagawa Iwatsuki 4556, L; - d. Kao 3891, US).

lateral lobes at the base (fig. $7 \mathrm{~b}$ ). Into each lobe runs a secondary vein that is slightly stronger than the veins in the rest of the lamina. Once this tendency is recognized in $P$. sheareri, it becomes apparent that it is also, but less distinctly, present in some specimens of $P$. drakeana (fig. 7 a).

The presence of these lateral lobes in $P$. sheareri apparently is not a fixed condition (see discussion under $P$. sheareri), and usually the lobes are developed slightly asymmetrically. In $P$. hastata (fig. $7 \mathrm{c}$ ) the presence of two approximately equally large lobes is fixed, and into both lobes a vein runs that is almost as strongly developed as is the costa. A small tooth may be present at the base of both lobes. In $P$. polydactyla (fig. $7 \mathrm{~d}$ ) there are at least two large lobes on each side of the lamina, which seems to be a fixed condition at least in mature, well-developed fronds. Each lobe has a midrib that is equally strong as and similar to the midrib of the lamina itself, now present in the middle lobe.

Under certain conditions $P$. polydactyla may form fronds that are similar in shape to those of $P$. hastata, and intermediate fronds with a varying number of lobes can also be found in the heteroblastic series (fig. 8). Linked to the increased importance of the lateral veins innervating the basal lobes, there is a downwards shift 


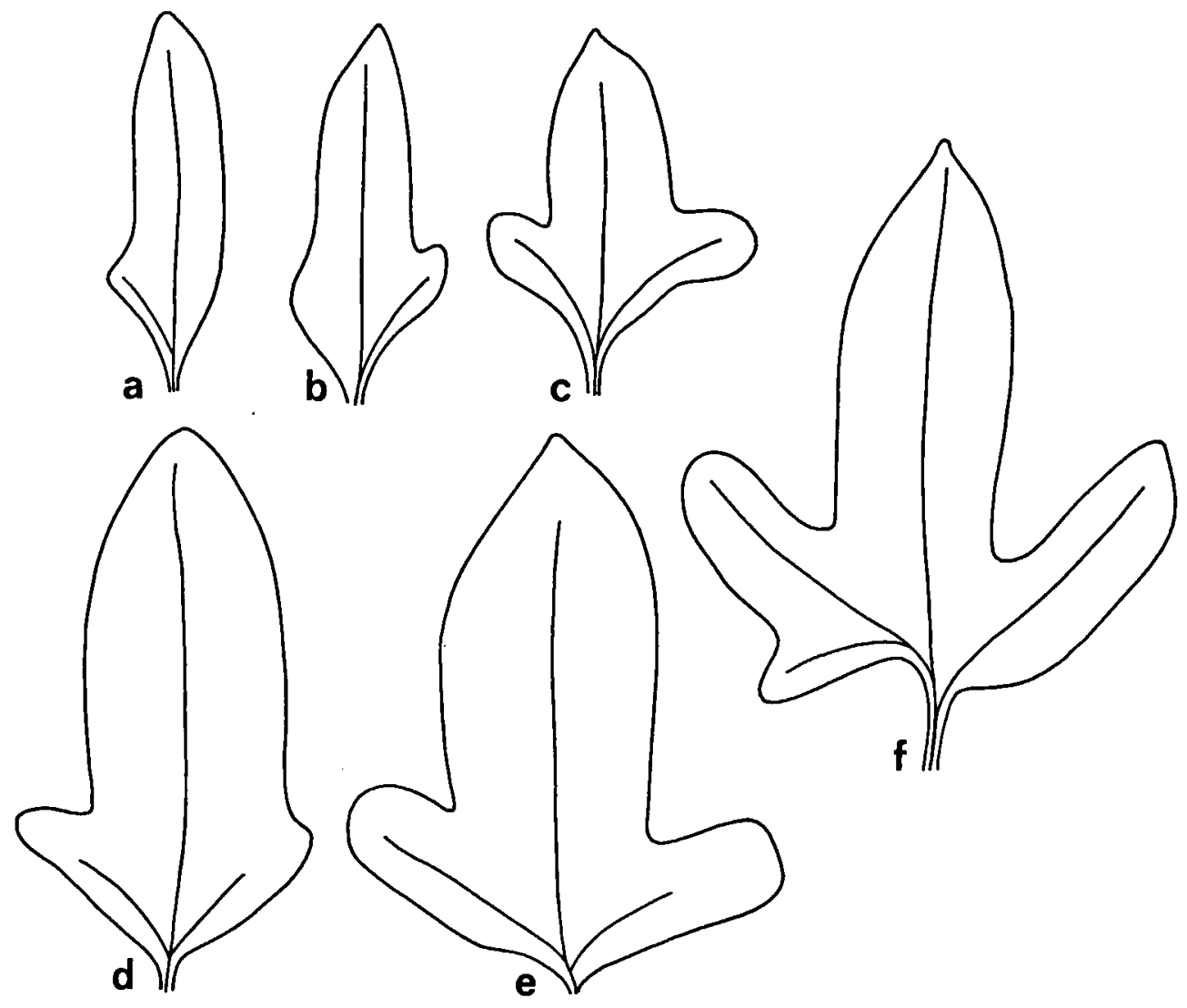

Fig. 8. Heteroblastic frond series of $P$. polydactyla (cult. Leiden). $\times \pm 1 \frac{1}{2}$.

of the point at which the veins branch off from the costa. Whereas in most species the upper part of the stipe shows the vascular configuration as described on $\mathrm{p}$. 30 , in $P$. polydactyla it is strongly dilated and contains three equally important bundles of vascular strands. Another, possibly related, feature is that in $P$. polydactyla and $P$. hastata the point of fusion of the two adaxial vascular strands is shifted downward, in $P$. polydactyla more so than in $P$. hastata.

In most other species furcate, cristate, or otherwise abnormally shaped fronds occur occasionally. More or less regularly furcate forms have sometimes been described as separate species (e.g.; Cyclophorus cornutus Copeland and C. xiphioides Christ), but the trait apparently has never become fixed even in small populations. Pectinately dissected fronds are absent except in $P$. mannii (see Taxonomical Part, p. 213). Even as a teratology such fronds do not occur in other species. 
Heteroblastic development. Throughout this work, the ontogeny of the individual organ or structure is considered separately from the development that can be seen on successive fronds formed by the developing plant. Tomlinson (1984) suggested to restrict the term "ontogeny" to the second process, and to use the term "primordial development" for the first. I find this use of the term "ontogeny" confusing considering the common usage of the term. I shall refer to the individual development as "ontogeny", or "ontogenetic" development, and to the second process as "heteroblastic" development. These two processes may result in similar intermediate structures, as in the case of the development of frond shape in $P$. polydactyla, discussed above. In other cases (e.g., development of lamina indument, see below), different intermediate structures may be found.

The heteroblastic development is not in all cases strictly unidirectional. Fronds of mature plants may, under unfavourable circumstances, take on the aspect of the fronds of a more juvenile stage. This is often seen when a piece of rhizome has been detached for some time and is then induced to form new fronds. The new fronds then formed are less distinctly stipitate than are older fronds.

An example of this reversal can be demonstrated in $P$. polydactyla. Before reaching the mature frond shape, $P$. polydactyla passes through a series of intermediate stages that corresponds roughly to the series of intermediate stages described above (p. 37). The first fronds formed are simple, the first sign of dissection being the occurrence of a single lateral lobe at the base of the lamina. In later formed fronds the number of lobes increases but the asymmetry is often retained for a long time: frequently one side has a larger number of lateral lobes than the other. A reversal of this development occurs if $P$. polydactyla is cultivated under suboptimal circumstances. In that case, the plant forms fronds that are less strongly dissected and are accordingly shaped like those of $P$. hastata.

Irregularities in heteroblastic development may underly the occurrence of other aberrant characters in otherwise normal, mature fronds: the rate at which the mature morphology is reached in the heteroblastic series may not be the same for all character complexes. On the other hand, also the strength of the reversal reaction in response to changed circumstances may vary for different characters. This may also result in the presence of aberrant structures on otherwise normal, mature fronds.

For 10 species the development of the lamina shape was followed in series of heteroblastic fronds. These 10 species were grown from spores in the Leiden Botanical Garden. Identification of each species was possible after some of the sporelings had developed into recognizable plants. Unfortunately, from one sample no plants ever reached that stage; this sample could be identified only as belonging to, the $P$. piloselloides-group. The other species investigated were: $P$. angustata, $P$. christii, $P$. gardneri, $P$. lingua, $P$. longifolia, $P$. nummulariifolia, $P$. polydactyla, $P$. princeps, and $P$. sphaerosticha (figs. 9, 10, see also fig. 12). 


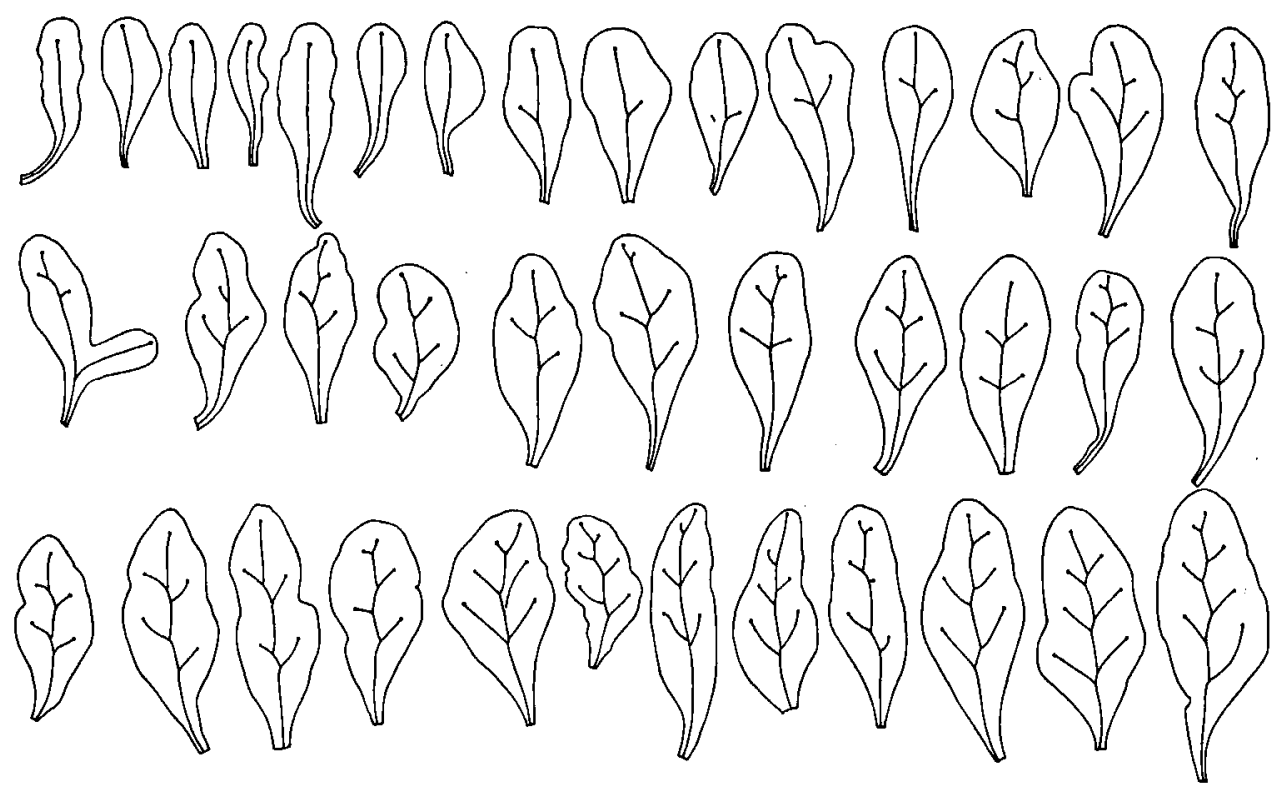

Fig. 9. Early sporophytic fronds, arranged according to increasing complexity of the venation. $P$. princeps (cult. Leiden). $\times 4$.

Development in all these species was conform the pattern indicated by Wagner (1952) for Polypodiaceae and Vittariaceae. The earliest fronds formed are simple, and in most species not distinctly differentiated into a stipe and a lamina. Only in $P$. polydactyla a distinct stipe was found to be present in all the first fronds. In the other species the lamina of the first fronds was variously narrowed towards the base. With regard to the degree to which a stipe is present in the first fronds there is little difference between species with distinctly stipitate adult fronds (e.g., $P$. christii) and species in which the adult fronds are estipitate (e.g., P. princeps). This uniformity persists roughly through the stage in which the rhizome is not yet elongated. As the rhizome starts to elongate, in the species where the mature plant has an elongate rhizome, the fronds formed successively on the elongating rhizome gradually take on the mature morphology.

Vernation of mature fronds is circinnate, though often very indistinctly so. In very small, reduced fronds the circinnate character may have become completely obscure.

\section{Lamina indument}

The indument of the fronds is almost exclusively composed of stellate hairs. The only exceptions are the occurrence in some species of scale-like filaments at the 


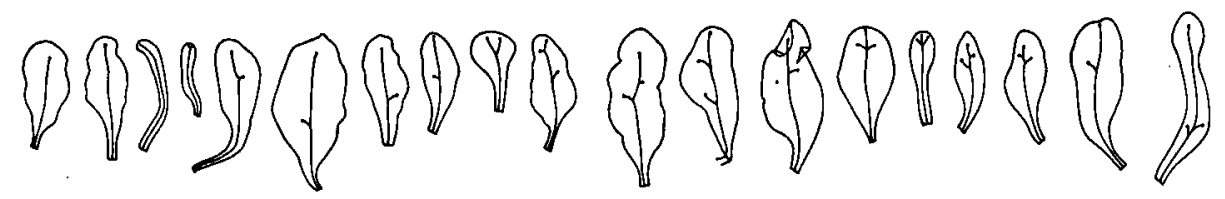

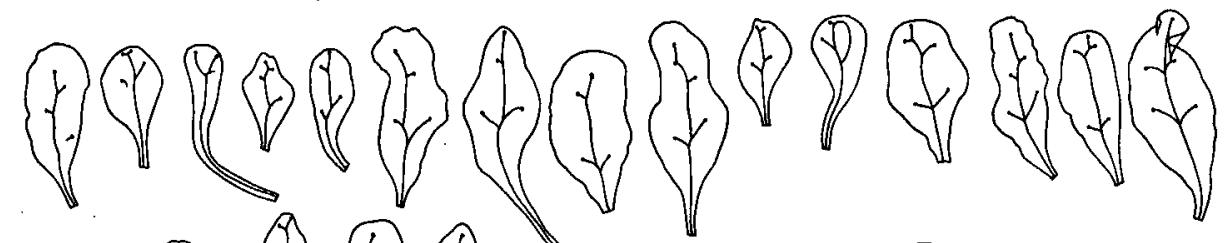

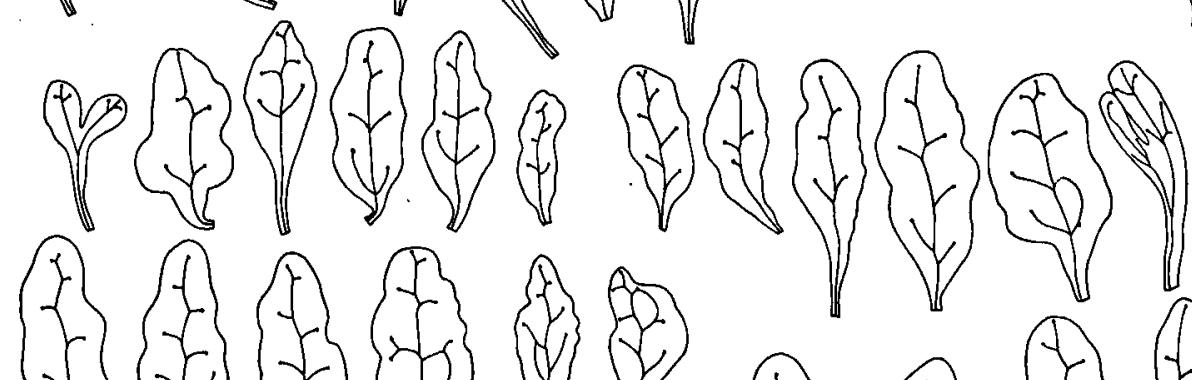
a $v(v)(v)$ PPDPNPSPPAPPP

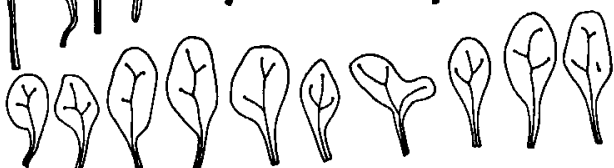
PPPP(YPP(Y) PrVP

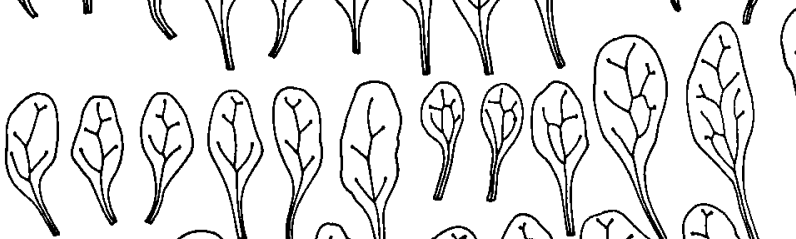
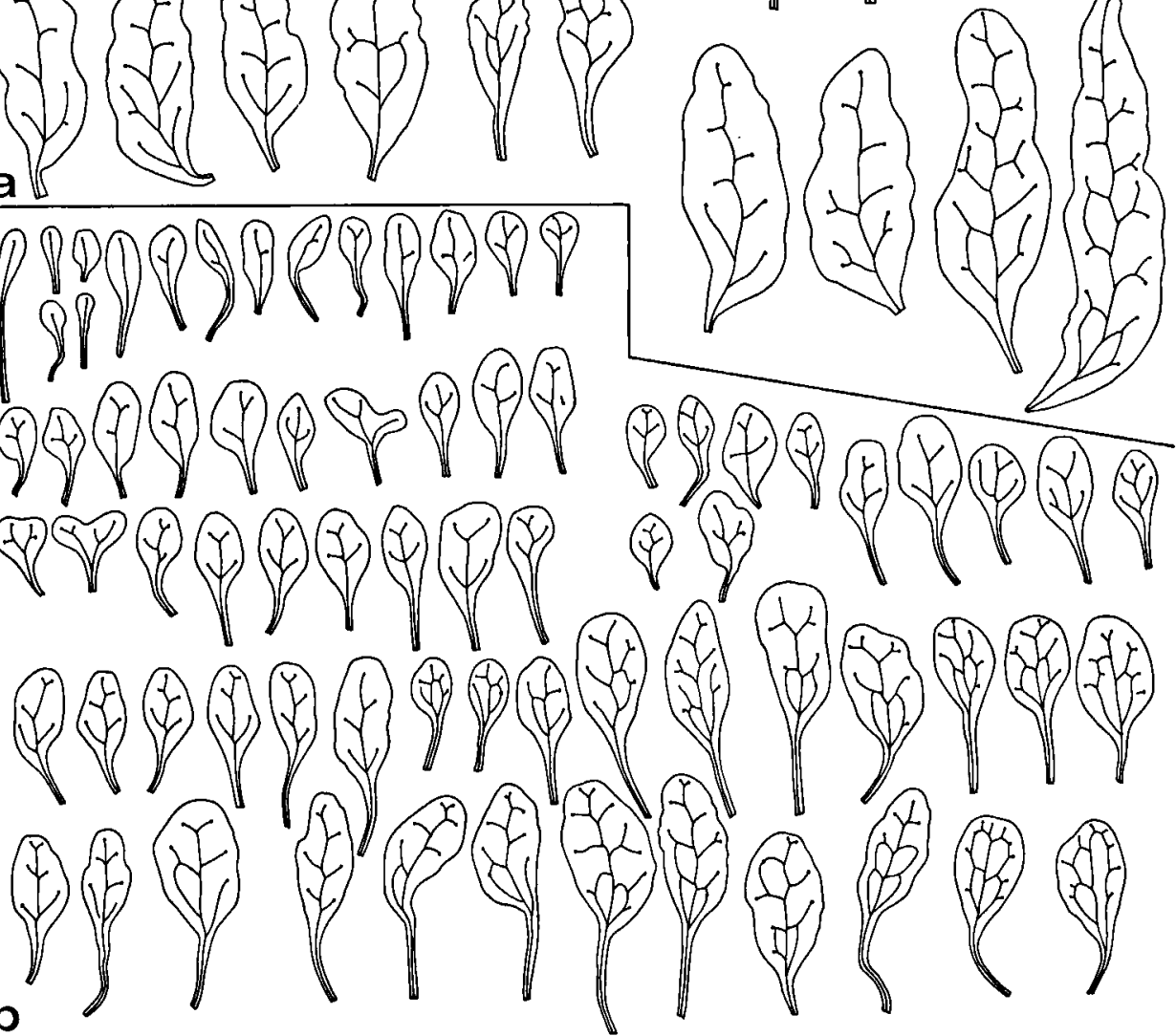

He

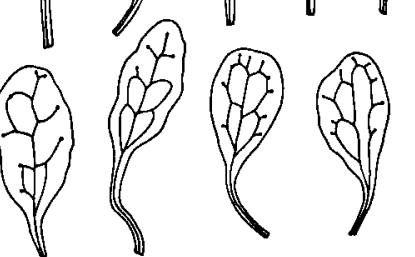

Fig. 10. Early sporophytic fronds, arranged according to increasing complexity of the venation. $\times$ 4. a. P. christii. - b. P. polydactyla. (Both from material cult. Leiden Bot. Garden). 
base of the stipe, and the occasional occurrence of glandular hairs, the latter probably representing remnants of the indument of juvenile fronds, or reversals to a more juvenile condition.

The stellate hairs cover the fronds completely from the point of articulation upwards. The transition, at the articulation, to the scales covering the rhizome is remarkably sudden and complete: only in $P$. princeps a thin cover of stellate hairs extends downwards over the phyllopodium under and among the scales. In many other species scale-like filaments occur that form another transition but they are usually scarce and restricted in distribution.

The indument is usually best developed on the abaxial (lower) surface of the lamina: here the highest diversity of hair-types is found as well as the greatest density of hairs. On the adaxial (upper) surface, and in many species on the stipe, the indument is less persistent. On the upper surface, moreover, the hairs are more sparsely distributed and have longer, narrower stellate rays that do not, or to a lesser extent, show the modifications found on the lower surface. Sometimes there may be a slight difference in indument between sterile and fertile parts of a frond; the indument on fully sterile fronds is generally similar to that of the sterile parts of fertile fronds. The following description refers to the indument of the sterile parts of fertile fronds or of fully sterile fronds, in all cases to that of the abaxial surface.

Modifications of the indument have always played an important part in systematic accounts of the genus, and keys given by, e.g., Giesenhagen (1901), Ching (1935), Holttum (1954), and Nayar \& Chandra (1965) rely heavily on characters of the indument. Shing (1983) has presented a subdivision of the genus based almost exclusively on characters of the indument.

In phylogenetic discussions of the affinities of Pyrrosia the indument is also an important character: the stellate hairs have been compared to the stellate hairs occurring in Gleicheniaceae (Nayar \& Chandra, 1967); to the peltate scales of Pleopeltis (Lepisorus) by Copeland (1947) and Jarrett (1980); and have by these authors been taken as indicative of affinity with the groups mentioned. In this respect Copeland and Jarrett follow Mettenius (1856, p. 9), though on a different taxonomic level.

The presence of stellate hairs in Platycerium similar to those in Pyrrosia is accepted by most authors (though only reluctantly by Pichi Sermolli, 1977b) as an argument in favour of a close connection between Pyrrosia and Platycerium (Nayar * Chandra, 1967; Hoshizaki, 1972; Crabbe e.a., 1975). Hennipman \& Roos (1982), using cladistic terminology and method of analysis consider the two genera as sister-groups (Hennig, 1966), mainly on the strength of the shared possession of stellate hairs.

The similar indument in Platycerium is found to play a part in the retention of water by the fronds (Froebe \& Strank, 1981). The similar indument in Pyrrosia may have the same function. 


\section{Morphology}

The stellate hairs are structurally comparable throughout Platycerium and Pyrrosia. They are composed of a uniseriate stalk with a terminal 'crown' of stellate, unicellular rays (fig. $11 \mathrm{e}$ ). Usually there are 6-12 rays in a crown, but, especially in the $P$. lanceolata-group and the $P$. confluens-group, the number of rays may be 15-20. Within a species this number may vary considerably, and the variation seems to have little, if any, significance from a systematical point of view. The same applies to Platycerium (Hennipman \& Roos, 1982 p. 26-27). The rays of each crown are attached to the apical cell of the stalk without any apparent regularity of insertion. This apical stalk-cell, serving as a point of attachment for up to 20 rays, is accordingly often distinctly enlarged compared with the other stalk cells.

The stellate rays of the hairs may have become modified in the following ways:

Boat-shaped rays (pl. 3 b, c, h):

The rays are broadly grooved (pl. $3 \mathrm{~b}$ ) or flat (pl. $3 \mathrm{c}$ ), generally less than 0.5 $\mathrm{mm}$ long, and are sometimes more or less distinctly striate. Usually, the rays of a single hair are all in the same plane, parallel to the surface of the lamina. Hairs with this type of stellate ray generally have short stalks (pl. $3 \mathrm{~h}$ ), so that the indument as a whole is rather appressed.

Acicular rays (pl. 3 a, d, g):

The rays are much narrower and longer than those of the boat-shaped type. Examined by scanning electron microscopy they appear to be narrowly grooved and often somewhat spiralized. The diameter of hairs with these rays is usually larger than that of hairs with boat-shaped rays, and in many cases their stalk is much longer. Induments with this type of hairs are thus usually rather loose and shaggy, and at first sight quite different from the appressed, monomorphic ones with boat-shaped rays. With SEM, however, it becomes apparent that there is no fundamental difference between both types of rays. The acicular type of rays appears to be a narrow, twisted form of a basic structure, of which the boat-shaped type may be considered a wider and flatter form. All intermediates are possible and actually can be found in Pyrrosia as well as in Platycerium.

From the variability in some species it also is obvious that there is no fundamental difference between acicular and boat-shaped rays, which can be illustrated by the situation in, e.g., $P$. flocculosa: here in some plants appressed, boat-shaped rays prevail, whereas in others the hairs are very long and distinctly acicular. A similar variablity is found in $P$. kinabaluensis, and in, e.g., $P$. angustata all different types of rays can be found in only a small sample of hairs.

Woolly rays ( $\mathrm{pl} .3 \mathrm{~d}, \mathrm{e}, \mathrm{f}, \mathrm{g}$ ):

These are very long, ribbon-shaped, and strongly and irregularly curled. Usually these woolly rays form, closely appressed to the epidermis, a more or less dense felt in which the individual rays are strongly intertwined. That there is no fundamental difference between straight rays and woolly ones is apparent from 
the occurrence of intermediate forms. These intermediates are more or less distinctly acicular at their base, but gradually become elongated and ribbonshaped towards the apex. Another intermediate condition is present in $P$. africana where the rays are mostly acicular, but may be more or less sinuose without ever becoming completely ribbon-shaped.

The modifications described above may occur in varying combinations, thus forming induments that look widely different. Two basic types of indument have generally been recognized: monomorphic and dimorphic induments.

Monomorphic induments (pl. $3 \mathrm{~b}, \mathrm{c}$ ). In this type of indument all the hairs have only straight stellate rays. The rays may be boat-shaped or acicular. Boatshaped rays are characteristic for many species of the $P$. lingua-group, for the $P$. confluens-group and the $P$. lanceolata-group. However, this type occurs also in several other apparently unrelated species ( $P$. schimperiana, $P$. sheareri, $P$. hastata). Monomorphic induments composed entirely of hairs with only acicular rays occur only in $P$. africana, $P$. penangiana and in the $P$. piloselloides-group. This type of indument occurs only incidentally in other species, and then obviously originated through the incidental loss of hairs with woolly rays.

Dimorphic induments (pl. $3 \mathrm{~d}, \mathrm{f}, \mathrm{g}$ ). In this type straight rays are always present (either acicular or boat-shaped), together with at least some hairs with woolly rays. The woolly rays either form a dense felt, close to the epidermis of the lamina (pl. $3 \mathrm{~g}$ ), or they occur more scattered on hairs with predominantly straight rays (pl. $3 \mathrm{~d}$ ). In the first case, the straight rays are usually appressed to the felt or are more or less raised above it, but if neither of the layers is very dense, the two layers may be mixed. Although often the straight rays appear to occur in a separate layer distinct from that of the woolly rays, closer examination shows that in most cases the two layers are not strictly separated. Most hairs have straight rays as well as woolly ones, and these two types do not occupy different "whorls", but they may be completely mixed, and not infrequently some of the uppermost rays are of the woolly type ( $\mathrm{pl} .3 \mathrm{e}$ ). Usually, though, the hairs closer to the epidemis have a larger proportion of woolly rays.

In the straight rays of the dimorphic indument the same differentiation is seen as in the rays of the monomorphic induments: they may be either boat-shaped (pl. 3 e) or acicular (pl. $3 \mathrm{~d}$ ), whereas intermediate forms also occur. The combination of woolly rays and boat-shaped straight ones is less common than the combination of woolly and acicular rays. The latter combination occurs in almost all members of the $P$. albicans-group and the $P$. porosa-group, and in several members of other groups. The combination of boat-shaped and woolly rays is restricted to members of the $P$. costata-group, to $P$. lingua var. heteracta and $P$. laevis. 
In many species the proportion of hairs with woolly rays varies strongly. In $P$. porosa and $P$. rhodesiana forms without woolly rays are rather frequent. In $P$. distichocarpa and $P$. drakeana similar monomorphic forms are rarer, and in $P$. rasamalae they occur sporadically.

A very distinct modification of the hairs is found in $P$. laevis $(\mathrm{pl} .3 \mathrm{f}$ ) and $P$. splendens (and occasionally, in a less distinct form, in $P$. costata and $P$. princeps). Here the straight rays overlying the woolly layer have developed distinct "dorsal spines", that is, one of the rays occupying a central position in a hair-crown has become distinctly modified. It stands out erect and is conspicuously longer than the other rays in the same hair-crown. This central ray has moreover become acicular in $P$. laevis (in $P$. splendens all rays are acicular), and in both species it contrasts strongly with the other rays that lie closely appressed to the lower, woolly layer.

\section{Development}

Ontogeny. The ontogeny of the stellate hairs of Pyrrosia has been studied by Nayar (1961, p. 169 fig. 35-37, p. 171) in unspecified material. The development of the stellate hairs present in the sori in $P$. lanceolata (as " $P$. nuda") was studied by Wilson (1958, p. 486-489, fig. 32-37). I have studied the development of the hairs of $P$. christii (grown from spores in the Leiden Botancial Garden) and have found a similar course of development as described by Nayar (fig. $3 \mathrm{v}-\mathrm{z}$ ).

In $P$. christii development of a hair starts with a cell of the epidermis that swells and begins to protrude. From this cell a number of cells are split off by repeated oblique divisions, each one in a different direction. These cells then elongate and form the crown of the hair. Only after this crown is almost fully differentiated the uniseriate stalk develops. It is not clear whether the initial epidermis cell or the apical cell of the stalk is involved in this process.

Heteroblastic development. In the heteroblastic development the firstformed indument on the juvenile fronds is composed almost entirely of glandular trichomes. These trichomes are similar to those occurring on the midrib of the prothallia of Pyrrosia (Nayar, 1961); and in the first stages there is no distinction between the indument of the lamina and that of the prothallium. The trichomes are composed of a basal cell with two glandular, swollen cells attached to it, one apically, one subapically-laterally. On the earliest fronds these trichomes form a sparse cover on both sides of the lamina, and only on the margin of the lamina a few hairs are present that are short-stalked, branched, and have one or two elongated rays apart from a glandular cell (fig. $11 \mathrm{~b}$ ). These hairs are similar to the other glandular trichomes, but apically they have a few acicular rays instead of only two glands.

In later fronds, the trichomes are replaced gradually by hairs with acicular and woolly rays similar to those of the mature plant, provided, of course, that both 
these two types are present in the mature plant. This cover is at first sparse, but as more mature fronds are formed the indument increases in density and the mature condition is approached gradually. The transformation of elongate, acicular rays to boat-shaped ones is the last to take place, and hairs with acicular rays usually persist as an upper cover over mature fronds, to be shed as the lamina expands. These acicular hairs are often slightly larger and darker in colour than the hairs of the lower strata and they can often be seen as a dense cover of the circinnate apices of developing fronds. In several species they are rather persistent, and on fully grown fronds they remain visible as a sparse cover of blackish hairs, giving the lower surface of the lamina a distinctly "punctate" appearance (often distinct in $P$. lingua var. heteracta). The uppermost layer of acicular hairs found in some species as a constant feature (e.g., in $P$. angustata, $P$. samarensis) may have a similar origin, as may also be true for the upper layer of hairs in $P$. princeps and $P$. splendens. This upper layer with patent rays $(P$. princeps) or with erect spines $(P$. splendens) can be seen to cover the apex of the developing lamina in a similar way as does the more deciduous layer of hairs in other species. This layer either has evolved from, or completely replaced, the upper layer of hairs.

\section{Filaments}

In a number of species (especially those of the $P$. sheareri-group) the indument at the base of the stipe is conspicuously more shaggy than that of the lamina. This is mainly due to the presence of hairs with strongly elongated stalks. Often structures are present among these hairs that consist merely of a long, uniseriate row of cells. These structures may be stalks that have lost the stellate crown, or they are different structures that never had a terminal crown of rays. From the frequency with which these filaments occur, and from the occurrence of similar filaments with a strongly reduced crown of only one or two rays, it can be inferred, however, that the absence of a crown is not due to its deciduous character.

Intermixed with these filaments and long-stalked hairs broader, dilated filaments occur sometimes that are uniseriate only at their base and the apex. The middle part of these filaments is multiseriate and laterally expanded to form a scale-like structure. Especially the occasional presence of a few acicular hairs at the apex of these filaments (similar to the rays of a hair-crown) as well as the presence of marginal cilia on the scale-like part makes these filaments appear fully intermediate between hairs and scales.

These scale-like filaments occur in all species of the $P$. sheareri-group, except $P$. hastata and $P$. polydactyla; also in the $P$. costata-group and in most species of the $P$. porosa-group. They may be present in young fronds only, as the indument at the base of the stipe in which they occur is often deciduous.

Somewhat similar filaments can be found in Platycerium, but here they appear to be present only at the base of base-fronds. However, their distribution over 


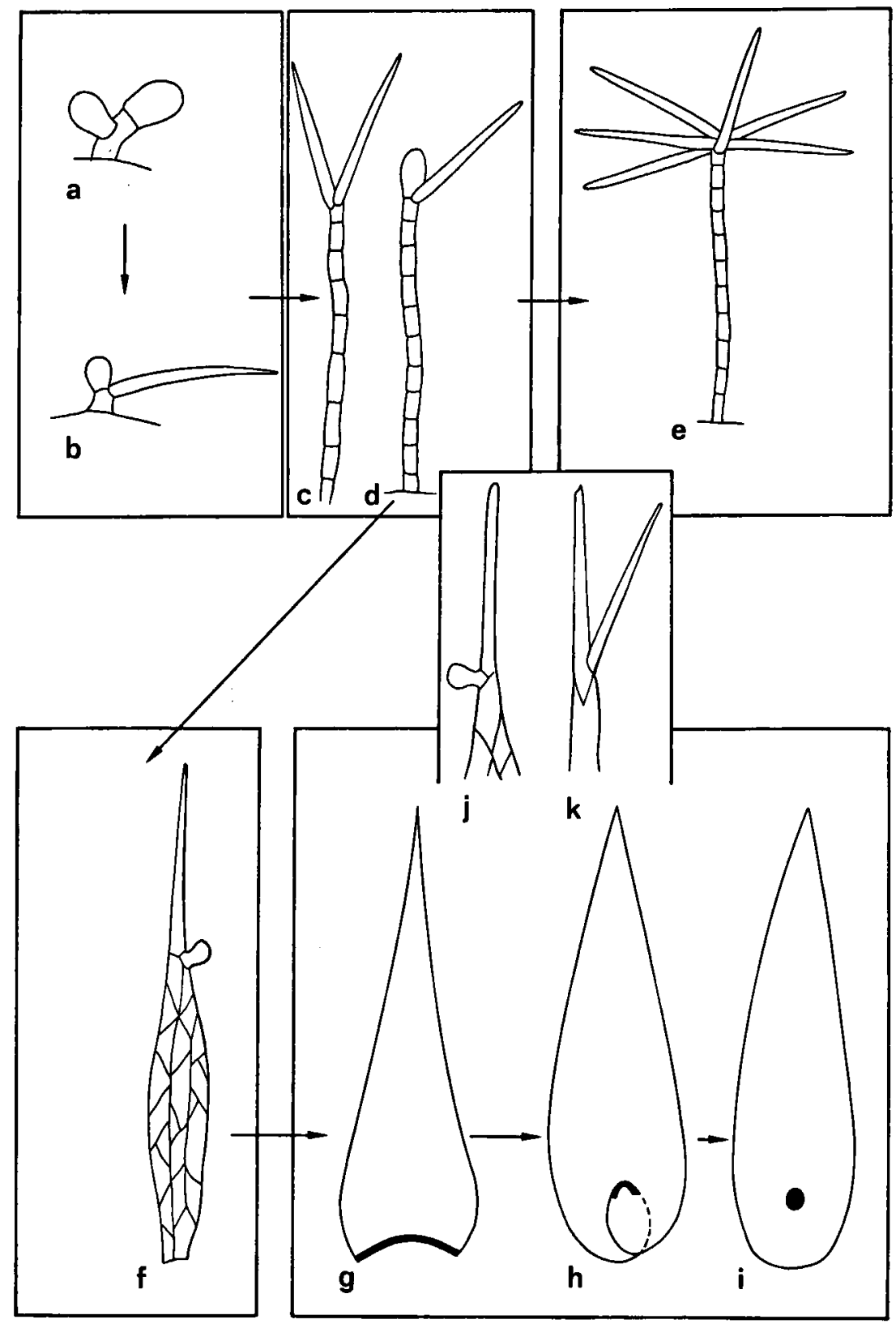

Fig. 11. Schematic representation of dermal appendages in Pyrrosia and their possible phylogenetic reiations. a, b. Gianduiar trichomes and nairs as occurring on gametophyte and juvenile sporophytes. $-c, d, f$. Filaments and filamentous scales as occurring on the base of the stipe. e. Hair as occurring on the lamina. - $\mathrm{g}-\mathrm{k}$. Scales as occurring on the rhizome (g: basifix scale; h: pseudopeltate scale; i: peltate scale; $j$, $k$ : two possible types of apex of the scales). 
other parts of the plant and throughout the genus has not been investigated extensively.

If these scale-like filaments are considered as intermediate between scales and hairs, they may be used to construct a transformation series along which the homology of both types of indument can be established. Both scales and hairs are then found to be derived from uniseriate hairs (fig. 11). The scales are derived from such hairs by lateral expansion; the stellate hairs by repeated division of the apical cell. If this homology is accepted, an entire, peltate scale is homologous with the stalk of a stellate hair; and the stellate crown of the hair is homologous at most with the marginal indument of the scale, and perhaps only with the acicular hair that is often present at the apex of scales. The homology that is supposed by some authors (Copeland, 1947; Jarrett, 1980) to exist between the stellate crown of a hair and the blade of a peltate scale is then false.

\section{Venation}

In most species the venation of the fronds, in fresh as well as in dried state, is obscured by the thickly coriaceous or succulent texture of the lamina. At most the secondary veins are more or less evident on the lower side of the lamina. Only when the lamina is comparatively thin the venation pattern is directly evident, in all other cases some treatment for clearing the fronds is necessary before the venation pattern exhibited by the tertiary and higher order veins can be studied (see page 4). The following descriptions of the venation therefore refer to the pattern as it is visible in cleared parts of the lamina. As there is often a slight difference between the patterns of sterile and fertile parts, the description refers only to sterile parts of the lamina. The difference between the patterns in the sterile and fertile parts will be discussed in connection with the insertion of the sori.

\section{Venation pattern}

Primary vein. There is always a primary vein, or costa, which follows the axis of symmetry of the lamina. It is distinct usually for most of its length, sometimes even almost up to the apex.

Secondary veins. The secondary veins are often conspicuously thicker than those of tertiary and higher order, and follow a more or less straight course from the costa some way towards the margin ( $\mathrm{pl} .4 \mathrm{c}, 5 \mathrm{c}, \mathrm{e})$. Usually they are distinct for most of that distance and only near the margin dissolve into a number of more or less equal branches taking part in the mesh of tertiary veins (pl. $5 \mathrm{e}$ ). The pattern formed by the secondary veins is relatively uniform. If the fronds are small or narrow (pl. $4 \mathrm{e}$ ), the secondary veins are usually less distinct from the higher- 
order veins and follow a zig-zag course towards the margin for a relatively short part of the way before dividing into branches indistinguishable from the tertiary veins. Only in $P$. africana (pl. $4 \mathrm{~d}$ ) and $P$. schimperiana the secondary veins follow such an irregular course also in relatively large fronds. In these two species the secondary veins are hardly distinct from the other veins.

Tertiary veins. The tertiary veins connect the secondary veins at regular intervals, thus delimitating series of areoles between the costa and the margin. They are straight (pl. $5 \mathrm{c}$ ) or more or less arched outwards (pl. $4 \mathrm{a}$ ), and run perpendicular or more or less oblique to the secondary veins. The areoles thus formed vary from more or less regular rectangles to parallellograms or are more irregularly shaped. The latter is mostly the case in small or narrow fronds, in which the secondary veins are indistinct. The number of areoles between one pair of secondary veins may be as much as 10 to 20 in wide fronds ( $\mathrm{pl} .5 \mathrm{c}$ ). The tertiary veins are usually distinctly thicker than the higher-order veins while they are thinner than the secondary ones, but in some species the distinction is not clear. This is the case in $P$. africana (pl. $4 \mathrm{~d}), P$. schimperiana, and in the narrow or small fronds mentioned before.

Included veins. Most of the variation in venation pattern is found in the patterns formed by the higher-order veins included in the areoles delimitated by the secondary and the tertiary ones.

In the simplest patterns the included veins are simple, straight, and excurrent (pl. $5 \mathrm{a}, \mathrm{c}, \mathrm{d}$ ). The number in each areole varies from 2 to 5 (occasionally 10). This simple type of venation is characteristic of the $P$. porosa-group and occurs in many species scattered through the other groups ( $P$. longifolia, $P$. gardneri, $P$. albicans). In the $P$. confluens-group (pl. $4 \mathrm{e}$ ) a similar pattern is present, but here the number of free veins is often reduced and many of the veins merge again distally with the tertiary veins.

A distinctly different pattern with regard to the direction of the free included veins is found in the $P$. piloselloides-group (Ravensberg Hennipman, 1986). Although in general the pattern in $P$. piloselloides, $P$. heterophylla, and $P$. niphoboloides is similar to the pattern of small fronds of other Pyrrosia species, the included veins of these species are recurrent instead of excurrent. This is curious as the direction of the included veins is a character that within the Polypodiaceae is constant for systematic groups of at least generic status.

A more complicated pattern arises if the included veins are forked or branched more than once. In such patterns the included veins form a more or less anastomosing pattern of varying complexity ( $\mathrm{pl} .4 \mathrm{a}$ ). The remaining free veinends are still mostly excurrent, but incidentally some recurrent vein-ends are also present. This more complicated pattern is often present in large fronds of species the smaller fronds of which show a more simple pattern like that described above (this is often the case in $P$. lanceolata). Apart from that, it is the prevalent pattern 
in the $P$. lingua-group, in $P$. pannosa, $P$. eleagnifolia, in the larger-fronded species of the $P$. albicans-group, and in many species of the $P$. sheareri-group.

The most complicated pattern occurs if the included veins branch and anastomose frequently and irregularly (pl. $4 \mathrm{c}, 5 \mathrm{e}$ ). In that case a very fine mesh is formed in which the free vein-ends are no longer mainly excurrent, but point to all directions. This pattern is characteristic of the $P$. costata-group, but a similar pattern occurs also in some species of the $P$. lingua-group ( $P$. abbreviata, $P$. christii, P. sphaerosticha).

Costal areole. In most patterns described above the situation is different in the areole directly adjoining the costa (the costal areole): here the included veins are predominantly recurrent, as they spring from the tertiary vein instead of from the costa (pl. $4 \mathrm{a}$ ). This costal areole often cannot be distinguished in basal parts of the lamina, where it may be completely obscured by and incorporated into the thick costa. It is usually evident near the apex, where the costa is less thick than it is at the base. A costal areole with these characteristics seems to be absent from the $P$. africana-group, or else it is indistinguishable there in the irregular mesh formed by the veins.

"Costular areoles". In some species of the $P$. lingua-group (especially the three with the most complicated pattern, viz., $P$. abbreviata, (pl. $4 \mathrm{c}$ ), $P$. christii, $P$. sphaerosticha) there is a tendency for the included veins to form a row of "costular" areoles alongside the secondary veins, analogous to the costal areoles alongside the costa. These costular areoles, in contrast to the areoles usually formed by secondary and tertiary veins, are themselves devoid of included veinlets.

Marginal veins. At the very margin of the lamina there is a distinct row of excurrent, free veins. This row is present in the $P$. piloselloides-group as well, although in this group the free veins are otherwise recurrent.

\section{Heteroblastic development}

The fronds formed successively by the developing sporeling show an increasing complexity of venation pattern. In the fronds of a single sporeling not all the stages of this process are necessarily represented (Wagner, 1952), so that large numbers of early sporophytic fronds have to be studied in order to obtain an image of the entire process. Large numbers of sporelings from evidently axenic cultures were available to me of $P$. princeps, $P$. polydactyla, and $P$. christii. The results obtained through study of the heteroblastic development of these species could be supplemented with the results obtained by studying smaller numbers of sporelings of the rest of the species already mentioned on p. 39 (figs. 9, 10, 12).

In all species studied the development of the very simple venation of the firstformed fronds into the complex patterns of the mature stages is a gradual one. 

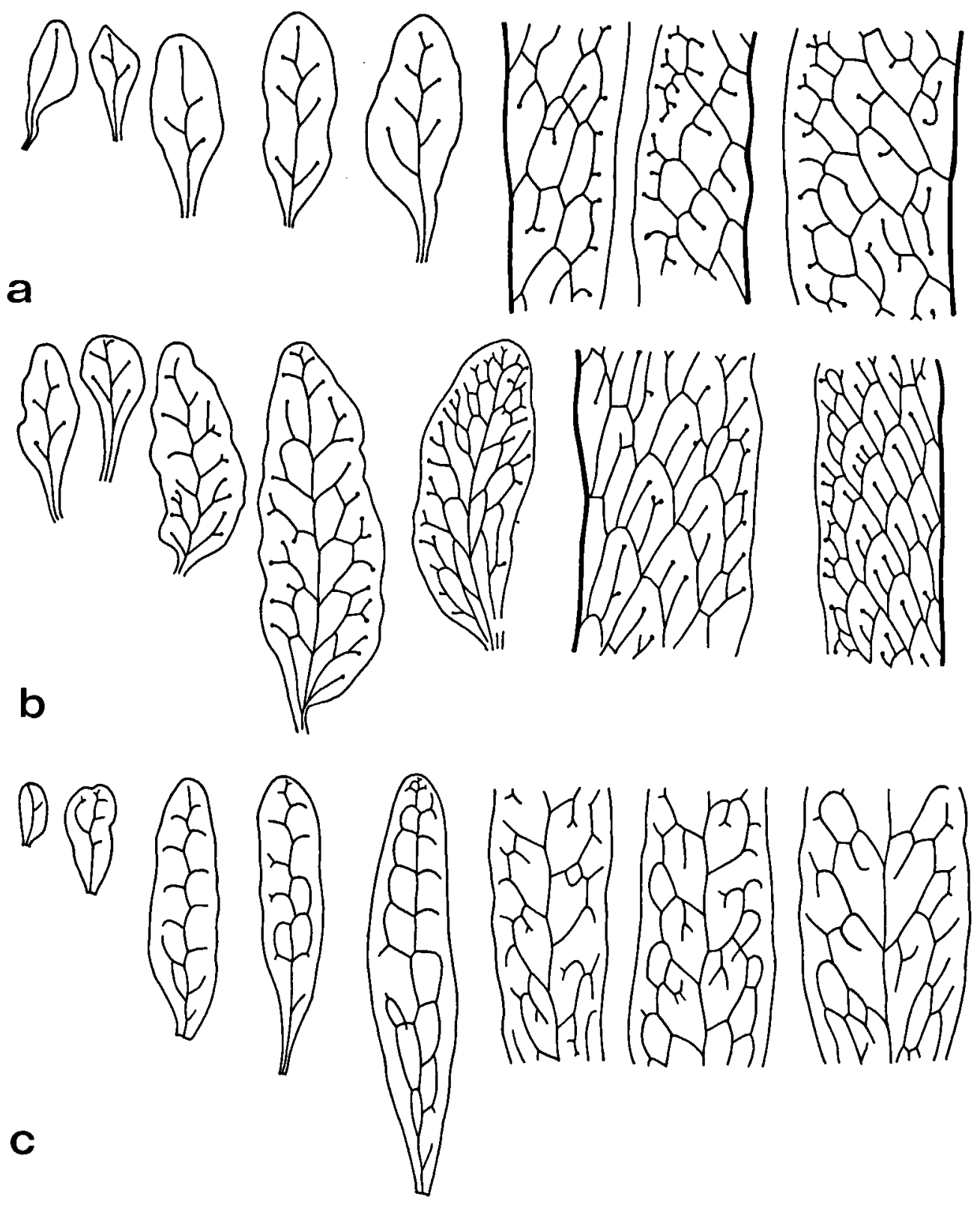

Fig. 12. Heteroblastic development of venation pattern. $\times$ 2.5. a. $P$. princeps. - b. $P$. gardneri. c. P. cf. piloselloides. (a. cult. Leiden Bot. Garden, LEI 20455; - b. cult. Leiden Bot. Garden, LEI 21730; - c. cult. Leiden Bot. Garden, s.n.) 
The first sporophytic fronds can be arranged according to increasing complexity of the venation pattern. As a measure of complexity I have chosen the number of branching points and of closed areoles and have accordingly orderly arranged c. 50 fronds of three species (fig. 9, 10). It then appears that there is a complete continuity from the simplest patterns of the first fronds to the complex patterns in later fronds. In this continuous range it is impossible to recognize distinct stages, as Wagner $(l . c$. ) noted, but did not illustrate, for Polypodiaceae and Vittariaceae.

In a general way the increase in complexity corresponds to the order in which the fronds develop, although fronds with a similar place in the succession are not necessarily similar (Wagner, l. c.: "'an individual leaf is not a morphological entity'). In the following, I shall accordingly consider the increase in complexity rather than the individual succession of the fronds.

The simplest fronds have a medial vein (costa) that is simple or pinnately branched, with few, simple, free branches. The number of branches may be 5 to 10 before the first anastomoses start to appear. In fronds with a larger number of branches usually one or more of these are forked or anastomose to form a closed areole alongside the costa.

The number of areoles then increases until most of the branches are involved in the formation of areoles, so that the costa is lined with a row of areoles on each side (the "costal" areoles). In this stage there is usually also a row of marginal, simple excurrent veinlets inserted on these areoles (the marginal excurrent veins). The extent to which this marginal row is developed varies somewhat between species: in $P$. longifolia distinctly fewer marginal veins are present than in most other species; and in P. piloselloides (fig. $12 \mathrm{c}$ ) in this stage very few marginal veins are present. These two rows persist more or less unchanged throughout the heteroblastic series, while the more complex, mature patterns appear to be "interpolated" between them as more mature fronds are formed.

As the width of the lamina gradually increases, the number of areoles increases accordingly, and successive rows of areoles are added to the costal row. The areoles are then filled with an increasing number of included veinlets, so that gradually the pattern of the mature fronds develops. When the first included veins appear, there is usually only one per areole. The pattern is therefore necessarily a simple one and reflects the mature pattern only to a limited extent.

In those species in which the mature fronds have a venation pattern with predominantly excurrent free veins $(P$. angustata, $P$. lanceolata, $P$. longifolia, $P$. lingua, $P$. gardneri, fig. $12 \mathrm{~b}, P$. nummulariifolia, $P$. polydactyla) the included veins occur first in the outer areoles (as opposed to the costal areoles). They are mostly excurrent, occasionally recurrent or anastomosing. In the costal areoles the included veins appear later and are mainly recurrent. This is similar to the situation in the mature fronds. 
In species with a more complex venation pattern in the mature fronds, with many anastomoses and free veins pointing to all directions ( $P$. princeps, fig. 12 a, $P$. christii and $P$. sphaerosticha) the included veins appear approximately simultaneously in the costal and in the outer areoles. They are predominantly recurrent, but this is less distinct in $P$. christii than in the other two species. As the number of included veins increases, the pattern becomes more complicated, with free veins, except those in the costal areoles, pointing to all directions.

In $P$. piloselloides only recurrent included veins occur throughout the heteroblastic series. The first included veins appear in the costal areoles and are recurrent. Recurrent veins appear later in the outer areoles and remain recurrent throughout the stages studied.

\section{Hydathodes}

In most species distinct hydathodes are present on the upper surface of the lamina (pl. 6 e). Structurally, the hydathodes are similar to those of Microsorum (Ogura, 1972, p. 124), but in Pyrrosia they are usually slightly sunken instead of being superficial, and occasionally deeply pitted or somewhat raised above the surface, the latter especially in dried fronds. Often they are covered with a small white scale, which dissolves in dilute hydrochloric acid and is probably composed of $\mathrm{CaCO}_{3}$.

The hydathodes are usually evenly scattered over the lamina. They are borne on the end of the free veins, but in the species with a strongly anastomosing venation pattern with relatively few free vein-endings they are also borne dorsally on the included veins. In the $P$. confluens-group, where free vein-endings are also relatively infrequent, the hydathodes occur on the ends of the marginal excurrent veins, so that they are restricted to a marginal row. In $P$. rupestris some hydathodes are occasionally present scattered over the lamina, and the marginal row is situated on the upper surface of the lamina. In $P$. serpens and $P$. confluens scattered hydathodes are completely absent and the marginal row is shifted towards the lower surface of the lamina. In $P$. serpens the hydathodes are located on the extreme margin of the frond, in $P$. confluens they occupy a position just inside the margin on the lower surface of the lamina.

Hydathodes are completely absent in the $P$. albicans-group and in most species of the $P$. lanceolata-group. In this last group some hydathodes are occasionally present in $P$. lanceolata, and more regularly so in forms of $P$. foveolata.

Heteroblastic development. The presence of hydathodes during heteroblastic development could be studied in the species already listed on p. 39. (see also fig. 12). Of these species, $P$. angustata, $P$. lanceolata, $P$. nummulariifolia, $P$. longifolia, and $P$. piloselloides lack hydathodes in the mature fronds. Nevertheless, in the early stages of the heteroblastic series hydathodes were found to be present 
in $P$. angustata, $P$. lanceolata and in $P$. nummulariifolia. In $P$. lanceolata and $P$. angustata it could be observed that the hydathodes in a marginal position tended to persist to later stages than those situated on the lamina. Only in $P$. longifolia and $P$. piloselloides hydathodes were not found throughout the heteroblastic series. In all other species hydathodes were present from the very first stages onwards.

\section{Lamina anatomy}

The anatomy of the lamina varies within species as well as between species. Giesenhagen (1901, p. 65-85, fig. 12-17) gave an extensive account, and described most of the variation encountered in the genus. He stressed the importance of anatomical characters for the delimitation of the species. However, the large variability of this character, which may well be due to environmental circumstances, requires caution in applying anatomical characters for this purpose.

\section{Upper epidermis}

In surface view the cells of the upper epidermis are oriented longitudinally; they usually have more or less strongly sinuose walls. In a few species only ( $P$. stigmosa, $P$. pannosa), the walls of the epidermis cells are practically straight; straight walls occur only occasionally in other species. In transverse sections the outer walls at the surface of the epidermis are either flat ( $\mathrm{pl} .6 \mathrm{~d}, \mathrm{f}, \mathrm{g}, \mathrm{h}$ ), or convex and then projecting outwards (pl. $6 \mathrm{a}, \mathrm{b}, \mathrm{c}$ ) to a variable degree. If they are strongly convex, the surface of the epidermis has a distinct papillose appearance resulting in a characteristic dull surface of the lamina. A flat epidermis gives a certain sheen to the surface of the lamina. Together with the overall thickness of the lamina, the latter influencing the "toughness" of the fronds, the shape of the epidermis cells appears to be responsible for most of the differences in texture between dried specimens. The extremes in this character are distinct, but many species have a more or less intermediate state, with only slightly projecting cells (e.g., $P$. serpens, $P$. sphaerosticha), or with both extremes occurring (e.g., $P$. lanceolata, $P$. lingua, $P$. foveolata). Despite the occurrence of these intermediate stages, some species similar in other characters, e.g., $P$. costata and $P$. platyphylla, or $P$. drakeana and $P$. boothii may be distinguished by the shape of the epidermis cells.

The walls of the epidermis cells are variously thickened. In many species the outer walls are particularly thickened; in others all walls are more or less equally thickened, or all walls are equally thin (the degree of thickening in the mesophyll may be used for comparison). In some cases the epidermis is separated from the mesophyll by distinctly thickened lower periclinal walls of the epidermis cells (pl. $6 \mathrm{~d})$. 
However, the variability in the degree to which the walls are thickened in many species is an indication that this character is probably easily modified by external circumstances.

\section{Mesophyll}

In most species the mesophyll is differentiated into three distinct layers. The uppermost of these layers, directly below the epidermis, is called the hypodermis (Payne \& Peterson, 1973) and may be composed of one or more layers of cells (pl. $6 \mathrm{c}-\mathrm{f})$. The size of the hypodermis cells as well as the degree to which the walls are thickened varies between species. If the hypodermis is composed of only one layer, the cells usually are rather small in transverse section and the walls are thickened in a similar way as are the walls of the epidermis. The aspect of the hypodermis in that case is similar to that of the epidermis (e.g., $P$. drakeana, pl. $6 \mathrm{c})$.

Often more layers of hypodermal tissue are present, and then the cells of the lower layers are usually distinctly enlarged and often have thinner walls than those of the upper layers. These large, thin-walled cells (pl. $6 \mathrm{f}, \mathrm{g}$ ) probably serve as a water-storage tissue. Towards the epidermis the less specialized character of the layer may still be evident, but in many species all cells of the hypodermis are specialized as water-storage tissue, and a distinct hypodermis is at first sight absent. In extreme cases (e.g., $P$. nummulariifolia, pl. $6 \mathrm{~g}$ ) the water-tissue can take up more than half of the total thickness of the lamina. In other cases the watertissue may be thin, and hardly different from a normal hypodermis. A structurally similar hypodermis probably is the most important water-retentive structure in Platycerium (Froebe \& Strank, 1981).

In several species a hypodermis is completely absent, and the palissade tissue directly adjoins the upper epidermis (e.g., in $P$. assimilis, $P$. mannii, $P$. pannosa). In other species the degree to which a hypodermis is present varies. In some the presence of a hypodermis is restricted to geographically or morphologically more or less distinct forms. In P. flocculosa (pl. $6 \mathrm{~b}$ ) a hypodermis is normally absent, but it is present in most specimens from Indo-China, which also differ in a few other characters. In $P$. porosa a hypodermis is usually absent from the type variety; it is present in var. tonkinensis and indistinctly present in var. stenophylla. In $P$. rhodesiana a layer which is indistinctly and weakly specialized as a waterstorage tissue is present only in specimens from Madagascar, and absent from specimens from continental Africa.

In some species the hypodermis is not continuous, but occurs patchily in the lamina, so that there are patches where a hypodermis is distinctly present and patches where it is absent (e.g., in P. stigmosa: Hennipman 3015; in other specimens of the same species a hypodermis is competely absent: Hennipman 3203). In other species the hypodermis shows a similar irregular occurrence $(P$. costata, $P$. 
sheareri). Such a discontinuous hypodermis may occur in the form of incidental groups of hypodermis cells or even isolated cells scattered through the lamina ( $P$. hastata, $P$. polydactyla, $P$. schimperiana). Below the hypodermis, or, when a hypodermis is absent, directly below the epidermis, a layer of palissade parenchyma is present in most species, and/or a third layer, the spongy parenchyma. The degree to which the mesophyll is differentiated, and thus the sharpness of the distinction between hypodermis (including water-tissue) or palissade- and spongy parenchyma cells, varies strongly. Especially in the more strongly succulent forms the mesophyll is often only weakly differentiated, and all cells are more or less similar to the cells of the water-tissue in other species.

In several species (e.g., $P$. flocculosa, $P$. penangiana, pl. 6 a, $P$. princeps) the degree to which a distinct palissade tissue is developed varies strongly within the species. External circumstances may play a role in this, but it is also possible that differentiation of the mesophyll is the last character for which the mature situation is reached in the heteroblastic development. In that case, differences may represent only juvenile aspects of otherwise apparently fully mature fronds (compare also p. 39).

If infraspecific variation is disregarded as much as possible, the least differentiated fronds are those with a relatively thin lamina ( $P$. laevis, $P$. christii, $P$. penangiana), and those with a thick strongly succulent lamina in which most of the cells probably have a function as water-storage cells rather than as specific palissade or water-storage cells (e.g., $P$. longifolia, $P$. serpens). This is only a rough correlation, to which there are several exceptions (e.g., $P$. costata, with a thin lamina but a well-differentiated mesophyll; $P$. nummulariifolia, with a succulent lamina but also a well-differentiated mesophyll).

The structure of the mesophyll in the P. piloselloides-group is aberrant (pl. $6 \mathrm{~h}$ ) in being completely undifferentiated. All the cells are large, thin-walled, and parenchymatous in character. This is either a separate, distinct development, or this state represents the final stage of the trend towards undifferentiated, succulent fronds as observed in other species.

\section{Lower epidermis}

The structure of the lower epidermis is rather similar to that of the upper one. In surface view the cell walls are more often straight, and in transverse section they are often more strongly thickened. In extreme cases more than half of the entire height of the cell may be taken up by the thickened wall (e.g., P. albicans, $P$. princeps, $P$. angustata). The lower epidermis usually directly adjoins the spongy parenchyma layer. Only in $P$. confluens a layer of hypodermis-like cells is present between spongy parenchyma and lower epidermis; this layer is interrupted at the stomata. 


\section{Stomata}

In mature fronds the stomata are restricted to the lower surface. Configuration of guard-cells and the ontogeny of the stomata has been studied by Giesenhagen (1901, 81-85) and Sen \& Hennipman (1980). The terminology used by Sen \& Hennipman will be adopted here.

Most species have pericytic stomata; desmocytic stomata occur incidentally. The occurrence of peri- or desmocytic stomata does not correlate with other characters. Polocytic stomata occur only in the $P$. africana-group and in $P$. mannii and $P$. penangiana. The configuration of the guard cells in the groups of $P$. lanceolata and $P$. confluens could not be investigated in all species as the stomata in these species are deeply sunken. Incidental observations, however, confirm the pericytic character of the stomata in these species.

In transverse view all intermediate stages can be seen between stomata that are slightly raised above the surface of the lamina and deeply sunken stomata. Stomata of the first type occur only in $P$. sheareri and $P$. drakeana $(\mathrm{pl} .6 \mathrm{c})$. Stomata that are flush with the surface of the epidermis or slightly sunken below it (the difference is often not clear owing to the protrusion of the epidermis-cells, compare pl. $6 \mathrm{~b}, \mathrm{~h}$ ) occur in most other species. Deeply sunken stomata (pl. $6 \mathrm{e}, \mathrm{f}$, g) are common in the $P$. albicans-, the $P$. lingua-, the $P$. confluens- and the $P$. lanceolata-group. They occur also in some forms of $P$. subfurfuracea. Often the stoma-groove is narrowed above the stoma. In most species the narrowest part is situated approximately halfway the depth of the stoma-groove, but in some species the narrowest part is often at the surface of the epidermis (e.g., in forms of $P$. lanceolata and in $P$. confluens).

\section{Sori}

Structure and disposition of the sori in Pyrrosia are diverse, and soral characters have always been important for the classification of the species. Mirbel (1803) used the number of sporangia in a sorus and the absence of a sporangium stalk to distinguish the (then monotypic) genus; his genus Candollea, now considered a synonym of Pyrrosia, was distinguished also on the basis of sorus characters. Desvaux (1811) recognized Cyclophorus on the basis of the distinct circular arrangement of the sori in several species.

The number of sori and the disposition in each areole was the main character by which Mettenius (1856) divided the genus (considered by him as a subgenus of Polypodium) into three sections.

The genus Drymoglossum Presl has long been considered as distinct from Pyrrosia mainly on account of the presence of elongated coenosori in the former. 


\section{Position}

Generally the sori are situated dorsally or terminally on the included veins. The venation of the soriferous part of the lamina is roughly similar to that of the sterile parts. Occasionally (e.g., in $P$. flocculosa) the soriferous veins are less branched and anastomose less than the sterile ones, so that the pattern in the soriferous part is less complicated. More often, however, the venation in the soriferous lamina is more complicated than that of the sterile parts, as the soriferous veins branch and anastomose more frequently (in most species of the $P$. lingua-group). A similar phenomenon can be observed in the $P$. costata-group. $n$ this group the sori are situated terminally on very short lateral branches of the included veins, so that a very dense venation pattern is formed, which is often sharply distinct from the sterile pattern ( $\mathrm{pl} .5 \mathrm{e}$ ).

In some species the insertion of the sori is shifted downwards along the included veins until they are situated on the junction of tertiary veins and included veins. This is accompanied by a "break-down" of the regular venation pattern in $P$. distichocarpa: the distinction between tertiary and included veinlets becomes less clear, and the areoles become irregular in shape.

Usually the sori are superficial on the lamina, or slightly impressed in mostly ill-defined and shallow depressions (e.g., $P$. schimperiana). More distinctly sunken sori occur in species of the $P$. confluens-group (particularly $P$. serpens) and in $P$. angustata. Sori that are deeply sunken in distinct, steep-sided pits are characteristic of the $P$. lanceolata-group.

The number of sori in each areole is highly variable. This seems to depend mainly on the size of the sori relative to the size of the lamina, so that it depends strongly on the size of the sori as well as on the size of the lamina. Mettenius (1856) used the number of sori in each areole as the main criterion for his subdivision of the genus; the distinction is indeed a useful one, even though in many species this number is not constant.

The very small sori of the $P$. africana-group, the $P$. costata-group, of $P$. pannosa, and of many species of the $P$. lingua- and $P$. sheareri-group occur in large numbers in one areole (pl. $4 \mathrm{~d}, 5 \mathrm{e}$ ) and are irregularly scattered over most of it. In some of these species there is a distinct tendency towards the contraction of the sori into two rows in each areole (e.g., $P$. lingua var. lingua, $P$. christii) or sometimes even one row ( $P$. lingua var. heteracta). In other species the sori are constantly situated in one row in each areole ( $\mathrm{pl} .5 \mathrm{c}$ ), although sometimes a second row is weakly and irregularly present (e.g., $P$. flocculosa).

In the species with one row of sori in each areole the number of sori in each row varies from c. 10 ( $P$. longifolia) to one ( $P$. angustata, $P$. serpens). The number of 2 seems to be fixed in many species, although incidentally a third sorus may be present. In some cases this low number of sori in each areole is correlated with enlargement of the sori $\left(P\right.$. foveolata, $P$. distichocarpa, $P_{-}$asterosora), in others the 
reduction in lamina size seems to have been the most important factor ( $P$. assimilis). The single sorus per areole that is characteristic for $P$. angustata, pl. 4 $\mathrm{b}, P$. serpens, and $P$. confluens is probably derived from a situation with two sori per areole through lateral contraction of the lamina and concomitant merging of the sori. This can be concluded if an aberrant specimen of $P$. angustata, in which 2 or 3 sori per areole are present (Wright \& Ismawi 32884), is interpreted as atavistic. Lateral contraction and fusion of the sori is also evident in $P$. serpens, in which species the intermediate condition of two sori per areole is rather frequent. The reduction of the number of sori to a single one in each areole is always accompanied by a reduction in the number of soriferous areoles between costa and margin, so that the sori are ultimately reduced to a single row on each side of the costa.

In a number of species the separate sori are replaced by a longitudinal sorus on each side of and parallel to the costa. This coenosorus is situated close to the margin or midway between costa and margin. The presence of a coenosorus is often accompanied by a strong reduction in width of the soriferous part of the lamina. In some species (e.g., $P$. heterophylla, $P$. fallax, $P$. novo-guineae) this has resulted in a strong dimorphism, in other cases the coenosorus is borne on an apical spike of the lamina ( $P$. samarensis).

In some cases it is evident that the presence of a coenosorus is directly derived from a situation with a single row of slightly elongate sori. In $P$. samarensis forms occur with an interrupted coenosorus (e.g., Ramos 946), which can be considered as transitional to the single row of sori as present in $P$. angustata. In $P$. confluens forms with a coenosorus and with separate sori both occur, and the conclusion seems obvious that here, too, the coenosorus originated through a similar process of fusion.

In the $P$. lanceolata-group the situation seems to be different. Here, intermediates between the small, circular sori of $P$. lanceolata and the coenosorus of $P$. fallax are absent. In $P$. lanceolata there is no tendency towards fusion of the sori. Thus the coenosorus of $P$. fallax, which is structurally similar to the sori of $P$. lanceolata, must be supposed to have originated by a more sudden transition from a circular to an elongate structure.

\section{Size and shape}

The smallest sori occur in the $P$. costata-group. Measured when ripe and with all sporangia present the sori in this group are c. $0.5 \mathrm{~mm}$ in diameter, and round in outline. In most other species the sori are more variable in size and shape. The diameter varies there from 1-2.5 mm, but distinctly larger sori occur in the larger species of the $P$. albicans-group (especially in $P$. distichocarpa), in the $P$. angustatagroup, and in the $P$. confluens-group. In these last two groups the large sori are often elongated longitudinally and may attain sizes of $3 \times 4 \mathrm{~mm}$. The size of the 
receptacle varies accordingly from small and insignificant to large and often strongly vaulted (in $P$. distichocarpa and $P$. confluens). In species with small sori the receptacle often spreads along the veins, so that the sori are irregularly elongated and often somewhat confluent (e.g., in $P$. lingua, strongly so in $P$. laevis, $P$. christii, $P$. petiolosa, pl. $5 \mathrm{~b}$ ). Small, closely packed sori may also appear to become confluent when they ripen and the sporangia increase in size while the sporangial stalks elongate. The spreading receptacles and the enlarged sori together may make ripe, fertile fronds appear completely acrostichoid (particularly in $P$. $a b$ breviata, $P$. christii, and $P$. sphaerosticha).

The occurrence of larger, elongated sori in the $P$. confluens-group and in $P$. angustata is also associated with confluence of the sori (leading, as shown above, to a coenosorus), but in this case the confluence is not along the soriferous veins, but generally across the secondary veins separating the areoles.

\section{Innervation}

Small sori, situated terminally or dorsally on the veins, are each innervated by a simple vein. In larger sori such a vein may be forked in the receptacle ( $P$. distichocarpa, $P$. confluens). The very large sori of $P$. angustata have apparently spread over a large part of the areole, and thus are innervated by several veins, which give off small branches that form a complicated network in the receptacle. A similar network of veins is present in the receptacle of the coenosorus of $P$. samarensis.

\section{Paraphyses}

When young, the sori of all species are covered with hairs similar to those covering the sterile lamina. The stalks of these hairs are slender and fragile, and it is difficult to ascertain whether the hairs are actually inserted on the receptacle or not, but in some cases they obviously are. According to common usage, these hairs should be called "paraphyses" (Wagner, 1964). The generality of that concept, however, makes it practically useless (Tryon, R., 1965; Tryon, A., 1965), and at least in Pyrrosia I would prefer to restrict the term "paraphyses" to trichomes on the receptacle that are homologous to but also at least slightly modified from the indument of the sterile lamina. Baayen \& Hennipman, however, in a survey of paraphyses in the Polypodiaceae (in prep.), will use the term conform to Wagner $(l . c$.$) , and this usage will, for the sake of conformity, be$ adopted here. Paraphyses often differ from the hairs on the sterile lamina in the following aspects:

- the stalk is longer,

- the stellate rays are fewer in number and they are often slenderer,

- the density of hairs (paraphyses) on the receptacle is higher than that on the lamina. 
Paraphyses modified in one or more of these ways occur in the $P$. albicansgroup, the $P$. angustata-group, the $P$. confluens-group, and the $P$. lanceolata-group. Their presence is not always evident, and they may be constantly absent in $P$. rasamalae, $P$. novo-guineae, $P$. nummulariifolia, and $P$. kinabaluensis.

In the $P$. albicans-group the paraphyses, where present, have stellate rays that are less strongly curled than the woolly rays of the sterile indument, but more so than the straight rays. In $P$. rasamalae small tufts of woolly hairs are often present loosely appressed to the sori, which may be paraphyses or alternatively, they may be "sterile" woolly hairs pushed away by the developing sporangia. Due to the fragile character of the stalks it is not possible to ascertain which is the case. If the hairs forming these tufts are true paraphyses, they form an intermediate stage between the distinctly modified paraphyses in, e.g., P. albicans and the unmodified hairs in the sori of $P$. nummulariifolia.

In the $P$. confluens- and $P$. lanceolata-group the paraphyses have stellate rays that are shorter and wider than the rays of the sterile hairs. Especially in the $P$. contluens-group paraphyses may be very numerous: only a few sporangia are sometimes present in each sorus, interspersed with large masses of paraphyses. In this group it is also evident that the paraphyses are distinct from the "sterile" hairs. Young sori have a thin cover of normal hairs, as the sorus develops these hairs are pushed away by the distinctly different paraphyses.

In the $P$. lanceolata-group the paraphyses are situated in a central bundle in the sorus. The sporangia are situated around this bundle in a distinct rosette-like arrangement. In $P$. fallax the coenosorus has a central row of paraphyses. This probably equivalent to the central bundle of paraphyses in other species of this group (Ravensberg \& Hennipman, 1986).

\section{Sporangia}

Structurally the sporangia are of the common polypodiaceous type as recognized by Wilson (1959). There is some, probably minor, variation in the configuration of the cells on the faces of the capsule of the sporangia. The shape of the capsule varies from more or less spherical in most species to distinctly elongated or ellipsoid in, e.g., $P$. rupestris or more or less obovate, especially in the $P$. costata-group. Most of the variation concerns the relation between stalk length and capsule height, and the number of indurated cells of the annulus (the "bow", Wilson, l. c.).

Capsule height. The height of the capsule varies from $0.3-0.4 \mathrm{~mm}$, but distinctly smaller as well as distinctly larger sporangia (to $0.6 \mathrm{~mm}$ ) occur scattered through the genus. There is little taxonomic significance in this character: none of the species-groups recognized can be characterized by sporangia of a certain size except the $P$. africana-group, of which both species have relatively small sporangia. 
Stalk length. The most striking variation in the sporangia is present in the length of the stalk relative to the capsule. Sessile or very shortly stalked sporangia (stalk at most half as long as the capsule) occur in the $P$. costata-group and in some species of the $P$. sheareri-group ( $P$. drakeana, $P$. sheareri, $P$. hastata), and in a few other species $(P$. mannii, $P$. porosa var. stenophylla). In most species the stalk is 1 to $1 \frac{1}{2} \times$ as long as the capsule, with lengths of c. $1 \times$ the capsule restricted mainly to the $P$. sheareri-, the $P$. africana- and the $P$. porosa-group. The longest sporangium-stalks ( $2 \frac{1}{2}$ to $3 \times$ the height of the capsule) occur in $P$. albicans, in $P$. angustata and $P$. samarensis, and in $P$. rupestris.

Modifications. In Pyrrosia the only modifications of the polypodiaceous type of sporangium are those found in the $P$. costata-group and in $P$. schimperiana. The sporangia of the $P$. costata-group are different in that the number of indurated annulus-cells is distinctly lower than in most other species; typically hardly more than 10 cells are indurated. This is not a consequence of the small sporangia in this group (as it is in, e.g., $P$. gardneri), but a result of the reduction of the induration of the annulus near the attachment of the sporangia. In the most extreme cases (present in $P$. princeps, $P$. platyphylla, and $P$. splendens) there is only a small apical part of the annulus that is indurated and the basal, non-indurated part is hardly recognizable as part of the annulus. The cells of this basal part do not have the typical shape of the indurated cells. In the other two species of this group ( $P$. costata, $P$. stigmosa) intermediates occur connecting this state to the normal sporangium type.

As a consequence of this peculiar development the sporangia, when they open, are not torn apart completely as in the other species, but the basal part remains intact and forms a hollow cup, whereas the apical part is lifted off and turned outwards. In these species there are, in each sorus, only c. 10 sporangia, arranged with the mouths facing towards the centre of the sorus. The ripe sori appear like distinct, small craters, the bottom being formed by the entire sporangium-bases, the sides by the apical parts that are turned outwards. This arrangement may be functional in that it effectively pushes away the dense mat of hairs overlying the young sori, thus completely exposing the spores. In herbarium specimens it can indeed be observed that old fronds often have hardly any spores left trapped in the tomentum, in contrast to what is found in many other species.

Another modification of the sporangial structure is found in $P$. schimperiana. Here the one or two annulus cells closest to the stomium are distinctly darker in colour and often swollen, and sometimes they are divided by a longitudinal wall.

Arrangement. Most species have an indefinite number of sporangia in each sorus, which do not ripen or shed their spores with any apparent, regular order. In some groups, however, there is some regularity in the number or arrangement of the sporangia. 
The peculiar arrangement of the sporangia in the sori in the $P$. costata-group is already discussed above.

A similar arrangement, though probably of independent origin, is found in several species of the $P$. lanceolata-group. Here the sporangia are arranged around a central bundle of paraphyses. In contrast to the situation in the $P$. costata-group, the number of sporangia is indefinite and rather large. The sporangia ripen in a centripetal order; first the outermost ones grow out and shed their spores, later the more centrally situated ones develop. In this way the sorus gradually forms a distinct rosette of ripe, empty sporangia around a central tuft of paraphyses. This central tuft may sometimes be hidden completely among the sporangia, as gradually more sporangia grow out and ripen.

Development of the sori. The sori are initiated at the growing apices of the fronds, and usually ripen at a constant rate. As a result, on a developing frond a succession can be found from very young sori at the apex to ripe sori closer to the base. The same succession is often found within a single elongated sorus: the young sporangia are present near the apex, the older ones near the base. In some species however (most notably in some species of the $P$. lingua-group) the sori seem to ripen simultaneously at apex and basis of the lamina. Development of the sori here is apparently arrested for some time after the initiation, until the lamina has developed fully. Thus most sporangia on a frond are at the same stage of development and all spores are shed simultaneously. The occurrence of this process, however, needs experimental confirmation, as the exact order in which the sporangia ripen often can not be ascertained in the herbarium.

Spore output. Usually 64 spores are formed in each sporangium. Deviating numbers are extremely rare and were found only in two cases during the present study. Once an aberrant sporangium of $P$. hastata (Ito 67) with an unusual number of indurated annulus cells (ca. 30) was found, which contained double the normal number of spores, but other sporangia from the same collection appeared to be normal. In the other case, in a sample of spores of $P$. christii collected by Geesink in 1982, several sporangia were found that contained 32 spores each, the spores all slightly larger than normal. In a larger sample of already shed spores the proportion of these larger spores was found to be less than $1 \%$. The sporangia producing these spores were not aberrant in any way except that the stomial region was relatively undifferentiated.

\section{Gametophytes}

Gametophytes of Pyrrosia have been studied by several authors, i.a. Nayar (1957; 1961) and Stokey (1951); the data have been summarized by Nayar \& Kaur (1971). The results of these studies indicate that within the genus no distinctions can be made on the basis of gametophyte characters. 
According to Nayar \& Kaur (l. c.) the mature gametophyte of the Platycerioidae is uniformly cordate-thalloid, with a thin median midrib. The margin is beset with unicellular, occasionally multicellular glands (Nayar,1961); on the surface of the gametophyte multicellular glandular trichomes are present, usually on the lower, but sometimes on the upper surface as well.

Development of the gametophyte is also reported to be uniform in the Platycerioidae. After germination of the spore a short "germ filament" is formed; subsequently an apical meristem is established and the cordate thallus begins to develop. Both antheridia and archegonia are formed on the same gametophyte (Nayar \& Kaur, 1971).

In the course of the present study only a few incidental observations were made on the gametophytes. From these the following results were obtained:

In at least three species ( $P$. princeps, $P$. gardneri, $P$. nummularifolia) the gametophytes appear to pass through a phase during which they are elongated and relatively narrow, before they attain a cordate shape. In mature prothallia this may be evident from a long, narrow strip attached to the base, continuous with the thickened midrib. In this phase of development only antheridia are present; the development of archegonia appears to occur during a later phase of development so that they are restricted to the cordate part of the thallus which is formed during this later phase. In view of this, Nayar \& Kaurs statement that all Platycerioidae show a similar development with a short-lasting, sterile filamentous stage, needs confirming. The possible presence of a phase in their development in which the prothallia are strap-shaped is especially interesting in view of the use that is sometimes made of the character "prothallium shape" in phylogenetic considerations (e.g., Jarrett, 1980, p. 831).

It should be stressed that a complete continuity exists between the indument of the gametophyte and of the juvenile sporophyte. The variety of different kinds of hair found on the gametophyte matches that of the first sporophytic fronds, up to the (identical) occurrence of acicular, elongated cells. This continuity probably has implications for the assessment of the homology between various types of dermal appendages in the polypodiaceous ferns; these considerations, however, lie outside the scope of this study. 


\section{KARYOLOGY AND HYBRIDIZATION}

\section{Karyology}

Knowledge of the cytology and the chromosome numbers in Pyrrosia is incomplete. Several reasons can be adduced to explain this, most of which are applicable to tropical ferns in general. One reason, however, is peculiar to Pyrrosia, viz., that the indument of the lamina effectively protects the young sori. Meiotic chromosome numbers, obtained from developing sporangia, are therefore difficult to establish. Mitotic counts, taken from developing roottips, are easier to obtain, but on account of the double number of chromosomes that has to be counted they are less reliable. In the literature mitotic counts appear more frequently.

\section{Results}

In table 2 the known data concerning Pyrrosia are summarized. The data presented are taken from Löve, Löve \& Pichi-Sermolli (1977, there also the references), supplemented with my own, as yet unpublished, results. These were obtained from plants grown in the Leiden Botanical Garden, from various, sometimes unknown, origins.

TABLE 2

\begin{tabular}{|c|c|c|c|c|}
\hline species & origin & count & level & reference \\
\hline abbreviata & unknown & $2 n= \pm 73$ & diploid & new, LEI 22980 \\
\hline angustata & unknown & $2 n= \pm 73$ & diploid & new, LEI 19713 \\
\hline christii & Borneo & $2 n=74$ & diploid & new, LEI 22450 \\
\hline $\begin{array}{l}\text { confluens } \\
\text { var. dielsii }\end{array}$ & Atherton & $2 n=74$ & diploid & new, LEI 23007 \\
\hline costata & E. India & $\begin{array}{l}2 n=74 \\
n=37\end{array}$ & diploid & $\begin{array}{l}\text { Patnaik } \\
\text { Panigrahi (1963) } \\
\text { as P. beddomeana } \\
\text { Trikha in } \\
\text { Loeve (1974), } \\
\text { as P. beddomeana }\end{array}$ \\
\hline eleagnifolia & New Zealand & $2 n=74$ & diploid & $\begin{array}{l}\text { Brownlie (1961) } \\
\text { as P. serpens }\end{array}$ \\
\hline flocculosa & India, Jowai & $\mathrm{n}=36$ & diploid & $\begin{array}{l}\text { Panigrahi } \\
\text { Patnaik (1961) }\end{array}$ \\
\hline
\end{tabular}




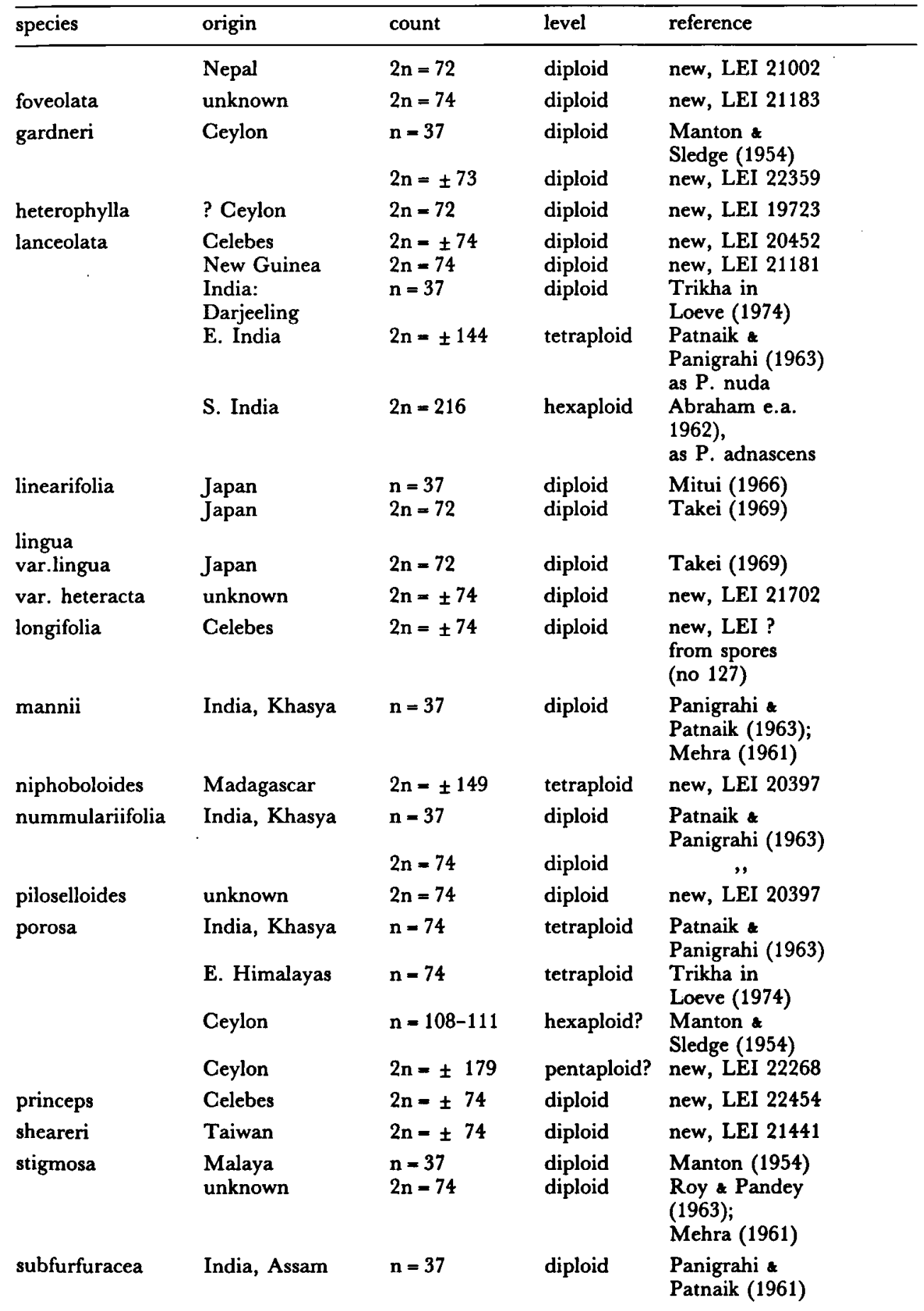




\section{Discussion}

Base-number. It is evident that within Pyrrosia base numbers of both 36 and 37 occur. The exact distribution of either number, however, is far from certain. This is due both to the incompleteness of the survey and to the uncertainty of some of the counts. In many of my own counts it was not possible to decide with certainty between counts of 72 and 74; in other published counts some uncertainty is similarly evident. For instance, in $P$. linearifolia a meiotic number of 37 is given by Mitui (1966), a mitotic number of 72 by Takei (1969). As both counts were taken from plants originating from Japan, this inconsistency is not likely to be due to the heterogeneity that is shown by this species between plants from Japan and from Taiwan. Most likely one of the counts is erroneous. In another case, a number of $2 \mathrm{n}=72$ is given by Takei (1972) for $P$. lingua. His published drawing and photograph, however, are not conclusive, and in my opinion it is equally likely that the diploid number for plants from Japan of this species is $2 n=74$.

A base number of 36 seems to be unequivocally established for $P$. flocculosa (both from meiotic and mitotic counts). It is likely that 36 is also the base number for $P$. heterophylla.

A base number of 37 seems to be prevalent not only in Pyrrosia, but also in Platycerium. In that genus, no other base numbers have been reported. Possibly, therefore, the number of 36 is incidentally derived from 37 by aneuploid reduction.

Polyploidy. More reliable than the determination of base numbers is the identification of polyploid series. There is no necessity to count the number of chromosomes with an accuracy of 1 (nor is it possible with the large numbers involved), but a reliable estimate of the level of polyploidy can be made relatively easily.

Polyploid series occur in Pyrrosia in at least three not closely related species groups.

$P$. porosa-group. Within $P$. porosa, tetraploid plants have been reported from Khasya (India) and from the Eastern Himalayas. One report from Ceylon refers to a possible hexaploid, although the data presented are not conclusive. The photograph presented by Manton \& Sledge (1954) illustrating their count of $\mathrm{n}=$ 108-111 does not show sufficient detail to tell with certainty whether the observed meiosis was fully regular, with completely paired chromosomes. My own findings for a plant from Ceylon, though not very reliable either, indicate a pentaploid level. The possibility exists that Manton \& Sledge's results and mine refer to the same (pentaploid) cytotype.

No diploids have so far been reported from $P$. porosa. $P$. linearifolia, included in the $P$. porosa-group in the present work, is unequivocally diploid. 
$P$. lanceolata-group. Another polyploid series is present in $P$. lanceolata, with diploid plants reported from New Guinea and from Darjeeling, a tetraploid plant reported from E. India, and a hexaploid from S. India.

From these scant data it cannot be ascertained whether in either of these two polyploid series a distinct correlation exists between cytotype and geography, ecology, or morphologically recognizable entities. Nevertheless, it is probably no coincidence that both species in which a polyploid series occurs are widespread, morphologically variable, and problematic in a systematic sense. A more thorough investigation and a broader survey are necessary before more farreaching conclusions can be drawn.

P. piloselloides-group. A third polyploid series is present in the "true" Drymoglossum's.

Both $P$. piloselloides and $P$. heterophylla are diploid, be it with different basenumbers, 37 and 36, respectively. The morphologically somewhat aberrant $P$. heterophylla from Madagascar is tetraploid. The number found, $2 \mathrm{n}= \pm 149$, indicates (though weakly) a base number of 37 rather than 36 . This suggests an autopolyploid origin with $P$. piloselloides as the possible parent species.

In contrast with the two polyploid complexes considered above, the species are morphologically distinct, and geographically separated.

The occurrence in Madagascar of a polyploid species with its closest possible parent species in Southeast Asia is curious. Polyploidy is thought to be associated, in a general way, with the occupation of new habitats, and this is contrary to the commonly held view that the flora of Madagascar is mainly composed of ancient relict species.

Assuming that $P$. niphoboloides originated by way of autopolyploidy from $P$. piloselloides, it is not obvious how it could have reached Madagascar. There is an unresolved conflict here between the probable phylogeny as reconstructed by cytological evidence and probabilities based on geographical distribution.

\section{Hybridization}

\section{Recognition of hybridization}

One of the problems encountered in the study of herbarium material is that it is difficult to assess whether hybridization has occurred in the plants studied.

Some criteria that can be used to recognize hybridization in herbarium specimens are given by Hennipman (1977) and Wagner (1983). Hennipman ( $l$. c.) gives four criteria, but points out that not all four criteria are equally useful and reliable, so that in his opinion each suspected case of hybridity should be confirmed by experimental work, or at least by direct observation of the meiotic 
behaviour of the chromosomes. Wagner's (l. c.) main criterion is based on intermediacy in morphological characters; other criteria are used as checks.

The role of hybridization has been thoroughly analyzed in a few groups, mainly from temperate regions (e.g., Asplenium and Dryopteris). From these investigations it has become clear that a thorough knowledge of the cytological aspects is a prerequisite for any analysis of the sometimes subtle and intricate patterns of morphological variation displayed in these "problem"-groups. In the absence of such detailed knowledge, any assessment of the role of hybridization is bound to remain speculative.

Morphological evidence. The morphological criteria, that according to Hennipman (1977) and Wagner (1983) can be used to detect hybridity, can be regarded as morphological expressions of a hybrid genome, through disturbance of the normal course of morphogenesis.

The first of these criteria, in Hennipman's $(l . c$.) enumeration, is the one of morphological instability. By this criterion, extreme morphological variation in a species is interpreted as an indication of the presence of two different genomes. This extreme variability, however, is in practice difficult to distinguish from variation due to plasticity under different circumstances. A wide range of variation is expected in most wide-ranging species growing in a variety of different environments, irrespective of any possible hybrid origin of these species. Study of large samples of well-annotated plants, combined with experimental work, is necessary to distinguish between the two possible causes of variability.

In Pyrrosia there are several instances of such wide-ranging species with a large range of morphological variation, e.g., $P$. lanceolata, $P$. confluens, $P$. lingua, and $P$. porosa. All these species may be suspected to contain "hidden" hybrid complexes but only in the case of $P$. lanceolata and $P$. porosa are there other reasons (see $\mathrm{p}$. 74) for assuming that this is actually the case.

A second morphological criterion is the one of morphological intermediacy. According to this criterion, a hybrid is generally expected to be morphologically intermediate between its parents. This intermediacy, however, as Hennipman (1977) points out, cannot be expected to take on a predictable form, and, if occurring in an unpredictable form, is difficult to recognize as an intermediate state. In morphologically rather simple plants like Pyrrosia, moreover, the assessment of intermediacy is particularly difficult, as many characters can be seen as intermediate between others.

The vagueness of the criterion may be obviated by considering as possible parent species only those that are morphologically similar; or those that grow in the immediate neighbourhood of the plant under consideration. On the other hand, the number of hybrids that can be detected is directly related to the number of parent species that are compared with it. Any restriction of the latter will diminish the general usefulness of the comparison. 
The last criterion is the one of "structural irregularity", first formulated by Wagner (1962). This criterion is relatively easy to observe, but it is not met with in all hybrids, nor is it with certainty absent in normal plants.

In Pyrrosia "structural irregularity" is possibly present in the form of asymmetrical fronds in the $P$. sheareri-group; perhaps the occasional laciniate fronds of $P$. mannii are another instance.

Spore sterility. The presence of large numbers of aborted or otherwise abnormal spores is one of the criteria that can be used to detect hybrids in herbarium material. Spore sterility is a direct reflection of the incompatibility of two different genomes if these are combined in a hybrid plant. Nevertheless, the criterion has no absolute value. Aborted spores may be present in small amounts even if no hybridity is involved (Wagner \& Lim Chen, 1965); spore abortion may also be caused by disturbance of the normal process of spore development by external factors. On the other hand, several mechanisms (autopolyploidization, various forms of apospory, cf. Walker, 1979) may result in the formation of normal spores in hybrid plants.

In Pyrrosia I have investigated the occurrence of spore sterility in two ways.

- by examining samples of shed spores, whenever possible several samples for each species,

- by examining the contents of one or more, apparently well-developed, sporangia, whenever possible also of several specimens of each species.

A summary of the results is given in the following list, in which each species is accounted for that had a large number of abnormal spores in at least one sample.

P. abbreviata: many abnormal spores in Holstvoogd 381 (L) and Lörzing 12734 (L), but mostly normai spores in $\bar{\nu} e$ Wilde c.s. 15001 (L). Sporangial contents were normal in De Wilde c.s. 12709 (L) and De Wilde c.s. 13561 (L).

P. angustata: many small or abnormal spores in Kostermans $138(\mathrm{~L})$, but spores mostly normal in Buwalda 6633 (L), Gurung 69 (L), Smitinand 10914 (L). sporangial contents normal in Meijer 2196 (L) and Smitinand 10914 (L).

P. asterosora: many small spores present in De Wilde c.s. 15120 (L); spores mostly normal in Bünnemeijer 9582 (L), Schiffner P 185 (L). Sporangium with normal spores in Bünnemeijer 9316 (L), with four spores very small in Schiffner P 185 (L).

P. boothii: many abnormal spores present in Levinge s.n. (M), spores mostly normal, but some distinctly larger than others, in Ludlow et al. 18646 (BM), 20555 (BM). Sporangium with normal spores in Ludlow et al. 18646 (BM), with slightly irregular spores in Levinge s.n. (M). 
P. christii: spores mostly normal in Endert s.n. (L) and Nielsen 948 (AAH). In a collection of fresh fronds made by Geesink (s.n.) some sporangia with 32 spores, which were distinctly larger than the spores of other collections; in a large sample of shed spores of these fronds less than $1 \%$ only turned out to be of this larger size.

P. confluens var. confluens: most spores normal in Franc (Rosenstock 107) (L), Fraser \& Vickery s.n. (L), Lam /202 (L), Smeth \& I indale /430 (L); many irregularly shaped or empty, thick-walled spores present in Coveny 9400 (L), Paterson s.n. (Norfolk Island) (BM), Verdon 106 (L). The empty spores in this species are often normally shaped, but they have a distinctly thicker perispore than normal spores and lack spore contents.

$P$. confluens var. dielsii: most spores empty, thick-walled, but some sporangia with normal spores in Dockrill 271 (L); most spores normal in Croft 980 (L).

$P$. distichocarpa: Lörzing $6078(\mathrm{~L})$ and a specimen from Kew Botanic Gardens with mainly irregular spores, De Wilde c.s. 18562 (L) and Yates $715(\mathrm{GH})$ with mostly normal spores.

P. drakeana: most spores abnormal in Chiao \& Fan 518 (A); Ching 21941 (A); many abnormal spores present in vruson $J J \angle J$ (Divi); must spures num ind in Kock 11033 (US) and C.W. Wang 64110 (A).

P. eleagnifolia: many irregular or empty spores present in Lam 7125 (L); most spores normal in Lam 7023 (L), Hynes s.n. (SING), Meebold 5822 (M), Schweinfurth 403 (M). Empty spores similarly thick-walled as in $P$. confluens.

P. flocculosa: spores normal in Banerjee 1535 (A), Trotter s.n. (M) and a plant cultivated in Kew Botanic Gardens; spores irregular in size in Hennipman 3352 (L); also irregular in size, with some spores very large and globose and frequently spores in unseparated dyads in Banerjee 3189 (US).

$P$. foveolata var. foveolata: most spores normal but many irregularly developed ones also present in Brass 11832 (L), 29539 (L), few irregular spores present in Kalkman 4274 (L).

P. foveolata var. lauterbachii: many irregular spores present in Clemens 155 (L), spores normal in Pulle 244 (L).

P. heterophylla: almost all spores normal in Davidse 8102 , L), many spores irregular in LObo s.n. (US), most spores irregular in schlieben 11665 (K).

P. kinabaluensis: most spores normal in Clemens $27479(\mathrm{~L})$ and Meijer $673(\mathrm{~L})$; some sporangia with only empty spores present in Meijer $699 \mathrm{~B}(\mathrm{~L})$.

$P$. longifolia: most spores normal in Millar NGF 35277 (L); many irregular or small spores present in Geesink 6665 (L) and most spores small or irregular in Darbyshire $389(\mathrm{~L})$.

P. mannii: spores mostly normal in Dickason 6745 (GH), Stainton et al. 5259 (BM); many small or collapsed spores present in Hansen et al. 12932 (L) and Mann

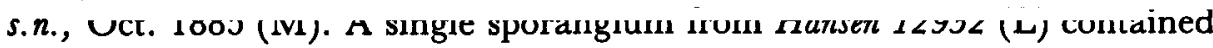
only 32 well-developed spores and an approximately equal number of abnormally developed ones. 
P. nummulariifolia: most spores normal in Bakhuizen 2887(L) and Schmutz 1369 (L), many irregular spores present in Schiffner $P 124(\mathrm{~L})$. A single sporangium of Schiffner $P 124$ (L) contained only 32 well-developed spores and an approximately equal number of irregular ones; of Iwatsuki et al. B $840(\mathrm{~L})$ only \pm 16 normal and many abnormal ones.

P. penangiana: many abnormal spores present in Schmutz 3682, few abnormal spores in Kuswata 255 (L).

P. petiolosa: most spores normal, few irregular or empty in Cavalerie $563(\mathrm{M})$, Fang sob/ (US), Meyer 958 (US); most spores normal but mixed with many irregular spores in Merrill 11349 (US).

P. platyphylla: most spores normal, but many irregular spores also present in Kostermans $13308(\mathrm{~L})$.

P. polydactyla: spores normal in Kao 3891 (US), all abnormal in Kramer et al. 8175 (L); most spores \pm irregular and many small or irregular in Faurie s.n., Dec. 1914 (L).

P. porosa var. porosa: spores normal in Van Beusekom 2498 (L), Dickason 7420 (GH), Hennipman 3149 (L); most spores abnormal in Geesink et al. 8123 (L), Dickason 8379 (GH), Fleming 877 (A), Feng 3361 (A), Jarrett \& Saldanha HFP 765 (US). $P$. porosa var. stenophylla: spores normal in Ludlow et al. 18610 (BM); many abnormal spores present in Watt $6132(\mathrm{~K})$; some sporangia containing only abnormal spores present in Griffith $2781(\mathrm{~K})$. Spore formation in Kingdon-Ward 19198 (BM) normal on some fronds, development of sporangia apparently arrested on other fronds of the same collection.

P. princeps: all spores normal in Grether \& Wagner 4220 (US), many spores irregular trom a specimen cultivated in Leiden Botanical Garden (coll. Hennipman, Celebes).

P. rasamalae: most sporangia with normal spores, but some with irregular spores in Nur 11134 (SING) and Topping 480 (L). Spores of other collections investigated were normal.

$P$. rupestris: most spores normal, but some sporangia with empty spores only in Hotchkiss 366 (US), Schodde 3242 (L); many empty, thick-walled spores (see also $P$. confluens) present in Lam 7655 (L), most spores irregular, empty, in Van Balgooy 1552 (L).

P. samarensis: spores normal in Univ. of San Carlos 750 (L), some small or empty spores present in Madulid et al. 858 (L), many small or empty spores present in Ramos BSc 30359 (US) and Weber 255 (US).

P. serpens: spores normal in Moore $61(\mathrm{~L})$, St. John $17182(\mathrm{GH})$; many abnormal spores present in Parks 20511 (US), St. John 14455 (US).

$P$. sheareri: spores mostly normal in Steward et al. 56 (US), many abnormal spores present in Steward \& Cheo 1009 (A), Fan \& Li 433 (L), Tsai 51491 (SING), most spores irregular and collapsed in Bartlett 6060 (US). 
P. sphaerosticha: spores normal in Posthumus 3436 (L); many irregular spores present in Celestino PNH 2547 (L).

P. stigmosa: spores normal in Van Beusekom et al. 3525 (L) and Kostermans 1403 (L), most spores normal but many irregular spores also present in Wirawan 376 (L).

From this list it is apparent that the occurrence of sometimes large numbers of abnormal spores is by no means restricted to those taxa that may, on account of other criteria, be suspected of hybrid origin. Several species that are apparently normal if evaluated by morphological criteria (e.g. $P$. asterosora, $P$. distichocarpa, $P$. longifolia, $P$. penangiana) turn out to have a fairly high incidence of abnormal spores. On the other hand, species with an irregular morphology, which may accordingly be suspected of hybridity (e.g. $P$. sheareri, $P$. drakeana): also contain specimens with mostly normal spores. This means that either hybridization is a much more common phenomenon in Pyrrosia than is apparent from the morphology of the specimens examined, or that spore sterility is only a poor indication of the occurrence of hybridization. In view of what is known about spore formation and the various ways in which that process may be interrupted by changes in the external circumstances, I suspect that the latter of these two possibilities is more probable, and that any correlation between the phenomena of spore sterility and hybridity is weak at best.

\section{Possible cases of hybridization}

If all these criteria are considered, the possibility of hybridization in Pyrrosia appears to be restricted to a few groups.

One of these groups is the $P$. sheareri-group. Almost all species in this group are variable in several aspects, though not strikingly more so than many species in other groups. This variability may be interpreted as morphological instability. The species may be arranged in a series, in which each is morphologically intermediate between the preceding and the following one, as follows:

$P$. subfurfuracea $-P$. boothii $-P$. drakeana $-P$. sheareri $-P$. hastata $-P$. polydactyla.

Moreover, in many of these species the lamina is markedly asymmetrical at the base (see p. 37). The degree of asymmetry in itself is not constant, and there are indications that it may be influenced by external factors.

Examination of the spores of these species, however, does not give any indication that hybridization in this group is more frequent than in other speciesgroups. Some of the morphologically distinctly intermediate plants in this group turn out to have a fair proportion of well-developed, normally-looking spores (e.g., Fang 3966, Wilson 5323). Some specimens may be supposed to be sterile hvbrids between $P$. sheareri and $P$. drakeana but no conclusive confirmation of their hybrid origin has been found so far. 
Some hybridization may have been involved in the morphologically complex species $P$. lingua, $P$. porosa, and $P$. lanceolata. Within these species there is a large variability, in which some more or less constant extremes can be recognized alongside with large numbers of more or less intermediate specimens connecting these extremes. Independent evidence for the occurrence of hybridization is found in the occurrence of aberrant chromosome numbers in $P$. lanceolata and $P$. porosa. Spore abortion as a more common phenomenon than in other groups of Pyrrosia, however, is found only in the $P$. porosa-group. Within this last group $P$. porosa var. stenophylla may more specifically be suspected of hybrid origin: the irregular venation-pattern and position of the sori most characteristic of this variety can be interpreted as structural irregularity.

Hybrid origin is also a possible explanation for the large variability shown in the few available specimens of $P$. kinabaluensis. Morphologically this species is intermediate between $P$. rasamalae and $P$. nummulariifolia, but of these two possible parent species only $P$. nummulariifolia occurs throughout the area occupied by $P$. kinabaluensis, whereas $P$. rasamalae is restricted to a relatively small part of it. The spores of $P$. kinabaluensis do not seem to be significantly abnormal.

Relatively few hybrids in Pyrrosia have been reported in the literature.

Pyrrosia $\times$ pseudopolydactylis Serizawa $(P$. matsudae $\times P$. polydactyla) has been reported from Taiwan (Serizawa, 1970). It appears to be highly similar to $P$. polydactyla, differing from that supposed parent species only in the somewhat lesser number of lamina lobes; also the spores are reported to be irregular. In my opinion neither the slightly aberrant frond shape (similar fronds occur not infrequently in $P$. polydactyla together with completely normally developed fronds); nor the irregular spores (which may have been aborted due to external circumstances) are sufficient evidence for a hybridogenous origin of this plant.

Pyrrosia $\times$ nipponica Beppu \& Serizawa $(P$. linearifolia $\times P$. hastata) has been reported from Japan (Beppu Serizawa, 1983). It has an irregular lamina outline and may be a true hybrid. I see no reason, however, to assume that $P$. linearifolia is one of the parents; a much more likely candidate is $P$. porosa.

Plants similar to $P$. nipponica have been collected on Taiwan and have been distributed under the name $P$. transmorissonensis (Tagawa 3728, Tamura \& Koyama 23138). P. matsudai Hayata, also described from Taiwan (Hayata, Ic. Pl. Form. 10: 73, fig. $48 ; 1921$ ), appears to be similar too. These plants have in common a relatively thin, short-creeping rhizome with blackish scales and a more or less distinctly stipitate, irregularly lobed lamina. If they are of hybrid origin, one of the parents is probably $P$. hastata in the case of the plants from Japan, $P$. polydactyla for plants from Taiwan. The other parent probably is $P$. porosa in both cases. 
On the other hand, the possibility that these specimens are aberrant forms of $P$. hastata or $P$. polydactyla, grown under unfavourable circumstances, cannot be ruled out. As far as could be investigated, the spores of these specimens were normal and well-developed (see also Van Uffelen \& Hennipman, 1985). 


\section{PHYLOGENY}

A hypothesis concerning the genealogical relations within the genus Pyrrosia is presented in the form of a cladogram (Fig. 13). In this figure, the cladogram is presented as a 'synapomorphy scheme': a branching scheme superimposed on a species/character matrix that has been ordered according to certain principles.

In theory, a taxon/character matrix can be ordered according to many different principles, of which the hierarchic principle generally used in taxonomy is only one (Ball, 1983). Also, any ordering of a group of taxa may be interpreted as some kind of a hypothesis concerning these taxa. The advantage of the particular type of ordering used in taxonomy, a hierarchical ordering, is that it is easily converted into a genealogical hypothesis. To do so, it is only necessary to accept the basic premise of evolutionary theory, viz., that taxa have come about by descent with modification. A hierarchical system represents genealogy in that each group in the hierarchy on any level represents a group of taxa descended from a common most recent ancestor. It has been argued not only that the initial assumption of evolution is a sufficient reason to interprete cladograms as genealogical hypotheses, but also that it is the only possible reason to prefer a hierarchical system over other systems expressing relationships (Beatty, 1982; Ball, 1983; Hull, 1983).

\section{Methodology}

Once the desirability of a hierarchical system has been established, a method must be chosen by which this hierarchy is to be constructed. In how far a genealogical interpretation of the hierarchic system is useful as a biological hypothesis depends on the following two factors:

- In how far the method used for the construction of the hierarchy can be considered to reflect the relevant evolutionary processes;

- The explanatory power of the ordering achieved.

The two factors are, of course, not fully independent of each other. If the explanatory power of a certain ordering (genealogical hypothesis) is great, that in itself may be taken as an indication that the ordering principles in some way reflect the processes in nature. On the other hand, if there are strong reasons to suppose that certain processes have been active, this may be taken as an indication that the hypothesis produced by using principles reflecting those processes 
will be a useful one. For the construction of hierarchical systems in biology it is desirable to choose a method that reflects as much as possible the course of historical events during speciation processes.

Such a method has been developed by Wagner $(1961,1969)$ and Hennig (1966); it has been used since without important modifications. This method is derived by applying the following considerations: 1) that during the course of evolution new species are formed out of older ones; 2) that any new species must have at least one new character to distinguish it from the parental species (this is not to say that species can always be "based on" a single character; the process of species recognition is a different one from that of phylogeny reconstruction); 3) that this newly acquired character persists unchanged or is modified uniformly throughout the species (anagenesis) until this uniformity is disrupted because the character is modified again, either in the process of the formation of a new daughter-species (cladogenesis) or afterwards, in one of the daughter-species.

Thus is the principle derived that only the shared possession of newly acquired (apomorphic) characters can be used as an argument for the sharing of a common most recent ancestor. The method consists of the search for a hierarchical pattern in the distribution of these apomorphic characters. The sharing between two taxa of an apomorphic character then is a direct reflection of the sharing of the ancestor in which that character evolved for the first time.

The recognition of apomorphic from plesiomorphic characters is thus an important element of the method.

There are two ways in which it is possible to approach this problem. The first, traditional, approach (advocated by Wagner, 1961, 1969, and applied, e.g., to the genus Platycerium by Hoshizakı, 19/L, and Hennipman and Koos, 198\%) is that the a priori recognition of transformation series is a prerequisite for the construction of a cladogram. The second possible approach (advocated by, e.g., Gaffney, 1979) is that transformation series, and thus the relative apomorphy of each character in such a series, are to be reconstructed in some way from the cladogram. This latter approach is here rejected, because of inconsistencies that are inherent to it. A more detailed comparison of both approaches to phylogeny reconstruction will be published elsewhere (Hovenkamp, in prep.)

For the purpose of analysing the consequences of either approach, phylogeny reconstruction can be conceived of as a process composed of three independent steps.

The first step is the construction of a data matrix in which the observations on the organisms are incorporated in a suitably coded form.

The second step is the construction of a network that connects the taxa in such a way that the total number of character changes along the segments of the netwerk is minimized (Wagner-network, Farris, 1970; Jensen, 1980). 
The third step, relevant only if the second approach is adopted, is the evaluation of this network as a 'synapomorphy scheme': for each group that is specified by the network it must be evaluated whether there are apomorphic characters that can be used as arguments for the monophyly of the group. This step has two different aspects: the assignment of characters to the nodes of the network, from which assignments the patterns of character change (character transformation series) can then be read off; and the establishing of a 'root' to the network, by which the direction of character change can be found. These two aspects are independent of each other.

The root of a network can be found by applying some kind of 'out-group analysis' (Lundberg, 1972; Farris, 1982). The network is then compared to a supposed sister-group of the group that is being analyzed, and the segment of the network is found where the sister-group can best be connected to it. This method relies heavily on a hypothesis about the phylogeny of a higher order; and, in principle, leads to an infinite regress (Colless, 1967, 1969).

In the reconstruction of the pattern of character change (the 'order' of the transformation series) some ambiguities may easily arise. This is the case if transformation series are involved that are composed of more than two characters, or, which is equivalent, if some homoplasy (parallelisms, convergence or secondary reversal) has occurred. Fitch (1972) presents a method by which all most parsimonious assignments of characters to the nodes in a network may be reconstructed in such cases. In many cases several characters can be assigned to a single node, which leads to ambiguities if the order of character changes is reconstructed along the lines of the network. Only in a few special cases the course of the character transformation can be reconstructed unambiguously (Watrous \& Wheeler, 1981). Several methods have been devised (Farris, 1970; Mickevich, 1982) to eliminate these ambiguities, but not all possible ambiguities can be eliminated by these methods, nor is it clear whether these methods do not make some arbitrary choices among the several possible solutions of the ambiguities.

The inclusion of this last, third, step in the reconstruction is, as already indicated above, necessary only if the transformation series are to be 'read off' from the data. If transformation series are specified in advance they can be incorporated in the first step. This "reading off' afterwards appears to be not always possible; from there it follows that we also have to reconsider the problems inherent in the first of the three steps.

In order to construct the network (step two), it is necessary to code the data (step one). This can be done either in such a way that no transformation series are implied ('neutral coding'), and above it has been argued that then the correct transformation series can not always be reconstructed. The only alternative is to code the data in a way that already incorporates transformation series ('additive 
coding'). Thus, the choice seems to be one between adoption of 'a priori' assumptions and unavoidable loss of information.

Moreover, even a method that tries to code the data in a way as 'neutral' as possible has to make assumptions about which two characters (or 'characterstates' as they are usually called) should be connected in a one-step transformation. It seems inconsequent to accept the ability to perceive a connection between two characters, and at the same time, to deny oneself the ability to perceive connections between more characters.

Another problem that follows directly from the avoidance of a priori assumptions is inherent in the second step, the construction of the network from the datamatrix. In principle, the problem of finding the minimum length network connecting the taxa is NP-complete (Felsenstein, 1982). This means that an efficient algorithm to find that network probably can never be constructed. The search for the minimum-length cladogram then must be made by comparing all possible cladograms; which is practically impossible if more than a few taxa are involved. The restriction that results from the adoption of a priori transformation series can reduce the number of cladograms that have to be compared.

Summarizing, I would like to stress that the search for an objective method of cladogram construction, avoiding a priori transformation series, has a number of disadvantages:

1) An arbitrariness in the choice of the cladogram from among all possible cladograms, a choice that is not explicit in most algorithms (exceptions are all fully implemented 'exhaustive search' algorithms).

2) The reliance, for the rooting of a cladogram, on a higher level phylogeny. Apart from leading to infinite regress, this will usually involve comparisons with groups less intensively studied than the group for which the cladogram is being constructed, and consequently, may weaken the conclusions rather than strengthen them.

3) The assumption that transformation series can be reconstructed from the data in an unambiguous way is unwarranted. Any results arrived at may in fact be due to arbitrary decisions that are not explicitly accounted for.

\section{Construction of the cladogram}

In order to avoid the problems indicated above I have chosen for a method in which several choices are made a priori. I consider a limited number of explicit though subjective decisions preferable over an unknown number of hidden, arbitrary choices. In this way, further discussion is made possible of these decisions and their consequences; in the other option neither the assumptions nor their consequences for the structure of the cladogram are clear. 
The a priori establishment of transformation series can in my opinion best be considered as the formation of hypotheses; a process that, according to many philosophers, defies rational analysis anyway. The procedure outlined here can relatively easily be fitted into a hypothetico-deductive model of scientific reasoning (Popder. 1959: compare also Gaffnev. 1981 and Cartmill. 1981). The 'a priori' postulation of transformation series is regarded as the formulation of the hypothesis; the construction of the cladogram, following the rules as set out above, is then the deductive phase by which testable predictions are (hopefully) derived.

The a priori choices made here are the following:

1) For each character used a transformation series is specified and given direction in advance of further analysis.

2) Also, prior to analysis, several groups of species are regarded as monophyletic units and the monophyly of these units has been considered a fixed matter. Only when in the course of the construction of the cladogram it was not possible to proceed further otherwise, the monophyly of these groups was reconsidered.

With regard to these points, the following remarks can be made.

ad 1. I have used 'out-group comparison' (in the 'global' sense, Zandee, in prep.) reluctantly. I consider that it may have some heuristic value, particularly when only two characters are involved. I have tried as much as possible to find other arguments first. These other arguments used in constructing transformation series (see below) are the following:

- Ontogenetic sequence (or heteroblastic series): used in characters 1B, 1D, 3B, 3C, 13B, 13C, 13D, 14B, 14D, 14E, 14F, 17B, 17E, 19B, 20B, 20C. The ontogeny (and heteroblastic series) of the relevant structures is discussed in Chapter 5. Generally, it has been supposed that structures arising earlier in the development are plesiomorphic; but I have also made the assumption that secondary reversals to the plesiomorphic state in these cases are relatively easily attained through neoteny.

- In some cases (characters 13B-D, 21D-E) the observed variability of the species concerned and the occurrence of incidental atavistic plants has been used as an argument.

- Biological considerations, based on the hypothesis that in Pyrrosia, evolution has led towards specialization as high epiphytes, have been used in characters $12 B$ and 20B-C.

- Generally, other arguments lacking, I have favoured hypotheses of trends towards increasing complexity, differentiation or regularity over those of reduction series. On the other hand, a mechanism of reduction (often resulting in an earlier stage from the heteroblastic series) is more likely to give rise to parallelisms 
than does a mechanism involving repeated "de novo" origin of complex structures.

In several cases, the characters occurring in small, restricted groups have been regarded as apomorphic without further arguments. This admittedly dubious "'in-group" common = primitive' argument was not used, however, in all these cases. An assessment of the primitive state for rhizome structure is not made as the possibility of a more complex transformation series than a one-step series could not be excluded.

ad 2. The initial acceptance of supposedly monophyletic groups is not justifiable by reference to some high principle. It is, however, firmly established taxonomic practice, and is equivalent to the initial recognition of species as units of evolution; it can also be regarded as equivalent to giving a heavy 'weight' to the characters that are used in recognizing the groups.

Application of these considerations have made it feasible to handle a dataset of this size without relegating the actual constructing to a computer. The number of possibilities is drastically reduced by accepting species-groups as cladogenetic units. Relatively little extra work was found to be necessary to analyze the groups themselves in order to arrive at a hypothesis about the ancestral states for those characters for which the groups were found to be heterogeneous.

Initial specification of the transformation series similarly reduced the number of possible cladograms.

\section{Character selection}

The characters used for this analysis were taken from as wide a range of morphological structures as possible. Some selection, however, is necessary. It was made with the aid of the following criteria:

\section{Fragmentary data}

Characters were excluded from the analysis if the information regarding the distribution of the characters over the species was only fragmentary. For this reason, the following characters were not used:

- degree of branching of the rhizome,

- configuration of frond- and branch gaps in the stele,

- structure of the rhizome scales (but see char. 7B),

- characters of the 'scale-like filaments' at the stipe base; these structures are so strongly deciduous that there can be no certainty that they are still present in herbarium specimens,

- chromosome number,

- all characters for which complete knowledge of the ontogenetic or heteroblastic development in the genus was necessary,

- all characters of the gametophyte. 


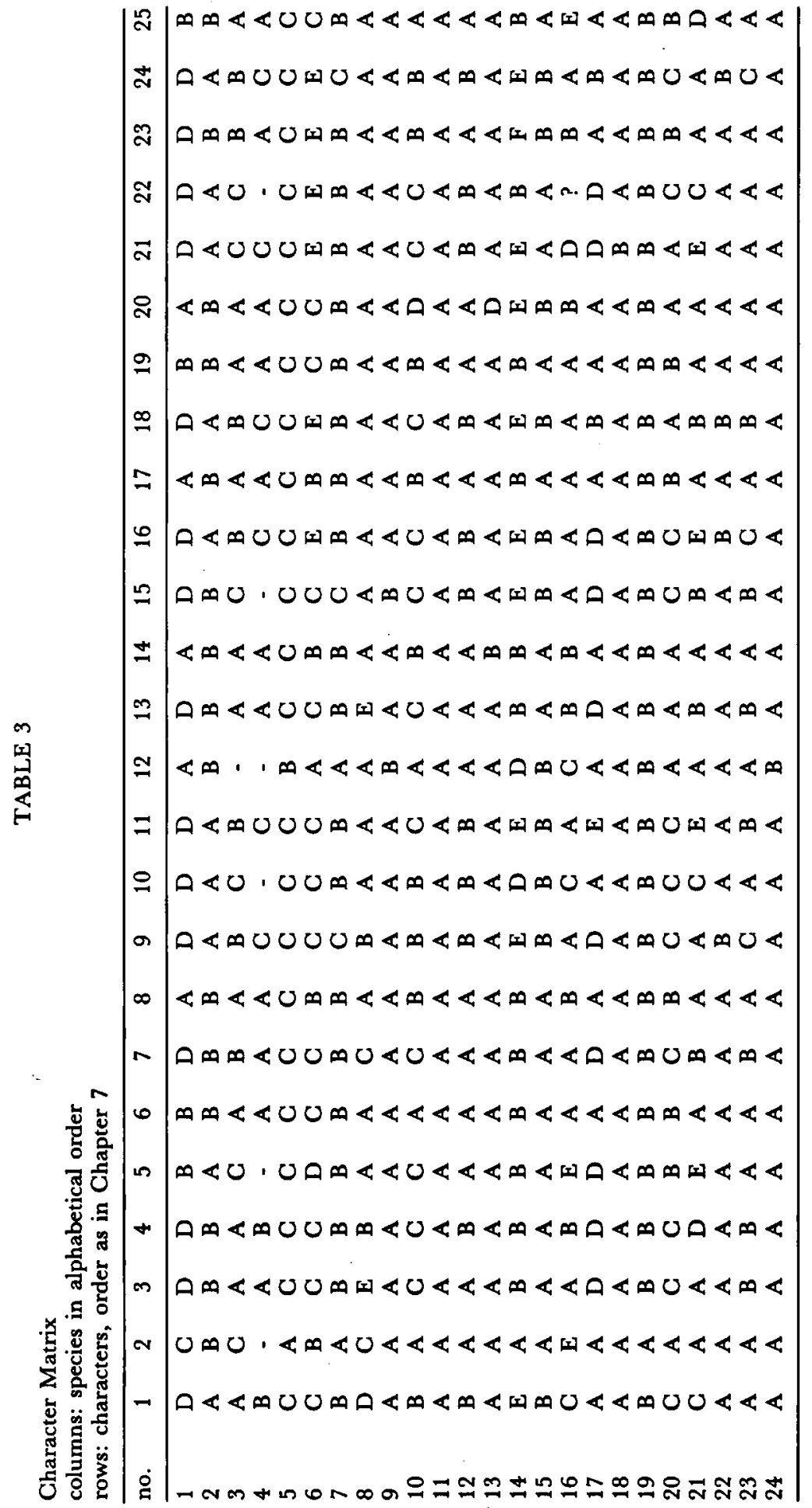




\section{Variability}

Characters were not used if the range of variation within several species was found to be as large as or almost as large as the range of variation within the entire genus. If such is the case, it is difficult or perhaps even impossible to assign values to the species concerned if those values are to be meaningful for the comparison with other species. It is of course always possible to select some statistical parameter and compare the values of that parameter; and the possibility can never be excluded that some significant difference between species can be found, or some significant trend. Difficulties encountered in this approach centre around the problem of obtaining comparable values for all species. Sample size, differences in distribution for the parameter selected etc. may give problems of which the exact gravity may be very difficult to assess.

Characters of which the use was rejected for these reasons were:

- the number of vascular strands in the rhizome or stipe,

- the distinctness of the sclerenchyma sheath

- the height of the phyllopodia,

- the size of the fronds,

- the number of indurated annulus cells in the sporangium and the length of the sporangium stalk.

The characters left after this selection was applied are given in Table 3.

\section{Unknown transformations}

Characters were finally rejected if no transformation series could be specified with at least a little plausibility. Characters that were initially considered but finally rejected for this reason were, e.g., the structure of the ground tissue of the rhizome; the surface structure of the spores (at the time under investigation, Van Uffelen \& Hennipman, 1985). These characters were used, however, in the initial delimitation of the species-groups, but confirmation of the monophyly of these groups was sought as much as possible in other characters with a specified transformation.

The postulated transformation series were used in recoding the characters in table 3; the results are presented as background to the cladogram (Fig. 13). A few additional characters, introduced later in the construction of the cladogram are given as ' $a$ ', ' $b$ ' and 'c'. 


\section{Proposed transformations}

Rhizome morphology (see p. 15).

$1 \mathrm{~A}-\mathrm{Rhizome}$ short, thick.

1B-Rhizome shortly elongated, with buds shifted.

1C-Rhizome shortly elongated, buds not shifted.

1D-Rhizome long-creeping, buds shifted.

For the assignment of values for these characters, the situation in the majority of specimens in each species is taken as a criterion for the assignment of a particular character code. Incidentally, aberrant specimens occur. A maximum internode length of $2 \mathrm{~cm}$ is taken as upper limit for the delimitation of 'shortly elongated' rhizomes. At first sight this value appeared to give the taxonomically most useful separation; this view is confirmed by the absence of parallelisms for this character in the final cladogram. "Buds situated opposite the phyllopodia" is not considered as a separate character, as this condition is rarely constantly present in a species.

On account of the different position of the lateral buds the superficially similar characters B and C are supposed to be independently derived. Characters A, C and $\mathrm{D}$ can be combined into a transformation series. The direction of the character transformations is indicated by out-group analysis with Platycerium as an out-group; this is strengthened by data obtained from the study of the development of the rhizome.

The proposed transformation is thus: $1 \mathrm{~A} \rightarrow 1 \mathrm{~B} \rightarrow 1 \mathrm{D}$ and $1 \mathrm{~A} \rightarrow 1 \mathrm{C}$

$2 \mathrm{~A}-\mathrm{Rhizome}$ rounded in cross-section.

$2 \mathrm{~B}-$ Rhizome ventrally grooved.

Rhizomes may be shallowly or narrowly grooved. Rhizomes with a narrow groove often have the vascular strands in a fixed number of five; this may be a condition derived independently compared to rhizomes with a more shallow groove and a larger, varying, number of vascular strands.

The proposed transformation is $2 \mathrm{~A} \rightarrow 2 \mathrm{~B}$.

Rhizome anatomy, non-vascular tissue (see p. 19)

3A-Rhizome with a large number of sclerenchyma strands.

3B-Rhizome with few sclerenchyma strands.

3C-Sclerenchyma strands absent.

4A-Sclerenchyma strands scattered. 
4B-Sclerenchyma strands situated peripherally in the parenchyma.

4C-Sclerenchyma strands situated centrally.

5A-Rhizome completely parenchymatous.

5B-Rhizome completely sclerified.

$5 \mathrm{C}-\mathrm{Rhizome}$ differentiated in parenchyma and sclerenchyma.

Characters 3A, 3B and 3C can easily be combined into a transformation series. The direction is indicated by the observation that in many species the loss of sclerenchyma in the rhizome is a not uncommon phenomenon so that reduction here seems a more plausible possibility than repeated 'de novo' origin of a similar sclerenchyma structure. As sclerenchyma strands appear rather late during the development of the rhizome a mechanism that is possibly involved is retention of the juvenile state.

The character transformation series thus constructed shows a distinct correlation with that hypothesized for characters $1 \mathrm{~A}, 1 \mathrm{~B}, 1 \mathrm{D}$ and $4 \mathrm{~A}, 4 \mathrm{~B}, 4 \mathrm{C}$.

For character $3 \mathrm{~B}$, the number of 10 strands is taken as a more or less arbitrary distinction between few and many; with regard to the frequent reduction pointed out above the highest number of strands found in a species is used as a criterion to assign a character to that species.

A transformation for characters $4 \mathrm{~A}, 4 \mathrm{~B}$ and $4 \mathrm{C}$ is proposed following the principle that structurally more complex features are to be considered derived if other arguments are lacking.

No transformation is proposed for the completely sclerified rhizomes of the $P$. costata-group (5B) and the almost completely parenchymatous rhizomes of the $P$. afrcana-group (5A). It is difficult to fit these two characters into a transformation scheme together with the differentiated rhizomes of the other species (5C). On the one hand, the lack of differentiation in both groups can be taken as a unifying character for the two groups; on the other hand, the presence of sclerenchyma can be considered a character shared between the $P$. costata-group and the other species-groups. A third possibility, viz. that the parenchymatous rhizome of the $P$. africana group is a reduction compared to 'normally' sclerified rhizomes also finds some support: other species from continental Africa have a relatively lightly sclerified rhizome (e.g., $P$. stolzii, $P$. rhodesiana), and it may be supposed that in Africa there are selective pressures against a sclerified rhizome.

The proposed transformation series are: $3 A \rightarrow 3 B \rightarrow 3 C ; 4 A \rightarrow 4 B, 4 A \rightarrow 4 C ; 5$ none.

Rhizome scales (see also p. 23)

6A-Scales basifix.

6B-Scales pseudopeltate. 
6C-Scales peltate.

$6 \mathrm{D}-$ Scales peltate, at least some scales without acumen.

$6 \mathrm{E}-$ Scales widest above the base.

$7 \mathrm{~A}-$ Cell walls thin.

7B-Cell walls distinctly thickened.

7C-Cell walls thickened, showing 'annular figures'.

8A-Margin of the scales variously and mostly irregularly ciliate-dentate.

8B-Margin entire.

8C-Margin coarsely dentate.

8D-Margin with long, curly cilia.

8E-Scales with superficial papillae or cilia.

9A-Scales with glands only at the apex.

$9 \mathrm{~B}-$ Glands present at the base of the scale.

The direction of the transformation series connecting the characters $6 \mathrm{~A}, 6 \mathrm{~B}$ and $6 \mathrm{C}, 7 \mathrm{~A}$ and $7 \mathrm{~B}$ is supposed to be towards increasing complexity of the structures involved (see also p. 80). The postulated series $6 \mathrm{~A} \rightarrow 6 \mathrm{~B} \rightarrow 6 \mathrm{C}$ implies that the presence of an acumen is to be considered plesiomorphic, the (occasional) absence as derived; the distinct shape of $6 \mathrm{E}$ is considered another derived character.

Fragmentary data from cross-sections of rhizome scales indicate that character 7B may actually be composed of two different, possibly independent characters (see p. 26). The distinction is not evident without sectioning the scales. The distinction between 7A and 7B that is recognized here is the following: in 7B the scales are distinctly thickened at least near the point of attachment, which is evident in translucent light; in 7A the scales are equally thickened and translucent throughout. $7 \mathrm{C}$. is a further modification.

Characters 8B, 8C, 8D, and 9B are restricted to small groups of species. Entire scales (8B) are found mainly in the $P$. albicans-group (also in the $P$. lanceolatagroun): coarsely dentate scales (8C) are characteristic for $P$. asterosora and $P$. distichocarpa (but occur also in $P$. africana); long, curly cilia (8D) only occur in the $P$. lingua-group. Basal marginal glands (9B) are characteristic for $P$. eleagnifolia and $P$. rupestris, they occur also in $P$. schimperiana and scattered throughout the $P$. costata-group. In this last group they may be more frequent than is observed as the scales are often severely damaged while being dissected from the rhizome.

No transformation is proposed involving character 8E: on the one hand, the presence of superficial papillae can be considered as indicating an increasing complexity, on the other hand it can be regarded as indicating a lack of differentiation between surface and margin of the scales.

The character transformations proposed are: $6 \mathrm{~A} \rightarrow 6 \mathrm{~B} \rightarrow 6 \mathrm{C} \rightarrow 6 \mathrm{D}, 6 \mathrm{C} \rightarrow 6 \mathrm{E}$; $7 \mathrm{~A} \rightarrow 7 \mathrm{~B} \rightarrow 7 \mathrm{C} ; 8 \mathrm{~A} \rightarrow 8 \mathrm{~B}, 8 \mathrm{~A} \rightarrow 8 \mathrm{C}, 8 \mathrm{~A} \rightarrow 8 \mathrm{D} ; 9 \mathrm{~A} \rightarrow 9 \mathrm{~B}$. 
10A-Fronds not stipitate.

10B-Fronds differentiated into stipe and lamina, stipe with lateral vascular strands.

10C-Fronds differentiated, stipe without lateral vascular strands.

10D-Fronds differentiated, stipe with lateral vascular strands, dorsal strands in stipe fusing below the lamina.

$11 \mathrm{~A}-$ Stipe without a central bundle of collenchyma.

11B-Stipe with a central bundle of collenchyma.

Here again, as in character $1 \mathrm{~B}$, the situation in the majority of specimens is taken as a criterion for the assignment of a character code to a species. Incidentally, an indistinct stipe may be found in otherwise estipitate species; conversely, stipes may be absent in highly reduced forms of stipitate species. In some species with constantly small fronds ( $P$. angustissima, $P$. piloselloides) the situation is not always quite clear. Both $10 \mathrm{C}$ and 10D are considered as further developments towards differentiation between lamina and stipe. Character 11B, occurring only in the $P$. costata-group, is considered a specialization.

The transformations proposed are: $10 \mathrm{~A} \rightarrow 10 \mathrm{~B}, 10 \mathrm{~B} \rightarrow 10 \mathrm{C}, 10 \mathrm{~B} \rightarrow 10 \mathrm{D}$; $11 \mathrm{~A} \rightarrow 11 \mathrm{~B}$.

Frond characters, lamina (see also p. 32)

12A-Specialized sterile fronds absent.

12B-Specialized sterile fronds present, generally shorter and wider than the fertile ones.

The presence of sterile fronds may be due to two different, independent developments. An indication that such is the case is found in the apparently different ways in which the sterile fronds seem to be derived from fertile ones ( $p$. $35)$ : either by complete suppression of the formation of sporangia $(P$. linguagroup), or by suppression of apical growth (e.g., $P$. angustata-group). Considering the very widespread occurrence of forms of frond dimorphism and the various expressions of it throughout the ferns it is not surprising that some parallellism apparently has occurred also within a single genus.

The general direction of the trend is set by the consideration that in spore producing species the presence of specialized sterile fronds is of necessity a secondary development.

The transformation proposed is: $12 \mathrm{~A} \rightarrow 12 \mathrm{~B}$. 


\section{$13 \mathrm{~A}$-Lamina \pm elliptic}

13B-Lamina often widest near the base, sometimes with a lateral lobe.

13C-Lamina often lobed near the base with several basal teeth.

13D-Lamina regularly hastate, or pedately dissected.

The transformation series involving characters $13 \mathrm{~A}, \mathrm{~B}, \mathrm{C}$ and $\mathrm{D}$ is more fully discussed on p. 37. The recognition of the first step in this series in $P$. drakeana was possible only after the general trend had been recognized. Due to considerable plasticity the characters in $P$. drakeana and $P$. sheareri are not evident in all specimens.

The transformation series proposed is $13 \mathrm{~A} \rightarrow 13 \mathrm{~B} \rightarrow 13 \mathrm{C} \rightarrow 13 \mathrm{D}$.

\section{Lamina indument (see also p. 40)}

14A-Woolly hairs absent.

14B-Woolly hairs present.

14D-Indument dimorphic, appressed.

$14 \mathrm{E}-$ Indument monomorphic, appressed.

$14 \mathrm{~F}-$ Some rays of the upper layer forming dorsal spines.

$15 \mathrm{~A}$-Straight rays acicular.

15B-Straight rays boat-shaped.

In contrast to the method used in characters $1 \mathrm{~B}$ and $10 \mathrm{~B}$, for the assignment of a character to a species the presence of woolly hairs in some specimens was considered sufficient here. Thus, the potential to form woolly rays is considered as more important than the degree to which this potential is actually realized. This is because of the notable plasticity with which this character may be expressed, and the possibility of asynchronous development of lamina shape and indument during the heteroblastic series. The procedure is crucial, however, only in assigning characters to $P$. assimilis and $P$. rhodesiana: in all other species a 'majority count' of the available specimens would have yielded the same results as the procedure followed.

Character 14D may be composed of two different characters: one with boatshaped, one with acicular straight rays (in the $P$. lingua- and the $r$. costata-group resp).

The direction of the transformations of these characters is indicated by the heteroblastic development (see p. 45). The thin, often sparse induments showing character $15 \mathrm{~B}$, and the distinct structure of character $14 \mathrm{~F}$ obviously represent a reduction resp. a specialization. The reduction leading to character 15B apparently is a common phenomenon, as highly similar induments of this type are 
found in widely different groups (e.g., $P$. schimperiana in the $P$. africana-group, $P$. sheareri in the $P$. sheareri-group, $P$. petiolosa in the $P$. lingua-group, $P$. novo-guineae in the $P$. angustata-group). A similar indument can also be found in some species of Platycerium (Hennipman \& Roos, 1982, p. 68, Pl. 11: c). In a strongly reduced form (as in forms of $P$. lanceolata and in the $P$. piloselloides-group) the difference between boat-shaped and acicular rays is obscured.

The transformation series proposed are: $14 \mathrm{~A} \rightarrow 14 \mathrm{~B} \rightarrow 14 \mathrm{D} \rightarrow 14 \mathrm{~F}, 14 \mathrm{~A} \rightarrow 14 \mathrm{E}$, $14 \mathrm{~B} \rightarrow 14 \mathrm{E}, 14 \mathrm{D} \rightarrow 14 \mathrm{E} ; 15 \mathrm{~A} \rightarrow 15 \mathrm{~B}$.

\section{Venation (see also p. 48)}

$16 \mathrm{~A}$ - Included veins mainly free, excurrent. $16 \mathrm{~B}$-Included veins frequently anastomosing, excurrent. $16 \mathrm{C}$-Included veins strongly anastomosing, free veins both re- and excurrent. $16 \mathrm{D}$-Included veins recurrent.

$16 \mathrm{E}-$ Venation \pm irregular, without regular areoles.

No transformation series is postulated for these characters. The pattern that emerges in the heteroblastic development is ambiguous: character $16 \mathrm{C}$ seems to be often preceded by a stage with a pattern similar to $16 \mathrm{D}$, whereas this seems not to be the case for characters $16 \mathrm{~A}$ and $16 \mathrm{~B}$. Apart from that, it would be most likely that a series $16 \mathrm{~A} \rightarrow 16 \mathrm{~B} \rightarrow 16 \mathrm{C}$ is present. The occurrence of venation patterns with recurrent veinlets in a genus with predominantly excurrent veinlets is curious, as the difference seems to be a consistent one between large groups in the Polypodiaceae. In the absence of a more general theory about the development of venation patterns I desist from postulating theories about transformations in Pyrrosia.

$17 \mathrm{~A}-$ Hydathodes scattered over the lamina, constantly present.

17B-Hydathodes scattered over the lamina, inconstantly present.

$17 \mathrm{C}-$ Hydathodes in a marginal row.

17D-Hydathodes absent.

$17 \mathrm{E}-$ Hydathodes in a row on the lower surface of the lamina.

The direction of these transformations is indicated by the heteroblastic development of the hydathodes (p. 53). In what way the characters can be combined in a transformation series is to some extent uncertain. The combination of characters $17 \mathrm{C}$ and $17 \mathrm{E}$ is obvious, as is the connection between characters $17 \mathrm{~B}$ and $17 \mathrm{D}$, but it is not clear whether character $17 \mathrm{C}$ has directly evolved from $17 \mathrm{~A}$ or whether character $17 \mathrm{~B}$ is an intermediate state also between these two characters.

The transformation proposed here is: $17 \mathrm{~A} \rightarrow 17 \mathrm{~B} \rightarrow 17 \mathrm{D}, 17 \mathrm{~A} \rightarrow 17 \mathrm{C} \rightarrow 17 \mathrm{E}$. 
18A-Mesophyll of lamina more or less differentiated into distinct tissue-layers. 18B-Mesophyll homogeneous, parenchymatous.

Character $18 \mathrm{~B}$ is restricted to the $P$. piloselloides-group. It seems to be an adaptation directly related to the succulent character of the lamina. Similar succulent fronds of, e.g., $P$. lanceolata or $P$. longifolia usually show some, if not much, differentiation; succulent fronds in the $P$. albicans-group (e.g., in $P$. nummulariffolia) show a completely different development, with a well-differentiated mesophyll with a very thick water-tissue (see also p. 56 ).

The transformation proposed is: $18 \mathrm{~A} \rightarrow 18 \mathrm{~B}$.

19A-Stomata polocytic.

19B-Stomata pericytic.

20A-Stomata superficial.

20B-Stomata impressed.

20C-Stomata immersed.

The direction of the transformation of character 19A and 19B is indicated by ontogenetic studies (Sen \& Hennipman, 1981).

Impressed or immersed stomata are an obvious adaptation to a xeric habitat; in the species were this character is present probably to the periodically dry conditions experienced by high epiphytes. The various degrees to which the stomata are sunken are accordingly interpreted as representing successive stages in a transformation series.

The transformation series postulated are: $19 \mathrm{~A} \rightarrow 19 \mathrm{~B} ; 20 \mathrm{~A} \rightarrow 20 \mathrm{~B} \rightarrow 20 \mathrm{C}$.

Sori and sporangia (see also p. 57)

$21 \mathrm{~A}$-Sori small, several to many in each areole.

$21 \mathrm{~B}$-Sori relatively large, $2(3)$ in each areole.

$21 \mathrm{C}$-Sori very small, closely packed and pseudo-acrostichoid when ripe.

21D-Sori in a single row between costa and margin.

$21 \mathrm{E}-$ Sori confluent in a coenosorus.

Small sori are 1-1.5 mm diam. when ripe, larger sori may be up to $4 \mathrm{~mm}$ diam. In very small-fronded species the number of sori may be reduced to 2 per areole without a concomitant increase in sorus size; this is considered a parallel development and is not scored as apomorphic ( $P$. assimilis). 
A single row of sori may be due to extreme reduction of the width of the lamina (as in P. schimperiana var. liebuschii, or in P. linearifolia), but this is regarded as a different character from the apomorphic character 21D.

Presence of character 21D is considered a further modification from character 21B. The connection is beautifully shown in an atavistic form of $P$. angustata (see p. 59). The last step in this transformation series composed of characters 21B and $21 \mathrm{D}$ is represented by character $21 \mathrm{E}$. Nevertheless, it is also likely that character $21 \mathrm{E}$ has arisen more than one time, and also through other mechanisms than those implied in the series $21 \mathrm{~A} \rightarrow 21 \mathrm{~B} \rightarrow 21 \mathrm{D} \rightarrow 21 \mathrm{E}$. In the $P$. lanceolata-group for instance, there are no intermediate stages between the small, separate sori in, e.g., $P$. lanceolata and the elongated coenosorus of $P$. fallax, although from the comparable distribution of the paraphyses in both types of sori it is clear that they are morphologically very close. A similar case is present in $P$. angustissima, where a coenosorus also occurs without an indication of intermediate stages in related species. Assessment of the situation in $P$. angustissima, however, is hindered by the absence of evidently closely related species.

Although the pseudo-acrostichoid soral patches of Platycerium are superficially similar to the pseudo-acrostichoid condition in Pyrrosia, I nevertheless consider the two characters as distinct. In Platycerium the receptacles are usually elongated across the network of veins (forming thus the so-called 'diplodesmic' venation), whereas in Pyrrosia the receptacles are elongated following the veins, and thus do not form a separate venation pattern.

The transformation series for these characters are then: $21 \mathrm{~A}-21 \mathrm{C}$; $21 \mathrm{~A} \rightarrow 21 \mathrm{~B} \rightarrow 21 \mathrm{D} \rightarrow 21 \mathrm{E}$.

$22 \mathrm{~A}$ - Sori superficial or shallowly immersed.

22B-Sori deeply immersed in distinct cavities.

In this transformation series an intermediate state might be distinguished, with sori more or less immersed, but not in steep-sided cavities. This distinction, however, is not as clear as the one presented here. Shallowly immersed sori occur in $P$. angustata, $P$. rupestris, $P$. eleagnifolia, $P$. serpens. In many other species very slightly immersed sori occur, but the exact degree of immersion can perhaps not be reconstructed from herbarium material.

The proposed transformation is: $22 \mathrm{~A} \rightarrow 22 \mathrm{~B}$.

$23 \mathrm{~A}$-Indument of the receptacle similar to that of the sterile lamina.

23B-Receptacle with distinct paraphyses 'scattered through the sorus.

23C-Paraphyses in a central bundle in the sorus.

The transformation involving characters $23 \mathrm{~A}, 23 \mathrm{~B}$ and $23 \mathrm{C}$ is postulated following the general notions of increasing complexity and differentiation: $23 \mathrm{~A} \rightarrow 23 \mathrm{~B} \rightarrow 23 \mathrm{C}$. 
$24 \mathrm{~A}-$ Annulus of sporangia with indurated cells extending to the stalk. 24B-Annulus with indurated cells only apically on the sporangium.

A partly indurated annulus is restricted to the $P$. costata-group (see p. 62). It is an obvious specialization.

The proposed transformation is accordingly: $24 \mathrm{~A} \rightarrow 24 \mathrm{~B}$.

\section{Are the groups monophyletic?}

Prior to the construction of the cladogram several species-groups were recognized (chapter 4) as possibly monophyletic ones. An assessment of the arguments for monophyly of these groups can be given at this stage. The acceptance of certain groups as monophyletic can break down the complexity of the cladogram into manageable parts.

\section{P. africana-group}

In the interpretation of the characters presented above, this group has no autapomorphies. Nevertheless, it is provisionally accepted as a monophyletic one on acount of the homogeneity with regard to rhizome morphology, rhizome anatomy and sporoderm structure.

\section{P. costata-group}

This group has the obvious autapomorphy of character 24B; moreover, it is homogeneous with regard to rhizome anatomy, venation, sorus structure and spores. It can confidently be regarded as a monophyletic one.

\section{P. porosa-group}

This group lacks autapomorphies. Moreover, none of the characters used for the delimitation of this group is an apomorphy in the interpretation presented above. The group cannot be regarded as monophyletic unless some characters are interpreted in a different way.

\section{P. sheareri-group}

This group has no autapomorphies. It is provisionally accepted as monophyletic because of the rather weak delimitations between the species in this group, suggesting that speciation is not fully completed.

\section{P. lingua-group}

This group has no evident autapomorphies among the characters enumerated above, but possibly a single one in the peculiar form of frond dimorphism ( $p$. 
35). In other aspects, particularly spore morphology, the group is markedly heterogeneous. It is certainly not a well-established monophyletic group.

\section{P. albicans-group}

Although autapomorphies are absent from this group as well, it is provisionally accepted as a monophyletic one on account of the uniformity with regard to the rhizome scales, the lamina anatomy and the spore sculpture. This last character, however, is shared between the species in this group and $P$. sphaerosticha, here provisionally placed in the $P$. lingua-group on account of rhizome scales and frond shape.

\section{P. angustata-group}

I confidently regard this group as monophyletic on account of great similarities between the species, e.g., in rhizome scales, sorus structure and spore sculpture. A similar sorus structure, regarded as apomorphic, is also found outside this group, but the other two characters are unique to it.

\section{P. confluens-group}

In this group a similar tendency towards the formation of coenosori is present as in the last one. The monophyly of the present group is accepted also on account of similarities in structure of the rhizome scales ( $c f$. p. 27) and the reduction of the hydathodes to a marginal row $(17 \mathrm{C}+\mathrm{E})$. Although this last character is absent from $P$. eleagnifolia, the similarities between this species and $P$. rupestris are so strong that $P$. eleagnifolia is confidently included in the monophyletic group.

\section{P. lanceolata-group}

This group has the obvious apomorphy of character 23C. $P$. foveolata is here added to this group on basis of character 23B.

\section{P. piloselloides-group}

This group has character $18 \mathrm{~B}$ as an autapomorphy. Its monophyly is confirmed by the homogeneity for characters $3 \mathrm{C}, 21 \mathrm{E}$, the unique venation pattern, and the marginal sori (Ravensberg * Hennipman, 1986).

\section{Relationships within the genus}

The actual construction of the cladogram (fig. 13) starts with those of the groups enumerated above that are most confidently regarded as monophyletic. Of these groups, the $P$. confluens- (8), $P$. lanceolata- (9) and $P$. piloselloides-group (10) share 


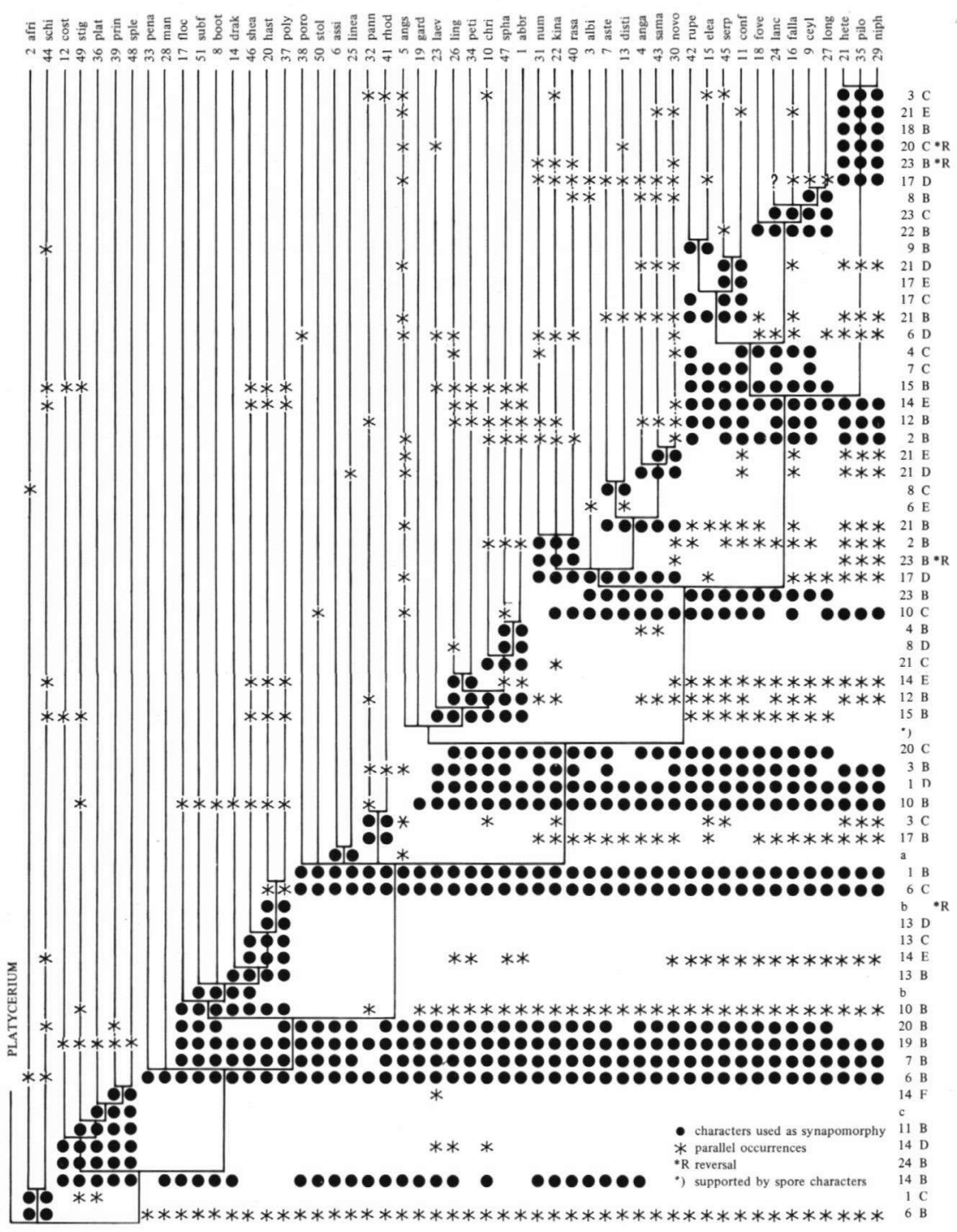

Fig. 13. Cladogram for Pyrrosia. o character used as synapomorphy. - * homoplasious occurrence of character. - ) supported by spore characters. - "R reversal. N.B.: each character occurs as many times as it is used as a synapomorphy on different levels in the cladogram.

the largest numbers of apomorphies; accordingly they are considered first. Of these three groups, those of $P$. confluens and $P$. lanceolata can be joined on basis of characters $4 \mathrm{C}, 7 \mathrm{C}$ and $15 \mathrm{~B}$. Of these, $4 \mathrm{C}$ and 15B have several homoplasious occurrences outside the formed group; the absences of $4 \mathrm{C}$ and $7 \mathrm{C}$ in a few species 
within it can be explained as reversals. Another grouping, of the $P$. lanceolata- and $P$. piloselloides-group, can be made supported by character $6 \mathrm{D}$, but this single character shows a lot of homoplasy. The $P$. piloselloides-group is joined to the two above on basis of characters 14E, 12B and 2B. The three groups now united also share a distinctive spore type (Van Uffelen \& Hennipman, 1985).

Character 2B occurs scattered outside this group, in some members of the $P$. alhirans-oroun some members of the $P$. lingua-group (here possibly in a slightly different form) and in $P$. angustissima. These occurrences have to be explained as parallelisms.

Character 12B has parallel occurrences in $P$. pannosa (weakly), in the $P$. linguagroup (but, again, possibly in a different, not homologous, form), in the $P$. angustata-group and in several species of the $P$. albicans-group. Resolution of the relations within the $P$. albicans-group (see below), however, indicates that the occurrences of character 12B are best explained as parallelisms, and that the ancestral state of the group probably is the corresponding plesiomorphic character 12A. The occurrence of this character in the $P$. angustata-group is discussed below.

It has already been indicated that character $14 \mathrm{E}$ probably arose more than once, and the occurrences outside the group considered here are accordingly considered to be parallelisms.

Within each group a higher resolution is possible with the aid of the characters $8 \mathrm{~B}$ and $23 \mathrm{C}, 9 \mathrm{~B}, 21 \mathrm{D}$, and 17E. Character 17D is not used for this purpose, due to the uncertain situation in $P$. lanceolata (see Taxonomic part, p. 195).

The next group considered is the $P$. angustata-group (7). This group shares with the joined group $(8,9,10)$ the character $12 \mathrm{~B}$, with group 8 only it shares the tendency towards the formation of a coenosorus (characters $21 \mathrm{~B} \rightarrow 21 \mathrm{D} \rightarrow 21 \mathrm{E}$ ). With the $P$. albicans-group (6) it shares character 17D, and the placement of group 7 is thus a matter of weighing character $12 B$ against character $17 \mathrm{D}$, unless other arguments can be found. One possible reason to unite group 7 with group 6 instead of with $(8,9,10)$ is that the perispore sculpture possibly is more easily brought into a relation to that of group 6 than to that of group $(8,9,10)$. If this argument is accepted and group 7 is accordingly placed next to group 6, the tendency towards formation of a coenosorus occurs at least three times (in group 7, 8 and 10).

The group formed by joining group 7 to group 6 has an apomorphy in character 17D. The ocurrences of this character outside the group can be explained by three parallel events.

Within group $(6,7)$ further resolution is possible if the initial assumption of monophyly of group 6 is abandoned. It is not supported by any apomorphies anyway. On basis of character 21B the group formed by $P$. asterosora and $P$. distichocarpa is then considered to be the sister-group of group 7. $P$. albicans can be joined to this group on basis of character $6 \mathrm{E}$, but that would require two other 
events: one in $6 \mathrm{E}$ and another concerning 21B. $P$. nummulariifolia, $P$. kinabaluensis and $P$. rasamalae share the character $2 \mathrm{~B}$ and are considered as a subgroup. The occurrence of character 2B here is parallel to its occurrence outside group $(6,7)$. These three species also share a secondary reduction of character $23 \mathrm{~B}$, parallel to a similar reduction in $P$. novo-guineae.

From the resolution thus obtained for groups $(6,7)$ and $(8,9,10)$ it follows that the ancestral state of both groups is likely to be 23B. Both groups can accordingly be united with character 23B and $10 \mathrm{C}$ as autapomorphy. A different interpretation of character 23B would require that it developed independently at least three times, with several reversals elsewhere. In the interpretation adopted here it arose only once, and reverted three times, in some cases probably as a result of reduction in sorus size.

The group thus formed shares with the $P$. lingua-group (5) the apomorphic characters 1D, 3B, and 20C and is at the next lower level united with that group. Many individual species in group (6-10) also share with group 5 the apomorphic characters $12 \mathrm{~B}$ and $15 \mathrm{~B}$, but from the distribution of these characters it follows that they probably arose as parallelisms in group $((6,7)(8,9,10))$. The occurrence of character 12B and 15B in group 5 accordingly can be regarded as an autapomorphy for that group. More resolution within group 5 can be obtained with the help of characters $4 \mathrm{~B}, 8 \mathrm{D}, 21 \mathrm{C}, 14 \mathrm{D}$ and $14 \mathrm{E}$.

If these characters are interpreted in this way, $P$. laevis can now be introduced in the cladogram. With the $P$. lingua-group it shares character 15B, and it can be placed as a sister-species of the $P$. lingua-group. The group thus formed has a synapomorphy in character $15 \mathrm{~B}$, whereas the $P$. lingua-group keeps one synapomorphy in character 12B. This position of $P$. laevis is confirmed by characters of the perispore (Van Uffelen \& Hennipman, 1985)

On the next lower level the $P$. porosa-group (3) comes into view. With the groups (5-10) it shares apomorphies $1 \mathrm{~B}$ and $6 \mathrm{C}$, and accordingly it can be united with $(5-10)$ on basis of these two characters. The initial supposition that the $P$. borosa-group as defined in Chapter 4 lacks autapomorphies is here confirmed, and the group (3,5-10) therefore has a basal polytomy with 6 branches. In this polytomy also $P$. pannosa can be included on basis of characters $1 \mathrm{~B}$ and $6 \mathrm{C}$, as it lacks characters $20 \mathrm{C}$ and $1 \mathrm{D}$, necessary to include it in a group higher up the cladogram. Reduction of the number of branches in this polytomy can be attained by recognizing small monophyletic groups within it: $P$. assimilis and $P$. linearifolia can be united on basis of the joint possession of narrow fronds (additional character "a"), in the remaining species a subgroup can be recognized formed by $P$. pannosa and $P$. rhodesiana, sharing characters $3 \mathrm{C}$ and $17 \mathrm{~B}$.

At this point in the construction of the cladogram the position of $P$. angustissima and $P$. gardneri can also be considered. $P$. gardneri shares all its synapomorphies with group (3, 5-10) and clearly should be included in it. With group (5-10) it 
shares one synapomorphy (character 10B), but it lacks all synapomorphies of the constituting groups. It can therefore be placed as a sister-group to group (5-10), but if characters of the perispore are taken into consideration (Van Uffelen \& Hennipman, 1985) another position is also possible. $P$. gardneri shares a peculiar spore type with $P$. laevis, $P$. lingua and other species of the $P$. lingua-group, and can accordingly be placed as a sister-group to the group formed by $P$. laevis and the $P$. lingua-group.

The position of $P$. angustissima is more equivocal. It shares a number of apomorphies with species from the $P$. angustata-group (characters $2 \mathrm{~B}, 10 \mathrm{C}, 21 \mathrm{E}$, 17D). On the other hand, on basis of the spore type (Van Uffelen \& Hennipman, l. c.) $P$. angustissima should be placed with the $P$. lingua-group, and that is the position here adopted. The characters in common with the $P$. angustata-group are then supposed to be parallelisms. Inclusion of $P$. angustissima in the $P$. angustata-group would require a number of reversals in other characters.

The next group added is the $P$. sheareri-group (4). This group shares with groups (5-10) the apomorphic character 10B (stipitate fronds); however, it lacks apomorphies $1 \mathrm{~B}$ and $6 \mathrm{C}$, common to group (5-10) and the $P$. porosa-group. Placing group 4 with group 5-10 would result in one homoplasy more than the adopted place.

The $P$. sheareri-group is joined to group $(3,5-10)$ with characters $7 \mathrm{~B}, 19 \mathrm{~B}$ and $20 \mathrm{~B}$ as synapomorphies. Further resolution within the group is obtained with the aid of characters 13B, 13C, 13D (dissection of the lamina) and by a character not contained in the full dataset, viz. the presence of a distinct hypoderm (marked " $b$ "). This character has not been evaluated for other groups than the $P$. shearerigroud. as there appeared to be no way to assess the presence or absence of a hypoderm in all species in a comparable way ( $c f$. p. 84 ). This is caused by the presence in many species of a hypoderm modified into water-tissue, and the obscure differentiation of the mesophyll in many of the more succulent species (p. 56). In the $P$. sheareri-group, however, the mesophyll is usually welldifferentiated and a water-tissue is never present; accordingly within this group presence or absence of a hypoderm could be assessed relatively easily. The presence of a hypoderm is here considered the apomorphic character, on account of the increased complexity of the mesophyll in these cases. The absence in $P$. hastata and $P$. polydactyla is then a secondary reduction, confirming the monophyly of these two species that is already established by the curious lamina shape.

At the next lower level in the cladogram there is a trichotomy formed by groups (4-10), $P$. penangiana and $P$. mannii. These last two species share character $6 \mathrm{~B}$ with group (4-10). Another possibility is that on this level the $P$. costata-group (2) is joined to (4-10) on basis of character 19B. It is difficult to assess the relative merit of either possibility, and the distribution of other characters gives no clear support for the choice made here. That I have chosen to unite $P$. mannii/P. penangiana to 
(4-10) on this level rests mainly on similarities in rhizome structure; these similarities, however, have not been interpreted in terms of plesio- or apomorphic. The decision therefore remains arbitrary to a relatively high degree.

A similar case occurs at the next lower fork, where the $P$. costata-group (2) is joined to the group formed so far (3-10). This decision is made on the basis of character 14B (the presence of woolly hairs). The occurrence of the plesiomorphic state for character 14B in many groups within (3-10) is here considered to be due to secondary reduction (considered as a separate character under 14E). There is also the possibility to join the $P$. africana-group to (3-10), with support from character 6B. There is thus no difference in support for any of the two possibilities, and the choice depends wholly on an interpretation of the other characters. The choice made here is in accordance with an interpretation of characters $5 \mathrm{~A}$ and $16 \mathrm{E}$ (in the $P$. africana-group) as plesiomorphic.

The relations within the $P$. costata-group itself are resolved more finely with the aid of characters 14F, 11B, and another additional character ("c"), viz. the presence or absence of thickened walls in the cells of the upper epidermis. As was also the case with the other additional characters ("a", " $b$ ", see above), this character was found to be difficult to apply to all Pyrrosia's, but could be used in a restricted group with relative ease.

\section{Is Pyrrosia monophyletic?}

At the lowest level of the cladogram the relationship of Pyrrosia with Platycerium should also be taken into account.

Platycerium is a well-established genus, the monophyly of which can be accepted unprovisionally (Hennipman \& Roos, 1982). The characteristically shaped fronds, the peculiar dimorphy, the pseudo-acrostichoid soral patches with narrow, linear, densely packed receptacles, the structure and indument of the rhizome scales can all be considered as apomorphic characters.

The analysis of Pyrrosia so far has failed to come up with any evident apomorphies that can be used as an argument for the monophyly of the entire genus. All peculiarities of Pyrrosia are either shared with Platycerium, or are absent from at least one of the groups that occupy a basal position in the constructed cladogram, or else they are not evidently apomorphies. In some cases they are even evidently plesiomorphies.

Characters shared with Platycerium are: the presence of massive sclerification in the rhizome and the presence of stellate hairs.

Characters absent from one or more groups (in Pyrrosia) are, e.g., the massive sclerification of the rhizome (absent in the $P$. africana-group); the pseudopeltate or peltate rhizome scales (basifix in the $P$. costata-group); the presence of woolly hairs in the indument (absent in the $P$. africana-group); the characteristic venation 
pattern (absent from the $P$. africana-group); the pericytic stomata (polocytic in the $P$. africana-group and two other species).

Characters that cannot confidently be considered apomorphic are: the entire lamina and the absence of pinnate division of the fronds.

All the characters that are apomorphies in Pyrrosia thus fail to delimit Pyrrosia as a genus in the circumscription that has so far been used.

This uncertainty regarding the monophyletic status of Pyrrosia is expressed in the cladogram by the basal trichotomy joining Platycerium, the Pyrrosia africanagroun (1) and the rest of Pyrrosia (2-10). As is indicated above, with only slightly less support another trichotomy can also be constructed at the base of the cladogram, with resp. Platycerium, the $P$. costata-group, and the rest of Pyrrosia on the three branches.

\section{Relationships with other Polypodiaceae}

At this basal level in the cladogram it may be relevant to consider also the possible relationships of the subfamily Platycerioidae to other polypodiaceous ferns. All remarks concerning these relationships necessarily are preliminary, as no full survey of the Polypodiaceae with regard to the relevant characters is as yet available.

When the Platycerioidae are compared to the rest of the Polypodiaceae, the following characters emerge as possible synapomorphies for the subfamily:

1 - rhizome often heavily sclerified,

2 - absence of pinnate dissection,

3 - presence of stellate hairs on the lamina.

Considering these characters more closely, the following remarks can be made:

ad 1. In Pyrrosia, heavy sclerification of the rhizome takes on the form of a sclerenchyma sheath or of massive sclerification throughout the rhizome. In Platycerium, knowledge of the rhizome structure is incomplete, but it appears that a sclerified rhizome is a common feature in the genus, and that both types of sclerification that are encountered in Pyrrosia also occur in Platycerium. No extensive survey of the Polypodiaceae has been made with regard to these aspects of rhizome structure, but from available data (unpublished) it apppears that sclerification occurs only in the form of separate strands.

Similar sclerenchyma sheaths can be found in the rhizomes of Oleandra (Davalliaceae). It is not likely that this sheath is synapomorphous with the sheath in Pyrrosia.

Rhizomes that are massively sclerified in a way somewhat reminiscent of the massively sclerified rhizomes of some Platycerium species and of the $P$. costatagroup are found in Dipteris and Cheiropleuria. These two genera have, for other reasons, sometimes been regarded as closely related to the platycerioid ferns 
(Bower, 1928). The similarity between the sclerification in the dipteroid and the platycerioid ferns can be regarded as an argument for their common origin, an origin then not shared with other Polypodiaceae.

ad 2. The absence of pinnate dissection in the Platycerioideae is puzzling. Pinnately dissected fronds are very common throughout the ferns; and also in most groups within the Polypodiaceae there are some members with a pinnate or pectinate dissection. Pinnate division seems to be most strikingly absent from some American genera, e.g., Microgramma, Niphidium, Campyloneurum, and Pleopeltis. The circumscription of these genera, however, is as yet far from clear, so that it seems that Platycerioideae is the only large, well-defined group in the Polypodiaceae without pinnate dissection.

It is difficult to provide an interpretation of this character. There is a point of similarity to the genera Dipteris and Cheiropleuria, in which genera pectinately or pinnately divided fronds are lacking too. In Dipteris, however, the character has always been considered as a primitive one, and if this interpretation is accepted, no arguments with regard to affinities can therefore be derived from it. On the other hand, within the higher ferns it is possible to regard the absence of pinnate dissection as a reduction, thus adding to the number of characters uniting the subfamily Platycerioidae with the dipteroid ferns.

ad 3. Compared to the two characters mentioned above, the interpretation of the stellate hairs of Platycerioidae is relatively easy. Both ontogenetic and blastogenetic data are available (p. 45) and a general survey of the presence of dermal appendages is easy to make.

It appears that the stellate hairs of Platycerium and Pyrrosia are structurally different from the peltate scales as well as from the stellate hairs that occur in other ferns. These unique structures are an obvious synapomorphy uniting Platycerium and Pyrrosia.

In other Polypodiaceae the scales present on the lamina are evidently structurally similar to those present on the rhizome, even if the former are sometimes deeply incised and therefore have the appearance of a stellate hair (e.g., in some drynarioid ferns). From the comparison of the ontogeny of stellate hairs and scales presented on pp. 45-48 it can be seen that a homology of hairs and rhizome scales in Pyrrosia, and probably in all Platycerioideae, is present only at the level of comparison where both are regarded as elongated dermal appendages.

Outside the Polypodiaceae, stellate hairs occur in Gleicheniaceae, Hymenophyllaceae, Thelypteridaceae, and Grammitidaceae. The structure of these stellate hairs, the ontogeny of which is not known, appears to be rather different, and the possibility that any of these hairs are homologous to the hairs of the platycerioid ferns seems to be remote. It may be that, in ferns in general, all hairs and scales are homologous as dermal appendages, but for a consideration of the affinities of the Platycerioidae the level of comparison must be less general. 
Such a level is perhaps reached if the indument of the rhizome is compared to that of the lamina. Within the Platycerioideae the indument on these two different locations has obviously undergone a separate development, giving rise to structurally different trichomes. In other Polypodiaceae a similar divergence between rhizome and frond indument is absent: the fronds, at least when they are young, are covered with trichomes that are structurally similar to those covering the rhizome, although there may be some minor variation in outline and shape. Searching through possibly related groups outside the Polypodiaceae, again the Dipteridaceae come up as showing a similar development, though in a less extreme form. In Dipteris the rhizome is covered with so-called 'bristles', structurally similar to hairs, but with a basal portion that is pluriseriate and thickened equally in all directions. The fronds of Dipteris are covered with uniseriate hairs. There is a more or less abrupt (though less so than in the Platycerioidae) transition between these two types of indument at the base of the stipe, just as there is a transition at the point of articulation in the Platycerioideae.

Thus, also in this character it appears that the Dipteridaceae share some similarity with the Polypodiaceae that can be interpreted as an apomorphic similarity, not shared with other Polypodiaceae. Although Dipteris has often been considered as a polypodiaceaous fern, it appears to be different from the Polypodiaceae in a number of characters often considered as important: sporangium type (Wilson, 1959), stomata type (Van Cotthem, 1970), gametophyte characters (Nayar \& Kaur, 1971). These characters must be interpreted as either apo- or plesiomorphic before their implications can be compared to those of the characters considered above.

\section{Postscript}

The subdivision of the genus and the phylogenetic analysis presented in this chapter are based on a set of data from which the sporoderm characters were left out, as a detailed analysis of the sporoderm was in preparation but not yet available. These data now being published (Van Uffelen \& Hennipman, 1985), it emerges that a classification can be based on spore type alone that is to a large extent concordant with the subdivision presented in Chapter 4. There are, however, a few discrepancies.

A subdivision based solely on spores would classify $P$. angustissima, $P$. gardneri, and $P$. laevis together with $P$. lingua, and this is the position adopted during the construction of the cladogram. Another difference between a classification exclusively on basis of the spores and the one presented here is that in the former, $P$. abbreviata and $P$. sphaerosticha would be classified not with $P$. lingua, but in the $P$. albicans-group.

In the following paragraphs I shall try to evaluate the result of the adoption of such a subdivision for the phylogenetic hypothesis presented here. 


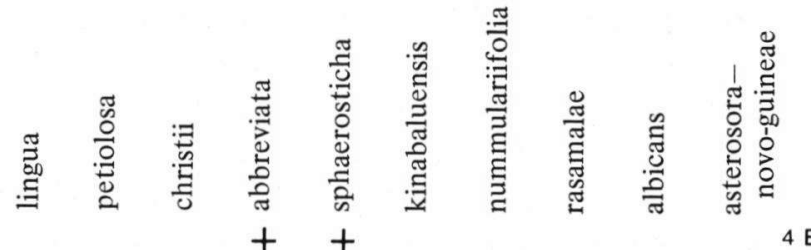

$$
\begin{aligned}
& \begin{array}{rrr}
+ & + & 4 \mathrm{~B} \\
+ & ++ & 8 \mathrm{D} \\
+\quad++ & 21 \mathrm{C}
\end{array}
\end{aligned}
$$

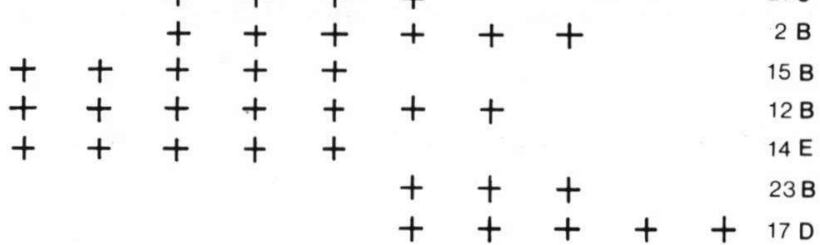
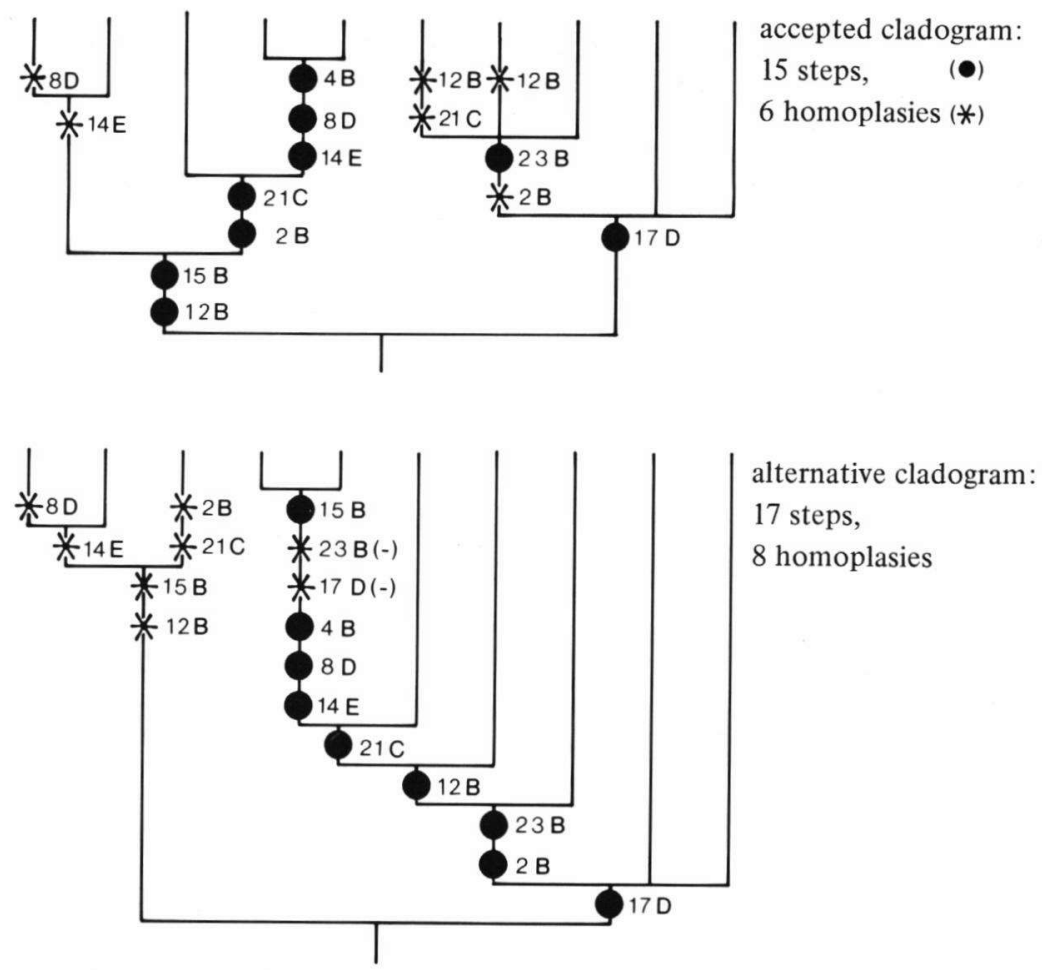

Fig. 14. Two alternatives for part of the cladogram of fig. 13 .

In all relevant characters $P$. abbreviata and $P$. sphaerosticha are similar, and transfer to the $P$. albicans-group is therefore most plausible in the form of the transfer of a single, supposedly monophyletic group. The interpretation of the following 
characters is affected: $2 \mathrm{~B}$ (the development of a shallowly grooved rhizome cannot be explained any more by a single origin for $P$. christii, $P$. abbreviata and $P$. sphaerosticha); 12B (as indicated on p. 35, the form of frond dimorphism that has developed in the $P$. albicans-group seems to differ from that developed in $P$. $a b$ breviata and $P$. sphaerosticha); 15B (one more separate origin of the monomorphic indument with boat-shaped hairs has to be assumed); $21 \mathrm{C}$ (the densely packed sori cannot be explained as synapomorphy for $P$. christii, $P$. abbreviata and $P$. sphaerosticha); 17D (if the absence of hydathodes should be considered a synapomorphy for the $P$. albicans-group, the presence in $P$. abbreviata and $P$. sphaerosticha must be assumed to be a reversal).

Frond dimorphism (12B) in $P$. abbreviata and $P$. sphaerosticha can then be linked to the dimorphism in $P$. kinabaluensis, as can be the densely packed sori (21C); so that $P$. abbreviata and $P$. sphaerosticha can be placed as a sister-group to a group formed by $P$. nummulariifolia and $P$. kinabaluensis.

This leads to an alternative arrangement of the species in the group as in fig. 14. In this arrangement even more homoplasies are present than in the original arrangement. The somewhat ambiguous position of $P$. sphaerosticha in the accepted cladogram, however, is emphasized by the occurrence of character $10 \mathrm{C}$. 


\section{GEOGRAPHY}

\section{Distribution and ecology}

The present distribution of Pyrrosia is shown in fig. 15. It is an almost exclusively paleotropical genus, which, in contrast to its sister-genus Platycerium, has no representatives in South America. Pyrrosia ranges from Mount Nimba in West Africa to Henderson Island in the Pacific Ocean; in the north it is bounded by the Sahara, the Himalaya, and the Asian deserts, in the south it ranges to New Zealand and Southeast Australia. It is mainly restricted to the tropical zone, and only along the eastern coasts of Africa and Australia, in New Zealand, and in China and Japan does it extend some way beyond the tropical zone. Apart from temperature, the main delimitation for the present distribution appears to be the line of $750 \mathrm{~mm}$ mean annual precipitation. Probably, therefore, rainfall is one of the most important restrictions for the present distribution of Pyrrosia. Within this area, species occur in both everwet and seasonally dry areas.

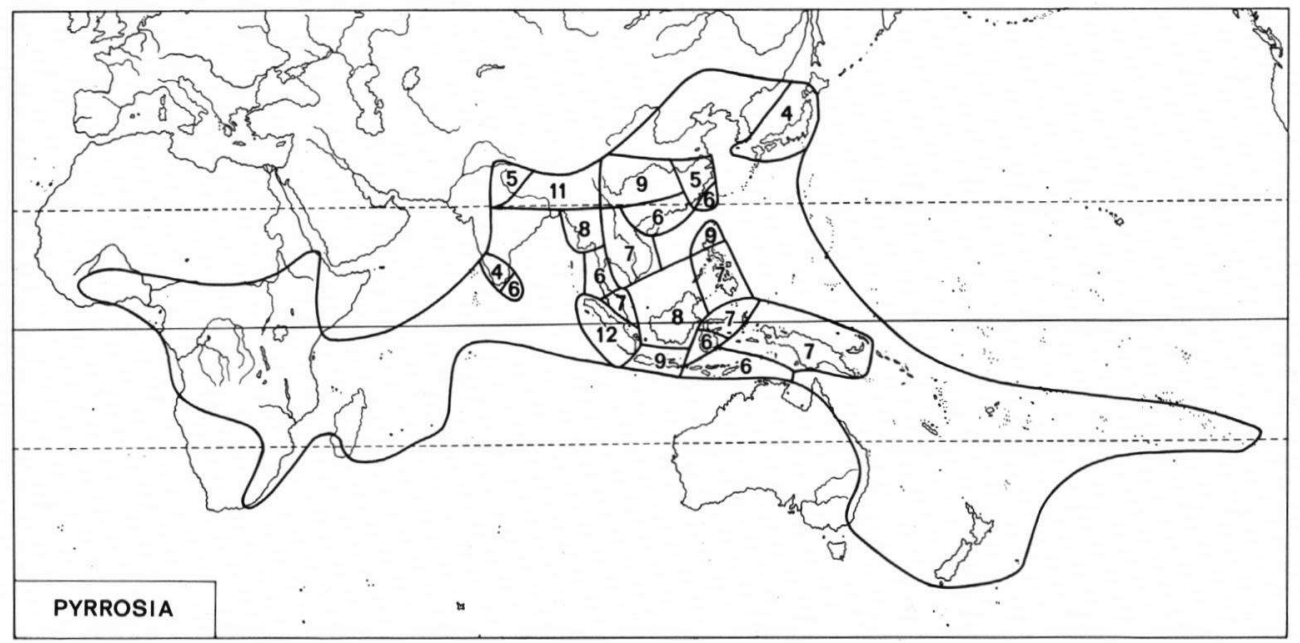

Fig. 15. Distribution of Pyrrosia. The boundaries between the restricted areas are drawn purely on basis of the distribution patterns of Pyrrosia-species. In each area the number of co-occurring species is indicated if more than 3; single areas with less than 3 species are not distinguished.

The distribution of the individual species is shown in Figs. 16-26. Most taxa inhabit continuous areas of varying sizes. Circa 10 taxa are truly wide-spread, 


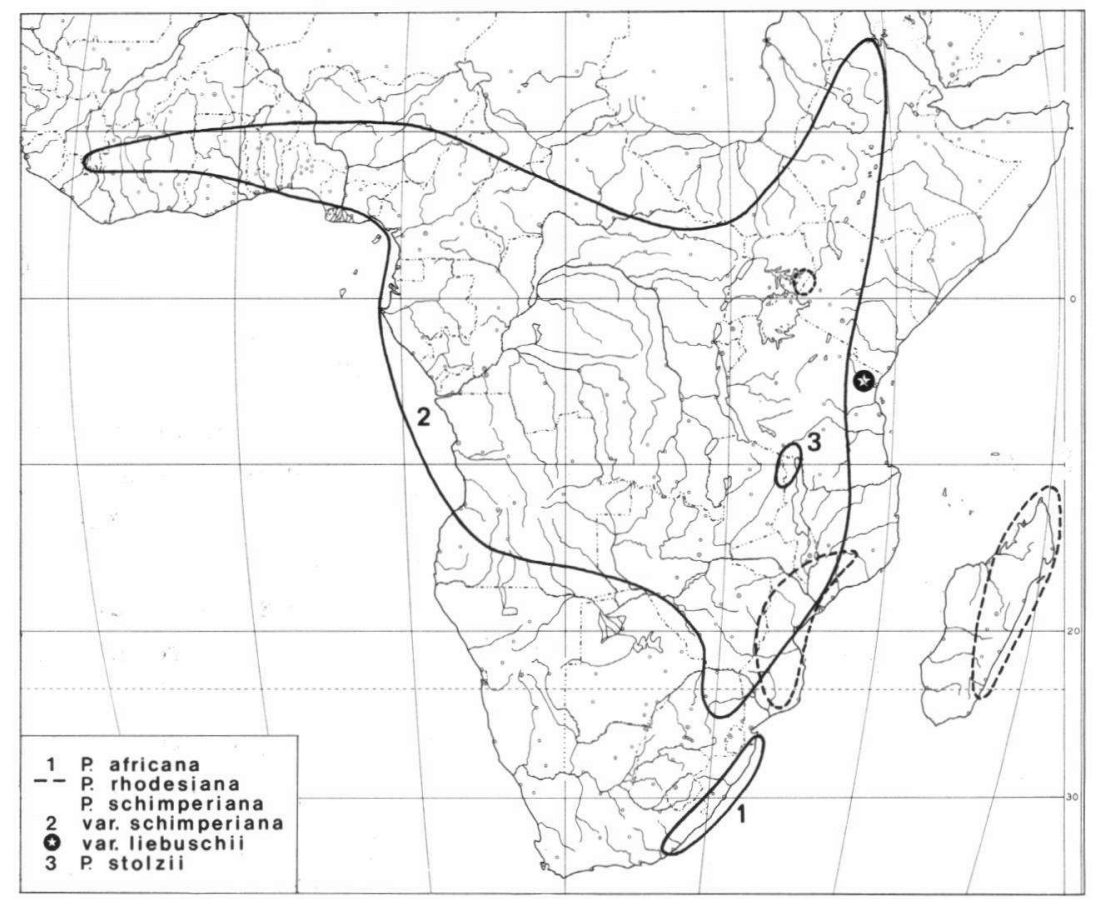

Fig. 16. Distribution of the species of Pyrrosia occurring in Africa. $P$. lanceolata not shown, see also Fig. 25. Data partly taken from Jacobsen (1984).

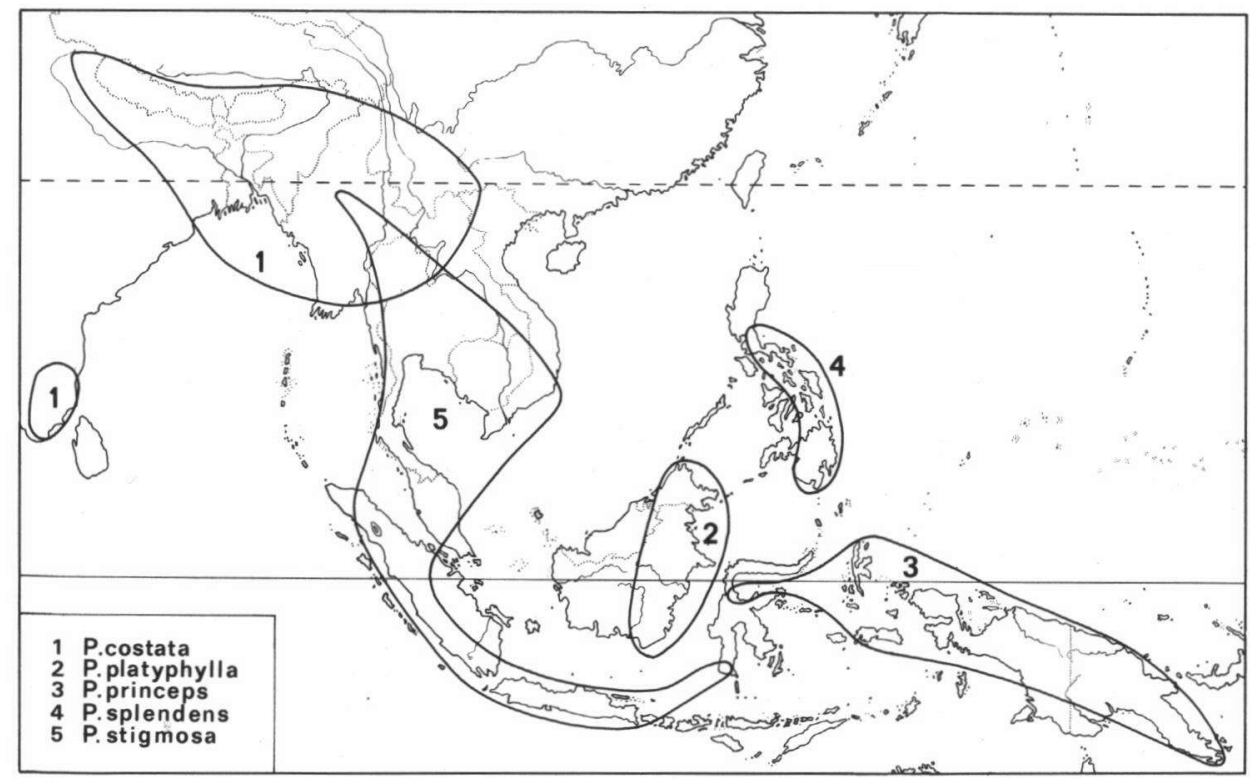

Fig. 17. Distribution of the $P$. costata-group. 


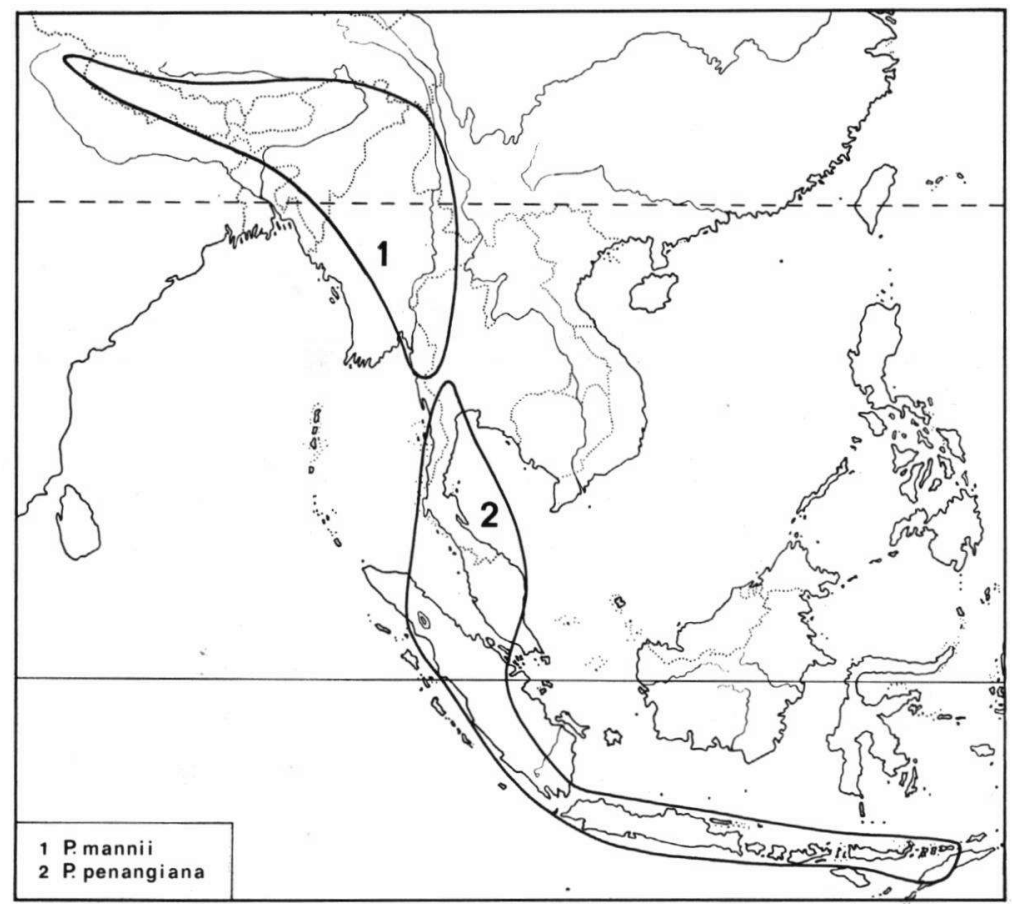

Fig. 18. Distribution of $P$. mannii and $P$. penangiana.

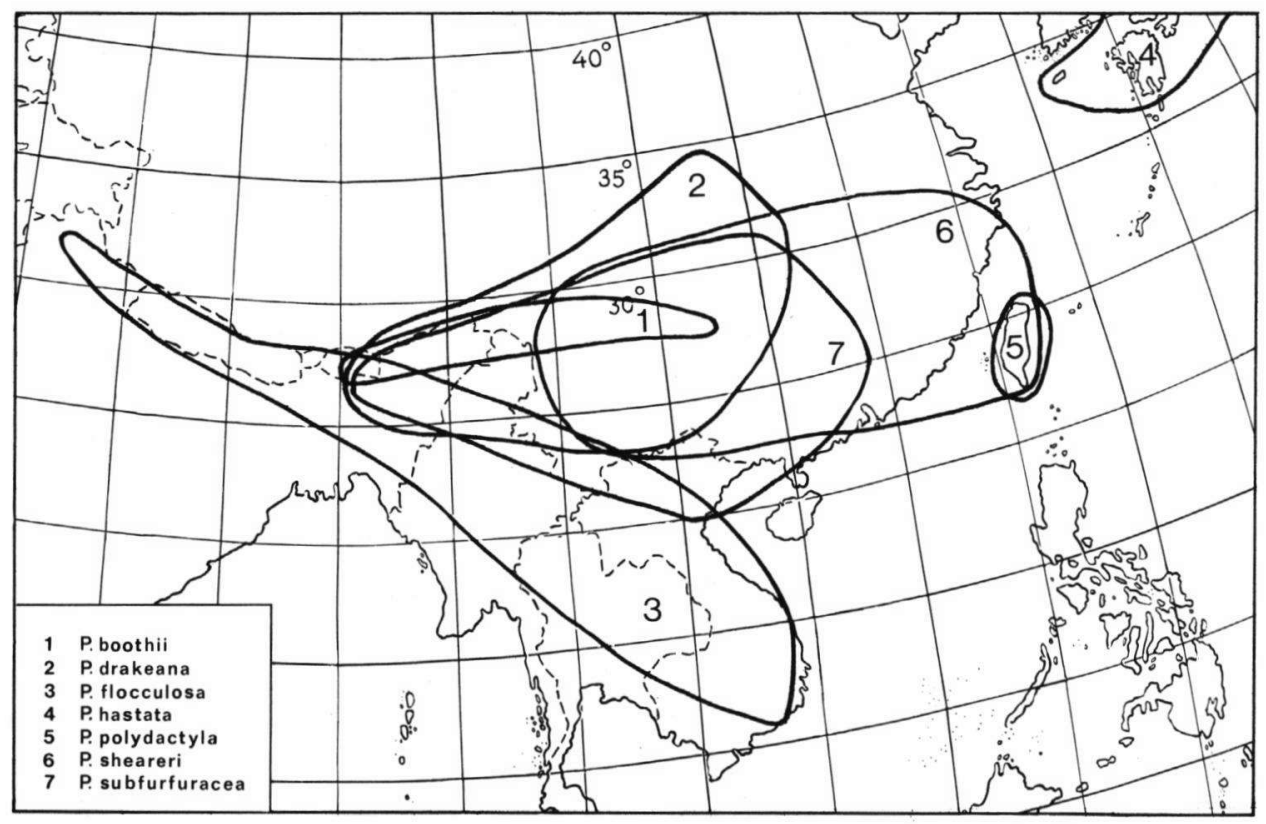

Fig. 19. Distribution of the $P$. sheareri-group. 

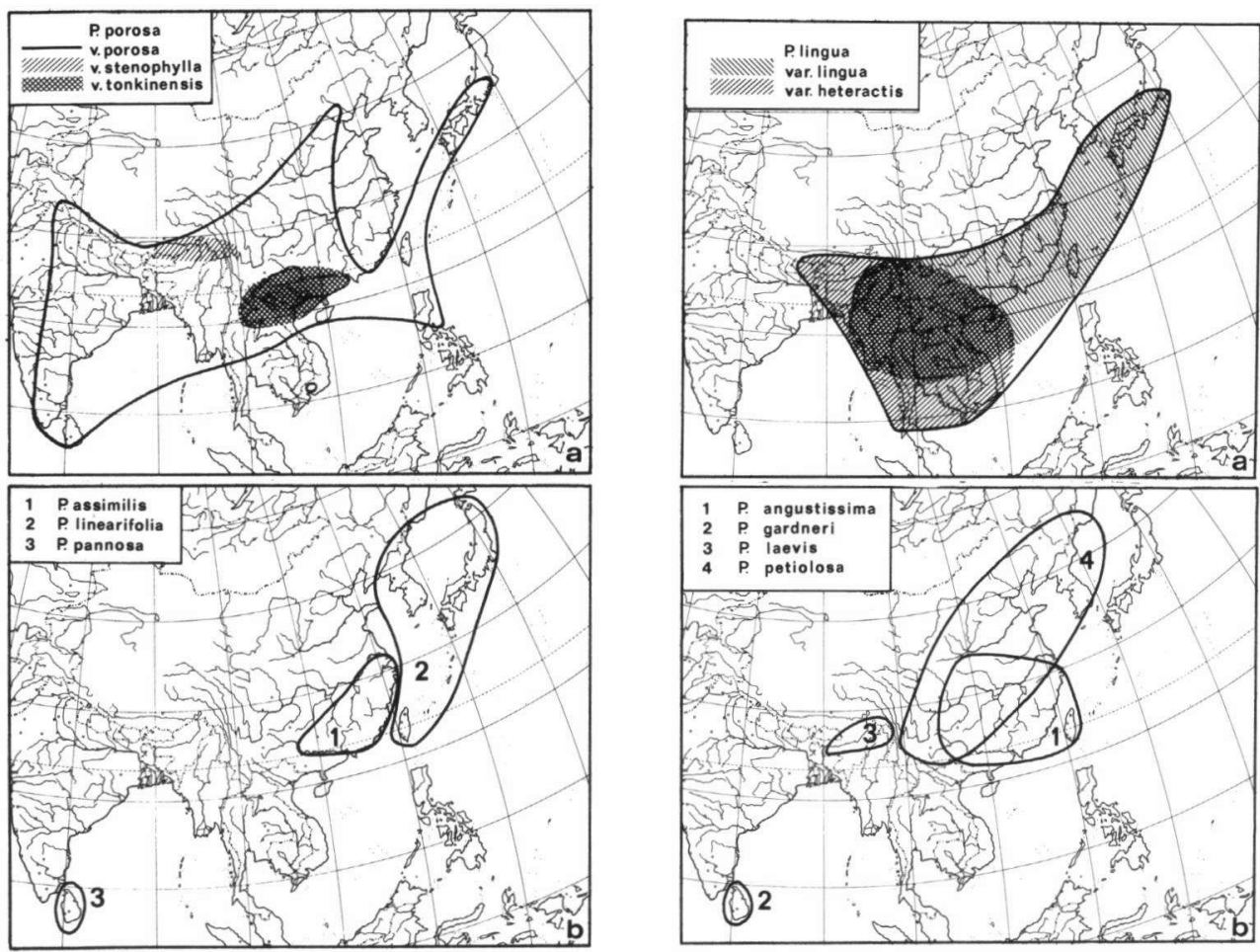

Fig. 20a. Distribution of $P$. porosa. Distribution in Japan taken from Kurata Nakaike (1981). Fig. 20b. Distribution of $P$. assimilis, $P$. linearifolia and $P$. pannosa.

Fig. 21a, b. Distribution of the species of the $P$. lingua-group on the mainland of Asia and Japan. 


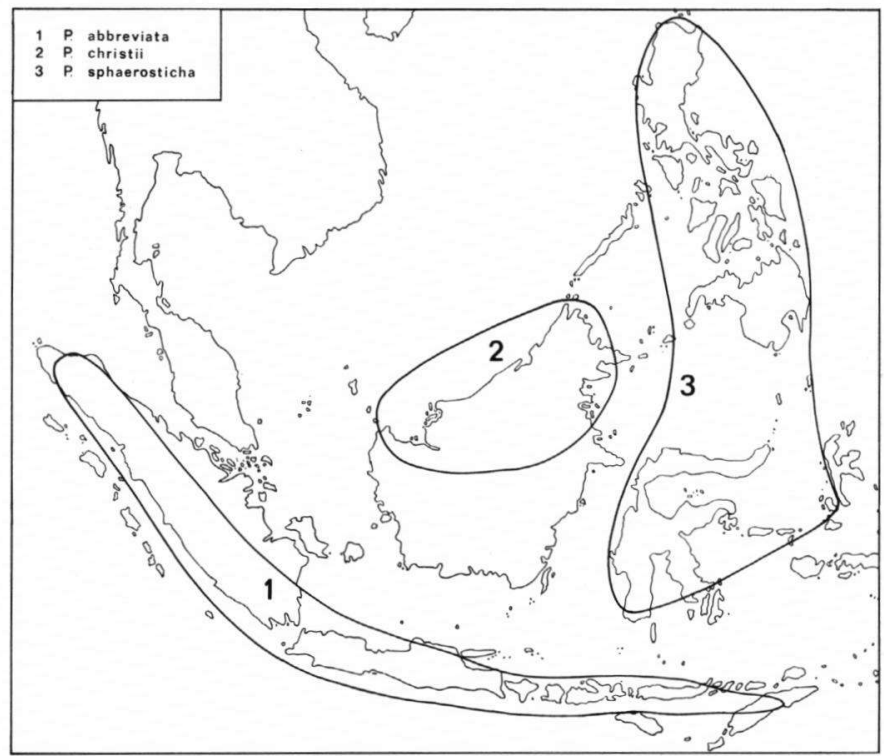

Fig. 22. Distribution of the Malesian species of the $P$. lingua-group, 


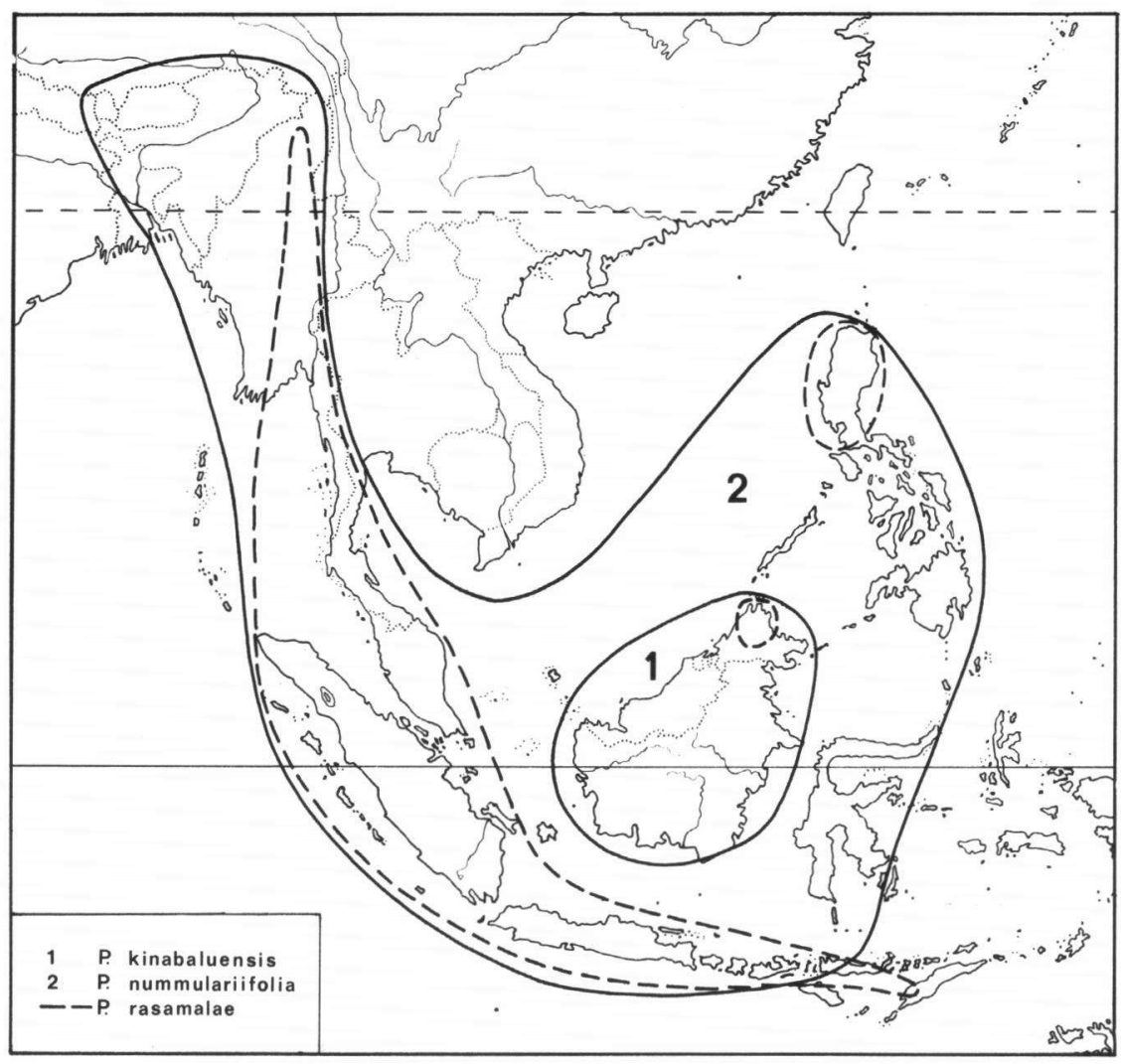

Fig. 23. Distribution of some species of the $P$. albicans-group. 


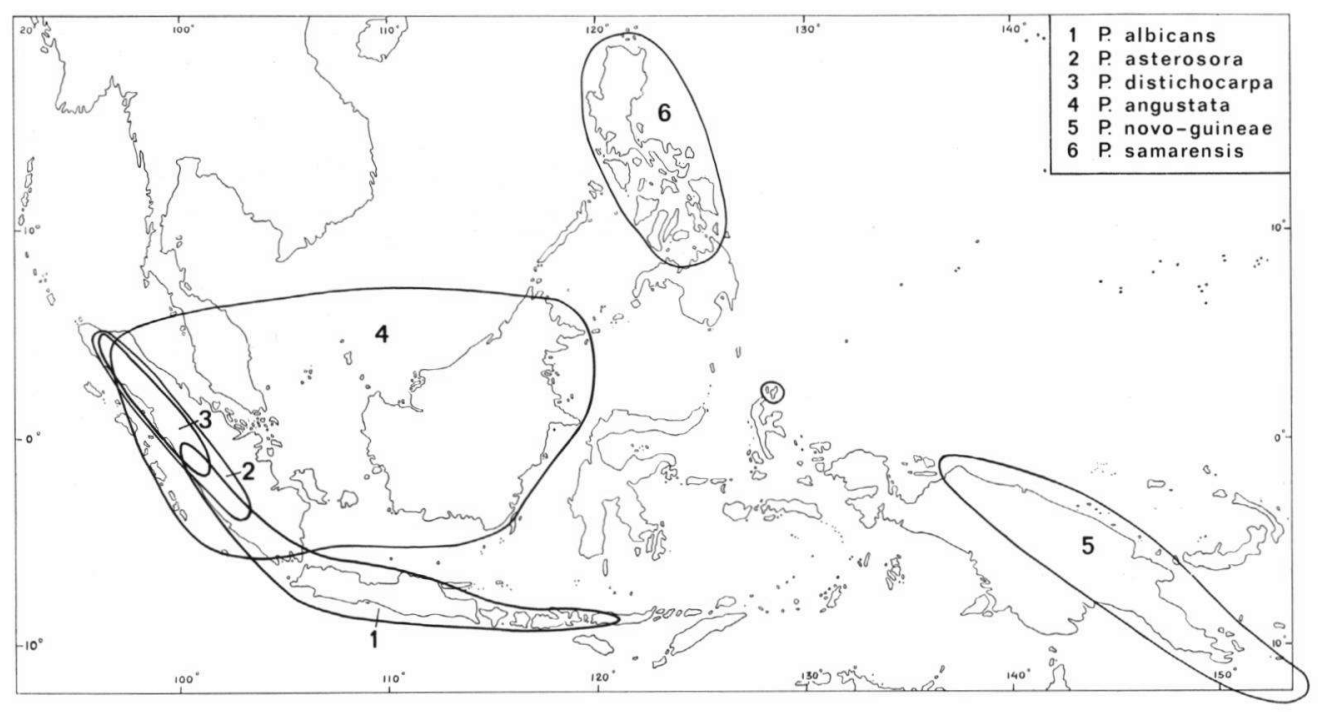

Fig. 24. Distribution of some species of the $P$. albicans-group and the $P$. angustata-group.

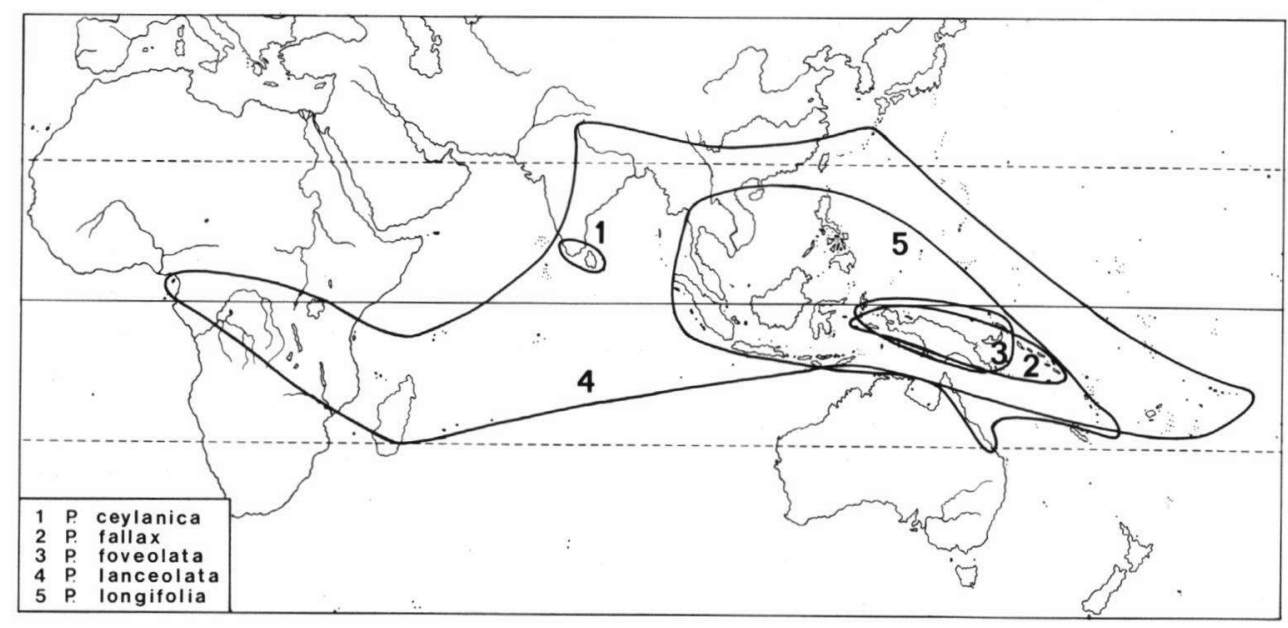

Fig. 25. Distribution of the $P$. lanceolata-group. 


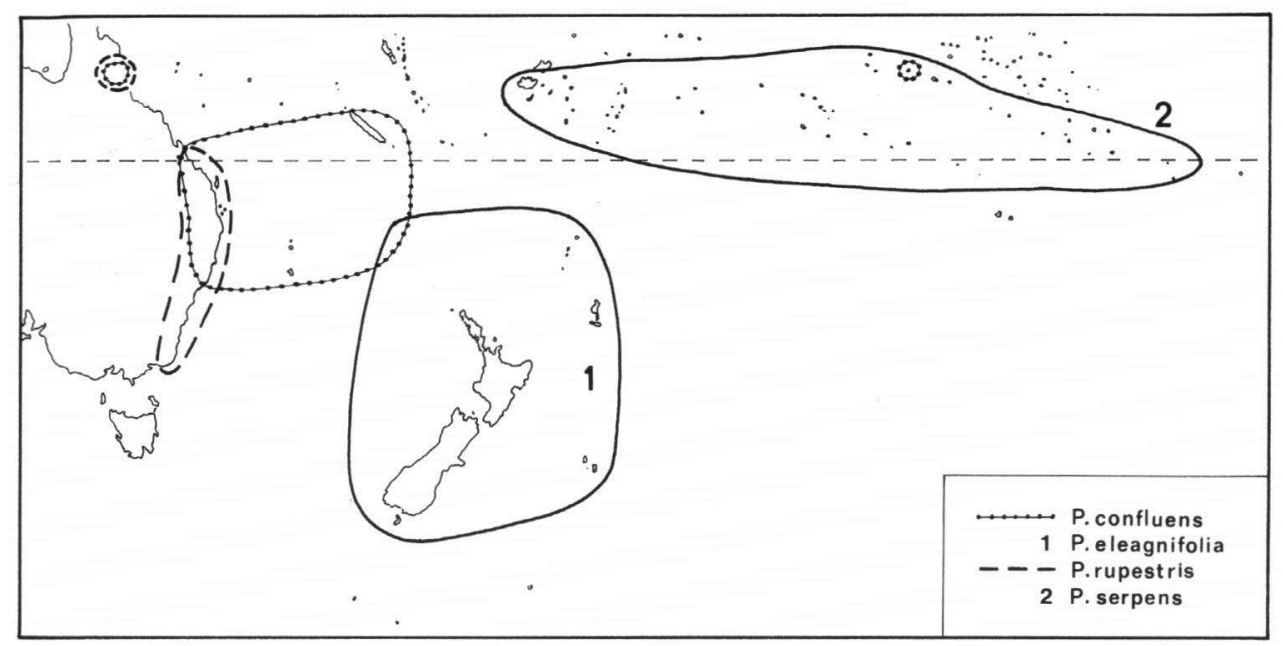

Fig. 26. Distribution of the $P$. confluens-group.

and about as many occupy small areas and might be regarded as endemics. Conspicuously disjunctive areas occur in the following species: $P$. angustata (fig. 24), with a main area on the Sunda Shelf and a probably isolated occurrence on Morotai, in the Moluccas; $P$. heterophylla (Ravensberg \& Hennipman, 1986, fig. 3), with isolated occurrences in Southern India and Ceylon and on the Seychelles; $P$. rhodesiana (fig. 16), with a main area of two parts, on continental Africa and Madagascar and an isolated occurrence on Mount Elgon; $P$. rasamalae (fig. 23), with a main area extending from Thailand to the Lesser Sunda Islands, but with two isolated areas on Luzon and in North Borneo; and in several species of the $P$. confluens-group (fig. 26), which inhabit relatively large areas extending over islands in the Pacific Ocean. In this group, a particularly wide disjunction, from New Caledonia to Tahiti, is shown by $P$. confluens.

Pyrrosia reaches its highest diversity in Asia, particularly in two areas: in the eastern Himalayas and the Khasya Hills and in Sumatra. In both areas twelve species occur, several of which are endemic to either area (Himalayas and Khasya: $P$. boothii, $P$. laevis; Sumatra: $P$. asterosora, $P$. distichocarpa). The relative richness in species of Sumatra compared to the other Malesian districts is contrary to the situation in many other groups of plants (Van Steenis, 1979), which are usually less diverse on Sumatra than on, e.g., Borneo (compare also Van der Meijden, 1982). Both areas are relatively mountainous, and their richness may be related to the preference of many species of Pyrrosia for hilly or mountainous areas, but then it is somewhat surprising that the third large tropical region with high mountains, New Guinea, is not particularly rich in Pyrrosia-species. 
Many species of Pyrrosia have adapted to more or less extended periods of drought. Two different growth-forms seem to have evolved with regard to drought resistance: a poikilohydrous and a succulent growth-form.

The poikilohydrous form is best exemplified by $P$. schimperiana. This species has been observed in the field to behave like a "resurrection" plant: in a period of drought it dries out without shedding its fronds; after rain the fronds take up water quickly, resuming metabolic activity probably within a few hours (Kornaś, 1978). P. schimperiana does not show any capacity for water-storage in the mesophyll, and other xerophytic adaptations are also lacking (e.g., thickened epidermis walls and sunken stomata). Although only few data are available, it seems reasonable to assume that other species exhibiting the same morphological syndrome (e.g., $P$. porosa) show a similar behaviour under water-stress.

The succulent growth-form can be exemplified by $P$. longifolia. This is a distinctly succulent species, with a large capacity for water-storage in its mesophyll (compare p. 56, see also Warmbrodt, 1984) as well as some other xerophytic adaptations, e.g., distinctly sunken stomata. Moreover, it has been shown that $P$. longifolia and $P$. piloselloides have Crassulacean Acid Metabolism (Wong \& Hew, 1976), a metabolic pathway that enables the plant to keep its stomata closed during the day (Madison, 1977).

Due to the preference of many Pyrrosia species for mountainous areas, with many local variations in climate, it is not possible to make detailed statements about the preference of each species for specific climatic conditions. Nevertheless, several species show a distinct preference for either an everwet or a distinctly seasonal climate.

Judging by the distribution of these species, combined with the exhibition of one of the two morphological syndromes discussed above, it seems likely that the poikilohydrous habit has evolved in response to a seasonal climate with long dry periods. Most species that clearly exhibit this syndrome (e.g., $P$. porosa, $P$. flocculosa, $P$. costata) are restricted to the mainly seasonally dry areas of continental Asia. The succulent habit may be a response to the circumstances under which high epiphytes occur, even in everwet climates: short, severe dry spells between torrential showers. Distinctly succulent plants are often found as high epiphytes, and the xerophytic anatomy of many species is at first sight in contradiction to their preference for everwet areas (e.g., $P$. angustata, $P$. rasamalae, $P$. nummulariffolia)

In general, the species of Pyrrosia are epiphytes, and they have a preference for hilly or mountainous areas. A considerable number, however, seems to be more often (but never exclusively) epilithic or terrestrial: from the available data this preference could be established for $P$. angustissima, $P$. assimilis, $P$. drakeana, $P$. hastata, $P$. lingua var. lingua, $P$. pannosa, $P$. petiolosa, $P$. princeps, $P$. rupestris, $P$. sheareri, and $P$. subfurfuracea. Most species that are preferentially epilithic occur in 
Asia. The $P$. sheareri group, which is restricted to the continent of Asia, is predominantly non-epiphytic.

There seems to be some correlation with growth form: among the terrestrial species those with a short, thick rhizome are relatively over-represented.

Among the epiphytic species many seem to be specialized as colonizing species. With their rapid growth and flexible reproductive strategy (compare p. 34) they are able to colonize entire trees, to the thinnest twigs. A probably correlated adaptation is that they seem to have acquired the ability to extract nutrition from the host-tree in the absence of collected humus and litter: according to Ruinen (1953) the epiphytism of $P$. piloselloides and (to a lesser extent) of $P$. nummulariifolia has some elements of parasitism; the plants also have deleterious effects on the hosttree and may even cause its death.

\section{Historical geography}

\section{Methodology}

For the analysis of the historical aspects of the distribution of a genus and of its species, two different approaches are possible (Nelson \& Platnick, 1981). These two approaches may be summarized as "dispersal model" and as "vicariance model". The dispersal model implies that dispersal has been the only process through which the distributional pattern has been attained, the vicariance model implies the same for vicariance processes. The processes implied in the two models differ mainly in the time sequence: dispersal assumes that natural "'barriers" were present before a certain taxon dispersed over a certain area, under the vicariance model it is assumed that dispersal took place before the "barrier" was in existence. As it seems obvious that both dispersal across "barriers" and vicariance through new "barriers" are processes occurring in nature, a more detailed comparison of both models is necessary. This comparison centres around the differences in pattern generated by both processes and the relation between these processes and speciation.

The difference in time sequence of events implied in both models results in patterns that can be expected to differ strongly under either model if it is taken into account in what way speciation may take place.

Under the dispersal model, dispersal across an existing "barrier", followed by speciation through "founder effect"' (or any other way that is directly related to geographical isolation) is an event with a low probability. The chance that the resulting pattern is repeated in several other taxonomic groups is slight. If a higher probability exists for a certain taxon to cross a "barrier", we would not expect this crossing to result in speciation, but rather in the establishment of a 
more or less continuous gene-flow across that "barrier". With regard to the formation of pattern the "barrier" would be non-existent. The patterns that can be expected to result from dispersal followed by speciation are therefore likely to be those in which a parent-species is surrounded by erratically distributed daughterspecies at some distance from the area of the parent-species. The degree to which the daughter-species are differentiated from the parent also would be variable. Moreover, these patterns are not likely to be similar in different groups ( $c f$. Van Steenis, 1979). An intermediate situation may of course be envisaged, in which "'barriers" occur that permit a slight but constant gene-flow. The patterns resulting from such a situation would be similar to those resulting from a stronger "'barrier", but with the daughter species less distinctly differentiated from the parent-species. In practice, the pattern generated by dispersal across a recent; strong "barrier" would be indistinguishable from a pattern generated by a weak but older "barrier".

On the other hand, a single vicariance event most probably would influence at least several species inhabiting the area involved, and speciation would be more or less simultaneous as well as showing a similar pattern repeatedly in different groups. Thus, the analysis of biogeographic patterns following a vicariance model is a matter of searching for similar patterns of speciation in different taxonomic groups. Such patterns, if found, are an indication that something more than chance has been at work.

Biogeographic analysis from a vicariance model is therefore not a method that is easily applicable to a relatively small group as it works best when large numbers of speciation patterns can be compared. At the same time, the exact resolution of the phylogeny of the groups that are compared is much more important than it would be under a dispersal model: primarily it is the sequence of speciation events that has to be compared, whereas in a dispersal model the exact order in which the different taxa have arisen is less crucial, given the importance of chance in the model.

For the initial analysis of the biogeography of a group it is certainly best to assume a vicariance model, although such an assumption is likely to overestimate the number of vicariance-speciation events, as certain dispersal events have similar results as vicariance events (cf. Nelson \& Platnick, l. c. p. 45-49).

Recent advances in geophysics, moreover, have confirmed that the splitting of land masses is a plausible mechanism to be held responsible for large-scale speciation. Dispersal, and particularly dispersal over relevant distances, is still a process that has not gained much plausibility, notwithstanding the number of times it has been invoked to explain distribution patterns (Van Steenis, l. c.). Therefore, in the analysis here presented a method is followed that first tries to identify those parts of the pattern that are possibly due either to vicariance or to dispersal in the absence of barriers. In the next stage of the analysis chance dispersal events can be invoked to account for those parts of the pattern that were left unexplained in the first stage of the analysis. 


\section{Geographical analysis of Pyrrosia.}

The first stage in the biogeographical analysis of Pyrrosia is the search for similar patterns of speciation in different monophyletic groups. In order to have any relevance for this kind of analysis, the distribution of the members of these groups should be mainly allopatric. Sympatric species either have become so through dispersal after speciation, or directly by way of some sympatric speciation process. In the former case it will generally not be possible to identify the area where the species originated, in the latter case the speciation obviously is uninformative with regard to vicariance processes. The explanation of patterns of this type should be left for the second of the two stages of analysis recognized above.

- A further restriction is that comparisons can be made only for groups roughly inhabiting the same area.

In Fig. 27, a number of monophyletic groups, derived from the cladogram in Chapter 7, is shown with the distribution of each species indicated. For reasons indicated above, those groups showing a mainly sympatric pattern $(P$. sheareri-

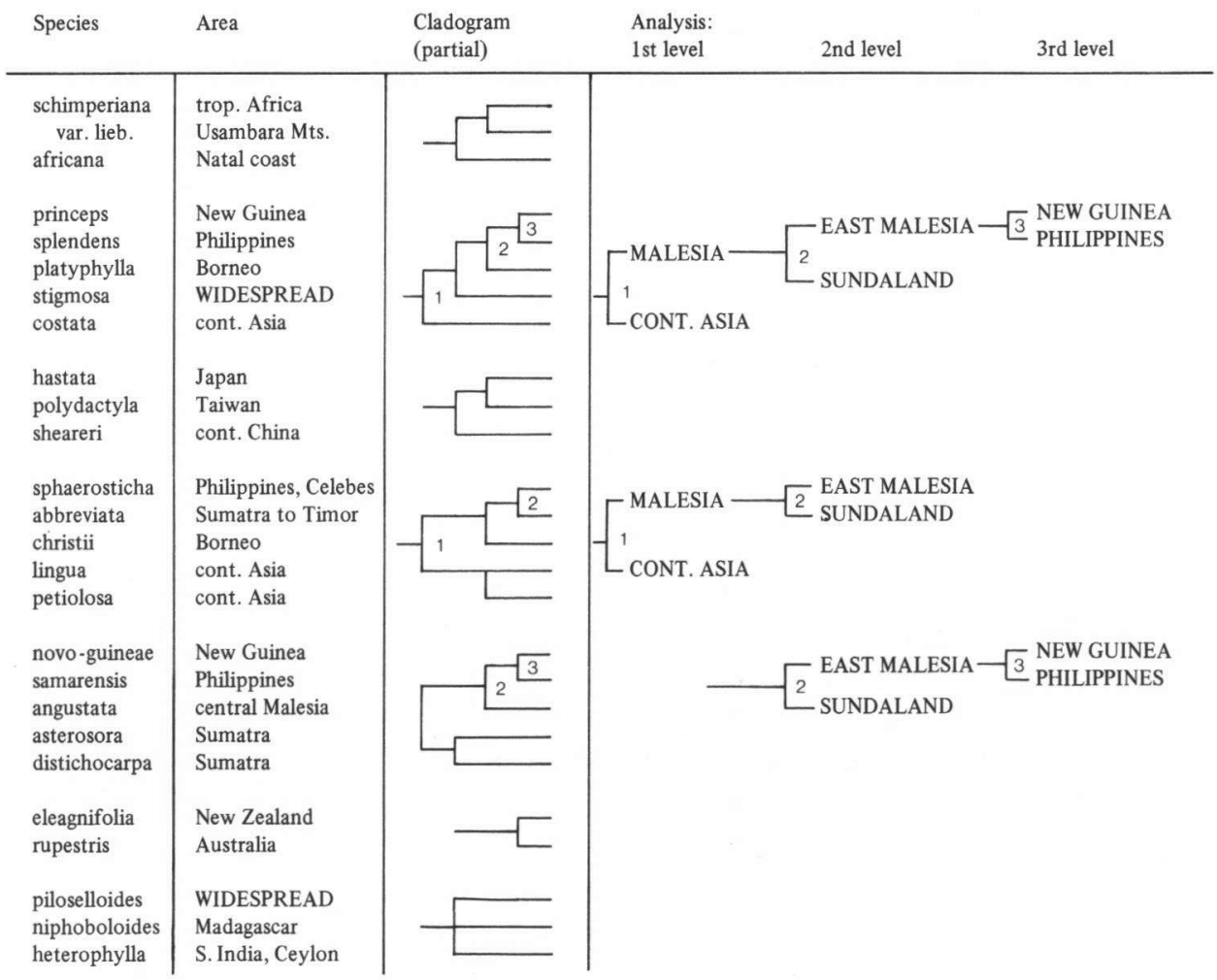

Fig. 27. Geographical analysis of monophyletic groups in Pyrrosia. 
group, $P$. porosa-group, $P$. lanceolata-group) cannot be used. Of the remaining groups, one occurs in Africa, one is restricted to continental Asia, one to Australia and New Zealand, and in one group a number of its members in the Malesian area are sympatric and should be disregarded. Three groups are left that fulfill all requirements (the $P$. costata-group, the group formed by the Malesian members of teh $P$. lingua-group, and the $P$. angustata-group). A comparison of their distribution patters in these groups is now possible, in which similarities emerge on three levels:

1. in two out of the three groups a dichotomy between continental Asia and Malesia is present at a relatively low level. In the $P$. costata-group this is the sistergroup relation between $P$. costata, occurring in continental Asia, and the other members, which are all Malesian in distribution. To obtain a clearer image of this pattern, the widespread $P$. stigmosa has to be left out of the picture: it may have dispersed to its present area from either way, and its present distribution therefore is uninformative with regard to the problem under consideration.

In the $P$. lingua-group a similar dichotomy is seen between the continental Asian members of the group around $P$. lingua and the Malesian members $P$. $a b$ breviata, $P$. christii, and $P$. sphaerosticha, both groups supposed to be monophyletic ones. The other group under consideration here, formed by uniting the $P$. anoustata-groun with $P$. distichocarpa and $P$. asterosora (see p. 96) has no representatives on continental Asia.

2. A dichotomy on some level between West/Central Malesia (Sunda Shelf) and East Malesia is visible in all three cladograms:

In the $P$. costata-group this dichotomy is present between $P$. platyphylla, on Borneo, and the monophyletic group formed by $P$. splendens and $P$. princeps, occurring in the Philippines and on New Guinea, Celebes and the Moluccas, respectively.

In the $P$. lingua-group the same dichotomy is present between $P$. abbreviata, occurring on Sumatra, Java and the Lesser Sunda Islands, and $P$. sphaerosticha, from Celebes and the Philippines.

In the $P$. angustata-group the Sundaland-East Malesia dichotomy is present in the sister-group relationship between $P$. angustata on the one hand and the monophyletic group formed by $P$. samarensis and $P$. novo-guineae on the other.

This second dichotomy between East and West Malesia follows the biogeographic demarcation line recognized by Merrill and Dickerson (cited in Van Steenis, 1979). This line is one of a complex of lines that can be recognized in East Malesia (see also Whitmore, ed., 1981). This complex is usually interpreted as representing various measures of balance between Australian and Malesian elements (Powell et al., 1981). Under a dispersal model (see above) these lines represent the sutures where two different biotas have merged and across which dispersal (followed by speciation) has taken place. Under a vicariance model, on the other hand, a line like this can only be explained as a line along 
which a unified biota has been ruptured, followed by speciation in many taxa on both sides of the line. The merging of two biota under a vicariance model may have led to dispersal, but not to concomitant speciation. The difference between the two interpretations thus depends on the relations of the species on both sides of the line: under a dispersal model both unrelated species and conspecific taxa are expected to occur on both sides of the line, under a vicariance model relatively large numbers of sister-group relations are expected to occur across the line.

The pattern of the three groups is not completely concordant. There is some contradiction regarding the sister-group relationships of East Malesian species: in two out of three groups the sister-group of the East Malesian representative(s) occurs on Borneo, but in one group ( $P$. lingua-group) this sister-group occurs on Sumatra and Java. This is an inconsistency that has to be left unexplained, or else it can be explained by invoking chance dispersal over the Sunda Shelf; both explanations are in fact an expression of ignorance. On the other hand, the possibility should be kept open that the cladogram in this place is erroneous and does not correctly reflect sister-group relationships within the $P$. lingua-group.

3. On a third level, a dichotomy is present in two groups between New Guinea and the Philippines. In the $P$. costata-group this dichotomy is evident in the sistergroup relation between $P$. splendens and $P$. princeps; in the $P$. angustata-group the same dichotomy is present between $P$. samarensis and $P$. novo-guineae.

If these similarities are interpreted as the results of events in earth history affecting all three groups, we can then search for these events among those that are documented by geophysics.

Obviously, none of these vicariance patterns can be related to the wellestablished main pattern of the break-up of Gondwanaland (Smith \& Briden, 1977). The precise details of the subsequent course of the subcontinents, however, is much less well-established. Reconstructions of the course of the continental areas in the relevant regions are full of uncertainties and blanks (Powell et al., l. c.). There are some indications that the Indian subcontinent, on its way to collision with the Laurasian continent, may have been in close but temporary contact with the southwestern margin of Southeast Asia. This may have taken place during the early Cenozoic (Powell et al., $l$. c.) The separation following this event may tentatively be identified with the dichotomy Asia-Malesia discussed under (1) above. An identification of the two vicariance events discussed under (2) and (3) is more difficult to find: the exact tectonic history of the area following the collision of Papaustralia with southeast Asia is far from clear (Powell et al., l. c., fig. 4). There is thus plenty of scope for speculation, and the possibility that the last two events indeed correspond to some episode in the history of this unstable area cannot be ruled out. The timing of this event would have to take into account that it has to be dated later than the first event. It seems obvious that the collision of Papaustralia with the Malesian area may have been concerned. A possible course 
of events is that an extensive island arc on the east side of the Southeast Asian subcontinent was involved, parts of which may have been incorporated into New Guinea, parts into the Philippines.

Starting from these assumptions, the evolutionary history of Pyrrosia may tentatively be filled in in the next stage of the analysis. In this stage, explanations can also be sought for unique patterns. The result of this stage is a scenario, constructed with the aid of the following considerations.

- From the assumption that the basal fork in the $P$. costata-group and the $P$. lingua-group refers to an event in which the Indian subcontinent was involved, it follows that the ancestors of both groups must have been present on this subcontinent before it came into close contact with Southeast Asia. We may then suppose that also the ancestors of the groups that split off on the cladogram between these two were also present on this subcontinent, and not in any of the other areas now occupied by Pyrrosia. From there, it is only a small step to assume that the basal dichotomy in the cladogram refers to the early break-up of Gondwana-land into an African part and a part formed by India, Australia and Antarctica.

- The two African members of the $P$. porosa-group ( $P$. stolzii, $P$. rhodesiana) as well as the African members of all groups other than the $P$. africana-group then must have reached Africa later, and probably by dispersal. The scattered occurrence in Africa of $P$. stolzii and $P$. rhodesiana satisfies rather well the expectations that were expressed above concerning patterns resulting from speciation after dispersal.

- On the Indian subcontinent therefore at least five of the groups recognized here were present. In three of these (the $P$. sheareri-group, the $P$. lingua-group, and the $P$. porosa-group) the collision of India with Laurasia was followed by dispersal and radiation, thus leading to the mainly sympatric patterns that are predominantly present on the continent of Asia.

- The other three groups have either a mainly Malesian 'P. albicans/angustatazroup) or a mainly Papaustralian/Pacific distribution ( $P$. confluens-group, as well as two of the least widely distributed members of the $P$. lanceolata-group), leaving aside the widely distributed species. It is therefore possible to search for another vicariance event involving Asia and this combined area. This event may tentatively be identified as the breaking away of the Indian subcontinent from the East Gondwanaland block.

- Possibly, a vicariance event involving the Papaustralian block and the Malesian area can then be found to account for the dichotomy between the $P$. albicans/angustata-group and the group formed by the $P$. lanceolata-group, the $P$. confluens-group, and the $P$. piloselloides-group. This last event may well be the same as the one that Van Steenis (1979) held responsible for many similarities between the Australian and the Malesian floras. Part of Pyrrosia is thus supposed to have developed mainly on the Australian subcontinent, and to have dispersed widely after this continent came into contact with Asia. 
The scenario that is thus developed is tabulated in table 4 and graphically represented in Fig. 28.

TABLE 4

\begin{tabular}{|c|c|c|c|}
\hline $\begin{array}{l}\text { appr. } \\
\text { time } \\
\text { BP }\end{array}$ & event & & relevance to Pyrrosia \\
\hline $\begin{array}{l}1-2 \\
\text { myr }\end{array}$ & (9) & $\begin{array}{l}\text { shelf seas } \\
\text { dry up }\end{array}$ & $\begin{array}{l}\text { overland dispersal possible } \\
\text { to e. Taiwan, Japan; followed } \\
\text { by speciation (e.g. P. hastata). }\end{array}$ \\
\hline$?$ & (8) & $\begin{array}{l}\text { separation of } \\
\text { New Guinea and } \\
\text { Philippines }\end{array}$ & speciation affecting 2 groups \\
\hline$?$ & (7) & $\begin{array}{l}\text { separation of } \\
\text { East Malesia } \\
\text { and the Sunda } \\
\text { Shelf }\end{array}$ & speciation affecting 3 groups \\
\hline 15 myr (a) & (6) & $\begin{array}{l}\text { collision Pap- } \\
\text { australia and } \\
\text { Southeast Asia }\end{array}$ & $\begin{array}{l}\text { dispersal followed by } \\
\text { radiation in the } \\
P \text {. lanceolata-group }\end{array}$ \\
\hline 55 myr (a) & $(5)$ & $\begin{array}{l}\text { first contact } \\
\text { India and Laur- } \\
\text { asia }\end{array}$ & $\begin{array}{l}\text { dispersal to China followed } \\
\text { by radiation, affecting } \pm \\
3 \text { groups }\end{array}$ \\
\hline 65 myr (a) & (4) & $\begin{array}{l}\text { temporary con- } \\
\text { tact India and } \\
\text { Malesia }\end{array}$ & $\begin{array}{l}\text { dispersal and speciation } \\
\text { through vicariance } \\
\text { in } 2, \text { possibly } 3 \text {, groups }\end{array}$ \\
\hline 100 myr (c) & (3) & $\begin{array}{l}\text { temporary con- } \\
\text { tact Papaustra- } \\
\text { lia and Malesia }\end{array}$ & $\begin{array}{l}\text { dispersal and vicariance } \\
\text { involved in genesis of } P \text {. } \\
\text { albicans/angustata-group }\end{array}$ \\
\hline 125 myr (a) & (2) & $\begin{array}{l}\text { separation of } \\
\text { Papaustralia } \\
\text { and India }\end{array}$ & $\begin{array}{l}\text { vicariance speciation } \\
\text { involving ancestor of } \\
P \text {. lingua-group }\end{array}$ \\
\hline $\begin{array}{l}120-140 \mathrm{myr} \\
\text { (b) }\end{array}$ & (1) & $\begin{array}{l}\text { separation of } \\
\text { E. Gondwana } \\
\text { and Africa }\end{array}$ & $\begin{array}{l}\text { vicariance speciation } \\
\text { involving ancestor of } \\
P . \text { africana-group }\end{array}$ \\
\hline
\end{tabular}

Several features of the distribution of Pyrrosia are not explained by this scenario. The most striking of these are the wide distribution of the $P$. lanceolata-group, and of other species that are of recent origin according to this scenario.

In the scenario presented here, these distributions have to be due entirely to long-range dispersal. Therefore, the possibility has to be considered seriously that the place assigned to the $P$. lanceolata-group in the cladogram is wrong and that the age of this group as it emerges from the scenario has been significantly underestimated. 


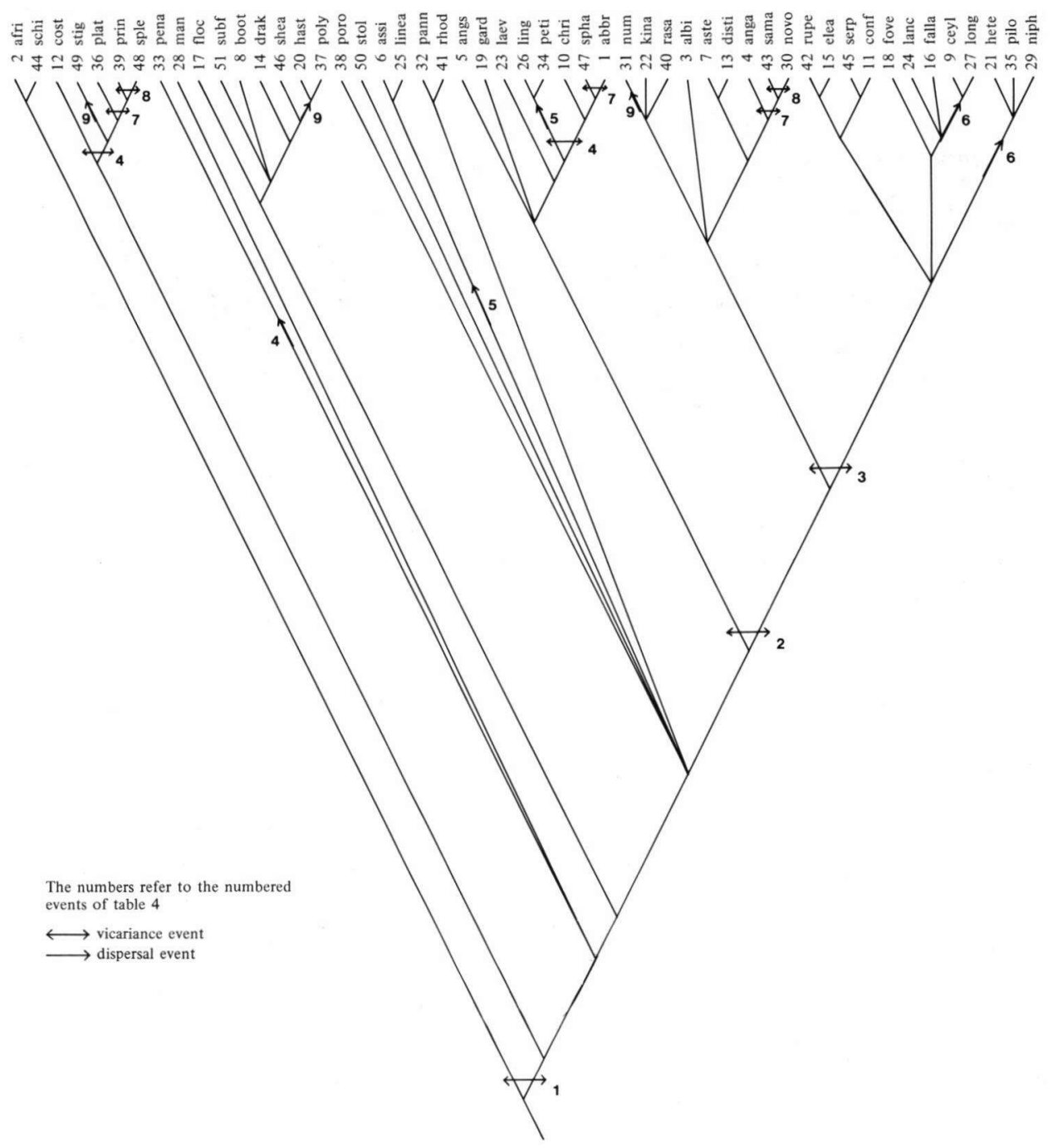

Fig. 28. Relations between geograpic history and speciation in Pyrrosia. N.B.: no constant vertical time-scale is implied.

On the other hand, it may be no coincidence that the growth form of most of the widespread species is similar (compare $P$. nummulariifolia, $P$. lanceolata, $P$. piloselloides). This growth form may have contributed to their rapid spreading (compare p. 34) and it cannot be excluded that these species are simply highly succesfull. 


\section{Implications}

The scenario as presented here has a number of implications that can be used to predict something about the distribution of fossil remains of Pyrrosia. No fossils of Pyrrosia have been found yet. If they are found in the future, these predictions can serve as a test for the scenario.

The first implication is that the present distribution of Pyrrosia on continental Asia has not been reached by overland dispersal around the mesozoic Tethys sea, but by rafting on the Indian subcontinent. The prediction derived from this is that fossils will be absent from western Asia, but that they may be found yet on the Indian subcontinent.

Another implication is that Pyrrosia must have been absent from the Malesian area before the Cretaceous. This implication is testable by way of fossils in a similar way as the one above.

Similarly, the presence of fossil Pyrrosia on the Australian mainland may be predicted from the assumption of widespread but relatively recent extinction in this area. This extinction is implicit from events (3) and (6) in the scenario, combined with the absence of Pyrrosia from most of this area now.

There is also a possible correlation with the ecology of the species concerned: those species that are supposed to have evolved in Australia mainly show the succulent growth-form discussed on p. 113; those that are supposed to have evolved on the Indian subcontinent mainly show the poikilohydrous growth-form. This even holds for species now co-occurring in Malesia: in the $P$. lingua- and $P$. costatagroup (that supposedly reached Malesia by way of India) a succulent habit has not developed; in the $P$. albicans-group, that reached Malesia via Australia, many strongly succulent species occur.

Another feature of the present distribution of Pyrrosia that can be tied in with this scenario is the species-richness of Sumatra. As discussed above, it is difficult to account for this relative richness with ecological considerations only. There may be a historical aspect, too: in the scenario presented here Sumatra has served as a centre of speciation in several groups, and in the past may have been in contact with both the Indian subcontinent and with Australia. This stands in contrast with New Guinea, which only relatively recently has become a contact zone between Malesia and Papaustralia, and is possibly a centre of speciation in only one group (the $P$. lanceolata-group). 


\section{REFERENCES}

Alderwerelt van Rosenburgh, C. R. W. K. van, 1908. Malayan ferns. Handbook to the determination of the ferns of the Malayan islands.

Audley-Charles, M. G. 1981. Geological history of the region of Wallace's line. in: Whitmore, T. C. (ed.), Wallace's line and plate tectonics.

Audley-Charles, M.G., A.M. Hurley \& A.G. Smith, 1981. Continental movements in the Mesozoic and Cenozoic. in: Whitmore, T. C. (ed.), Wallace's line and plate tectonics.

BaAyen, R. J., E. Hennipman. The paraphyses of the Polypodiaceae. In prep.

Backer, C. A., O. Posthumus, 1939. Varenflora voor Java.

BALL, I. R. 1983. On groups, existence and the ordering of nature. Syst. Zool. 32 (4): 446-451. BeAtTY, J. 1982. Classes and cladists. Syst. Zool. 31: 25-34.

BEDDOME, R. H. 1863-5. The ferns of Southern India.

Beddome, R. H. 1883. Handbook to the ferns of British India, Ceylon and the Malay Peninsula.

Beppu, M., Serizawa, S. 1983. On a Japanese fern currently referred to Pyrrosia davidii. J. of Phytogeography \& Taxonomy 30 (1): 45-47.

Blume, C. L. 1828. Enumeratio plantarum Javae et insularum adjacentium. Fasc. II. Filices.

Blume, C. L. 1829. Flora Javae nec non insularum adjacentium. Filices.

Bower, F. O. 1928. The ferns (Filicales). III. The leptosporangiate ferns.

BrackenRIDGE, W. D. 1854. United States exploring expedition Vol. XVI. Botany. Cryptogamia. Filices.

Burmann, N. L. 1768. Flora Indica.

Cavanilles, A. J. 1799. Diez especies nuevas del genero Acrostichum. Anales de Historia Natural 1 (2): 101-107.

Ching, R. C. 1933. Saxiglossum, a new genus of Polypodiaceous fern in China. Contr. Inst. Bot. Nat. Acad. Peiping 2 (4): 1-5.

Ching, R. C. 1935. On the genus Pyrrosia Mirbel from the mainland of Asia incl. Japan and Formosa. Bull. Chin. Bot. Soc. 1 (1): 36-72.

Christensen, C. 1906. Index Filicum.

Christensen, C. 1929. Taxonomic fern-studies I-II. Dansk. Bot. Ark. 6: 1-102.

Colless, D. H. 1967. The phylogenetic fallacy. Syst. Zool. 16: 289-295.

Colless, D. H. 1969. The phylogenetic fallacy revisited. Syst. Zool. 18: 115-126.

Copeland, E. B. 1947. Genera Filicum.

Cotthem, W. R. J. van, 1970. Comparative morphological study of the stomata in the Filicales. Bull. Jard. Bot. Nat. Belg. 40: 81-239

Crabbe, J. A., A. C. Jermy, \& J. T. Mickel. 1975. A new generic sequence for the pteridophyte herbarium. Fern Gaz. 11: 141-162.

DeVol, C. E. 1975. Polypodiaceae. in: Flora of Taiwan I. Pteridophyta and Gymnospermae.

Desvaux, A. N. 1811. Observations sur quelques nouveaux genres de fougères. Magaz. Gesellsch. naturf. Freunde zu Berlin 5: 297-330.

Desvaux, A. N. 1827. Prodrome de la famille des fougères. Mém. Soc. Linn. Paris, 1827: 171-337.

Dickason, F. G. 1946. A phylogenetic study of the ferns of Burma. Ohio J. Sc. 46(2): 73-108.

Diels, L. 1899. in: Engler \& Prantl, Die natürlichen Pflanzenfamilien 1,4:112-336.

FARRIS, J. S. 1970. Methods for computing Wagner trees. Syst. Zool. 19: 83-92.

FARRIS, J. S. 1982. Outgroups and parsimony. Syst. Zool. 31: 328-334.

Farwell, O. A. 1931. Fern notes II. Amer. Midl. Naturalist 12: 233-311.

FÉE, A. L. A. 1853? Genera Filicum. Exposition de la famille des Polypodiacées (Classe des fougères). 
Felsenstein, J. 1982. Numerical methods for inferring evolutionary trees. Quart. Rev. Biol. 57: 379-404.

Frтсн, W. M. 1971. Toward defining the course of evolution: minimum change for a specific tree topology. Syst. Zool. 20: 406-416.

FORSTER, G. 1786. Florulae insularum australicum prodromus.

Froebe, H. A., \& K. J. Strank, 1981. Zum Wasserhaushalt von Platycerium Desv. Beitr. Biol. Pflanzen 56: 275-291.

GeEsink, R. 1984. Scala Millettiearum. Leiden Bot. Series 8.

Giesenhagen, K. 1901. Die Farngattung Niphobolus.

Hennig, W., 1966. Phylogenetic Systematics.

Hennipman, E. 1977. A Monograph of the fern genus Bolbitis (Lomariopsidaceae). Leiden Bot Series 2.

Hennipman, E. 1979. The collection of Pteridophytes at the Rijksherbarium. Blumea 25: 103-106.

Hennipman, E., * M. C. Roos. 1982. A monograph of the fern genus Platycerium (Polypodiaceae). Verh. Kon. Ned. Akad. Wetensch. Afd. Natuurk., Tweede Reeks 80.

HiRsch, A. M., D. R. Kaplan. 1974. Organography, branching and the problem of leaf vs. bud differentiation in the vining epiphytic fern genus Microgramma. Amer. J. Bot. 61(3): 217-229.

HoltTum, R. E. 1955. A revised flora of Malaya II. Ferns of Malaya.

HoOKER, W. J. 1842. Genera Filicum.

HOOKER, W. J. 1863. Species Filicum 5.

Houttuyn, F. 1783. Natuurlijke Historie II(14).

Hovenkamp, P. H. 1984. Some new names and species in Pyrrosia (Polypodiaceae). Blumea 30: 207-208.

Hovenkamp, P. H. Transformations and the philosophy of cladistics. In prep.

Hull, D. L. 1983. Karl Popper and Plato's metaphor. in: Platnick, N. I. and V. A. Funk (eds.) Advances in Cladistics II, 177-189.

JARRETT, F. M. 1980. Studies in the classification of the leptosporangiate ferns. I. The affinities of the Polypodiaceae sensu stricto and the Grammitidaceae. Kew Bull. 34(4): 825-833.

JENSEN, R. J. 1981. Wagner networks and Wagner trees: a presentation of methods for estimating most parsimonious solutions. Taxon 30 (3): 576-590.

Joe Hoshizaki, B. 1972. Morphology and phylogeny of Platycerium species. Biotropica 4(2): 93-117.

Kaulfuss, G. F. 1824. Enumeratio Filicum.

Kornas, J. 1978. Life-forms and seasonal patterns in the pteridophytes in Zambia. Acta Soc. Bot. Polon. 46 (1977): 668-690.

Kunze, G. 1848. Pteridographia Japonica. Bot. Zeit. 6.

Labillardière, J. J. H. de. 1806. Novae Hollandiae plantarum specimen 2.

LiN, B.-L., \& C. E. DeVol. 1978. The use of stipe characters in fern taxonomy II. Taiwania 23: 77-95.

LiNK, H. F. 1841. Filicum species in horto regio botanico Berolinensis cultae.

Linnaeus, C. 1753. Specier Plantarum ed. I.

Linnaeus, C. 1762. Species Plantarum, ed. II.

Löve, A., D. Löve, R. E. G. Pichi Sermolli, 1977. Cytotaxonomical atlas of the Pteridophyta.

Luerssen, C. 1882. Zur Farnflora Hinterindiens und West-Sumatra's. Bot. Zentralblatt 11: 76-79.

LUNDBERG, J. 1972. Wagner networks and ancestors. Syst. Zool. 21: 398-413.

Madison, W. 1977. Vascular epiphytes: their systematic occurrence and salient features. Selbyana 2(1): 1-13.

Mettenius, G. 1856. Ueber einige Farngattungen. 1: Polypodium.

MEIJDEN, R. VAN DER. 1982. Systematics and evolution of Xanthophyllum (Polygalaceae). Leiden Bot Series 7.

Mickevich, M. F. 1982. Transformation series analysis. Syst. Zool. 31: 461-478.

Mirbel-Brisseau, C. 1803. Histoire naturelle des végétaux 5. In Buffon, Cours complet d'Histoire Naturelle, éd. Déterville.

MOORE, T. 1857. Index Filicum. 
Müller, L., G. Starnecker, * S. WinkLer, 1981. Zur Oekologie epiphytischer Farne in Südbrasilien. I. Saugschuppen. Flora 171: 55-63.

NAKAI, T. 1928. Notes on Japanese ferns VII. Bot. Mag. Tokyo 42: 203-218.

NAKaike, T. 1975. Enumeratio Pteridophytarum Japonicarum. Filicales.

NAYAR, B. K. 1957. Studies in Polypodiaceae. IV. Drymoglossum. J. Ind. Bot. Soc. 36: 167-179.

Nayar, B. K. 1961. Studies in Polypodiaceae. VII. Pyrrosia. J. Ind. Bot. Soc. 40: 164-186.

Nayar, B. K., S. Chandra. 1965. Ferns of India. 15. Pyrrosia. Bull. Nat. Bot. Gard. Lucknow 117.

Nayar, B. K., S. Chandra. 1967. Morphological series within the genus Pyrrosia, and their phylogenetic interpretation. Can. J. Bot. 45: 615-634.

NaYAR, B. K., \& S. KAUR, 1971. Gametophytes of homosporous ferns. Bot. Rev, 37: 295-396.

Nelson, G., N. I. Platnick, 1981. Systematics and biogeography, cladistics and vicariance.

O'Brien, T. P., I. Von Teichmann, 1974. Autoclaving as an aid in the clearing of plant specimens. Stain Techn. 49: 175-176.

Ogura, Y. 1972. Comparative anatomy of the vegetative organs of the Pteridophytes. 2nd ed.

PARris, B. S. 1983. A taxonomic revision of the genus Grammitis Sw. (Grammitidacae: Filicales) in New Guinea. Blumea 29: 13-222.

Payne, W. W., K. M. Peterson. 1973. Observations of the hypodermis of ferns. Amer. Fern J. 63(2): 34-42.

Pichi Sermolli, R. E. G. 1953. The nomenclature of some fern-genera. Webbia 9 (2): 387-454.

Pichi Sermolli, R. E. G. 1972. Fragmienta pteridologiae III. Webbia 27(2): 389-460.

Pichi Sermolli, R. E. G. 1977a. Fragmenta pteridologiae VI. Webbia 31(1): 237-259.

Pichi Sermolli, R. E. G. 1977b. Tentamen Pteridophytorum genera in taxonomicum ordinem redigendi. Webbia 31 (2): 313-512.

Powell, C. McA., B. D. Johnson, \&. J. Veevers, 1981. The early Cretaceous break-up of eastern Gondwanaland, in: A. Keast (ed.), Ecological Biogeography of Australia.

Prest, K. B. 1836. Tentamen Pteridographiae.

PresL, K. B. 1851. Epimeliae Botanicae.

Price, M. G. 1974. Nine new fern names. Kalikasan, Phil. J. Biol. 3 (3): 175-178.

Ravensberg, W. J., \& E. Hennipman. 1986. The Pyrrosia species formerly referred to Drymoglossum and Saxiglossum (Filicales, Polypodiaceae). Leiden Bot. Series 9: 281-310.

Rheede tot Drakestein, H. van. 1703. Hortus Malabaricus 12.

Ruinen, J. 1953. Epiphytosis. A second view on epiphytism. Ann. Bogor. 1(2): 101-158.

Schelpe, E. A. C. L. E. 1952. The genus Pyrrosia (Polypodiaceae) in Africa. Journ. S. Afr. Bot. 18: $123-134$.

Schmid, R. 1982. The terminology and classification of steles: Historical perspective and the outline of a system. Bot. Rev. 48(4): 817-931.

Sen, U., E. Hennipman. 1981. Structure and ontogeny of stomata in Polypodiaceaeae. Blumea 27: 172-201.

Serizawa, S. 1970. Taxonomical notes on Asian ferns (1). J. Jap. Bot. 45 (4): 120-121

Shing, K. H. 1983. A reclassification of the fern genus Pyrrosia. Amer. Fern J. 73 (3): 73-78.

Sledge, W. A. 1960. The Polypodiaceae and Grammitidaceae of Ceylon. Bull. Brit. Mus. (Nat. Hist.) Bot. 2 (5): 131-158.

SMITH, J. 1842. An arrangement and definition of the genera of ferns with observations on the affinities of each genus. Hookers J. of Bot. IV: 38-70, 147-198.

SMITH, J. 1857. Cultivated ferns, or, a catalogue of exotic and indigenous ferns cultivated in British gardens.

SMITH, J. 1875. Historia Filicum.

Smith, A. G., J. C. Briden, 1977. Mesozoic and Cenozoic Paleocontinental Maps.

Steenis, G. G. G. J. van, 1979. Plant-geography of east Malesia. Bot. J. Linn. Soc. 79 (2): 97-178.

Steenis, C. G. G. J. Van, 1981. Rheophytes of the world.

STOKEY, A. G. 1951. The contribution of the gametophyte to the classification of the homosporous ferns. Phytomorphology 1: 39-58.

Swartz, O. 1801. Genera et species Filicum ordine systematico redactarum. Schrad. Journ. 1800-II. 
Swartz, O. 1806. Synopsis Filicum.

TAKEI, M. 1969. Karyological studies in Polypodiaceae. Bot. Mag. Tokyo 82: 482-487.

Tindale, M. D. 1961. The pteridophyta of S. E. Australia. Contr. N. S. W. Nat. Herb. Fl. Ser. 210: $1-78$.

Tomlinson, B. P. 1984. Homology: an empirical view. Syst. Bot. 9(4): 374-381.

ThunBerg, C. P. 1784. Flora Japonica.

TRYON, A. F. 1965. Trichomes and paraphyses in ferns. Taxon 14: 214-218.

TRYON, R. 1965. Paraphyses in the ferns. Taxon 14: 213-214.

Underwood, L. N. 1903. A Summary of our present knowledge of the ferns of the Philippines. Bull. Torr. Bot. Glub 30: 665-683.

Van Uffelen, G. A., E. Hennipman, 1985. The spores of Pyrrosia Mirbel, a SEM study. Pollen et Spores 27: 155-197.

Wagner, W. H. 1952. Types of foliar dichotomy in living ferns. Amer. J. Bot. 39: 578-592.

WaGner, W. H. 1961. Problems in the classification of ferns. Rec. adv. in Botany 2: 841-844.

WAGNER, W. H. 1962. Irregular morphological development in hybrid ferns. Phytomorphology 12 (1): 87-100.

WAGNER. W. H. 1964. Paraphyses: Filicinae. Taxon 13: 56-64.

WAGNer, W. H. 1969. The construction of a classification. in: Systematic Biology, Publ. 1692 N. A. S. Washington, 67-90.

WAGNER, W. H. 1983. Reticulistics: the recognition of hybrids and their role in cladistics and classification. in: Platnick, N. I. V. A. Funk, (eds.) Adv. in Cladistics 2: 63-79.

WAGNER, W. H., K. LiM CHEN. 1965. Abortion of spores and sporangia as a tool in the detection of Dryopteris hybrids. Amer. Fern. J. 55: 9-29.

WAGNER, W. H., F. S. WAGNER. 1977. Fertile-sterile leaf dimorphy in ferns. Gard. Bull. 30: 251-267.

WALKER, T. G. 1979. The cytogenetics of ferns. in: Dyer, A. F. (ed.) The Experimental Biology of ferns,

Warmbrodt, R. D. 1984. Structure of the leaf of Pyrrosia longifolia - a fern exhibiting Crassulacean acid metabolism. Amer. J. of Bot. 71(3): 330-347.

Watrous, L. E., Q. D. WheELER, 1981. The out-group comparison method of character analysis. Syst. Zool. 30: 1-11.

WhITMORE, T. C. (ed.), 1981. Wallace's line and plate tectonics.

WhitMore, T. C. 1982. Wallace's line: A result of plate tectonics. Annals Mo. Bot. Garden 69: 668-676.

WILson, K. A. 1958. Ontogeny of the sporangia in Xiphopteris serrulata and Pyrrosia nuda. J. Arn. Arb. 39: 478-493.

WiLson, K. A. 1959. Sporangia of the fern genera allied with Polypodium and Vittaria. Contr. Gray Herb. 185: 97-127.

Wong, S. C., C. S. Hew. 1976. Diffusive resistance, titratable acidity, and $\mathrm{CO}_{2}$ fixation in two tropical epiphytic ferns. Amer. Fern J. 66: 121-124. 
Plate 1 , rhizome anatomy. a. $P$. stigmosa; non-vascular tissue completely sclerified; $15 \times .-$ b. $P$. africana; non-vascular tissue parenchymatous; phyllopodium with sclerified abscission pad; $16 \times$ - c. $P$. rhodesiana; weak sclerenchyma sheath present; $15 \times-$ d. $P$. lingua; distinct sclerenchyma sheath present; $22 \times-$ e. $P$. sphaerosticha; sclerenchyma present in sheath, periferally scattered and in central strand; $22 \times-\mathrm{f}$. $P$. lanceolata; five vascular strands, central sclerenchyma strand; 29 $x-$ g. $P$. angustata; slerenchyma in sheath and periferally among vascular strands; $24 \times-h$. P. distichocarpa; structure of sclerenchyma in sheath; $96 \times$ (a. Geesink 6944, L; - b. Rawson 943, BM; - c. Chase 5795, BM; - d. cult. Leiden Bot. Garden; - e. Hennipman 5200, L; - f. Brass 27786, L; - g. Lewis 80, L; - h. Surbeck 813, L).

Plate 2, rhizome scales. a. $P$. princeps; cross-section through scale just above insertion; $115 \times-$ b. $P$. porosa; cross-section through scale at point of attachment; $122 \times-c$. $P$. serpens; cross-section through scale at point of attachment; $102 \times-\mathrm{d}$. $P$. confluens; cells at base of scale showing "annular figures"; $229 \times-$ e. $P$. subfurfuracea; base of scale showing overlapping auricles; $37 \times-$ f. $P$. distichocarpa; margin of scale showing teeth composed of two cells; $508 \times-$ g. $P$. porosa; marginal zone of scale with superficial papillae; $221 \times-h$. P. abbreviata; margin of scale with cilia; $266 \times$ (a. Womersley NGF 37106, BM; - b. Teng 90059 A; - c. A. C. smith 6052, L; - d. Franc 1132, M; - e. Tsiang 9249, M; - f. Bartlett 7932, L; - g. Van Beusekom Phengkhlai 2498, L; h. Surbeck 809, L)

Plate 3, lamina indument. a. $P$. angustata; upper layer of the indument with hairs with patent, \pm acicular rays; $85 \times-$ b. $P$. hastata; hairs with appressed, boat-shaped rays; $154 \times-\mathrm{c}$. $P$. lanceolata; hairs with appressed, flat rays; $91 \times-$ d. $P$. mannii; dimorphic indument with upper and lower layer mixed, hairs with woolly and patent, acicular rays visible; $173 \times-$ e. $P$. laevis; upper layer, hair with woolly and boat-shaped rays mixed in a single whorl; $371 \times-f$. $P$. laevis; upper layer with a "dorsal spine" visible; $79 \times-$ g. $P$. nummulariifolia; cross-section through lamina and indument; $260 \times-h$. $P$. longifolia; cross-section through appresseu stenate nair; 0.34 $\times$ (a. Shimizu \& Fukuoka $M$ 13216, i; - i. Tuguwa \& Iwatsuki 448, L; - c. Hennipman 3498, L; - d. Mann s.n., Mar. 1888, L; - e, f. Mann s.n., Aug. 1889, L; - g. cult. Leiden Bot. Garden; - h. cult. Leiden Bot. Garden)

Plate 4, venation patterns. a. $P$. angustata; sterile lamina. - b. $P$. angustata; fertile lamina. - c. $P$. abbreviata; highly anastomosing with "costular areoles' (c. a.). - d. $P$. africana; secondary and tertiary veins hardly distinct from each other. - e. P. confluens; sterile and fertile frond. (a. Buwalda 6646, L; - b. cult. Royal Botanic Gardens Kew; - c. cult. Leiden Botanical garden; - d. De Joncheere SAC 254, L; - e. Constable NSW P 7958, U). Scale bar $=1 \mathrm{~cm}$.

Plate 5, venation patterns. a. $P$. petiolosa; sterile. - b. $P$. petiolosa; fertile; confluent sori. - c. $P$. penangiana; included veins simple, excurrent. - d. $P$. rhodesiana; fertile lamina. - e. $P$. princeps; fertile area with numerous small sori. (a, b. Dorsett \& Dorsett 3049, U; - c. De Wilde -Duyfjes 14577, L; - d. Torre 4577, WAG; - e. cult. Leiden Botanical Garden). b, c: scale bar = $5 \mathrm{~mm}$; , d, e: scale bar $=1 \mathrm{~cm}$. 
Plate 6, lamina anatomy. a. $P$. penangiana; u. e.: projecting cells with moderately thickened walls; m.: undifferentiated; l. e.: thin cell-walls; $156 \times-$ b..P. flocculosa; u. e.: distinctly projecting cells with thin walls; p. p. \pm distinct; 1 . e.: thin walls, stomata slightly sunken; $111 \times-$ c. $P$. drakeana; u. e.: projecting cells with slightly thickened walls; p. p. very distinct; 1 . e.: moderately thickened cell-walls, stomata slightly raised; $109 \times-$ d. $P$. splendens; u. e.: flat cells with strongly thickened walls; $\mathbf{m}$.: hypodermis distinct, otherwise not differentiated; 1 . e.: moderately thickened cell-walls, stomata superficial; $200 \times-$ e. $P$. sphaerosticha; u. e.: slightly projecting cells with thin walls; $m$.: w. t. moderately thick, p. p. distinct; 1 . e.: moderately thickened cell-walls, stomata sunken; $87 \times$ - f. P. angustata; u. e.: flat cells with moderately thickened walls; m.: w. t. moderately thick, p. p. distinct; l. e.: strongly thickened cell-walls, stomata sunken; $39 \times-$ g. $P$. nummulariifolia; $u$. e.: flat cells with thick walls; $m$.: $w$. t. very thick; 1 . e.: thickened cell-walls, stomata sunken; 38 $x-h$. $P$. niphoboloides; u. e.: flat cells with thin walls; $m$. undifferentiated; 1 . e.: thin cell-walls, stomata superficial; $42 \times$ (a. De Wilde -Duyfjes 14577, L; - b. Hennipman 3352, L; - c. Wang 66315, A; - d. Mendoza, PNH 42474-, L; - e. Elmer 21962, L; - f. Kostermans 138, L; - g. Van Beusekom \& Phengkhlai 432, L; - h. Bogner s.n., s.d, K) u. e.: upper epidermis; m.: mesophyll; w. t.: water-tissue; p. p.: palissade parenchyma; l. e.: lower epidermis. 

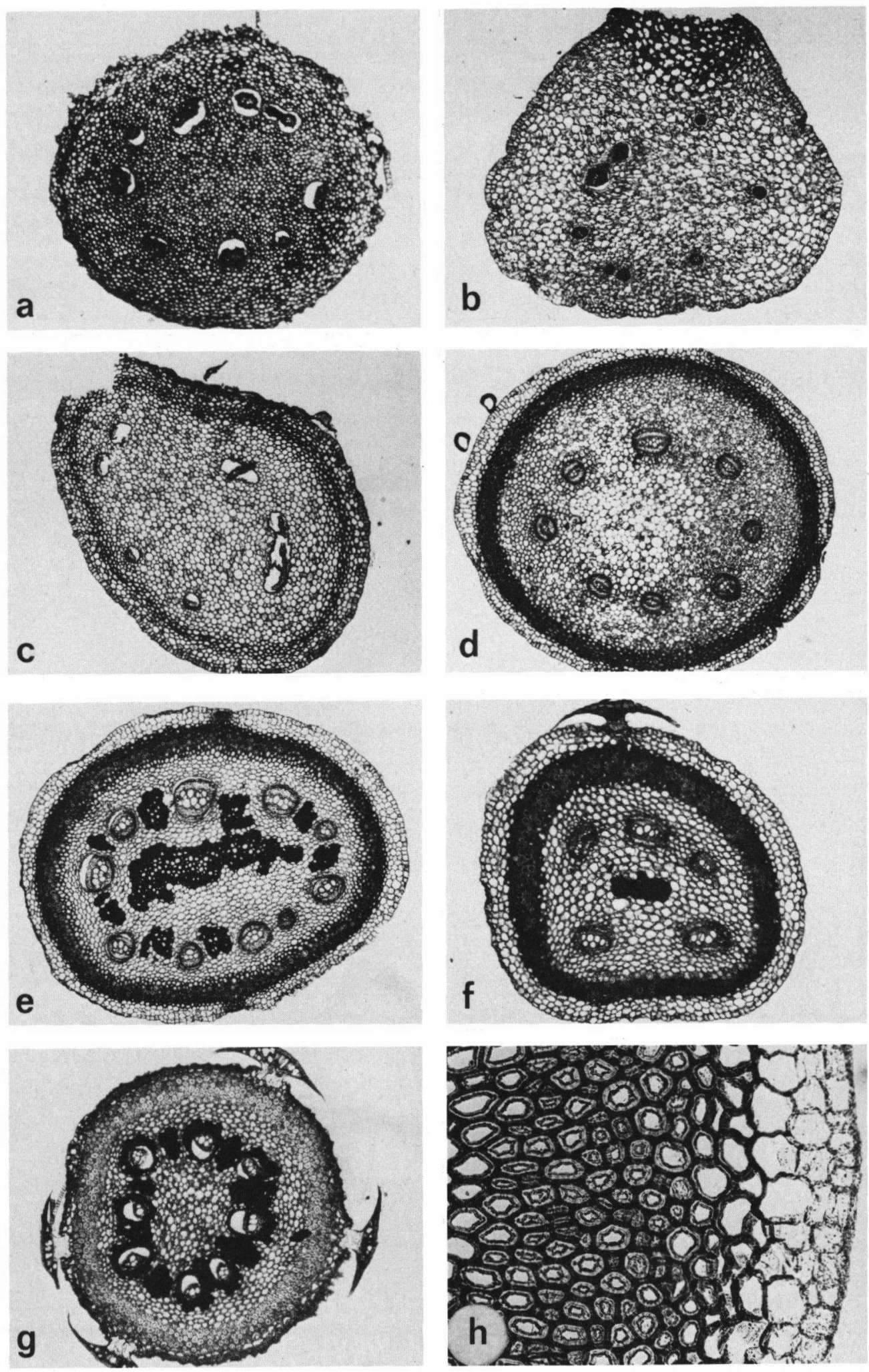

Plate 1 

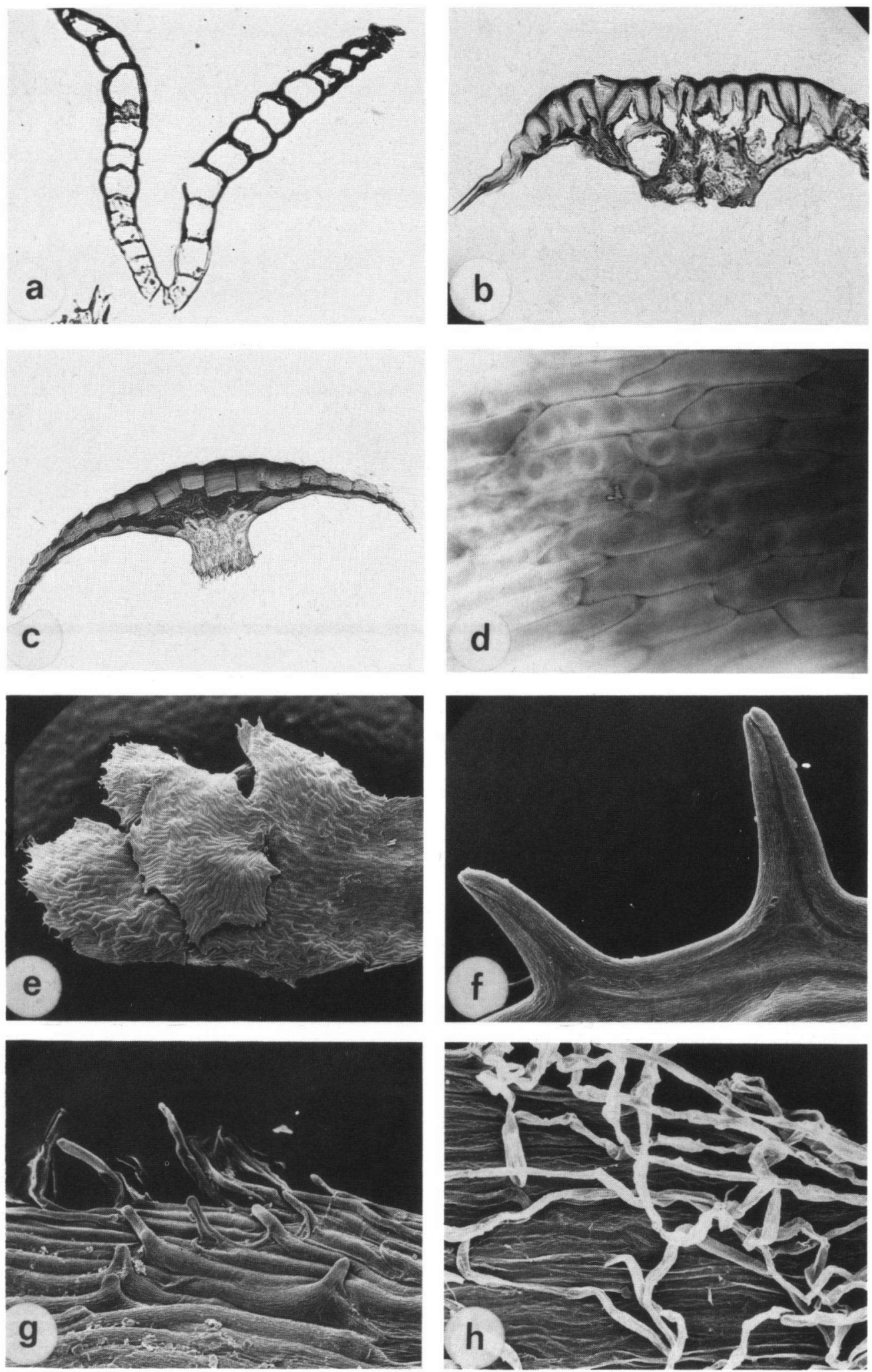

Plate 2 

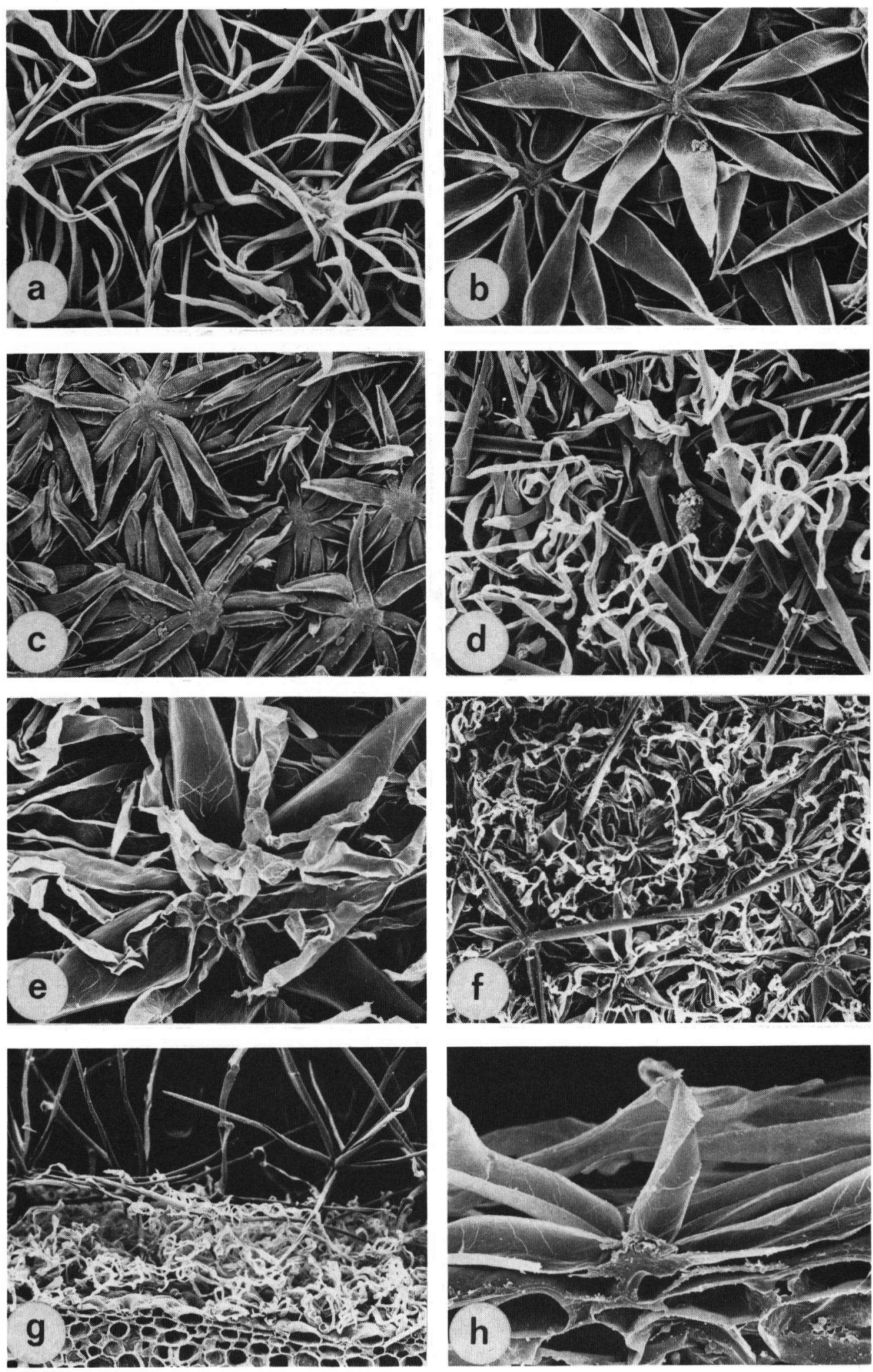

Plate 3 

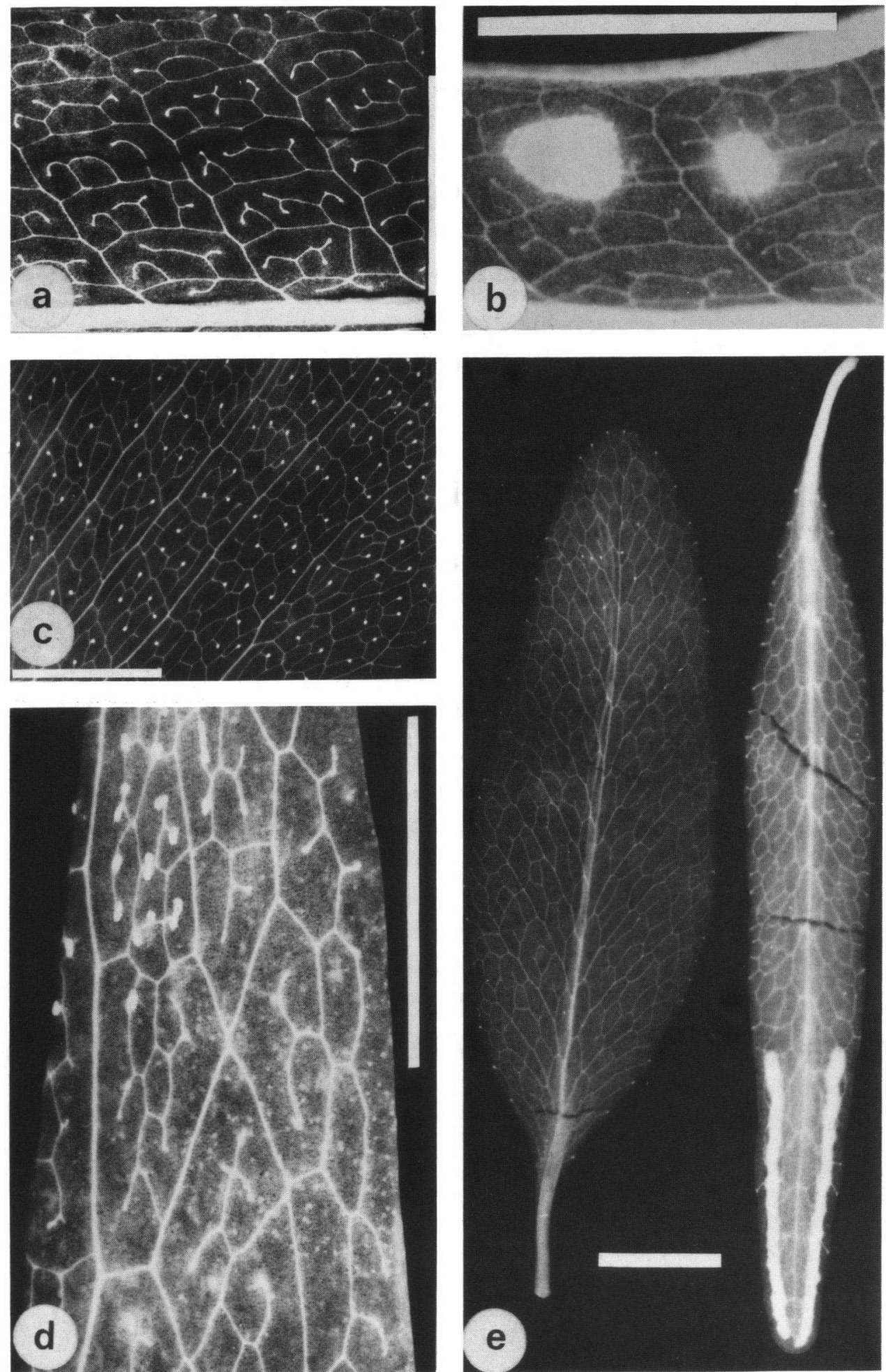

Plate 4 

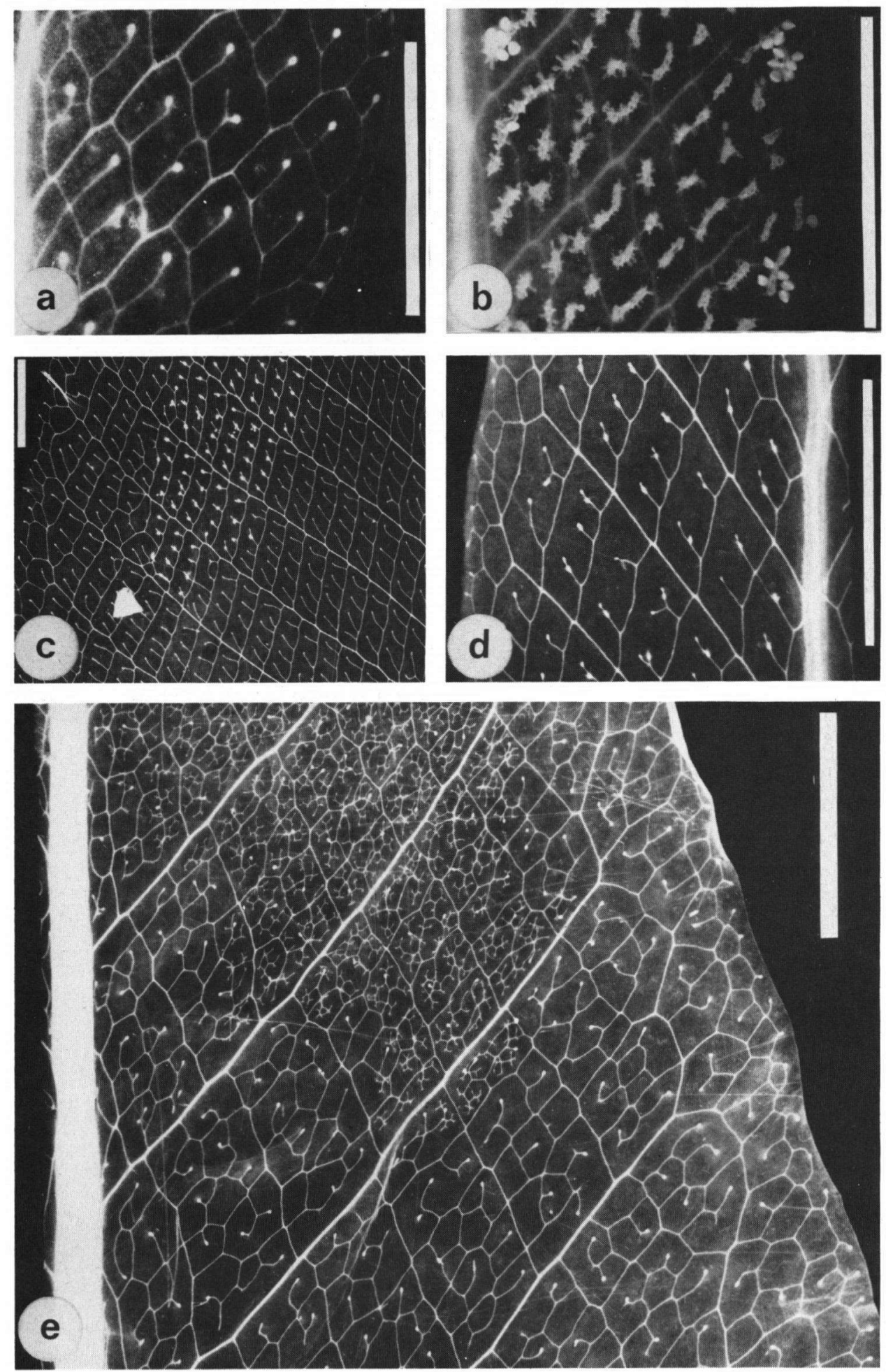

Plate 5 

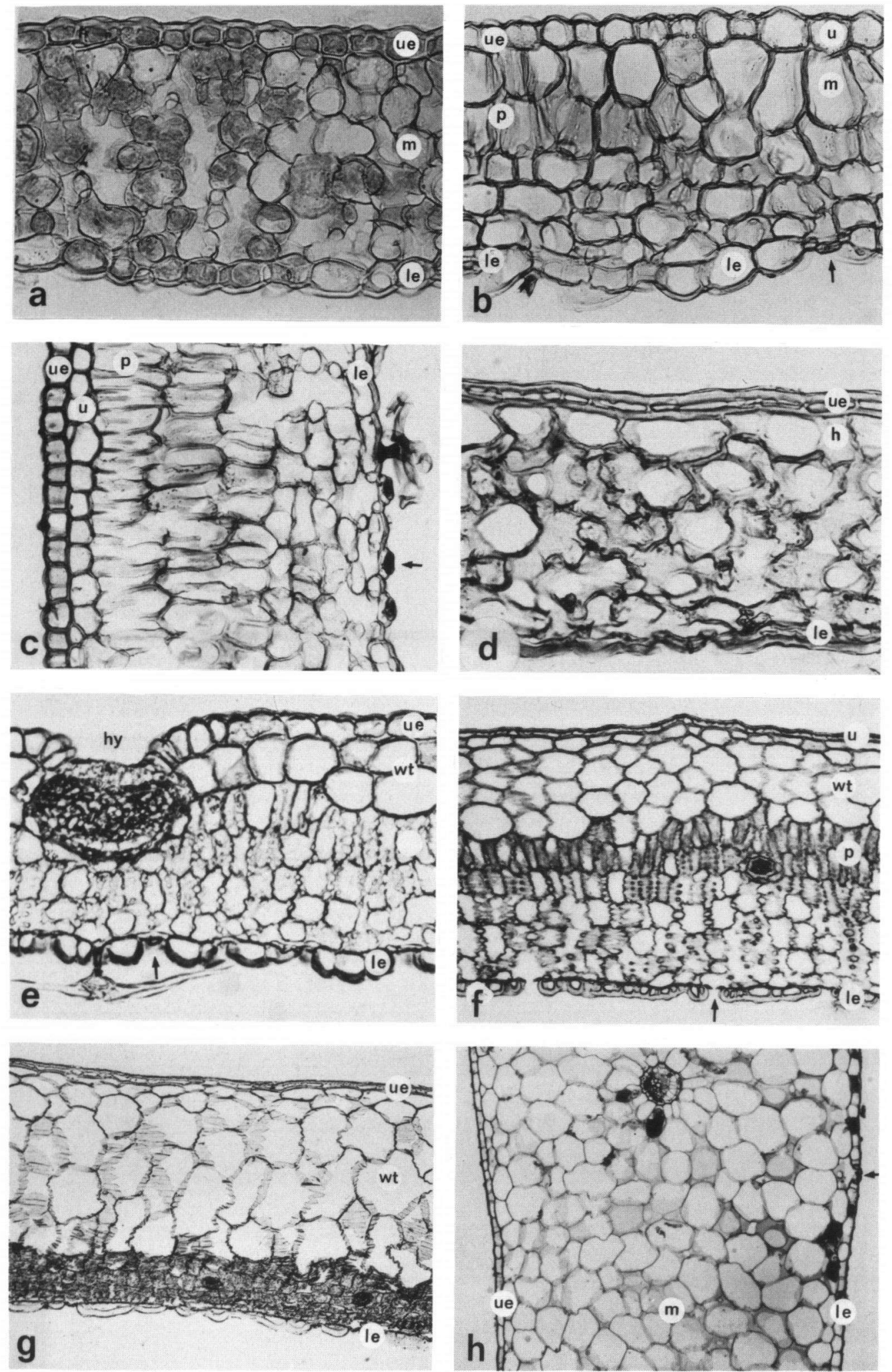

Plate 6 


\section{TAXONOMIC PART}

\section{PRESENTATION OF DATA}

\section{General}

In the taxonomic part all species of Pyrrosia are treated except those that were retained in Drymoglossum by Christensen (1929) and one species often considered as constituting the monotypic genus Saxiglossum. I hese species are treated separately (Kavensberg \& Hennipman, 1986).

The species are arranged in alphabetical order. They have been numbered consecutively, together with the species not treated. Synonymy is listed in full, a relevant selection of the literature is given. Basionyms and homotypic synonyms are listed chronologically. For author abbreviations Stafleu \& Cowan (Tax. Lit. 2) are followed as much as possible. For authors not yet treated there, common usage is followed. Most types were studied, but those not seen are indicated 'not seen' if no attempt was made to study them; 'not found' if the type was searched for in the herbarium indicated but was not found there. The abbreviation "q.n.s." ( quoad nomen solum) has been used where a validly published name has been consistently misapplied. Lectotypes are selected for the accepted taxa and in some other cases where it was thought necessary to avoid confusion. The herbarium abbreviations are according to the Index Herbariorum. Notes on habitat and abundance have been compiled from the collectors notes, unless it is indicated otherwise.

For Chinese place-names, the Wade-Giles transcriptions have been used. Although recently another transcription (Pinyin) has become generally accepted, on almost all labels of plants from China in western herbaria localities are given in the Wade-Giles transcription, if any; and I have thought it better to conform to that usage than to transcribe all names to the Pinyin system.

\section{Key}

The key is designed to identify all species of which well-developed material is available, and as many species as possible if only sterile plants are at hand. Aberrant forms are incorporated as much as possible. Careful examination of rhizome 
scales and lamina indument may be necessary, and plants on which either of these or both are lost may sometimes be impossible to identify. I have had no intention to reflect anything else in the key than an arrangement as convenient as I could devise for assigning names to unknown plants.

\section{Descriptions}

The descriptions were prepared from adult, well-developed material. They are partly (especially those sections concerning anatomy) based on relatively small numbers of observations (5-10, but sometimes only one) whereas other sections have been based on larger samples or, in case of rarer species, on all available material. This difference is expressed as much as possible in a different degree of exactness of the terms used in the various sections. Thus, for the thickness of the various layers of the mesophyll, no exact measurements are given but only terms that should be interpreted as relative, and representing a rather large variation. The use of these and other terms may become clearer by comparison with the plates, where they are given in the legend. Similarly, the units in which measurements are given are intended to reflect the exactness of the measurements. Thus, the various dimensions of the fronds are expressed in $\mathrm{cm}$, with further precision in decimals only when necessary. The height of the capsule of the sporangia is not expressed in micrometres but in fractions of millimetres, as it had often to be reconstructed from more or less widely opened sporangia.

\section{Rhizome}

Thickness of the rhizome as given in the descriptions refers to the largest crosssection in a rhizome that has been boiled in water for several minutes. As the rhizome is often dorsiventrally somewhat flattened, in most cases this represents the horizontal width. The position of the lateral buds is indicated relative to the next phyllopodium apical to the bud on the same side of the rhizome. Rhizome anatomy is described from cross-sections from parts at some distance behind the growing tip.

\section{Scales}

Scales were preferentially taken from the rhizome at $1-2 \mathrm{~cm}$ behind the growing apex. Here they are fully developed and not yet eroded in any way. In short, slow-growing rhizomes scales may be taken closer to the apex. If an apex was not present in a collection, scales were taken, if necessary, from a part of the rhizome where they had apparently been well-protected during the process of drying and mounting. Scales from the phyllopodia are often different and are not included in the descriptions, but in some cases they are described separately in the notes. 


\section{Stipe}

As length of the stipe the distance is given between the phyllopodium and the first dilated part of the lamina, viz., where the lamina is more than $\pm 1 \mathrm{~mm}$ wide on each side of the stipe. If the lamina base is unequal, only the distance to the lower side is given. The anatomy of the stipe refers to the situation at ca. $1 \mathrm{~cm}$ above the phyllopodium, or, in cases of short or absent stipes, directly below or at the base of the lamina.

\section{Lamina}

Length and width of the lamina were measured in dry material (fresh material may be wider by a factor of $11 / 2$ !) and were reconstructed as much as possible if the lamina was strongly rolled inwards. Indument is described from the sterile fronds or from sterile parts of the lamina; the venation is described from cleared parts of the lamina (see section Methods in the General Part) and is also taken from sterile parts of the lamina or sterile fronds. For the purpose of description, the hypodermis and water-tissue are treated as separate layers (see, however, p. p. 55). The thickness of the lamina has been measured in cross-sections prepared as indicated in the section Methods.

\section{Sori}

Size of the sori refers to the diameter of well-developed, mature sori and includes the outermost sporangia. Spore ornamentation is described as far as made visible by light microscopy. A more detailed description and a structural analysis is given by Van Uffelen \& Hennipman (1985). Spore size has usually been measured in samples of 10 spores from three collections. In some cases a different number of spores has been measured, depending on the availability of material. The dimensions given include the perispore and its protuberances. The following generalization has been derived: the dimensions given represent the range of the means of the samples, between brackets the extremes are given. The first value given is the length, the second the width in equatorial view.

\section{Glossary}

In the descriptions the following terms are used in a way that may not be directly evident from common usage:

- acicular (of the rays of a hair): narrowly or spirally grooved, relatively narrow (plate 3: a, $f$ ).

- acumen (of the rhizome scales): the part of the scale apical from the point of attachment (compare fig. 11: h, i) 
- appressed (of the rays of a hair): with all stellate rays parallel to the epidermis (plate 3: b, c)

h, i).

- base (of the rhizome scale): the part below the point of attachment (fig. 11:

- bisculptate (of spores): with two different elements in the ornamentation, which cover the entire surface (Van Uffelen \& Hennipman, 1985)

- boat-shaped (of the rays of a hair): flat or shallowly grooved, relatively wide (plate 3: b, c, e, h).

- dimorphic (of the indument): with both straight and woolly rays. The term refers to the indument as a whole; individual hairs may have only straight or only woolly rays.

- dimorphic (of the fronds): with sterile fronds present in shape differing at least slightly from fertile fronds. This is usually the case: sterile fronds not differing in shape from the fertile fronds are only found in $P$. pannosa.

- dorsal spine: a single ray standing out distinctly, erect from among the other, appressed, rays of a hair (plate 3: $\mathrm{f}$ ).

- hypodermis: a tissue layer below the epidermis, in general aspect somewhat similar to the epidermis (plate 6: c).

- long-creeping: rhizome with internodes longer than ca. $2 \mathrm{~cm}$ (fig. 1: d), or less in thin, filiform, rhizomes (fig. 1: c).

- paraphyses: vegetative structures in the sori. In many species distinctly different from the hairs on sterile parts of the lamina, either in size, in shape, or density; or in more than one of these characters.

- patent (of the rays of a hair): stellate rays pointing to all directions, under various angles away from the epidermis (fig 3: a, g).

- pseudoacrostichoid: with small sori that completely cover the lamina and are seemingly confluent when old.

- pseudopeltate (of a rhizome scale): apparently peltate; the base of the scales not of one piece, but composed of overlapping, separate auricles (plate 2: e).

- short, short-creeping (of the rhizome): horizontally creeping, the phyllopodia placed contiguously (fig. 1: b).

- shortly elongated (of the rhizome): with distinct but short internodes, intermediate between short-creeping and long-creeping (fig. 1: a, e).

- vascular strand: following Schmid (Bot. Rev. 48 (1982) 817-931) the term vascular strand is used, it is equivalent to "meristele" as used by Ravensberg * Hennipman (1986).

- water-tissue: a layer between epidermis and palissade parenchyma, with strongly enlarged, thin-walled cells (plate 6: $f, g$ ).

- woolly (of the rays of a hair): long, flat, ribbon-shaped and strongly curled or spirally twisted (plate $3: \mathrm{b}-\mathrm{g}$ ). 


\section{PYRROSIA MIRBEL}

\section{PYRROSIA. Fig. 15.}

Pyrrosia Mirbel, Hist. Nat. Gen. 4 (1803) 70; Mirbel, Hist. Nat. Vég. 5 (1803) 91; Desv., Mém. Soc. Linn. Paris 6 (1827) 225; Farwell, Amer. Midl. Nat. 12 (1931) 245, 'Pyrrhosia'; Ching, Bull. Chin. Bot. Soc. 1 (1935) 36; Tard. C. Chr., Fl. Indoch. (1941) 503, 'Pyrthosia'; Morton, J. Wash. Acad. Sc. 36 (1946) 166; Copeland, Gen. Filic. (1947) 192; Holttum, Biol. Rev. 24 (1949) 282; Schelpe, J. S. Afr. Bot. 18 (1952) 123; Pic. Ser., Webbia 9 (1953) 441; Holttum, Fl. Malaya 2 (Ferns) (1954) 141; Tardieu, Fl. Madagasc. (1960) 102; Copeland, Fern Fl. Philipp. (1960) 469; Nayar, J. Ind. Bot. Soc. 40 (1961) 164-185; Nayar S. Chandra, Bull. Nat. Bot. Gard. Lucknow 117 (1965); Nayar \& S. Chandra, Can. J. Bot. 45 (1967) 615-634; DeVol, Fl. Taiwan 1 (1975) 205; Pic. Ser., Webbia 31 (1977) 376; Shing, Amer. Fern J. 73 (1983) 7. - Type: Pyrrosia chinensis Mirbel = Pyrrosia stigmosa (Sw.) Ching.

Candollea Mirbel, Hist. Nat. Gen. (1803) 69, non Candollea Labill. (1806) (Angiosp.); Mirbel, Hist. Nat. Vég. 5 (1803) 86; Farwell, Amer. Midl. Nat. 12 (1931) 244; Alston, J. Bot. Lond. 69 (1931) 102; Morton, J. Wash. Acad. Sc. 36 (1946) 166; Pic.-Ser., Webbia 9 (1953) 331. Lectoty pe (Morton, 1946): Candollea longifolia Mirbel = Pyrrosia longifolia (Burm.) Morton.

Cyclophorus Desv., Berl. Mag. 5 (1811) 300; Presl, Epim. Bot. (1851) 129; T. Moore, Ind. Fil. (1861) 275; Underwood, Bull. Torr. Bot. Club 30 (1903) 670; C. Chr., Ind. Fil. (1906) 197; Alderwerelt, Malayan Ferns (1909) 678; Copeland, Univ. Cal. Publ. Bot. 16 (1929) 102; Alston, J. Bot. Lond. 69 (1931) 102; Backer \& Posth., Varenfl. Java (1939) 237; Holttum, J. Linn. Soc. Bot. 53 (1946) 127. - Niphobolus Kaulf., Enum. (1824) 124, nom. superfl.; Blume, Enum. Pl. Jav. 2 (1828) 102; Blume, Fl. Jav. Fil. (1829) 48; Presl, Tent. Pter. (1836). 200; J. Sm., Hook. J. Bot. 4 (1842) 57; Hooker, Gen. Fil. (1842) Pl. 83; Presl, Epim. Bot. (1851) 124; Fée, Gen. Fil. (1853) 260; J. Sm., Cat. Cult. Ferns (1857) 11; T. Moore, Ind. Fil. (1857) lxxv; Bedd., Ferns S. India (1864-5) 61; J. Sm., Hist. Fil. (1875) 97; Bedd., Handb. ferns Brit. Ind. (1883) 324; Giesenh., Niphobolus (1901); Engl., Veg. Erde 2 (1908) 55. - Polvhadium subo. Niphobolus Hooker, Sp. Fil. 5 (1863) 43; Baker in Hooker Baker, Syn. Fil. (1867) 349; Baker, Ann. Bot., Lond. 5 (1891). - Cyclophorus sect. Niphobolus Alderwerelt, Malayan Ferns (1909) 678, nom. superfl. - Lectot y pe (Copeland, 1929): Cyclophorus adnascens (Sw.) Desv. = Pyrrosia lanceolata (L.) Farwell.

Pleropsis Desv., Mém. Soc. Linn. Par. 6 (1827) 218, nom. rej; further references in Ravensberg * Hennipman (1986). - Type: Acrostichum heterophyllum L. = Pyrrosia heterophylla (L.) Price.

Drymoglossum Presl, Tent. Pter. (1836) 227, nom. cons.; further references in Ravensberg \& Hennipman (1986). -Type: Drymoglossum piloselloides L. = Pyrrosia piloselloides (L.) Price.

Niphobolus section Caespitoseae J. Sm., Hook. J. Bot. 4 (1842) 57; J. Sm., Hist. Fil. (1875) 98; J.Sm., Ferns Br. \& For. ed. 2 (1877) 100. - Ty pe not indicated.

Niphobolus section Repenteae J. Sm., Hook. J. Bot. 4 (1842) 57; J. Sm., Hist. Fil. (1875) 98; J.Sm., Ferns Br. \& For. ed. 2 (1877) 100. - Type not indicated.

Apalophlebia Presl, Epim. Bot. (1851) 137. - T y pe not indicated.

Galeoglossa Presl, Epim. Bot. (1851) 132. - Type not indicated.

Gyrosorium Presl, Epim. Bot. (1851) 139.-Ty pe not indicated.

Polycampium Presl, Epim. Bot. (1851) 135. - T y pe not indicated.

Scytopteris Presl, Epim. Bot. (1851) 133. - Ty pe and sole species: Scytopteris acrostichoides Presl = Pyrrosia confluens (R. Br.) Ching.

Sphaerostichum Presl, Epim. Bot. (1851) 134. - Type and sole species: Sphaerostichum acrostichoides Presl = Pyrrosia sphaerosticha (Mett. ex Kuhn) Ching. 
Niphopsis J. Sm., Cat. Cult. Ferns (1857) 6; J. Sm., Hist. Fil. (1875) 105. - Cyclophorus sect. Niphopsis Alderwerelt, Malayan Ferns (1909) 678. - Pyrrosia subg. Niphopsis Shing, Amer. Fern J. 73 (1983) 77. - Ty pe: Niphopsis angustatus (Sw.) J. Sm. - Pyrrosia angustata (Sw.) Ching. Neoniphopsis Nakai, Bot. Mag. Tokyo 42 (1928) 21. - Ty pe and sole species: Neoniphopsis linearifolia (Hk.) Nakai = Pyrrosia linearifolia (Hk.) Ching.

Saxiglossum Ching, Contr. Inst. Bot. Nat. Acad. Peiping 2 (1933) 1-4. - Type: Saxiglossum angustissimum (Baker) Ching = Pyrrosia angustissima (Diels) Tag. Iwats.

Pyrrosia ser. costatae Ching \& Shing, Amer. Fern J. 73 (1983) 77. - Ty pe: Pyrrosia costata (Presl) Tag. Iwats.

Pyrrosia sect. Dichlamys Ching Shing, Amer. Fern J. 73 (1983) 77. - Type: Niphobolus mollis Kunze, ' = Pyrrosia mollis Ching' ( = Pyrrosia porosa (Presl) Hovenkamp, see note 1).

Pyrrosia ser. drakeanae Ching Shing, Amer. Fern J. 73 (1983) 77. - Ty pe: Pyrrosia drakeana (Fr.) Ching.

Pyrrosia ser. Heteractides Ching \& Shing, Amer. Fern J. 73 (1983) 77. - Type: Pyrrosia heteractis (Mett. ex Kuhn) Ching = Pyrrosia lingua var. heteractis (Mett. ex Kuhn) Hovenkamp.

Herbs, epiphytic or epilithic, occasionally terrestrial, in small tufts or forming extensive colonies. Rhizome $0.5- \pm 7.0 \mathrm{~mm}$ thick, shortly creeping to widely trailing, appressed to or just immersed in the substrate, densely set with scales, rarely ( $P$. princeps) with some woolly hairs on the phyllopodia; ventrally rooting diffusely or in two rows, dorsally with two alternating rows of more or less prominent phyllopodia, the phyllopodia contiguous or up to $9 \mathrm{~cm}$ distant; branching sparsely to regularly from lateral buds placed basally on the phyllopodia or up to a full internode behind each phyllopodium on the rhizome. Rhizome anatomy. In cross-section with a peripheral parenchyma several cells thick; central region either completely sclerified, or with a more or less distinct sclerenchyma sheath and a varying number of sclerenchyma strands within the sheath, or completely parenchymatous. Stele enclosed within the sclerenchyma sheath, composed of 3\pm 12 vascular strands; frond traces with $2-4(-9: P$. princeps $)$ strands; branch traces with a single, $U$-shaped or cylindrical strand to 4-6 strands. Rhizome scales appressed to patent or squarrose, \pm orbicular to lanceolate, $2-14 \times 0.5-$ $1.5(-3.3) \mathrm{mm}$, widest at or below (occasionally above) the attachment; either basifix with a more or less deeply cordate base, or pseudopeltate, or peltate with a short, more or less stout stalk; blade thin and translucent to variously thickened and opaque, cell walls either thin or all more or less strongly but equally thickened, rarely ( $P$. costata-group) a few cells \pm clathrate; margin entire, dentate or ciliate, at the base of the scale sometimes with one or more, sessile or stalked, glandular cell(s); apex narrowly (to broadly) acute (occasionally rounded), terminated by 1 or 2 glandular cells and/or 1 or 2 acicular cells; abaxial surface smooth or finely striate, rarely with cilia or papillae similar to the cilia on the margin; colour varying from hyaline to light or dark brown or blackish, darker near the point of attachment. Fronds articulated to the phyllopodia, mono- or dimorphic; sessile to stipitate, entire or rarely hastately ( $P$. hastata) or pedately ( $P$. polydactyla) dissected; covered with stellate hairs; texture pergamentaceous to (thick-) coriaceous, often succulent to $2 \mathrm{~mm}$ thick in vivo. Indument sparse to dense on either side of the lamina, usually denser on the lower side, often particu- 
larly thick and dense at the base of the stipe and containing scale-like filaments there; hairs stellate; stellate rays broad and flat or shallowly grooved, to narrow and narrowly grooved, or long, ribbon-shaped, curly and intertwined. Venation. Veins (in sicco) prominent on the abaxial side of the lamina or immersed, flat or occasionally grooved on the adaxial side; secondary veins usually distinct, running from the costa under an angle of (35-)40-50(-60) ${ }^{\circ}$, not reaching the margin; tertiary veins connecting the secondary veins, thus forming series of few to many more or less rectangular areoles; included veins either free, simple or forked, or anastomosing into a more or less complicated network, often with a dorsal or terminal hydathode; a marginal zone with a row of free, excurrent veins mostly present. Lamina anatomy. Upper epidermis with the cells in surface view with more or less sinuose (occasionally almost straight) walls, in cross-section with the cells flat to distinctly projecting outward; mesophyll usually welldifferentiated into palissade and spongy parenchyma, often with a distinct hypoderm or water-tissue. rarelv with both: rarelv ( $P$. piloselloides-group) not differentiated, composed of parenchymatous cells; lower epidermis often with very strongly thickened cell-walls; stomata confined to the lower surface, pericytic (occasionally polocytic), superficial to deeply sunken. Sori round to slightly elongated, sometimes confluent, occasionally forming a coenosorus; situated dorsally or terminally on the included veins, rarely at the junction with the tertiary veins, occasionally on short side-branches of the included veins ( $P$. costata-group); superficial to deeply sunken; with \pm 10 ( $P$. costata-group) to many sporangia; sporangia mostly implanted irregularly but sometimes in a concentric arrangement and maturing centripetally. Indument on the receptacle similar to that on the lamina or with more or less modified hairs in distinctly greater density, sometimes in a central bundle. Sporangia sessile to long-stalked; capsule 0.2-0.6 $\mathrm{mm}$ high, of the polypodiaceous type, glabrous; annulus with 15-22 indurated cells arranged in a regular 'bow', occasionally ( $P$. costata-group) with 9-14 indurated cells situated on the apical side of the capsule. Spores usually 64 , very rarely 32 or 128 in each capsule.

Notes. 1. Pyrrosia sect. Dichlamys: Although Ching \& Shing cite Niphobolus mollis Kze. as type of the section Dichlamys, the description of this section does not apply to that species as interpreted here. Following Ching (1935) they erroneously identify $N$. mollis with $P$. porosa. 


\section{KEY TO THE SPECIES}

Specimens marked with * are fully treated in Ravensberg \& Hennipman (1986).

1a Rhizome completely sclerified; scales basifix, cordate; spores smooth

1b Rhizome with parenchymateous ground tissue; scales pseudopeltate or peltate; spores variously ornamented .........................6 6

2a Fronds distinctly stipitate; costa narrowly grooved above; sori spread all over the lamina..................................... $49 P$. stigmosa

2b Fronds sessile, sometimes indistinctly stipitate; costa shallowly grooved or flat above; sori apical ................................ 3

3a Phyllopodia 1-2 cm distant ....................... 36 P. platyphylla

3b Phyllopodia \pm contiguous .......................................... 4

4 Hairs with erect spines, otherwise appressed ......... 48 P. splendens

4b Hairs with appressed rays, or if not, rays of one hair all \pm equally long, pointing to various directions............................... 5

5a Central bundle of collenchyma present in stipe or lower part of costa; acumen of scales dentate or ciliate, rarely entire (Celebes); indument loose or appressed ...................................39 P. princeps

5b Central bundle of collenchyma absent from stipe or lower part of costa; acumen of scales entire; indument appressed .... $12 P$. costata

6a (1) Sporangia in an (interrupted) longitudinal coenosorus ............ 7

6b Sporangia in separate, round or irregularly shaped, sometimes elongated sori (or fertile fronds absent) ......................... 14

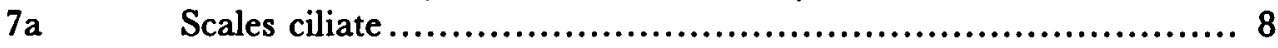

$7 \mathrm{~b} \quad$ Scales entire................................................... 12

8a Paraphyses absent or inconspicuous, free veins recurrent .......... 9

$8 \mathrm{~b} \quad$ Paraphyses abundant, free veins excurrent..................... 11

9a Apex of fertile fronds acute; coenosorus often interrupted below

$29 *$ P. niphoboloides

9b Apex of fertile fronds obtuse; coenosorus not interrupted below. 10

10a Coenosorus situated \pm medially between costa and margin, almost completely covering the width of the lamina .....21 * $P$. heterophylla

$10 \mathrm{~b}$ Coenosorus situated \pm marginally, leaving free a distinct sterile zone on both sides of the costa ..........................35* P. piloselloides

11a Paraphyses in a medial row in the sorus; fertile fronds $0.2-0.4 \mathrm{~cm}$ wide $.16^{*}$ P. fallax 
11b Paraphyses intermixed with the sporangia; fertile fronds $0.5-1.5 \mathrm{~cm}$ wide ............................................11 $P$. confluens

12a Indument monomorphic; sterile fronds conspicuously wider than the fertile ones...................................... $30^{*} P$. novo-guineae

12b Indument dimorphic; sterile fronds often absent, if present not conspicuously wider than at least the basal part of the fertile ones .. 13

13a Fertile fronds widened at the base into a $0.8-2.6 \mathrm{~cm}$ wide, sterile basal part with a narrow fertile 'apical spike'; sorus \pm superficial

$43 P$. samarensis

13b Fertile fronds not widened at the base, less than $0.7 \mathrm{~cm}$ wide throughout; sori sunken, hidden by a conspicuous fold of the margin at least when young................................ * $P$. angustissima

14a (9) Sori in a single row between costa and margin ................. 15

14b Sori in at least 2 rows between costa and margin (or fertile fronds absent $)$........................................................ 21

15a Indument dimorphic, with woolly rays present at least among the sori

15b Indument monomorphic throughout .......................... 18

16a Scales ciliate; fronds not distinctly stipitate; hydathodes present

25 P. linearifolia

16b Scales entire; fronds distinctly stipitate; hydathodes absent ...... 17

17a Acumen of scales uniformly brown; lamina to $0.7 \mathrm{~cm}$ wide

3 P. albicans

(an aberrant form occurring only on Flores; but compare also narrow forms of $P$. rasamalae)

17b Acumen of scales with a distinct hyaline margin and a dark central area; lamina $1-4.5 \mathrm{~cm}$ wide ......................... $4 P$. angustata

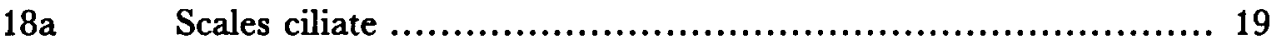

18b Scales entire or dentate ..................................... 20

19a Hydathodes conspicuous, situated near the margin on the abaxial side of the lamina; sori \pm superficial ..................... $11 P$. confluens

19b Hydathodes inconspicuous, situated on the margin of the lamina, or absent; sori distinctly sunken, often protuberant on the adaxial face

45 P. serpens

20a Scales peltate; hydathodes absent; sori 1-2.5 mm in diam., distinctly sunken; sterile fronds to 2-5 mm wide $18 P$. foveolata var. lauterbachii

20b Scales pseudopeltate; hydathodes distinct; sori ca. $1 \mathrm{~mm}$ in diam., superficial; all fronds less than $2 \mathrm{~mm}$ wide

$44 P$. schimperiana var. liebuschii

21a (14) Sori sunken in distinct pits ..................................... 22

21b Sori superficial or in shallow pits (or fertile fronds absent)...... 26

22a Paraphyses mixed with the sporangia................. $18 P$. foveolata 
Scales round or occasionally elongated, $1.3-4 \times 0.6-1.5 \mathrm{~mm}$, index 1-5; rhizome terete, $1.8-2.7 \mathrm{~mm}$ thick, terete. Scales 3.6-7.4 $\times 0.4-2.9 \mathrm{~mm}$, index 4-10; rhizome 0.8-1.5 mm thick, with a ventral groove

25a Indument dense, persistent; fronds mostly small, hardly dimorphic, $3.5-8 \times 0.7-1.4 \mathrm{~cm}$

$25 \mathrm{~b} \quad$ Indument sparse, glabrescent, fronds dimorphic, the sterile ones 3$20 \times 1.2-3.5 \mathrm{~cm}$................................. $30^{*} P$. novo-guineae

26a (21) Hydathodes absent ............................................. 27

$26 \mathrm{~b}$

Hydathodes present (note 1) Indument dimorphic, or, if monomorphic, neither closely appressed nor sparse

Lateral buds situated close to but opposite the phyllopodia

18 P. foveolata

Scales entire; sclerenchyma strands present in the rhizome (sterile plants)

Scales dentate or ciliate, if entire then sclerenchyma strands absent from the rhizome

Scales entire or dentate

$15 P$. eleagnifolia Scales ciliate

A distinct sclerenchyma strand usually present centrally in the rhizome

(these two species are difficult to distinguish in the vegetative state)

Fronds usually densely hairy on lower surface, lamina not much changing in drying $45 P$. serpens Fronds sparsely hairy, lamina strongly wrinkled after drying Indument not appressed, hairs with acicular straight rays present 35 Rhizome with a ventral groove; sclerenchyma strands absent

22 P. kinabaluensis Rhizome terete, scattered sclerenchyma strands usually present $26 P$. lingua var. heteracta 
Scales entire................................................... 36

$35 \mathrm{~b} \quad$ Scales dentate or ciliate ..................................... 38

$36 \mathrm{a}$ Scales with hyaline margin, often squarrosely recurved on young parts of the rhizome

$4 P$. angustata or

43 . samarensis

(these two species are very difficult to distinguish in the vegetative state)

36b Scales brown, not conspicuously recurved

37a Paraphyses many, persistent, mixed with the sporangia; sori 1-2.5 (-4) $\mathrm{mm}$ in diam.; lamina (1.1) $1.5-4(-5.7) \mathrm{cm}$ wide; scales $7.5-$ $14 \times(1.2-) 1.5-2.5 \mathrm{~mm}$, usually widest above the attachment

$3 P$. albicans

37b Paraphyses not differentiated; sori 1-1.5 $\mathrm{mm}$ in diam.; lamina to 1 $(-1.4) \mathrm{cm}$ wide; scales $4-9.5 \times 0.4-1.4 \mathrm{~mm}$, widest at or below the attachment ............................................. 40 P. rasamalae

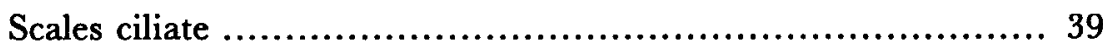

$38 \mathrm{~b}$

Scales dentate. ...

$39 a$

Fronds strongly dimorphic; sterile fronds ovate to rounded, 0.8-0.6-2 $\mathrm{cm}$; index 1-2(-4), apex rounded .............. $31 \mathrm{P}$. nummulariifolia

$39 \mathrm{~b}$

$40 a$ Fronds slightly dimorphic; sterile fronds elongate, $3-13 \times 1-1.8 \mathrm{~cm}$, index 3-8, apex acute ........................... $22 P$. kinabaluensis

$40 \mathrm{~b}$

$41 \mathrm{a}$

$41 \mathrm{~b}$ Fronds not distinctly stipitate; scales papillose at base $41 P$. rhodesiana Fronds distinctly but sometimes shortly stipitate; scales smooth . 41 Scales with long, sheathing base and a squarrose (note 2) acumen, to $1.3 \mathrm{~mm}$ wide, widest near the attachment; stipe $2-16 \mathrm{~cm}$; lamina to

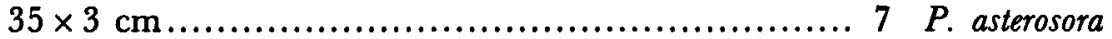
Scales not squarrose, to $3 \mathrm{~mm}$ wide, usually widest above the attachment; stipe to $2 \mathrm{~cm}$ long; lamina to $62(-97) \times 5.5 \mathrm{~cm}$

$13 P$. distichocarpa

42a (26) Hydathodes mainly marginal ................................ 43

42b Hydathodes scattered (at least on sterile fronds)................. 44

43a Scales ciliate .......................................... $11 P$. confluens

43b Scales denticulate, occasionally entire ............... 42 P. rupestris

44a Lateral buds close to and opposite the phyllopodia .. 18 P. foveolata

44b Lateral buds \pm halfway between the phyllopodia or close to the phyllopodia but on the same side of the rhizome................. 45

45a Fronds distinctly stipitate .................................... 46

45b Fronds not stipitate or at most a short distance at the base free of the gradually decurrent lamina ...................................... 61

46a Rhizome long-creeping; phyllopodia $0.5-9 \mathrm{~cm}$ apart; lateral buds halfway down the internodia or more ......................... 47 
47a Rhizome filiform, to $1 \mathrm{~mm}$ thick; scales to $0.6 \mathrm{~mm}$ wide, lamina 5$21 \times 0.5-1.3 \mathrm{~cm}$, usually slightly falcate; indument with dorsal spines (these sometimes fugacious) ......................... $23 P$. laevis

47b Rhizome 1-3.7 mm thick; scales (0.4-)0.6-1.6 mm wide; lamina not falcate; indument never with dorsal spines ....................... 48

48a Scales dentate; indument thin, \pm fugacious ......... $10 P$. christii 48b Scales with long cilia (note 3); indument dense, persistent....... 49 49a Rhizome dorsiventrally flattened, with a shallow ventral groove; sclerenchyma strands in a peripheral region of the central parenchyma

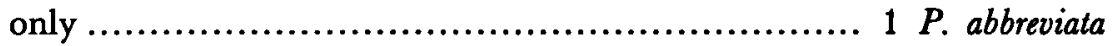

49b Rhizome terete or with a narrow ventral groove, sclerenchyma strands if present not restricted to the peripheral region of the inner

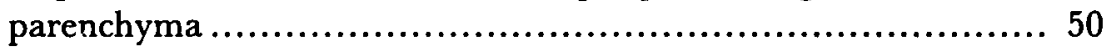

50a Acumen of scales ciliate to the apex; scales appressed or patent; indument brownish; sori mostly individually distinct when old ....... 51

50b Acumen of scales ciliate at base only, entire at the apex; scales appressed with a distinctly patent, crisped apex; indument whitish; sori pseudo- acrostichoid when old ....................47 $P$. sphaerosticha

51a Indument dimorphic ..................... 26 P. lingua var. heteracta

51b Indument monomorphic .................................... 52

52a Scales 2.2-4.4 $\times$ 0.6-1 mm, with up to $150 \mu \mathrm{m}$ long, rather clear cells in the apex; lamina $1-10 \times 0.5-3.3 \mathrm{~cm}$, index 1-5; hydathodes pitted

$34 P$. petiolosa

52b Scales $(2.2-) 4-7(-8) \times 0.7-1.5 \mathrm{~mm}$, with up to $350 \mu \mathrm{m}$ long, obscure cells in the apex; lamina $5-22 \times 0.8-5.5 \mathrm{~cm}$, index 2-12; hydathodes mostly superficial.......................... $26 P$. lingua var. lingua

$53 a(46)$ Scales entire or dentate; indument dimorphic ................... 54

$53 \mathrm{~b} \quad$ Scales (shortly) ciliate; indument mono- or dimorphic ............ 55

54a Phyllopodia 2-8 mm distant; sclerenchyma strands absent; lamina 7$12 \times 1.7-3.7 \mathrm{~cm}$, elliptic ......................... $32 P$. pannosa

54b Phyllopodia contiguous; sclerenchyma strands present; lamina 12.5$32 \times 1.5-7.8 \mathrm{~cm}$, often slightly lyrate ................ $17 P$. flocculosa 55a Lamina hastately or pedately dissected; indument monomorphic 56

$55 \mathrm{~b}$ Lamina simple or slightly lobed at the base; indument mono- or dimorphic....................................................... 57

56a Lamina hastate, with 3-5 divisions including the small teeth at the base; the middle lobe $3-11 \times 1.5-3.5 \mathrm{~cm}$, index $2-3 ; 20 P$. hastata 56b Lamina pedately divided into 6-8 divisions including the small teeth at the base; the middle lobe $6-14 \times 1-2 \mathrm{~cm}$, index 4-10;

37 P. polydactyla 


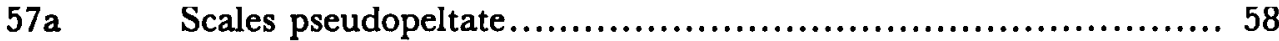

57b Scales peltate ................................................... 62

58a Indument monomorphic; rays of the hairs boat-shaped $46 P$. sheareri

58b Indument dimorphic, rays of the hairs mostly acicular........... 59

$59 \mathrm{a}$ Indument thin, greyish, often fugacious ......... $51 P$. subfurfuracea

59b Indument brown, persistent.................................. 60

60a Stipe (0.5) 1-2 $x$ as long as the lamina; lamina 8-25 $\times 2.4-8 \mathrm{~cm}$, index mostly 3; base usually truncate, often unequal; sori usually completely immersed in the indument; stomata distinctly raised $14 P$. drakeana

60b Stipe $0.5-1 \times$ as long as the lamina; lamina $12-37 \times 4-7.5 \mathrm{~cm}$, index mostly \pm 5 ; base usually cuneate, more or less equal; sori somewhat emergent from the indument; stomata slightly sunken.. $8 P$. boothii

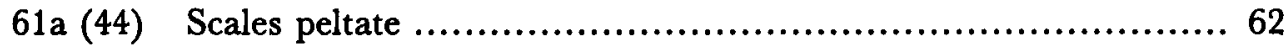

$61 \mathrm{~b} \quad$ Scales pseudopeltate............................................ 69

$62 \mathrm{a}(56,60)$ Indument monomorphic, woolly hairs if present only among the sori

62b Indument dimorphic, woolly hairs present also well away from the soriferous area .................................................. 65

63a Rays of one hair very unequal; lamina linear; $0.3-1.1 \mathrm{~cm}$ wide

$6 P$. assimilis

63b Rays of one hair all equal or differing at most by a factor 2 in length; lamina $0.7-3.5 \mathrm{~cm}$ wide ........................................ 64

64a Phyllopodia 0.5-2 cm distant; sclerenchyma strands absent

$41 P$. rhodesiana

64b Phyllopodia to $0.5 \mathrm{~cm}$ distant; sclerenchyma strands presen

38 P. porosa

65a Anticlinal walls of hypoderm in cross-section strongly thickened; phyllopodia very prominent, to $2.5 \mathrm{~cm}$ high; scales $1.6-4.2 \times 1-1.6$ $\mathrm{mm}$, index 3-5, shining black........................ $19 P$. gardneri

65b Anticlinal walls of hypoderm in cross-section not strongly thickened; phyllopodia not very prominent, to $10 \mathrm{~mm}$ high; scales $1.4-10 \times 0.5-2$ $\mathrm{mm}$, index 2-10, dull brown or blackish ...................... 66 66a Phyllopodia to $0.5 \mathrm{~cm}$ apart ........................... $38 P$. porosa 66b Phyllopodia $0.5-2 \mathrm{~cm}$ apart...................................... 67 67a Fronds narrow, 1-5 mm wide...................... $25 P$. linearifolia 67b Fronds wider, $8-30 \mathrm{~mm}$ wide ............................... 68 68a Scales ciliate, appressed; indument greyish ............ 50 P. stolzii 68b Scales dentate, patent; indument brown ............ $41 \quad P$. rhodesiana 69a (60) Sclerenchyma sheath present; phyllopodia usually contiguous ... 70 69b Sclerenchyma sheath absent; phyllopodia $0.5-2 \mathrm{~cm}$ apart ........ 72 70a Indument monomorphic; scales dentate ........... $33 \mathrm{P}$. penangiana 70b Indument dimorphic (sometimes fugacious); scales entire or ciliate 71 
71a Scales entire; indument persistent; sporangia sessile... 28 P. mannii 71b Scales ciliate; indument fugacious; sporangia stalked

$51 P$. subfurfuracea

72a Indument appressed, whitish; rays of hairs boat- shaped; scales 2.8$8 \times 0.9-1.9 \mathrm{~mm}$, slightly dentate ................44 $P$. schimperiana

72b Indument shaggy, brown; rays of hairs acicular; scales 7-9 2 2-3 mm, strongly dentate ....................................... $2 P$. africana

Notes. 1. Hydathodes are sometimes present only in a marginal row, sometimes on the abaxial side of the margin.

2. The difference between a squarrose scale and other scales is most easily seen if a scale is flattened under a coverslip; a squarrose scale will remain folded in some way.

3. The cilia may be lost on older scales, they should be searched for on young or protected parts of the rhizome. 


\section{DESCRIPTIONS}

\section{Pyrrosia abbreviata (Zoll. Moritzi) Tagawa. Fig. 22, 29.}

Pyrrosia abbreviata Tagawa, Acta Phytotax. Geobot. 25 (1973) 180; Hovenkamp, Blumea 30 (1984) 208. - Niphobolus abbreviatus Zoll. Moritzi, Nat. \&en. Arch. 1 (1844) 397; Kunze, Bot. Zeit. (1848) 121; Giesenh., Niphobolus (1901) 160.-Sphaerostichum abbreviatum Presl, Epim. Bot. (1851) 135.-Polypodium abbreviatum Mett., Fil. Lips. (1856) 33; [non Polypodium abbreviatum (Fée) C. Chr., Ind. Fil. Suppl. 2 (1917), nom. illeg., = Lemmaphyllum abbreviatum (Fée) C. Chr.]; Mett., Polyp. (1856) 131; Mett., Ann. Mus. Lugd. Bat. 2 (1866) 232; Racib., Pterid. Buitenz. (1898) 98. - Cyclophorus abbreviatus C. Chr., Ind. Fil. (1906) 197; Alderwerelt, Malayan Ferns (1909) 692; Backer \& Posth., Varenfl. Java (1939) 241.-Lect ot y pe: Zollinger 1984 (holo P; iso B, Z), Java, 'In arboribus prope Djamba Deepa'.

Polypodium lingua auct. non (Thunb.) Swartz: Baker, J. Bot. Lond. 18 (1880) 214.

Rhizome long-creeping, shallowly grooved ventrally, 2.9-3.6 mm thick; phyllopodia (2-)4-8 cm apart, lateral buds situated \pm halfway down the internodia. Anatomy: ground tissue parenchymatous, sclerenchyma sheath distinct, sclerenchyma strands situated peripherally in the inner parenchyma, 15-20; vascular strands 9-12. Scales peltate, 3-7 × 1-1.3(-1.5) mm; base entire; acumen shining brown to blackish with a distinct lighter margin, with relatively long, curly marginal cilia. Fronds moderately dimorphic, distinctly stipitate. Fertile fronds: stipes $8-26 \mathrm{~cm}, 1-2 \frac{1}{2} \times$ as long as the lamina; lamina, index 2-3(-7); widest at or below the middle, $5-10 \times(1-) 3-5 \mathrm{~cm}$, base cuneate to truncate, apex rounded to acuminate. Sterile fronds: stipes $(2-) 5-17(-30) \mathrm{cm}, 1 / 2-3 \times$ as long as the lamina; lamina, index $1 \frac{1}{2}-2(-3)$; otherwise similar to the fertile ones. Venation: secondary veins distinct, with the tertiary veins forming regular areoles; included veins much branched and strongly anastomosing, forming a distinct row of 'costular' areoles along the secondary veins; free veins relatively few, pointing to all directions. Hydathodes distinct, scattered over the lamina, superficial to slightly prominent. Anatomy: stipe with 6-10 central and 1-2 lateral vascular strands; lamina $0.5-0.8 \mathrm{~mm}$ thick, upper epidermis with slightly projecting cells with thin or slightly thickened walls, hypodermis absent but a distinct, moderately thick water-tissue present, palissade and spongy parenchyma distinct, lower epidermis with strongly thickened cell-walls; stomata sunken, pericytic. Indument monomorphic, a dense mat, persistent, dirty whitish; hairs 0.4-0.5 mm in diam. with appressed, boat-shaped rays. Sori situated all over the lamina or in a sharply defined, irregularly shaped patch, closely packed, superficial; many in each soriferous areole, often confluent along the veins; developing 


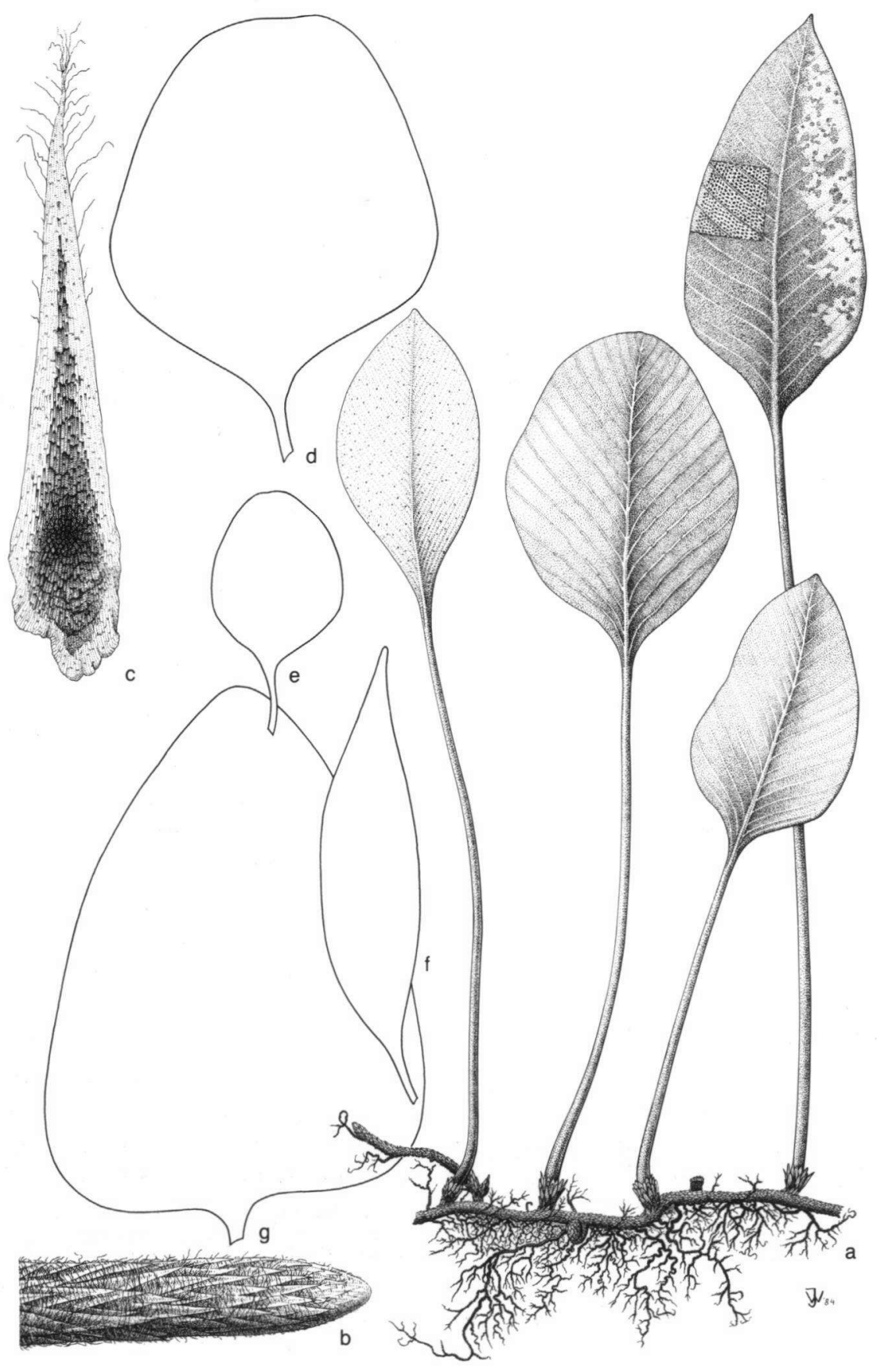

Fig. 29. P. abbreviata. a. Habit $\times 1 / 2 .-$ b. Apex of rhizome $\times 4 .-$ c. Rhizome scale $\times 14 .-$ u-y. Vartation in trond outline $\times 2 / 5-2 / 3$. (a. De Wilde c.s. 12709, L; - b. cult. Leiden Bot Garden; - c. Jacobson s.n., L; - d. Alston 13846, BM; - e. Giesenhagen 15, M; - f. Schmutz 146, L; g. Goebel s.n., M). 
all more or less simultaneously, when old pseudoacrostichoid, exserted from the indument. Sporangia on stalks $1-1 \frac{1}{2} \times$ as long as the capsule, capsule $0.3-0.4$ $\mathrm{mm}$ high, with 15-24 indurated annulus cells. Paraphyses not differentiated. Spores (68-)70.4-82.4(-92) $\times(46-) 49.8-64.4(-74) \mu \mathrm{m}$, coarsely tuberculate.

Habitat: Epiphytic or epilithic, usually in more or less disturbed or exposed sites (lakesides, cliffs, solitary trees, etc.), locally very common.

Altitudinal range: $350-1500 \mathrm{~m}$.

SUMATRA. 39 collections.

JAVA. Ernst 69 (Z), Hancock s.n., (1892) (BM, K), Holstvoogd 381 (BM, L), Junghuhn s.n., s.d. (L), Nagler 420 (B), Raciborski s.n. (6-1898) (BO, M, P), Rawson 1282 (BM), De Vriese Teysmann (171 ?) (L).

LESSER SUNDA ISLANDS. Sumbawa: Warburg 17230 (B). - Flores: 9 collections. - Timor: $\mathrm{Da}$ Castro 32 (BO).

Notes. 1. The \pm orbicular fronds with long stipes are characteristic. Plants with relatively narrower fronds that are attenuate at both ends occur, especially on Flores (Warburg 127; Schmutz 0146. fig. 29 f: Schmutz 5117). These are superficially similar to $P$. sphaerosticha and can best be distinguished from that species by the characteristic rhizome scales.

2. The scales on the phyllopodia often form a distinct tuft around the base of the stipe. They are wider and more flaccid than the stiff, brittle, appressed scales on the rhizome.

\section{Pyrrosia africana (Kunze) Ballard. Fig. 16, 30.}

Pyrrosia africana Ballard, Kew Bull. (1937) 349; Schelpe, J. S. Afr. Bot. 18 (1952) 124; Jacobsen, Ferns and Fern All. S. Africa (1983) 303, fig. 218, map 91.-Niphobolus africanus Kunze, Linnaea 10 (1836) 501; Fée, Gen. Fil. (1853) 263; T. Moore, Ind. Fil. (1857) lxxvi; Pappe * Rawson, Syn. Fil. (1858) 41; Keyserl., Polyp. Herb. Bunge (1873) 38; J. Sm., Hist. Fil. (1875) 98; J. Sm., Ferns Br. For. ed. 2 (1877) 296; Diels in E. \& P., Nat. Pfl. Fam. 1,4 (1899) 325; Giesenh., Niphobolus (1901) 177; Engl., Veg. d. Erde 9,2 (1908) 55.-Niphobolus africanus var. major Kunze, Linnaea 10 (1836) 501 nom. illeg. -Gyrosorium africanum Presl, Epim. Bot. (1851) 140.-Polypodium africanum Mett., Polyp. (1856) 131, pl. 3 fig. 11, 12; [non Desv., Mém. Soc. Lin. Par. 6 (1827) 239; = Thelypteris pozoi (Lagasca) Morton]; Hooker, Sp. Fil. 5 (1863) 46; Baker in Hooker Baker, Syn. Fil. (1867) 352; Kuhn, Fil. Afr. (1868) 145.-Cyclophorus africanus C. Chr., Ind. Fil. (1906) 197; Christ, Geogr. Farne (1910) 112, Bonap., Notes Ptérid. 7 (1918) 321.- Lec to t y pe: Drege 3860 (22-5-1832) (holo B, iso in BM, L, P,WAG), S. Africa, prope missionis coloniam inter Omgaziana et Omtata, in praerupto rupestris, alt. 800 ped.'.

Niphobolus africanus var. minor Kunze, Linnaea 10 (1836) 501.-Lect ot ype: Drège s.n., (22-5-1832) (holo B, iso BM, L, P, WAG), S. Africa, 'prope missionis coloniam inter Omgaziana et Omtata, ad truncos arborum'.

Rhizome shortly elongated, not grooved ventrally, 3-4 $\mathrm{mm}$ thick; phyllopodia $0.5-2 \mathrm{~cm}$ apart, lateral buds situated close to the phyllopodia. Anatomy: ground tissue parenchymatous, sclerenchyma sheath and sclerenchyma strands absent; 

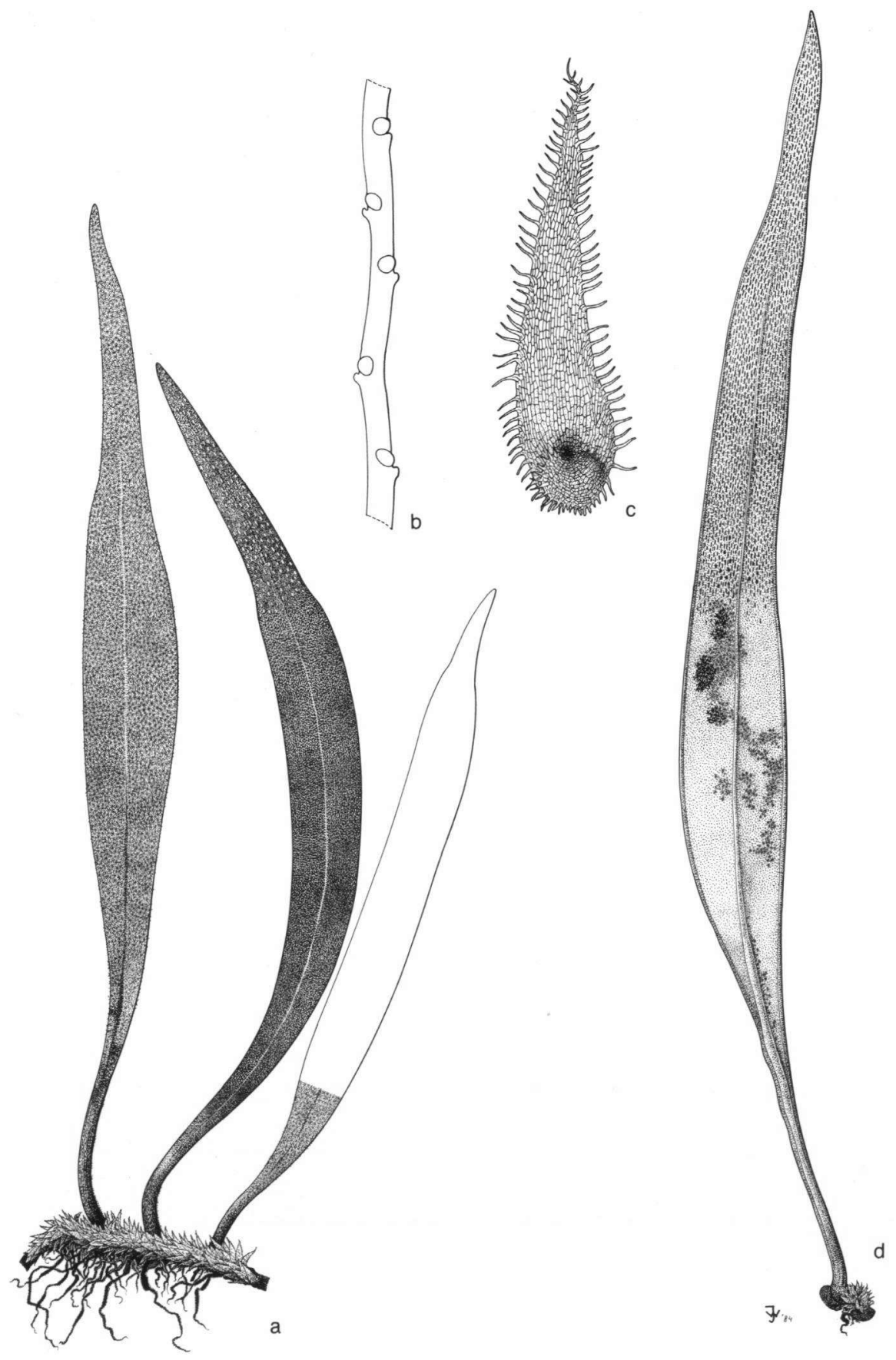

Fig 30. P. africana. a. Habit $\times 1 / 2 .-$ b. Rhizome, scales removed $\times 2 / 3 .-$ c. Rhizome scale $\times$ 7.J. - u. Feriü irond, hairs and sporangia removed $\times 1 / 2$. (a, b. Drège s.n., L; - c. Eshowe 12625, M; - d. Rawson 943, BM). 
vascular strands 9-12. Scales pseudopeltate, 7-9 7 2-3 mm; coarsely dentate; acumen light brown, dull. Fronds monomorphic, sessile, index 7-15, widest above the middle, 8-33 $\times 1-3 \mathrm{~cm}$, base gradually narrowed to the phyllopodium, apex acute. Venation: secondary veins indistinct, with the tertiary veins forming an irregular pattern; included veins much branched and often anastomosing; free veins many, pointing to all directions. Hydathodes absent. Anatomy: lower part of costa with \pm 3 central and \pm 4 lateral strands; lamina 0.5-0.9 mm thick, upper epidermis with slightly projecting cells with slightly thickened walls, hypodermis absent but an indistinct, moderately thick water-tissue present, palissade and spongy parenchyma indistinct, lower epidermis with slightly to strongly thickened cell-walls: stomata superficial. polocytic. Indument monomorphic, a dense, shaggy mat, persistent, dirty whitish to cinnamon-brown; hairs 1.3-2.6 mm in diam., with patent, acicular to sinuose rays. Sori apical, in a more or less sharply defined patch, closely packed, superficial; many scattered throughout each soriferous areole, occasionally confluent along the veins, 0.5-1 $\mathrm{mm}$ in diam.; when old individually distinct, immersed in the indument. Sporangia on stalks $1 / 2-3 / 4 \times$ as long as the capsule, capsule $0.25-0.3 \mathrm{~mm}$ high, with 12-17 indurated annulus cells. Paraphyses not differentiated. Spores (54-)57.4(-68) x(38-)40(-44) $\mu \mathrm{m}, \pm$ smooth.

Habitat: Epiphytic, sometimes epilithic; in forest. Often in coastal forest but not confined to it.

Altitudinal range: Low altitudes.

\section{REPUBLIC OF SOUTH AFRICA. 17 collections.}

Notes. 1. The often slightly asymmetric, falcate fronds are characteristic. They are somewhat similar in outline to the juvenile foliage fronds of Platycerium. The soriferous region is often somewhat contracted.

2. $P$. africana is strictly confined to the "'Tongaland-Pondoland Regional Mosaic" of the Indian Ocean Coastal Belt, an area with a high degree of endemism (Werger in Werger, M.J.A. (ed.), 1978. Biogeography and ecology of southern Africa, 145-170. W. Junk, The Hague).

\section{Pyrrosia albicans (Blume) Ching. Fig. 24}

Pyrrosia albicans Ching, Bull. Chin. Bot. Soc. 1 (1935) 72. - Niphobolus albicans Bl., Enum. Pl. Jav. (1828) 107; Blume, Fl. Jav. Fil. (1829) 60, pl. 25; Presl, Tent. Pterid. (1836) 202; Fée, Gen. Fil. (1853) 262; T. Moore, Ind. Fil. (1857) lxxvi; J. Sm., Hist. Fil. (1875) 98; Giesenh., Niphobolus (1901) 185. - Cyclophorus albicans Presl, Epim. Bot. (1851) 131; T. Moore, Ind. Fil. (1861) 275; C. Chr., Ind. Fil. (1906) 197; Alderwerelt, Malayan Ferns (1909) 688; Backer Posth., Varenfl. Java (1939) 242.-Polypodium albicans Mett., Polyp. (1856) 127; Hooker, Sp. Fil. 5 (1863) 51; Mett., Ann. Mus. Lugd. Bat. 2 (1866) 231; Baker in Hooker \& Baker, Syn. Fil. (1867) 352; Racib., Pterid. Buitenz. (1898) 101. - Lectoty pe: Keinwardt s.n., s.d. (holo L, sheet nr. 908.329 - 1031, iso B?), Java, Mt. Siembar. 
Niphobolus flocciger 3lume, Enum. Pl. Jav. 2 (1828) 107; Blume, Fl. Jav. Fil. (1829) 61, pl. 26; Presl, Teni. Pierid. (1836) 202; Fée, Gen. Fil. (1853) 262; Bedd., Suppl. Ferns S. \& Br. Ind. (1876) 22, pl. 386 q.n.s.; Bedd., Handb. ferns Brit. Ind. (1883) 331, q.n.s.; Diels in E. \& P., Nat. Pfl. Fam. 1,4 (1899) 325, q.n.s.; Giesenh., Niphobolus (1901) 189, q.n.s.; Copeland, Polyp. Philipp. (1905) 113, q.n.s.; Copeland, Fern Fl. Philipp. (1960) 473, q.n.s.--Cyclophorus flocciger Presl,

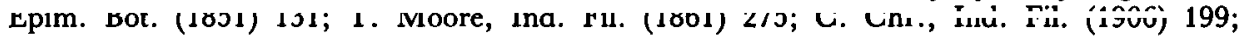
Alderwerelt, Malayan Ferns (1909) 687, q.n.s. Backer * Posth., Varenfl. Java (1939) 243.Polypodium floccigerum Mett., Polyp. (1856) 129; Baker in Hooker Baker, Syn. Fil. (1867) 351 q. n.s.; Baker, Ann. Bot., Lond. 5 (1891) 472, q.n.s.; Racib., Pterid. Buitenz. (1898) 101, q.n.s.; Giesenh., Niphobolus (1901) 189.-Polypodium floccigerum var. latifolium Mett., Polyp. (1856) 129 nom. superfl. - Polypodium fissum var. floccigerum C. B. Clarke, Tr. Linn. Soc. II Bot. 1 (1880) 425, q.n.s.; Pyrrosia floccigera Ching, Bull. Chin. Bot. Soc. 1 (1935) 71; Holttum, Fl. Malaya 2 (Ferns) (1954) 147, q.n.s. - Lectoty pe (see note 3): Anon. (Blume?), (holo L, sheet no. 916.68-31), sine loco

Niphobolus flocciger var. loriformis Kunze, Bot. Zeit. (1848) 120; Giesenh., Niphobolus (1901) 189.Polypodium floccigerum var. loriforme Mett., Polyp. (1856) 129; Hooker, Sp. Fil. 5 (1863) 45; Mett., Ann. Mus. Lugd. Bat. 2 (1866) 231. - Lectotype: Zollinger 2022 (holo L, iso in BO), Java, see note 4.

Niphobolus blumeanus Kunze, Bot. Zeit. (1848) 120; T. Moore, Ind. Fil. (1861) 275.-Cyclophorus blumeanus Presl, Epim. Bot. (1851) 130 . - Ty pe: Zollinger 2387 (L, BM, P), Java.

Cyclophorus lancifolius Alderwerelt, Bull. Jard. bot. Buitenz. II, 23 (1916) 8; Alderwerelt, Malayan Ferns Suppl. (1917) 414; C. Chr., Ind. Fil. Suppl. 3 (1934) 65.-T y pe: Ajoeb 329 (BO), Sumatra.

Cyclophorus nigropunctatus Rosenst., Meded. Rijks Herb. 31 (1917) 4; C. Chr., Ind. Fil. Suppl. 3 (1934) 65.-Type: Korthals s.n, s.d. (L, sheet no. 916.68-21), Sumatra.

Cyclophorus elaphoglossoides Alderwerelt, Bull. Jard. bot. Buitenz. III, 2 (1920) 139; C. Chr., Ind. Fil. Suppl. 3 (1934) 65. - I sot y pes: Bünnemeijer 4825 (BO), 4970 (BO), Sumatra.

Rhizome long-creeping, not grooved ventrally, 3-4 mm thick, phyllopodia 3-9 cm apart, lateral buds situated \pm halfway down the internodia. Anatomy: ground tissue parenchymatous, sclerenchyma sheath distinct, sclerenchyma strands scattered through the inner parenchyma, 0-20 or more; vascular strands 7-11. Scales peltate, 8-14 $\times 1.5-2.5 \mathrm{~mm}$; entire, shining brown. Fronds monomorphic, stipitate; stipe $2-27 \mathrm{~cm}, 1 / 10-1 / 5(-1 / 2) \times$ as long as the lamina; lamina, index 10-12 ( \pm linear); widest about the middle, $22-65 \times(1.1-) 1.5-4.0(-5.7) \mathrm{cm}$, base cuneate, apex obtuse to acute. Venation: secondary veins distinct, with the tertiary veins forming regular areoles; included veins simple or occasionally forked, free, excurrent. Hydathodes absent. Anatomy: stipe with 4-8 central and no lateral vascular strands; lamina $\pm 0.6 \mathrm{~mm}$ thick, upper epidermis with flat cells with strongly thickened walls, hypoderm absent or composed of 1 cell-layer, water-tissue distinct, thick, palissade and spongy parenchyma distinct, lower epidermis with strongly to very strongly thickened cell-walls; stomata sunken, pericvtic. Indument dimorphic, a dense mat, persistent, whitish to brown; upper layer composed of hairs $0.5-1.3(-1.6) \mathrm{mm}$ in diam., with erecto-patent, acicular rays, \pm mixed with a lower layer composed of hairs with mainly woolly rays. Sori apical, closely packed, in a sharply defined patch, superficial; 3-4 in a row in each soriferous areole, 1-2.5 mm in diam.; when old individually distinct, exserted from the indument. Sporangia on stalks $1-21 / 2 \times$ as long as the capsule, capsule 0.3-0.4 mm high, with 15-21 indurated annulus cells. Paraphyses present, mixed 
with the sporangia, with long, curly rays. Spores (64-)71.2-77.8(-94) $\times(46-)$ $52.6-60.0(-70) \mu \mathrm{m}$, with irregular ridges and protuberances.

Habitat: Epiphytic (sometimes as a high epiphyte), mostly in primary forest, but also on roadside trees, in abandoned coffee-plantations, etc.; occasionally epilithic or terrestrial. In everwet to seasonally dry areas.

Altitudinal range: $900-1800 \mathrm{~m}$.

SUMATRA. Ajoeb 329 (BO), Brooks $69 \mathrm{~J}$ (BM), Bünnemeijer 4825 (BO), Forbes 2547 B (B, BM, BO, L, P), Korthals 236 (B, L), Van Steenis 3884 (BO, L).

JAVA: many collections.

LESSER SUNDA ISLANDS. Bali: 10 collections. - Sumbawa: Zollinger s.n., (10-1847) (L). - Flores: Jaag 1831 (BO, L), Posthumus 3216 (BO), Rensch 1525 (B, BO), Schmutz F 135 (L), Verheijen 1579 (L), 1580 (L).

Notes. 1. Four plants from Flores, all from around Ruteng (Jaag 1831, Schmutz F 135, Verheijen 1579, 1580;1400-1900 $\mathrm{m}$ alt.) differ in having only a single row of relatively large (2-3 $\times 2-4 \mathrm{~mm})$ sori on each side of the costa. They differ from typical $P$. albicans also in the following aspects: - Scales smaller (7.5-9.1 $\times 1.2-$ $1.4 \mathrm{~mm})$; - lamina narrower $(0.3-0.7 \mathrm{~cm}) ;-$ indument more shaggy (hairs to $2.0 \mathrm{~mm}$ in diam.). Another collection from another locality on Flores (Rensch 1525, from Geli Moetoe, alt. $1500 \mathrm{~m}$ ) is intermediate between this form and typical $P$. albicans: it has two rows of distinctly separate sori, comparable to the arrangement in $P$. asterosora, somewhat wider fronds but narrow rhizome scales. More intensive exploration on Flores is necessary to decide whether the form represents a distinct taxon or whether it grades into $P$. albicans.

2. The rhizome scales usually are widest above the point of attachment.

3. Niphobolus flocciger Blume. The specimens on which $N$. flocciger Blume was based seem to have been lost. In L there is only a small scrap left which is annotated in Blume's handwriting; it is clearly conspecific with $P$. albicans. Moreover, the plant depicted in the Flora Javae as N. flocciger (Plate 26) is also undoubtedly $P$. albicans as here construed.

According to Giesenhagen the types (1901, p. 189) were sent to Buitenzorg (Bogor), where he studied them and found them to be conspecific with $\mathrm{N}$. rasamalae $\mathrm{Racib}$. It is possible, though, that Giesenhagen, who did not pay much attention to types (compare his treatment of Polypodium serpens Forster!), did not refer to types of $\mathrm{N}$. flocciger but to some specimens later identified by Blume.

4. N. flocciger var. loriformis Kunze. Zollinger 2022 and 2022A, syntypes of this variety, are mixtures. They are represented in $\mathrm{L}$ and $\mathrm{BO}$ by specimens of, i. a., $P$. albicans, in several other herbaria $(\mathrm{B}, \mathrm{BM}, \mathrm{E}, \mathrm{L}, \mathrm{P}, \mathrm{Z})$ specimens of $P$. rasamalae, and in B there is also a specimen that is no Pyrrosia at all. As Kunze's types have been destroyed (Stafleu \& Cowan, Tax. Lit. II), I have lectotypified the variety in a way that does not differ substantially from the interpretation of the type variety. 
5. Much confusion of the present species with Pyrrosia penangiana (Hooker) Holttum and $P$. porosa (Presl) Hovenk. seems to have been due to another mixed collection by Zollinger. Zollinger 3183, syntype of $N$. mollis Kunze, in most herbaria is represented by specimens of $P$. penangiana, but in $\mathrm{K}$ by a specimen of $P$. albicans, and in $\mathrm{P}$ by specimens of $P$. rasamalae and $P$. lanceolata.

\section{Pyrrosia angustata (Swartz) Ching. Fig. 24}

Pyrrosia angustata Ching, Bull. Chin. Bot. Soc. 1 (1935) 49; Holttum, Fl. Malaya 2 (Ferns) (1954) 143, fig. 58; Copeland, Fern Fl. Philipp. (1960) 470; Tagawa, Acta Phytotax. Geobot. 22 (1967) 185; Tagawa Iwats., Acta Phytotax. Geobot. 23 (1968) 52; Hoshizaki, Baileya 21 (1981) 57, fig. 1; Shing, Amer. Fern J. 73 (1983) 76, fig. 1, 11. - Polypodium angustatum Swartz, Syn. Fil. (1806) 27, 224; [non Blume, Fl. Jav. Fil. (1829) 148 pl. 162, = Crypsinus taeniatus (Swartz) Copeland]; Schkuhr, Krypt. Gew. 1 (1809) 187, pl. 8c fig. a; Willd., Sp. Pl. 5 (1810) 154; Hooker, Sp. Fil. 5 (1863) 43; Mett., Ann. Mus. Lugd. Bat. 2 (1866) 230; Baker in Hooker Baker, Syn. Fil. (1867) 356; C. B. Clarke, Tr. Linn. Soc. II Bot. 1 (1880) 559; Baker, Ann. Bot., Lond. 5 (1891) 475; Drake, Fl. Polyn. fr . (1893) 312 q.n.s.; Christ, Verh. Nat. Ges. Basel 11 (1897) 245, 445; Racib., Pterid. Buitenz. (1898) 100.-Cyclophorus angustatus Desvaux, Mag. Ges. Naturf. Freunde Berlin (Berl. Mag.) 5 (1811) 300 nom. inval., (ICBN art. 33.1); T. Moore, Ind. Fil. (1861) 275 nom. inval., (ICBN art. 34.4); C. Chr., Ind. Fil. (1906) 198; Alderwerelt, Malayan Ferns Suppl. (1917). 413; Copeland, Saraw. Mus. Journal 2 (1917) 410; Holttum, J. Mal. Br. As. Soc. VI (1928) 20; Dickason, Ohio J. Sc. 46 (1946) 129.-Niphobolus angustatus Spr., Syst. 4 (1827) 44; T. Moore, Ind. Fil. (1857); T. Moore, Ind. Fil. (1862); Hooker, Garden Ferns (1862) pl. 20; Bedd., Ferns S. India (1864-5) 62, pl. 185; Keyserl ., Polyp. Herb. Bunge (1873) 38; Bedd., Suppl. Ferns S. \& Br. Ind. (1876) 22; Diels in E. P., Nat. Pfl. Fam. 1,4 (1899) 326; Giesenh., Niphobolus (1901) 193; Copeland, Polyp. Philipp. (1905) 115. - Drynaria angustata Fée, Gen. Fil. (1853) 270.-Niphopsis angustata J. Sm., Cat. Cult. Ferns (1857) 6; J. Sm., Hist. Fil. (1875) 105; (type of Niphopsis J. Sm.).-Pleopeltis angustata Presl, Tent. Pter. (1836) 193; [non (Blume) T. Moore, Ind. Fil. (1857) lxxviii, = Crypsinus taeniatus (Swartz) Copeland]; Presl, Epim. Bot. (1851) 126. - Polypodium coriaceum Roxb., Calc. J. Nat. Hist. IV (1844) 481, pl. 28 nom. superfl.; Morton, Contr. U.S. Nat. Herb. 38 (1964) 339.-T y pe: Rottler s.n, s.d., Trankebar (holo S, not seen), India? (probably erroneous).

Niphobolus sphaerocephalus Hooker * Grev., Ic. Filic. (1828) pl. 94.-Polypodium sphaerocephalum Wallich, Cat. (1828) no. 272; Mett., Polyp. (1856) 122, pl. 3 fig. 5.-Phymatodes sphaerocephala Presl, Tent. Pter. (1836) 196.-T y pe: Wallich 272 (BM, BR, E, K, L), India.

Cyclophorus micraster Copeland, Univ. Calif. Publ. Bot. 12 (1931) 405; C. Chr., Ind. Fil. Suppl. 3 (1934) 65.-Pyrrosia micraster Tagawa, J. Jap. Bot. 22 (1949) 163.-Ty pe: Moh. Nur 12060 (K, SING), Malaya.

Rhizome long-creeping, not grooved ventrally, 1.4-2.6 mm thick, phyllopodia 2-7 cm apart, lateral buds situated \pm halfway down the internodia. Anatomy: ground tissue parenchymatous, sclerenchyma sheath distinct, sclerenchyma strands \pm 15 , often confluent, situated peripherally in the inner parenchyma; vascular strands 5-11. Scales peltate, 5-10(-11) $\times 0.5-1.0 \mathrm{~mm}$; base entire; acumen shining, hyaline, entire or dentate. Fronds dimorphic, stipitate. Fertile fronds: stipes $0.5-15(-25) \mathrm{cm}$, to $1 / 2(-3 / 4)$ as long as the lamina; lamina, index 5 to over 20; widest below the middle, $8-44 \times 1-3.5 \mathrm{~cm}$; base cuneate, decurrent; apex acute to acuminate. Sterile fronds: stipes $0.5-9 \mathrm{~cm}$, to $\pm 1 / 2$ as long as the lamina; lamina, index 2-7; widest about the middle, 5-22 $\times 1.5-4.5 \mathrm{~cm}$; other- 
wise similar to the fertile ones. Venation: secondary veins distinct, with the tertiary veins forming regular areoles; included veins frequently forked or more copiously branched, frequently anastomosing; free veins many, mostly excurrent. Hydathodes absent. Anatomy: stipe with 3-6 central and no lateral vascular strands; lamina $0.5-1.5 \mathrm{~mm}$ thick, upper epidermis with flat cells with slightly to very strongly thickened walls, hypodermis absent but a distinct, moderately thick water-tissue present, palissade and spongy parenchyma distinct, lower epidermis with strongly to very strongly thickened cell-walls; stomata sunken, pericytic. Indument dimorphic, a thin to thick mat, often fugacious, light whitish brown; upper layer composed of hairs $0.4-1.0 \mathrm{~mm}$ in diam., with erecto-patent or appressed, boat-shaped to acicular rays, mixed with a lower layer composed of hairs with mainly woolly rays. Sori apical to all over the lamina, separate, in a single row between margin and costa, slightly sunken, one in each soriferous areole, 3-4 mm wide, often elongate, to $7 \mathrm{~mm}$ long; developing from the apex downwards, when old exserted from the indument. Sporangia on stalks 2-3 $\times$ as long as the capsule or sometimes longer, capsule $0.3-0.4 \mathrm{~mm}$ high, with 16-19 indurated annulus cells. Paraphyses present, mixed with the sporangia, with short, straight rays. Spores (72-)82.6-94.4(-98) × (46-) 48.0-58.4(-68) $\mu \mathrm{m}$, with longitudinal ridges.

Habitat: Epiphytic in various situations, in primary or secondary forest, in dipterocarp forest, along roadsides, in open places; also epilithic or terrestrial, on sand. Once collected from a tile roof. Mainly restricted to the everwet lowlands. Altitudinal range: Sea-level to $900 \mathrm{~m}$.

THAILAND. Peninsular: Larsen \&arsen 32702 (K, L), Sangkhachand Nimanong 1265 (K, L), Eryl Smith 2006 (K, SING), Smitinand 10914 (K, L).

SUMATRA. Sumatra: 28 collections. - Batu Is.: Raap 583 (BO). - Mentawei Is.: Van Borssum Waalkes 2606 (BO), 2643 (BO, L), Iboet 59 (BO), 128 (BO, L, SING). - Bangka: Bünnemeijer 1659 (BO, L), 1993 (BO), Kostermans 96 (BO, L), 138 (BO, L), 324 (BO, L), Teysmann 40 (L), 43 (L), 45 (L). - - Lingga Arch.: Bünnemeijer 6802 (BO, L, P), 7271 (BO, L, U).

MALAYA, incl. P. Penang and Singapore. 65 collections.

BORNEO. Borneo: 24 collections. - Anambas \& Natuna Is.: Van Steenis 999 (BO, L).

MOLUCCAS. Morotai: Main * Aden 1508 (BO).

Doubtful localities.

HONGKONG. Robinson s.n., (6-1925) (K).

JAVA. Göbel s.n., s.d. (M), Hillebrand s.n., s.d. (B), Zollinger 3098 (BM).

NEW GUINEA. Treub s.n., s.d. (BO).

Notes. 1. Older fronds that have lost the indument may be confused with $P$. serpens Forster. $P$. angustata, however, is distinct in the entire rhizome scales.

2. In Wright Ismawi 32554 there are several rows of sori between costa and margin. This probably atavistic feature suggests an origin of the single, large, sorus through fusion of several smaller sori.

3. On young parts of the rhizome the scales are often distinctly recurved. They are, however, not structurally squarrose as in $P$. asterosora. On older parts of the rhizome the apex of the scales is often completely lost. 


\section{Pyrrosia angustissima (Diels) Tagawa \& Iwatsuki. Fig. 21 b}

Fully treated in Ravensberg \& Hennipman (1986).

\section{Pyrrosia assimilis (Baker) Ching. Fig. 20 b, 31.}

Pyrrosia assimilis Ching, Bull. Chin. Bot. Soc. 1 (1935) 49; Fu, Ill. Imp. Ch. Pl. (1957) 236, fig. 316; Steward, Man. Vasc. Pl. L. Yangtze (1958) 53.-Polypodium assimile Baker, J. Bot. London 13 (1875) 201; [non Polypodium assimile? Kunze, Linnaea 23 (1850) 275, nom. nud. (see note 2)]; Franch., Pl. David. 1 (1884) 335; Baker, Ann. Bot., Lond. 5 (1891) 90; Dunn \& Tutch., Fl. Kwangtung (1912) 352.-Niphobolus assimilis Diels, Bot. Jb. 29 (1900) 207; Giesenh. , Niphobolus (1901) 129. - Cyclophorus assimilis C. Chr., Ind. Fil. (1906) 198; Hand.-Mazz., Symb. Sin. VI (1929) 46; Wu et al., Bull. Inst. Biol. Sun Yatsen Univ. (1932) 334, pl. 158.Type: Shearer 287 (holo K), China.

Cyclophorus assimilis var. mollifrons Hand.-Mazz., Symb. Sin. VI (1929) 46.-Ty pe: Handel-Mazzetti 11881 (W, not seen), China.

Cyclophorus assimilis fo. lobata Wu et al., Bull. Dept. Biol. Sun Yatsen Univ. 3 (1932) 336, pl. 154.Pyrrosia assimilis fo. lobata Ching, Bull. Chin. Bot. Soc. 1 (1935) 50. - Type: Sin 108 B (not seen), China.

Pyrrosia assimilis var. longissima Ching, Lingnan Sc. J. (1945) 33.-Type: W.T.Tsang 26223 (not seen), China.

Rhizome shortly elongated, not grooved ventrally, (0.5-)1.8-2.2 $\mathrm{mm}$ thick, phyllopodia $0.2-0.5 \mathrm{~cm}$ apart, lateral buds situated up to halfway down the internodia. Anatomy: ground tissue parenchymatous, sclerenchyma sheath present, indistinct, sclerenchyma strands scattered in the inner parenchyma, 10 to 20 or sometimes more; vascular strands 6-9. Scales peltate, 1.6-5.8 $\times$ 0.7-1.1 mm; base entire to denticulate; acumen dull brown to blackish with a lighter margin, dentate. Fronds monomorphic, sessile, linear, 6-24 $\times 0.3-1.1 \mathrm{~cm}$. Venation: secondary veins distinct, with the tertiary veins forming regular areoles; included veins simple, free, excurrent. Hydathodes distinct, scattered over the lamina, sunken. Anatomy: lower part of costa with \pm 4 central and \pm 2 lateral vascular strands; lamina $\pm 0.5 \mathrm{~mm}$ thick, upper epidermis with distinctly projecting, thin-walled cells, hypoderm absent, palissade and spongy parenchyma distinct, lower epidermis with thin-walled cells; stomata slightly sunken, pericytic. Indument monomorphic, sparse; hairs $0.5-1.8 \mathrm{~mm}$ in diam., with erecto-patent, acicular rays of very unequal length. Sori apical, separate, superticial; $\angle-3$ in a row in each soriterous areole, $1-1.5 \mathrm{~mm}$ in diam.; when old individually distinct, exserted from the indument. Sporangia on stalks up to $1 \times$ as long as the capsule, capsule 0.3-0.4 mm high, with 18-22 indurated annulus cells. Paraphyses not differentiated. Spores $(70-) 80.6(-86) \times(48-) 53.0(-56) \mu \mathrm{m}$, finely granulate.

Habitat: Usually epilithic, occasionally epiphytic.

Altitudinal range: Generally at low altitudes, up to $1200 \mathrm{~m}$.

CHINA. Peking: Hancock 8 (K). - Kweichow: Tsiang 6851 (A, BO, E, M, SING, US). Chekiang: Faber s.n., (5-1897) (P), Hancock 27 (K). - Kiangsi: H.C. Cheo 41 (E, K), Shearer 

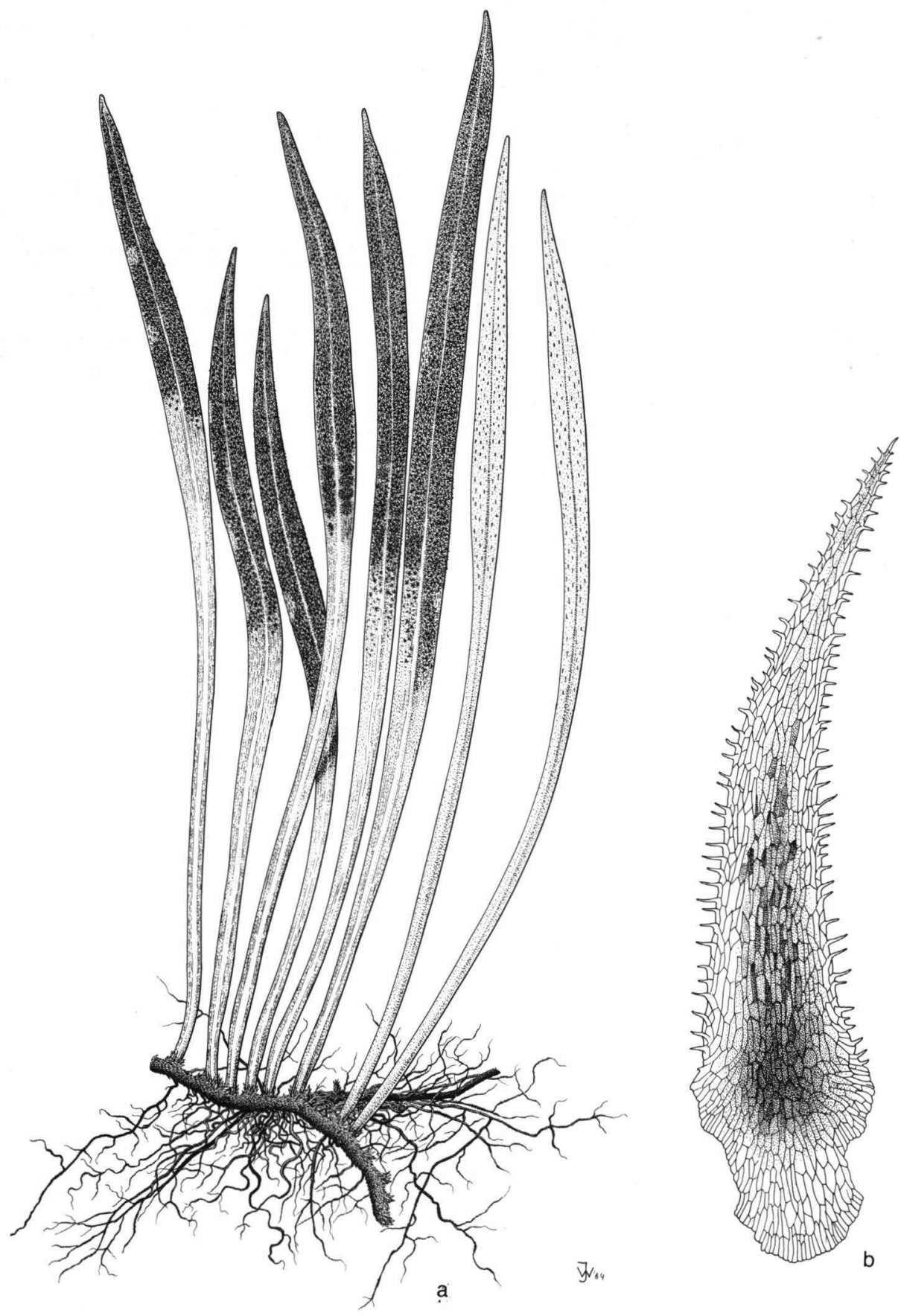

Fig. 31. P. assimilis. a. Habit $\times 1$. - b. Rhizome scale $\times$ 40. (a. Tsiang 6851, GH; - b. Tsang $21356, \mathrm{~L})$. 
287 (K). - Fukien: Schindler 415 (B, E, K, P, Z). - Hunan: Fan \&i 660 (A, BO, L, P), W. T. Tsang 23648 (P). - Kwangtung: Ford 217 (K), S.K. Lau 2542 (GH), Matthew s.n., (2-121907) (K), W.T. Tsang 20896 (A, B, BO, K, L, P, SING, US), 21356 (A, K, SING, US, Z), 21447 A (A), 26077 (A). - Kwangsi: W.T. Tsang 27772 (A, US), Tsui 55 (K, US).

Notes. 1. Fronds of $P$. assimilis are similar to those of narrow forms of $P$. porosa with a more or less monomorphic indument. The best character to distinguish the species is the very irregular length of the stellate rays of a single hair in $P$. assimilis. In $P$. porosa the rays of a single hair rarely differ as much as a factor 2 in length, in $P$. assimilis almost each hair has a few very short as well as some long rays. Older fronds however, particularly those of $P$. assimilis, may have lost most hairs.

2. Polypodium assimile? Kunze 1850 is based on Goniophlebium assimile Lodd. 1849. This was probably published in the catalogue of Loddiges \& Sons Nurserymen for the year 1849, but I have not been able to locate and study this catalogue. If $G$. assimile Lodd. was validly published, the epithet 'assimilis' in Pyrrosia has to be ascribed to Diels (1900).

\section{Pyrrosia asterosora (Baker) Hovenkamp. Fig. 24, 32.}

Pyrrosia asterosora Hovenkamp, Blumea 30 (1984) 208. - Polypodium asterosorum Baker, J. Bot. Lond. 18 (1880) 214; Baker, Ann. Bot., Lond. 5 (1891) 473. - Cyclophorus asterosorus C. Chr., Ind. Fil. (1906) 198; Alderwerelt, Malayan Ferns (1909) 694; Alderwerelt, Malayan Ferns Suppl. (1917) 413. - Type: Beccari 458 (holo $\mathrm{K}$, iso BM, BO), Sumatra.

Cyclophorus asterosorus fo. subfurfuracea Alderwerelt, Bull. Jard. bot. Buitenz. III, 2 (1920) 145.-

Type: Bünnemeijer 5153 (BO, iso L), Sumatra.

Rhizome long-creeping, not grooved ventrally, 2-2.8 $\mathrm{mm}$ thick, phyllopodia 2-9 $\mathrm{cm}$ apart, lateral buds situated more than halfway down the internodia. Anatomy: ground tissue parenchymatous, sclerenchyma sheath distinct, sclerenchyma strands scattered through the inner parenchyma, $0-5$; vascular strands 69. Scales peltate, 10.5-13.3 $\times 1-1.3 \mathrm{~mm}$, base \pm sheathing, entire; acumen squarrose, shining brown, increasingly dentate towards the apex. Fronds monomorphic, stipitate, stipes $2-26 \mathrm{~cm},\left({ }^{1} / 7\right) 1 / 5-1 / 2 \times$ as long as the lamina; lamina, index $6-12$; widest about the middle, $8-35 \times 1.2-3 \mathrm{~cm}$, base narrowly cuneate, somewhat decurrent, apex obtuse to acuminate. Venation: secondary veins distinct, with the tertiary veins forming regular areoles; included veins simple, free, excurrent. Hydathodes absent. Anatomy: stipe with \pm 4 central and no lateral vascular strands; lamina $\pm 0.6 \mathrm{~mm}$ thick, upper epidermis with flat cells with strongly thickened walls, hypodermis composed of 1 cell-layer, an indistinct water-tissue present, palissade and spongy parenchyma distinct, lower epidermis with very strongly thickened cell-walls; stomata sunken, pericytic. Indument dimorphic, a dense mat, persistent, brown; upper layer composed of hairs 1.2$1.8 \mathrm{~mm}$ in diam., with erecto-patent, acicular, rays, distinctly separate from a lower layer composed of hairs with mainly woolly rays. Sori apical to all over the lamina, closely packed to shortly spaced, superficial; 2 (3) in each soriferous 


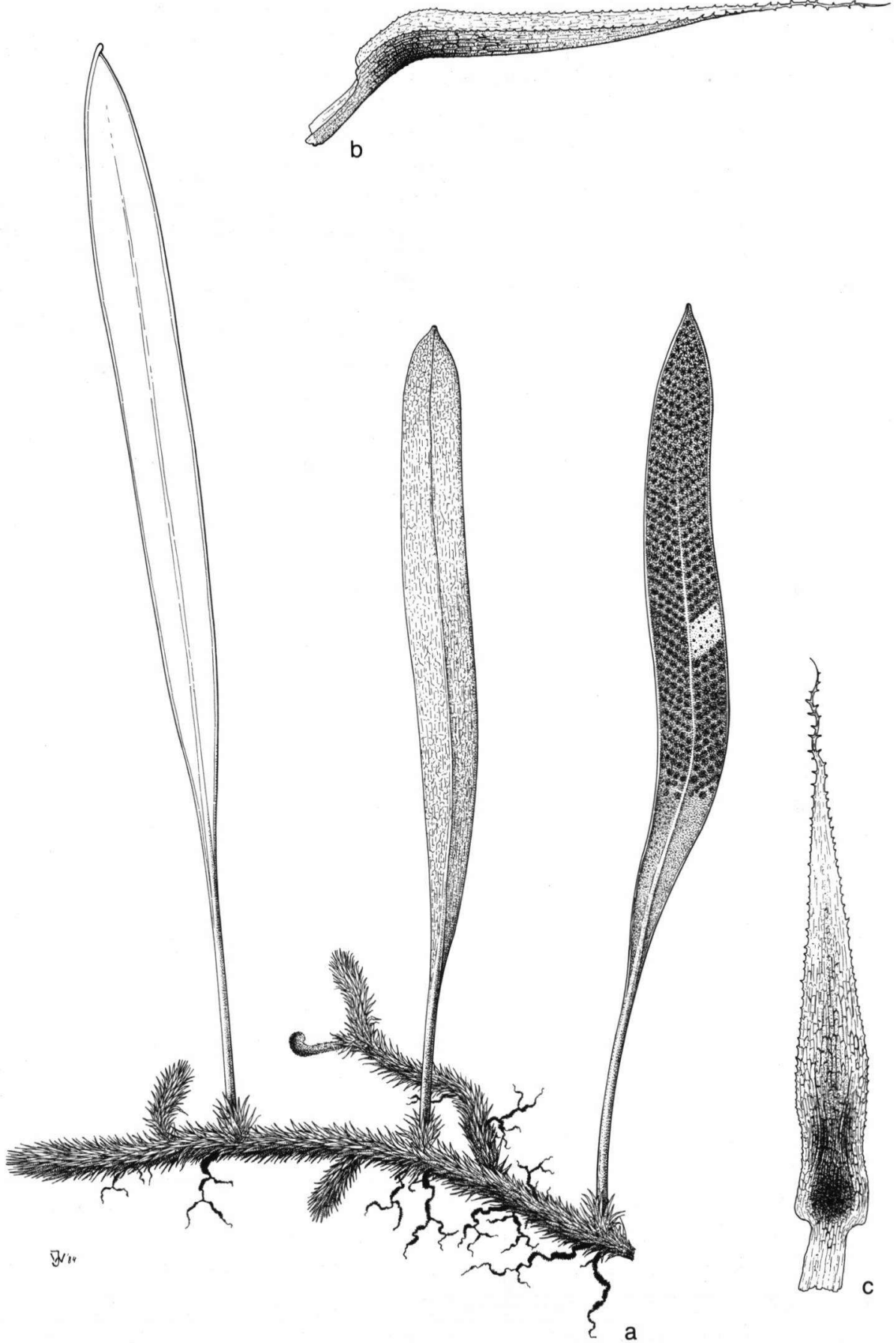

Fig. 32. $P$. asterosora. a. Habit $\times 1 / 2 .-$ b. Rhizome scale, lateral view $\times 9 .-$ c. Rhizome scale, dorsal view $\times$ 9. (a. Schiffner $P 185, \mathrm{~L} ;-$ b, c. Bünnemeijer $9426, \mathrm{~L}$ ).

161 
areole, not confluent; $1.5-2.5 \mathrm{~mm}$ in diam.; developing from the apex downwards, when old individually distinct, \pm exserted from the indument. Sporangia on stalks to $1 \times$ as long as the capsule, capsule $\pm 0.4 \mathrm{~mm}$ high, with 18-20 indurated annulus cells. Paraphyses present, mixed with the sporangia, with curly rays. Spores $(68-) 75.4-82.2(-90) \times(50-) 55.6-59.8(-62) \mu \mathrm{m}$, with irregular ridges.

Habitat: Epiphytic, in montane forest. Restricted to the middle elevations of the higher mountains of Sumatra.

Altitudinal range: $1350-2100 \mathrm{~m}$.

SUMATRA. 19 collections (6 localities: G. Bandahara, G. Dempo, G. Kerinci, G. Singgalan, G. Talang, G. Tandikat).

Notes. 1. $P$. asterosora is easily recognized by the distinctive rhizome scales (fig. $32 \mathrm{~b}, \mathrm{c}$ ). These have a sheathing base extending farther down from the point of attachment than in other Pyrrosia species; thus the attachment in $P$. asterosora is situated at $1 / 4-1 / 5$ of the scale, in other species it is generally situated at $1 / 5-1 / 10$. From this sheathing base the acumen is curved outwards, with the central region structurally modified to preserve the angle under which it is curved outwards.

2. The occurrence of this species on only a few mountains may be a collecting artefact: mountains of intermediate height may be undercollected if a higher mountain is present in the neighbourhood, affording the collector an easier way to sample all vegetation zones on a single trip. Occurrences on mountains of intermediate height may therefore be overlooked.

\section{Pyrrosia boothii (Hooker) Ching. Fig. 19.}

Pyrrosia boothii Ching, Bull. Chin. Bot. Soc. 1 (1935) 66; H. Hara, Fl. Eastern Himal., 2nd Rep. (1971) 219; Nayar Kaur, Comp. Bedd. Handb. (1974) 81.-Polypodium boothii Hooker, Sp. Fil. 5 (1863) 53; Baker in Hooker \& Baker, Syn. Fil. (1867) 352; C. B. Clarke, Tr. Linn. Soc. II Bot. 1 (1880) 555. - Niphobolus boothii Bedd., Ferns Brit. India (1868) pl. 258; J. Sm., Hist. Fil. (1875) 98; Bedd., Handb. (1883) 333; Bedd., Suppl. Handb. (1892) 92; Giesenh., Niphobolus (1901) 115. - Cyclophorus boothii C. Chr., Ind. Fil. (1906) 198. - Ty pe: Griffith, s.n., s.d. (holo K, 2 sheets; iso B, BM), Bhutan.

Niphobolus subvelutinus Christ, Ann. Cons. Jard. bot. Gen. 7-8 (1904) 331.-Cyclophorus subvelutinus C. Chr., Ind. Fil. (1906) 201.-Pyrrosia subvelutina Ching, Bull. Chin. Bot. Soc. 1 (1935) 50.Syntypes: Griffith 2782 (G, not seen; photo in BM), 2786 (not seen), Bhutan.

Rhizome short, not grooved ventrally, to $\pm 7 \mathrm{~mm}$ thick, phyllopodia close together. Anatomy: ground tissue parenchymatous, sclerenchyma sheath distinct, sclerenchyma strands scattered through the inner parenchyma, many; vascular strands \pm 12 . Scales pseudopeltate, 7-11 $\times 0.7-1.5 \mathrm{~mm}$; dull brown, dentate-ciliate. Fronds monomorphic, distinctly stipitate; stipes (8-)17-26 cm, $1 / 2-1 \times$ as long as the lamina; lamina, index $3-6(-7)$, widest at or below the middle, 12-37 $\times 4-7.5 \mathrm{~cm}$, base cuneate, more or less unequal, apex acute to slightly acuminate. Venation: secondary veins distinct, with the tertiary veins forming 
regular areoles; included veins frequently forked and anastomosing; free veins pointing to all directions. Hydathodes distinct, superficial, scattered over the lamina. Anatomy: stipe with \pm 9 central and \pm 2 lateral vascular strands; lamina $\pm 0.3 \mathrm{~mm}$ thick, upper epidermis with flat cells with slightly thickened walls, hypodermis distinct, composed of one cell-layer, water-tissue absent, palissade and spongy parenchyma distinct, lower epidermis with strongly thickened cell-walls; stomata superficial to slightly sunken, pericytic. Indument dimorphic, a dense mat, persistent, brown; upper layer composed of hairs 1.2$1.7 \mathrm{~mm}$ in diam., with erecto-patent, acicular rays, more or less mixed with a lower layer composed of hairs with mainly woolly rays. Sori situated apically to all over the lamına in an ill-detıned patch, shortly spaced, superficial; many scattered throughout each soriferous areole, not confluent; $1-1.5 \mathrm{~mm}$ in diam.; when old individually distinct, \pm exserted from the indument. Sporangia on stalks $1 / 2-3 / 4 \times$ as long as the capsule, capsule $0.4-0.5 \mathrm{~mm}$ high. Paraphyses not differentiated. Spores (74-)82.4-103.6 (110) $\times(56-) 60.8-72.0(-80) \mu \mathrm{m}$, finely and densely granulose.

Habitat: Epilithic or epiphytic; in open sites or in dense forest. Altitudinal range: $1500-2100 \mathrm{~m}$.

CHINA. Tibet: Kingdon-Ward 9363 (BM).

BHUTAN. Griffith 2783 (K), Griffith s.n. (B, BM, K), Hara et al. 11309 (E), Ludlow et al. 18646 (BM), 20555 (BM), Nuttall s.n., s.d. (K).

INDIA. Sikkim: Burr s.n. (1884) (K, P), King's coll. s.n. (Oct. 1883) (B, K, P), 60 (M), Levinge (?Booth) s.n. (Nov. 1882) (?K, P), Levinge s.n. (Oct. 1883) (BO, L, M, P, US).

Notes. 1. Pyrrosia boothii combines characters of $P$. drakeana, which it resembles most closely, and $P$. subfurfuracea, and is sometimes difficult to distinguish especially from the former. The distinguishing characters are given in the key. $P$. boothii may be of hybridogenous origin, although the spores are not aberrant in any way. In its most typical form it occurs in the Eastern Himalayas; but there is a single record from further East (Von Rosthorn 1707, from Szechuan). This specimen has a relatively narrow lamina and is therefore more similar to $P$. subfurfuracea. If the Himalayan population represents a stabilized hybrid population, the Szechuan specimen may well be part of another hybrid population that originated independently. Both postulated parents occur in the vicinity. The number of specimens that could be studied was, however, too small to draw more firm conclusions. The limits of herbarium study are here reached, and only special collecting and field-work can bring further elucidation.

\section{Pyrrosia ceylanica (Giesenh.) Sledge. Fig. 25.}

Pyrrosia coylanica Sledge, Bull. Br. Mus. (Nat. Hist) Bot. 2 (1960) 133; Abeywickrama, Ceyl. J. Sc. Sect. A 13 (1956) 26 (invalid comb.). - Niphobolus ceylanicus Giesenh., Niphobolus (1901) 216, fig. 19.-Cyclophonus ceylanicus C. Chr., Ind. Fil. (1906) 198.-T y pe: G. Wall, s.n. (1887); herb.

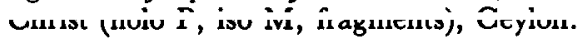


Rhizome long-creeping, grooved ventrally, 0.8-1 mm thick, phyllopodia 1.5-4 cm apart, lateral buds situated \pm halfway down the internodia. Anatomy: ground tissue parenchymatous, sclerenchyma sheath distinct, a single sclerenchyma strand present situated centrally in the parenchyma; vascular strands \pm 4. Scales peltate, 3.6-7.4 $\times 0.5-0.9 \mathrm{~mm}$; shining light brown, entire. Fronds moderately dimorphic, distinctly stipitate. Fertile fronds: stipes $0.5-3 \mathrm{~cm}, 1 / 8- \pm$ $1 / 3 \times$ as long as the lamina; lamina, index $4-10$, widest at or below the middle, $3.5-8 \times 0.7-1.4 \mathrm{~cm}$, base cuneate, apex acute to obtuse. Sterile fronds: stipes $0.5-1 \mathrm{~cm}, 1 / 8-1 / 5 \times$ as long as the lamina; lamina, index $3-4 ; 3.5-5 \times 1.2-1.4 \mathrm{~cm}$; otherwise similar to the fertile ones. Venation: secondary veins distinct, with the tertiary veins forming regular areoles; included veins simple, free, excurrent. Hydathodes absent. Anatomy: stipe with \pm 3 central and 0-2 lateral vascular strands; lamina $\pm 1 \mathrm{~mm}$ thick, upper epidermis with distinctly projecting cells with thin to slightly thickened walls, hypodermis absent but a distinct, moderately thick water-tissue present, palissade and spongy parenchyma distinct, lower epidermis with slightly to strongly thickened cell-walls; stomata slightly to distinctlv sunken. pericvtic. Indument monomorphic, a dense mat, persistent, whitish brown; hairs $0.3-0.7 \mathrm{~mm}$ in diam., with appressed, boat-shaped rays. Sori apical, closely packed, sunken; several in a row in each soriferous areole, not confluent; $\pm 1 \mathrm{~mm}$ in diam.; developing from the apex downwards, when old individually distinct, exserted from the indument. Sporangia on stalks $\pm 1 \times$ as long as the capsule, capsule $\pm 0.3 \mathrm{~mm}$ high, with 17-19 indurated annulus cells. Paraphyses present, in a central bundle in the sorus, with short, relatively wide, straight rays. Spores (64-)72.8-80.6(-90) $\times(40-) 49.6-54.0(-58) \mu \mathrm{m}$, bisculptate.

Habitat: Epiphytic or epilithic. Restricted to the wettest parts of southern India and Ceylon.

Altitudinal range: India: a single record from $700-750 \mathrm{~m}$; Ceylon: no data are recorded.

INDIA. Kerala: Gough s.n., s.d. (K), Kramer \& Nair 6180 (Z).

CEYLON. Beckett s.n., s.d. (K), Chevalier s.n., s.d. (BM), Faden * Faden 76-300 (US), Thwaites CP 993 (B, BM, SING), 3293 (BM, P), Wall s.n. (1887) (B, M, P).

Notes. 1. Deceptivelv similar to $P$. lanceolata, and in older collections both species are often mounted on the same sheet. The somewhat shorter, relatively wider fronds are perhaps a useful field character; the entire rhizome scales are distinctive.

2. Occasionally annular figures are visible in the scales similar to those occurring in $P$. confluens.

\section{Pyrrosia christii (Giesenh.) Ching. Fig. 22, 33.}

Pyrrosia christii Ching, Bull. Chin. Bot. Soc. 1 (1935) 58. - Niphobolus christii Giesenh., Niphobolus (1901) 140, 158. - Cyclophorus christii C. Chr., Ind. Fil. (1906) 198; Alderwerelt, Malayan Ferns 


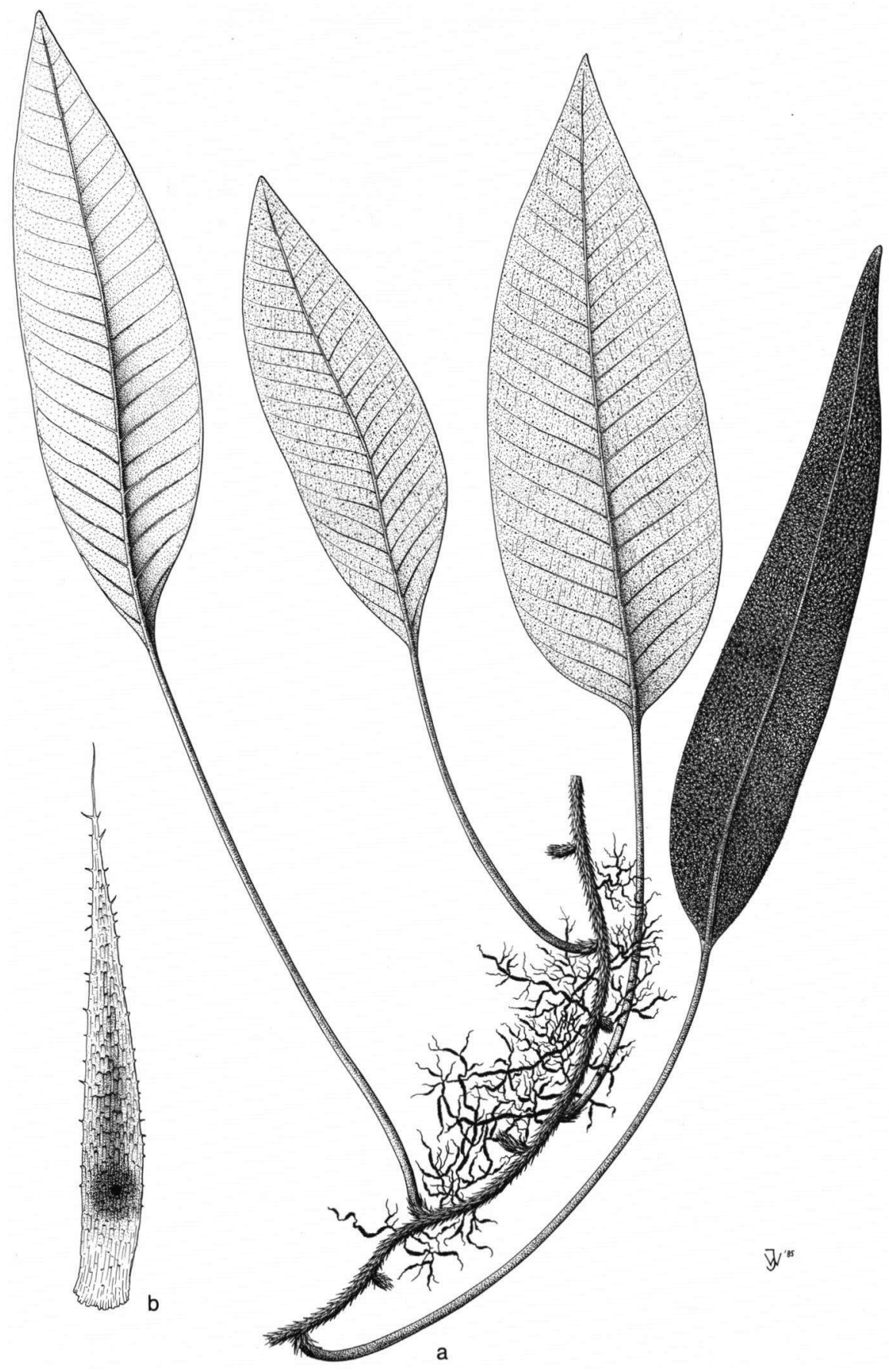

Fig. 33. $P$. christii. a. Habit $\times 1 / 2 .-$ b. Rhizome scale $\times 11$. (a. Endert 4666, L; - b. Endert 3146 , L). 
(1909) 963; C. Chr. Holttum, Gard. Bull. S. S. 7 (1934) 313.-Ty pe: G. Singapore \& Sarawak (also known as Bishop Hose), s.n., (1894) (holo P), Sarawak, Bishop's House.

Polypodium lingua auct. non (Thunb.) Sw.: Hooker, Sp. Fil. 5 (1863) 49, quoad specimina Bomeensia.

Rhizome long-creeping, shallowly grooved ventrally, $1.3-3 \mathrm{~mm}$ thick, phyllopodia 2-9 cm apart, lateral buds situated \pm halfway down the internodia. Anatomy: ground tissue parenchymatous, sclerenchyma sheath distinct, sclerenchyma strands absent; vascular strands 6-8. Scales peltate, 3.1-7.5 $\times 0.4-0.7 \mathrm{~mm}$; base entire to irregularly dentate; acumen light brown, ciliate. Fronds moderately dimorphic, distinctly stipitate. Fertile fronds: stipes $2-18 \mathrm{~cm}, 1 / 5-1 \times$ as long as the lamina; lamina, index 3-10; widest at or below the middle, 5.5-22 $\times 1.5-5.5$ $\mathrm{cm}$, base cuneate, apex obtuse to acuminate. Sterile fronds: stipes $1-11 \mathrm{~cm}$, $1 / 10-1 / 2 \times$ as long as the lamina; lamina, index $2-3$; widest below or occasionally at the middle, $9-22 \times 3.5-9 \mathrm{~cm}$, base cuneate to \pm cordate-truncate, apex acute to acuminate. Venation: secondary veins distinct, with the tertiary veins forming regular areoles; included veins simple or forked, frequently anastomosing; free veins pointing to all directions, many. Hydathodes distinct, scattered over the lamina, superficial to slightly prominent. Anatomy: stipe with \pm 7 central and \pm 3 lateral vascular strands; lamina $\pm 0.4 \mathrm{~mm}$ thick, upper epidermis with flat cells with slightly thickened walls, hypodermis composed of 1 cell layer, watertissue absent, palissade and spongy parenchyma little different, lower epidermis with strongly thickened cell-walls: stomata sunken. pericytic. Indument dimorphic, a very thin mat, often fugacious, hyaline; upper layer composed of hairs $0.25 \mathrm{~mm}$ in diam., with appressed, boat-shaped rays, closely appressed to a lower layer composed of hairs with mainly woolly rays. Sori

detıned, irregularly shaped patch, very closely packed, supertıcıal; many in each soriferous areole, often confluent along the veins; developing simultaneously, when old pseudoacrostichoid, exserted from the indument. Sporangia on stalks $3 / 4-11 / 2 \times$ as long as the capsule, capsule 0.3-0.4 mm high, with 17-20 indurated annulus cells. Paraphyses not differentiated. Spores (54-)61.0-71.0(-76) $\times(34-) 42.0-48.8(-56) \mu \mathrm{m}$, coarsely and irregularly tuberculate.

Habitat: Mainly epiphytic, in sheltered sites (but see note 2). Restricted to everwet areas.

Altitudinal range: $300-1150 \mathrm{~m}$.

BORNEO. - Sarawak: Brooks s.n. (12-1907) (BM), Ch. Hose s.n., s.d. (BM, K), G. Hose s.n., s.d. (P), Jermy 14018 (BM), Lobb s.n., s.d. (K), Nielsen 9428 (AAH). - Sabah: Boden Kloss 19052 (BM, BO, K, SING, US), Chew, Corner \& Stainton 1727 (BO, K, SING), Nooteboom 1226 (L), $1227(\mathrm{~L})$. - Kalimantan: 6 collections.

Notes. 1. The thin indument is easily overlooked. On young fronds a more conspicuous indument is also present, composed of hairs larger than those left on older fronds, with patent, acicular rays. This probably corresponds to the juvenile indument of other species but in $P$. christii it appears to be frequently present in 
mature fronds that are not yet fully developed. A more distinct woolly layer is also present on the stipe of young fronds.

2. The almost glabrous, often thin fronds at first sight are characteristic for a hygromorphic plant. According to Geesink, however, (pers. comm.) it may grow in full sun on dry rocks; in the greenhouse it also appears to be quite resistant to desiccation.

3. $P$. christii is probably not rare but may be undercollected, as it appears to be sterile over large areas (Geesink, pers. comm.; cf. also Iwatsuki \& Kato, 1981).

4. A spore sample collested by Geesink (s.n., 1981) contains a small proportion (less than $1 \%$ ) of abnormally large spores (82-)88.4(-92) $\times(58-) 62.0(-74) \mu \mathrm{m}$, indicating that diploid spores may occasionally be formed. This is confirmed by the occurrence of a few sporangia containing only 32 spores in this collection.

\section{Pyrrosia confluens (R. Br.) Ching. Fig. 26.}

Rhizome long-creeping, occasionally grooved ventrally, 1-2 $\mathrm{mm}$ thick, phyllopodia 1-3 cm apart, lateral buds situated more than halfway down the internodia. Anatomy: ground tissue parenchymatous, sclerenchyma sheath distinct, sclerenchyma strands situated centrally in the inner parenchyma, 0-5; vascular strands 5-7. Scales peltate, $1.8-5.3 \times 0.5-0.9 \mathrm{~mm}$; base entire, rarely with a few marginal glands; acumen shining brown, often with a distinct lighter margin, ciliate. Fronds moderately to distinctly dimorphic, distinctly stipitate. Fertile fronds: stipes $0.3-4.5 \mathrm{~cm}$, up to $\pm 1 / 2 \times$ as long as the lamina; lamina, index (1-)2.5 to over 20; widest below or about the middle, $1-19 \times 0.5-1.5 \mathrm{~cm}$, base gradually narrowed to cuneate, apex shortly apiculate, rounded, truncate or slightly emarginate. Sterile fronds: stipes $0.2-2.5 \mathrm{~cm}$, up to $1 / 3(-1 / 2) \times$ as long as the lamina; lamina, index $1 \frac{1}{2-} \pm 13$; widest below to about the middle, 1.5$15 \times 0.4-2 \mathrm{~cm}$; otherwise similar to the fertile fronds. Venation: secondary veins indistinct, with the tertiary veins forming \pm irregular areoles; included veins simple or forked, frequently anastomosing; free veins excurrent, few. Hydathodes distinct to indistinct, in an abaxial-marginal or marginal row, \pm superficial. Anatomy: stipe with \pm 3 central and no lateral vascular strands; lamina 0.8-2.1 mm thick, upper epidermis with slightly projecting cells with slightly to strongly thickened walls, hypodermis composed of 1,2 or more cell layers, water-tissue indistinct, palissade and spongy parenchyma indistinct, lower epidermis with slightly to strongly thickened cell-walls; stomata usually deeply. sometimes verv deeply. sunken. pericvtic. Indument monomorphic, a thin mat, more or less fugacious, whitish; hairs $0.4-0.9 \mathrm{~mm}$ in diam., with appressed, \pm boat-shaped, rays. Sori apical, separate in a single row, or confluent into a longitudinal coenosorus, superficial to slightly sunken, $1-3 \mathrm{~mm}$ wide, if separate often somewhat elongated; developing from the apex downwards, when old exserted from the indument. Sporangia on stalks $1-2 \times$ as long as the capsule, cap- 
sule $0.4-0.5 \mathrm{~mm}$ high, with $15-22$ indurated annulus cells. Paraphyses abundant, mixed with the sporangia, with short, straight rays. Spores (72-)76.0-91.2($102) \times(46-) 53.0-70.4(-76) \mu \mathrm{m}$, more or less strongly bisculptate.

\section{Key to the varieties}

- Fronds moderately dimorphic, apex narrow, texture leathery, hydathodes inframarginal ................................................. var. confluens

- fronds distinctly dimorphic, apex wide, often truncate or emarginate, texture thick-leathery, often brittle when dry, hydathodes marginal..... b. var. dielsii

\section{a. var. confluens}

Pyrrosia confluens Ching, Bull. Chin. Bot. Soc. 1 (1935) 49; [non Polypodium confluens Roxb., Calc. J. Nat. Hist. IV (1844) 494, nom. illeg., = Ctenitis thodolepis (C.B. Clarke) Ching, teste Morton, Contr. U.S. Nat. Herb. 38 (1974) 338; nec Polypodium confluens Liebm., Mex. Bregner (1849) 39, nom. illeg., = Polypodium plesiosorum Kunze, teste A. R. Smith, Fl. of Chiapas 2 (1981) 189; nec Polypodium confluens Fée, Cr. Vasc. Brés. (1869) 89, nom. illeg., = Polypodium apiculatum Kunze, teste Vareschi, Fl. Venez. 1, 2 (1969) 921]; Tindale, Contr. N.S.W. Nat. Herb. Fl. ser. 210 (1961) 34; Brownlie, Fl. N. Caled. (1969) 280; pl. 38 fig. 1; Jones \& Clemesha, Austr. Ferns (1976) 254, fig. 237.-Polypodium confluens R. Br., Prodr. (1810) 146; Hooker, Sp. Fil. 5 (1863) 46; Baker in Hooker \& Baker, Syn. Fil. (1867) 349, Benth., Fl. Austr. (1878) 767, F.M. Bailey, Cat. P1. Queensl. (1890) 60; Baker, Ann. Bot., Lond. 5 (1891) 471; F.M. Bailey, Lith. Ferns (1892) 151; Christ in Warb., Monsunia 1 (1900) 61. - Niphobolus confluens Spr., Syst. 4 (1827) 44; F.M. Bailey, Handb. Ferns Queensl. (1874) 43; Diels in E. \& P., Nat. Pfl. Fam. 1,4 (1899) 326; Giesenh., Niphobolus (1901) 172; Schumann Lauterb., Fl. Schutzgeb. Süds. (1901). 141. - Cyclophorus confluens C. Chr., Ind. Fil. (1906) 198; Christ, J. Bot. Paris 21 (1908) 238; Alderwerelt, Malayan Ferns (1909) 690; Domin, Bibl. Bot. 85 (1914) 188; Brause, Bot. Jb. 56 (1920) 205; Goy, Queensl. Nat. 10 (1937) 47, pl. 5; Dickason, Ohio J. Sc. 46 (1946) 129.Ty pe: Robert Brown, s.n., 9 Oct.- Nov. 1804 (holo BM), Australia, Hunters \& Patersons River.

Niphobolus acrostichoides Presl, Tent. Pterid. (1836) 202, nom. nud.; [non Niphobolus acrostichoides J. Sm., Hooker J. Bot. 3 (1841) 396, nom. nud., = Pyrrosia sphaerosticha (Mett.) Ching; nec Niphobolus acrostichoides (G. Forster) Bedd., Ferns Brit. India (1868) pl. 85, = Pyrrosia longifolia (N.L. Burm.) Morton]. -Scytopteris acrostichoides Presl, Epim. Bot. (1851) 134.-Niphobolus scytopleris Fée, Gen. Fil. (1853) 262.-Polypodium glabrum Mett., Polyp. (1856) 123, pl. 3 fig. 6-8, nom. illeg.; [non Polypodium glabrum N.L. Burm., Fl. Ind. (1768) 235, nom. dub., type from Java; nec Polypodium glabrum Roxb., Calc. J. Nat. Hist. IV (1844). 482, nom. illeg. = Polypodium polycarbon Cav., teste Morton, Contr. U.S. Nat. Herb. 38 (1964) 347]; Baker in Hooker \& Baker, Syn. Fil. (1867) 356; Baker, Ann. Bot., Lond. 5 (1891) 475.-Pleopeltis glabra E. Fourn., Bull. Soc. Fr. 16 (1869) 424.-Cyclophorus scytopteris E. Fourn., Ann. Sc. Nat. V, 18 (1873) 286.-Pyrrosia confluens ssp. scytopteris Tindale, Contr. N.S.W. Nat. Herb. Fl. ser. 210 (1961) 36.-Ty pe: Sieber, exsicc. no. 94 (P, BR?, L, K), Australia.

Scytopteris acrostichoides var. brevipes Presl, Epim. Bot. (1851) 263.-Synt y pes: Bauer, Cunningham, Norfolk Island (not seen).

Drymoglossum camosum Cunn. ex J. Sm., Hooker J. Bot. 4 (1842) 66, nom. nud.; [non Drymoglossum carnosum Hooker, Gen. Filic. (1842) pl. 78 A, = Lemmaphyllum camosum (Hooker) Presl].-

Drymoglossum cunninghamii T. Moore, Ind. Fil. (1857) xxxi, nom. nud.; T. Moore, Ind. Fil. (1862) 343, nom. nud., J. Sm., Hist. Fil. (1875) 118, nom. nud.-T y pe: A. Cunningham, 'Niphobolus carnosus' (B?, BM?, K?), Norfolk Island.

Polypodium confluens var. lobatum F.M. Bailey, Proc. Roy. Soc. Queensl. 1 (1884) 15; F.M. Bailey, Queensl. Flora 5 (1902) 1984; Bailey, Lith. Ferns (1892) 152._Cyclophorus confluens fo. lobatus Domin, Bibl. Bot. 85 (1914) 188; Goy, Queensl. Nat. 10 (1937) 48.-Ty pe: not indicated, Australia. 
Cyclophorus spicatus Domin, Bibl. Bot. 85 (1914) 189, pl. 8, fig. 1, 2; C. Chr., Ind. Fil. Suppl. 2 (1917) 11. - Type: Domin, s.n., (1910) (not seen), Australia, Tambourine \& Beech Mts.

Polypodium serpens et syn. homot, auct. non Forster: Endl. Fl. Norfolk (1833) 8, F. v. Muell., Fragm. 5 (1866) 129 p.p.; Benth., Fl. Austr. (1878) 767 p.p.; F.M. Bailey, Cat. Pl. Queensl. (1890) 60; Baker, Ann. Bot., Lond. 5 (1891) 471; Domin, Bibl. Bot. 85 (1914) 187.

Fronds moderately dimorphic. Fertile fronds: stipes $0.3-4.5 \mathrm{~cm}$, up to $\pm 1 / 3 \times$ as long as the lamina; lamina, index \pm 3 to over 20 ; widest about the middle, 3$19 \times 0.5-1.5 \mathrm{~cm}$, base gradually narrowed to cuneate, apex round to very shortly apiculate. Sterile fronds: stipes $0.2-0.4 \mathrm{~cm}$, up to $1 / 3(-1 / 2) \times$ as long as the lamina; lamina, index $1.5- \pm 13 ; 1.5-15 \times 0.4-2 \mathrm{~cm}$. Hydathodes distinct to indistinct, in an abaxial-marginal row. Lamina 0.8-1.6 $\mathrm{mm}$ thick, hypodermis composed of 1 or 2 cell layers, stomata, usually deeply, sunken, Sori apical, separate in a single, submarginal, row or confluent into a longitudinal coenosorus.

Habitat: Mostly epiphytic, often near the margin of rainforest but also in other types of forest (secondary forest, dry sclerophyll forest, gallery forest), or on exposed trees; less frequently epilithic, on various substrates (basalt, limestone, schists).

Altitudinal range: Low altitudes up to $1000 \mathrm{~m}$.

AUSTRALIA. Queensland: 16 collections. - New South Wales: 20 collections. - Lord Howe Island: anon. (Gov't. Botanist) s.n., s.d. (B, BM, BO, K, L), anon. (H.M.S. Herald) (BM), Fullagan s.n., s.d. (P), F. v. Mueller s.n., s.d. (P), Telford 7012 (BISH). - Ash Island: F. v. Mueller s.n., s.d. (P).

NORFOLK ISLAND: 10 collections.

NEW CALEDONIA: 54 collections.

LOYALTY ISLANDS. Lifu: Bergeret 30 (P), Sarasin 724 (?729) (P, Z), Thiebault (?31) (B, P), Däniker 2323 (Z), 2394 (Z), 2394 a (Z). - Maré: Franc s.n., s.d. (Bonati no 1132) (M, P, SING), Sarasin $408(P, Z), 409(P, Z)$.

TAHITI: Nadeaud s.n., s.d. (P), Pancher 22 (P).

Notes. 1. Variability: The plants from New Caledonia have been distinguished as a subspecies (Tindale, 1961). They differ from the plants from Australia in the generally separate sori and the longer, narrower fronds. Plants from Norfolk Island are often intermediate with respect to these two characters. Plants from both islands have generally less appressed rhizome scales than plants from Australia have, and more conspicuous hydathodes, with large, conspicuous, calcareous incrustations. These differences with the form from Australia, however, are not constant. Some collections from New Caledonia are indistinguishable from the Australian plants (Franc 1132, Sarasin 269, Vieillard 1590). On the other hand, some collections from Australia have a row of separate sori (Telford 5417, Gray 2177). Other plants are intermediate in character, with distinct hydathodes as well as an apical coenosorus (e.g., Sarasin 408). Moreover, the sorus character is not constant, as in some collections (e.g., Franc, s.n.; Brousmiche 30) both soral types occur together. I therefore do not follow Tindale (1961) in separating the plants from New Caledonia as a distinct taxon. 
2. Plants from Norfolk Island sometimes have a densely, fastigiately, branched rhizome (Robinson s.n., Green 1465, Patterson s.n.). In appearance these rhizomes are similar to those in $P$. eleagnifolia with a gall induced by a mite (see note 3 under P. eleagnifolia).

3. The rhizome scales, when viewed in transmitted light, often show some or many of the basal cells filled with more or less distinct annular structures (plate $2 \mathrm{~d})$. These have a diameter of $25-30 \mu \mathrm{m}$ and are composed of a light peripheral band 3-8 $\mu \mathrm{m}$ wide and a darker central zone of 10-15 $\mu \mathrm{m}$ in diam. The zones are not sharply delimitated. These images probably should be interpreted as annular thickenings of the (relatively light-coloured) cell-walls, contrasted with the darker cell contents.

Within $P$. confluens the presence of these structures is not constant. Outside $P$. confluens they occur in $P$. rupestris, $P$. eleagnifolia, $P$. serpens, and are most conspicuous in this last species. Sporadically they are found in $P$. lanceolata as well.

4. $P$. confluens shows a disjunction between Eastern Australia, New Caledonia and Norfolk Island as a more or less continuous range and Tahiti, where it has been found twice, once with the exact location unknown (Pancher 22, P) and once on a mountain top of $1200 \mathrm{~m}$ alt. (Nadeaud s.n., P). Considering the character of this last locality it is not probable that its occurrence on Tahiti is due to human activities.

5. The nomenclatural confusion surrounding this species is due to Sieber's identification of his no 94 as Polypodium acrostichoides Forster.

6. Polypodium glabrum Mett. This species is based on Niphobolus glaber Kaulf. ex parte; Mettenius only cited material from New Holland. Thereby he excluded the type of $N$. glaber (which is based on Cyclophorus glaber Desv., with a type from Java). Thus $P$. glabrum Mett. should be regarded as a nomen novum, based on Sieber 94.

\section{b. var. dielsii}

Pyrrosia confluens (R. Br.) Ching var. dielsii Hovenkamp, Blumea 30 (1984) 208. - Cyclophorus dielsii C. Chr., Dansk Bot. Ark. 9(3) (1937) 57, pl. 6, fig. 2.-Pyrrosia dielsii Tindale, Contr. N.S.W. Nat. Herb. Fl. ser. 210 (1961) 36; Jones \&lemesha, Austr. Ferns (1976) 254, fig. 238, pl. 29.-Type: Diels 8406 (holo B, iso BM, fragment), Australia.

Cyclophorus intermedius Goy, Queensl. Nat. 10 (1937) 48, pl. 6.-Pyrrosia intermedia Shing, Amer. Fern J. 73 (1983) 78.-Type: E.W. Bick s.n., (June 1913) (P, K), Atherton.

Fronds distinctly dimorphic. Fertile fronds: stipes $1-3.5 \mathrm{~cm}, 1 / 4^{-1 / 2} \times$ as long as the lamina; lamina, index (1-)2.5-6(-10); widest below the middle, 1-8.5 $\times 0.8-$ $1.2 \mathrm{~cm}$, often slightly and obtusely hastately dilated above the base, apex often

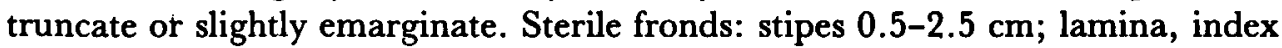
1.5-3, 2-6 $\times 1-1.7 \mathrm{~cm}$. Hydathodes rather indistinct, marginal. Lamina 1.6-2.1 $\mathrm{mm}$ thick, hypodermis very strongly developed, stomata very deeply sunken. Sor $i$ 
often separate, rarely in a coenosorus, often distinctly marginal, when old protruding from the margin.

Habitat: Mostly epiphytic, in exposed sites; somtimes epilithic and then apparently more sheltered. According to Jones \& Clemesha (1976) particularly abundant on trees left after clearing.

Altitudinal range: $500-1000 \mathrm{~m}$.

AUSTRALIA. Queensland: 15 collections (several localities around Atherton).

Notes. 1. Some plants cultivated in the Leiden Botanical Garden occasionally form fertile fronds with the sori weakly in two rows, thus obscuring the difference between $P$. confluens and $P$. serpens.

\section{Pyrrosia costata (Presl) Tagawa \& Iwatsuki. Fig. 17.}

Pyrrosia costata Tagawa \& Iwatsuki, Acta Phytotax. Geobot. 22 (1967) 100; Holttum, Nov. Bot. Inst. Bot. Univ. Car. Prag. (1968) 27; H. Hara, Fl. Eastern Himal., 2nd Rep. (1971) 219; Iwatsuki, Acta Phytotax. Geobot. 25 (1972) 71, 75; Nayar * Kaur, Comp. Bedd. Handb. (1974) 80; Shing, Amer. Fern J. 73 (1983) 76;-Niphobolus costatus Wallich, Cat. (1828) 265, nom. nud.; Presl, Tent. Pterid. (1836) 200; J. Sm., Hooker J. Bot. 4 (1842) 57; J. Sm., Cat. Kew Garden Ferns (1846) 12; Fée, Gen. Fil. (1853) 263; Bedd., Ferns Brit. India (1868) pl. 120 q.n.s. (the plate represents Pyrrosia stigmosa); J. Sm., Hist. Fil. (1875) 98; J. Sm., Ferns Br. \& For. ed. 2 (1877) 100; Diels, Bot. Jb. 29 (1900) 207. - Apalophlebia costata Presl, Epim. Bot. (1851) 139. Polypodium costatum Mett., Polyp. (1856) 131, pl. 3 fig. 14, nom. illeg.; [non Polypodium costatum Kunze, Linnaea 9 (1935) 38, type from Cuba; nec Polypodium costatum (Brack.) Hooker, Sp. Fil. 5 (1863) 7, nom. illeg., = Pneumatopteris costata (Brack.) Holttum]; Hooker, Sp. Fil. 5 (1863) 50.Niphobolus beddomeanus Giesenh., Niphobolus (1901) 101, nom. superfl.; Holttum, Nov. Bot. Inst. Bot. Univ. Car. Prag. (1968) 27.-Cyclophorus beddomeanus C. Chr., Ind. Fil. (1906) 198, nom. superfl.; Copeland, Sar. Mus. J. 2 (1917) 410; Alderwerelt, Bull. Jard. bot. Buitenz. II, 28 (1918) 16; C. Chr., Contr. U.S. Nat. Herb. 26 (1931) 326; Dickason, Ohio J. Sc. 46 (1946) 129.-Pyrrosia beddomeana Ching, Bull. Chin. Bot. Soc. 1 (1935) 68, nom. superfl.; Nayar, J. Ind. Bot. Soc. 40 (1961) 164-168; H. Hara, Fl. Eastern Himal. (1966) 489; Hoshizaki, Baileya 21 (1981) 61, fig. 3 p.p.; Ching Lin, Acta Phytotax. Sinica 22 (1984) 403.-T y pe: Wallich 265 (holo PRC, not seen, iso in B, BM, BR, K, L, M, P, US), India.

Niphobolus beddomeanus fo. fallax Giesenh., Niphobolus (1901) 103.-Synt y pes: Henry 12704, 12704 $A$ (K, P, US), China.

Polypodium stigmosum et syn. homot., auct. non Swartz: Baker in Hooker \& Baker, Syn. Fil. (1867) 350; C. B. Clarke, Tr. Linn. Soc. II Bot. 1 (1880) 553; Bedd., Handb. (1892) 329; Hope, J. Bomb. Nat. Hist. Soc. 15 (1903) 88; Wu et al., Bull. Dep. Sun Yatsen Univ. 3 (1932) 340, pl. 161; Ching $* \mathrm{Wu}, \mathrm{Fl}$. Xizang. 1 (1983) 327.

Rhizome short, not grooved ventrally, to $5 \mathrm{~mm}$ thick, phyllopodia close together, lateral buds situated on the phyllopodia. Anatomy: ground tissue sclerenchymatous, sclerenchyma sheath and sclerenchyma strands absent; vascular strands 12-13. Scales basifix, 8-10 mm long; basal margin often with glands on long, apex-like projections; acumen entire, shining brown; shorter scales regularly present. Fronds monomorphic, substipitate or estipitate; stipes occasionally to $20 \mathrm{~cm}$; lamina, index 6-14; widest at or above the middle, 32$64 \times 3.2-7.2 \mathrm{~cm}$, base very gradually narrowed, apex acuminate. Venation: 
secondary veins distinct, with the tertiary veins forming regular areoles; included veins much branched and strongly anastomosing; free veins many, pointing to all directions. Hydathodes distinct, scattered over the lamina, \pm superficial. Anatomy: stipe or lower part of costa without central bundle of collenchyma, with 5-13 central and 4-7 lateral vascular strands; lamina $0.3 \mathrm{~mm}$ thick, upper epidermis with distinctly projecting cells with slightly thickened walls, hypodermis absent, or composed of 1 cell layer, or an indistinct water-tissue present, palissade and spongy parenchyma indistinct, lower epidermis with slightly to strongly thickened cell-walls; stomata slightly sunken, pericytic. Indument dimorphic, a dense mat, persistent, greyish brown; upper layer composed of hairs 0.4-1.9 mm in diam., with appressed, narrowly boat-shaped rays, appressed to a lower layer composed of hairs with mainly woolly rays. Sori apical, closely packed in an ll-detıned patch, superticial; many in each soriferous areole, not confluent; $\pm 0.5 \mathrm{~mm}$ in diam.; developing from the apex downwards, when old distinctly separate, immersed in but breaking through the indument. Sporangia sessile or on short stalks to $1 / 4 \times$ as long as the capsule, capsule $0.3-0.4 \mathrm{~mm}$ high, with 12-14 indurated annulus cells. Paraphyses not differentiated. Spores (44-) $49.0(-52) \times(28-) 33.2(-36) \mu \mathrm{m}$, smooth.

Habitat: Epiphytic or epilithic, in various situations (in ravines, on dry banks, stone walls, in open forest). Mostly in areas with a high but seasonal rainfall. Altitudinal range: $250- \pm 2100 \mathrm{~m}$ alt.

CHINA. Yunnan: Forrest 9464 (E, K), 9508 (E), 18269 (E, K), Henry 12704 and 12704 A (K, P, US), Rock 7161 (US), 7703 (BM, K, US).

NEPAL. 8 collections.

BHUTAN. Clarke 27962 (K), Griffith s.n., s.d. (B, M), Ludlow et al. 7226 (BM).

INDIA. Uttar Pradesh: 10 collections. - Sikkim \& Darjeeling: 17 collections. - Bihar \& Orissa: Clarke 24862 (P, K), Haines 5377 (K). —Assam: 19 collections. -Tamil Nadu Kerala: Beddome (?122) (K).

BURMA. Kingdon-Ward 20455 (A, BM), Kurz 3200 (K), Lobb s.n., s.d. (K), Parish s.n., s.d. (P), Toppin $6351(\mathrm{~K})$.

THAILAND. Northern: Larsen et al. 2599 (L), Tagawa et al. T 4079, mixed with $P$. stigmosa, (US), T 7510 (L, US).

VIETNAM. Colani (?Pételot) 4526 (BM, P).

Notes. 1. $P$. costata is very similar to $P$. platyphylla from Borneo; diagnostic differences are given under that species.

2. More or less stipitate forms of $P$. costata can be confused with $P$. stigmosa, especially as the two species sometimes occur together (as in Thailand). $P$. costata can best be distinguished from $P$. stigmosa by the flat or only shallowly grooved costa and the absence of collenchyma centrally in the stipe. In $P$. stigmosa costa and secondary veins are usually narrowly grooved on the upper surface, especially in the lower half of the lamina; in well-developed plants the distinctly elongated rhizome is characteristic. Some specimens of $P$. costata seem to have an elongated rhizome (e.g., Griffith, s.n.; Mann, s.n., Aug. 1888); this may be an in- 
cidental aberration or it may be due to the tearing of the rhizome during the collecting of the fronds.

3. Occasionally the hairs have distinct dorsal spines comparable to those occurring regularly in $P$. splendens (Rock 7703).

4. Niphobolus costatus Presl: Presl's names of 1836 are generally considered nomina nuda (e.g., Holttum, 1968). Some of the names, however, are accompanied by a short and specific description in the text; e.g., on p. 201: 'Sori in $N$. costato annuliformes, disco pellucide et apicibus venularum liberarum inserti sunt', and should therefore be considered as validly published.

\section{Pyrrosia distichocarpa (Mett.) Shing. Fig. 24, 34.}

Pyrrosia distichocarpa Shing, Amer. Fern J. 73 (1983) 76.-Polypodium distichocarpum Mett., Ann. Mus. Lugd. Bat. 2 (1866) 231; Baker in Hooker \& Baker, Syn. Fil. (1867) 352. - Niphobolus distichocarpus Giesenh. ex Diels in E. \& P., Nat. Pfl. Fam. 1,4 (1899) 325.-Cyclophorus distichocarpus J. Chr., Ind. Fil. (1906) 198; Alderwerelt, Malayan Ferns (1909) 693; Alderwereit, sviasay an reins Suppl. (1917) 413; Backer \& Posth., Varenfl. Java (1939) 242.-T y pe: Korthals s.n., s.d. (holo B, no. 52; iso BO, L?), Sumatra occid.

Cyclophorus winkleri Rosenst., Feddes Rep. 7 (1909); C. Chr., Ind. Fil. Suppl. (1913) 23; Alderwerelt, Malayan Ferns Suppl. (1917) 413.-Pyrrosia winkleri Tagawa. Acta Phvtotax. Geobot. 25 (1973) 180. - Ty pe: J. Winkler (Rosenstock Fil. Sumatr. Exsicc. 66), (B, BM, K, L, M, P, US), Sumatra, Pea Radja, Taroetoeng.

Cyclophorus grandis Ridley J. Mal. Br. R. As. Soc. 1 (1923) 112.-Type: Ridley s.n., (Febr. 1921)

(K), Sumatra, Berastagi.

Rhizome long-creeping, not grooved ventrally, (1.2) $2.7-5 \mathrm{~mm}$ thick, phyllopodia 3-7 cm apart, lateral buds situated \pm halfway down the internodia. Anatomy: ground tissue parenchymatous, sclerenchyma sheath distinct, sclerenchyma strands scattered through the inner parenchyma, 0-many; vascular strands (5) 8-15. Scales peltate, 8-14 $\times 1.1-1.3 \mathrm{~mm}$; base \pm entire; acumen shining brown, towards the apex increasingly dentate. Fronds monomorphic, stipitate; stipes up to $2 \mathrm{~cm}$, lamina; lamina, index 5 to \pm over 20 ; widest below the middle, $22-62(-97) \times 2.5-5.5 \mathrm{~cm}$, base truncate or \pm cordate to attenuate, apex mostly acute, occasionally obtuse. Venation: secondary veins distinct, with the tertiary veins forming regular areoles; included veins much branched, frequently anastomosing; free veins many, pointing to all directions. Hydathodes absent. Anatomy: stipe with 4-6 central and no lateral vascular strands; lamina \pm 0.5 $\mathrm{mm}$ thick, upper epidermis with flat cells with strongly thickened walls, hypodermis absent but a distinct, moderately thick water-tissue present, palissade and spongy parenchyma distinct, lower epidermis with strongly thickened cellwalls: stomata superficial. pericvtic. Indument mono- to dimorphic, a dense mat, persistent, brown to greyish-brown; upper layer composed of hairs 0.6-1.6 mm in diam., with erecto-patent acicular rays, often more or less mixed with a lower layer composed of hairs with mainly woolly rays. Sori apical, slightly spaced, separate, superficial; 2 (3) in each soriferous areole, not confluent; $1.5-3 \mathrm{~mm}$ in 


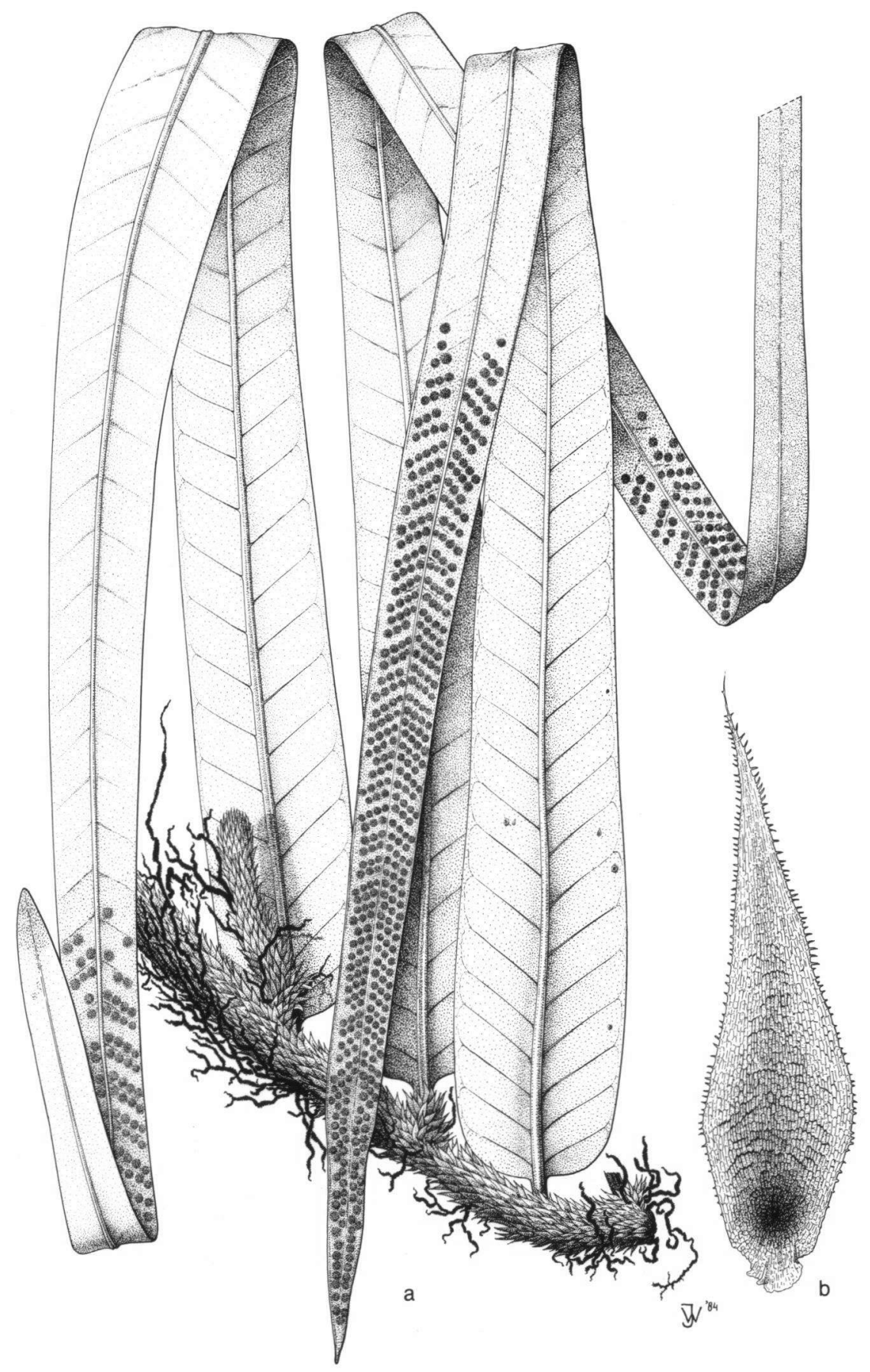

Fig. 34. P. distichocarpa. a. Habit $\times 1 / 2 .-$ b. Rhizome scale $\times 8$. (a. Bartlett $6576, \mathrm{~L}$; - b. Bünnemeijer 4jj, ij. 
diam.; developing from the apex downwards, when old individually distinct, exserted from the indument. Sporangia on stalks up to $2 \times$ as long as the capsule, capsule $0.3-0.4 \mathrm{~mm}$ high, with 18-19 indurated annulus cells. Paraphyses mixed with the sporangia, with slender, \pm curled rays. Spores (54-)63.4-78.2(-90) $\times$ (38-)44.0-52.6(-62) $\mu \mathrm{m}$, with irregular ridges and protuberances.

Habitat: Mostly epiphytic, in various situations, (tall trees in primary forest, hedgerows, orchards, and wayside trees); occasionally epilithic. Probably confined to seasonally dry 'pockets' in Sumatra.

Altitudinal range: $750-1900 \mathrm{~m}$.

SUMATRA. 43 collections (mainly from the mountains around Lake Tawar, G. Leuser, Lake Toba, and Padang Pandjang).

Notes. 1. An easily recognized species. The rhizome scales are large and conspicuous, and have their greatest width distinctly above the point of attachment. The only other sneries with rhiznme srales thwe shaned is $P$. albicans, which has entire scales. $P$. distichocarpa has coarse marginal teeth on the scales, each one formed by two projecting cells (plate $2 \mathrm{f}$; fig. $34 \mathrm{~b}$ ).

2. The woolly hairs of the indument do not form a distinct layer. In some specimens (e.g., Rahmat si Boeea 11013, Surbeck 666) woolly hairs are absent; in most specimens, however, a few woolly rays can always be found interspersed with the acicular rays.

3. Variability: The base of the lamina is either distinctly truncate-cordate or gradually attenuate. Both shapes, however, may occur in a single collection (e.g., Lörzing 6078), the distinction thus cannot be used to separate a fo. attenuata (Rosenst., ined.).

4. Vernacular names: Hare-hare-dolok (Tapianoeli)

\section{Pyrrosia drakeana (Franch.) Ching. Fig. 17.}

Pyrrosia drakeana Ching, Bull. Chin. Bot. Soc. 1 (1935) 65; Ching, Ic. Fil. Sin. (1935) pl. 148; Fu, Ill. Imp. Chin. Pl. (1957) 239; Ching * Wu, Fl. Xizang. 1 (1983) 340; Shing, Amer. Fern J. 73 (1983) 76.-Polypodium drakeanum Franch., Pl. David. 1 (1884) 355; Franch., Pl. David. 2 (1988) 161; Baker, Ann. Bot., Lond. 5 (1891) 472; Christ, Bull. Herb. Boiss. 6-11 (1898) 871. - Niphobolus drakeanus Diels, Bot. Jb. 29 (19.00) 206, p.p.; Giesenh., Niphobolus (1901) 117 p.p.; Christ, Bull. Acad. int. Géogr. bot. 9 (1902) 223, q.n.s.; Christ, Bull. Soc. Fr. 52 Mém. 1 (1905) 25 p.p.-Cyclophorus drakeanus C. Chr., Ind. Fil. (1906) 198; Christ, Bull. Acad. int. Géogr. bot. 20 (1909) 175; Christ, Geogr. der Farne (1910) 11; H. Lev., Fl. Kouy-Tchéou (1915) 478, p.p.?; Hand.-Mazz., Symb. Sin. VI (1929) 45; C. Chr., Contr. U.S. Nat. Herb. 26 (1931) 326.-T y pe: David s.n., s.d., (holo P), China, 'Monts Tsingling'.

Niphobolus drakeanus fo. elongata Christ ex Diels, Bot. Jb. 29 (1900) 207.-T y pe: Von Rosthom 3123 (B), China.

Rhizome short, not grooved ventrally, 3.5-7 mm thick, phyllopodia contiguous (up to $1 \mathrm{~cm}$ distant), lateral buds situated on or shortly behind the internodia. Anatomy: ground tissue parenchymatous, sclerenchyma sheath distinct, sclerenchyma strands scattered through the inner parenchyma, many; vascular 
strands 6-10. Scales pseudopeltate, 2.5-6.2 $\times 0.6-1.2 \mathrm{~mm}$; base irregularly dentate to ciliate; acumen dull brown to blackish with a straw-coloured margin, dentate to ciliate. Fronds monomorphic, stipitate; stipes $8.5-24.5 \mathrm{~cm},(1 / 2-) 1-2 \times$ as long as the lamina; lamina, index 2.5-5; widest below the middle, 8.5-25 $\times 2.4-8$ $\mathrm{cm}$, base truncate to \pm abruptly cuneate, usually unequal, a few $\mathrm{cm}$ narrowly decurrent, sometimes with an obtuse, short tooth on one side, apex obtuse, acute, or acuminate. Venation: secondary veins distinct, with the tertiary veins forming regular areoles; included veins frequently forked or branched, frequently anastomosing; free veins ? (note 3). Hydathodes distinct, scattered over the lamina, superficial to slightly prominent. Anatomy: stipe with \pm 7 central and \pm 3 lateral vascular strands; lamina $0.4-0.6 \mathrm{~mm}$ thick, upper epidermis with distinctly projecting cells with slightly thickened walls, hypodermis composed of 1 cell-layer, water-tissue absent, palissade and spongy parenchyma very distinct, lower epidermis with slightly to strongly thickened cell-walls; stomata slightly prominent. pericytic. Indument

layer composed of hairs (0.8-)1-1.6 mm in diam., with erecto-patent, acicular rays, \pm mixed with a lower layer composed of hairs with woolly rays. Sori all over the lamina or in an ill-defined patch, slightly spaced, superficial; many scattered throughout each soriferous areole, not confluent; $0.5-1 \mathrm{~mm}$ in diam.; developing more or less simultaneously, when old individually distinct, immersed in the indument. Sporangia sessile or on stalks up to $1 / 3 \times$ as long as the capsule, capsule 0.3-0.4 mm high, with 17-20 indurated annulus cells. Paraphyses not differentiated. Spores (64-)69.2-82.8(-86) × (46-) 50.2-54.8(-58) $\mu \mathrm{m}$, densely granulate.

Habitat: Usually epilithic or terrestrial, mostly in sheltered situations, sometimes epiphytic.

Altitudinal range: $1500-3500 \mathrm{~m}$, reaching highest altitudes at lower latitudes (see also note 3 under $P$. sheareri).

CHINA. Tibet: Kingdon-Ward 19235 (BM), Ludlow et al. 5362 (BM), 6683 (BM), 6985 (BM), 12053 (BM). - Shensi: 10 collections. - Kansu: Licent 4934 (BM, P). - Hupeh: Wilson 2629 (B, BM, E, K, P), SABE 18 (NA), 519 (NA). - Szechuan: 25 collections. - Yunnan: 33 collections.

INDIA. Assam: Panigrahi BSI $15714(\mathrm{~K})$.

Notes. 1. $P$. drakeana is often confused with $P$. sheareri. It can be distinguished by the dimorphic indument, the larger, acicular rays of the hairs, and the sori that are immersed in the indument even when ripe. Moreover, $P$. drakeana usually has a relatively longer stipe and a relatively wider lamina.

Several specimens, however, mainly from Szechuan, are intermediate with regard to some characters (Dai 104588, Von Rosthorn 1713, Wilson 5323, Fang 3056. 3966, 12848, but the specimen of Fang 3966 in SING is $P$. sheareri in all characters). These have relatively small hairs (diam. less than $1 \mathrm{~mm}$ ) with more appressed and more distinctly boat-shaped rays than is usual in $P$. drakeana, and the sori are more exserted from the indument. With $P$. drakeana these specimens 
share the dimorphism of the indument, the relatively long stipes, and the wide lamina.

2. Confusion is also possible between $P$. drakeana and $P$. boothii. Usually the much larger fronds of $P$. boothii are characteristic; however, small fronds may be distinguished from $P$. drakeana by the more cuneate base, the less dense indument, the more exserted sori and the slightly sunken stomata. $P$. boothii is not a common species, and more extensive collecting may show that the transition between $P$. drakeana and $P$. boothii is more gradual than can be anticipated from the material at hand.

3. Due to the very coriaceous texture the detailed configuration of the included veins could not be studied.

\section{Pyrrosia eleagnifolia (Bory) Hovenkamp. Fig. 26.}

Pyrrosia eleagnifolia Hovenkamp, Blumea 30 (1984) 208. - Polypodium eleagnifolium Bory in Dup., Voy. Bot. 1 (1829) 259. - Type: Lesson s.n., s.d., (holo L, fragment), New Zealanu, Däı ues 11es.

Polypodium serpens et syn. homot., auct. non Forster; quoad specim. Nov.-Zeel.: Cunningham, Hooker Comp. Bot. Mag. 2 (1836) 363; Baker in Hooker Baker, Syn. Fil. (1867) 349; Giesenh., Niphobolus (1901) 179, 219, 223; Domin, Bibl. Bot. 85 (1914) 187; Allan, Fl. New Zeal. 1 (1961) 44; Sykes, Kermadec I. Flora (1977) 69.

Polypodium rupestre et syn. homot., auct. non $\mathrm{R}$. Br.; quoad specim. Nov.-Zeel. : Cunningham, Hooker Comp. Bot. Mag. 2 (1836) 363; Presl, Epim. Bot. (1851) 128; Brack., U.S. Expl. Exp. (1854) 36; Alderwerelt, Malayan Ferns (1909) 680.

Rhizome long-creeping, shallowly to distinctly grooved ventrally, (1-)1.5-2 $\mathrm{mm}$ thick, phyllopodia $1.5-4 \mathrm{~cm}$ apart, lateral buds situated more than halfway down the internodia. Anatomy: ground tissue parenchymatous, sclerenchyma sheath distinct, sclerenchyma strands absent; vascular strands 4-6. Scales peltate, 3-10 $\times 0.6-1.8 \mathrm{~mm}$; base entire, with $0-2$ shortly stalked marginal glands; acumen shining light brown, entire to dentate. Fronds dimorphic, stipitate. Fertile fronds: stipes $0.2-5 \mathrm{~cm}, 1 / 10^{-1 / 2(-1)} \times$ as long as the lamina; lamina, index $2-13$; widest about the middle to \pm linear, $1-13 \times 0.6-2.2 \mathrm{~cm}$, base attenuate, apex rounded to acute. Sterile fronds: stipes $0.2-3.5 \mathrm{~cm}$; lamina, index 1-4 (-11); widest about to above the middle, $1-9 \times 0.5-3 \mathrm{~cm}$, base truncate to attenuate, apex rounded to obtuse; otherwise similar to the fertile fronds. Venation: secondary veins indistinct, with the tertiary veins forming \pm irregular areoles; included veins frequently forked and anastomosing; free veins few, mainly excurrent. Hydathodes absent. Anatomy: stipe with 3 central and no lateral vascular strands; lamina $\pm 1.4 \mathrm{~mm}$ thick, upper epidermis with flat cells with slightly thickened walls, hypodermis composed of 1 cell-layer and an indistinct water-tissue present, palissade and spongy parenchyma indistinct, lower epidermis with slightly thickened cell-walls; stomata sunken, pericytic. Indument monomorphic, a dense mat, persistent, light whitish brown; hairs 0.5-1(-1.8) $\mathrm{mm}$ in diam., with appressed, boat-shaped to \pm acicular rays. Sori apical to all 
over the lamina, slightly spaced, distinctly sunken; $2-3$ in a row in each soriferous areole, occasionally confluent along the veins; $1.5-4 \mathrm{~mm}$ in diam.; developing from the apex downwards, when old individually distinct, exserted from the indument. Sporangia on stalks $1.5-2 \times$ as long as the capsule or somewhat more, capsule 0.3-0.4 mm high, with (14) 18-22 indurated annulus cells. Paraphyses mixed with the sporangia, with short, straight rays. Spores (66-)73.4-82.8(-92) $\times(42-) 53.0-57.0(-72) \mu \mathrm{m}$, bisculptate.

Habitat: Usually epiphytic or epilithic, sometimes terrestrial, in sheltered as well as exposed situations; often on coastal rocks.

Altitudinal range: Sea-level to $800 \mathrm{~m}$

NEW ZEALAND. North Island: 28 collections. - South Island: 27 collections. - Stewart Island: Lysaght 33 (BM), Schweinfurth 94 (M). - Chatham Island: Kruk s.n., s.d. (B), Scott s.n., (12-1871) (US), Travers s.n., s.d. (P).

NORFOLK ISLAND. Cunningham 33 (U).

KERMADEC ISLANDS. Cheeseman 110 (K), McGillivray (?3, H.M.S. Herald 958 B) (B), Milne $61(\mathrm{~K}), 62(\mathrm{~K})$, Sykes 267-K (K).

Doubtful localities.

NEW CALEDONIA. Ile des Pins: Vieillard 91 (P).

SAMOA. W. Fasken 179 (BM).

AITSTR AI.IA. Stranore s n s.d. (RM).

'Polypodium spissum Willd.' (P).

Notes. 1. P. eleagnifolia has been confused with $P$. serpens (Forster) Ching and $P$. rupestris $(\mathrm{R}$. Br.) Ching. Diagnostic differences are given under those species. The confusion with $P$. serpens is due to Forster's mislabelling of his specimen as collected in New Zealand. That his specimen differs from the common New Zealand species was already noted by Giesenhagen (1901), who cited it under Niphobolus tricholepis, but did not draw the necessary nomenclatural consequences. As a similar mislabelling of a Forster specimen is known in $P$. longifolia (Copeland, B. P. Bish. Mus. Bull. 93 (1932) 66), it is almost certain that Forster's specimen is not from New Zealand but from one of the other Pacific Islands he also visited.

2. Variability: Specimens from the Kermadec Islands deviate in having rhizome scales with a narrowly \pm tubular acumen that is more strongly dentate than in typical $P$. eleagnifolia. The base of the scale of these specimens also consistently lacks marginal glands.

3. In a few specimens (Helms, s.n., 1882-1883 (M), Lambrechtsen $10 \mathrm{~A}(\mathrm{~L})$ ) the rhizome is in some places densely and fastigiately branched. According to a note to Lambrechtsen $10 \mathrm{~A}$ this is a gall due to a mite (Aceria spec.). A similar aberration is found in several specimens of $P$. confluens (see note 2 under that species). In $P$. eleagnifolia the gall is apparently not restricted to a single locality.

4. The rhizome scales may show a few annular figures in the cells as described under $P$. confluens. 
5. There is a single record for $P$. eleagnifolia from New Caledonia (Vieillard 91, $P$ ), and it has not been found there since. I suspect that this specimen has been mislabelled.

6. Typification: no original specimen could be traced in $P$, where most of Bory's material is located. In $\mathrm{L}$ there is a small fragment labelled 'Polypodium Eleagnifolium Bory Coquille, Nouvelle Zélande, partagé en 1834 avec le savant Blume' in what is almost certainly Bory's handwriting. Lesson collected during the trip of the Coquille, and I have no doubt that this is part of the original collection.

\section{Pyrrosia fallax (Alderw.) Price}

Fully treated in Ravensberg * Hennipman (1986).

\section{Pyrrosia flocculosa (D. Don) Ching. Fig. 19.}

Pyrrosia flocculosa Ching, Bull. Chin. Bot. Soc. 1 (1935) 66; C. Chr. \& Tard., Not. Syst. 8 (1939) 205; Tard. C. Chr., Fl. Indo-Ch. (1941) 512; Nayar, J. Ind. Bot. Soc. 40 (1961) 164-186; Nayar Chandra, Bull. Nat. Bot. Gard. Lucknow 117 (1965); Nayar \& S. Chandra, Can. J. Bot. 45 (1967) 615-634; H. Hara, Fl. Eastern Himal. (1966) 498; Tagawa \& Iwatsuki, Acta Phytotax. Geobot. 24 (1969) 61; H. Hara, Fl. Eastern Himal., 2nd Rep. (1971) 219; Bir Shukla, Nova Hedw. 21 (1972) 195; Morton, Contr. U.S. Nat. Herb. 38 (1973) 257; Nayar * Kaur, Comp. Bedd. Handb. (1974) 81.-Polypodium flocculosum D. Don, Prodr. Fl. Nepal. (1825) 1; Baker in Hooker \& Baker, Syn. Fil. (1867) 351; Christ, Bull. Herb. Boiss. 611 (1898) 872; Hope, J. Bomb. Nat. Hist. Soc. 15 (1903) 88.-Niphobolus flocculosus Spr., Syst. 4 (1827) 45; J. Sm. Hooker J. Bot. 4 (1842) 57; Kunze, Linnaea 24 (1851) 258; J. Sm., Hist. Fil. (1875) 98; Bedd., Suppl. Ferns S. \& Br. Ind. (1876) 22; Bedd., Handb. ferns Brit. Ind. (1883) 331, fig. 180; Giesenh., Niphobolus (1901) 125.-Apalophlebia flocculosa Presl, Epim. Bot. (1851) 139. Cyclophorus flocculosus C. Chr., Ind. Fil. (1906) 199; C. Chr., Contr. U.S. Nat. Herb. 26

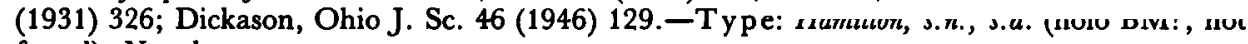
found), Nepal.

Polypodium tomentosum Roxb., Calc. J. Nat. Hist. IV (1844) 483, nom. illeg.; [non Polypodium tomentosum Thouars, Fl. Trist. da C. (1804) 32, pl. 3, = Thelypteris tomentosa (Thouars) Ching; nec Polypodium tomentosum Bory in Bél., Voy. Ind. Or. 2 Bot. (1833), nom. illeg., = ? Dryopteris, type from Mauritius]; Morton, Contr. U.S. Nat. Herb. 38 (1974) 364.-Lectotype (Morton, 1974): Roxburgh, E. Ind. Comp. Herb. 269-3 (K, not found), India.

Polypodium detergibile Hooker, Sp. Fil. 5 (1863) 49; Morton, Contr. U.S. Nat. Herb. 38 (1974) 364.- Niphobolus detergibilis Bedd., Ferns Br. India (1868) pl. 162. - Lectotype (Morton, 1974): Sirachey and Winterbottom 2 (Morton, l.c.: '402', K), India.

Niphobolus annamensis Christ, J. Bot. Paris 19 (1905) 74.-Cyclophorus annamensis C. Chr., Ind. Fil. (1906) 198; Bonap., Notes Ptérid. 7 (1918) 126, 190. - T y pe: Cadière 38 (P, BM), Indo-China.

Cyclophorus thomboidalis Bonap., Notes Ptérid. 7 (1918) 126, 191; C. Chr., Ind. Fil. Suppl. 3 (1934) 65.-Pyrrosia thomboidala Ching, Bull. Chin. Bot. Soc. 1 (1935) 72.-Pyrrosia mollis fo. rhomboidalis C. Chr. Tard., Not. Syst. 8 (1939) 206. -Synt y pes: Eberhardt 106 (P, BM); 119 (P), Indo-China.

Rhizome short, not grooved ventrally, 3.4-6 mm thick; phyllopodia close together, lateral buds situated on the phyllopodia. Anatomy: ground tissue parenchymatous, sclerenchyma sheath distinct, sclerenchyma strands scattered through 
the inner parenchyma, 10- \pm 25; vascular strands 10-13. Scales pseudopeltate, 4-5.7 $\times 0.5-1.0 \mathrm{~mm}$; base entire to irregularly dentate; acumen dull brown to blackish, dentate, entire towards the apex. Fronds monomorphic, stipitate; stipes 4-21 cm, 1/4-1 $\times$ as long as the lamina; lamina, index 3-12; widest about or below the middle, often slightly lyrate, $9-32 \times 1.3-7.8 \mathrm{~cm}$, base cuneate to truncate, occasionally \pm cordate, apex acuminate, occasionally acute. Venation: secondary veins distinct, with the tertiary veins forming regular areoles; included veins simple, forked, or branched, occasionally anastomosing; free veins many, mainly excurrent. Hydathodes distinct, scattered over the lamina, superficial to distinctly pitted. Anatomy: stipe with \pm 9 central and \pm 3 lateral vascular strands; lamina $0.3-0.6 \mathrm{~mm}$ thick, upper epidermis with distinctly projecting cells with thin walls, hypodermis absent or composed of 1 cell-layer, water-tissue absent, palissade and spongy parenchyma distinct, lower epidermis with thin cellwalls; stomata slightly sunken, pericytic. Indument dimorphic, a thin to dense mat, persistent, light dirty greyish; upper layer composed of hairs $0.3-2.2 \mathrm{~mm}$ in diam., with erecto-patent to appressed, boat-shaped to acicular rays, \pm mixed with a lower layer composed of hairs with mainly woolly rays. Sori apıcal to all over the lamına, sligntly spaced in an il-detıned patch, superncial; several in a single row in each soriferous areole, often elongated along the veins, 1-1.5 mm in diam.; developing from the apex downwards, when old individually distinct, exserted from the indument. Sporangia on stalks $1 / 3-1 \times$ as long as the capsule, capsule $0.3-0.5 \mathrm{~mm}$ high, with 15-21 indurated annulus cells. Paraphyses not differentiated. Spores (62-)67.8-88.8(-96) $\times(40-) 43.8-57.8(-64) \mu \mathrm{m}$, finely and sparsely granulate.

Habitat: Mostly epiphytic, recorded from Pine, Mango and Oak; sometimes epilithic, in sheltered places; occasionally terrestrial, e.g., on stream banks.

Altitudinal range: Low altitudes to $2400 \mathrm{~m}$.

NEPAL. 8 collections.

BHUTAN. 6 collections.

BANGLA DESH. Clarke 18514 (K).

INDIA. Punjab * Himachal Pradesh: Edgeworth s.n., s.d. (K), Stewart \& Stewart 2077 (US), Trotter s.n., (6-1886) (M). - Uttar Pradesh: 26 collections. - Sikkim \& Darjeeling: 15 collections. - Assam: 18 collections.

BURMA. Dickason 6747 (GH), Lace 4915 (K), Rock 7462 (US).

THAILAND. Northern: Hennipman 3352 (B, K, L, U, Z).

VIETNAM. 16 collections (Annam Tonkin).

Notes. 1. Variability: the indument varies from a very thin, appressed mat to a dense one with shaggy hairs, but no other characters can be found that correlate with this difference.'The transition between the two types of indument is gradual. In northern Indo-China a form occurs (which has been called $P$. annamensis and $P$. rhomboidalis) with a more coriaceous texture, often narrowly inrolled fronds, and relatively longer stipes. If this form has a thin indument, it is at first sight 
difficult to distinguish from long-stipitate forms of $P$. subfurfuracea; however, the ciliate scales of the latter are characteristic. Similar plants occur more sporadically in Bhutan.

2. Uses: 'Employé contre les maux de gorge' (Annam, note to Poilane 10223).

\section{Pyrrosia foveolata (Alston) Morton. Fig. 25, 35.}

Rhizome long-creeping, narrowly grooved ventrally, 1-2.6 $\mathrm{mm}$ thick; phyllopodia 1-3 cm apart, lateral buds situated \pm opposite the phyllopodia. Anatomy: ground tissue parenchymatous, sclerenchyma sheath distinct, usually a single, central sclerenchyma strand present, sometimes sclerenchyma strands absent; vascular strands 5-7(-10). Scales peltate, 4-9.5 × 0.5-1.4 mm; base entire; acumen hyaline to light brown, entire or dentate to ciliate; short, \pm round to ovate scales occasionally present. Fronds slightly to distinctly dimorphic, distinctly or indistinctly stipitate. Fertile fronds: stipes to $1-11 \mathrm{~cm}, 1 / 10^{1 / 2} \times$ as long as the lamina; lamina, index (5-)8 to \pm over 20 ; widest about or below the middle, $(2.3-) 5-27 \times 0.2-1.7 \mathrm{~cm}$, base cuneate to attenuate, apex acute to narrowly acuminate. Sterile fronds: stipes to $0.5-6.5 \mathrm{~cm}$; lamina; index (1-)2-15; widest about the middle, $1-18.5 \times 0.3-1.8 \mathrm{~cm}$, base cordate to attenuate, apex sometimes round or obtuse; otherwise similar to the fertile fronds. Venation: secondary veins distinct, with the tertiary veins forming regular areoles; included veins simple or rarely forked, free, excurrent. Hydathodes absent or indistinct, scattered over the lamina. Anatomy: stipe with \pm 4 central and no lateral vascular strands; lamina 0.5-1.0 mm thick, upper epidermis with flat cells with moderately thickened walls, hypodermis absent but an indistinct water-tissue present, palissade and spongy parenchyma distinct. lower epidermis with thickened cell-walls: stomata sunken. pericytic. Indument monomorphic, a thin mat, often fugacious; hairs $0.2-0.8 \mathrm{~mm}$ in diam., with appressed, boat-shaped rays. Sori apical, closely packed but distinctly separate, deeply sunken, not contluent, $1-3$ in each soriferous areole, $1.5-2.5 \mathrm{~mm}$ in diam.; when old individually distinct, exserted from the indument. Sporangia on stalks $1.5-2 \times$ as long as the capsule, capsule $\pm 0.3 \mathrm{~mm}$ high, with 15-20 indurated annulus cells. Paraphyses mixed with the sporangia, with short, straight rays. Spores (64-)73.2-78.4(-86) $\times(44-) 50.8-61.0(-70) \mu \mathrm{m}$, bisculptate.

Key to the varieties

- fronds only moderately dimorphic, fertile fronds usually over $0.5 \mathrm{~cm}$ wide a. var. foveolata

- fronds strongly dimorphic, fertile fronds less than $0.5 \mathrm{~cm}$ wide

b. var. lauterbachii 


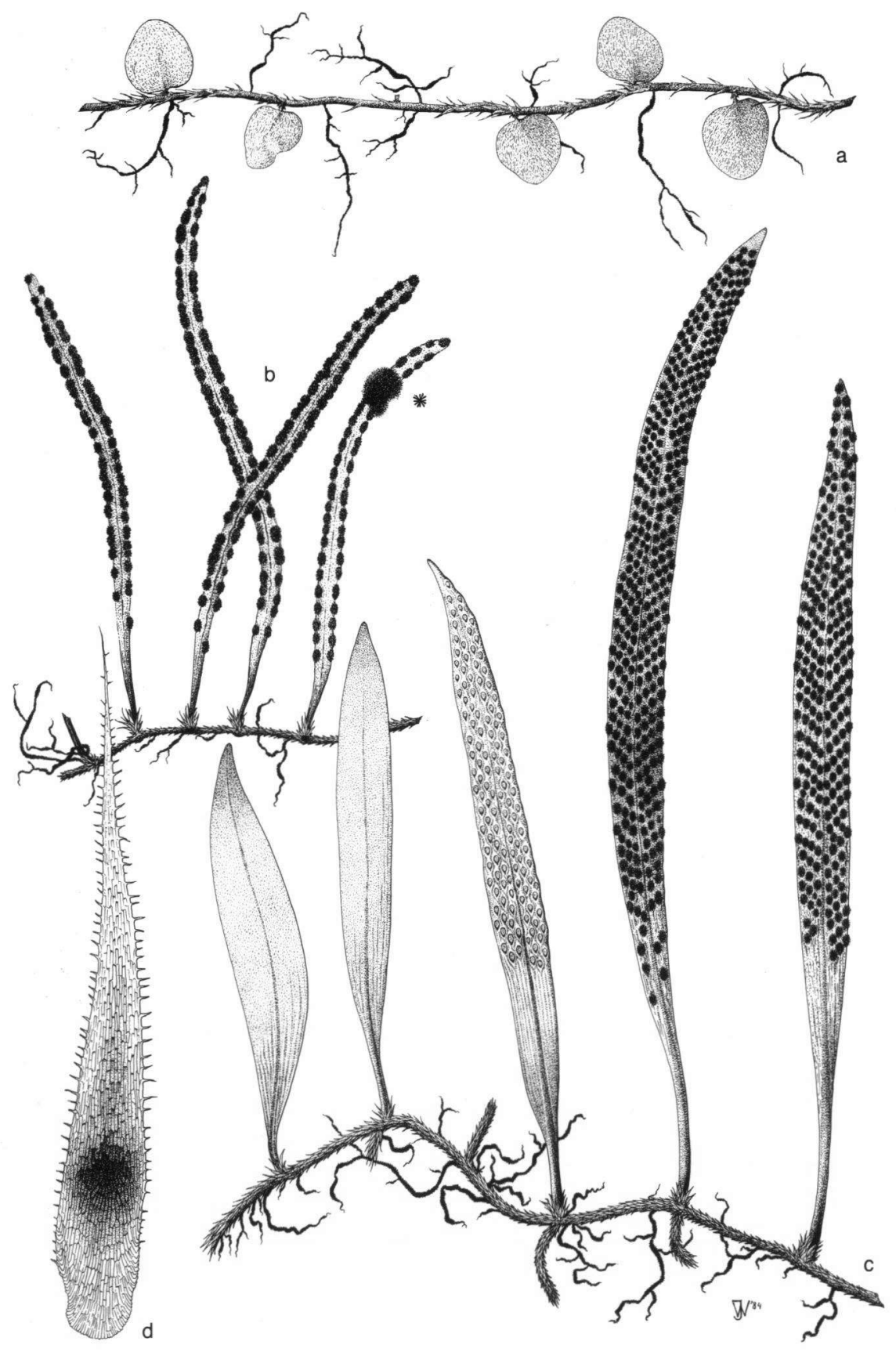

Fig. 35. P. foveolata. a. var lauterbachii, rhizome with sterile fronds $\times 1$. - b. var. lauterbachii, fertile fronds (*: galled receptacles) $\times 1$. - c. var. foveolata, habit $\times 3 / 4 .-$ d. var. foveolata, rhizome scale × 19 (a, b. Pulle 128, L; - c. Brass 31095, A, L; - d. Veldkamp \& Stevens 5509, L). 
a. var. foveolata. Fig. 35 c, d.

Pyrrosia foveolata Morton, Contr. U.S. Nat. Herb. 38 (1973) 234. - Cyclophorus foveolatus Alston, J. Bot. Lond. 78 (1940) 226; Alston, Nova Guinea N.S. 4 (1940) pl. 4 fig. 4. -Ty pe: Carr 13039 (holo BM, iso K, L, SING), New Guinea.

Cyclophorus brassii Copeland, Univ. Calif. Publ. Bot. 18 (1948) 226. - Pyrrosia brassii Pic. Ser., Webbia 31 (1977) 249.-Type: Brass 11372 (A, BM, L), New Guinea.

Rhizome 1-2.6 mm thick. Scales 4.2-8.8 $\times 0.5-1.4 \mathrm{~mm}$; entire or dentate to ciliate. Fronds slightly dimorphic, stipitate. Fertile fronds: stipes $1-11 \mathrm{~cm}$; lamina, index (5-)8 to over $20 ; 5-27 \times 0.4-1.7 \mathrm{~cm}$. Sterile fronds: stipes $0.5-6.5 \mathrm{~cm}$; lamina; index $2-15 ; 2-18.5 \times 0.6-1.8 \mathrm{~cm}$, base cuneate to attenuate, apex sometimes obtuse; otherwise similar to the fertile fronds. Hydathodes absent or indistinct, scattered over the lamina. Sori 2-3 in each soriferous areole.

Habitat: Usually epiphytic in primary or secondary forest, often in mountain forest; occasionally on solitary trees, e.g., in savannahs; often near rivers; sometimes epilithic.

Altitudinal range: (550-)1000-2100 m.

MOLUCCAS. Bacan: De Vogel 3680 (L). -Obi: De Vogel 4129 (K, L).

NEW GUINEA. Irian Jaya: 8 collections. - Papua New Guinea: 28 collections.

BISMARCK ARCHIPELAGO. New Ireland: Croft 65281 (L), Sands et al. 2129 (K).

Notes. 1. $P$. foveolata var. foveolata is often confused with $P$. lanceolata. It can be distinguished from $P$. lanceolata by the larger sori, in which paraphyses and sporangia are completely mixed. Apart from that, the rhizome scales of $P$. foveolata are, if ciliate, more sparsely so than those of $P$. lanceolata.

2. Variability: entire or dentate rhizome scales are found mainly on the thinner rhizomes (or rhizome parts), whereas on thicker rhizomes some cilia almost always are present. This seems to be a difference in development rather than a taxonomic distinction; both types of scales may occur in the same collection. Hydathodes may be absent or present, but there is no correlation with the heterogeneity in rhizome scales nor with any other character.

3. Vernacular names: Bobola (Eipomek); Taitpook (Dani, Baliem Valley).

\section{b. var. lauterbachii. Fig. 35 a, b.}

Pyrrosia foveolata (Alston) Morton var. Lauterbachii Hovenkamp, Blumea 30 (1984) 208. - Niphobolus lauterbachii Christ in Schumann * Lauterb., Fl. Schutzgeb. Süds. (1901) 142; Giesenh., Niphobolus (1901) 221, fig. 20.-Cyclophorus lauterbachii C. Chr., Ind. Fil. (1906) 199; Alderwerelt, Malayan Ferns (1909) 690; Brause, Bot. Jb. 56 (1920) 207.-Pyrrosia lauterbachii Ching, Bull. Chin. Bot. Soc. 1 (1935) 49.-Lectotype: Lauterbach 519 b (holo P, iso BO, L, SING), New Guinea.

Cyclophorus dispar Christ, Nova Guinea 8 (1909) 155; Alderwerelt, Bull. Jard. bot. Buitenz. II, 1 (1911) 4, pl. 2 fig. 2, 3; C. Chr., Ind. Fil. Suppl. (1913) 22; Alderwerelt, Malayan Ferns Suppl. (1917) 410; Brause, Bot. Jb. 56 (1920) 207; Copeland, J. Arn. Arb. 24 (1943) 443. - Pyrrosia dispar Shing, Amer. Fern J. 73 (1983) 77. - Syntypes: Versteeg 1254 (B, BO, K, L, U, US); 1532 (B, BM, BO, K, L, P, U), New Guinea. 
Rhizome 1-1.2 mm thick. Scales 4-9.5 $\times 0.5-1.0 \mathrm{~mm}$; entire. Fronds distinctly dimorphic, not or indistinctly stipitate. Fertile fronds: stipes to $2 \mathrm{~cm}$; lamina, index \pm 5 to over $20 ; 2.3-16 \times 0.2-0.5 \mathrm{~cm}$. Sterile fronds: stipes up to $1 \mathrm{~cm}$; lamina, index $1-8 ; 1-5.5 \times 0.3-1 \mathrm{~cm}$, base cordate to cuneate, apex rounded to acuminate. Hydathodes absent. Sori 1-2 in each areole.

Habit at: Epiphytic, on mossy branches, silted trunks, leaning trees; generally at lower altitudes than the type variety.

Altitudinal range: $100-1000 \mathrm{~m}$.

NEW GUINEA. Irian Jaya: Pulle 128 (BM, BO, L, U), 244 (BM, L), Versteeg 1254 (B, BO, K, L, U, US), 1532 (B, BM, BO, K, L, P, U). - Papua New Guinea: 15 collections. L).

BISMARCK ARCHIPELAGO. New Ireland: Dissing et al. 2343 (K), Croft LAE 68294 (BM,

Notes. 1. The most pronouncedly dimorphic fronds occur in collections from low altitudes (up to $500 \mathrm{~m}$ ). Less distinctly dimorphic forms (e.g., Clemens 155, Croft $L A E 68294$ ) occur at higher altitudes (to $1000 \mathrm{~m}$ ). These are \pm transitional to the type variety, which occurs generally above $1000 \mathrm{~m}$. It may be that the transition from the tvpe varietv to var. lauterbachii is a more or less gradual one. In that case, the apparent discontinuity in the variation represented in the collections at hand may be due to the scarcity of specimens from intermediate altitudes; this, in its turn, may be due to the extensive deforestation at these elevations due to population pressures (R.J. Johns, pers. comm.).

2. Occasionally plants are infested by a galling Sawfly (Blasticotoma spec., det. Dr. J.C. Roskam, Leiden). This gall infests the receptacle and causes it to enlarge strongly so that it protrudes from the soral cavity. The formation of sporangia is suppressed, in favour of the formation of large numbers of long-stalked paraphyses. The bundles of paraphyses thus formed are visible as distinct 'puffs' on the fertile fronds (fig. $35 \mathrm{b:}{ }^{*}$ ). On each infested frond usually several receptacles are galled. Van Alderwerelt Van Rosenburgh (1911, p. 4, plate 2: a) erroneously interpreted this as a '(...) lidlike, introrse, deciduous, lateral outgrowth of the leaf-tissue (...) covered with (...) hairs' covering the young sori, and illustrated it as such.

These galls occur in Versteeg 1254, Versteeg 1532, Pulle 128, Schlechter 19020. Obviously they are not restricted to a single locality. It is curious that the gall is completely absent from the type variety, which is much more common at higher altitudes than var. lauterbachii is at lower altitudes. This indicates that the galling fly is restricted to lower altitudes.

\section{Pyrrosia gardneri (Mett.) Sledge. Fig. 21 b.}

Pyrrosia gardneri Sledge, Bull. Br. Mus. (Nat. Hist) Bot. 2 (1960) 134; Nayar Kaur, Comp. Bedd. Handb. (1974) 81. - Polypodium gardneri Mett., Polyp. (1856) 129, Thwaites, Enum. Pl. Zeyl. (1864) 395; Hooker, Sp. Fil. 5 (1863) 51, Baker in Hooker \& Baker, Syn. Fil. (1867) 352.- 
Niphobolus gardneri J. Sm., Cat. Cult. Ferns (1857) 12; Hooker, Fil. Ex. (1859) pl. 68; Bedd., Ferns S. India (1864-5) 81, pl. 241; J. Sm., Hist. Fil. (1875). 98; J. Sm., Ferns Br. \& For. ed. 2 (1877) 100; Bedd., Handb. ferns Brit. Ind. (1883) 331, fig. 181; Giesenh., Niphobolus (1901) 145. - Niphobolus gardneri Kunze ex T. Moore, Ind. Fil. (1857) lxxvi, nom. nud.; T. Moore, Ind. Fil. (1861) pl. 61 fig. 1-5. - Cyclophorus gardneri C. Chr., Ind. Fil. (1906) 199; Willis, Cat. Pl. Ceyl. (1911) 123. - Type: Gardner 53 (holo $\mathrm{K}$, iso in P), Ceylon.

Gyrosorium angustatum Presl, Epim. Bot. (1851) 141; Holttum, Nov. Bot. Inst. Bot. Univ. Car. Prag. (1968) 33. - Ty pe: Huegel (PRC, teste Holttum, 1968, photograph K), Philippines.

Rhizome shortly elongated, not grooved ventrally, $\pm 2.5 \mathrm{~mm}$ thick, phyllopodia $0.5-1 \mathrm{~cm}$ apart, lateral buds situated \pm on the phyllopodia to \pm halfway down the internodia. Anatomy: ground tissue parenchymatous, sclerenchyma sheath distinct, sclerenchyma strands scattered through the inner parenchyma, many; vascular strands \pm 9 . Scales peltate, $1.6-4.2 \times 1-1.6 \mathrm{~mm}$; base \pm entire; acumen shiny black with a conspicuous hyaline or light brown margin, shortly and densely ciliate. Fronds monomorphic, distinctly to indistinctly stipitate; stipes 2-16 cm; lamina, index 10-20; widest at or above the middle, $13-51 \times 1.2-4.1 \mathrm{~cm}$, base and apex gradually narrowed. Venation: secondary veins very distinct, with the tertiary veins forming regular areoles; included veins simple or occasionally forked, free, or occasionally anastomosing; free veins many, excurrent. Hydathodes distinct, scattered over the lamina, \pm superficial. Anatomy: stipe or lower part of costa with \pm 11 central and \pm 4 lateral vascular strands; lamina $0.4-0.5 \mathrm{~mm}$ thick, upper epidermis with slightly projecting cells with moderately thickened walls, hypodermis composed of 1 cell-layer, the anticlinal cell-walls strongly thickened, water-tissue absent, palissade and spongy parenchyma distinct, lower epidermis with moderately thickened cell-walls; stomata sunken. pericvtic. Indument dimorphic, a dense mat, persistent, light brown; upper layer composed of hairs 0.6-1.4 $\mathrm{mm}$ in diam., with erecto-patent, acicular rays, \pm mixed with a lower layer composed of hairs with mainly woolly rays. Sori apıcal to all over the Iamına, shortly spaced, supertıcial; several in a row in each soriferous areole, not, or occasionally slightly, confluent along the veins; 1-2 $\mathrm{mm}$ in diam.; developing from the apex downwards, when old individually distinct, exserted from the indument. Sporangia on stalks $1.5-3 \times$ as long as the capsule, capsule $\pm 0.2 \mathrm{~mm}$ high, with $14-16$ indurated annulus cells. Paraphyses not differentiated. Spores (46-)52.2-58.0(-64) $\times(34-) 37.2-42.8(-48) \mu \mathrm{m}$, irregularly verrucate to cristate.

Habitat: Epiphytic or epilithic, in sheltered sites. According to Sledge (1960) P. gardneri is frequent and widespread in the Central \& Southern Provinces of Ceylon.

Altitudinal range: $225-1050 \mathrm{~m}$.

CEYLON. 36 collections.

Notes. 1. $P$. gardneri is superficially similar to $P$. porosa. The rhizome, however, is characteristic, with unusually high (up to $2.5 \mathrm{~cm}$ ) phyllopodia, and covered 
with conspicuously shining, appressed, black scales. The lamina anatomy is also characteristic, with the cell-walls in the hypodermis peculiarly thickened (illustrated by Giesenhagen, 1901: fig. $14 \mathrm{~g}$ ).

2. The lamina is often narrowly attenuate at base, so that the transition to the stipe is very gradual, but the stipe is always free of the decurrent lamina for a short distance at its base.

\section{Pyrrosia hastata (Thunb. ex Houtt.) Ching. Fig. 19.}

Pyrrosia hastata Ching, Bull. Chin. Bot. Soc. 1 (1935) 48; Hoshizaki, Baileya 21 (1981) 61, fig. 4.Acrostichum hastatum Houtt., Nat. Hist. 2, 14 (1783) 68, pl. 95 fig. 2; [non Acrostichum hastatum Liebm., Kong. Dansk Vid. Selsk. Skript. 5,1 (1849) 172, = Bolbitis hastata (Fourn.) Hennipm.]; Thunb., Fl. Jap. (1784) 331, pl. 34; Merrill, J. Arn. Arb. 19 (1938) 312.-Polypodium tricuspe Swartz, Schrad. J. 1800, 2 (1801) 21; Swartz, Syn. Fil. (1806) 30; Desvaux, Mag. Ges. Naturf. Freun de Berlin (Berl. Mag.) 5 (1811) 300; Spr., Syst. 4 (1827) 49; Hooker, Sp. Fil. 5 (1863) 44; Mett., Ann. Mus. Lugd. Bat. 2 (1866) 231; Baker in Hooker \& Baker, Syn. Fil. (1867) 350; Franch. \& Sav., Enum. Pl. Jap. 2 (1876) 245. - Niphobolus hastatus Kunze, Bot. Zeit. (1848) 505; Fée, Gen. Fil. (1853) 263; T. Moore, Ind. Fil. (1857) lxxvi; T.Moore, Ind. Fil. (1861) 276; Hooker, Fl. Hongk. (1857) 355.-Polycampium hastatum Presl, Epim. Bot. (1851) 137.Cyclophorus tricuspis Desv. ex T. Moore, Ind. Fil. (1861) 276, nom. superfl.-Niphobolus tricuspis J. Sm., Hist. Fil. (1875) 98, nom. superfl.; Diels in E. P., Nat. Pfl. Fam. 1,4 (1899) 325, fig. 168 b,c; Giesenh., Niphobolus (1901) 165. - Cyclophorus hastatus C. Chr., Ind. Fil. (1906) 199; Christ, Bull. Acad. int. Géogr. bot. 20 (1909) 148; Christ, Geogr. der Farne (1910) 112; Bonap., Notes Ptérid. 7 (1918) 75.-Pyrrosia tricuspis Tagawa, J. Jap. Bot. 32 (1957), nom. superfl.; Nakaike, Enum. Pterid. Jap. (1975) 354; Kurata Nakaike, Ill. Pterid. Jap. 2 (1981) 624-626. - Lectotype: Houttuyn, 1.c., plate 95 fig. 2.

Rhizome short, not grooved ventrally, to $\pm 5 \mathrm{~mm}$ thick, phyllopodia close together, lateral buds situated on the phyllopodia. Anatomy: ground tissue parenchymatous, sclerenchyma sheath distinct, sclerenchyma strands scattered through the inner parenchyma, many; vascular strands 8-10. Scales peltate, 1.5$2.5 \times 0.5-0.9 \mathrm{~mm}$, blackish with a distinct light margin, ciliate. Fronds monomorphic, stipitate; stipes $4-23 \mathrm{~cm}, 1-3 \times$ as long as the lamina; lamina (in outline) index $0.8-1.5$; widest near the base, $4-13 \times 4-14 \mathrm{~cm}$; pedately lobed to $\pm 4 / 5$ in 3-5 divisions, the middle one index 2-3, 3-11 $\times 1.5-3.5 \mathrm{~cm}$, the lateral ones increasingly smaller; lamina base truncate to cordate, often slightly unequal, slightly decurrent. Venation: secondary veins distinct, with the tertiary veins forming regular areoles; included veins branched and frequently anastomosing; free veins many, pointing to all directions. Hydathodes distinct, scattered over the lamina, superficial to slightly pitted. Anatomy: stipe with \pm 5 central and \pm 2 lateral vascular strands; lamina 0.3-0.6 mm thick, upper epidermis with flat to distinctly projecting cells with thin walls, hypodermis and water-tissue absent, palissade and spongy parenchyma distinct, lower epidermis with thin cell-walls; stomata superficial. pericytic. Indument monomorphic, a dense mat, persistent, brown; hairs $0.3-0.5(-0.8) \mathrm{mm}$ in diam., with appressed, boat-shaped rays. Sori apical to all over the lamina, closely packed, superficial; many in 1-2 rows in each 
soriferous areole, occasionally confluent along the veins; $0.5-2(-2.5) \mathrm{mm}$ in diam.; developing \pm simultaneously, when old individually distinct, exserted from the indument. Sporangia sessile, capsule 0.3-0.4 (0.5) $\mathrm{mm}$ high, with 16-20 indurated annulus cells. Paraphyses not differentiated. Spores (58-)63.8-74.8 $(-82) \times(40-) 43.4-50.0(-52) \mu \mathrm{m}$, finely and densely granulate.

Habitat: Mostly epilithic, sometimes epiphytic, on Oak, Chestnut, in forest. Altitudinal range: $200-400 \mathrm{~m}$, but probably occurring at higher altitudes as well.

JAPAN. Hokkaido: 10 collections. - Honshu: 11 collections. - Shikoku: Kowai s.n., (29-81907) (K).

S. KOREA (incl. Cheju-do). 10 collections, mainly from Cheju-do (formerly Quelpaert).

Notes. 1. $P$. hastata can be very similar to forms of $P$. polydactyla; the distinctions between these two species are discussed under the latter.

2. The lamina may have three or five lobes, in the latter case the two smallest ones near the base are often no more than small teeth.

3. The two main vascular strands of the stipe fuse some distance before entering the lamina (in other species except $P$. polydactyla they unite a short distance before or after entering the lamina). This may be an indication that the, for the genus unusually strongly, truncate base is formed by a basal constriction of the lamina.

4. Distribution: a detailed map of the distribution in Japan is given in Kurata \& Nakaike (1981).

5. Lectotypification: few of Houttuyn's types are preserved in L; the type of Acrostichum hastatum is not among these. Houttuyn explicitly refers to Thunberg for the specimen he describes, but in Thunberg's collection (UPS, IDC microfiches) no specimen of $P$. hastata could be located. Both Houttuyn's and Thunberg's figures are unmistakably $P$. hastata, and Houttuyn's one is selected as lectotype.

\section{Pyrrosia heterophylla (L.) Price}

Fully treated in Ravensberg \& Hennipman (1986).

\section{Pyrrosia kinabaluensis Hovenkamp. Fig. 23, 36.}

Pyrrosia kinabaluensis Hovenkamp, Blumea 30 (1984) 208. - T y pe: Clemens 26984 (holo L, iso BM, BO, K, SING), Borneo.

Rhizome long-creeping, grooved ventrally, 1.2-3 mm thick, phyllopodia 2-5, $\mathrm{cm}$ apart, lateral buds situated \pm halfway down the internodia. Anatomy: ground tissue parenchymatous, sclerenchyma sheath distinct, sclerenchyma strands absent; vascular strands 6-8. Scales peltate, 2.6-4.4 $\times 0.4-0.8 \mathrm{~mm}$; base entire to ciliate; acumen light brown, shining, ciliate; short, \pm orbicular to ovate 


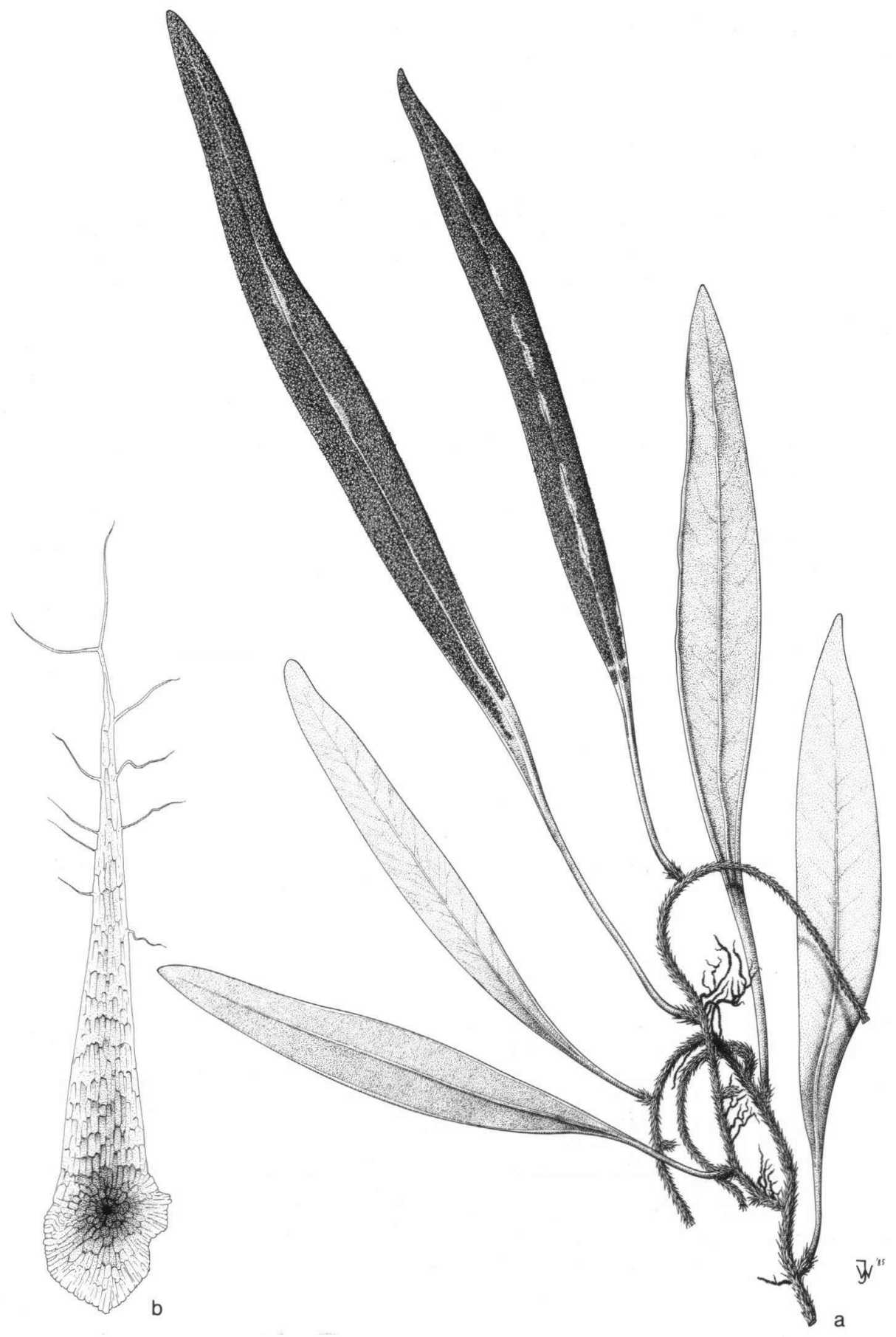

Fig. 36. P. kinabaluensis. a. Habit $\times 4 / 5 .-$ b. Rhizome scale $\times 31$ (a. Clemens 27479, L; - b. Topping iồ, L) 
scales regularly present. Fronds moderately dimorphic, stipitate. Fertile fronds: stipes $1.5-5 \mathrm{~cm}, 1 / 5- \pm 1 / 2 \times$ as long as the lamina; lamina, index 8-20; widest about the middle, $7-19 \times 0.7-1.2 \mathrm{~cm}$, base narrowly cuneate, apex obtuse to acute. Sterile fronds: stipes $0.5-3 \mathrm{~cm}, 1 / 10-1 / 2 \times$ as long as the lamina; lamina, index 3-8; widest below the middle, 3-13 $\times 1-1.8 \mathrm{~cm}$; otherwise similar to the fertile ones. Venation: secondary veins distinct, with the tertiary veins forming regular areoles; included veins forked and anastomosing; free veins ? (note 3). Hydathodes absent. Anatomy: stipe with 3-5 central and no lateral vascular strands; lamina 0.3-0.9 mm thick, upper epidermis with flat cells with thin to moderately thickened walls, hypodermis absent or composed of 1 cell-layer, water tissue indistinct or thick, palissade and spongy parenchyma distinct or indistinct, lower epidermis with thin or thickened walls; stomata slightly to strongly sunken. pericvtic. Indument dimorphic, a dense mat, persistent, whitish brown; upper layer composed of hairs $0.4-1.2 \mathrm{~mm}$ in diam., with erecto-patent to appressed, boat-shaped to acicular rays, separate from or appressed to a lower layer composed of hairs with mainly woolly rays. Sori all over the lamina, closely packed, supernicial many in each soriterous areole, occasionally confluent along the veins; $\pm 1 \mathrm{~mm}$ in diam.; when old pseudoacrostichoid. Sporangia on stalks 1 $2 \times$ as long as the capsule, capsule $0.3-0.4 \mathrm{~mm}$ high, with 18-22 indurated annulus cells. Paraphyses not differentiated. Spores (74-)83.0-88.2(-100) $\times(50-)$ $60.4-66.2(-74) \mu \mathrm{m}$, with irregular ridges and protuberances.

Habitat: Epiphytic, sometimes epilithic, in deep shade, e.g., in ravines. Altitudinal range: $100-1500 \mathrm{~m}$.

BORNEO. Sarawak: Jacobs 5132 (B, L, US). - Sabah: Clemens 26984 (BM, BO, K, L, SING), 27479 (BM, BO, K, L, US), 27479 bis (A, K, US), Nooteboom 1405 A (L), Topping 1809 (GH). - Kalimantan: Iwatsuki et al. B 2128 (L), Meijer 673 (BO, L), 681 (BO), 698 (BO), 699 B (BO, L), 847 (BO).

Notes. 1. This is a rather heterogeneous assemblage of relatively few collections. The variability in rhizome scales is similar to that found in $P$. nummulariifolia: the base may be entire or ciliate, and both types sometimes occur in the same collection. The variation in frond structure is marked: both forms with a thick lamina with well-developed hypodermis and distinct other tissue-layers, and forms with a thin, relatively undifferentiated mesophyll occur, but the different forms may represent adaptations to different habitats (a roughly similar variability is found in $P$. lingua var. heteracta). The variation in the indument (thin, appressed, to dense and loosely shaggy) may have a similar origin. There is no correlation between these three character complexes.

2. Specimens here regarded as $P$. kinabaluensis were included by Copeland (1917) in Cyclophorus borneensis, and many collections of later date have been identified as such (e.g., by C. Chr. \& Holttum, Gard. Bull. S. S. 7, 1934). Copelands 
description, however, clearly refers to entire rhizome scales; his type is conspecific with $P$. rasamalae.

$P$. kinabaluensis differs from $P$. rasamalae in the ciliate rhizome scales as well as in the markedly dimorphic fronds and the more closely packed sori. It is in many characters intermediate between $P$. nummulariifolia and $P$. rasamalae, but distinct from either in the closely packed sori. Both the intermediate character and the relatively strong heterogeneity indicate a hybridogenous origin. This is not supported by examination of the spores: the percentage of abnormal spores is not higher than in other species (see also p. 71).

3. Venation: due to the very thick-coriaceous character of many fronds the venation could not be studied in detail.

\section{Pyrrosia laevis (J. Sm. ex Bedd.) Ching. Fig. 21 b.}

Pyrrosia laevis Ching, Bull. Chin. Bot. Soc. 1 (1935) 52; Nayar Kaur, Comp. Bedd. Handb. (1974) 80. - Niphobolus laevis J. Sm. ex Bedd., Ferns Br. India (1868) pl. 161; Bedd., Suppl. Ferns S. ar. Ind. (1876) 21; Bedd., Handb. ferns Brit. Ind. (1883) 325; Giesenh., Niphobolus (1901) 141.-Polypodium breve Baker, Ann. Bot., Lond. 5 (1891) 472 (see note 3);-Polypodium laeve Baker, Summ. New Ferns (1892) 89, nom. illeg., non Polypodium laeve Mett. ex Kuhn, see note 2. - Cyclophorus laevis C. Chr., Ind. Fil. (1906) 199. - Ty pe: Dr. Thomson s.n., s.d. (holo K), Khasya, India.

Polypodium laeve Mett. ex Kuhn, Linnaea 36 (1869) 139. - Ty pe: Hooker Thomson s.n. s.d., (B), Khasya, India.

Polypodium jaintense C. B. Clarke, Tr. Linn. Soc. II Bot. 1 (1880) 552, pl. 82: 4;-Pyrrosia jaintensis Ching in Ching \& Wu, Fl. Xizang. 1 (1983) 335.-T y pe: Clarke 17883 (K, BM), Jaintea, India.

Rhizome long-creeping, not grooved ventrally, 0.9-1 mm thick, phyllopodia 1-3 cm apart, lateral buds situated more than halfway down the internodia. Anatomy: ground tissue parenchymatous, sclerenchyma sheath distinct, sclerenchyma strands scattered through the inner parenchyma, up to \pm 10 ; vascular strands 5-6. Scales peltate, 3.1-4 × 0.3-0.6 mm; base entire; acumen light brown, entire or occasionally with long cilia near the apex; short, \pm orbicular to ovate scales regularly present. Fronds monomorphic, stipitate; stipes $0.5-4.5 \mathrm{~cm}$, up to $1 / 4(-1 / 3) \times$ as long as the lamina; lamina, index $4-20$; widest below the middle, $5-21 \times 0.5-1.3 \mathrm{~cm}$, base cuneate to narrowly cuneate, apex narrowly acute to acuminate. Venation: secondary veins not very distinct, with the tertiary veins forming regular areoles; included veins simple, forked or more copiously branched, free or anastomosing; free veins many, mainly excurrent. Hydathodes indistinct, scattered over the lamina, more or less superficial. Anatomy: stipe with \pm 4 central and \pm 2 lateral vascular strands; lamina $0.3 \mathrm{~mm}$ thick, upper epidermis with flat cells with moderately thickened walls, hypodermis composed of a single cell-layer, water-tissue, palissade and spongy parenchyma indistinct, lower enidermic with thirkened cell-walls' stomata sliohtlv sunken nerirvtir Indument dimorphic, a thin mat, persistent, light greyish brown; upper layer often fugacious, composed of hairs $0.4-0.5 \mathrm{~mm}$ in diam., with appressed, boat-shaped 
or acicular rays, often with a distinct dorsal spine, appressed to a lower layer composed of hairs with mainly woolly rays. Sori apical to all over the lamina, shortly spaced but often confluent along the veins, superficial; several scattered throughout each soriferous areole, $1-2.5 \mathrm{~mm}$ in diam.; when old individually distinct, exserted from the indument. Sporangia on stalks to $\pm 1 \times$ as long as the capsule, capsule $\pm 0.3 \mathrm{~mm}$ high, with 17-21 indurated annulus cells. Paraphyses not differentiated. Spores (62-)66.2-66.8(-78) $\times(44-) 48.8-49.2(-56) \mu \mathrm{m}$, irregularly coarsely verrucate.

Habitat: Hardly any data available. Probably mostly epiphytic; locally common.

Altitudinal range: Probably $900-1200 \mathrm{~m}$, possibly $600-1500 \mathrm{~m}$.

INDIA. Assam: 13 collections.

BURMA. Kingdon-Ward 20669 (BM), Toppin 6330 (K).

CHINA. Tibet: Kingdon-Ward s.n. (1926) (K). - Yunnan: Sino-Russian Exp. Yunnan 7935 (Kunming, photograph seen taken by Roos).

Notes. 1. $P$. laevis has been confused with $P$. lanceolata. It can easily be distinguished by the superficial sori, the almost entire rhizome scales, the dimorphic indument with dorsal spines often present. The lamina is usually slightly falcate and distinctly willow-like in appearance.

2. Polypodium laeve Mett. ex Kuhn: this name is based on a specimen from the herbarium Hooker \& Thomson identified as Niphobolus laevis J. Sm. Several sheets have been distributed under this name, and a sheet in B is selected as lectotype. Niphobolus laevis J. Sm. ex Bedd., on the other hand, is based on a different sheet, now in $\mathrm{K}$, as can be ascertained by comparison with Beddome's (1868) plate 161; due to the lack of information on the labels it cannot be identified with certainty as a duplicate of the sheet in B. Kuhn does not refer to Beddome's name, and Kuhn's name is here regarded as a heterotypic synonym.

3. Polypodium breve Baker: this is obviously a misspelling for $P$. laeve, and is accordingly 'corrected' in the separate reprint of 1892 (Summ. New Ferns, 1892, 89). The reference to the basionym is also misleading ('Niphobolus brevis Beddome, Ferns Brit. Ind. 325'): it does not refer to the Ferns of British India (1868), but to the Handbook of the ferns of British India (1883).

\section{Pyrrosia lanceolata (L.) Farwell. Fig. 25.}

Pyrrosia lanceolata Farwell, Amer. Midl. Nat. 12 (1930) 245 ('Pyrrhosia lanceolatus'); Ching, Bull. Chin. Bot. Soc. 1 (1935) 70; C. Chr. * Tard., Not. Syst. 8 (1939) 205; Tard. * C. Chr., F1. Indo-Ch. (1941) 515; Schelpe, J. S. Afr. Bot. 18 (1952) 131; Alston, Ferns W. Trop. Afr. (1959) 46; Sledge, Bull. Br. Mus. (Nat. Hist) Bot. 2 (1960) 133; Tardieu, Fl. Madagasc. (1960) 102; Nayar, J. Ind. Bot. Soc. 40 (1961) 164-186; Nayar * S. Chandra, Bull. Nat. Bot. Gard. Lucknow 117 (1965) 58; Nayar \& S. Chandra, Can. J. Bot. 45 (1967) 615-634; Schelpe, Fl. Zambes. (1970) 146; Nayar Kaur, Comp. Bedd. Handb. (1974) 80; Gill \& Mwasumbi, Nova Hedw. 27 (1976) 943; Schelpe \& Diniz, Fl. Moçamb. (1979) 149; Ching \& Wu, Fl. Xizang. 1 (1983) 335, fig. 87: 4, 5; Jacobsen, Ferns and Fern All. S. Africa (1983) 305, fig. 221, map 
91.-Acrostichum lanceolatum L., Sp. Pl. 2 (1753) 1067; L., Sp. Pl. ed. 2 (1763) 1523; N.L. Burm., Fl. Ind. (1768) 228; Houtt., Nat. Hist. 2, 14 (1783) 68; Trimen, J. Linn. Soc. 24 (1888) 130; Ching, Bull. Chin. Bot. Soc. 1 (1935) 46; Morton, J. Wash. Acad. Sc. 36 (1946) 168.Candollea lanceolata Mirb. ex Desv., Mém. Soc. Linn. Paris 6 (1827) 224, pro syn.; Farwell, Amer. Midl. Nat. 12 (1930) 245. - Gymnopteris lanceolata T. Moore, Ind. Fil. (1857) 10. - Niphobolus lanceolatus Trimen, J. Linn. Soc. 24 (1888) 152, nom. illeg. [non Niphobolus lanceolatus Keyserl., Polyp. Herb. Bunge (1873) 39, = Pleopeltis macrocarpa (Willd.) Kaulf.]. - Cyclophorus lanceolatus Alston, J. Bot. London 69 (1931) 102; C. Chr., Ind. Fil. Suppl. 3 (1934) 65; Backer \& Posth., Varenfl. Java (1939) 238; Dickason, Ohio J. Sc. 46 (1946) 129. - Ty pe: Herb. Hermann I, fol. 3 (holo BM, iso L), Ceylon.

Polypodium adnascens Swartz, Syn. Fil. (1806) 25, 222, pl. 2 fig. 2; Willd., Sp. Pl. 5 (1810) 145; Hooker, Sp. Fil. 5 (1863) 47; Mett., Ann. Mus. Lugd. Bat. 2 (1866) 130; Thwaites, Enum. Pl. Zeyl. (1864) 395; Baker in Hooker \& Baker, Syn. Fil. (1867) 349; C. B. Clarke, Tr. Linn. Soc. II Bot. 1 (1880) 552; Baker, J. Bot. Lond. 18 (1880) 214; Hemsley, Chall. Exp. (1885) 255; Trimen, J. Linn. Soc. 24 (1888) 152; Schum. Hollr., Fl. Kais. Wilh. land (1889) 9; Kuhn, Gazelle Exp. Farne (1889) 11; Beccari, Malesia 3 (1890) 48, 57; Warb., Bot. Jb. 16 (1892) 12; Christ, J. Bot. Paris 8 (1894) 152; Christ, Verh. Nat. Ges. Basel (1897) 20; Christ, Ann. Jard. bot. Buitenz. 15 (1898) 164; Christ, Bull. Herb. Boiss. 6 (1898) 199; Racib., Pter. Buitenz. (1898) 98; Christ in Warb., Monsunia 1 (1900) 60; Hope, Ferns N. W. India (1903) 87; Dunn \& Tutch., Fl. Kwangtung (1912) 351.-Cyclophorus adnascens Desvaux, Mag. Ges. Naturf. Freunde Berlin (Berl. Mag.) 5 (1811) 300; Desv., Mém. Soc. Linn. Paris 6 (1827) 224 (by Desvaux erroneously ascribed to Raddi); C. Chr., Ind. Fil. (1906) 197; Copeland, Leafl. Phil. Bot. 2 (19) (1908) 414; Alderwerelt, Malayan Ferns (1909) 681; Willis, Cat. Ceyl. (1911) 123; Copeland, Sarawak Mus. J. 2 (1917) 409; Bonap., Notes Ptérid. 7 (1918) 125, 190; Brause, Bot. Jb. 56 (1920) 206; Holttum, J. Mal. Br. R. As. Soc. 6 (1928) 20; C. Chr. Holttum, Gard. Bull. S. S. 7 (1934) 313; C. Chr., B. P. Bish. Mus. Bull. 177 (1943) 121.-Niphobolus adnascens Kaulf., Enum. (1824) 124; Spr., Syst. 4 (1827) 44; Blume, Enum. Pl. Jav. 2 (1828) 275; Blume, Fl. Jav. Fil. (1829) 53; Presl, Tent. Pter. (1836) 201; Presl, Epim. Bot. (1851) 126; Fée, Gen. Fil. (1853) 262; Brack, U.S. Expl. Exp. (1854) 38; J. Sm., Cat. Cult. Ferns (1857) 12; T. Moore, Ind. Fil. (1861) 275; Hooker, Gard. Ferns (1862) pl. 19; Bedd., Ferns S. India (1864-5) 62, pl. 184; Carruth. in Seem., Fiji Ferns (1873) 367; Keyserl., Polyp. Herb. Bunge (1873) 37; J. Sm., Ferns Br. For. ed. 2 (1877) 100; Bedd., Handb. ferns Brit. Ind. (1883) 325; fig. 176; Diels in E. \&., Nat. Pfl. Fam. 1,4 (1899) 325; Diels, Bot. Jb. 29 (1900) 207; Schumann * Lauterb., Fl. Schutzgeb. Süds. (1901). 141; Giesenh., Niphobolus (1901) 196, 206, 209, fig. 18; Christ, Bull. Soc. Fr. 52 Mém. 1 (1905) 23; Christ, J. Bot. Paris 19 (1905) 74; Copeland, Polyp. Philipp. (1905) 114; C. Chr., Acta Horti Gothob. 1 (1924) 105.-Pyrrosia adnascens Ching, Bull. Chin. Bot. Soc. 1 (1935) 45; C. Chr. Tard., Not. Syst. 8 (1939) 204; Tard. C. Chr., Fl. Indo-Ch. (1941) 505; Tagawa, J. Jap. Bot. 24 (1949) 116; Holttum, Fl. Malaya 2 (Ferns) (1954) 144, fig. 60; Abeywickrama, Ceyl. J. Sc. Sect. A 13 (1956) 26; Tagawa, J. Jap. Bot. 32 (1957) 354, Fu, Ill. Imp. Chin. Pl. (1957) 235, fig. 315; Gopeland, Fern Fl. Philipp. (1960) 471; Nayar, J. Ind. Bot. Soc. 40 (1961) 164-186; Holttum, Dansk Bot. Ark. 23 (1965) 230; Nakaike, Enum. Pter. Jap. (1975) 351; Nayar \& S. Chandra, Bull. Nat. Bot. Gard. Lucknow 117 (1965) 48; H. Hara, Fl. Eastern Himal. (1966) 497; Nayar \& S. Chandra, Can. J. Bot. 45 (1967) 615-634; Holttum, Dansk Bot. Ark. 25 (1967) 48; Tagawa, Acta Phytotax. Geobot. 22 (1967) 106, 185; Iwats., Acta Phytotax. Geobot. 25 (1972) 71; Iwats., Amer. Fern J. 63 (1973) 131; Nayar * Kaur, Comp. Bedd. Handb. (1974) 80; DeVol, Fl. Taiwan 1 (1975) 205; Jones Clemesha, Austr. Ferns (1976) 253, pl. 30, 47; Brownlie, Fl. Fiji (1977) 367; Hoshizaki, Baileya 21 (1981) 57, fig. 2; Kurata Nakaike, Ill. Pter. Japan 2 (1981) 592-4.-Type: Rottler s.n., s.d., (S, not seen), India, 'Malabar, mixed with Pteris piloselloides'.

Polypodium spissum Bory ex Willd., Sp. Pl. 5 (1810) 146; Mett., Polyp. (1856) 125; Hooker, Sp. Fil. 5 (1863) 48; Kuhn, Fil. Afr. (1868) 153; Ching, Bull. Chin. Bot. Soc. 1 (1935) 46._Cyclophorus spissus Desvaux, Mag. Ges. Naturf. Freunde Berlin (Berl. Mag.) 5 (1811) 301; Desv., Mém. Soc. Linn. Paris 6 (1827) 224; C. Chr., Ind. Fil. (1906) 201; H. Lev., Fl. Kouy-Tchéou (1915) 479; Bonap., Notes Ptérid. 16 (1925) 123; C. Chr., Dansk Bot. Ark. 7 (1932) 160, pl. 61 fig. 1-3; Dickason, Ohio J. Sc. 46 (1946) 129.-Niphobolus spissus Kaulf., Enum. (1824) 126; Spr., Syst. 4 (1827) 44; Presl, Tent. Pter. (1836) 202; Pres, Epim. Bot. (1851) 128; Fée, Gen. Fil. 
(1853) 262; T. Moore, Ind. Fil. (1861) 276; Giesenh., Niphobolus (1901) 198, 204, 209; Engl., Veg. d. Erde 9,2 (1908) 55; Peter, Fedde Rep. Beih. 40 (1938) 33. - Niphobolus adnascens var. spissum Keyserl., Polyp. Herb. Bunge (1873) 37. - Type: Bory s.n., s.d., herb. Willdenow 19627 (holo B, iso P), Réunion.

Acrostichum dubium Poir. in Lam., Enc. Suppl. 1 (1810) 120. - Polypodium dubium Kuhn, Fil. Afr. (1868) 147.-T ype: Herb. DesFont. \&uss., 'Ile Bourbon' (P), Réunion.

Cyclophorus heterophyllus Desvaux, Mag. Ges. Naturf. Freunde Berlin (Berl. Mag.) 5 (1811) 301; Desv., Mém. Soc. Linn. Paris 6 (1827) 224. - Niphobolus heterophyllus Spr., Syst. 4 (1827) 44; Presl, Epim. Bot. (185 1) 129; T. Moore, Ind. Fil. (1861) 276.-Type: Commerson s.n., s.d. (P), Seychelles, Port Praslin.

Cyclophorus glaber Desvaux, Mag. Ges. Naturf. Freunde Berlin (Berl. Mag.) 5 (1811) 301; Desv., Mém. Soc. Linn. Paris 6 (1827) 224; Gaud. in Freyc., Voy. Uranie (1829) 326; E. Fourn., Ann. Sc. Nat. V, 18 (1873) 286. - Niphobolus glaber Kaulf., Enum. (1824) 127, _non Niphobolus glaber Presl, Rel. Haenk. (1825) 28, = Microsorium myriocarpum (Presl) Ching]; Spr., Syst. 4 ( 1827) 45; Blume, Enum. Pl. Jav. 2 (1828) 107; Blume, Fl. Jav. Fil. (1829) 62, pl. 27, q.n.s.; Presl, Tent. Pter. (1836) 202; J. Sm., Hooker J. Bot. 4 (1842) 57; Fée, Gen. Fil. (1853) 262; Brack, U.S. Expl. Exp. (1854). 38. - Type: Commerson s.n., s.d. (P), Java.

Niphobolus varius Kaulf., Enum. (1824) 125; Spr., Syst. 4 (1827) 44; Blume, Enum. Pl. Jav. 2 (1828) 106; Blume, Fl. Jav. Fil. (1829) 54, pl. 21; Presl, Tent. Pter. (1836) 201; J. Sm., Hooker J. Bot. 3 (1841) 396 p.p.; J. Sm., Cat. Cult. Ferns (1857) 12; Kunze, Bot. Zeit. (1848) 120; Presl, Epim. Bot. (1851) 127; Brack, U. S. Expl. Exp. (1854). 38; T. Moore, Ind. Fil. (1861) 276; Hooker, Sp. Fil. 5 (1863) 47; Giesenh., Niphobolus (1901) 151, 198, 208; Schumann Lauterb., Fl. Schutzgeb. Süds. (1901) 141; Copeland, Polyp. Philipp. (1905) 114._Cyclophorus varius Gaud. in Freyc., Voy. Uranie (1829) 364; E. Fourn., Ann. Sc. Nat. V, 18 (1873) 287; C. Chr., Ind. Fil. (1906) 201; Copeland, Leafl. Phil. Bot. 2 (19) (1908) 414; Alderwerelt, Malayan Ferns (1909) 682; Copeland, Sarawak Mus. J. 2 (1917) 409; Bonap., Notes Ptérid. VII (1918) 126; Backer \& Posth., Varenfl. Java (1939) 239, fig. 57.-Polypodium varium Mett., Polyp. (1856) 126, nom. illeg. [non Polypodium varium L., Sp. P1. 2 (1753) 1090, = Polystichum spec.]; Mett., Ann. Mus. Lugd. Bat. 2 (1866) 230; Kuhn, Gazelle Exp. Farne (1889) 11; Racib., Pter. Buitenz. (1898) 100.-Niphobolus adnascens var. varius Keyserl., Polyp. Herb. Bunge (1873) 37.-Pyrrosia varia Farwell, Amer. Midl. Nat. 12 (1931) 302; Ching, Bull. Chin. Bot. Soc. 1 (1935) 70; Holttum, Fl. Malaya 2 (Ferns) (1954) 146, fig. 61; Copeland, Fern Fl. Philipp. (1960) 471; Nayar, J. Ind. Bot. Soc. 40 (1961) 164-186; Nayar S. Chandra, Bull. Nat. Bot. Gard. Lucknow 117 (1965) 87; Nayar \& S. Chandra, Can. J. Bot. 45 (1967) 615-634; Tagawa, Acta Phytotax. Geobot. 22 (1967) 185; Tagawa Iwats. Acta Phytotax. Geobot. 23 (1968) 52; Nayar * Kaur, Comp. Bedd. Handb. (1974) 80; Hoshizaki, Baileya 21 (1981) 76, fig. 13.-Ty pe: Chamisso s.n., s.d., (holo LE, not seen; iso P, B), 'Guaham Manilla'.

Niphobolus caudatus Kaulf., Enum. (1824) 127; Spr., Syst. 4 (1827) 45; Blume , Enum. Pl. Jav. 2 (1828) 106; Blume, Fl. Jav. Fil. (1829) 56, pl. 22; Presl, Tent. Pter. (1836) 202; Presl, Epim. Bot. (1851) 127; Fée, Gen. Fil. (1853) 262.-Polypodium caudatum Mett., Polyp. (1856). 126, nom. illeg., [non Polypodium caudatum Raddi, Syn. Fil. Bras. (1819), = ?, type from Brasil; nec Polypodium caudatum Kaulf., Enum. (1824) 113, = ?, type from Rio de Janeiro]; Beccari, Malesia 3 (1890) 45. - Pyrrosia caudata Ching, Bull. Chin. Bot. Soc. 1 (1935) 46.-T y pe: Willdenow herb. no. 19728, 'Pleopeltis commersoniana' (B).

Polypodium pertusum Roxburgh ex Hooker, Exot. Flora 2 (1825) pl. 26; Wallich, Cat. (1828) nr. 267; Roxb., Calc. J. Nat. Hist. IV (1844) 483, pl. 29; Mett., Polyp. (1856) 125; Mett., Fil. Lips. (1856) 33; Morton, Contr. U.S. Nat. Herb. 38 (1964) 353.-Niphobolus pertusus Spr., Syst. 4 (1827) 201; J. Sm ., Hooker J. Bot. 4 (1842) 57; J. Sm., Cat. Cult. Ferns (1857) 12; Presl, Epim. Bot. (1851) 127; Fée, Gen. Fil. (1853) 262; T. Moore, Ind. Fil. (1857) lxxvi; Hooker, Fl. Hongkong (1857) 355.-Craspedaria pertusa Link, Fil. Sp. (1841) 118, nom. superfl.Lectotype (Morton, l.c.); Roxburgh s.n., s.d., (BR), Bangla Desh, 'Delta of the Ganges'.

Niphobolus koenigii Blume, Fl. Jav. Fil. (1829) 50, footnote. - Polypodium koenigii Baker in Hooker * Baker, Syn. Fil. (1867) 350; Beccari, Malesia 3 (1890) 57.-T y pe: Koenig s.n., s.d. (L), Ceylon.

Niphobolus carnosus Blume, Enum. Pl. Jav. 2 (1828) 105; Blume, Fl. Jav. Fil. (1829) 50, pl. 19; Presl, Tent. Pter. (1836) 201; Presl, Epim. Bot. (1851) 126; Fée, Gen. Fil. (1853) 262; Brack, U.S. Expl. Exp. (1854) 36; T. Moore, Ind. Fi 1. (1857) lxxvi; Hooker, Fl. Hongkong (1857) 355.- 
Polypodium carnosum Mett., Polyp. (1856) 124. - Ty pe: Blume s.n., s.d., (L?, not found, see note 6), Java.

Niphobolus elongatus Blume, Enum. Pl. Jav. 2 (1828) 105; Blume, Fl. Jav. Fil . (1829) 52; pl. 20; Presl, Tent. Pter. (1836) 201; Presl, Epim. Bot. (1851) 126; Fée, Gen. Fil. (1853) 262.Polypodium camosum var. elongatum Mett., Polyp. (1856) 124.-T y pe: Blume s.n., s.d., (L, 899 314 -14), Java, 'Noesa Kambanga'.

Niphobolus spathulifer Bory in Bél., Voy. Ind. Or. Bot. 2 (1833) 24.-T y pe: Bélanger s.n., s.d., (P, L), Java, Buitenzorg.

Niphobolus chamissonianus Presl, Tent. Pter. (1836) 201. - Ty pe: Chamisso, 'Niphobolus varius', partim (PRC, not seen).

Cyclophorus vittarioides Presl, Epim. Bot. (1851) 129; Holttum, Nov. Bot. Inst. Bot. Univ. Car. Prag. (1968) 31; non Cyclophorus vittarioides Christ, Bull. Acad. int. Géogr. bot. 20 Mém. (1909) 175, nom. illeg. = Pyrrosia porosa (Presl) Hovenkamp. - Niphobolus vittarioides Presl, Tent. Pter. (1836) 202, nom. nud. - Polypodium vittarioides Mett., Polyp. (1856). 126.-Niphobolus vittarioides $T$. Moore, Ind. Fil. (1861) 276; Diels in E. \& P., Nat. Pfl. Fam. 1,4 (1899) 325. - Type: Wallich 270 (holo PRC, not seen, iso in B, BR, K, M, P, US), Nepal.

Polypodium pachydermum Baker, J. Linn. Soc. 15 (1877) 108; Hemsley, Chall. Exp. (1885) 210; Baker, Ann. Bot., Lond. 5 (1891) 472. - Cyclophorus pachydermus C. Chr., Ind. Fil. (1906) 200; Alderwerelt, Malayan Ferns (1909) 680; Brause, Bot. Jb. 56 (1920) 206. - Pyrrosia pachyderma Ching, Bull. Chin. Bot. Soc. 1 (1935) 47. - Ty pe: Moseley s.n., s.d. (K), Little Kei Island.

Drymoglossum martinicense Christ, Bot. Jb. 24 (1897) 137; Christ, Farrnkr. Erde (1897) 131; Diels in E. \& P., Nat. Pfl. Fam. 1,4 (1899) 303; C. Chr., Ind. Fil. (1906) 246.-Pteropsis martinicense Maxon, Contr. U.S. Nat. Herb. 16 (1912) 16.-T y pe: Duss 250 B (B), Martinique.

Niphobolus nudus Giesenh., Niphobolus (1901) 149. - Cyclophorus nudus C. Chr., Ind. Fil. (1906) 200; C. Chr., Contr. U.S. Nat. Herb. 26 (1931) 326; Dickason, Ohio J. Sc. 46 (1946) 129. - Pyrrosia nuda Ching, Bull. Chin. Bot. Soc. 1 (1935) 70; C. Chr. Tard., Not. Syst. 8 (1939) 206; Tard * C. Chr., Fl. Indo-Ch. (1941) 514, H. Hara, Fl. Eastern Himal. (1966) 498; Tagawa \& Iwats Acta Phytotax. Geobot. 23 (1968) 110. - Lectot y pe (Ching, 1935): Henry 12884 A (BM, US, P), China.

Niphobolus tener Giesenh., Niphobolus (1901) 211._Cyclophorus tener C. Chr., Ind. Fil. (1906) 201.-Type: De Cordemoy s.n. (1892) (M, P), Réunion.

Niphobolus giesenhageni Christ, Ann. Cons. Jard. bot. Gen. 7-8 (1904) 330. -Cyclophorus giesenhageni C. Chr., Ind. Fil. (1906) 199. - Ty pe (see note 8): W. Griffith 1689 \& 2787 (P), Bhutan.

Niphobolus spissus var. continentalis Hieron. ex Engl., Veg. Erde 9, 2 ( 1908) 55, fig. 53; Peter, Fedde Rep., Beih. 40 (1938) 33. - Cyclophorus spissus var. continentalis Hieron, Bot. Jb. 46 (1911) 399. - Type: Engler 382 (B, P), Tanzania.

Cyclophorus adnascens var. minor Alderwerelt, Malayan Ferns (1909) 681. - Ty pe: Raap 127 (BO), Batu Islands.

Cyclophorus pustulosus Christ, Notul. Syst. 1 (1910) 187; C. Chr., Ind. Fil. Suppl. 1 (1913) 22; Bonap. Notes Ptérid. 7 (1918) 126, 191. - Type: Bon 1327 (P, BM), Tonkin.

Cyclophorus adnascens fo. pernuda Alderwerelt, Bull. Jard. bot. Buitenz. II, 7 (1912) 10; Alderwerelt, Malayan Ferns Suppl. (1917) 411.-Type: Gjellerup 806 (BO, L), New Guinea.

Cyclophorus varius var. flabelliformis Alderwerelt, Bull. Jard. bot. Buitenz. II, 16 (1914) 57; Alderwerelt, Malayan Ferns Suppl. (1917) 412. - Type: Matthew 702 (BO?, not found, E, K, L), Sumatra.

Cyclophorus adnascens fo. dichotoma Alderwerelt, Bull. Jard. bot. Buitenz. III, 5 (1922) 192.-T y pe: Docters van Leeuwen 1659 (BO?, not found), 'Saleijer: Bitombang'.

Cyclophorus stellatus Copeland, J. Arn. Arb. 10 (1929) 179; C. Chr., Ind. Fil. Suppl.3 (1934) 65.Pyrrosia stellata Parris, Fern Gaz. 12 (1980) 119.-Ty pe: W. A. Setchell, s.n. (March 1904) (A, US), New Guinea, 'Friedrich Wilhelms Hafen'.

Cyclophorus dimorphus Copeland, J. Arn. Arb. 10 (1929) 180; C. Chr., Ind. Fil. Suppl. 3 (1934).Pyrrosia dimorpha Parris, Fern Gaz. 12 (1980) 119.-T ype: Brass 1575 (GH), New Guinea.

Cyclophorus cornutus Copeland, Brittonia 1 (1931) 77, pl. 3; C. Chr., Ind. Fil. Suppl. 3 (1934) 65;Pyrrosia cornuta Tagawa, J. Jap. Bot. 22 (1949) 163; Wagner, Amer. J. Bot. 39 (1952) $587 .-$ Type: Clemens 21483 (K), Borneo. 
Rhizome long-creeping, narrowly grooved ventrally, $1.2-2.1 \mathrm{~mm}$ thick, phyllopodia 1-2 cm apart, lateral buds situated \pm halfway down the internodia. Anatomy: ground tissue parenchymatous, sclerenchyma sheath distinct, a single, central sclerenchyma strand usually present; vascular strands $5(-7)$. Scales peltate, 1-7.8 $\times 0.3-1.3 \mathrm{~mm}$; base entire to ciliate; acumen light brown, often with a distinct hyaline margin, ciliate; short, \pm orbicular to ovate scales usually present. Fronds moderately to distinctly dimorphic, distinctly to indistinctly stipitate. Fertile fronds: stipes up to $5(-9) \mathrm{cm}$; lamina, index \pm 5 to over 20; widest below or about the middle, $3.5-31 \times 0.3-3.5 \mathrm{~cm}$, base cuneate to narrowly cuneate, apex obtuse to acute. Sterile fronds: stipes to $3(-5) \mathrm{cm}$; lamina, index 2-20 (occasionally more); widest below, about or above the middle, 2-24 $\times 0.3-$ $3.5(-4.3) \mathrm{cm}$, base attenuate, cuneate or narrowly cuneate, apex rounded, obtuse or acute. Venation: secondary veins distinct to indistinct, with the tertiary veins forming more or less regular areoles; included veins simple, occasionally forked or more copiously branched, mainly free; free veins excurrent. Hydathodes absent, rarely present, few and indistinct, scattered over the lamina. Anatomy: stipe or lower part of costa with 3 central and 0-1 lateral vascular strands; lamina 0.7$1.5 \mathrm{~mm}$ thick, upper epidermis with flat to distinctly projecting cells with thin to moderately thickened walls, hypodermis not distinct from the water-tissue, these together composed of 1-4 cell layers, palissade and spongy parenchyma distinct, lower epidermis with moderately thickened cell-walls; stomata strongly sunken, pericvtic. Indument monomorphic, a sparse, thin, or dense mat, persistent to fugacious, whitish to brown; hairs $0.2-1.2 \mathrm{~mm}$ with erecto-patent to appressed, boat-shaped to \pm acicular rays. Sor $i$ apical to all over the lamına, closely packed in a more or less sharply detıned patch, distinctly sunken; several to \pm 10 in a row in each soriferous areole, not confluent; $0.5-1(-2) \mathrm{mm}$ in diam.; developing from the apex downwards, when old individually distinct, exserted from the indument. Sporangia on stalks $1.5-2 \times$ as long as the capsule, capsule $0.2-0.3(-0.4)$ $\mathrm{mm}$ high, with 13-18 indurated annulus cells. Paraphyses in a central bundle, with short, straight rays. Spores (46-)55.2-67.6(-74) $\times(32-) 36.6-51.0(-56) \mu \mathrm{m}$, irregularly verrucate to distinctly bisculptate.

Habitat: Common throughout most of its range. Mostly epiphytic, also epilithic, in a wide variety of situations; rarely terrestrial.

Altitudinal range: Mostly sea-level to low altitudes, sometimes to $1000-1500 \mathrm{~m}$.

CHINA. Yunnan: 14 collections. - Fukien Amoy: H.H. Chung 1390 (K), 1391 (K), Schindler 400 (BM, K), Swinkoe s.n., s.d. (K). - Kwangtung * Canton: 9 collections. - Kwangsi: Ching 7316 (US), Maire 17 (K). - Hainan: 23 collections.

TAIWAN. 6 collections.

HONGKONG \& MACAO: 32 collections.

NEPAL. Khwaunsu 1222 (K), Shruthra 1782 (US), Wallich 270 (B, BR, K, M, P, US).

BHUTAN. Griffith s.n., s.d, (K), Nuttal Booth s.n., s.d. (K).

INDIA. Uttar Pradesh: Duthie 3696 (BM), MacKinnon 43 (M), Strachey \& Winterbottom 4 (BM, BR, K). - Sikkim Darjeeling: 17 collections. - Assam: 37 collections. - Madhya 
Pradesh: Nayaranaswami 628 (K). - Orissa: Haines 4049 (K), Mooney 1366 (K), 3080 (K). Tamil Nadu Kerala: 11 collections.

CEYLON. 23 collections.

BANGLA DESH. 6 collections.

BURMA. 13 collections.

THAILAND. Many collections.

ANDAMANS * NICOBARS. 7 collections.

LAOS. Colani 4258 (P), Pételot 4090 (US).

VIETNAM. 20 collections.

SUMATRA. Many collections.

MALAYA SINGAPORE. Many collections.

JAVA. Many collections.

LESSER SUNDA ISLANDS. Bali. O. Jaag 1706 (L), Posthumus 3651 (L). - Lombok: Anon.,

Sun Hong Fan herb. 9298 (L), 9316 (L). - Sumbawa: Kostermans 18278 (L). - Sumba:

Teysmann 10679 (L). - Flores: Verheijen 3514 a (L), Schmutz 57 (L), 634 (L), 956 (L). - Alor:

O. Jaag 1003 (L). - Timor: Bloembergen 3509 (L), Forbes 3625 (BM). - Wetar: Elbert 4621 (A,

L). - Timor Laut: Buwalda 4485 (A, L).

BORNEO. Many collections.

PHILIPPINES. Many collections (throughout the archipelago, 38 from Luzon).

CELEBES. 19 collections.

MOLUCCAS. Talaud Is.: Lam 2476 (L), 3147 (L), 3389 (L). - Halmaheira: Anang 421 (L),

De Haan 1756 (L, P), De Vogel 3312 (L), S. Yoshida 2304 (L), 2442 (L). - Ternate: Pleyte 128

(L). - Tidore: Lam 3756 (L). - Bacan: De Vriese * Teysmann s.n. (1859-60) (L). - Obi: De

Vogel 4252 (L). - Ceram: Kornassi 928 (L), Rutten 2024 (L), De Vriese \& Teysmann 21 (L). Ambon: Buwalda 6137 (L), C.B. Robinson 1932 (L, US). - Kei Is.: Jensen 153 (BM, L), 155

(BM), Moseley s.n., s.d. (K).

NEW GUINEA. Many collections.

-d'Entrecasteaux Is., Fergusson I.: Brass 27341 (L). Normanby I.: Brass 25147 (L), 25450 (L),

Womersley \& Gray NGF 8618 (A, BM, L, SING).-Woodlark I.: Kairo 242 (L). - Mapia I.: Vink

NGF 12081 (L). - Aru Is.: Buwalda 4925 (L, SING). - Louisiade Is., Rossel I.: Brass 28364 (L).

Sudest I.: Brass 27786 (BO, L). Misima I.: Brass 27853 (BO, L).

BISMARCK ARCHIPELAGO. Long I.: Womersley NGF 43636.-New Ireland: Labillardière

s.n., s.d. (BM), Leschenault s.n., s.d. (P), Lesson s.n., s.d. (P). - New Britain: 6 collections. -

Admiralty Is.: 8 collections.

AUSTRALIA. Queensland: Brass 19247 (L, SING).

BOUGAINVILLE. Craven \& Schodde 357 (A, L, BISH), Van Royen NGF 16399 (L), Schodde

\& Craven $4086(\mathrm{~L}, \mathrm{~A})$.

SOLOMON IS. 8 collections.

NEW HEBRIDES. Espiritu Santo: Braithwaite 1474 (K, L). - Aneityum: Bernardi 13041 (L,

P, Z), A. Morrison 26 (US). - Erumanga: C. Moore s.n., s.d. (BM).

FIJI IS. 29 collections.

SAMOA IS. 29 collections.

TONGA. Hürlimann 558 (Z), Parks 16300 (BISH, M, UC, US), Yuncker 15497 (BISH, U, US), 16038 (BISH, U, US), 16195 (US). MARIANAS. Guam: 25 collections. - Rota: 6 collections. - Saipan: Courage 51 (US), B.C. Stone 1387 (BISH), Wagner 3232 (US).

PALAU IS. Hosokawa 7325 (US), Kanehira 2015 (US), Ledermann 14076 (B), Salsedo 328

(US), Takamatsu 1413 (BISH, US).

CAMEROON. 8 collections.

CENTRAL AFRICAN REPUBLIC. Equipe de Boukoko 1199 (P).

PRINCIPE. Keulemans s.n., s.d. (L), Quintas 30 (BM, P, Z).

GABON. Klein $38(\mathrm{P})$, R. Sita $550(\mathrm{P})$.

CONGO. 10 collections.

UGANDA. Dümmer 788 (BM, P, US, Z), Loveridge 74 (A), Millburn 39 (BM).

TANZANLA. 11 collections.

MOÇAMBIQUE. Surcouf s.n. (Nov. 1926) (P), Torre 4189 a (BM, BR, WAG).

MADAGASCAR. 7 collections. 
MASCARENE IS. Réunion: 22 collections.-Mauritius: Commerson s.n., s.d. (P), Rawson 935 (BM). - Rodriguez: 9 collections.

Doubtful localities.

NEW GALEDONIA. Vieillard 101 (P), 1589 (P).

TAHITI. U.S. South Pacific Expl. Exp. 4 (P).

ECUADOR. Spruce 5240 (P).

Notes. 1. Infraspecific taxa.

Many species have been distinguished in this large and variable aggregate. In the following survey of the variation a number of extremes is recognized and identified by names derived from the species under which these entities have been separated. It is not my intention to give a formal status to any of these entities. 'adnascens'. An entity with small, conspicuously dimorphic fronds: the fertile ones, index (7-) 10 to over $20,3.5-29 \times 0.3-1.3 \mathrm{~cm}$; the sterile ones, index $2-10(-$ $15), 2-12 \times 0.4-2 \mathrm{~cm}$; apex often rounded and the venation often obscure. The rhizome scales are very small (the larger scales on a rhizome are 1-3 mm long), and closely appressed to the rhizome. Typically the indument is very thin, but more densely pubescent specimens also occur (e.g., Coert 3915; Kostermans, s.n., P. Peutjang), which form a transition to the entities 'stellata' and 'vittarioides'. Typical representatives of this entity occur in the Malesian Archipelago (e.g., Schiffner s.n., 1892; Holstvoogd 767; Mousset 129; Palmer \& Bryant 100; Edaño PNH 15124). Relatively large forms occur often at low altitudes on islands (Siantan: Henderson 20149; Talaud Is.; Lam 2476; 3389); and throughout the Pacific part of the area of the species a large form occurs that has slightly longer rhizome scales. Specimens with long, narrow sterile fronds (Buwalda 3718; van Balgooy 4076; Edaño PNH 35870, 35879) constitute a transition to 'vittarioides'.

'pustulosa'. This entity is very similar to 'adnascens' but generally has longer rhizome scales, 3.4-4.4 mm long. The fertile fronds are mostly narrow and \pm linear; the sterile fronds are often very shortly stalked, and elliptic rather than spathulate as they are in 'adnascens'.

It occurs in southern China and northern Indo-China and extends southwards to Thailand and Cambodia, but is there often not distinct from 'adnascens' or 'vittarioides'. Typical representatives are, e.g., W.T. Tsang 255; Poilane 7820; Eryl Smith 1522; Squires 315, S.Y. Hu 9518.

'vittarioides'. A rather small entity with monomorphic or hardly dimorphic fronds: the fertile ones, index 7-20 or more, 3.5-6(-16.5) $\times 0.3-0.9 \mathrm{~cm}$; the sterile ones, index 5-17, 2-14 ×0.3-1.2 cm; a dense, light brown indument; and with rhizome scales that are often distinctly longer than those of 'adnascens' and usually patent rather than closely appressed to the rhizome.

In its most typical form, 'vittarioides' occurs in India, extending to Thailand; and in Cieylon where it gradually merges with forms with longer and narrower fronds that occur on the Mascarene Islands. Typical representatives are, e.g., Dickason 6633; Giesenhagen 17; Mann, s.n. (Apr. 1886); Hennipman 3498. Larger, 
more glabrescent forms (e.g., H.M. Smith 201; Hennipman 3750) constitute a transition to 'adnascens'.

'spissa'. Under this name the African specimens are taken together. They are similar to 'vittarioides' from Asia, but generally larger in all aspects. The fertile fronds are 7-21.5 $\times 0.5-1.4 \mathrm{~cm}$; the sterile ones $3.5-9(-17) \times 0.5-1.4 \mathrm{~cm}$; the rhizome scales are 4.2-6.6 $\mathrm{mm}$ long. The scales are usually distinctly patent, and have several glands at the apex instead of a single one as most other Pyrrosia.

Typical representatives are, e.g., Brause 317; Quintas 30; Loveridge 74. Through forms occurring on the Mascarene Islands this form is connected to 'vittarioides' 'stellata'. This is similar to 'adnascens', but often smaller, and with a more persistent, often conspicuously whitish, indument. The rhizome scales have a distinct hyaline margin and are usually ciliate all around.

Typical representatives are, e.g., Kanis 1091; Brass 23857, 24063; Hoogland 5070. Less distinctly dimorphic specimens (e.g., Schlechter 16477) are very similar to 'vittarioides'. The entity is restricted to New Guinea and surrounding islands.

'dimorpha'. These are large plants with distinctly dimorphic fronds: the fertile ones, index 5-20 or more, $6.5-22 \times 0.6-1.6 \mathrm{~cm}$; the sterile ones, index 2-9, $3.5-12(-15) \times 1-2.5 \mathrm{~cm}$; the rhizome scales are larger than in 'adnascens' and often have a characteristic, entire, narrow apex. The indument is sparse and appressed. On the one hand 'dimorpha' thus is similar to large forms of 'adnascens' like those occurring on the Pacific islands, on the other hand it is somewhat similar to 'varia' (see below), from which it differs mainly in the rhizome scale characters mentioned above. This is not a constant character: fully ciliate scales are found in, e.g., Brass 7577, 27786; Brass 7586 has both tully cllate scales and scales with an entire apex.

Like 'stellata', it is restricted to New Guinea and surrounding islands. Typical representatives are, e.g., Brass 22063; Millar NGF 35287; Darbyshire 986.

'varia'. This entity has usually rather wide fronds that are often only indistinctly dimorphic. Distinctly dimorphic fronds (the fertile ones, index (5-)8-20 or more, $6-31 \times 0.7-3.5 \mathrm{~cm}$; sterile ones, index $2-8(-10), 2.5-24 \times 1-3.5(-4.3)$ $\mathrm{cm}$ ) occur mainly in the Malesian Archipelago (e.g., De Wilde c.s. 14645; Iwatsuki et al. S 716; Jacobs 5157; Endert 5384; Van Balgooy 3043); narrower, less distinctly dimorphic fronds (fertile fronds, index 6-20 or more, 6.5-29 $\times$ 0.8$2.1 \mathrm{~cm}$; sterile ones, index 4-12, 5.5-17 $\times 0.9-2)$ occur mainly on the mainland of Asia and on the Philippines (e.g., Dickason 9175; Kingdon-Ward 4; C.W. Wang 73862, 70605; Edaño PNH 11255; Elmer 22015). These forms have been called Niphobolus nudus. In all forms the rhizome scales are large $(3.9-7.8 \mathrm{~mm}$ long), and distinctly patent. The texture of the lamina is usually more papyraceous than in the other entities, and the veins are more prominent. The indument is often patent instead of appressed. 
This entity occupies roughly the same area as 'adnascens', and is in its extreme expression very distunct trom it. It is considered as a distinct species in most floras covering part of this area (e.g., Holttum, 1954; Backer \& Posthumus, 1939). Nevertheless, even within this area there are intermediate forms that cannot be ascribed to either species unless the distinction is based on a single character which then must be arbitrarily chosen from among the complex indicated above. Such specimens (e.g., Clemens 159; De Vriese \& Teysmann 16) are relatively rare, but a distinction that can be kept up only on basis of a single character is to me insufficient for recognizing a species. Moreover, the distinction between 'adnascens' and 'varia' disappears completely if the other entities from other areas are taken into account, most of which combine characters of 'varia' and 'adnascens', often without having distinct characters of their own.

2. Variability in lamina anatomy. There is much variation in lamina anatomy, which partly correlates with the variation described above. The most variable characters are:

- degree to which the stoma-groove is contracted above the stomata;

- number of cells adjoining the stoma-groove;

- thickness of the combined hypodermis and water-tissue layer;

- the degree to which the cells of the upper epidermis project outwards.

- Stoma-groove. In 'adnascens', 'pustulosa' and 'dimorpha' the stoma-groove is strongly constricted at the mouth. In the other entities it is less distinctly, and more variably, constricted. It is not constricted at all in some forms of 'varia'.

- Number of cells adjoining the stoma-groove. According to Giesenhagen (1901) Nipohobolus varius can be distinguished from $N$. adnascens by the number of epidermis cells surrounding the stoma-groove; the numbers being $6-7$ or $3-5$, respectively.

If the other entities here recognized are also taken into consideration, the following results are obtained:

\begin{tabular}{ll}
\hline entity & no. of cells \\
\hline adnascens & $(3-) 6.35-7.00(-9)$ \\
pustulosa & $(5-) 6.00-7.10(-9)$ \\
stellata & $(4-) 6.05-6.45(-9)$ \\
dimorpha & $(6-) 7.55-8.25(-10)$ \\
varia & $(2-) 3.65-5.40(-8)$ \\
vittarioides & $(3-) 4.50-5.80(-7)$ \\
spissa & $(3-) 4.20-4.40(-6)$
\end{tabular}

The values given are the ranges of the means of 20 observations for 2-9 specimens of each entity; the extremes are given between brackets.

It appears that the entities can be ordered in two groups according to this character: one, composed of entities around 'adnascens' ('adnascens', 'pustulosa', 'stellata', 'dimorpha'), with an average of more than 6 cells adjoining the stoma- 
groove; another one, of groups around 'varia' ('varia', 'vittarioides', 'spissa'), with less than 6 cells around the groove.

An extremely large number of cells seems to be characteristic for 'dimorpha'. Stomata with such a large number of adjoining cells tend to stand out distinctly in dried fronds, probably due to the large numbers of cell-walls strengthening the area immediately around the pore.

Thus, with the aid of this character the otherwise often rather similar 'varia' and 'dimorpha' can be separated, but otherwise no useful distinction is found. The variation is almost continuous, and is even more so if the the total range of the numbers observed is considered.

- Thickness of hypoderm and water-tissue layer. In 'vittarioides' this combined layer is one cell thick; in 'varia' it is 1-3 cells thick, in 'pustulosa' and 'stellata' 2-3 cells; in 'adnascens' and 'dimorpha' 2-4 cells. In case of layers more than 2 cells thick the cells increase in size towards the inner parenchyma, thus showing a slight differentiation into hypoderm and water-tissue.

- Projecting epidermis-cells. Strongly projecting cells are found in 'vittarioides' and 'stellata', other entities are more variable in this respect. A completely smooth upper epidermis is restricted to some specimens of 'varia' and 'dimorpha'.

3. Frequently annular figures are present in the scales similar to those in $P$. confluens.

4. Although hydathodes are generally absent from this species, occasionally some specimens do have a few of them. Niphobolus giesenhagenii is based on such a specimen; and Giesenhagen (1901) reports their occurrence in $N$. nudus.

5. Typification of $P$. lanceolata. Acrostichum lanceolatum is typified by a Hermann specimen (Trimen, 1888). The specimen in the Linnean herbarium (LINN) is a fertile frond of Elaphoglossum sp. and probably a later acquisition.

6. Niphobolus varius: The interpretation of this name in many floras (Backer \& Posthumus, 1939; Holttum, 1954; Copeland, 1960) probably goes back to Blume (Fl. Jav. Fil. (1829), pl. 21).

The species, however, is based on collections of Chamisso, which would have been considered as belonging to $N$. adnascens by those who consider the two distinct.

7. Niphobolus carnosus. Under this name Blume (1828) cited Rheede's Plate no 29 (Hortus Malab. 12 (1703)), which represents a plant from southern India. Judging by the plate and by the origin given, the specimen depicted probably is Pyrrosia heterophylla (L.) Price. Niphobolus carnosus is accordingly cited by Kaulfuss, under Notochlaena piloselloides, which in Kaulfuss' circumscription includes Pyrrosia heterophylla. Blume's original material has been lost. $N$. carnosus is here interpreted on the basis of the plate in Blume's Flora Javae $(1829$, pl. 19), which clearly represents $P$. lanceolata.

8. Craspedaria pertusa: As Link cites Niphobolus varius Kaulf., he should have made the combination Craspedaria varia. 
9. Niphobolus giesenhagenii: This name refers to specimens with a few, scattered, hydathodes. Two numbers of Griffith' are cited by Christ, from the herb. Delessert (G). In $P$ however both numbers are given on a label attached to a single sheet with only a single piece of rhizome. I do not know to which collection in $\mathrm{G}$ this plant corresponds, but it seems obvious that this is the specimen Christ had at hand.

10. Vernacular names: Ka Kam Kwa Fat (Hainan); Tjakweikjon (Karieng, Thailand); Ueang Pae (Laotian: Orchid Rock); Apatpat an dodologapdi (Luzon); Holog (Ifugao dialect, Luzon); Humang anapatpat (Luzon); Kapal (Dusun dialect, Sandakan); Pakoe Tamaga (Java); Tetumpang (Malaya, Perak); Ilofilifeh (Mekeo, New Guinea); Tarawalla (Orne language, New Guinea); Rumbaro (Orne language, New Guinea); Mampoopaivior (Biak, New Guinea); Kwalu Kwalu (Serva, Fiji); Mokomoko Uiivi (Fiji); Laumafatifati (Samoa, Utulei); Fue ulu (Samoa, Tutuila).

11. Uses: 'Crush and mix it with jintan itam and onion. Then apply externally to forehead to relieve headache' (Malaya; note to Noorudin 6750). 'For dysentery' (Malaya, note to Haniff, SING 15887). 'Use from leaves used by natives as a dressing for fresh cuts.' (Samoa, Tutuila, note to McMullin 19). 'The leaves are used to treat cuts' (Palau Is., note to Salsedo 328).

\section{Pyrrosia linearifolia (Hooker) Ching. Fig. 20 b.}

Pymosia linearifolia Ching, Bull. Chin. Bot. Soc. 1 (1935) 48; Tagawa, J. Jap. Bot. 24 (1969) 116; Tagawa, J. Jap. Bot. 32 (1957) 12; Nakaike, Enum. Pter. Jap. (1975) 352; DeVol, Fl. Taiwan (1975) 206; Kurata * Nakaike, Ill. Pter. Jap. (1981) 600-602.-Niphobolus linearifolius Hooker, 2nd Cent. Ferns (1861) pl. 58; Diels in E. \& P., Nat. Pfl. Fam. 1,4 (1899) 326, fig. 168 D; Diels, Bot. Jb. 29 (1900) 207; Giesenh., Niphobolus (1901) 171; Hayata, Bot. Mag. Tokyo 23 (1909) 34.-Polypodium linearifolium Hooker, Sp. Fil. 5 (1863) 53; Baker in Hooker \& Baker, Syn. Fil. (1867) 356; Baker, Ann. Bot., Lond. 5 (1891) 475; Franch. Savat. Enum. Pl. Jap. 2 (1876) 246; Christ in Warb., Monsunia 1 (1900) 61; Dunn * Tutch., Fl. Kwangt. (1912) 352.Cyclophorus linearifolius C. Chr., Ind. Fil. (1906) 199; Christ, Bull. Acad. int. Géogr. bot. 20 Mém. (1909) 148; Bonap., Notes Ptérid. 7 (1918) 75; Fomin, Fl. Sib. et Or. 5 (1930) 191.Neoniphopsis linearifolia Nakai, Bot. Mag. Tokyo 42 (1928) 217.-T y pe: Wilford s.n., s.d. (holo $\mathrm{K}$, iso $\mathrm{B}, \mathrm{BM}$.), Japan, Tsus-sima.

P. linearifolia var. heterolepis Гagawa, J. Jap. Bot. 24 (1949) 116.-T y pe: not indicated (not seen), Taiwan.

Rhizome long-creeping, occasionally grooved ventrally, 1-1.8 mm thick, phyllopodia $0.5-1(-1.5) \mathrm{cm}$ apart, lateral buds situated close to the phyllopodia. Anatomy: ground tissue parenchymatous, sclerenchyma sheath absent or indistinct, sclerenchyma strands scattered through the inner parenchyma, 5- \pm 20 ; vascular strands $6-7$. Scales peltate, $2.2-5 \times 0.5-1 \mathrm{~mm}$; base entire or ciliate; acumen light brown, ciliate. Fronds monomorphic, sessile; index 5 to over 20; $1.5-12(-15) \times 0.1-0.5 \mathrm{~cm}$, base more or less gradually narrowed, apex obtuse or rounded. Venation: secondary veins not distinct, with the tertiary veins forming irregular areoles; included veins simple, mainly free, few, mainly excurrent. 
Hydathodes more or less distinct, usually in a marginal row, distinctly sunken. Anatomy: lower part of costa with 1-2 central and 1-3 lateral vascular strands; lamina $0.4-0.5 \mathrm{~mm}$ thick, upper epidermis with distinctly projecting cells with thin walls, hypodermis and water-tissue absent, palissade and spongy parenchyma indistinct, lower epidermis with thin cell-walls; stomata slightly sunken, pericytic. Indument dimorphic, a loose mat, persistent, brown; upper layer composed of hairs $0.5-2.2 \mathrm{~mm}$ in diam., with erecto-patent, acicular rays, mixed with a lower layer composed of hairs with mainly woolly rays, lower layer often present only between the sori. Sori apical, shortly spaced, superticial; 1-2 in each soriterous areole, occasionally confluent; $1-2(-2.5) \mathrm{mm}$ in diam., often slightly elongated; when old individually distinct, \pm immersed in the indument. Sporangia on stalks to $1 \times$ as long as the capsule, capsule $\pm 3 \mathrm{~mm}$ high, with $17-$ 21 indurated annulus cells. Paraphyses not differentiated. Spores (58-)70.4$73.2(-80) \times(44-) 49.4-54.6(-64) \mu \mathrm{m}$, sparsely granulate.

Habitat: Epiphytic, mostly on forest trees; or epilithic; in sheltered to exposed situations.

Altitudinal range: Sea level to $1400 \mathrm{~m}$.

JAPAN (Honshu, Shikoku \& Kyushu). 55 collections.

- Ryukyu Is., Okinawa: Kurata Nakaike 2655 (NA), 2657 (NA), T. Shinjo s.n. (10-8-1965)

(US), Sonohara s.n. (19-6-1966) (US).

CHINA. Kirin: Ross s.n. (10-77) (K).

TAIWAN. 9 collections.

KOREA. Mainland, South \& North: Faurie 708 (B, BM, P), 77 (B, BM, P), Mills 280 (K), Oldham 1048 (K), Smith s.n., s.d. (A, US), Warburg s.n., s.d. (B). - Cheju-do: 10 collections (mainly Taquet).

Notes. 1. Variability. Plants from Taiwan differ from those occurring on Cheju-do (Quelpaert) and Japan in having slightly shorter and wider rhizome scales (index to $\pm 5,2-4 \mathrm{~mm}$ long; compared with index to $\pm 9,3-5 \mathrm{~mm}$ long) with a base that is less deeply lacerate-ciliate.

2. Lamina indument: the indument is sometimes somewhat similar to that of $P$. assimilis, which has hairs with unequally long branches. In $P$. linearifolia also very unequal branch-lengths occur on a single hair (differing up to a factor 7).

3. Occasionally slightly dimorphic plants can be found (e.g., Hancock Yb, Linsley Giressit $33 /$, Ugata 240 ). I hese have a tew sterule tronds that are distinctly shorter and wider than the fertile ones.

\section{Pyrrosia lingua (Thunb.) Farwell. Fig. 21 a.}

Rhizome long-creeping, not grooved ventrally, 1.2-3.7 mm thick, phyllopodia (0.5-)2-8 cm apart, lateral buds situated halfway or more down the internodia. Anatomy: ground tissue parenchymatous, sclerenchyma sheath distinct, a single, central sclerenchyma strand present or sclerenchyma strands scattered through the inner parenchyma, 0-10; vascular strands.5-9. Scales peltate, (2.2-)4- 
$9.5 \times 0.7-1.6 \mathrm{~mm}$; base entire to irregularly dentate; acumen shining light brown, with long, curly marginal or superficial cilia; short, \pm ovate scales occasionally present. Fronds moderately dimorphic, stipitate. Fertile fronds: stipes $1.5-25 \mathrm{~cm},\left({ }^{1} / 5-\right)^{1 / 4-1}(-11 / 2) \times$ as long as the lamina; lamina, index 2-12; widest at or below the middle, $5-25 \times 0.8-5 \mathrm{~cm}$, base truncate to more or less gradually attenuate, apex rounded, obtuse to acuminate or occasionally apiculate. Sterile fronds: stipes $1-30 \mathrm{~cm},\left({ }^{1} / 10-\right)^{1 / 5-} \pm 1 \times$ as long as the lamina; lamina, index 2-8; widest at or below the middle, 5-27 $\times 1-7.2 \mathrm{~cm}$; otherwise similar to the fertile ones. Venation: secondary veins distinct, with the tertiary veins forming regular areoles; included veins frequently forked and anastomosing; free veins many, mainly excurrent. Hydathodes distinct, scattered over the lamina, more or less superficial, rarely distinctly sunken; occasionally absent. Anatomy: stipe with 4-9 central and 1-2 lateral vascular strands; lamina 0.4-0.8 $\mathrm{mm}$ thick, upper epidermis with flat to distinctly projecting cells with thin to moderately thickened walls, hypodermis composed of 1-3 cell-layers, water-tissue absent, palissade and spongy parenchyma distinct to indistinct, lower epidermis with thickened cell-walls: stomata sunken. Dericvtic. Indument mono- or dimorphic, persistent. Sori apical to aus uver unc sanuna ur uccassunally in a weakly denned, irregularly shaped patch, closely packed, superficial; several in a single row or to \pm 10 scattered throughout each soriferous areole, often confluent along the veins; $0.5-2(-2.5) \mathrm{mm}$ in diam.; developing all more or less simultaneously, when old individually distinct, exserted from the indument. Sporangia on stalks $3 / 4-1 \times$ as long as the capsule, capsule $0.2-0.4 \mathrm{~mm}$ high, with $16-22$ indurated annulus cells. Paraphyses not differentiated. Spores $(60-) 64.6-76.2(-80) \times(44-)$ $47.2-55.8(-60) \mu \mathrm{m}$, irregularly verrucate.

Key to the varieties

- indument monomorphic ....................................... a. var. lingua

- indument dimorphic ....................................... b. var. heteractis

\section{a. var. lingua}

Pyrrosia lingua Farwell, Amer. Midl. Nat. 12 (1931) 302; Ching, Bull. Chin. Bot. Soc. 1 (1935) 60; C. Chr. Tard., Not. Syst. 8 (1939) 205; Tard. * C. Chr., Fl. Indo-Ch. (1941) 508; Tagawa, J. Jap. Bot. 24 (1949) 117; Tagawa, J. Jap. Bot. 32 (1957) 357; Fu, Ill. Imp. Chin. Pl. (1957) 238, fig. 320; Steward, Man. Vasc. Pl. L. Yangtze (1958) 53; Holttum, Dansk Bot. Ark. 23 (1965) 230; Nayar * S. Chandra, Bull. Nat. Bot. Gard. Lucknow 117 (1965) 60; Nayar * S. Chandra, Can. J. Bot. 45 (1967) 615-634; DeVol, Fl. Taiwan (1975) 206; Nakaike, Enum. Pter. Jap. (1975) 353; Kurata Nakaike, Ill. Pter. Jap. (1981) 610; Hoshizaki, Baileya 21 (1981) 63, fig. 6; Shing, Amer. Fern J. 73 (1983) 76.-Acrostichum lingua Thunb., Fl. Jap. (1784) 330, pl. 33; Schkuhr, Krypt. Gew. 1 (1809) 1, pl. 1 ; [non Acrostichum lingua Raddi, Syn. Fil. Brasil. (1819) 5, nom. illeg., - Elaphoglossum lingua (Raddi) Brack]. - Polypodium lingua Swartz, Syn. Fil. (1806) 29; [non Polypodium lingua Vahl, Ecl. Amer. 3 (1807) 50, nom. illeg., = ?, type from Montserrat]; Langsd. Fischer, Pl. Voy. Russes (1810) 7, pl. 5; Willd., Sp. Pl. 5 (1810) 162; Desvaux, Mag. Ges. Naturf. Freunde Berlin (Berl. Mag.) 5 (1811) 300; Mett., Polyp. (1856) 130; Mett., Fil. Lips. (1856) 33; Hooker, Sp. Fil. 5 (1863) 49, p.p.; Mett., Ann. Mus. Lugd. 
Bat. 2 (1866) 231; Baker in Hooker \& Baker, Syn. Fil. (1867) 350 p.p.; Milde, Fil. Eur. Atl. (1867) 17; Franch. Savat., Enum. Pl. Jap. 2 (1876) 245; Franch., Pl. David. 1 (1884) 335; Franch., Pl. David. 2 (1988) 161; Baker, Ann. Bot., Lond. 5 (1891) 472, q. n.s.; Christ, J. Bot. Paris 8 (1894) 152; Christ, Bull. Herb. Boiss. 7 (1899) 5; Christ in Warb., Monsunia 1 (1900) 60; Dunn. Tutch., Fl. Kwangtung (1912) 351.-Niphobolus lingua Spr., Syst. 4 (1827)45; J. Sm., Hooker J. Bot. 4 (1842) 57; J. Sm., Cat. Kew Garden Ferns (1846) 12; Kunze, Bot. Zeit. (1848) 506; Fée, Gen. Fil. (1853) 262-3; Hooker, Hooker J. Bot. 9 (1857) 355; J. Sm., Cat. Cult. Ferns (1857) 12;T. Moore, Ind. Fil. (1857) lxxvi; Bedd., Ferns S. India (1864-5) 81, pl. 240; Keyserl., Polyp. Herb. Bunge (1873) 37; J. Sm., Hist. Fil. (1875) 98; J. Sm., Ferns Br. * For. ed. 2 (1877) 100; Bedd., Suppl. Ferns S. Br. Ind. (1876) 22, pl. 385; Diels in E. P., Nat. Pfl. Fam. 1,4 (1899) 325; Diels, Bot. Jb. 29 (1900) 206, Giesenh., Niphobolus (1901) 148, 156; Christ, Bull. Acad. int. Géogr. bot. 9 (1902) 222; Christ, J. Bot. Paris 19 (1905) 74; Christ, Bull. Soc. Fr. 52 Mém. 1 (1905) 23; Christ, Bull. Acad. int. Géogr. bot. (1906) 109; Hayata, Bot. Mag. Tokyo 23 (1909) 24. - Polycampium lingua Presl, Epim. Bot. (1851) 136. - Cyclophorus lingua Desv., Mém. Soc. Linn. Paris 6 (1827) 224; C. Chr., Ind. Fil. (1906) 199; Christ, J. Bot. Paris 21 (1908) 238; Christ, Bull. Acad. int. Géogr. bot. 20 Mém. (1909) 148; H. Lev., Fl. Kouy-Tchéou (1915) 479; Bonap., Notes Ptérid. 7 (1918) 75, 126, 191; C. Chr., Acta Horti Gothob. 1 (1924) 106; Hand.-Mazz., Symb. Sin. VI (1929) 46; Wu et al., Bull. Dep. Biol. Sun Yatsen Univ. 3 (1932) 332; C. Chr., Ind. Fil. Suppl. 3 (1934) 65; Ching, Bull. Chin. Bot. Soc. 1 (1935) 36.-Type: Thunberg s.n., s.d. (holo UPS, not seen; iso BM), Japan.

Polypodium taiwanense Christ in Warb., Monsunia 1 (1900) 60. - Cyclophorus taiwanensis C. Chr., Ind. Fil. (1906) 201; Hayata, Ic. Pl. Form. V (1915) 264.-Synty pes: Warburg 9552 ('9556', err. Christ) (B, P?), Warburg 9526 (B, P?), Taiwan.

Niphobolus martini Christ, Bull. Soc. Fr. 52 Mém. (1905) 2-Cyclophorus martini C. Chr., Ind. Fil. (1906) 199; H. Lev., Fl. Kouy-Tchéou (1915) 479; C. Chr., Acta Horti Gothob. 1 (1924) 105; Hand.-Mazz., Symb. Sin. VI (1929) 46. - Pyrrosia martini Ching, Acta Phytotax. Sin. 10 (1965) 304. - Syntypes: Martin \& Bodinier 2128 (P, M), David s.n., s.d. 'Moupin' (P), Delavay 4954 (P), China.

Cyclophorus bodinieri H. Lev., Fl. Kouy-Tchéou (1915) 478; C. Chr., Ind. Fil., Suppl. 2 (1917) 10; C. Chr., Ind. Fil., Suppl. 3 (1934) 64, pro syn.; Ching, Bull. Chin. Bot. Soc. 1 (1935) 61, pro syn.-Type: Esquirol 2696, (P, not found), China.

Cyclophorus lingua var. attenuata Rosenst., Hedwigia 56 (1915) 347; Tagawa, J. Jap. Bot. 24 (1949) 117, pro syn.; Nakaike, Enum. Pter. Jap. (1975) 353, pro syn. - Ty pe: Faurie 223, (III-1914) (not seen), Taiwan.

Cyclophorus lingua var. angustifrons Hayata, Ic. Pl. Form. V (1915) 264; Tagawa, J. Jap. Bot. 24 (1949) 117, pro syn.; Nakaike, Enum. Pter. Jap. (1975) 353, pro syn. - T y pe: T. Ito \& B. Hayata s.n., s.d. (TI, not seen, photograph Z), Taiwan, 'Mt. Arisan'.

Pyrrosia caudifrons Ching, Boufford Shing, J. Arn. Arb. 64 (1983) 37, fig. 7 d-g.-Ty pe: SinoAmer. Bot. Exp. 1159 (A, NA), China.

Polypodium pannosum et syn. homot., auct. non Kuhn, quoad specim. As. cont. (see note 2): Bedd., Ferns S. India (1864-5) pl. 240; Bedd., Suppl. Ferns S. Br. Ind. (187 6) 22; Bedd., Handb. ferns Brit. Ind. (1883) 328; Alderwerelt, Malayan Ferns (1909) 683; Dickason, Ohio J. Sc. 46 (1946) 129; Nayar \& Kaur, Comp. Bedd. Handb. (1974) 80.

Rhizome. Anatomy: single, central sclerenchyma strand sometimes present. Scales with marginal cilia. Fertile fronds: lamina, index 2-12; 5.5-22 $\times 0.8-3 \mathrm{~cm}$, base more or less gradually attenuate, apex obtuse, acute or slightly acuminate. Sterile fronds: lamina, index 2-8; 5-23 × 1.2-2.5 cm. Hydathodes distinct, more or less superficial, rarely distinctly sunken. Anatomy: upper epidermis with flat cells. hvpodermis combosed of 1-3 cell-lavers. Indument monomorphic, a thin mat, persistent, light to greyish brown; hairs $0.3-0.5 \mathrm{~mm}$ in diam., with appressed, boat-shaped rays. Sori closely packed, to \pm 10 scattered throughout each soriferous areole. 
Habitat: Mostly epilithic, less often epiphytic, sometimes terrestrial; usually in more or less exposed places (dry rocks, walls, seashore rocks, open forest, etc.). Altitudinal range: Sea-level up to $\pm 2500 \mathrm{~m}$.

JAPAN (Honshu, Shikoku, Kyushu). 71 collections. - Ryukyu Is.: 7 collections.

KOREA. S. Korea: O. Yong Sok 8003 (E). - Cheju-do: 7 collections.

CHINA. Peking: Carles s.n. (1882) (BM). - Hupeh: Henry 5128 (B), 5810 (B, BM), SinoAmerican Bot. Exp. 1159 (A, NA), 1929 (NA). - Szechuan: 25 collections. - Kweichow: 9 collections. - Yunnan: 21 collections. - Kiangsu (incl. Shanghai): Chiao 18640 (Z), Ching 3429 (SING), Faber s.n. (1886) (B). - Anhwei: Ching 4120 (US), 4404 (US), Fan \& Li 61 (P). Chekiang: 7 collections. - Kiangsi: 7 collections. - Fukien (incl. Amoy): 10 collections. Hunan: Tsang 23483 (P). - Kwangtung: 30 collections. - Kwangsi: 7 collections. - Hainan: How $73428(\mathrm{GH})$, Liang 65113 (P, US), Eryl Smith 1535 (K, US).

TAIWAN. 27 collections.

HONGKONG. 28 collections. (M).

INDIA. Assam: Gustav Mann s.n. (9-1886) (B, BM, M), (3-1887) (M), (9-1890) (M), (11-1890)

BURMA. Dickason 9206 (GH), Lobb s.n., s.d. (K), Parish s.n. (1860) (P), 160 (K).

THAILAND. Northern: Van Beusekom \& Phengkhlai 1277 (L), 1285 (B, L, US), Hennipman 3145 a (L), Eryl Smith 1156 (K, SING), 1287 (SING). - Northeastern: Din 168 (K), Hennipman 3569 (L).

LAOS. Cadière $164(\mathrm{P})$, Poilane $15871(\mathrm{P})$

VIETNAM. Tonkin: 18 collections. - Annam: Pételot (coll. Sallet) 3538 (P).

Notes. 1. Variability.

Three forms can be distinguished but not sharply demarcated:

- Rhizome scales stiffly appressed, lamina relatively narrow, ovate-lanceolate, index $(21 / 2-) 4-9(-12)$, widest $\pm 1 / 3$ above the base (e.g., Tsang 22200, 24911, Tagawa Iwatsuki 716, Tsai 51130, Cadière 972, Wang 73801). This form occurs throughout the range of the variety.

- Rhizome scales and lamina shape similar but plants distinctly smaller, lamina to $\pm 10 \times 1 \mathrm{~cm}$ (e.g., Coert 1473, Cheng 1179, Taam 429, Bon 2655). A single collection, however, may contain both large and smaller plants (e.g., Tsang 23483, Faber 1064, Taam 563, Tanaka \& Shimada 13496). Small plants appear to be particularly frequent in Southeast China, especially around Hongkong.

- Rhizome scales often patent and relatively wide; lamina elliptic, index 2-5 $\left(-7^{1 / 2}\right)$, widest $1 / 3$ to $1 / 2$ above the base, apex often distinctly acuminate (e.g., Cavalerie 606, 1054, H. Smith 1898, Chiao 1679, Fang 272). This form has been recoenized as a separate species (Pyrrosia caudifrons) by Ching. Apart from the characteristic lamina shape there are no other constant differential characters. Appressed and patent rhizome scales seem to be structurally similar. Moreover, distinctly flaccid scales sometimes occur in combination with narrow, ovate fronds (e.g., How 73428); or appressed scales in combination with a relatively wide lamina (e.g., Fang 1095, Steward et al. 409). The often slightly more herbaceous texture of these wide laminas suggests that it is a form of sheltered sites.

2. Parish 160 (K) from Moulmein, illustrated in Beddome, Fl. S. Ind. pl. 240 as Niphobolus pannosus represents a form with a very dense indument and distinctly pitted hydathodes. It is more similar in these aspects to $P$. petiolosa than to $P$. pan- 
nosa; the rhizome scales, however, point to affinity rather with $P$. lingua. Similar are Lobb s.n., Moulmein (K) and Anon. 383, Moulmein (K).

3. Ching (1935) considered $P$. lingua conspecific with Pyrrhosia chinensis Mirbel, type of the genus. Desvaux, however, already noted (teste Mett., Ann. Mus. Lugd. Bat. 2 (1866) 232) that $P$. chinensis is conspecific with Polypodium stigmosum Sw.

4. Numerous furcate and crispate forms have been cultivated, mainly in Japan. They are often described as formae, varieties or monstrosities. For a review of many of these forms see Nakaike, Enum. Pt. Jap. (1975) 354 and Hoshizaki, Baileya 21 (1981).

\section{b. var. heteractis}

Pyrrosia lingua (Thunb.) Farwell var. heteractis Hovenkamp, Blumea 30 (1984) 208. - Polypodium heteractis Mett. ex Kuhn, Linnaea 36 (1869) 140; Baker in Hooker \& Baker, Syn. Fil. (1867) 512; C. B. Clarke, Tr. Linn. Soc. II Bot. 1 (1880) 425. - Niphobolus heteractis J. Sm., Ferns Br. For. ed. 2 (1877) 296; Bedd., Handb. ferns Brit. Ind. (1883) 327; Giesenh., Niphobolus (1901) 153, 158. - Cyclophorus heteractis C. Chr., Ind. Fil. (1906) 199; Alderwerelt, Malayan Ferns (1909) 684, p.p.; Copeland, Sarawak Mus. J. 2 (1917) 409; C. Chr., Contr. U.S. Nat. Herb. 26 (1931) 326; Dickason, Ohio J. Sc. 46 (1946) 29.-Pyrrosia heteractis Ching, Bull. Chin. Bot. Soc. 1 (1935) 52; Nayar, J. Ind. Bot. Soc. 40 (1961) 164-186; Nayar \& S. Chandra, Bull. Nat. Bot. Gard. Lucknow 117 (1965) 54; H. Hara, Fl. Eastern Himal. (1966) 498; Nayar S. Chandra, Can. J. Bot. 45 (1967) 615-634; H. Hara, Fl. Eastern Himal., 2nd Rep. (1971) 219; Nayar \& Kaur, Comp. Bedd. Handb. (1974) 80; Hoshizaki, Baileya 21 (1981) 61, fig. 5; Ching \& Wu, Fl. Xizang. 1 (1983) 337, fig. 88 5-8; Shing, Amer. Fern J. 73 (1983) 76.-Lectoty pe: Hooker * Thomson s.n., s.d., (holo $\mathrm{B}$, iso $\mathrm{K}$ ), India, Khasya.

Cyclophorus eberhardtii Christ, J. Bot. Paris 21 (1908) 237, 270; C. Chr., I nd. Fil., Suppl. 1 (1913) 22; Bonap. Notes Ptérid. 7 (1918) 126, 191. - Pyrrosia eberhardtii Ching, Bull. Chin. Bot. Soc. 1 (1935) 59; C. Chr. * Tard., Not. Syst. 8 (1939) 204; Tard. * C. Chr., Fl. Indo-Ch. (1941) 507; Tagawa, Acta Phytotax. Geobot. 22 (1967) 106; Shing, Amer. Fern J. 73 (1983) 76. Type: Eberhardt $78(\mathrm{P})$, Indo-China.

Cyclophorus heteractis var. minor C. Chr., Contr. U.S. Nat. Herb. 26 (1931) 335.-Pyrrosia heteractis var. minor Ching, Bull. Chin. Bot. Soc. 1 (1935) 58.-T y pe: J. Rock 349 (BM, US), 1508 (US), Thailand.

Pyrrosia oblonga Ching, Bull. Chin. Bot. Soc. 1 (1935) 58; C. Chr. Tard., Not. Syst. 8 (1939) 206; Tard. \&. Chr., Fl. Indo-Ch. (1941) 507.-T ype: Ching 8117 (not seen), China.

Rhizome. Anatomy: sclerenchyma strands scattered through the inner parenchyma, 0-5; Scales 5.1-9.5 $\times 0.9-1.6 \mathrm{~mm}$; with marginal or superficial cilia; short, \pm ovate scales occasionally present. Fertile fronds: lamina, index 2-7; widest at or below the middle, 5-25 $\times 1-5 \mathrm{~cm}$, base truncate to more or less cuneate, apex round to acuminate or occasionally apiculate. Sterile fronds: lamina, index 2-5; 4-27 $\times 1-7.2 \mathrm{~cm}$; otherwise similar to the fertile ones. Hydathodes occasionally absent. Anatomy: upper epidermis with flat to distinctly projecting cells, hypodermis indistinct to distinct, composed of a single cell-layer, Indument dimorphic, a dense mat, persistent, whitish to greyish brown; upper layer composed of hairs $0.4-0.8 \mathrm{~mm}$ in diam., with appressed, boat-shaped rays, appressed to a lower layer composed of hairs with mainly woolly rays. Sori closely 
packed to shortly spaced; several in a row or scattered through each soriferous areole.

Habitat: Usually epiphytic or epilithic, sometimes terrestrial, in more or less sheltered situations, on sand- or limestone, often in open pine-forest, also in evergreen wet forest.

Altitudinal range: $350-1500(-3000) \mathrm{m}$.

CHINA. Tibet: Kingdon-Ward 19337 (BM), Ludlow et al. 12120 (BM). - Yunnan: 13 collections. - Hainan: 11 collections.

NEPAL. Ghose 12 (P), Hooker s.n., s.d. (K).

BHUTAN. 7 collections.

INDIA. Sikkim \& Darjeeling: 13 collections. - Assam: 23 collections. - Kerala * Tamil Nadu: Foreau s.n. (1955) (M).

BURMA. 7 collections.

THAILAND. Northern: 8 collections. - Northeastern: 9 collections. -Central: Hansen et al. 11376 (K), Hennipman 3944 (L), Larsen et al. 10679 (K), Maxwell 74-867 (L). - Southeastern: Morton 88 (K). - Peninsular: Van Beusekom \& Phengkhlai 855 (B, L), Hennipman 3831 (B, L), Iwatsuki et al. T 8443 (L), Larsen et al. 30864 (L), Tagawa et al. T 4670 (L, US), 4779 (L, US).

CAMBODIA. Abbe et al. 9626 (A), Bouillod 50 (P), Poilane 28788 (P), Eryl Smith 2608 (K), 2863 (K), H.M. Smith 310 (US).

LAOS. Poilane 16079 (P), 16154 (P), 28373 (P).

VIETNAM. Tonkin: Cadière $1016(\mathrm{P})$, Colani $1567(\mathrm{P})$, Pételot $3736(\mathrm{P})$, Tsang 27394 (A, K, P). - Annam: 18 collections. - Cochinchina: Evrard 1008 (P), 1014 (P), Hayata 132 (P), $288(\mathrm{P})$, Pierre s.n., s.d. (BM, P).

Notes. 1. Variability. Var. heteractis is more variable than var. lingua, nevertheless it is not possible to distinguish forms clearly. The main variability concerns three forms:

- Scales very distincly flaccid, lamina with a pronounced apiculus, sori shortly spaced (e.g., Ludlow \& Sherriff 2966, Rock 7491, Mann s.n. May 1878, Wang 66951). This form occurs mainly in N. India, Burma and Yunnan.

- A larger form, scales appressed, sori often closely packed (e.g., Van Beusekom \& Phengkhlai 855, 2998, Tagawa et al. T 4670). This occurs mainly in Thailand. - Mostly small plants, scales appressed, lamina with a rounded apex, indument very dense and hydathodes often absent (e.g., Abbe et al. 9432, 9626, Tsane \& Fung 674). This form has been called $P$. oblonga, and occurs mainly in eastern IndoChina and on Hainan.

The forms are connected by series of intermediates and any line dividing them can only be drawn arbitrarily. Thus, the first form is connected to the second one by plants with increasingly larger fronds (Ludlow Sherriff 2966; Rock 7499); to the third one by plants with gradually narrower fronds and more appressed rhizome scales (Dickason 6713, Wang 78534, 78938, Mann s.n. Sep. 1886).

2. In many cases the marginal indument of the rhizome scales extends over the abaxial surface, so that it is slightly hairy or papillose. This is most conspicuous in relatively short, patent scales.

The marginal indument itself is also variable. Some plants have almost entire scales throughout (e.g., Wang 73616, Hennipman 3569), some have conspicuously 
hairy scales on some parts of the rhizome, almost entire scales on other parts (Hansen 11152). The very long, curly cilia are often deciduous and are best observed at the apex of a young rhizome.

3. In var. heteractis the density of woolly hairs may vary considerably; in var. lingua woolly hairs are usually absent from the lamina, but occasionally present in small numbers at the base of the stipe and sometimes higher upwards on the costa (e.g., in Steward \& Cheo 409). Var. heteractis is often considered specifically distinct from the type variety, the main differential character being the presence of a woolly layer in the indument. Although this is a conspicous character, it is not sufficiently consistent to warrant specific recognition.

The same holds for other characters.

The variation in frond shape is slightly different in the two varieties, but there is an almost complete overlap:

\begin{tabular}{lll}
\hline & heteractis & lingua \\
\hline length $(\mathrm{cm})$ & $4-27$ & $6-23$ \\
width $(\mathrm{cm})$ & $1-7$ & $1-5.5$ \\
index & $2-7$ & $2-10$ \\
widest at & $1 / 4-1 / 2$ & $1 / 3-1 / 2$
\end{tabular}

In both varieties the shape of the lamina apex varies from rounded-obtuse to acuminate, but the extremes of this range (both rounded and acuminate) are more distinct and more frequent in var. heteractis.

Scattered black hairs occur in both varieties in varying density. They are most conspicuous in young fronds, and tend to be more persistent on stipe and costa. They are most likely homologous to the upper layer of hairs that bear the dorsal spines in $P$. laevis.

In both varieties the rhizome scales can be patent or appressed. In var. lingua appressed scales are more common, in var. heteractis patent scales dominate.

In var. heteractis, the sori are more often distinctly spaced, in the var. lingua the sori are mostly contiguous, though individually distinct when old.

Thus, it appears that the weak distinction that can be made on basis of the indument is not supported by other characters. For this reason the two taxa are here treated as varieties, not as separate species.

\section{Pyrrosia longifolia (N.L. Burm.) Morton. Fig. 25.}

Pyrrosia longifolia Morton, J. Wash. Acad. Sc. 36 (1946) 168; Holttum, Fl. Malaya 2 (Ferns) (1954) 148, fig. 63; Holttum, Dansk Bot. Ark. 25 (1967) 48; Tagawa, Acta Phytotax. Geobot. 22 (1967) 106, 185; Tagawa * Iwats., Acta Phytotax. Geobot. 23 (1968) 52; Brownlie, Fl. N. Caled. (1969) 282; Nayar \& Kaur, Comp. Bedd. Handb. (1974) 80; Jones \& Clemesha, Austr. Ferns (1976) 255, pl. 32; Hoshizaki, Baileya 21 (1981) 67, fig. 7.-Acrostichum longifolium N.L. Burm., Fl. Ind. (1768) 228; [non Acrostichum longifolium Jacq., Coll. 2 (1789) 105, nom. illeg., = 
Elaphoglossum longifolium (Presl) J. Sm.] - Candollea longifolia Mirb. Hist. Nat. Vég. 5 (1803) 89; Desvaux, Mag. Ges. Naturf. Freunde Berlin (Berl. Mag.) 5 (1811) 299. - Cyclophorus longifolius Desvaux, Mag. Ges. Naturf. Freunde Berlin (Berl. Mag.) 5 (1811) 301; [non Cyclophorus longifolius (Cav.) C. Chr., Dansk Bot. Ark. 9 (1937) 11, nom. illeg., = Niphidium longifolium (Gav.) Morton \& Lellinger]; Desv., Mém. Soc. Linn. Paris 6 (1827) 224; Gaudich. in Freyc., Voy. Uranie (1829) 364; Presl, Epim. Bot. (1851) 130; Backer * Posth., Varenfl. Java (1939) 240.-Niphobolus longifolius Spr., Syst. 4 (1827) 45; [non Niphobolus longifolius (Bl.) Keyserl., Polyp. Herb. Bunge (1873) 38, nom. illeg. - Paragramma longifolia (Bl.) T. Moore]. - Ty pe: D. Pryon s.n., s.d. (holo G, not seen), Java.

Polypodium acrostichoides G. Forster, Prodr. (1786) 81; Swartz, Syn. Fil. (1806) 29, 225, p.p.; Willd., Sp. Pl. 5 (1810) 156 p.p.; R. Br. Prodr. (1810) 146; A. Rich. in Dumont d'Urville, Voy. Astrolabe (1832) 63; Mett., Polyp. (1856) 127; Hooker, Sp. Fil. 5 (1863) 44 p.p.; Thwaites, Enum. Pl. Zeyl. (1864) 396; Mett., Ann. Mus. Lugd. Bat. 2 (1866) 231; F. v. Muell., Fragm. 5 (1866) 129; Baker in Hooker \& Baker, Syn. Fil. (1867) 350; F. v. Muell., Fragm. 7 (1869-71) 156; Wall, Cat. Ceyl. (1873) 9; Benth., Fl. Austr. (1878) 767; Kuhn, Gazelle Exp. Farne (1889) 11; Beccari, Malesia 3 (1890) 25, 48; F.M. Bailey, Cat. Pl. Queensl. (1890) 60; F.M. Bailey, Lith. Ferns Queensl. (1892) 155; Drake, Fl. Polyn. fr. (1893) 312; Christ, Verh. Nat. Ges. Basel (1897) 20, 245; Christ, Ann. Jard. Bot. Buitenz. 15 (1898) 165; Christ, Bull. Herb. Boiss. 6 (1898) 198; Hieron. in Schum., Fl. Neu-Pommern (1898) 83; Christ in Warb., Monsunia 1 (1900) 60; Giesenh., Niphobolus (1901) 151; Backer \& Posth., Varenfl. Java (1939) 240. Cyclophorus acrostichoides Presl, Epim. Bot. (1851) 130; C. Chr., Ind. Fil. (1906) 197; Christ, Nova Guinea 8 (1909) 155; Alderwerelt, Malayan Ferns (1909) 683; Willis, Cat. Pl. Ceylon (1911) 123; Domin, Bibl. Bot. 85 (1914) 189; Copeland, Sarawak Mus. J. 2 (1917) 409; Bonap., Notes Ptérid. 7 (1918) 125, 189; Brause, Bot. Jb. 56 (1920) 207; Holttum, J. Mal. Br. R. As. Soc. 6 (1928) 20; Farwell, Amer. Midl. Nat. 12 (1930) 245, q.n.s.; C. Chr. Dansk Bot. Ark. 9 (1937) 7; Goy, Queensl. Nat. 10 (1937) 49, pl. 7. - Niphobolus acrostichoides Bedd., Ferns Brit. India (1868) pl. 81; [non Niphobolus acrostichoides Presl, Tent. Pter. (1836) 202, nom. nud., = Pyrrosia confluens (R. Br.) Ching; nec Niphobolus acrostichoides J. Sm., Hooker J. Bot. 3 (1841) 396, nom. nud., = Pyrrosia sphaerosticha (Mett.) Ching]; Keyserl., Polyp. Herb. Bunge (1873) 37; Carr. in Seem., Fiji Ferns (1873) 367; J . Sm., Hist. Fil. (1875) 98; Bedd., Handb. ferns Brit. Ind. (1883) 327; Diels in E. \&., Nat. Pfl. Fam. 1,4 (1899) 325; Schumann Lauterb., Fl. Schutzgeb. Süds. (1901) 142; Giesenh., Niphobolus (1901) 213; Christ, J. Bot. Paris 19 (1905) 74.Pyrrosia acrostichoides Ching, Bull. Chin. Bot. Soc. 1 (1935) 69; C. Chr. \& Tard., Not. Syst. 8 (1939) 203; Tard. \& C. Chr., Fl. Indo-Ch. (1941) 514; Copeland, Fern Fl. Philipp. (1960) 4712; Sledge, Bull. Brit. Mus. (Nat. Hist.) Bot. 2(5) (1960) 134; Holttum, Nov. Bot. Inst. Bot. Univ. Car. Prag. (1968) 50.-T y pe: Forster s.n., s.d. (BM, M), 'Ins. Societatis', see note 3.

Acrostichum bicolor Cav., Anal. Hist. Nat. 1 (1799) 103; [non Niphobolus bicolor Kaulf., Enum. (1824) 128 et syn. homot., = Pyrrosia serpens (Forst.) Ching]; C. Chr., Dansk Bot. Ark. 9 (1937) 7.Type: Née s.n., s.d. (MA, not seen, teste C. Chr., op. cit.), Luzon.

Cyclophorus scolopendrium Desv., Mém. Soc. Linn. Paris 6 (1827) 225; Presl , Epim. Bot. (1851) 132.-Niphobolus scolopendrium T. Moore, Ind. Fil. (1861) 276.-T y pe: anon. s.n., s.d., (P), 'India Or.'.

Niphobolus puberulus Blume, Enum. Pl. Jav. 2 (1828) 108; Blume, Fl. Jav. Fil. (1829) 57, pl. 23; Presl, Tent. Pter. (1836) 202; Presl, Epim. Bot. (1851) 130; Fée, Gen. Fil. (1853) 262; T. Moore, Ind. Fil. (1857) lxxvi; T. Moore, Ind. Fil. (1861) 275.-T y pe: Blume? s.n., s.d. (L, BR, P?), Java.

Niphobolus fissus Blume, Enum. Pl. Jav. 2 (1828) 106; Blume, Fl. Jav. Fil. (1829) 58, pl. 24; Presl, Tent. Pter. (1836) 202; Fée, Gen. Fil. (1853) 263; Giesenh., Niphobolus (1901) 109. Gyrosorium fissum Presl, Epim. Bot. (1851) 141; Polypodium fissum Baker in Hooker \& Baker, Syn. Fil. (1867) 351, q.n.s. - Cyclophorus acrostichoides var. fissum Bonap., Notes Ptérid. 7 (1918) 125, q.n.s.?.-Pyrrosia fissa Mehra, Ferns of Mussoorie (1939) 26, ('fissus'), q.n.s. - Type: Blume? s.n., s.d. (L), Java.

Polypodium macropodum Baker, J. Linn. Soc. Lond. 15 (1877) 108; Hemsley, Chall. Exp. (1885) 210; Baker, Ann. Bot., Lond. 5 (1891) 472. - Cyclophorus macropodus C. Chr., Ind. Fil. (1906) 199; Alderwerelt, Malayan Ferns (1909) 683; Brause, Bot. Jb. 56 (1920) 205.-Pyrrosia macropoda Ching, Bull. Chin. Bot. Soc. 1 (1935) 70.-T y pe: Moseley s.n., s.d. (BM, K), Aru Islands. 
Cyclophorus acrostichoides var. gracilis Copeland, Leafl. Phill. Bot. 1 (13) (1907) 234; Alderwerelt, Malayan Ferns (1909) 683.-Synt ypes: Elmer 7751 (BO, K, M, Z), 7867 (not seen), Luzon. Cyclophorus induratus Christ, J. Bot. Paris 21 (1908) 238, 271; C. Chr., Ind. Fil. Suppl. (1913) 22; Bonap., Notes Ptérid. 7 (1918) 126; Ching, Bull. Chin. Bot. Soc. 1 (1935) 70, pro syn.-T y pe: Eberhardt s.n.?, s.d.? (P?, not found), Indo-China, 'Annam, Tam Dao, $900 \mathrm{~m}$ alt.'.

Cyclophorus valleculosus Alderwerelt, Bull. Jard. bot. Buitenz. II, 7 (1912) 10; C. Chr., Ind. Fil. Suppl. 1 (1913) 23; Alderwerelt, Malayan Ferns Suppl. (1917) 412; Backer Posth., Varenfl. Java (1939) 241.-T y pe: Backer 1229 (BO), Java.

Cyclophorus acrostichoides var. backeri Alderwerelt, Bull. Jard. bot. Buitenz. II, 7 (1912) 10; Alderwerelt, Malayan Ferns Suppl. (1917) 412.-Ty pe: Backer 2936 (BO?, not found), Java.

Cyclophorus acrostichoides fo. camosa Alderwerelt, Bull. Jard. bot. Buitenz. II, 23 (1916) 8; Alderwerelt, Malayan Ferns Suppl. (1917) 412. -Ty pe: Brooks 203-S (BO?, not found, L, BM), Sumatra.

Cyclophorus cinnamomeus Alderwerelt, Bull. Jard. bot. Buitenz. III, 5 (1922) 192; C. Chr., Ind. Fil. Suppl. 3 (1934) 65; Backer \& Posth., Varenfl. Java (1939) 240. - Ty pe: Backer 31539 (BO), Java.

Pyrrosia coccideisquamata Gilli, Ann. Nat. Mus. Wien 81 (1978) 26.-Type: Gilli 603 (W), New Guinea.

Rhizome long-creeping, not grooved ventrally, 1.8-2.7 mm thick, phyllopodia 2-6 cm apart, lateral buds situated \pm halfway down the internodia. Anatomy: ground tissue parenchymatous, sclerenchyma sheath distinct, sclerenchyma strands scattered through the inner parenchyma, sometimes confluent and almost replacing the parenchyma, many; vascular strands 5-7. Scales peltate, 1$3.4 \times 0.6-1.5 \mathrm{~mm}$; shining brown or blackish with a distinct light margin, entire, with 1 or 2 stalked glandular cells at the apex. Fronds monomorphic, distinctly to indistinctly stipitate; stipes $0.5-10(-22) \mathrm{cm}$; lamina, index \pm 5 to over 20 ; strapshaped, often \pm narrowed in the fertile part, base \pm gradually narrowed, apex acute to rounded. Venation: secondary veins distinct, with the tertiary veins forming regular areoles; included veins simple or occasionally forked, free, excurrent. Hydathodes absent. Anatomy: stipe or lower part of costa with \pm 5 central and no lateral vascular strands; lamina 1-2 $\mathrm{mm}$ thick, upper epidermis with flat cells with moderately thickened walls, mesophyll only weakly differentiated into water-tissue, palissade and sponge parenchyma, lower epidermis with moderately thickened cell-walls; stomata deeply sunken. pericytic. Indument monomorphic, a sparse to thin mat, persistent to \pm fugacious; hairs $0.3-0.4 \mathrm{~mm}$ in diam., with appressed, boat-shaped rays. Sori

slightly spaced, sunken; several in a row in each soriterous areole, not contluent; $\pm 1 \mathrm{~mm}$ in diam.; developing from the apex downwards, when old individually distinct, exserted from the indument. Sporangia on stalks to $2 x$ as long as the capsule, capsule $0.2-0.3 \mathrm{~mm}$ high, with $12-15$ indurated annulus cells. Paraphyses in a central bundle in the sorus, with short, straight rays. Spores (52-) $56.6-62.8(-72) \times(28-) 31.0-33.8(-38) \mu \mathrm{m}$, irregularly verrucate.

Habitat: Usually low- or high-epiphytic, rarely epilithic or terrestrial; in primary or secondary forests, swamp forests, evergreen forests; also frequently in disturbed or open sites (plantations, village- or wayside trees, riversides, lake 
shores, forest edges, etc.) and in the littoral zone, in mangrove; sometimes on savanna trees.

Altitudinal range: Sea-level to $200-300(-c .1000) \mathrm{m}$.

CHINA. Hainan: Fung 20204 (B, BM, K, P, US), Eryl Smith 1532 (K, US).

BURMA. Parish 20 (BM)

THAILAND. Northeastern: Phloenchit 1382 (A, L). - Central: Hennipman 4007 (L). -

Eastern: Charoenphol et al. 4535 (P), Larsen et al. 3119 (L), 31769 (L), Maxwell 76-194 (L), Murata et al. T 16275 (L). - Southeastern: Geesink et al. 6315 (L), 6665 (L), Larsen et al. 1672 (L, SING ), A. Marcan 1223 (BM), Murata et al. T 17623 (L), T 17677 (L), Smitinand 203 (L), 1244 (A, L). - Peninsular: 9 collections.

CAMBODIA. Ernst 1338 (Z)

LAOS. Poilane 13362 (P).

VIETNAM. Annam: Clemens \& Clemens 3334 (BM, U, US, Z), Poilane 5234 (BM, P, US).

- Cochinchina: Gaudichaud 2a (P).

SUMATRA. Sumatra: 22 collections. - Mentawei Is., Siberut: Iboet 58 (BO), Sipora: BodenKloss 14759 (BO, SING, US), Iboet 479 (BO, L, SING). - Krakatau: Van Borssum Waalkes 858 (BO, L), Docters van Leeuwen-Reijnvaan 3626 (BO). - Bangka: 9 collections. - Riouw - Lingga Is: Bünnemeijer 6281 (BO, L, U), 7635 (BO), 7889 (BO).

MALAYA and SINGAPORE. 41 collections.

JAVA. Java: 68 collections. - Christmas I.: Andrews 212 (BM). - Kangean: Backer 26903 (BO), 27967 (BO), 28883 (BO). - Bawean: Buwalda 3025 (BO), 3269 (BO). - Madoera: Jeswiet 1026 (WAG).

LESSER SUNDA ISLANDS. Bali: Van Steenis 7721 (BO). - Lombok: Ernst 1383 (Z), Rensch 48 (BO), Sun Hong Fan 9093 (L). - Sumbawa: Ernst 1394 (Z). - Flores: Kostermans 22084 (BO, L), Kostermans \& Wirawan 339 (L), Rensch 1025 (BO), Schmutz 2422 (L), Verheijen 2241 (L), 3703 (L). - Timor: Castro s.n. (1911) (BO), Cinatti 357 (L), Kooy 419 (L). - Tanimbar Is.: Van Borssum Waalkes 3243 (BO), 3327 (BO, L), Pleyte 54 (BO, L).

BORNEO. Sarawak: 17 collections. - Brunei: Hotta 12661 (L), Van Niel 3388 (L), 3425 (L). - Sabah: J. M.S. Clemens s.n. (2-2-1932) (BM), Elmer 21334 (BM, BO, BR, L, M, P, SING, U, Z), Ding Hou $174(\mathrm{~L})$. - Kalimantan: 22 collections - Anambas \& Natuna Is.: Henderson 20362 (BO, SING, US), Van Steenis 1158 (BO, L, SING).

PHILIPPINES. Palawan: Elmer 13222 (BO, BM, L, M, P, U, Z), Sulit PNH 12642 (BO, BM, SING). - Mindoro: Mc Gregor 254 (US). - Luzon: 15 collections. - Polillo: Mc Gregor BS 10311 (P). - Sibuyan: Elmer 12133 (BO, BM, L, M, U, Z). - Samar: Edañno BS 24740 (US), Guttierez et al. 660 (L), Madulid et al. 1297 (L). - Leyte: Wenzel 543 (US). - Cebu: Mc Gregor BS 1703 (P, US), Univ. San Carlos 58 (L). - Negros: Whitford 1577 (US). - Sulu Is.: Herre 1245 (US). - Basilan: Reillo BS 16190 (SING). -Mindanao: 15 collections.

CELEBES. 22 collections.

MOLUCCAS. Morotai: Main * Aden 335 (BO, L, SING), 699 (BO, L, SING), 1508 (BO), Lam 3599 (BO, L). - Halmaheira: De Haan 1799 (BO, L), Idjan-Moehtar 104 (BO, L), De Vogel 3090 (L). -Obi: Nedi 677 (BO, L), Saanam s.n. (1914) (BO). - Sula: Bloembergen 4542 (BO, L, SING), 4758 (BO, L). - Buru: Toxopeus s.n., (9-1921) (BO, L). - Ceram: Buwalda 6052 (BO, L), Kornassi 1216 (BO, L), Kuswata \& Supadmo 62 (L). -Ambon: Rant 626 (BO).

NEW GUINEA. Irian Jaya: 11 collections. - Papua New Guinea: 36 collections. - d'Entrecasteaux Is., Ferguson I.: Brass 25943 (L), 27317 (L), Goodenough I.: Brass 24376 (BM, L, US), Normanby I.: Lelean Streimann LAE 52508 (A, BO, L). - Aru Is.: Buwalda 5089 (BO), 5419 (BO, L), Moseley s.n., s.d. (BM, K).

BISMARCK ARCHIPELAGO. New Ireland: Coode et al. NGF 29644 (BM), Croft LAE 68320 (L), Croft Lelean LAE 65408 (L, M), Rau 355 (L), Womersley et al. 7985 (A). - New Britain: Barker Vinas LAE 66573 (BM, L), Croft et al. NGF 41300 (L, US), Van Royen NGF 16467 (L), Sohmer et al. LAE 75402 (L), Stevens \& Lelean LAE 58582 (L), Womersley 3404 (A, BISH, BM, BO, K, L, SING), 3406 (A, BO, L).

AUSTRALIA. Queensland: 11 collections. - New South Wales: Banks s.n. (1770) (BM), Coveny * Hind 7122 (US, Z). 
BOUGAINVILLE. Lavarack * Ridsdale NGF 31241 (BM, L).

SOLOMON ISLANDS. Kolombangara: Whitmore \& Grubb BSIP 2172 (L, SING, US), Whitmore * Womersley BSIP 830 (L, US). - Malaita: E. S. Brown 955 (BM), Mauriasi et al. BSIP 13546 (L), B. C. Stone 2316 (U, US). - Guadalcanal: Brown 389 (BM), Dennis BSIP 7940 (L), A. Nakisi BSIP 7344 (L, SING), Pendleton 435 (BO). - San Cristobal: Brass 2554 (L), Whitmore BSIP 4389 (L).

NEW HEBRIDES. Efate: McKee 3128 (BM, P, US). - Tanna: Barclay s.n., s.d. (BM), Bernardi 12865 L, US, Z), Kajewski 101 (B). - Aneityum: Kajewski 714 (BO, US), Mc Gillivray s.n., s.d. (BM).

LOYALTY ISLANDS. Lifu: Deplanche 9 (P).

MICRONESIA. Carolines: Salsedo 386 (US).

Doubtful localities.

NEPAL: Wallich 72, herb. Hooker * Thomson (P).

SOCIETY ISLANDS: Forster s.n., s.d. (BM, M).

Notes. 1. Small plants of $P$. longifolia are similar to $P$. lanceolata. The two species have often been confused, especially by early authors (Kaulfuss, Swartz, Willdenow, R. Brown). P. longifolia is best distinguished by the completely entire rhizome scales (ciliate in $P$. lanceolata).

2. Niphobolus fissus Blume: As pointed out by Giesenhagen, Blume's Niphobolus fissus is an abnormal, furcate form of $P$. longifolia. It has been confused with $\boldsymbol{P}$. porosa and $P$. mannii by many authors who followed Hooker. The confusion is probably caused by the incidental occurrence of laciniate fronds in $P$. mannii.

3. $P$. longifolia probably does not occur on the Society Islands, the type locality of Polypodium acrostichoides Forst., see Copeland, B. P. Bish. Mus. Bull. 93 (1932): 66.

4. Uses: 'Used in labour; leaves rubbed in cold water and the juice drunk, only used by the Sakais (Malacca)', note to Burkill \& Haniff 15748.

5. Vernacular names. Kadoka (Sundanese); Soloi (Sakais, Malacca); Janglu (Batek, Malacca); Pakoe Watjeh (Korintji, Sumatra); Hare hare koris (Prapat, Sumatra); Sunwengto, or Sbeuwongto (Weda, Halmaheira); Djela-djela (Halmaheira), Teke (Bian dialect, Merauke, New Guinea); Taal (Je dialect, Merauke, New Guinea); Egina (Gabgab dialect, Merauke, New Guinea); Tobonallingu (Wapi, Wigote, New Guinea); Bunu (Sepik, New Guinea); Momabo (Kutubu, Wasemi I., New Guinea), Ango'ango'ae (Kwara'ea, Guadalcanal).

\section{Pyrrosia mannii (Giesenh.) Ching. Fig. 18.}

Pyrrosia mannii Ching, Bull. Chin. Bot. Soc. 1 (1935) 55; Nayar \& S. Chandra, Bull. Nat. Bot. Gard.

Lucknow 117 (1965) 63; H. Hara, Fl. Eastern Himal. (1966) 498; Nayar \& S. Chandra, Can.

J. Bot. 45 (1967) 625-634; H. Hara, Fl. Eastern Himal., 2nd Rep. (1971) 219; Iwats., Acta

Phytotax. Geobot. 71; Nayar Kaur, Comp. Bedd. Handb. (1974) 81; Hoshizaki, Baileya 21

(1981) 69, fig. 8 p.p.-Niphobolus mannii Giesenh., Niphobolus (1901) 107. - Lectotype: Gustav Mann s.n. (Sep. 1890) (holo M), India, Khasya, Molim.

Rhizome short, not grooved ventrally, 2.6-3.3 mm thick, phyllopodia contiguous, lateral buds situated on the phyllopodia. Anatomy: ground tissue parenchymatous, sclerenchyma sheath mostly distinct, sometimes indistinct, 
sclerenchyma strands scattered through the inner parenchyma, 4- \pm 20 ; vascular strands 7-10. Scales pseudopeltate, 5-7.4 $\times 0.5-1.2 \mathrm{~mm}$; base entire; acumen straw-coloured, entire to dentate. Fronds monomorphic, not or indistinctly stipitate; stipes up to $3 \mathrm{~cm}$; lamina, index 10-20 or more; widest at or above the middle, $14-44 \times 0.8-3 \mathrm{~cm}$, base gradually narrowed, apex acute to narrowly acuminate. Venation: secondary veins little distinct, with the tertiary ones forming regular areoles; included veins simple or occasionally forked, free, excurrent. Hydathodes distinct, scattered over the lamina, sunken to \pm superficial. Anatomy: stipe or lower part of costa with \pm 6 central and \pm 2 lateral vascular strands; lamina $0.3 \mathrm{~mm}$ thick, upper epidermis with distinctly projecting cells with thin walls, hypodermis and water-tissue absent, palissade and spongy parenchyma distinct, lower epidermis with thin cell-walls; stomata superficial, polocvtic. Indument dimorphic, a dense mat, persistent, brown; upper layer composed of hairs (0.5-)0.8-2.0 mm in diam., with erecto-patent, acicular rays, \pm mixed with a lower layer composed of hairs with mainly woolly rays. Sori apical to all over the lamina, in an ill-detıned patch, shortly spaced, superticial; several in a row in each soriferous areole, not confluent; 1-1.5 mm in diam.; developing from the apex downwards, when old individually distinct, \pm exserted from the indument. Sporangia sessile, capsule 0.4-0.6 mm high, with 20-25 indurated annulus cells. Paraphyses not differentiated. Spores $(48-) 64.6-82.2(-90) \times(36-)$ 44.8-57.0 (-62) $\mu \mathrm{m}$, finely granulate.

Habitat: Mostly epiphytic, sometimes epilithic; in evergreen or open forest. Restricted to areas with high, seasonal, rainfall.

Altitudinal range: $300-2100 \mathrm{~m}$.

CHINA. Yunnan: Wang 72889.

NEPAL. Banerji 1534 (A), Banerjee 3518 (A), Hooker s.n., s.d. (K), Nicolson 2293 (US), Stainton et al. 5259 (BM), Zimmerman 2032 (BM).

BHUTAN. Ghose s.n. (1913) (L, P), Griffith s.n., s.d. (B).

INDIA. Uttar Pradesh: (Campbell \&) Hope 83 (M, P), Inayat 26040 a (K, P). - Sikkim \& Darjeeling: 21 collections. - Assam: 21 collections.

BURMA. Dickason 6745 (BM, GH, US), Parish s.n. (1863) (K).

THAILAND. Northern: Hansen et al. 10892 (L), 12932 (K, L).

Doubtful localities. CEYLON. Gardner $1226(\mathrm{~K})$.

Notes. 1. A curious form of' $P$. mannii sccurs in which the lamina has a varying number of narrow, lateral teeth that may be up to several $\mathrm{cm}$ long. This form has been collected several times in the Khasi Hills by Gustav Mann (May 1878, Oct. 1885, Sep. 1890), C.B. Clarke (38759, 43659) and Griffith (s.n., 11-11-1835, acc. to his Journal of Travels he was at the time travelling through the Khasi Hills). I have not seen any more recent collections of this form.

The lateral teeth of this form probably confused Hooker and led him to identify these plants erroneously with Niphobolus fissus Blume, which represents a furcate form of Pyrrosia longifolia. 
2. The form of $P$. mannii that lacks lateral teeth is very similar to $P$. porosa. It is often found together with that species on herbarium sheets: Griffith 2781, Kew distr. no. 948 (B, K); Griffith s.n, Mishmee, Kew distr. no. 949 (P, B); Hooker \& Thomson, (7 Nov. 1849 25 Aug. 1849) (K); Hooker \& Thomson, (28 Jun. 1850) (K); Hooker \& Thomson, s.n., s.d. Khasia (BM); Hope 287 (P); Thomson, (25 Aug. 1849) (K).

$P$. porosa can best be distinguished from $P$. mannii by the shortly elongated rhizome, the phyllopodia ususally separated by at least their own width; by the peltate, usually ciliate or at least distinctly dentate scales and by the pericytic stomata. In $P$. mannii the rhizome is short, with contiguous phyllopodia, the scales are pseudopeltate and entire or at most obscurely dentate; the stomata are polocytic.

\section{Pyrrosia niphoboloides (Baker) Price}

Fully treated in Ravensberg \& Hennipman (1986).

\section{Pyrrosia novo-guineae (Christ) Price}

Fully treated in Ravensberg \& Hennipman (1986).

\section{Pyrrosia nummulariifolia (Swartz) Ching. Fig. 23.}

Pyrrosia nummulariifolia Ching, Bull. Chin. Bot. Soc. 1 (1935) 52; Holttum, Fl. Malaya 2 (Ferns) (1954) 144, fig. 59; Copeland, Fern Fl. Philipp. (1960) 475; Patnaik, Bull. Bot Surv. India 5 (1963) 115-118; Nayar S. Chandra, Bull. Nat. Bot. Gard. Lucknow 117 (1965) 73; Holttum, Dansk Bot. Ark. 25 (1967) 48; Nayar \& S. Chandra, Can. J. Bot. 45 (1967) 615-634; Tagawa, Acta Ph ytotax. Geobot. 22 (1967) 185; Nayar \&aur, Comp. Bedd. Handb. (1974) 81; Hoshizaki, Baileya 21 (1981) 69, fig. 9A. - Acrostichum nummulariifolium Swartz, Syn. Fil. (1806) 191, 419, pl. 2 fig. 1; Willd., Sp. Pl. 5 (1810) 100.-Gymnopteris nummulariifolium Presl, Tent. Pter. (1836) 244. - Niphobolus nummulariifolius J. Sm., Hooker J. Bot. 3 (1841) 396; Kunze, Bot. Zeic. (1848) 120; Fée, Gen. Fil. (1853) 262, 94, pl. 9 fig. 3; T. Moore, Ind. Fil. (1857) lxxvi; Bedd., Ferns Brit. India (1868) pl. 320; Keyserl., Polyp. Herb. Bunge (1873) 38; J. Sm., Hist. Fil. (1875) 98; Bedd., Handb. ferns Brit. Ind. (1883) 334, fig. 183; Bedd., Suppl. Handb. (1892) 92; Diels in E. P., Nat. Pfl. Fam. 1,4 (1899) 325; Giesenh., Niphobolus (1901) 179; Christ, Ann. Jard. Bot. Buitenz. 19 (1904) 38; Copeland, Polyp. Philipp. (1905) 114. Galeoglossa nummulariifolia Presl, Epim. Bot. (1851) 133. - Polypodium nummulariifolium Mett., Polyp. (1856) 123, pl. 3 fig. 9-10; Hooker, Sp. Fil. 5 (1863) 54; Mett., Ann. Mus. Lugd. Bat. 2 (1866) 230; Baker in Hooker \& Baker, Syn. Fil. (1867) 351; Baker, J. Bot. Lond. 18 (1880) 216; C. B. Clarke, Tr. Linn. Soc. II Bot. 1 (1880) 553; Christ, J. Bot. Paris 8 (1894) 152; Christ, Verh. Nat. Ges. Basel (1897) 20; Christ, Ann. Jard. bot. Buitenz. 15 (1898) 165; Christ, Bull. Herb. Boiss. 6 (1898) 199; Racib., Pter. Buitenz. (1898) 101.-Cyclophorus nummulariifolius C. Chr., Ind. Fil. (1906) 200; Christ, J. Bot. Paris 21 (1908) 238; Alderwerelt, Malayan Ferns (1909) 685; Christ, Geogr. der Farne (1910) 113, (fig 78 probably represents Crypsinus pyrolifolius); Copeland, Sarawak Mus. J. 2 (1917) 409; Bonap., Notes Ptérid. 7 (1918) 126; Holttum, J. Mal. Br. R. As. Soc. 6 (1928) 20; C. Chr., Ind. Fil. Suppl. 3 (1934) 65; Backer \& Posth., Varenfl. Java (1939) 239, fig. 58; Dickason, Ohio J. Sc. 46 (1946) 129.-T y pe: Thunberg s.n., s.d. (holo $\mathrm{S}$, not seen), Java. 
Acrostichum obovatum Blume, Enum. Pl. Jav. 2 (1828) 102; Blume, Fl. Jav. Fil. (1829) 35, pl. 11 fig. 3. - Niphobolus obovatus Kunze, Bot. Zeit. (1848) 120; Fée, Gen. Fil. (1853) 262; T. Moore, Ind. Fil. (1857) lxxvi.-Galeoglossa obovata Presl, Epim. Bot. (1851) 133.-Polypodium obovatum Mett., Polyp. (1856) 124; Hooker, Sp. Fil. 5 (1863) 54; Mett., Ann. Mus. Lugd. Bat. 2 (1866) 230; Racib., Pter. Buitenz. (1898) 101;-Polypodium nummulariaefolium var. obovatum C. B. Clarke, Tr. Linn. Soc. II Bot. 1 (1880) 554.-Cyclophorus obovatus Alderwerelt, Malayan Ferns (1909) 685; C. Chr., Ind. Fil. Suppl. 3 (1934) 65.-Pyrrosia obovata Ching, Bull. Chin. Bot. Soc. 1 (1935) 47; Patnaik, Bull. Bot. Surv. India 5 (1963) 215-218; Nayar \& S. Chandra, Bull. Nat. Bot. Gard. Lucknow 117 (1965) 76; Nayar \&. Chandra, Can. J. Bot. 45 (1967) 615-634; Nayar \& Kaur, Comp. Bedd. Handb. (1974) 81; Hoshizaki, Baileya 21 (1981) 69, fig. 9 B. - Cyclophorus nummularifolius var. obovatus Bonap., Notes Ptérid. 7 (1918) 126.-T y pe: Anon. s.n., s.d. (Blume?) (L), Java.

Acrostichum nummularifolium var. subpeltatum Blume, Fl. Jav. Fil. (1829) 33, pl. 11 fig. 2._Galeoglossa rotundifolia Presl, Epim. Bot. (1851) 133. - Niphobolus rotundifolia Fée, Gen. Fil. (1853) 262.Type: not indicated (L?, not found), Java.

Cyclophorus nummularifolius var. rufus Alderwerelt, Bull. Dep. Agr. Ind. Neer. 21 (1908) 8; Alderwerelt, Malayan Ferns (1909) 685.-Pyrrosia nummulariifolia var. rufa Ching, Bull. Chin. Bot. Soc. 1 (1935) 47; Tagawa \& Iwats., Acta Phytotax. Geobot. 23 (1968) 52.-T y pe: Raap 742 (BO), Sumatra.

Rhizome long-creeping, narrowly grooved ventrally, 0.6-1.6 $\mathrm{mm}$ thick, phyllopodia 0.5-1.5 cm apart, lateral buds situated more than halfway down internodia, sometimes opposite the phyllopodia. Anatomy: ground tissue parenchymatous, sclerenchyma sheath distinct, a single, central sclerenchyma strand present or sclerenchyma strands absent; vascular strands 3-7. Scales peltate, 3.3$5.7 \times 0.3-0.7 \mathrm{~mm}$; base entire to ciliate; acumen light brown, ciliate; short, \pm round to ovate scales regularly present. Fronds strongly dimorphic, distinctly to indistinctly stipitate. Fertile fronds: stipes to $2.5 \mathrm{~cm}$, to $1 / 2(-1) \times$ as long as the lamina; lamina, index 3 to \pm over 20; widest about the middle, $1.5-12.5 \times 0.3-$ $1.1 \mathrm{~cm}$, base cuneate to gradually attenuate, apex rounded. Sterile fronds: \pm sessile or with stipes to $2.5 \mathrm{~cm}$, to $\pm 1 / 2 \times$ as long as the lamina; lamina, index $1-2(-4)$; widest below or about the middle, $0.8-5 \times 0.6-2(-3) \mathrm{cm}$, base cordate to rounded or occasionally cuneate, apex rounded. Venation: secondary veins little distinct, with the tertiary ones forming \pm irregular areoles; included veins simple or occasionally forked, occasionally anastomosing; free veins many, mainly excurrent but some recurrent. Hydathodes absent. Anatomy: stipe or lower part of costa with 1-2 central and 0-1 lateral vascular strands; lamina $1 \mathrm{~mm}$ thick or more, upper epidermis with flat cells with thick walls, hypodermis absent or composed of a single cell-layer, water-tissue usually very thick, palissade and spongy parenchyma distinct to indistinct, lower epidermis with thick cell-walls; stomata slightly to strongly sunken. pericytic. Indument dimorphic, a dense mat, persistent, brown, the lower layer mostly whitish; upper layer composed of hairs 0.7-1.4 mm in diam., with erecto-patent, acicular rays, usually distinctly raised above a lower layer composed of hairs with mainly woolly rays. Sori all over the lamina or in an irregularly shaped patch, closely packed, superficial; several in a row or more or less scattered in each soriferous areole, not confluent; $1-1.5 \mathrm{~mm}$ in diam.; developing from the apex downwards, when old often pseudo- 
acrostichoid, \pm immersed in the indument. Sporangia on stalks $1-1.5 \times$ as long as the capsule, capsule $0.3-0.4 \mathrm{~mm}$ high, with 20-23 indurated annulus cells. Paraphyses not differentiated. Spores (60-)76.2-84.4(-96) × (50-)55.2-66.0(-82) $\mu \mathrm{m}$, with irregular ridges and protuberances.

Habitat: Epiphytic, often high up or in exposed places, in gardens, plantations, clearings etc.; often also epilithic, and then preferably on limestone, often in exposed places. Apparently absent from regions with a pronounced dry season. Altitudinal range: Low altitudes to $\pm 1200 \mathrm{~m}$, in N. India to $2000-2700 \mathrm{~m}$.

BHUTAN. Ghose s.n. (1913) (P), s.n. (26-2-1922) (K, P), Grierson Long 2399 (BM), INDIA. Sikkim Darjeeling: Beddome s.n., s.d. (K). - Assam: 19 collections - Cachar: Keenan (coll. Jallyhally) s.n. (21-3-1873) (B, K).

BURMA. Griffith s.n., s.d. (B), Kurz 3196 (B, K), Parish s.n. (1856) (P), Toppin 4410 (K). THAILAND. Southwestern: Van Beusekom \& Phengkhlai 432 (L), Bloembergen, Kwae Noi R. Basin Exp. 20 (A, BO, L, P, SING). - Peninsular: 16 collections.

SUMATRA. Sumatra: 13 collections. - Batu Is: Raap 742 (BO). - Mentawei Is., Siberut: Boden-Kloss 14495 (BM, BO, SING, US).

MALAYA, incl. P. Penang. 14 collections.

JAVA. 24 collections.

LESSER SUNDA ISLANDS. Bali: Posthumus 3700 (BO), 4167 (BO), Van Steenis 7726 (BO).

-Flores: Schmutz F 19 (L), F 139 (L), 1369 a (L), 2129 b (L), Verheijen 463 (L).

BORNEO. 23 collections.

PHILIPPINES. Palawan: Edaño BS 77927 (BO, MICH, US), BS 77940 (MICH), BS 77960 (MICH), PNH 482 (MICH), Weber 1562 (BO). - Luzon: 15 collections. - Polillo: Mc Gregor BS 10310 (MICH, P). - Leyte: Elmer 7061 (BO, L, M, MICH, P, Z). — Bohol: Ramos BS 42994 (G, L, UC, US), - Panay: Martellino \& Edaño BS 35591 (P, US), Ramos * Edaño BS 30965 (SING). - Mindanao: 9 collections. - Basilan: Reillo BS 16204 (MICH, P). - Jolo: Merrill 5316 (MICH, P).

CELEBES. 10 collections.

Notes. 1. The pronounced frond dimorphism is characteristic. In nearly all specimens the small, orbicular, sterile fronds are markedly different from the elongated fertile ones. As far as can be reconstructed from the data at hand, the sterile fronds are usually appressed to the substrate, whereas the fertile ones are usually erect. The difference, however, is sometimes obscured by the occurrence of fronds of intermediate shape, which are partly fertile (e.g., in Van Beusekom \& Phengkhlai 432; Schiffner P 124); or of completely sterile fronds with the outline of fertile ones. A single plant may produce these 'intermediate' fronds as well as normal ones. Aberrations like these occur frequently in cultivated specimens and may be induced by adverse conditions. Forms with these more elongated sterile fronds have been considered as a separate species ( $P$. obovata (Blume) Ching).

2. Fresh fronds may be markedly succulent, the water-tissue in such fronds may take up more than one half of the thickness of the fresh lamina.

3. Pteropsis nummularifolia: This name is cited by C. Chr., Ind. Fil. (1906) 200 under Cyclophorus nummularifolius, and ascribed to Desvaux. Desvaux, however, did not use this name but made the combination Pteropsis nummularia Desv. (Prodr., 1827, 218), which probably represents Pyrrosia heterophylla. It is based, 
however, on Piper nummularium Lamarck, but both other references (Acrostichum heterophyllum L. and Rheede, Hort. Malab. 12 pl. 29) represent $P$. heterophylla.

4. W. J. Dress (Baileya 21, 1981, p. 69 footnote) points out that the correct spelling is 'nummulariifolia', although Swartz used 'nummularifolia'.

\section{Pyrrosia pannosa (Mett. ex Kuhn) Ching. Fig. $20 \mathrm{~b}$.}

Pyrrosia pannosa Ching, Bull. Chin. Bot. Soc. 1 (1935) 58; Sledge, Bull. Brit. Mus. (Nat. Hist.) Bot. 2 (1960) 135.-Polypodium pannosum Mett. ex Kuhn, Linnaea 36 (1869) 141; Baker in Hooker * Baker, Syn. Fil. ed. 2 (1874) 512.-Niphobolus pannosus Bedd., Suppl. Ferns S. * Br. Ind. (1876) 22, p.p.; Bedd., Handb. ferns Brit. Ind. (1883) 328, fig. 177, p.p.; Giesenh., Niphobolus (1901) 105.-Cyclophorus pannosus C. Chr., Ind. Fil. (1906) 200; Alderwerelt, Malayan Ferns (1909) 683 p.p.; Willis, Cat. Fl. Ceylon (1911) 123.-Ty pe: Thwaites CP 1294 (holo B, iso BM, BO, K, L, P), Ceylon.

Polypodium lingua, auct. non (Thunb.) Sw., quoad specim. Zeyl.: Hooker, Sp. Fil. 5 (1863) 44; Thwaites, Enum. Pl. Zeyl. (1864) 395; Baker in Hooker Baker, Syn. Fil. (1867) 350.

Rhizome shortly elongated, not grooved ventrally, 1-2(-4) $\mathrm{mm}$ thick, phyllopodia $0.2-0.8 \mathrm{~cm}$ apart, lateral buds situated up to halfway down the internodia. Anatomy: ground tissue parenchymatous, sclerenchyma sheath indistinct to distinct, sclerenchyma strands absent; vascular strands 4-6(-9). Scales pseudopeltate or occasionally peltate, $2.4-4.5 \times 0.7-1.6 \mathrm{~mm}$; dull brown, or blackish with distinctly lighter margin, dentate. Fronds monomorphic, stipitate; stipes $6-19.5 \mathrm{~cm}$, to $11 / 2 \times$ as long as the lamina; lamina, index $4-5$; widest below or about the middle, $7-12.5 \times 1.7-3.7 \mathrm{~cm}$, base cuneate to attenuate, apex obtuse to acuminate. Venation: secondary veins distinct, with the tertiary veins forming regular areoles; included veins frequently forked or more branched; free veins many, pointing to all directions. Hydathodes distinct, scattered over the lamina, or, in fertile fronds, in a marginal zone. Anatomy: stipe with \pm 4 central and usually 1 lateral vascular strands; lamina $0.3 \mathrm{~mm}$ thick, upper epidermis with distinctly projecting cells with thin walls, hypodermis and water-tissue absent, palissade and spongy parenchyma distinct, lower epidermis with thin cell-walls; stomata superficial, pericytic. Indument dimorphic, a dense mat, persistent, greybrown; upper layer composed of hairs 0.9-1.6 mm in diam., with erecto-patent, acicular rays, \pm mixed with a lower layer composed of hairs with mainly woolly rays. Sori all over the lamina or in an ul-detined, often apical patch, shortly spaced, superficial; to \pm 10 irregularly scattered through each soriferous areole, occasionally confluent along the veins; $0.5-1.5 \mathrm{~mm}$ in diam.; developing from the apex downwards, when old individually distinct, immersed in the indument. Sporangia on stalks to $1 \times$ as long as the capsule, capsule $\pm 0.2 \mathrm{~mm}$ high, with 15-20 indurated annulus cells. Paraphyses not differentiated. Spores (40) 47.0$49.2(-52) \times(26-) 29.6-33.6(-36) \mu \mathrm{m}$, finely and sparsely granulate. 
Habitat: Few records are available, indicating epilithic or terrestrial occurrence, in shade. Sledge (1960) calls this species characteristic for the intermediate zone between the wet and the drier parts of Ceylon.

Altitudinal range: $250-550 \mathrm{~m}$.

\section{CEYLON. 10 collections.}

Notes. 1. This is the only species in which I could not detect any difference in size or shape between sterile and fertile fronds. It may be that the number of specimens available was too small to detect slight differences (e.g., like those in $P$. petiolosa).

Hydathodes in fertile fronds are confined to the narrow, sterile marginal zone; in fertile fronds they occur scattered all over the lamina.

2. In some collections (most distinctly in Wall s.n., s.d., M) the rhizome scales have a dark central part that is sharply demarcated from the lighter marginal zone.

3. $P$. pannosa has been erroneously reported from Burma by Beddome (1892) and Dickason (1946). These reports are probably all based on the same few collections by Parish and Lobb. These collections are here referred to and discussed in a note (2) under $P$. lingua var. lingua.

\section{Pyrrosia penangiana (Hooker) Holttum. Fig. 18.}

Pyrrosia penangiana Holttum, Fl. Malaya 2 (Ferns) (1954) 146, fig. 62; Tagawa * Iwats., Acta Phytotax. Geobot. 23 (1968) 52; Nayar * Kaur, Comp. Bedd. Handb. (1974) 81. - Niphobolus penangianus Hooker, Ic. Pl. 3 (1840) pl. 203; Hooker, Gen. Fil. (1842) pl. 83; Fée, Gen. Fil. (1853) 263; T. Moore, Ind. Fil. (1857) lxxvi; Bedd., Ferns Brit. India (1868) pl. 121; J. Sm., Hist. Fil. (1875) 98; Bedd., Handb. ferns Brit. Ind. (1883) 332, fig. 182; Bedd., Suppl. Handb. (1892) 92; Giesenh., Niphobolus (1901) 97.-Polycampium penangianum Presl, Epim. Bot. (1851) 136.-Polypodium penangianum Hooker, Sp. Fil. 5 (1863) 52; Baker in Hooker \&aker, Syn. Fil. (1867) 352; Baker, Ann. Bot., Lond. 5 (1891) 473.-Cyclophorus penangianus C. Chr., Ind. Fil. (1906) 200; Alderwerelt, Malayan Ferns (1909) 686; Backer Posth., Varenfl. Java (1939) 242; Dickason, Ohio J. Sc. 46 (1946) 129.-T y pe: Lady Dalhousie s.n., s.d. (holo K, iso E), Malaya, Penang $\mathrm{I}$.

Niphobolus mollis Kunze, Bot. Zeit. (1848) 121; Holttum, Nov. Bot. Inst. Bot. Univ. Car. Prag. (1968) 31. - Cyclophorus mollis Presl, Epim. Bot. (1851) 131; C. Chr., Ind. Fil. (1906) 199; Alderwerelt, Malayan Ferns (1909) 688; Dickason, Ohio J. Sc. 46 (1946) 129. - Polypodium molle Mett., Polyp. (1856) 128, nom. illeg.; [non Polypodium molle Schreb., Spic. F1. Lips. (1771) 70, = Athyrium filix-femina (L.) Roth]; Kuhn, Gazelle Exp. Farne (1889) 11.-Pyrrosia mollis Ching, Bull. Chin. Bot. Soc. 1 (1935) 53, q. n.s.; Holttum, Nov. Bot. Inst. Bot. Univ. Car. Prag. (1968) 31. - Lect ot y pe (Ching, l.c.): Zollinger 3183 (B, BM, K, L, P, Z, see note 4), Java.

Cyclophorus brevipes Alderwerelt, Bull. Jard. bot. Buitenz. III, 2 (1920) 139; C. Chr., Ind. Fil. Suppl. 3 (1934) 64. - Ty pe: Docters van Leeuwen, s.n. (Jan. 1920) (BO, L), Sumatra (cult. in Hortus Bogor).

Rhizome short, not grooved ventrally, 3-6 mm thick, phyllopodia contiguous, lateral buds situated on the phyllopodia. Anatomy: ground tissue parenchymatous, sclerenchyma sheath distinct, sclerenchyma strands scattered through 
the inner parenchyma, many; vascular strands 7-13. Scales pseudopeltate, 2.6$9.4 \times 0.7-1.3 \mathrm{~mm}$; base dentate; acumen light brown, entire to denticulate. Fronds monomorphic, sessile; index 6-20 ; widest above the middle, 11-72 $\times 1-8$ $\mathrm{cm}$, base gradually narrowed, apex acute to acuminate. Venation: secondary veins distinct, with the tertiary veins forming regular areoles; included veins simple or rarely forked, free, excurrent. Hydathodes distinct, scattered over the lamina, \pm superficial to distinctly pitted. Anatomy: lower part of costa with \pm 7 central and \pm 3 lateral vascular strands; lamina $0.3-0.4 \mathrm{~mm}$ thick, upper epidermis with slightly to distinctly projecting cells with thin to moderately thickened walls, hypodermis and water-tissue absent, palissade and spongy parenchyma indistinct, lower epidermis with thin cell-walls; stomata superficial, Dolocvtic. Indument monomorphic, a sparse to dense mat, persistent or fugacious, brown; hairs (0.3-)0.6-1.7 mm in diam., with erecto-patent, acicular rays. Sori apical, in a sharply defined patch, closely packed or shortly spaced, superficial; several in a row in each soriferous areole, not confluent; $1.5-2.5 \mathrm{~mm}$ in diam.; developing from the apex downwards, when old individually distinct, exserted from the indument. Sporangia on stalks $1-1 / 2 \times$ as long as the capsule, capsule 0.3-0.4 mm high, with 17-23 indurated annulus cells. Paraphyses not differentiated. Spores $(66-) 76.0-80.0(-88) \times(46-) 53.8-57.2(-64) \mu \mathrm{m}$, finely and sparsely granulate.

Habitat: Mostly epiphytic, in forest or on solitary trees; also epilithic, in sheltered places. In Malaya and Thailand with a distinct preference for limestone areas: Chin (1975) mentions $P$. penangiana as preferentially, but not exclusively on limestone. Substrate preference in Malesia otherwise not indicated on the labels.

Both in regions with a perhumid climate and in areas with a strong dry season, apparently restricted to higher altitudes in the latter case. Although not a mountain plant proper, $P$. penangiana exactly follows Van Steenis' (Bull. Jard. bot. Buitenz. III, 13, 1934) Sumatran Entry Track.

Altitudinal range: Low altitude to $500 \mathrm{~m}$ on Sumatra, to $900 \mathrm{~m}$ in Malaya and in Thailand, to $1550 \mathrm{~m}$ on Java and the Lesser Sunda Islands.

BURMA. Parish 143 (K, P?), s.n., s.d. (K).

THAILAND. Southwestern: Van Beusekom et al. 3648 (L), Geesink et al. 6238 (L), Eryl Smith 2589 (K). - Peninsular: Eryl Smith 2012 (K), 2013 (K, SING), 2606 (K).

MALAYA. 25 collections.

SUMATRA. 13 collections.

JAVA. 13 collections.

LESSER SUNDA ISLANDS. Bali: Zollinger 3761 (B, BM, K, P). - Lombok: Elbert 1598 (BO, K, L, SING), Rensch 128 (B, BO), 301 (B, BO). - Sumbawa: Kuswata 255 (A, BO, K, L), Rensch 677 (B, BO). - Flores: Schmutz 3682 (BO, L). - Alor: Jaag 989 (BO). - Timor: Naumann s.n., (24-5-1875) (B), Schmutz 2230 (BO, L), 2253 (L), Teysmann 16420 (BO).

Notes. 1. Small forms are superficially similar to $P$. porosa and have been confused with it. $P$. penangiana can be distinguished by the strictly monomorphic in- 
dument, the pseudopeltate, almost entire rhizome scales, and the polocytic stomata.

2. Specimens from Malaya and Sumatra are often large and sparsely hairy, whereas specimens from the Lesser Sunda Islands are more compact and densely hairy. The latter have a more coriaceous texture and more distinctly pitted hydathodes. These characters may be functionally correlated and may represent a complex of adaptations to a pronounced dry season.

3. Lateral teeth on the lamina, similar to those found in specimens of $P$. mannii, occur in one specimen from Malaya (Matthew s.n., 13 Jan. 1912).

4. Zollinger 3183 (type of Niphobolus mollis Kunze) is a rather mixed bag and probably is responsible for much of the confusion surrounding the species:

In $\mathrm{K}$ this number contains specimens of $P$. albicans and $P$. penangiana; in $\mathrm{BM}$ a specimen of $P$. penangiana, named $P$. albicans; in $P$ it contains specimens of $P$. rasamalae, $P$. albicans, and $P$. penangiana, all named $P$. albicans, as well as an unlabelled specimen of $P$. lanceolata.

The collections in $\mathrm{L}, \mathrm{B}$ and $\mathrm{Z}$ under this number are $P$. penangiana.

The greater part of Zollinger 3761 is also $P$. penangiana, but the specimen in BR is $P$. porosa, labelled as coming from Java, but probably not collected there. It is possible that there are other specimens of $P$. porosa mixed with other Zollinger collections that may have induced Ching to consider $P$. mollis conspecific with $P$. porosa.

\section{Pyrrosia petiolosa (Christ) Ching. Fig. 21 b.}

Pyrrosia petiolosa Ching, Bull. Chin. Bot. Soc. 1 (1935) 59; Fu, Ill. Imp. Chin. Pl. (1957) 237, fig. 319; Tagawa, J. Jap. Bot. 34 (1957) 356; Steward, Man. Vasc. Pl. L. Yangtze (1958) 53.Polypodium petiolosum Christ in Baroni \& Christ, Nu. Giorn. Bot. It. n.s. 4 (1897) 96, pl. 1 fig. 2; Christ, Bull. Herb. Boiss. 6 (1898) 872; Christ in Warb., Monsunia 1 (1900) 61.-Niphobolus petiolosa Diels, Bot. Jb. 29 (1900) 207; Giesenh., Niphobolus (1901) 146; Christ, Bull. Acad. int. Géogr. bot. 9 (1902) 223; Christ, Bull. Soc. Fr. 52 Mém. 1 (1905) 24. - Cyclophorus petiolosus C. Chr., Ind. Fil. (1906) 200; Christ, Bull. Acad. int. Géogr. bot. 20 Mém. (1909) 148; Christ, Geogr. der Farne (1910) 112; H. Lev., Fl. Kouy-Tchéou (1915) 479; L.H. Bailey, Gentes Herb. (1920) 9; C. Chr., Acta Horti Gothob. 1 (1924) 105; Hand.-Mazz., Symb. Sin. VI (1929) 46. -Lectotype: Giraldi s.n., (20 Sep. 1890) (holo P), China, Huo Gia Ziez.

Polypodium lingua et syn. homot., auct. non Thunberg: Baker, Ann. Bot., Lond. 5 (1891) 472; Fomin, Fl. Sibir. et Or. (1930) 190.

Rhizome long-creeping, not grooved ventrally, 1-2.5 mm thick, phyllopodia 0.5-2.5 cm apart, lateral buds situated more than halfway down the internodia. Anatomy: ground tissue parenchymatous, sclerenchyma sheath distinct, sclerenchyma strands scattered through the inner parenchyma, (0) 1-5; vascular strands 5-6. Scales peltate, $2.2-4.4 \times 0.6-1 \mathrm{~mm}$; base entire to dentate; acumen dull brown with a shining black spot near the attachment, ciliate. Fronds slightly dimorphic, stipitate. Fertile fronds: stipes $0.5-12 \mathrm{~cm}, 1 / 2-11 / 2 \times$ as long as the lamina; lamina, index 2-5; widest about the middle, 1-8.5 $\times 0.5-2 \mathrm{~cm}$, base cuneate to attenuate, apex acute to rounded. Sterile fronds: stipes $1-16 \mathrm{~cm}$, 
$\left({ }^{1} / 15\right) 1 / 5-1 \frac{1}{2} \times$ as long as the lamina; lamina, index $( \pm 1) 2-5,1.5-7(-10.5) \times$ $0.7-2.2(-3.3) \mathrm{cm}$; otherwise similar to the fertile ones. Venation: secondary veins distinct, with the tertiary veins forming regular areoles; included veins simple or occasionally forked, mainly free, excurrent. Hydathodes distinct, scattered over the lamina, distinctly pitted. Anatomy: stipe with \pm 4 central and \pm 2 lateral vascular strands; lamina $0.5-0.7 \mathrm{~mm}$ thick, upper epidermis with distinctly projecting cells with moderately thickened walls, hypodermis composed of a single cell-layer, water-tissue absent, palissade and spongy parenchyma distinct, lower epidermis with moderately thickened cell-walls; stomata slightly sunken, pericytic. Indument monomorphic, a dense mat, persistent, light grey to brown; hairs 0.4-0.6 mm in diam., with appressed, boat-shaped rays. Sori all over the lamina or sometımes in a sharply detıned patch, closely packed, superficial; several scattered through each soriferous areole, elongated and mostly confluent along the veins; $0.5-1.0 \mathrm{~mm}$ in diam.; developing all \pm simultaneously, when old usually pseudoacrostichoid, exserted from the indument. Sporangia on stalks 1-2 $\times$ as long as the capsule, capsule $0.3-0.4 \mathrm{~mm}$ high, with 16-23 indurated annulus cells. Paraphyses not differentiated. Spores $(54-) 56.2-71.2(-76) \times(40-)$ 41.8-54.4 (-60) $\mu \mathrm{m}$, irregularly verrucate.

Habitat: Almost exclusively epilithic, on rocks, walls, cliffs etc., often in exposed, sunny places, occasionally in sheltered situations in forest; only rarely epiphytic. Extending northwards to regions with up to 5 months of frost yearly. Altitudinal range: Up to $2000-3000 \mathrm{~m}$ alt.

USSR. Soviet Far East: Gorelkina s.n. (13-9-1959) (US), Komarov s.n. (27-5-1896) (P), Korshinsky s.n. (1891) (US), Maximowicz 16 (B, BM, K, M, P,).

KOREA (South \& North): Faurie 79 (B, P), Komarov s.n. (31-8-1897) (B), K. Uno 23891 (US), Warburg s.n. (7-1887) (B), s.n. (1888) (P).

CHINA. Heilungkiang: Dorsett * Dorsett 3049 (GH, L, SING, U, US). - Kirin: Chen 219 (A), H.E.M. James s.n. (5-8-1886) (K) (2 localities). - Mongolia: Licent 3590 (BM, K, P), 3615 (BM, K, P). - Hopeh Peking: 17 collections. - Shantung: 5 collections. - Shansi: Licent 2492 (BM, K, P), H. Smith 6743 (BM). - Shensi: 7 collections. - Hupeh: 6 collections. - Szechuan: 14 collections. -Kweichow: 9 collections. - Yunnan: Delavay 34 (P), Henry 10263 (P, US), Maire s.n., s.d. (P), s.n. (11-1910), Bonati 6582 (?6982) (B, M, US, Z). - Kiangsu: 7 collections. Honan: L.H. Bailey 36 (US). - Chekiang: Faber s.n. (5-1897) (P).

Notes. 1. $P$. petiolosa is usually distinct from $P$. lingua in its small size, more distinctly pitted hydathodes, more frequently confluent sori, and more thickly coriaceous fronds.

The rhizome scales differ from those of $P$. lingua in the following characters: $P$. petiolosa - apex of the scales short, \pm obtuse, with up to $150 \mu \mathrm{m}$ long, clear, translucent cells; $P$. lingua - apex of the scales mostly long, narrow, with up to $350 \mu \mathrm{m}$ long, narrow, obscure cells.

This last character appears to be the most constant one and is decisive for the identification of several specimens from Moulmein (also discussed under P. pannosa) as $P$. lingua var. lingua. 
2. The difference between sterile and fertile fronds is very slight, and there is an almost full overlap of the ranges of the various dimensions and indices. The majority of fertile fronds, however, is $4 \mathrm{~cm}$ long or less and $1 \mathrm{~cm}$ wide or less, whereas the majority of sterile fronds is $4 \mathrm{~cm}$ or more long and $1 \mathrm{~cm}$ or more wide.

3. Licent $13099(\mathrm{P})$ is an extremely small specimen, with stipes up to $2-3 \mathrm{~mm}$ long and the lamina to $8 \times 5 \mathrm{~mm}$.

4. Uses: 'the fronds are used as tea' (Shantung, note to Cheo \& Yen 279).

\section{Pyrrosia piloselloides (L.) Price}

Fully treated in Ravensberg \& Hennipman (1986).

\section{Pyrrosia platyphylla Hovenkamp. Fig. 17.}

Pyrrosia platyphylla Hovenkamp, Blumea 30 (1984) 207. - Type: Elmer 20659 (holo L, iso A, B, $\mathrm{BM}, \mathrm{BO}, \mathrm{BR}, \mathrm{K}, \mathrm{M}, \mathrm{P}$, SING, U, Z), Borneo.

Rhizome shortly elongated, not grooved ventrally, 4-4.5 mm thick, phyllopodia to 1-2 cm apart, lateral buds situated on the phyllopodia. Anatomy: ground tissue sclerenchymatous, sclerenchyma sheath and sclerenchyma strands absent; vascular strands 9-11. Scales basifix, 3-10 mm long; base often ciliate, with several stalked marginal glands; acumen brown, entire, shorter scales interspersed with the larger ones present. Fronds monomorphic, not or indistinctly stipitate: stipes up to $13 \mathrm{~cm}$; lamina, index 7-20; widest above the middle, 26$111 \times 2.5-7.3(-10) \mathrm{cm}$, base very gradually narrowed, apex acuminate. Venation: secondary veins distinct, with the tertiary veins forming regular areoles; included veins much branched and strongly anastomosing; free veins many, pointing to all directions. Hydathodes distinct, scattered over the lamina, \pm superficial. Anatomy: stipe or lower part of costa with central bundle of collenchyma and 7-8 central and 3-5 lateral vascular strands; lamina $\pm 0.3 \mathrm{~mm}$ thick, upper epidermis with flat cells with thickened walls, hypodermis composed of a single cell-layer, water-tissue absent, palissade and spongy parenchyma little different, lower epidermis with thickened cell-walls; stomata superficial, pericytic. Indument dimorphic, a dense mat, persistent, greyish brown; upper layer composed of hairs $0.4-1.9 \mathrm{~mm}$ in diam., with appressed, narrowly boat-shaped to acicular rays, appressed to a lower layer composed of hairs with mainly woolly rays. Sori apical, in a more or less sharply detıned patch, closely packed, supertıcial; many irregularly scattered through each soriferous areole, situated on short side-branches of the included veins, not confluent; $\pm 0.5 \mathrm{~mm}$ in diam.; developing from the apex downwards, when old individually distinct, exserted from the indument. Sporangia sessile or on stalks up to $1 / 4 \times$ as long as the capsule, capsule 0.3-0.4 mm high, with 12-14 indurated annulus cells. Paraphyses not differentiated. Spores (52-)59.2-63.6(-68) $\times(28-) 34.4-39.0(-40) \mu \mathrm{m}$, smooth. 
Habitat: Epiphytic (to $40 \mathrm{~m}$ high) or epilithic, preferentially on limestone. Altitudinal range: Sea level to $600 \mathrm{~m}$.

BORNEO. Sabah: anon. (Kew distr. no 4195) (L), Elmer 20659 (A, B, BM, BO, BR, K, L, M, P, SING, U, Z), Meijer SAN 23618 (L), Wood 2011 (K). - Kalimantan: 12 collections.

Notes. 1. $P$. platyphylla differs from $P$. costata, which it superficially resembles, in the following characters:

\begin{tabular}{ll}
\hline$P$. platyphylla & $P$. costata \\
\hline Rhizome shortly elongated. & Rhizome short-creeping. \\
Rhizome scales \pm abruptly & Rhizome scales gradually \\
narrowed & narrowed \\
Costa in dry state triangular, & Costa in dry state \pm \\
distinctly keeled. & quadrangular, not keeled. \\
Costa with a central bundle of & Costa without central \\
collenchyma. & bundle of collenchyma. \\
Upper epidermis with distinct- & Upper epidermis with \pm \\
ly thickened walls. & thin walls. \\
Hypodermis constantly present. & Hypodermis frequently absent. \\
Stomata superficial. & Stomata slightly sunken.
\end{tabular}

$P$. platyphylla has long been considered a part of $P$. costata. Iwatsuki \& Kato (1981, p. 21) suggested that it might be distinguished from that species by the more strongly keeled stipe and the more coriaceous lamina. The most directly obvious distinction, the elongated rhizome, is not always represented in collections; good collections are: Elmer 20659 (SING, L, U, Z); Meijer SAN 23618 (L); Endert 5217 (L); Kostermans 5624 (L), 5680 a (L), 13308 (BO, L). In young plants the elongated rhizome may be indistinct. Occasionally, slighty elongated rhizomes can also be found in P. costata (e.g., Griffith, s.n., s.d., B).

\section{Pyrrosia polydactyla (Hance) Ching. Fig. 19.}

Pyrrosia polydactylis Ching, Bull. Chin. Bot. Soc. 1 (1935) 48; Tagawa, J. Jap. Bot. 24 (1949) 117; Holttum, Fl. Malaya 2 (Ferns) (1954) 142; DeVol, Fl. Taiwan (1975) 207; Hoshizaki, Baileya 21 (1981) 73, fig. 11.-Polypodium polydactylon Hance, J. Bot. Lond. 21 (1883) 269; Baker, Ann. Bot., Lond. 5 (1891) 472. - Niphobolus polydactylon Giesenh. ex Diels in E. \& P., Nat. Pfl. Fam. 1,4 (1899) 325; Giesenh., Niphobolus (1901) 167; Hayata, Bot. Mag. Tokyo 23 (1909) 34.Cyclophorus polydactylus C. Chr., Ind. Fil. (1906) 200; Christ, Geogr. der Farne (1910) 112; Bonap., Notes Ptérid. 7 (1918) 76. - Type: Hancock 33 (Herb. Hance 22168) (BM, iso US), Taiwan.

Pyrrosia $\times$ pseudopolydactylis Serizawa, J. Jap. Bot. 45 (1970) 120-121, fig. 1.-Type: Serizawa 537 (TNS, not seen), Taiwan.

Rhizome short, not grooved ventrally, 4-6 $\mathrm{mm}$ thick, phyllopodia contiguous, lateral buds situated on the phyllopodia. Anatomy: ground tissue parenchymatous, sclerenchyma sheath distinct, sclerenchyma strands scattered through the parenchyma, many; vascular strands 8-9. Scales peltate, 1.5-2.1 $\times 0.6-0.9$ mm; blackish with a light margin, ciliate. Fronds monomorphic, stipitate; stipes 
$10-26 \mathrm{~cm}, \pm 1-2.5 \times$ as long as the lamina; lamina outline, index ${ }^{4} / 5-11 / 2$; widest below the middle, $8-18 \times 10-17.5 \mathrm{~cm}$, base cordate-truncate to cuneate, sometimes unequally narrowed into the dilated stipe; pedately divided to $4 / 5$ into 6-8 divisions, the middle one, index 4-10, 6-14 $\times 1-2 \mathrm{~cm}$, the lateral ones increasingly smaller. Venation: secondary veins distinct, with the tertiary veins forming regular areoles; included veins simple or occasionally forked, free, excurrent. Hydathodes distinct, scattered over the lamina, slightly to distinctly pitted. Anatomy: stipe with 7-8 central and 2-5 lateral vascular strands; lamina $\pm 0.5 \mathrm{~mm}$ thick, upper epidermis with slightly to distinctly projecting cells with thin to slightly thickened walls, hypodermis and water-tissue absent, palissade and spongy parenchyma distinct, lower epidermis with thin to slightly thickened cell-walls; stomata slightly sunken, pericytic. Indument monomorphic, a dense mat, persistent, greyish-brown; hairs $0.5-1.0 \mathrm{~mm}$ in diam., with \pm appressed, narrowly boat-shaped rays. Sori apical to all over the lamina, in an ill-defined patch, closely packed, superticial; several in a row in each soriferous areole, not confluent; 1-1.5 mm in diam.; developing from the apex downwards, when old individually distinct, exserted from the indument. Sporangia on stalks to $2 / 3 \times$ as long as the capsule, capsule $0.3-0.4 \mathrm{~mm}$ high, with $14-25$ indurated annulus cells. Paraphyses not differentiated. Spores $(66-) 71.0-75.6(-82) \times(48-) 51.8 \times$ $52.8(-60) \mu \mathrm{m}$, densely granulate.

Habitat: Epilithic, terrestrial (on earth banks); epiphytic. Altitudinal range: $400-1500(-2500$ ? $) \mathrm{m}$.

TAIWAN. 16 collections.

Notes. 1. $P$. polydactyla differs from $P$. hastata mainly in the more finely dissected lamina, with relatively narrower divisions. Study of plants cultivated in the Botanical Garden in Leiden, however, indicates that this character is not strongly fixed.

Plants were cultivated from two fragments of rhizome, collected in the field by K.U. Kramer in 1980. One plant has been kept in a phytotron under permanently warm, moist conditions, the other in a greenhouse with a more temperate regime, with cool winters. The first plant developed the lamina shape typical of $P$. polydactyla, the second one developed a seasonal rhythm in which early fronds were formed which were shaped exactly like those of $P$. hastata, whereas fronds formed later in the season gradually assumed a shape more characteristic for $P$. polydactyla.

Other characters are available to separate the two species in the herbarium: - the diameter of the stellate hairs. In $P$. hastata the hairs measure generally less than $0.5 \mathrm{~mm}$ in diam., in $P$. polydactyla the diameter is often up to $1.0 \mathrm{~mm}$. - the degree of branching and anastomosing of the included veins. In $P$. hastata the veins appear to be more strongly anastomosing than in $P$. polydactyla, in which relatively more included free veinlets are present. 
Both of these characters seem to be more constant under cultivation than the lamina shape. In other species it appears, however, (see under $P$. sheareri), that the diameter of the hairs at least to some degree depends on the environment. Moreover, both characters may show changes during the heteroblastic development that completely encompass the variation between $P$. hastata and $P$. polydactyla. More extensive experiments involving both $P$. polydactyla and $P$. hastata are necessary to decide whether the two species are perhaps only environmentally determined forms, whether they are better distinguished as subspecies, or whether a distinction on the species level can be maintained.

2. $P . \times$ pseudopolydactylis is supposed to be a hybrid between $P$. matsudae and $P$. polydactyla. From $P$. polydactyla, however, it appears to differ merely in the slightly lower number of lobes of the lamina. Considering the plasticity of that character I see no reason to suppose that another species is involved in the parentage of the specimens referred to $P$. pseudopolydactylis.

\section{Pyrrosia porosa (Presl) Hovenkamp. Fig. 20.}

Rhizome shortly elongated, not grooved ventrally, $1.6-3.1 \mathrm{~mm}$ thick, phyllopodia $0.3-0.7 \mathrm{~cm}$ apart, lateral buds situated up to halfway down the internodia. Anatomy: ground tissue parenchymatous, sclerenchyma sheath distinct or occasionally indistinct, sclerenchyma strands scattered through the inner parenchyma, 2-many; vascular strands 5-13. Scales peltate, 1.4-6.8 $\times 0.5-2.1 \mathrm{~mm}$; base entire to ciliate; acumen light brown to dull blackish with a distinct lighter margin, ciliate to dentate. Fronds monomorphic, not or indistinctly stipitate; stipes to $13 \mathrm{~cm}$; lamina, index 6 to \pm over 20 ; widest above the middle, 9-31($55) \times 0.3-3.5 \mathrm{~cm}$, base gradually narrowed, apex acute to acuminate. Venation: secondary veins usually distinct, sometimes little distinct, with the tertiary veins forming regular to irregular areoles; included veins simple or rarely forked, free, excurrent. Hydathodes distinct, scattered over the lamina, \pm superficial. Anatomy: stipe or lower part of costa with 5-9 central and 1-4 lateral vascular strands; lamina 0.3-0.7 mm thick, upper epidermis with distinctly projecting cells with thin walls, hypodermis absent or occasionally present, composed of a single cell-layer, water-tissue absent, palissade and spongy parenchyma distinct, lower epidermis with thin cell-walls; stomata superficial to slightly sunken, pericytic. Indument dimorphic, occasionally monomorphic, a dense or occasionally sparse mat, persistent, brown, or the lower layer whitish; upper layer composed of hairs $0.2-1.6 \mathrm{~mm}$ in diam., with erecto-patent to occasionally appressed, acicular rays, usually \pm mixed with a lower layer composed of hairs with mainly woolly rays. Sori apical to all over the lamina, closely packed or occasionally irregularly spaced, superficial; several in a row in, or scattered through each soriferous areole, rarely confluent; 1-2 $\mathrm{mm}$ in diam.; developing from the apex downwards, when old individually distinct, immersed in to exserted from the in- 
dument. Sporangia \pm sessile or on stalks to as long as the capsule, capsule 0.3$0.5 \mathrm{~mm}$ high, with 14-25 indurated annulus cells. Paraphyses not differentiated. Spores (56-)63.4-81(-86) $\times(42-) 48.0-55.8(-70) \mu \mathrm{m}$, finely granulate.

Key to the varieties

1. sporangia sessile or short-stalked, the stalk up to $1 / 3$ of the length of the capsule ........................................................ var. stenophylla -sporangia distinctly stalked, stalk $1 / 2-1 \times$ as long as the capsule ........... 2

2. fronds $0.7-3.5 \mathrm{~cm}$ wide and/or indument with mostly erecto-patent straight

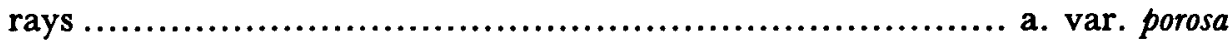
-fronds $0.4-1.1 \mathrm{~cm}$ wide, indument appressed ............ b. var. tonkinensis

\section{a. var. porosa}

Pyrrosia porosa Hovenkamp, Blumea 30 (1984) 208. - Polypodium porosum Wallich, Cat. (1828) no 266, nom. nud. - Niphobolus porosus Presl, Tent. Pter. (1836) 200; Kunze, Linnaea 24 (1851) 258; T. Moore, Ind. Fil. (1857) lxxvi; T. Moore, Ind. Fil. (1861) 276; Bedd., Ferns S. India (18645) 61, pl. 183; J. Sm., Hist. Fil. (1875) 98.-Cyclophorus porosus Presl, Epim. Bot. (1851) 130; C. Chr., Ind. Fil. (1906) 200; Alderwerelt, Malayan Ferns (1909) 687 p.p.; Bonap., Notes Ptérid. 16 (1925) 122; C. Chr., Ind. Fil. Suppl. 3 (1934) 65.-Polypodium porosum Mett., Polyp. (1856) 128; Hooker, Sp. Fil. 5 (1863). 48; Thwaites, Enum. Pl. Zeyl. (1864) 395.-T y pe: Wallich no 266 (holo PRC, teste Holttum, iso in B, BM, BR, K, M, P, US), 'India Orientalis'.

Niphobolus sticticus Kunze, Linnaea 24 (1851) 257; Giesenh., Niphobolus (1901) 135; Christ, Bull. Acad. int. Géogr. bot. 9 (1902) 221; Christ, Bull. Acad. int. Géogr. bot. (1906) 109; Christ, Bull. Soc. Fr. 52 Mém. 1 (1905) 24.-Polypodium sticticum Mett., Polyp. (1856) 128.-Cyclophorus sticticus C. Chr., Ind. Fil. (1906) 201; Christ, J. Bot. Paris 21 (1908) 238; Alderwerelt, Malayan Ferns (1909) 687, p.p.; H. Lev., Fl. Kouy-Tchéou (1915) 479; Bonap., Notes Ptérid. 7 (1918) 126; C. Chr., Acta Horti Gothob. 1 (1924) 105; Hand.-Mazz., Symb. Sin. 6 (1929) 46; C. Chr., Contr. U.S. Nat. Herb. 26 (1931) 326.-Pyrrosia stictica Holttum, Nov. Bot. Inst. Bot. Univ. Car. Prag. (1968) 31, nom. superfl. - Ty pe: Leschenault 149 (G, not seen, iso P), India.

Polypodium davidii Baker, Ann. Bot., Lond. 5 (1891) 472, nom. illeg.; [non Polypodium davidii Franch., Pl. David. 2 (1888) 156, ? = Athyrium spec.]; Baroni * Christ, Nu. Gior. Bot. It. n.s. 4 (1897) 96; Christ, Bull. Herb. Boiss. 6 (1898) 872. - Niphobolus davidii Giesenh. ex Diels in E. . P., Nat. Pfl. Fam. 1,4 (1899) 325; Diels, Bot. Jb. 29 (1900) 207; Giesenh., Niphobolus (1901) 132; Christ, Bull. Acad. int. Géogr. bot. 11 (1904) 107; Christ, Bull. Soc. Fr. 52 Mém. 1 (1905) 24. - Cyclophorus pekinensis C. Chr., Ind. Fil. (1906) 200, nom. superfl.; C. Chr., Acta Horti Gothob. 1 (1924) 44; C. Chr., Contr. U.S. Nat. Herb. 26 (1931) 326.-Cyclophorus davidii H. Lev., Fl. Kouy-Tchéou (1915) 478; Hand.-Mazz., Symb. Sin. VI (1929) 46. - Pyrrosia pekinensis Ching, Bull. Chin. Bot. Soc. 1 (1935) 35, nom. superfl.; Fu, Ill. Imp. Chin. Pl. (1957) 236, fig. 317; Kurata, J. Geobot. Kanazawa 8 (1959) 17.-Pyrrosia davidii Ching, Acta Phytotax. Sin. 10 (1965) 301.-Ty pe: David 448 (K), China.

Polypodium mollissimum Christ, Bull. Herb. Boiss. 7 (1899) 5, nom. illeg.; [non Polypodium mollissimum Fée, 11e Mém. (1866) 47, pl.12 fig. 2, = Ctenopteris mollissima (Fée) Copeland].-Cyclophorus malacophyllus C. Chr., Ind. Fil. (1906) 199;-Pyrrosia mollis var. mollissima Ching, Bull. Chin. Bot. Soc. 1 (1935) 54.-Lect ot y pe: Henry 9061 (Christ: '9061 B') (holo P, see note 3), China.

Niphobolus gralla Giesenh., Niphobolus (1901) 128; Christ, Bull. Acad. int. Géogr. bot. 9 (1902) 221; Christ, Bull. Soc. Fr. 52 Mém. 1 (1905) 24.-Cyclophorus gralla C. Chr., Ind. Fil. (1906) 199; H. Lev., Fl. Kouy-Tchéou (1915) 478; C. Chr., Contr. U.S. Nat. Herb. 26 (1931) 326.Pyrrosia gralla Ching, Bull. Chin. Bot. Soc. 1 (1935) 50; Tagawa, J. Jap. Bot. 24 (1949) 118. Lectotype: Henry $9061 \mathrm{~A}$ (holo $\mathrm{M}$, iso P; see note 3), China. 
Niphobolus acrocarpus Christ ex Giesenh. in Christ, Bull. Acad. int. Géogr. bot. 9 (1902) 221.Cyclophorus acrocarpus C. Chr., Ind. Fil. (1906) 197. - Syn ty pes: Bodinier s.n., (17 Dec. 1896) (M, P, E), China, 'Yunnan Sen'; Bodinier s.n., (4 Apr. 1897) (not seen), China, 'Ma Kay'.

Niphobolus xiphioides Christ, Bull. Soc. Fr. 52 Mém. 1 (1905) 25. - Cyclophorus xiphioides C. Chr., Ind. Fil. (1906) 202; H. Lev., Fl. Kouy-Tchéou (1915) 479.-T y pe: Cavalerie s.n., (1899) (P?, not found), China, 'Kouy-Tchéou, Tou-Chan'.

Niphobolus sticticus var. major Christ, Bull. Acad. int. Géogr. bot. 15 (1906) 109.-T y pe: Wilson 5329 ('5339' err. Christ) (P, BM, K), China.

Cyclophorus alcicornu Christ, J. Bot. Paris 21 (1908) 238, 270; Christ, Geogr. der Farne (1910) 112; C. Chr., Ind. Fil., Suppl. 1 (1913) 22 ; Bonap., Notes Ptérid. 7 (1918) 125.-Pyrrosia mollis fo. alcicomu Ching, Bull. Chin. Bot. Soc. 1 (1935) 54; C. Chr. Tard., Not. Syst. 8 (1939) 206. Synt y pes: Eberhardt 40 (BM), 51 (BM, P), 135 (P), Indo-China.

Cyclophorus subfissus Hayata, Ic. PI. Form. 5 (1915) 264; C. Chr., Ind. Fil. Suppl. 2 (1917) 11; DeVol, Fl. Taiwan (1975) 207, pro syn.-Pyrrosia subfissa Ching, Bull. Chin. Bot. Soc. 1 (1935) 72; Tagawa, J. Jap. Bot. 24 (1949) 118, pro syn.-Type: Ito s.n., (Apr. 1914) (not seen), Taiwan, 'Mt. Arisan'.

Cyclophorus pekinensis fo. minor C. Chr., Acta Horti Gothob, 1 (1924) 105.-Type: $\dot{H}$. Smith 4610 (BM), China.

Pyrrosia nudicaulis Ching, Bull. Chin. Bot. Soc. 1 (1935) 52.-Type: G. Forrest 10108, ('20108' err. Ching) (E), China.

Pyrrosia nayariana Ching Chandra, Amer. Fern J. 54 (1964) 62, fig. 1-10; Nayar \& S. Chandra, Bull. Nat. Bot. Gard. Lucknow 117 (1965) 70; Nayar \&. Chandra, Can. J. Bot. 45 (1967) 615-634.-Type: Chandra 74310 (LWG, not seen), India.

Polypodium acrostichoides et syn. homot., auct. non G. Forster, quoad specim. Zeyl.: Willis, Cat. Pl. Ceyl. (1911) 123; Manton \& Sledge, Phil. Tr. R. Soc. Lond. B 654 (1954) 169.

Niphobolus mollis et syn. homot., auct. non Kunze: Ching, Bull. Chin. Bot. Soc. 1 (1935) 53; C. Chr. * Tard., Not. Syst. 8 (1939) 206; Tard. \& C. Chr., Fl. Indo-Ch. (1941) 506; Fu, Ill. Imp. Chin. Pl. (1957) 236, fig. 318; Copeland, Fern Fl. Philipp. (1960) 473; Sledge, Bull. Br. Mus. (Nat. Hist) Bot. 2 (1960) 134; Nayar \& S. Chandra, Bull. Nat. Bot. Gard. Lucknow 117 (1965) 67; H. Hara, Fl. Eastern Himal. (1966) 498; Nayar \& S. Chandra, Can. J. Bot. 45 (1967) 615-634; H. Hara, Fl. Eastern Himal., 2nd Rep. (1971) 220; Bir \& Shukla, Nova Hedw. 21 (1972) 195; Nayar Kaur, Comp. Bedd. Handb. (1974) 81; DeVol, Fl. Taiwan (1975) 207; Ching Wu, Fl. Xizang. 1 (1983) 399; Shing, Amer. Fern J. 73 (1983) 77. Type of ser. Molles Shing 1983; Type of sect. Dichlamys Shing 1983.

Niphobolus fissus et syn. homot., auct. non Blume (p.p., partly this refers to $P$. mannii too): Hooker, Sp. Fil. 5 (1863) 49; Baker in Hooker \& Baker, Syn. Fil. (1867) 351; Bedd., Suppl. Ferns S. Br. Ind. (1876) 22; C. B. Clarke, Tr. Linn. Soc. II Bot. 1 (1880) 554; Bedd., Handb. ferns Brit. Ind. (1883) 330; Bedd., Suppl. Handb. (1892) 91; Christ, J. Bot. Paris 8 (1894) 152; Christ, Bull. Herb. Boiss. 6 (1898) 198; Racib., Pter. Buitenz. (1898) 102; Diels in E. \& P., Nat. Pfl. Fam. 1,4 (1899) 325; Hope, J. Bomb. Nat. Hist. Soc. 15 (1903) 152; Copeland, Polyp. Philipp. (1905). 113; Hayata, Bot. Mag. Tokyo 23 (1909) 34; Bonap., Notes Ptérid. 7 (1918) 125; Mehra, Ferns of Mussoorie (1939) 26.

Niphobolus flocciger et syn. homot., auct. non Blume: Baker in Hooker \& Baker, Syn. Fil. (1867) 351, p.p.; Alderwerelt, Malayan Ferns (1909). 687, p.p.

Rhizome. Anatomy: sclerenchyma strands 15-many. Scales 1.4-5.7 $\times$ 0.5-2.1 $\mathrm{mm}$; base entire to ciliate; acumen dull brown to blackish with a distinct lighter margin, ciliate to dentate. Fronds. Lamina, index 6 to \pm over 20; widest above the middle, 9-31 $\times 0.7-3.5 \mathrm{~cm}$. Venation: secondary veins distinct, with the tertiary veins forming regular areoles. Anatomy: hypodermis and water-tissue absent. Indument occasionally monomorphic, upper layer composed of hairs 0.5-1.6 $\mathrm{mm}$ in diam., with erecto-patent to occasionally appressed rays. Sori closely 
packed, several in a row in each soriferous areole. Sporangia on stalks $1 / 2-1 \times$ as long as the capsule.

Habitat: Epilithic, often in exposed places but also under more sheltered conditions (ravines, rock crevices, by streams etc.); frequently on limestone, less often on granitic rock; epiphytic, in various situations (open forest, thickets, shaded riparian forest etc.); sometimes terrestrial, on earth banks or on the forest floor.

Altitudinal range: Lowlands to $3200 \mathrm{~m}$, mainly between 700 and $2000 \mathrm{~m}$.

CHINA. Mongolia: Licent 3558 (P), 3646 (K, P). - Tibet: Kingdon-Ward s.n. (1926) (K). Hopeh: 12 collections. - Shansi: 6 collections. - Shensi: 12 collections. -Szechuan: 14 collections. - Kweichow: 10 collections. - Yunnan: 72 collections. - Hunan: SABE 805 (NA). Kwangsi: Ching 7172 (US), S. P. Ko 55633 (A), S.K. Lau 28505 (A); Steward * Cheo 373 (P).

- Hainan: Hancock s.n. (Kew distr. no. 110) (K).

TAIWAN: 11 collections.

NEPAL. 9 collections.

BHUTAN. Cooper 1392 (BM), Ludlow et al. 20543 (BM).

INDIA. Himachal Pradesh: 11 collections. - Uttar Pradesh: 12 collections. - Sikkim \& Darjeeling: 6 collections. - Assam: 9 collections. - Mysore: Barth s.n. (1846) (M), Bogner 507 (M), Jarrett \& Saldanha HFP 765 (US), Gassner \& Kramer s.n. (Nov. 1977) (Z), Richter s.n. (1887) (P).

-Tamil Nadu Kerala: 36 collections.

CEYLON. 17 collections.

BURMA. 7 collections.

THAILAND. Northern: 15 collections. - Southeastern: Eryl Smith 1577 (K).

LAOS. Anon. (?Colani) 4527 (BM, P), Poilane 26321 (P).

VIETNAM. Tonkin: 8 collections. - Annam: Evrard 340 (P).

JAPAN. Namegata 10784 (US).

PHILIPPINES. Luzon: 32 collections, mostly from northern Luzon, one collection from Cadig Mountains.

Doubtful localities.

MADAGASCAR. Blagrave $2(\mathrm{~K})$.

Notes. 1. This is a variable and widespread species. In its present circumscription it contains a number of forms formerly considered separate species. With the ample material at hand I can find no consistent differences between these forms, but biosystematic research might reveal distinct entities among them.

- Small plants with a dense, often monomorphic indument have been called $P$. gralla (Tsai 57140, Schneider 1144, Wang 63009, Schoch 143).

- Similar forms but with a dimorphic indument have been called $P$. davidii and Niphobolus acrocarpus (e.g., Meyer 1037, Licent 12175, Wang 62536, Forrest 11355). - Larger forms, with relatively wide lamina and a thin, rather appressed indument, have been called $P$. mollissima (Wang 64132, 64145, Rock 11580). P. nudicaulis is similar but has a more distinct stipe.

- Plants from Taiwan and Japan generally have a sparse indument in which a few woolly rays may be present. These forms can be confused with $P$. assimilis, but may be distinguished from that species by the equal-sized rays of the stellate hairs (see note 1 under $P$. assimilis). 
2. Niphobolus porosus Presl is validated by a short description in the text (1836, p. 200): 'Fasciculi vasorum in stipite (...) in $N$. poroso quatuor teretes aequales'.

3. Polypodium mollissimum Christ and Niphobolus gralla Giesenh. are typified by Henry $9061 B$ and Henry 9061 A, respectively. Specimens distributed under this number have been variously marked:

was first cited by Christ (Bull. Herb. Boiss. 6, Nov. 1898), under che following headings:

Polypodium flocculosum Don. 9061, Mengtze, Mts. to E., 6000' 9061 A bis, Mile District

Polypodium davidii Bak. $\quad 9061$ A, Mile District

- At the same time, Nov. 1898, Henry 9061 B was separated (according to a handwritten letter by Christ, P). The following numbers and labels are present in other herbaria:

Henry 9061, (B, US); Henry 9061, Mengtze, Mts. to E (E); Henry 9061, Mengtze, SW Mts., 6000' (E, K); Henry 9061, Mengtze, 7 0ct. May Kuo Chan (L); Henry 9061, 14 Sep., Lou Chan Mts., $1 / 2$ way up, on rocks (L); Henry 9061, Mengtze, S. Mts., 6000' (P); Henry 9061 A, Mile distr. (BM, M, P); Henry 9061 B, E. Mts., $6000 \mathrm{~m}(\mathrm{BM})$; Henry $9061 \mathrm{C}, 5000^{\prime}(\mathrm{P}, \mathrm{K})$.

From the above, it is obvious that the numbering is of no great help in the identification of type specimens. The selection of lectotypes therefore is not based on correspondence between herbarium labels and the citation of the type, but on the presence of handwritten notes to the specimens. I have based my selection of a specimen in $\mathrm{P}$ as lectotype of Polypodium mollissimum Christ on handwritten notes of Christ; the specimen is not indicated $A$ or $B$. I have selected a specimen in M as lectotype of Niphobolus gralla Giesenh. based on handwritten annotations by Giesenhagen; an isolectotype in $\mathrm{P}$ is accompanied by more extensive notes by Giesenhagen.

\section{b. var. tonkinensis (Giesenh.) Hovenkamp}

Pyrrosia porosa (Presl) Hovenkamp var. tonkinensis Hovenkamp, Blumea 30 (1984) 208. - Niphobolus tonkinensis Giesenh., Niphobolus (1901) 144. - Cyclophorus tonkinensis C. Chr., Ind. Fil. (1906) 201; Bonap., Notes Ptérid. 7 (1918) 126.-Pyrrosia tonkinensis Ching, Bull. Chin. Bot. Soc. 1 (1935) 55; C. Chr. * Tard., Not. Syst. 8 (1939) 206; Tard. C. Chr., Fl. Indo-Ch. (1941) 506.-Type: Dr. Billet s.n., (1896) (holo P, iso M), Indo-China, Cao Bang.

Cyclophorus vittarioides Christ, Bull. Acad. int. Géogr. bot. 20 Mém. (1909) 175: nom. illeg. [non Cyclophorus vittarioides Presl, Epim. Bot. (1851) 129, = Pyrrosia lanceolata (L.) Farwell]; C. Chr., Ind. Fil. Suppl. (1913) 23; H. Lev., Fl. Kouy-Tchéou (1915) 479.-Ty pe: Cavalerie 2874 (P, BM, E, K, SING), China.

Rhizome. Anatomy: sclerenchyma strands 4- \pm 15 . Scales $3.6-6.2 \times 0.5-1.3$ $\mathrm{mm}$; base entire to dentate; acumen light brown, dentate. Fronds \pm over 20, 0.4$1.1 \mathrm{~mm}$ wide. Venation: secondary veins distinct, with the tertiary veins forming 
regular areoles. Anatomy: hypodermis absent or sometimes present, composed of a single cell layer. Indument dimorphic, upper layer composed of hairs $0.2-0.8 \mathrm{~mm}$ in diam., with usually appressed rays. Sori closely packed, sporangia on stalks $1 / 2-1 \times$ as long as the capsule.

Habitat: Epiphytic, in open forest; or epilithic, often on limestone or near watercourses; also in drier places; sometimes terrestrial, in similar places as the type variety.

Altitudinal range: $200-1600 \mathrm{~m}$, usually at lower altitudes than the type variety.

CHINA. Kweichow: 6 collections. - Kwangsi: S.P. Ko 55175 (A), 55739 (A), W.T. Tsang 21904 (GH, P), 22143 (P). - Hainan: 14 collections.

THAILAND. Northern: 9 collections. - Northeastern: Van Beusekom \& Phengkhlai 2983 (L), Eryl Smith 2146 (K), Tagawa et al. T 1225 (K, L, US). - Eastern: Van Beusekom et al. 4129 (BISH, L), Geesink et al. 6943 (L), 7002 A (L).

LAOS. Poilane 16793 (P), 25936 (P).

VIETNAM. Tonkin: 19 collections.

Notes. 1. P. porosa var. tonkinensis is distinguished as a variety on the basis of a combination of correlated characters that, taken singly, also occur in the type variety. The rhizome scales are brown instead of blackish, their margin dentate instead of ciliate. In the type variety similar scales occur in some specimens from southern India that in all other aspects are typically $P$. porosa var. porosa (e.g., Bogner 507, Saldanha \& Jarrett 16978). Judging from the description, $P$. nayariana is similar to these last plants. In addition, $P$. porosa var. tonkinensis has quite narrow fronds (a character that may be more distinct in dried than in fresh plants) and an appressed indument (but a similar indument is found in specimens of $P$. porosa var. porosa with black rhizome scales and wider fronds; e.g., Rock 11535; Larsen et al. 2012).

\section{c. var. stenophylla (Bedd.) Hovenkamp}

Pyrrosia porosa (Presl) Hovenkamp var. stenophylla Hovenkamp, Blumea 30 (1984) 208. - Niphobolus fissus var. stenophyllus Bedd., Suppl. Handb. (1892) 92.-Niphobolus stenophyllus Giesenh., Niphobolus (1901) 131.-Cyclophorus stenophyllus C. Chr., Ind. Fil. (1906) 201.-Pyrrosia stenophylla Ching, Bull. Chin. Bot. Soc. 1 (1935) 55; Nayar Kaur, Comp. Bedd. Handb. (1974) 81.-Ty pe: Watt s.n., s.d., (holo K), India, 'Munipore, $6000 \mathrm{ft}$ '.

Pyrrosia tibetica Ching, Lingnan Sci. J. 21 (1945) 34; Ching Wu, Fl. Xizang. 1 (1983) 338, fig. 4-6.-T y pe: T.T. Yü 20530 (PE, not seen, A), China.

Pyrrosia tibetica var. angustata Ching, Lingnan Sci. J. 21 (1945) 34.-Ty pe: T. T. Yü 19928 (PE, not seen), China.

Rhizome. Anatomy: sclerenchyma strands 2-many. Scales 3.5-6.8 $\times$ 0.7-1.2 $\mathrm{mm}$; base entire to dentate, acumen light brown, dentate; short, \pm round to ovate scales occasionally present. Fronds \pm linear, to $23-55 \times 0.3-1.9 \mathrm{~cm}$. Anatomy: hypoderm indistinct, composed of a single cell layer. Venation: secondary veins little distinct. with the tertiary veins forming \pm irregular areoles $I n d u$ ment dimorphic, often thin. Sori often distinctly spaced, \pm scattered throughout each soriferous areole. Sporangia on stalks to $1 / 3 \times$ as long as the capsule. 
Habitat: Epiphytic or epilithic, on dry limestone, wet boulders; in mixed or evergreen forest.

Altitudinal range: $1300-3300 \mathrm{~m}$.

CHINA. Tibet: Ludlow et al. 6682 (BM), 12147 (BM), 12221 (BM). - Yunnan: T.T. Yü 20530 (A), 20861 (A).

NEPAL. Khwaunju 1225 (K).

BHUTAN. Ghose s.n. (1913) (P), Gould 648 (K), Griffith 978 (P), 2781 (B, K), Ludlow et al. 18610 (BM).

INDIA. Assam: 11 collections.

BURMA: Forrest 25022 (E, K).

Notes. 1. $P$. porosa var. stenophylla differs from the type variety chiefly in the very long fronds that are very narrow or, if wider, have the sori characteristically and irregularly scattered over the surface. It is also characteristic that in contrast to the other taxa in the $P$. porosa-group, the lamina in drying curls back over the sori instead of curling upwards and exposing the sori. The plants with wider fronds have been called $P$. tibetica. The rhizome scales are rather similar to those of var. tonkinensis.

\section{Pyrrosia princeps (Mett.) Morton. Fig. 17, 37.}

Pyrrosia princeps [Copeland, Fern Fl. Philipp. (1960) 474, comb. inval.] Morton, Amer. Fern J. 60 (1970) 118. - Polypodium princeps Mett., Ann. Mus. Lugd. Bat. 2 (1866) 232; Baker in Hooker Baker, Syn. Fil. (1867) 351; Beccari, Malesia 3 (1890) 48; Baker, Ann. Bot., Lond. 5 (1891) 472. - Niphobolus princeps Giesenh. ex Diels in E. \& P., Nat. Pfl. Fam. 1,4 (1899) 325.Cyclophorus princeps C. Chr., Ind. Fil. (1906) 200; Alderwerelt, Malayan Ferns (1909) 684; Brause, Bot. Jb. 56 (1920) 205.-T y pe: Zippelius s.n., s.d. (holo L), New Guinea.

Cyclophorus aglaophyllus Copeland, J. Arn. Arb. 10 (1929) 179; C. Chr., Ind. Fil., Suppl. 3 (1934) 64; Copeland, Fern Fl. Philipp. (1960) 474.-Ty pe: Brass 1143 (GH), New Guinea.

Rhizome short, not grooved ventrally, to $\pm 5 \mathrm{~mm}$ thick, phyllopodia contiguous, lateral buds situated on the phyllopodia. Anatomy: ground tissue sclerenchymatous, sclerenchyma sheath and sclerenchyma strands absent; vascular strands \pm 10 . Scales basifix, 4.5-10 mm long; base dentate to ciliate; acumen light brown, dentate or with long, sometimes curly cilia, short scales regularly present. Fronds monomorphic, not or indistinctly stipitate, stipes to \pm $13 \mathrm{~cm}$; lamina, index 6-14; widest above the middle, 24-125 $\times 3.4-12 \mathrm{~cm}$ or sometimes longer, base gradually narrowed, apex acuminate. Venation: secondary veins distinct, with the tertiary veins forming regular areoles; included veins much branched and strongly anastomosing; free veins many, pointing to all directions. Hydathodes distinct, all over the lamina, \pm superficial. Anatomy: stipe or lower part of costa with a central strand of collenchyma and 8-9 central and \pm 6 lateral vascular strands; lamina 0.2-0.4 mm thick, upper epidermis with slightly projecting cells with thickened walls, hypodermis composed of a single layer; water-tissue absent, palissade and spongy parenchyma \pm distinct, lower epidermis with thickened cell-walls; stomata slightly sunken, pericytic. Indument dimorphic, a dense mat, persistent, brown to greyish brown; upper layer com- 


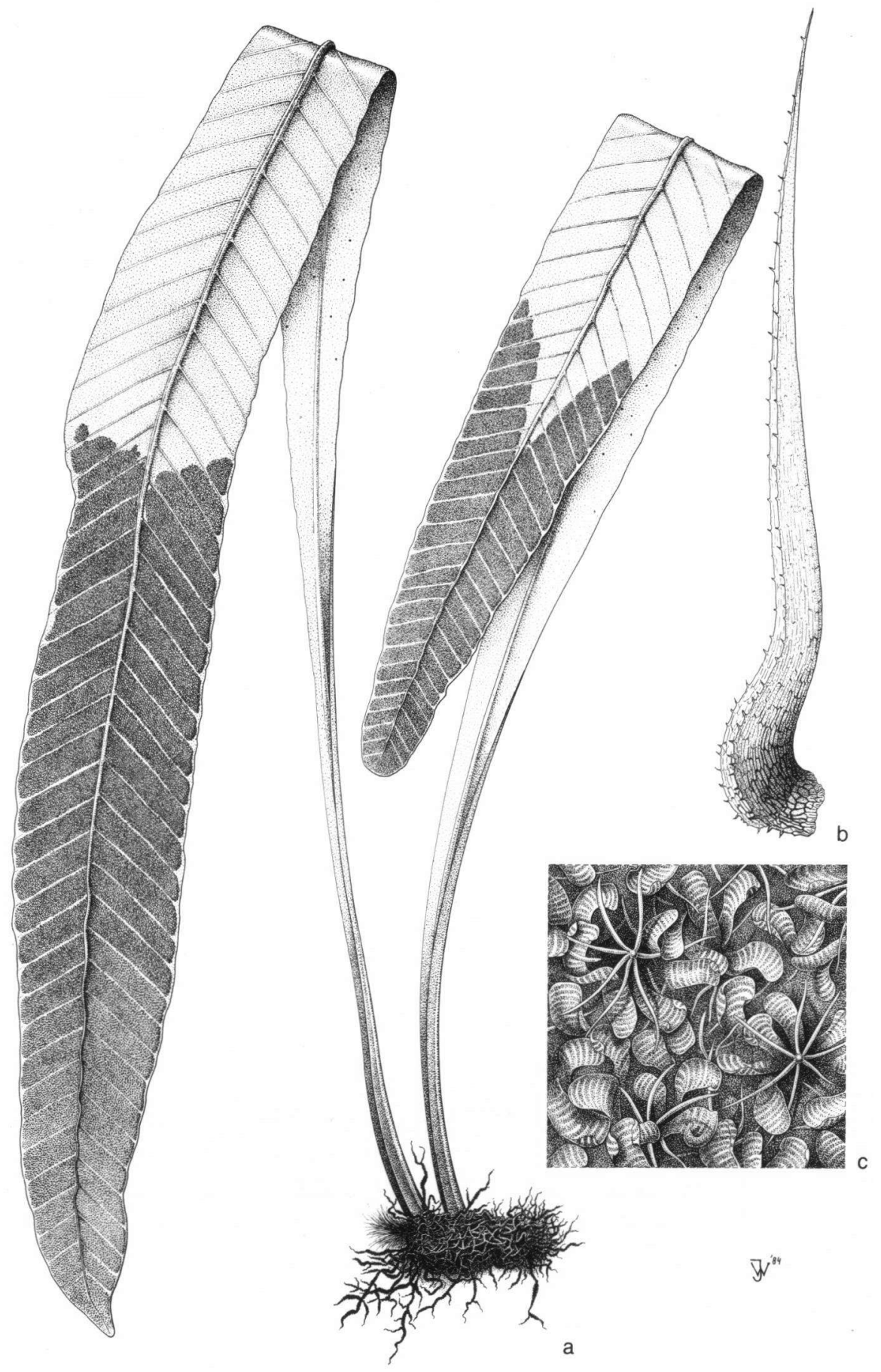

Fig. 37. $P$. princeps. a. Habit $\times 1 / 2 .-$ b. Rhizome scale $\times 23 .-$ c. fertile area $\times 40 .(a, b, c$. Brass 8859, L). 
posed of hairs $0.4-1.4 \mathrm{~mm}$ in diam., with erecto-patent or appressed, acicular rays, sometimes with a distinct dorsal spine, appressed to but separate from a lower layer composed of hairs with mainly woolly rays. Sori apical in a snarply detıned, near the base sometımes interrupted patch, closely packed, superficial; many scattered through each soriferous areole, not confluent; $\pm 0.5 \mathrm{~mm}$ in diam.; developing from the apex downwards, when old individually distinct, exserted from the indument. Sporangia sessile, capsule $0.3 \mathrm{~mm}$ high, with 9-10 indurated annulus cells. Paraphyses not differentiated. Spores (54-)60.2-68.2(-74) $\times(34-) 41.4-43.6(-46) \mu \mathrm{m}$, smooth.

Habitat: Mostly epilithic or terrestrial, often near rivers, also on (limestone) cliffs and steep hillsides; or epiphytic, mostly on rainforest trees, sometimes in open secondary forest or in rubber plantations.

Altitudinal range: Sea level to $\pm 1000 \mathrm{~m}$.

CELEBES. Hennipman 5036 (L), 5729 (L).

MOLUCCAS. Morotai: Main \& Aden 903 (BO, L). - Halmaheira: Idjan \& Mochtar 180 (BO, L), 350 (BO, L), Alston 16890 (BM). - Ceram: 5 collections. - Ambon: 6 collections.

NEW GUINEA. Waigeo: Van Royen 5189 (L), 5458 (BM, L). - Biak: Grether Wagner 4220 (US), J.J.E. De Wilde 1247 (L). - Japen I.: Aet \& Idjan 33 (BO,L), Barclay s.n., s.d. (BM). Irian Jaya: 6 collections. - Papua New Guinea: 25 collections.

Notes. 1. $P$. princeps can be confused with $P$. splendens and $P$. platyphylla. $P$. princeps can usually be distinguished from both by the indument, which has an upper layer of hairs with patent, acicular rays. Forms occur with more or less distinct dorsal spines, which are superficially similar to $P$. splendens; other forms (e.g., Kanis 1153, Brass 8859) lack the characteristic upper layer and then strongly resemble $P$. platyphylla. Detached fronds, from which both rhizome and rhizome scales are lacking, cannot be identified with certainty in all cases. The most constant distinguishing character is found in the rhizome scales, which in $P$. princeps have an acumen that is at least slightly dentate, but usually distinctly dentate or ciliate. In $P$. splendens and $P$. platyphylla the scales have an entire acumen. From $P$. platyphylla the present species can moreover be distinguished by the short rhizome (shortly elongated in $P$. platyphylla).

A slightly aberrant form occurs on Celebes. These specimens have practically entire rhizome scales. They have the indument characteristic for $P$. princeps.

2. The distinction between the indument on the rhizome and that on the lamina is slightly less sharp in $P$. princeps than in other species: sometimes a distinct layer of woolly hairs is present on the phyllopodium among the scales. The apices of the scales may be furcate, with long, straight cilia somewhat resembling the crown of a stellate hair.

40. Pyrrosia rasamalae (Racib.) Shing. Fig. 23.

Pyrrosia rasamalae Shing, Amer. Fern J. 73 (1983) 78. - Polypodium rasamalae Racib., Pter. Buitenz. (1898) 99. - Niphobolus rasamalae Giesenh., Festschr. zu S. Schwendener (1899) 12; Giesenh., 
Niphobolus (1901) 187.-Cyclophorus rasamalae C. Chr., Ind. Fil. (1906) 200; Alderwerelt, Malayan Ferns (1909) 686; Backer \& Posth., Varenfl. Java (1939) 240; Holttum, Fl. Malaya 2 (Ferns) (1954) 147. - Lectoty pe: Raciborski s.n., s.d. (BO, nr. 83, iso K, L, M, P, US), Java, Telaga Bodas.

Anthrophyum niphoboloides Kunze, Bot. Zeit. (1848) 209; Hooker, Sp. Fil. 5 (1863) 174. -Taenitis niphoboloides T. Moore, Ind. Fil. (1857) xxx, 81; [non Taenitis niphoboloides Luerss., Abh. Naturw. Ver. Bremen 7 (1883) 49, nom. illeg., = Pyrrosia niphoboloides (Baker) Price].-Ty pe: Zollinger 2223 (L, BM, P), Java.

Niphobolus lanuginosus Giesenh., Niphobolus (1901) 190. - Cyclophorus lanuginosus C. Chr., Ind. Fil. (1906) 199; Christ, Bull. Herb. Boiss. II, 6 (1906) 987; Alderwerelt, Malayan Ferns (1909) 685.-Pyrrosia lanuginosa Copeland, Fern Fl. Philipp - (1960) 472.-Ty pe: A. Loher, Herb. Philipp. 1266 (M, P), Luzon.

Cyclophorus rasamalae fo. minor Alderwerelt, Bull. Dep. Agr. Ind. Neer. 21 (1908) 8.-Ty pe: JJ. Smith s.n., s.d. (BO), Java, Preanger Regencies.

Cyclophorus borneensis Copeland, Phil. J. Sc. 12 C (1917) 64; Copeland, Sarawak Mus. J. 2 (1917) 409; C. Chr., Ind. Fil. Suppl. 3 (1934) 64; C. Chr. \& Holttum, Gard. Bull. S. S. 7 (1934) 313314, q.n.s;-Pyrrosia bomeensis Shing, Amer. Fern J. 73 (1983) 78.-T y pe: Topping 1508 (GH), Borneo.

Niphobolus flocciger et syn. homot, auct. non Blume: Baker in Hooker Baker, Syn. Fil. (1867) 351 p.p.; Diels in E. \& P., Nat. Pfl. Fam. 1,4 (1899) 325; Giesenh., Niphobolus (1901) 189; Copeland, Polyp. Philipp. (1905) 113; Alderwerelt, Malayan Ferns (1909) 687 p.p.; C. Chr. Holttum, Gard. Bull. S.S. 7 (1934) 313; Holttum, Fl. Malaya 2 (Ferns) (1954) 147; Copeland, Fern Fl. Philipp. (1960) 473.

Rhizome long-creeping, narrowly grooved ventrally, 1-3 $\mathrm{mm}$ thick, phyllopodia 1-5 cm apart, lateral buds situated more than halfway down the internodia. Anatomy: ground tissue parenchymatous, sclerenchyma sheath distinct, sclerenchyma strands scattered through the inner parenchyma, $0- \pm 10$; vascular strands 4-8. Scales peltate, 4-9.5 $\times 0.4-1.4 \mathrm{~mm}$; base entire; acumen shining light brown or hyaline, entire, rarely dentate; short, \pm round to ovate scales regularly present. Fronds monomorphic, stipitate; stipes $1-10 \mathrm{~cm}$, to $1 / 4(-$ $1 / 2) \times$ as long as the lamina; lamina \pm linear, $3.5-36 \times 0.3-1.4 \mathrm{~cm}$, Venation: secondary veins distinct, with the tertiary veins forming regular areoles; included veins simple, free, excurrent. Hydathodes absent. Anatomy: stipe with 3-4 central and no lateral vascular strands; lamina 0.9-1.4 mm thick, upper epidermis with flat cells with thick walls, hypodermis composed of 1-2 cell-layers or absent, water-tissue distinct, thick, palissade and spongy parenchyma distinct, lower epidermis with thickened cell-walls; stomata sunken, pericytic. Indument dimorphic, a dense mat, persistent, light brown; upper layer composed of hairs 0.8-3.0 $\mathrm{mm}$ in diam., with erecto-patent, acicular rays, separate from a lower layer composed of hairs with mainly woolly rays. Sori apical to all over the lamina, closely packed, superticial; $z-3$ in a row in each soriferous areole, not confluent; 1-1.5 $\mathrm{mm}$ in diam.; developing from the apex downwards, when old individually distinct to pseudoacrostichoid, \pm immersed in the indument. Sporangia on stalks to $1 \times$ as long as the capsule, capsule 0.3-0.4 mm high, with 17-23 indurated annulus cells. Paraphyses not differentiated (?, see note 3). Spores (66-)76.0-96.4($110) \times(44-) 53.4-72.4(-88) \mu \mathrm{m}$, with irregular ridges and protuberances. 
Habitat: Epiphytic, often a high epiphyte, in primary, deciduous or evergreen forest; also in abandoned plantations, ladangs, wayside trees etc.; occasionally epilithic or on earth banks.

Altitudinal range: Mostly 500-1500 m, occasionally to $1900 \mathrm{~m}$.

BURMA. Keenan et al. 797 (A), Kingdon-Ward 20454 (BM).

THAILAND. Northern: Smitinand 6036 (K). - Southwestern: Van Beusekom \& Phengkhlai 240 (B, L, US), 388 (B, L). - Peninsular: 5 collections.

MALAYA. 19 collections.

SUMATRA. 36 collections.

JAVA. 43 collections.

LESSER SUNDA ISLANDS. Bali: Kostermans et al. 86 (BO), Posthumus 3655 (BO, L), 3744 (BO, L), Zollinger 3747 (P). - Lombok: Rensch 666 (B, BO). - Sumbawa: 5 collections. Flores: 5 collections. - Timor: Schmutz 2326 (L), 2336 (L).

BORNEO. Sabah: 6 collections.

PHILIPPINES. Luzon: 20 collections, all from northern Luzon.

Notes. 1. $P$. rasamalae can be confused with $P$. kinabaluensis, which, however, has distinctly ciliate scales and dimorphic fronds.

2. Variability: Large plants have been separated as Niphobolus lanuginosus. I cannot find any differences, other than size, between large and small plants. Moreover, for size there is a gradual transition. The difference is more pronounced for rhizome scales than for fronds.

3. Paraphyses: hairs with woolly rays often form small tufts over sori that have just ripened. I have not been able to ascertain whether these hairs had been attached to the receptacles in any greater density than to the sterile lamina, and thus whether in my circumscription they represent paraphyses or not.

4. $P$. rasamalae has been known generally under the name of $P$. floccigera (Bl.) Ching, a synonym of $P$. albicans.

5. Anthrophyum niphoboloides Kunze: In the description of this species Kunze explicitly mentioned the sori as being linear. His own material unfortunately has been lost (Stafleu \& Cowan, Tax. Lit. II). All duplicates of the type (Zollinger 2223 ) that I have seen have separate sori and are without doubt $P$. rasamalae. In some other cases it was found that collections by Zollinger contained mixtures of sometimes more than 2 species; it is therefore most likely that the material Kunze had at hand was mixed with $P$. piloselloides or some other species with coenosori.

6. Raciborski's description of Polypodium rasamalae contains phrases that cannot be applied to the present species: rhizome 1-3 mm thick, scales contracted to a ciliate acumen, fronds $1-10 \mathrm{~cm}$ distant. They can refer only to a piece of rhizome of a Davalliaceous fern found mixed with a collection from Telaga Bodas (BO, nr. 83). Accordingly, the specimen of $P$. rasamalae on this sheet is here selected as lectotype.

\section{Pyrrosia rhodesiana (C. Chr.) Schelpe. Fig. 16.}

Pyrrosia rhodesiana Schelpe, J. S. Afr. Bot. 18 (1952) 126; Schelpe, Fl. Zambes. (1970) 147; Schelpe * Diniz, Fl. Moçamb. (1979) 151; Jacobsen, Ferns and Fern All. S. Africa (1983) 304, fig. 219, 
map 91.-Cyclophorus thodesianus C. Chr., Dansk Bot. Ark. 7 (1932) 161; C. Chr., Ind. Fil. Suppl. 3 (1934) 65. - Type: Eyles 4472 (holo K), Zimbabwe.

Cyclophorus madagascariensis C. Chr., Dansk Bot. Ark. 7 (1932) 161, pl. 61 fig. 7-10; C. Chr., Ind. Fil. Suppl. 3 (1934) 65. - Pyrrosia madagascariensis Schelpe, J. S. Afr. Bot. 18 (1952) 133; Tardieu, Fl. Madagasc. (1960) 104. - Type: Decary 6960 (BM, P), Madagascar.

Cyclophorus oblanceolatus C. Chr., Dansk Bot. Ark. 7 (1932) 160; pl. 61 fig. 4-6; C. Chr., Ind. Fil.

Suppl. 3 (1934) 65. - Pyrrosia oblanceolata Tardieu, Fl. Madagasc. (1960) 103. - Ty pe: Decary

1753 (BM, P), Madagascar.

Rhizome shortly elongated, not grooved ventrally, $1.3-3.6 \mathrm{~mm}$ thick, phyllopodia $0.5-3 \mathrm{~cm}$ apart, lateral buds situated up to halfway down the internodia. Anatomy: ground tissue parenchymatous, sclerenchyma sheath absent or indistinct, sclerenchyma strands absent; vascular strands 4-10. Scales peltate, 4$9.7 \times 0.6-1.6 \mathrm{~mm}$; base entire to dentate; acumen light brown, dentate to shortly ciliate. Fronds monomorphic, not or indistinctly stipitate; stipes up to $8 \mathrm{~cm}$; lamina, index $\pm 8-20$ or more; widest at or above the middle, $7-45 \times 0.7-3.0$ $\mathrm{cm}$, base gradually narrowed, apex acute to acuminate. Venation: secondary veins distinct, with the tertiary veins forming regular areoles; included veins simple or occasionally forked, free, excurrent. Hydathodes absent or indistinct, scattered over the lamina or in a marginal zone only, pitted or \pm superficial. Anatomy: stipe or lower part of costa with 3-4 central and 0-2 lateral vascular strands; lamina 0.4-0.9 mm thick, upper epidermis with slightly to distinctly projecting cells with thin walls, hypodermis absent but an indistinct water-tissue often present, palissade and spongy parenchyma distinct, lower epidermis with thin to moderately thickened cell-walls; stomata slightly sunken, pericytic. Indument mono- to dimorphic, a sparse to dense mat, fugacious or persistent, brown; upper layer composed of hairs 1.2-3.1 mm in diam., with erecto-patent, acicular rays, \pm mixed with a lower layer composed of hairs with mainly woolly rays, or hairs with woolly rays few or absent. Sori apical to all over the lamina, closely packed to shortly spaced, superticial; $\angle-3$ in a row in each soriferous areole, not confluent; 1-2.5 mm in diam.; developing from the apex downwards, when old individually distinct, immersed in the indument. Sporangia on stalks to $\pm 1 \times$ as long as the capsule, capsule 0.4-0.5 mm high, with 19-21 indurated annulus cells. Paraphyses not differentiated. Spores (66-)71.6-95.5(-102) $\times(44-) 46.2-$ $68.8(-74) \mu \mathrm{m}$, finely granulate.

Habitat: Epiphytic or epilithic, in moist forest ('cloudlands') or near waterfalls or streams.

Altitudinal range: $700-1950 \mathrm{~m}$.

UGANDA. Snowden 787 (B, BM).

MOZAMBIQUE. 11 collections.

MALAWI. Buchanan 28 (K), Last s.n. (1877) (K), s.n. (6-1887) (K), Morris $74(\mathrm{~K})$, Scott Elliot 8523 (BM, K).

ZIMBABWE. 20 collections.

MADAGASCAR. 25 collections. 
Doubtful localities.

RÉUNION. G. Carb s.n., s.d. (P).

Notes. 1. $P$. rhodesiana differs from $P$. porosa mainly in the more elongated, lightly sclerified rhizome. Christensen (1932) was the first to distinguish it from $P$. porosa. He described Cyclophorus rhodesianus simultaneously with two other, similar species ( $C$. madagascariensis and $C$. oblanceolatus). The characters he used to differentiate between the three species can be summarized as follows:

\begin{tabular}{llll}
\hline & madagascariensis & oblancealata & thodesiana \\
\hline indument & dimorphic & \pm monomorphic & \pm dimorphic \\
hydathodes & absent & absent & distinct \\
scales & short-ciliate & entire & ciliate/ \\
& & & short-ciliate
\end{tabular}

Investigation of more material than Christensen had at his disposal gives the following results with regard to the characters used by him:

\begin{tabular}{llll}
\hline & madagascariensis & oblancealata & rhodesiana \\
\hline indument & dimorphic & $\begin{array}{l}\text { mono- to } \\
\pm \text { dimorphic }\end{array}$ & $\begin{array}{l}\text { di- to } \\
\pm \text { monomorphic } \\
\text { hydathodes }\end{array}$ \\
& sparse, & $\begin{array}{l}\text { absent to } \\
\text { indistinct }\end{array}$ & distinct \\
indistinct & $\begin{array}{l}\text { ciliate to } \\
\text { sentes }\end{array}$ & $\begin{array}{l}\text { ciliate to } \\
\text { dentate }\end{array}$ & $\begin{array}{l}\text { ciliate to } \\
\text { dentate }\end{array}$
\end{tabular}

Apart from these characters, the specimens from Madagascar differ from those of the mainland of Africa in having narrower scales (to $\pm 1 \mathrm{~mm}$ wide vs. to 1.6 $\mathrm{mm}$ for specimens from the mainland) with distinct abaxial papillae, especially near the base (specimens from Africa have smoother scales). In my opinion these characters do not support the recognition of 3 separate species.

\section{Pyrrosia rupestris (R. Br.) Ching. Fig. 26.}

Pyrrosia rupestris Ching, Bull. Chin. Bot. Soc. 1 (1935) 49; Tindale, Contr. N.S.W. Herb. Fl. ser. 210 (1961) 32; Jones Clemesha, Austr. Ferns (1976) 256; Hoshizaki, Baileya 21 (1981) 73, fig. 10 B.-Polypodium rupestre R. Br. Prodr. (1810) 146; [non Polypodium rupestre Blume, Enum. Pl. Jav. 2 (1828) 124, nom. illeg., = Crypsinus enervis (Cav.) Copeland]; nec Polypodium rupestre Roxb., Calc. J. Nat. Hist. IV (1844) 488, nom. illeg., = Crypsinus taeniatus (Swartz) Copeland; Mett., Polyp. (1856) 125; Mett., Fil. Lips. (1856) 33, pl. 24 fig. 9, 10; Hooker, Sp. Fil. 5 (1863) 46 p.p. - Niphobolus rupestris Spr., Syst. 4 (1827) 44, Hooker * Grev., Ic. Filic. (1828) pl. 93 p.p.; Link, Hort. Berol. (1833) 111; Presl, Tent. Pter. (1836) 201; J. Sm., Hooker J. Bot. 4 (1842) 57; J. Sm., Cat. Kew Garden Ferns (1846) 12; Presl, Epim. Bot. (1851) 128 p.p.; Fée, Gen. Fil. (1853) 262; Brack., U.S. Expl. Exp. (1854) 36 p.p.; J. Sm., Cat. Cult. Ferns (1857) 12; T. Moore, Ind. Fil. (1857) lxxvi; J. Sm., Hist. Fil. (1875) 98; J. Sm., Ferns Br. \& For. ed. 2 (1877) 100; Giesenh., Niphobolus (1901) 170, 220, 223. - Craspedaria rupestris Link, Fil. Sp. 
(1841) 118; Presl, Epim. Bot. (1851) add., 262.-Cyclophorus rupestris C. Chr., Ind. Fil. (1906) 200; Alderwerelt, Malayan Ferns (1909) 780; Christ, Geogr. der Farne (1910) 113; Goy, Queensl. Nat. 10 (1937) 46, pl. 4.-Cyclophorus serpens var. rupestris Domin, Bibl. Bot. 85 (1914) 187. - Type: Robert Brown s.n., s.d. (holo BM, iso K, B, P), Australia, Port Jackson.

Niphobolus cuneatus Kuhn, Bot. Zeit, 26 (1868) 40; Diels in E. P., Nat. Pfl. Fam. 1,4 (1899) 325; Morton, Amer. Fern J. 61 (1971) 94.-Cyclophorus cuneatus C. Chr., Ind. Fil. (1906) 198.Type: Hohenacker $5(\mathrm{~B}, \mathrm{~K}, \mathrm{P})$, Ecuador, see note 3 .

Polypodium serpens et syn. homot., auct. non G. Forster, quoad specim. Austr.: F. v. Muell., Fragm. 5 (1866) 129; Baker in Hooker * Baker, Syn. Fil. (1867) 349; Benth., Fl. Austr. (1878) 767 p.p.; F.M. Bailey, Cat. Pl. Queensl. (1890) 60; F.M. Bailey, Lith. Ferns (1892) 151; Diels in E. a P., Nat. Pfl. Fam. 1,4 (1899) 325, fig. 168 A.

Rhizome long-creeping, narrowly grooved ventrally, 0.5-1.3 mm thick, phyllopodia $0.5-2.5 \mathrm{~cm}$ apart, lateral buds situated more than halfway down the internodia. Anatomy: ground tissue parenchymatous, sclerenchyma sheath distinct, sclerenchyma strands scattered through the inner parenchyma, 0-5; vascular strands 5-6. Scales peltate, 3.7-7.5 $\times 0.4-1.1 \mathrm{~mm}$; base entire, with up to 4 marginal glands; acumen light brown, entire to denticulate. Fronds distinctly dimorphic, distinctly to indistinctly stipitate. Fertile fronds: stipes $0.2-5(11) \mathrm{cm}$, to $\pm 1 \times$ as long as the lamina, rarely longer; lamina, index $2- \pm 20$; widest at or above the middle, $1.3-11 \times 0.3-1 \mathrm{~cm}$, base gradually narrowed, apex acute to narrowly rounded. Sterile fronds: stipes to $2(-6) \mathrm{cm}$, to $1 \times$ as long as the lamina or rarely longer; lamina, index 1-5(-15); widest shortly above or occasionally \pm at the base, $0.5-7 \times 0.4-1.5 \mathrm{~cm}$, base cuneate to attenuate, occasionally cordatetruncate, apex widely obtuse or rounded. Venation: secondary veins indistinct, with the tertiary veins forming \pm irregular areoles; included veins few, simple, excurrent, free. Hydathodes distinct, in a single marginal row, slightly sunken. Anatomy: stipe or lower part of costa with \pm 2 central and no lateral vascular strands; lamina 1-1.3 mm thick, upper epidermis with distinctly projecting cells with thin to moderately thickened walls, hypodermis absent but an indistinct, moderately thick water-tissue present, palissade and spongy parenchyma indistinct, lower epidermis with moderately thickened cell-walls; stomata sunken, pericytic. Indument monomorphic, a dense mat, fugacious or persistent, whitish to light brown; hairs $0.3-0.9 \mathrm{~mm}$ in diam., with appressed, boat-shaped to \pm acicular rays. Sori apical to all over the lamina, shortly spaced, slightly sunken; z-3 in each soriferous areole, occasionally confluent; 1-2.5 mm wide, often elongated longitudinally; developing from the apex downwards, when old individually distinct, exserted from the indument. Sporangia on stalks $1 \frac{1}{2}-2$ $1 / 2 \times$ as long as the capsule, capsule $\pm 0.3 \mathrm{~mm}$ high, with $16-21$ indurated annulus cells. Paraphyses mixed with the sporangia, with short, straight rays. Spores $(66-) 75.2-82.4(-96) \times(48-) 53.2-58.4(-66) \mu \mathrm{m}$, bisculptate.

Habitat: Epilithic, on basalt, granite or sandstone; also on trees and logs; in rainforest and on mountain tops.

Altitudinal range: Low altitudes to $1150 \mathrm{~m}$. 
AUSTRALIA. Queensland: 28 collections. - New South Wales: 34 collections. - Victoria: Pescott s.n. (2-1901) (P, US).

Doubtful localities.

NEW ZEALAND. Day s.n. (1879) (P), Helms s.n. (16-12-1884) (B, P), Mossman 627 (B, P).

Notes. 1. $P$. rupestris often has characteristically angular, rhomboid sterile fronds, but orbicular sterile fronds also occur.

$P$. rupestris has been confused with $P$. eleagnifolia. It can most easily be distinguished from that species by the presence of a marginal row of hydathodes, which is completely absent in $P$. eleagnifolia. The hydathodes are best observed near the apices of the sterile fronds, but it may be necessary to remove some of the indument. Occasionally a few hydathodes occur scattered over the lamina. In the rhizome scales annular structures similar to those found in $P$. confluens are sometimes present.

2. $P$. rupestris is restricted to the mainland of Australia. A few collections are labelled as coming from New Zealand. It seems to me less likely that $P$. rupestris is native to New Zealand in a few scattered localities than that a few labels have been accidentally changed for those of $P$. eleagnifolia, which is common in New Zealand and which has long been confused with $P$. rupestris.

3. Niphobolus cuneatus is certainly conspecific with $P$. rupestris. It is hardly possible that $P$. rupestris occurs in Ecuador and it has not been found there since Hohenacker; it is more likely that some of Hohenacker's labels have become mixed (see also Morton, l.c.).

\section{Pyrrosia samarensis (Presl) Ching. Fig. 24.}

Pyrrosia samarensis Ching, Bull. Chin. Bot. Soc. 1 (1935) 49; Holttum, Nov. Bot. Inst. Bot. Univ. Car. Prag. (1968) 34; Price, Phil. J. Biol. 2 (1973) 110; Hoshizaki, Baileya 21 (1981) 73, fig. 12; Shing, Amer. Fern J. 73 (1983) 77. - Gyrosorium samarense Presl, Epim. Bot. (1851) 140. - Niphobolus samarensis Fée, Gen. Fil. (1853) 263; T. Moore, Ind. Fil. (1857) lxxvi; Giesenh., Niphobolus (1901) 191; Copeland, Polyp. Philipp. (1905) 115.-Polypodium samarense Mett., Polyp. (1856) 123, pl. 3 fig. 1-4; Hooker, Sp. Fil. 5 (1863) 45; Baker in Hooker \& Baker, Syn. Fil. (1867) 356; Christ, Bull. Herb. B oiss. 6 (1898) 199; Christ, Bull. Herb. Boiss. II, 6 (1906) 991.-Cyclophorus samarensis C. Chr., Ind. Fil. (1906) 200; Alderwerelt, Malayan Ferns (1909) 691. - Ty pe: Cuming 323 (holo PRC, teste Holttum, l.c.; iso in B, BM, K, P), Samar.

Cyclophorus argyrolepis Christ, Bull. Herb. Boiss. II, 6 (1906) 991; Alderwerelt, Malayan Ferns (1909) 694; C. Chr., Ind. Fil., Suppl. 3 (1934) 22.-Ty pe: Loher s.n. (III-06)(P), Luzon, Rizal, Macabal.

Pyrrosia philippinensis Copeland, Phil. J. Sc. 81 (1952) 43, nom. superfl.; Copeland, Fern Fl. Philipp. (1960) 471; Holttum, Nov. Bot. Inst. Bot. Univ. Car. Prag. (1968) 34.-T y pe: Ramos 946 । M, U, US, Z), Luzon.

Rhizome long-creeping, shallowly grooved ventrally, $1.5-3 \mathrm{~mm}$ thick, phyllopodia (1.5-)3-6 cm apart, lateral buds situated \pm halfway down the internodia. Anatomy: ground tissue parenchymatous, sclerenchyma sheath distinct, sclerenchyma strands situated peripherally in the inner parenchyma, \pm 15 , vascular strands \pm 10 . Scales peltate, $7-8 \times 0.6-0.9 \mathrm{~mm}$; base entire; acumen hyaline, entire. Fronds dimorphic, stipitate. Fertile fronds: stipes $1-6 \mathrm{~cm}$, to 
$1 / 6(-1 / 4) \times$ as long as the lamina; lamina widest in the basal, sterile part, the apical, fertile, part contracted into a \pm distinct, narrow spike; $17-37 \times 0.8-2.2$ $\mathrm{cm}$, base cuneate to attenuate, apex acute. Sterile fronds: stipes $1-9 \mathrm{~cm}$, to almost $1 / 2 \times$ as long as the lamina; lamina, index $\pm 10-20$; widest below the middle, 13.5-42 $\times 1.4-4 \mathrm{~cm}$; otherwise similar to the basal, sterile part of the fertile fronds. Venation: secondary veins distinct, with the tertiary veins forming regular areoles; included veins frequently forked, occasionally more copiously branched, frequently anastomosing; free veins many, mainly excurrent. Hydathodes absent. Anatomy: stipe with \pm 4 central and no lateral vascular strands; lamina 0.5-1.0 mm thick, upper epidermis with flat cells with thickened walls, hypodermis absent or indistinct, water-tissue distinct, moderately thick, palissade and spongy parenchyma distinct, lower epidermis with moderately thickened cell-walls; stomata sunken, pericytic. Indument dimorphic, a dense mat, persistent, dirty whitish, the upper layer often brown; upper layer usually sparse, composed of hairs $1-1.6(-2.0) \mathrm{mm}$ in diam., with erecto-patent, acicular rays, separate from a lower layer composed of hairs with mainly woolly rays. Coenosorus apical, sometimes extending downwards almost to the base of the lamina, superficial, medial between costa and margin, occasionally interrupted below, rarely so at both ends; 2-4 $\mathrm{mm}$ wide, ripening from the apex downwards. Sporangia on stalks $1 \frac{1}{2-2} 2^{1 / 2} \times$ as long as the capsule, capsule 0.3-0.4 mm high, with 1421 indurated annulus cells. Paraphyses mixed with the sporangia, inconspicuous, with short, straight rays. Spores (70-)77.2-83.2(-88) $\times(46-) 49.8-58.6(-64) \mu \mathrm{m}$, with longitudinal ridges.

Habitat: Epiphytic, in forest or logged-over areas. Altitudinal range: Low altitudes to $750 \mathrm{~m}$.

PHILIPPINES. Samar: 7 collections. - Panay: Martellino \& Edaño BS 35278 (US), BS 35626 (P), Ramos \& Edaño BS 31375 (P, US), BS 31467 (P, US). - Mindoro: Edaño PNH 3877 (BR), McGregor 255 (B, K, P, US), Merrill 5996 (P). - Luzon: 7 collections. - Catanduanes: Ramos BS 30259 (BO, US). - Mindanao: San Carlos Univ. 750 (L), Weber 1181 (GH, K, P, US, Z).

Notes. 1. $P$. samarensis shows a peculiar form of frond-dimorphism. Fertile fronds differ from sterile ones only in the presence of an apical spike (not unlike the apical spike of species of Belvisia) and in a slight difference in size. The coenosorus takes up the whole width of the lamina in this apical part. The basal part of fertile fronds is expanded and similar in shape to a sterile frond and probably corresponds morphogenetically to a sterile frond; sterile fronds probably being derived from fertile ones by the arrestment of the apical development. The lamina may be abruptly constricted into the apical spike (e.g., Ramos \& Edaño 31467 ) or the transition may be more gradual (Madulid et al. 858).

Fully sterile fronds appear to be rare, and were present in only a few of the specimens studied. Most of the fully sterile fronds are conspicuously larger than fertile ones of other collections; collections with both fertile and sterile fronds are 
few. A reliable evaluation of the morphological difference and co-occurrence between sterile and fertile fronds is especially difficult because of the following factors:

- The apical fertile part develops only after the basal sterile part of the lamina is fully expanded; the absence of a fertile part on a developing frond is therefore no indication that the frond is a sterile one. It might not yet have become fertile at the time of collecting.

- The apical fertile spike is apparently fragile as in many collections it is broken off somewhere. All fronds with a damaged apex therefore could have been fertile ones.

Even after considering this, there appears to be a tendency for sterile fronds to be distinctly larger than the corresponding basal part of fertile fronds. This may be an indication that in this species luxurious vegetative growth in some way inhibits the formation of sori.

2. Apart from the presence of a coenosorus (which may be interrupted for some or all of its length) the following characters distinguish $P$. samarensis from $P$. angustata:

- The indument is more distinctly differentiated into an upper layer with acicular rays only and a lower layer with woolly rays; in $P$. angustata these two layers merge more gradually.

- The fertile part of the lamina is more strongly contracted than in $P$. angustata.

3. According to Copeland (1960), Presl's name Gyrosorium samarense cannot be applied to the present species, as it refers to a species more similar to $P$. lanceolata. Holttum (1968), however, pointed out that the type specimen in PRC is $\boldsymbol{P}$. samarensis. Moreover, Presl's description seems unambiguous to me and certainly not applicable to $P$. longifolia or $P$. lanceolata, but only to a plant of $P$. samarensis with an interrupted coenosorus. Copeland's name Pyrrosia philippinensis is superfluous.

4. P. samarensis has occasionally been confused with Diblemma samarensis J. Sm., which is based on Cuming 332.

5. See Christensen (1937) for a discussion of Acrostichum bicolor Cav. (=P. longifolia).

\section{Pyrrosia schimperiana (Kuhn) Alston. Fig. 16.}

Rhizome shortly elongated, not grooved ventrally, 1-3 mm thick, phyllopodia $0.2-1.5 \mathrm{~cm}$ apart, lateral buds situated on the phyllopodia. Anatomy: ground tissue parenchymatous, sclerenchyma sheath and sclerenchyma strands absent; vascular strands 6-12. Scales pseudopeltate, 2.1-8 $\times 0.9-1.9 \mathrm{~mm}$; base entire, with 1-7 marginal glands; acumen dull light brown, entire. Fronds monomorphic, sessile; index 7 to over 20; widest at or above the middle, $5-40 \times 0.1-2.5 \mathrm{~cm}$, base gradually narrowed, apex acute to narrowly acuminate. Venation: secondary 
veins not distinct, with the tertiary veins forming irregular areoles; included veins copiously branched and anastomosing; free veins many, pointing to all directions. Hydathodes distinct, scattered over the lamina or in a marginal zone only. Anatomy: lower part of costa with \pm 4 central and \pm 6 lateral vascular strands; lamina $\pm 0.5 \mathrm{~mm}$ thick, upper epidermis with distinctly projecting cells with thin walls, hypodermis and water-tissue absent, palissade and spongy parenchyma distinct, lower epidermis with thin cell-walls; stomata slightly sunken, polocytic. Indument monomorphic, a dense mat, persistent, white to light brown; hairs 0.3$0.9 \mathrm{~mm}$ in diam., with appressed, boat-shaped rays. Sori apical or all over the lamina, in an ull-detıned patch, closely packed, superficial; several scattered throughout each soriferous areole, occasionally confluent along the veins; 1-2 $\mathrm{mm}$ in diam.; developing from the apex downwards, when old individually distinct, \pm exserted from the indument. Sporangia on stalks $1 / 2-1 \times$ as long as the capsule, capsule $\pm 0.3 \mathrm{~mm}$ high, with $13-15$ indurated annulus cells. Paraphyses not differentiated. Spores (52-)64.6-73.8(-78) $\times(34-) 40.0-47.2(-50)$ $\mu \mathrm{m}$, densely verrucate.

Key to the varieties

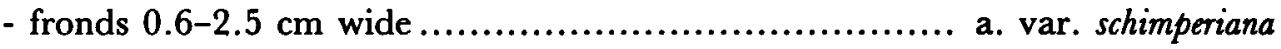

- fronds gramineous, 0.1-0.2 cm wide ....................... b. var. liebuschii

\section{a. var. schimperiana}

Pyrrosia schimperiana Alston, J. Bot. London 72, suppl. (1934) 8; Schelpe, J. S. Afr. Bot. 18 (1952) 128; Schelpe, Fl. Zambes. (1970) 147, pl. 45 fig. A1, A2; Vorster, Bothalia 11 (1974) 287; Gill * Mwasumbi, Nova Hedw. 27 (1976) 943; Schelpe Diniz, Fl. Moçamb. (1979) 150; Jacobsen, Ferns and Fern All. S. Africa (1983) 304, fig. 220, map 91.-Polypodium schimperianum Mett. ex Kùhn, Fil. Afr., (1868) 152; Hieron., Bot. Jb. 46 (1911) 395.-Niphobolus schimperianus Giesenh. ex Diels in E. P., Nat. Pfl. Fam. 1,4 (1899) 325; Giesenh., Niphobolus (1901) 111; Engl., Veg. d. Erde 9,2 (1908) 55. - Cyclophonus schimperianus C. Chr., Ind. Fil. (1906) 200; Christ, Geogr. der Farne (1910) 112. - Lectotype (Schelpe, 1952): Schimper 1441 (holo B, iso BR, P), Ethiopia.

Cyclophorus mechowii Brause Hieron. ex Hieron., Bot. Jb. 46 (1911) 395; C. Chr., Ind. Fil. Suppl. (1913) 22.-Niphobolus mechowii Brause * Hieron., Engl. Veg. d. Erde 9,2 (1908) 55, nom. nud. - Pyrrosia schimperiana var. mechowii Schelpe, J. S. Afr. Bot. 18 (1952) 129. - Pyrrosia mechowii Alston in Mendonça, Estud. Ens. Doc. Junta Invest. Ultramar. 12 (1954) 37; Alston, Ferns W. Trop. fr. (1959) 46.-Lectotype: Theusz 32 (B), Angola, see note 3.

Rhizome $1.5-3 \mathrm{~mm}$ thick, phyllopodia $0.5-1.5 \mathrm{~cm}$ apart. Anatomy: vascular strands 6-12. Scales 2.8-8 $\times 0.9-1.9 \mathrm{~mm}$; base with 1-7 marginal glands. Fronds; index 7- \pm over 20 ; widest at or above the middle, $11-40 \times 0.6-2.5 \mathrm{~cm}$. Hydathodes scattered over the lamina or in a marginal zone only. Indument; hairs 0.3-0.9 $\mathrm{mm}$ in diam. Sori apical.

Habitat: Mainly epiphytic, on trunks and branches, on a large variety of host trees (e.g., Ficus spp., Mimusops sylvestris, Entandrophragma utile, Coffea), most frequently in forest or in gallery forest, also in wooded savannas, gardens, or in 
degraded forest; also epilithic, on mossy rocks, in crevices, etc.; occasionally terrestrial; once reported growing on a termite hill.

Altitudinal range: $200-2000 \mathrm{~m}$, reported from $4200 \mathrm{~m}$ on Mt. Kenya ("above the giant heath zone", Mearns 1626), but this needs confirmation.

GUINEE. Schnell 5040 (K, P).

LIBERIA. Johansson $808(\mathrm{~K})$.

TOGO. Seku * Bowling GC 37092 (K).

NIGERIA. Hepburn 95 (K).

CAMEROON. 19 collections.

CENTRAL AFRICAN REPUBLIC. 8 collections.

ZAIRE. 18 collections.

BURUNDI. Caljon 2169 (Z), Lewalle 4343 (BR, U), 5323 (BR), 6470 (BR).

SUDAN. Sillitoe $115(\mathrm{~K})$.

ETHIOPIA. 24 collections.

UGANDA. 17 collections.

KENYA. 13 collections.

TANZANIA. Polhill \& Paulo 1673 (B, K), Schlieben 1600 (B, BR, M, P, Z), Stolz 1507 (B, BM, M, Z).

MOZAMBIQUE. 10 collections.

MALAWI. Gomes \& Sousa 1285 (BM).

ZAMBIA. 6 collections.

ZIMBABWE. 8 collections.

ANGOLA. 6 collections.

Notes. 1. The ripe sori stand out conspicuously against the light background of the indument. The contrast is particularly striking as the sori are more blackish than is usual in Pyrrosia; this is due to a modification of the one or two cells of the indurated annulus closest to the stoma. These cells are very dark and slightly swollen, and are often longitudinally divided as well and therefore bulge sideways. These modified annulus cells I have found only in $r$. schimperiana var. schimberiana and in var. liebuschii.

2. According to Prof. Dr. J. Kornaś (comm. Edinburgh, 1983) P. schimperiana behaves like a 'resurrection fern': the fronds dry out in dry weather but are able to resume metabolic activity soon after rain.

3. Although Schelpe (1952: 130) cites Mann 788 as lectotype of Cyclophorus mechowii, this specimen could not be located in B. Another specimen, however, has been annotated as a lectotype by Schelpe in 1959 and this selection has been followed here.

\section{b. var. liebuschii (Hieron.) Hovenkamp}

Pyrrosia schimperiana (Mett. ex Kuhn) Alston var. liebuschii Hovenkamp, Blumea 30 (1984) 208. Cyclophorus liebuschii Hieron., Bot. Jb. 46 (1911) 398; C. Chr., Ind. Fil. Suppl. (1913) 22.Niphobolus liebuschii Peter, Fedde's Rep. Beih. 40 (1938) 32.- Pyrrosia liebuschii Schelpe, J. S. Afr. Bot. 18 (1952) 131; Gill \& Mwasumbi, Nova Hedw. 27 (1976) 943.-Lectotype (Schelpe, 1952): Libusch s.n. (1900) (holo B), Tanzania, Lutindi.

Rhizome 1-1.8 mm thick, phyllopodia $0.2-0.5 \mathrm{~cm}$ apart. Anatomy: vascular strands 6-7. Scales 2.1-3.5 $\times$ 0.9-1.3 mm; base with 1-5 marginal glands. Fronds 
linear, 5-21 $\times 0.1-0.2 \mathrm{~cm}$. Hydathodes in a single row. Indument; hairs 0.3-0.5 $\mathrm{mm}$ in diam. Sori all over the lamina.

Habitat: Almost exclusively epiphytic, on trunks and branches in more or less open forest or along roadsides; sometimes on mossy rocks.

Altitudinal range: 500-1200 m.

TANZANIA. 18 collections, all from the Usambara mountains.

\section{Pyrrosia serpens (G. Forster) Ching. Fig. 26.}

Pymosia setpens Ching, Bull. Chin. Bot. Soc. 1 (1935) 49, q.n.s.; Allan, Fl. N. Zeal. 1 (1961) 44, q.n.s.; Sykes, Kermadec I. Flora (1977), q.n.s.-Polypodium serpens G. Forster, Prodr. (1786) 81; [non Polypodium serpens Swartz, Prodr. (1788) 131, nom. illeg., - Microgramma heterophylla L.]; Baker in Hooker \& Baker, Syn. Fil. (1867) 349 p.p.; Drake, Fl. Polyn. fr. (1893) 312. Polypodium stoloniferum Gmelin, Syst. Nat. 2 (1791) 1305, nom. superfl. - Polypodium stellatum Vahl, Symb. 3 (1794) 104, nom. superfl.; Swartz, Syn. Fil. (1806) 25; Schkuhr, Krypt. Gew. 1 (1809) 10, pl. 8 fig. 1; Willd., Sp. Pl. 5 (1810) 151. - Niphobolus bicolor Kaulf., Enum. (1824) 128, nom. superfl. - Niphobolus serpens Endl., Prodr. Norf. (1833) 8, q.n.s.; Cunn., Hooker Comp. Bot. Mag. 2 (1836) 363; Keyserl., Polyp. Herb. Bunge (1873) 38; Carr., Seem. Fiji Ferns (1873) 367; J. Sm., Hist. Fil. (1875) 98; Giesenh., Niphobolus (1901) 170, 219, 223, q.n.s. - Polypodium bicolor Mett., Polyp. (1856) 125, nom. superfl., p.p.-Craspedaria serpens Presl, Epim. Bot. (1851) 263 p.p. - Cyclophorus serpens C. Chr., Ind. Fil. (1906) 201.-Cyclophorus serpens var. normalis Domin, Bibl. Bot. 85 (1914) 187, nom. inval.-Pyrrosia bicolor Ching, Bull. Chin. Bot. Soc. 1 (1935) 49, nom. superfl. - Lectotype: Forster s.n., s.d. (holo BM, iso B, M), 'New Zealand'.

Niphobolus macrocarpus Hooker \& Arnott, Bot. Beech. Voy. (1832) 74, pl. 18.-Pleopeltis macrosora Presl, Epim. Bot. (1851) 125-6. - Drynaria macrosora Fée, Gen. Fil. (1853) 270, nom. superfl.Cyclophorus macrocarpus Copeland, Univ. Cal. Publ. Bot. 12 (1931) 381; Copeland, B. P. Bish. Mus. Bull. 93 (1932) 66.-Pyrrosia macrocarpa Shing, Amer. Fern J. 73 (1983) 78.-Type: Beechey s.n., s.d. (K), Society Islands, 'Coral Island'.

Polypodium tricholepis Mett. ex Kuhn, Linnaea 36 (1869) 139, nom. illeg.; [non Polypodium tricholepis Schrad., Gött. Gel. Anz. (1824) 867, = Polypodium lepidopteris Kunze]; -Niphobolus tricholepis Carr., Seem. Fiji Ferns (1873) 367; Giesenh., Niphobolus (1901) 175, 220.-Cyclophorus blepharolepis C. Chr., Ind. Fil. (1906) 198, nom. superfl.; Copeland, B. P. Bish. Mus. Bull. 93 (1932) 65.-Pyrrosia blepharolepis Ching, Bull. Chin. Bot. Soc. 1 (1935) 49, nom. superfl.; Brownlie, Fl. Fiji (1977) 366.-Pyrrosia tricholepis Ching, Acta Phytotax. Sin. 10 (1965) 301. Lect o ty pe: Jelineck 152 (B), Society Islands.

Rhizome long-creeping, occasionally grooved ventrally, 1-1.4 mm thick, phyllopodia $1.5-3(-4) \mathrm{cm}$ apart, lateral buds situated more than halfway down the internodia. Anatomy: ground tissue parenchymatous, sclerenchyma sheath distinct, sclerenchyma strands absent; vascular strands (4) 5. Scales peltate, 1.9$3.4 \times 0.8-1.0 \mathrm{~mm}$; base entire to dentate, occasionally with a marginal gland; acumen light brown with a distinct light margin, ciliate. Fronds moderately dimorphic, stipitate. Fertile fronds: stipes $1-5 \mathrm{~cm}, \pm 1 / 10-1 / 2 \times$ as long as the lamina; lamina, index \pm 6 -over 20; widest about or above the middle, 4.5-23 $\times 0.6-1.9$ $\mathrm{cm}$, base narrowly attenuate, apex obtuse to rounded. Sterile fronds: stipes $0.5-3$ $\mathrm{cm}, 1 / 10-1 / 3 \times$ as long as the lamina; lamina, index $3-12,3-14.5 \times 0.8-2.2 \mathrm{~cm}$, base cuneate to attenuate, apex obtuse to widely rounded; otherwise similar to 
the fertile ones. Venation: secondary veins little distinct, with the tertiary veins forming \pm regular areoles; included veins simple, free or anastomosing; free veins few, excurrent. Hydathodes absent or indistinct, in a marginal row, slightly sunken. Anatomy: stipe with $\pm \mathbf{3}$ central and no lateral vascular strands; lamina 0.5-1.4 mm thick, upper epidermis with flat to slightly projecting cells with moderately thickened walls, hypodermis absent or indistinct, water-tissue indistinct, moderately thick, palissade and spongy parenchyma indistinct, lower epidermis with moderately thickened cell-walls; stomata sunken, pericytic. Indument monomorphic, a thin to \pm dense mat, persistent, sometimes fugacious, whitish to light brown; hairs $0.4-0.9 \mathrm{~mm}$ in diam., with appressed, \pm boatshaped rays. Sori apical to all over the lamina, in $1-2$ rows on each side of the costa, spaced, usually distinctly sunken; 1-2 in each soriferous areole, often more or less confluent; $1.5-4 \mathrm{~mm}$ wide, often elongated longitudinally or \pm obliquely; developing from the apex downwards, when old individually distinct, exserted from the indument. Sporangia on stalks $1-1 / 2 \times$ as long as the capsule, capsule 0.3-0.4 mm high, with 16-21 indurated annulus cells. Paraphyses mixed with the sporangia, with short, straight rays. Spores $(66-) 74.8-101.4(-110) \times(50-) 57.6-$ 67.6(-74) $\mu \mathrm{m}$, bisculptate.

Habitat: Epiphytic, in forests, thickets, often on Hibiscus, mainly in valleys; sometimes epilithic, on mossy rocks. Apparently common or abundant at most of its stations.

Altitudinal range: Sea level to $\pm 900 \mathrm{~m}$.

NORFOLK ISLAND. Hügel s.n., s.d. (M).

FIJI ISLANDS. Viti Levu: Parks 20511 (BM, GH, K, M, US), A.C. Smith 5384 (K, L, US), $6052(\mathrm{~K}, \mathrm{~L})$.

SOCIETY ISLANDS. Tahiti: 27 collections. - Raiatea: Moore 61 (L, U). - Borabora: d'Urville 48 (B, P). - Moorea: H. M. Smith 11 (A, US). - Huahine: St. John 17182 (BISH, GH). COOK ISLANDS. Rarotonga: 10 collections. - Mangaia: Gill 13 (K).

AUSTRAL ISLANDS. Tubuai: St. John 16055 (BO, US). - Raivavae: St. John \& Fosberg 15828 (BO, US). - Rurutu: St. John \& Fosberg 16556 (BO, K, US). - Rapa: St. John \& Maireau 15345 (BO).

GAMBIER ISLANDS. Mangareva: Le Guillou s.n. (1841) (P), Hombron 19 (P), St. John 14455 (BO, US), Zimmermann s.n. (4-6-1934) (K).

PITCAIRN ISLAND. Belt s.n. (1875) (BM), Chanter s.n. (1855) (K), Matthews 13 (K).

HENDERSON ISLAND. St. John * Fosberg 15154 (BO, US).

Doubtful localities.

EASTER ISLAND. Mission Franco-Belge de l'Île de Pâques s.n. (1935) (P), see note.

Notes. 1 . The name $P$. serpens has been used widely for $P$. eleagnifolia. The confusion is caused by a probably erroneous location given by Forster. Although the locality given for the type of Polypodium serpens is New Zealand, the specimen concerned is definitely not conspecific with the New Zealand species. It most likely was collected on one of the Pacific Islands that Forster visited. A similar mistake was probably made in labelling the type specimen of Polypodium acrostichoides 
Forster (see under $P$. longifolia). $P$. serpens has been known under the names $P$. tricholepis and $P$. blepharolepis, these are antedated by $P$. serpens.

2. $P$. serpens is similar to $P$. confluens. The differences between the two species are as follows:

\begin{tabular}{ll}
\hline$P$. serpens & $P$. confluens \\
\hline $\begin{array}{l}\text { hydathodes absent or situated } \\
\text { on the extreme margin or } \\
\text { slightly adaxially }\end{array}$ & $\begin{array}{l}\text { hydathodes always present, } \\
\text { situated distinctly abaxially }\end{array}$ \\
$\begin{array}{l}\text { sori distinctly sunken, often } \\
\text { slightly protruding on the }\end{array}$ & sori superficial \\
$\begin{array}{l}\text { upper surface } \\
\text { a weakly developed second row } \\
\text { of sori between costa and } \\
\text { margin usually present }\end{array}$ & sori strictly uniseriate \\
\end{tabular}

3. Variability: Large forms with a single row of sori, and without or with indistinct hydathodes, occur mainly on Cook Island (e.g., Parks \& Parks 22098, Garrett, s.n., s.d.) and on the Austral Islands (e.g., St. Iohn \& Fosberg 15828). They have been separated as $P$. macrocarpa and have occasionally been confused with $P$. angustata, which is, however, only superficially similar.

smaller torms, with smaller sori, often situated in two rows, occur mainly on the Society Islands and on Fiji (e.g., Van Balgooy 1915, H. Moore 252, Parks 20511, Smith 5384).

No sharp distinction can be made between the two forms.

4. The rhizome scales occasionally have annular figures in the cells similar to those found in $P$. confluens.

5. There is some confusion as to whether $P$. serpens extends eastwards to Easter Island: in $\mathrm{P}$ there is a specimen labelled ' Mission Franco-Belge de l'île de Pâques', in a folder marked 'Pitcairn'; see also Tardieu-Blot, Bull.Mus. Nat. Hist. II, 8 (1936) 556. In Christensen \& Skottsberg's list of the ferns of Easter Island (C.Chr. Skottsb., Nat. Hist. of Juan Fernandez and Easter I. 2 (1920) 47-53) no Pyrrosia species are reported. I have seen no other specimens from Easter Island, and it seems likely that the specimen concerned has been mislabelled.

\section{Pyrrosia sheareri (Baker) Ching. Fig. 19.}

Pyrrosia sheareri Ching, Bull. Chin. Bot. Soc. 1 (1935) 64; Ching, Ic. Fil. Sin. (1935) pl. 147; C. Chr. Tard., Not. Syst. 8 (1939) 206; Tard. \& C. Chr., Fl. Indo-Ch. (1941) 509; Tagawa, J. Jap. Bot. 24 (1949) 116; Steward, Man. Vasc. Pl. L. Yangtze (1958) 53; Fu, Ill. Imp. Chin. Pl. (1957) 239, fig. 322; DeVol, Fl. Taiwan 1 (1975) 208.-Polypodium sheareri Baker, J. Bot. Lond. 13 (1875) 201; Baker, Ann. Bot., Lond. 5 (1891) 472; Baroni * Christ, Nu. Giorn. Bot. It. n.s. 4 (1897) 95. - Niphobolus sheareri Diels in E. \&., Nat. Pfl. Fam. 1,4 (1899) 325; Diels, Bot. Jb. 29 (1900) 207; Christ, Bull. Soc. Fr. 52 Mém. 1 (1905) 26. -Cyclophorus sheareri C. 
Chr., Ind. Fil. (1906) 201; C. Chr., Acta Horti Gothob. 1 (1924) 105.-Ty pe: Shearer 282 (holo K), China.

Niphobolus inaequalis Christ, Bull. Soc. Fr. 52 Mém. 1 (1905) 25; Christ, Bull. Acad. int. Géogr.

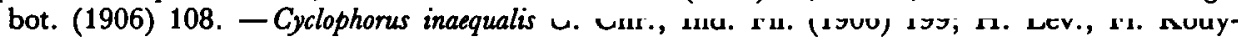

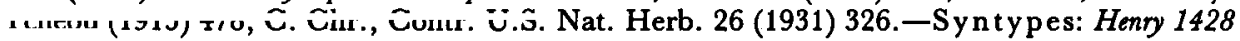
(K, P); Delavay 4954 (P), China.

Cyclophorus grandissimus Hayata, Ic. Pl. Form. 4 (1914) 255, fig. 179; C. Chr., Ind. Fil. Suppl. 3 (1934) 10. - Pyrrosia grandissima Ching, Bull. Chin. Bot. Soc. 1 (1935) 63; Tagawa, J. Jap. Bot. 24 (1949) 116.-Type: Hayata Sasakii s.n., (Jan. 1912) (TI, not seen, photograph Z), Taiwan, 'Mt. Arisan'.

? Cyclophorus drakeanus fo. maxima Wu et al., Bull. Dep. Biol. Sun Yatsen Univ. 3 (1932) 338, pl. 140.-Cyclophorus sheareri fo. maxima C. Chr., Bull. Dep. Biol. Sun Yatsen Univ. 6 (1933) 18.Type: Sin 438 (not seen), China.

Pyrrosia nanchuanensis Ching, Bull. Chin. Bot. Soc. 1 (1935) 65.-Syntypes: W. P. Fang 4539 (K, E), 51335 (not seen), 5727

Rhizome short (rarely shortly elongated), not grooved ventrally, 2.4-7 mm thick, phyllopodia contiguous, rarely $0.5 \mathrm{~cm}$ apart, lateral buds situated on the phyllopodia. Anatomy: ground tissue parenchymatous, sclerenchyma sheath distinct, sclerenchyma strands scattered through the inner parenchyma, many; vascular strands \pm 6 . Scales pseudopeltate, $2.7-4.7 \times 0.7-1.2 \mathrm{~mm}$; dull brown to blackish, ciliate. Fronds monomorphic, stipitate, stipes $9-40 \mathrm{~cm}, 1 / 2-1 \times$ as long as the lamina; lamina, index 3-10; widest near the base, $16-50 \times 2.3-8.5 \mathrm{~cm}$, base cordate-truncate to \pm cuneate, often unequal, apex acuminate. Venation: secondary veins distinct, with the tertiary veins forming regular areoles; included veins simple, forked or occasionally more copiously branched; free veins many, mainly excurrent. Hydathodes distinct, scattered over the lamina, \pm distinctly pitted. Anatomy: stipe with \pm 7 central and \pm 3 lateral vascular strands; lamina $\pm 0.6 \mathrm{~mm}$ thick, upper epidermis with slightly projecting cells with moderately thickened walls, hypodermis composed of 1-2 cell-layers, water-tissue absent, palissade and spongy parenchyma distinct, lower epidermis with thin cell-walls; stomata superficial. pericvtic. Indument monomorphic, a dense mat, persistent, brown to greyish-brown; hairs $0.3-0.5(-1.0) \mathrm{mm}$ in diam., with appressed, boatshaped rays. Sori covering the lamina or in an ill-detıned, irregularly shaped patch, closely packed, superficial; many scattered throughout each soriferous areole, occasionally confluent along the veins; $0.5-1.0 \mathrm{~mm}$ in diam.; developing from the apex downwards, when old individually distinct, exserted from the indument. Sporangia on stalks to $1 / 2 \times$ as long as the capsule, capsule $0.3-0.4 \mathrm{~mm}$ high, with 17-19 indurated annulus cells. Paraphyses not differentiated. Spores $(62-) 68.4-73.2(-80) \times(38-) 43.6-46.2(-52) \mu \mathrm{m}$, finely and densely granulate.

Habitat: Epilithic, on rocks and cliffs; less often epiphytic, mainly in forests, rarely in open places.

Altitudinal range: 500-2000 m, where sympatric with $P$. drakeana usually at lower altitudes than the latter.

CHINA. Hupeh: 6 collections. - Szechuan: 10 collections. - Kweichow: 11 collections. Yunnan: 16 collections. - Anhwei: Ching 8845 (K, US), 8910 (US), Fan \& Li 107 (K, US). - 
Chekiang: 7 collections. - Kiangsi: L.H. Bailey 45 (GH, US), N.K. Ip 1776 (US), Maries s.n., s.d. (K), Steward 4649 (US). - Hunan: Fan \& Li 433 (A, BO, L, P). - Kwangtung: Tsang 20908 (B, K). - Kwangsi: 6 collections.

TAIWAN. 17 collections.

VIETNAM. Tonkin: 6 collections.

Notes. 1. P. sheareri has often been confused with $P$. drakeana. Typical representatives of both species differ in the following characters:

\begin{tabular}{lll}
\hline & sheareri & drakeana \\
\hline stipe/lamina index & $1 / 2-1$ & $1-2$ \\
lamina length $(\mathrm{cm})$ & $9-50$ & $8-25$ \\
lamina index & $3-7$, mostly & $2-5$, mostly \\
& $5-6$ & 3 \\
indument & monomorphic, & dimorphic, \\
& appressed & \pm shaggy \\
diam. of hairs (mm) & $0.3-0.5(-1)$ & $(0.8-) 1.0-1.6$ \\
sori & exserted from & immersed in the \\
& the indument & indument when ripe \\
& when ripe &
\end{tabular}

In a few specimens, however, these characters are combined in a different way, which makes identification sometimes difficult. Some of these specimens have fronds shaped like $P$. sheareri but a more or less dimorphic indument (e.g., Henry 9114 ), or a monomorphic indument but with relatively large, \pm acicular hairs (Kramer et al. 8130). In other cases the lamina may be similar in shape to that of P. drakeana, but the hairs are small and the sori more or less exserted (Dai 104588, Fang 3966, 12848, Wilson 5323). Although these specimens can be considered intermediate between $P$. sheareri and $P$. drakeana, there are no other reasons for supposing that they are of hybrid origin (see also note 3 ).

2. The lamina of $P$. sheareri is often characteristically lobed at the base with a varying number of lateral lobes or teeth on one or both sides. Often the base itself is highly asymmetric. Similarly asymmetric, unstable frond shapes are sometimes supposed to be an indication of hybridity ('structural irregularity' Wagner, Phytomorphology 12, 1962: 87-100). In this case there is, however, no reason to assume that $P$. sheareri, as recognized here, contains a large number of hybrid specimens, as neither the spores are more often abnormal than in other species of Pyrrosia, nor is the chromosome number of one plant that was examined aberrant in the genus. Moreover, there are indications that the shape of the lamina is liable to variation that depends more on environmental circumstances than on the genetic constitution of the plant (see note 3).

3. Plasticity: Two plants collected by K.U. Kramer in the field on Taiwan in close proximity to each other have been cultivated in the Leiden Botanical Garden: one in a phytotron with constantly warm, moist atmosphere, the other in a greenhouse with a cooler regime in winter. After one year the plant grown under constantly warm conditions had developed the characteristic irregular 
lamina shape; the other plant had developed much smaller fronds, with an almost symmetrical (though still unequal) base. This type of plasticity is comparable to that discussed under $P$. polydactyla, in which a diminishing degree of lamina dissection could also artificially be induced.

Between the two plants of $P$. sheareri a slight difference also developed with regard to the diameter of the hairs: The one grown under cool conditions had hairs most of which were $0.25-0.40 \mathrm{~mm}$ in diam.; the other, from the warmer phytotron, had hairs most of which were $0.2-0.25 \mathrm{~mm}$ in diam. This variation falls completely within the range of $P$. sheareri, and therefore is not a sufficient explanation for the difference between $P$. sheareri and $P$. drakeana found for this character. It should be noted, however, that the correlation found between hair diameter and climate when $P$. drakeana and $P$. sheareri are compared is similar to the correlation found when the two plants of $P$. sheareri grown under different climatic regimes are compared. Wherever $P$. drakeana and $P$. sheareri occur together, $P$. drakeana, which has the larger hairs of the two, tends to occur at higher altitudes than $P$. sheareri, where the climate may be supposed to be cooler. In the plants from cultivation similarly larger hairs were found on the plant from a cooler regime. It is curious that if the same correlation is considered between $P$. hastata and $P$. polydactyla, the converse effect is found: larger hairs are found on $P$. polydactyla, which grows at a considerably lower latitudes than $P$. hastata.

These considerations show that, although environmental conditions certainly play a part in the expression of characters, they nevertheless cannot fully explain the differences found between $P$. sheareri and $P$. drakeana.

4. In the field this species has a conspicuous, yellow, costa (Kramer, in litt.)

\section{Pyrrosia sphaerosticha (Mett.) Ching. Fig. 22.}

Pyrrosia sphaerosticha Ching, Bull. Chin. Bot. Soc. 1 (1935) 62; Copeland, Fern Fl. Philipp. (1960) 474; Holttum, Nov. Bot. Inst. Bot. Univ. Car. Prag. (1968) 50.-Niphobolus acrostichoides J. Sm., Hooker J. Bot. 3 (1841) 396, nom. nud.; [non Polypodium acrostichoides G. Forster, Prodr. (1786) 81 et syn. homotyp., = Pyrrosia longifolia (N.L. Burm.) Morton]; Fée, Gen. Fil. (1853) 262, nom. nud.-Niphobolus smithianus T. Moore, Ind. Fil. (1857) lxxvi, nom. nud. - Sphaerostichum acrostichoides Presl, Epim. Bot. (1851) 135.-Polypodium sphaerosticha Mett., Polyp. (1856) 130, pl. 3 fig. 13; Baker in Hooker \& Baker, Syn. Fil. (1867) 350; Christ, Verh. Nat. Ges. Basel (1897) 244; Christ, Ann. Jard. bot. Buitenz. 15 (1 898) 165. - Niphobolus sphaerostichus C. Chr., Ind. Fil. (1906) 201; Alderwerelt, Malayan Ferns (1909) 682; C. Chr., Leafl. Phil. Bot. 9 (124) (1933) 3256.-Type: Cuming 127 (holo PRC, iso BM, B, K, P), Luzon, see note 4.

Niphobolus sarasinorum Giesenh., Niphobolus (1901) 162. - Cyclophorus sarasinorum C. Chr., Ind. Fil. (1906) 200; Copeland, Leafl. Phil. Bot. 2 (19) (1908) 414; Alderwerelt, Malayan Ferns (1909) 693; Alderwerelt, Malayan Ferns Suppl. (1917) 413. - Syntypes: Sarasin 1181, (9-IV-1895) (P), Sarasin 27, (13-III-1894) (P), Celebes.

Niphobolus warburgii Giesenh., Niphobolus (1901) 163. - Cyclophorus warburgii C. Chr., Ind. Fil. (1906) 202; Alderwerelt, Malayan Ferns (1909) 692. -Syntypes: Warburg s.n. (1888) (P); Sarasin s.n. (1895) (P), Celebes.

Cyclophorus pseudo-lingua Alderwerelt, Bull. Jard. bot Buitenz. II, 8 (1913) 6; Alderwerelt, Malayan Ferns Suppl. (1917) 413; C. Chr., Ind. Fil. Suppl. 2 (1917) 11. - Ty pe: Elmer 9804 (B, BO, BM, A, K, L, M, P, US, U, Z), Philippines, Negros. 
Rhizome long-creeping, narrowly grooved ventrally, (1) $1.5-2.6 \mathrm{~mm}$ thick, phyllopodia $2-7 \mathrm{~cm}$ apart, lateral buds situated \pm halfway down the internodia. Anatomy: ground tissue parenchymatous, sclerenchyma sheath distinct, a single, central sclerenchyma strand as well as \pm 10 peripherally situated sclerenchyma strands present in the inner parenchyma; vascular strands 6-10. Scales peltate, 3.2-7.2 $\times 0.6-1.5 \mathrm{~mm}$; base entire; acumen hyaline to light brown, with long, curly, cilia up to \pm halfway towards the apex. Fronds dimorphic, stipitate. Fertile fronds: stipes 3-16 cm, $1 / 3- \pm 1 \times$ as long as the lamina; lamina, index (2-)4-8; widest below or at the middle, $5-16 \times 1-3 \mathrm{~cm}$, base cuneate to more or less gradually attenuate, apex obtuse to acuminate. Sterile fronds: stipes 1-14 cm, $\left({ }^{1} / 10^{-}\right)^{1 / 5-} \pm 1 \times$ as long as the lamina; lamina, index $2-4(-5)$; widest about the middle, 3.5-17 $\times 1.3-6 \mathrm{~cm}$, base cuneate to attenuate, apex obtuse or \pm rounded to longly acuminate. Venation: secondary veins distinct, with the tertiary veins forming regular areoles; included veins much branched and copiously anastomosing, forming a distinct row of empty areoles along the secondary veins; free veins many, pointing to all directions. Hydathodes distinct, scattered over the lamina, \pm superficial. Anatomy: stipe with \pm 6 central and no lateral vascular strands; lamina $\pm 0.5 \mathrm{~mm}$ thick, upper epidermis with slightly projecting cells with thin walls, hypodermis absent but a distinct, moderately thick water-tissue present, palissade and spongy parenchyma distinct, lower epidermis with moderately thickened cell-walls: stomata sunken. pericytic. Indument monomorphic, a thin mat, persistent, light brown to whitish; hairs $0.3-0.5 \mathrm{~mm}$ in diam., with appressed, boat-shaped rays. Sori all over the lamina or in a sharply detıned, irregularly shaped patch, very closely packed, superficial; many scattered through each soriferous areole, not confluent; developing all more or less simultaneously, when old pseudoacrostichoid, exserted from the indument. Sporangia on stalks $1 / 2-1 \times$ as long as the capsule, capsule $\pm 0.4 \mathrm{~mm}$ high, with $21-24$ indurated annulus cells. Paraphyses not differentiated. Spores (82-)91.4-93.4(-102) $\times(58-)$ 69.0-74.4(-90) $\mu \mathrm{m}$, with irregular ridges and protuberances.

Habitat: Epiphytic, in forest or sometimes on exposed trees; occasionally epilithic.

Altitudinal range: $200-2000 \mathrm{~m}$.

PHILIPPINES. Luzon: 13 collections. - Negros: Elmer 9512 (BM, BO, K, L, M, P, US, Z), 9804, (A, B, BM, BO, K, L, M, P, U, US, Z). - Mindanao: 8 collections.

CELEBES. North penins.: Alston 15631 (BM), 15958 (BM), C. Hose s.n. (1895) (BM, K), Posthumus s.n. (1-6-1941) (BO), Wisse 79 (BO, WAG). - Central: 6 collections. - Southwest penins.: Bünnemeijer 11336 (BO, L), Posthumus 2724 (BO, L), 3436 (BO, L, SING), Warburg 16521 (B), 16565 (B).

MOLUCCAS. Bacan: Alston 16995 (BM), De Vriese \& Teysmann 23 (L).

Notes. 1. $P$. sphaerosticha is superficially similar to $P$. lingua, but is easily recognized by the very closely packed, pseudoacrostichoid sori and by the characteristic rhizome scales. 
The rhizome scales are constantly ciliate in the lower half of the acumen; the apex, which is entire again, is moreover strongly and irregularly crisped and \pm squarrosely curved outwards.

The scales on the phyllopodia are often enlarged and form a more or less distinct tuft around the base of the stipe similar to that in $P$. abbreviata.

2. Alston 16995 from Batjan is a slender plant with a rhizome only $1 \mathrm{~mm}$ thick, almost entire scales and small fronds.

3. In SING is a specimen of $P$. sphaerosticha labelled 'Sempadi, Sarawak, 1893', the collector of which can be deciphered as 'G. F. S. \& S. (G.F. Hose, bishop of Singapore \& Sarawak). This locality lies outside the range of $P$. sphaerosticha. The same locality is indicated on two specimens of $P$. christii (which is restricted to Borneo) collected by Ch. Hose, his nephew. According to Van Steenis-Kruseman (Fl. Males. 1, 1950: 246) Ch. Hose also made some collections on Celebes, whereas his uncle did not. Therefore, it seems most likely that somewhere the labels of two collections, one by $\mathrm{Ch}$. Hose and one by his uncle, have been changed.

4. The specimen in L of Cuming 127 represents $P$. rasamalae.

\section{Pyrrosia splendens (Presl) Ching. Fig. 17.}

Pyrrosia splendens Ching, Bull. Chin. Bot. Soc. 1 (1935) 68; Copeland, Fern Fl. Philipp. (1960) 473; Holttum, Nov. Bot. Inst. Bot. Univ. Car. Prag. (1968) 27. - Niphobolus splendens J. Sm., Hooker J. Bot. 3 (1841) 396, nom. nud.; J. Sm., Hooker J. Bot. 4 (1842) 57, nom. nud.; T. Moore, Ind. Fil. (1857) lxxvi, nom. nud.-Apalophlebia splendens Presl, Epim. Bot. (1851) 138. - Niphobolus splendens T. Moore, Ind. Fil. (1858) 83; J. Sm., Hist. Fil. (1875) 98; Giesenh., Niphobolus (1901) 99; Copeland, Polyp. Philipp. (1905) 115.-Polypodium splendens Hooker, Sp. Fil. 5 (1863) 52; non Polypodium splendens Hooker, Sp. Fil. 5 (1863) 95, nom illeg., = Aglaomorpha splendens (Hooker) Copeland; Christ, Bull. Herb. Boiss. 6 (1898) 198.-Polypodium nitens Baker in Hooker Baker, Syn. Fil. (1867) 353, nom. illeg.; : Polypodium nitens Desv., Mém. Soc. Linn. Paris $6(1827) 240,=$ ? Thelypteris sp., type from Peru. - Cyclophorus splendens C. Chr., Ind. Fil. (1906) 201; Christ, Bull. Herb. Boiss. II, 6 (1906) 990; Alderwerelt, Malayan Ferns (1909) 696; Christ, Geogr. der Farne (1910) 112; Alderwerelt, Bull. Jard. bot. Buitenz. II, 28 (1918) 16.-Ty pe: Cuming 331 (holo PRC, teste Holttum, l.c., iso BM, K, P), Philippines, Samar.

Rhizome short, not grooved ventrally, 6-8 $\mathrm{mm}$ thick, phyllopodia contiguous, lateral buds situated on the phyllopodia. Anatomy: ground tissue sclerenchymatous, sclerenchyma sheath and sclerenchyma strands absent; vascular strands \pm 12 . Scales basifix, $4.7-7.8 \times \pm 1.7 \mathrm{~mm}$; base \pm entire; acumen brown, entire. Fronds monomorphic, sessile or indistinctly stipitate; stipes to $\pm 5 \mathrm{~cm}$; lamina, index 8-14; widest above the middle, $33-100 \times 3.2-11.5 \mathrm{~cm}$, base gradually narrowed, apex rather abruptly acuminate to apiculate. Venation: secondary veins distinct, with the tertiary veins forming regular areoles; included veins much branched and copiously anastomosing; free veins many, pointing to all directions. Hydathodes distinct, scattered over the lamina, \pm superficial. Anatomy: stipe or lower part of costa with a central strand of collenchyma and \pm 8 central and \pm 4 lateral vascular strands; lamina $0.2-0.3 \mathrm{~mm}$ thick, upper 
epidermis with flat cells with thickened walls, hypodermis distinct to indistinct, water-tissue absent, palissade and spongy parenchyma distinct to indistinct, lower epidermis with moderately thickened cell-walls; stomata superficial, pericytic. Indument dimorphic, a dense but rather thin mat, persistent, the upper layer brown, the lower layer light greyish brown; upper layer composed of hairs $0.5-1.6 \mathrm{~mm}$ in diam., with appressed, acicular rays and with an erect, up to 2.5 $\mathrm{mm}$ long dorsal spine, appressed to but distinctly separated from a lower layer composed of hairs with mainly woolly rays. Sori apical, in a sharply defined patch, closely packed, supertıcial; many scattered throughout each soriferous areole, not confluent; $\pm 0.5 \mathrm{~mm}$ in diam.; developing from the apex downwards, when old individually distinct, exserted from the indument. Sporangia sessile, capsule \pm $0.3 \mathrm{~mm}$ high, with 8-11 indurated annulus cells. Paraphyses not differentiated. Spores (44-)51.6-58.0(-64) $\times(26-) 30.2-33.0(-38) \mu \mathrm{m}$, smooth.

Habitat: Very few data are available; mostly epiphytic, on trees near to or overhanging a river.

Altitudinal range: Low altitudes, to $200 \mathrm{~m}$ (acc. to Copeland, Fern Fl. Philipp., 1960 , up to $600 \mathrm{~m}$ ).

PHILIPPINES. Luzon: 10 collections. - Samar: Cuming 331 (BM, K, P), Edaño BS 24827 (US, P), Guttierez et al. 423 (L). - Leyte: Ramos 1157 (M, U, US, Z). - Mindanao: 10 collections. - Siargao: Ramos \& Pascasio BS 24425 (P).

Notes. $1 P$. splendens is easily recognized by the distinctive indument. The indument of $P$. princeps may be \pm similar but never has dorsal spines as distinct as those in $P$. splendens. The rhizome scales are unique in the $P$. costata-group in that the margin at the base is entire, or crenulate with protruding outer cell-walls; in scales of other species of this group the crenulations are formed by the protruding anticlinal walls.

\section{Pyrrosia stigmosa (Swartz) Ching. Fig. 17.}

Pyrrosia stigmosa Ching, Bull. Chin. Bot. Soc. 1 (1935) 67; C. Chr. Tard., Not. Syst. 8 (1939) 206; Tard. C. Chr., Fl. Indo-Ch. (1941) 513; Holttum, Fl. Malaya 2 (Ferns) (1954) 148; Holttum, Dans k Bot. Ark. 23 (1965) 230; Iwats., Amer. Fern J. 63 (1973) 131; Nayar \&aur, Comp. Bedd. Handb. (1974) 80; Shing, Amer. Fern J. 73 (1983) 78, 'P. strigosa'.-Polypodium stigmosum Swartz, Schrad. J. 1800 (2) (1801) 21; Willd., Sp. Pl. 5 (1810) 162; Swartz, Syn. Fil. (1806) 29, 226; Spr., Syst. 4 (1827) 48; Mett., Ann. Mus. Lugd. Bat. 2 (1866) 232; Christ, Verh. Nat. Ges. Basel (1897) 445; Christ, Ann. Jard. bot. Buitenz. 15 (1898) 166; Racib., Pter. Buitenz. (1898) 102; Christ in Warb., Monsunia I (1900) 62.-Niphobolus stigmosus T. Moore, Ind. Fil. (1861) 276; Bedd., Ferns Brit. India (1868) pl. 120; Bedd., Suppl. Ferns S. \& Br. Ind. (1876) 22; Bedd., Handb. ferns Brit. Ind. (1883) 329, p.p. pl. 178; Diels in E. \& P., Nat. Pfl. Fam. 1,4 ( 1899) 325; Giesenh., Niphobolus (1901) 113.-Cyclophorus stigmosus Desvaux, Mag. Ges. Naturf. Freunde Berlin (Berl. Mag.) 5 (1811) 301; Desv., Mém. Soc. Linn. Paris 6 (1827) 224; Presl, Epim. Bot. (1851) 224; C. Chr., Ind. Fil. (1906) 201; Alderwerelt, Malayan Ferns (1909) 695; Alderwerelt, Bull. Jard. bot. Buitenz. II, 28 (1918) 16; Backer Posth., Varenfl. Java (1939) 242; Dickason, Ohio J. Sc. 46 (1946) 129.-Ty pe: Thunberg s.n., s.d. (holo S, not seen), Java. 
Pyrrosia chinensis Mirbel, Hist. Nat. Vég. 5 (1803) 92; Desv., Mém. Soc. Linn. Paris 6 (1827) 225; Mett., Ann. Mus. Lugd. Bat. 2 (1866) 232, pro syn.; Ching, Bull. Chin. Bot. Soc. 1 (1935) 36, q.n.s. - Type: Moreau s.n., s.d. (herb. Jussieu 1058, P), 'China'. Type of the genus

Niphobolus venosus Blume, Fl. Jav. Fil. (1829) 63 pl. 28 fig. 1 a-d; Presl, Tent. Pter. (1836) 202;

Kunze, Bot. Zeit. (1848) 121; Fée, Gen. Fil. (1853) 263; T. Moore, Ind. Fil. (1857) lxxvi. Apalophlebia venosa Presl, Epim. Bot. (1851) 139. - Ty pe: Zippelius s.n., s.d. (L?), Java, Bogor.

Rhizome shortly elongated, not grooved ventrally, 4-4.5 mm thick, phyllopodia 1-2 cm apart, lateral buds situated on the phyllopodia. Anatomy: ground tissue sclerenchymatous, sclerenchyma sheath and sclerenchyma strands absent; vascular strands 7-13. Scales basifix, 2.6-6 $\times 0.9-1.6 \mathrm{~mm}$; base dentate, sometimes with stalked marginal glands; acumen brown, entire or dentate. Fronds monomorphic, stipitate; stipes $3-24(-37) \mathrm{cm},\left({ }^{1 / 6-}\right)^{1 / 4}-{ }^{2} / 3 \times$ as long as the lamina; lamina, index 4-13; widest about the middle, 11-48 $\times 1.5-5.2 \mathrm{~cm}$, base cuneate, apex acute to acuminate, occasionally rounded or obtuse. Venation: secondary veins distinct, with the tertiary veins forming regular areoles; included veins much branched and anastomosing; free veins many, pointing to all directions. Hydathodes distinct, scattered over the lamina, \pm superficial. Anatomy: stipe with a central strand of collenchyma and 6-7 central and 5-6 lateral vascular strands; lamina $0.2-0.3 \mathrm{~mm}$ thick, upper epidermis with distinctly projecting cells with thin walls, hypodermis absent or composed of a single cell-layer, watertissue absent, palissade and spongy parenchyma distinct, lower epidermis with thin cell-walls; stomata superficial. pericytic. Indument dimorphic, a dense mat, persistent, light greyish-brown; upper layer composed of hairs $\pm 0.5 \mathrm{~mm}$ in diam., with appressed, boat-shaped rays, appressed to or \pm mixed with a lower layer composed of hairs with mainly woolly rays. Sori apical to all over the lamina, in an ill-defined patch, shortly spaced, superficial; many scattered through each soriferous areole, not confluent; $\pm 0.5 \mathrm{~mm}$ in diam.; when old individually distinct, slightly exserted from the indument. Sporangia sessile, capsule \pm 0.2 mm high, with 14-20 indurated annulus cells. Paraphyses not differentiated. Spores (42-)49.2-60.0(-66) ×(28-)31.4-38.6(-42) $\mu \mathrm{m}$, smooth.

Habitat: Epilithic, in forest or open places, frequently on limestone; also epiphytic, in forest or on roadside trees. Mainly in areas with a more or less seasonal rainfall, in perhumid climates perhaps restricted to limestone, at least so in Malaya (Chin, 1975).

Altitudinal range: Sea level to $1500 \mathrm{~m}$.

BURMA. Lace 5511 (E, K), Parish s.n., s.d., (K), Parish 17 (K).

THAILAND. Northern: 14 collections. - Northeastern: Kerr 8407 (Eryl Smith 2143) (K), Tagawa et al. T 1256 (A, K, L, US). - Eastern: Geesink et al. 6944 (L), Richards 5447 (K). Central: Nai Nol 99 (K). - Southeastern: Larsen 10623 (L), Larsen et al. 1148 (L), Maxwell 751100 (L). - Southwestern: Van Beusekom * Santisuk 2783 (K, L, Z), Van Beusekom et al. 3525 (L), Kostermans, Kwae Noi River Basin exp. 1403 (BM, GH, L), Larsen et al. 1371 (L), Shimizu et al. T 7743 (K, L). - Peninsular: Eryl Smith 2014 (K), Smitinand Sleumer 1256 (L, SING).

CAMBODIA. 8 collections. 
VIETNAM. Annam: Poilane 5593 (P, US), 10033 (P). - Cochinchina: Matthew 41 (K). MALAYA, incl. Langkawi Is. 13 collections.

SUMATRA. 12 collections.

JAVA. 58 collections.

LESSER SUNDA ISLANDS. Bali: Kostermans et al. 49 (A, BO, K, L), Posthumus 3707 (BO, L), Zollinger 147 (2015) (P).

CELEBES. Bünnemeijer 10789 (B, BO, L, SING), 11757 (B, BO, L, P), Buwalda 3776 (BO, L). Posthumus 3505 (BO), P. F. Sarasin 1199 (P).

Notes. 1. $P$. stigmosa can be deceptively similar to $P$. costata. Generally the elongated rhizome and the distinctly stipitate fronds are distinctive, but specimens with only partially collected rhizome and strongly inrolled fronds may cause confusion, especially with the more or less stipitate forms that may occur in $P$. costata. These specimens can be identified with the aid of one or more of the following characters:

- In $P$. stigmosa the costa and secondary veins are narrowly grooved above (more distinct in dried than in fresh fronds), in $P$. costata costa and veins are practically flat or shallowly and broadly grooved;

- In P. stigmosa a central strand of collenchyma is present in the stipe, in $P$. costata the stipe or lower part of the costa lacks a central strand of collenchyma;

- In $P$. stigmosa the sori are shortly spaced and usually spread over the whole length of the lamina, in $P$. costata the sori are more closely packed and usually restricted to the apical part of the lamina;

- In $P$. stigmosa the rhizome scales are more distinctly dentate at the base than in $P$. costata.

2. Ching (1935) identified Pyrrosia chinensis Mirbel with $P$. lingua (Thunb.) Ching. He may have been influenced by the fact that several cultivated forms that have been called 'sinensis', e.g., Niphobolus sinensis Loud., Hort. Brit. Suppl. (1839) 651, Craspedaria sinensis Link, Fil. Sp. (1841) 118, generally have been identified as $P$. lingua (J. Sm., Cat. Cult. Ferns (1857) 12; Mett., Polyp. (1856) 130). The type specimen of $P$. chinensis, however, is conspecific with $P$. stigmosa. Also the characters on which Mirbel based his genus Pyrrosia agree much better with $P$. stigmosa than with $P$. lingua: 'fructifications en points nus, 5-8 boites sessiles (...)'. This can only refer to a species of what $I$ have called the $P$. costatagroup; other species have usuaily stailked sporangia in greater numbers in each sorus.

One may wonder why Desvaux did not already identify $P$. chinensis with Polypodium stigmosum Swartz, a species he apparently knew and referred to under Cyclophorus (Mag. Ges. Naturf. Freunde Berlin 5 (1811) 301). From Desvaux' own herbarium (now dispersed in P) it appears that Desvaux misapplied the name Polypodium stigmosum $\mathrm{Sw}$. to $P$. longifolia. Taking this into account, the genus Cyclophorus in his circumscription is identical with the $P$. lanceolata-group and based on the same characters: sori separate, placed in small hollows, with the sporangia in a circular arrangement. 
3. The type of Niphobolus venosus Blume cannot be traced in $\mathrm{L}$, as there are no sheets with this name in Blume's handwriting. The plate in the Flora of Java, however, clearly represents $P$. stigmosa.

4. The indurated part of the annulus in $P$. stigmosa is not as regularly reduced as in other species in the $P$. costata-group. In many sporangia the indurated part of the annulus does not extend down to the base of the capsule, but frequently completely normal sporangia are found.

\section{Pyrrosia stolzii (Engl.) Schelpe. Fig. 16.}

Pyrrosia stolzii Schelpe, J. S. Afr. Bot. 18 (1952) 33; Schelpe, Fl. Zambes. (1970) 147; Gill Mwasumbi, Nova Hedw. 27 (1976) 943.-Niphobolus stolzii Hieron. ex Engl., Veg. d. Erde 9,2 (1908) 55.-Cyclophorus stolzii Hieron., Bot. Jb. 46 (1911) 396; C. Chr., Ind. Fil., Suppl. (1913) 22. - Ty pe: Stolz 96 (holo B, iso P), Tanzania.

Rhizome shortly elongated, not grooved ventrally, 2.1-3.1 $\mathrm{mm}$ thick, phyllopodia $0.5-1.5 \mathrm{~cm}$ apart, lateral buds situated up to $1 / 3$ down the internodia. Anatomy: ground tissue parenchymatous, sclerenchyma sheath absent or indistinct, sclerenchyma strands scattered through the inner parenchyma, 0-15; vascular strands 6-11. Scales peltate, 2.6-5.2 $\times 0.6-1.0 \mathrm{~mm}$; base dentate to ciliate; acumen dull light brown, ciliate. Fronds monomorphic, sessile or indistinctly stipitate; stipes up to $7 \mathrm{~cm}$; lamina, index $5- \pm 20$; widest at or above the middle, $8-27 \times 0.8-24 \mathrm{~cm}$, base gradually narrowed, apex more or less narrowly acute. Venation: secondary veins distinct, with the tertiary veins forming regular areoles; included veins simple or occasionally forked, free or occasionally anastomosing; free veins many, excurrent. Hydathodes distinct, scattered over the lamina, \pm superficial. Anatomy: stipe or lower part of costa with \pm 7 central and no lateral vascular strands; lamina $\pm 0.4 \mathrm{~mm}$ thick, upper epidermis with distinctly projecting cells with thin walls, hypodermis and water-tissue absent, palissade and spongy parenchyma distinct, lower epidermis with moderately thickened cell-walls: stomata slightly sunken. pericytic. Indument dimorphic, a rather thin mat, persistent, dirty whitish to very light brown; upper layer composed of hairs 1-1.4 mm in diam., with \pm appressed, acicular rays, \pm distinct from a lower layer composed of hairs with mainly woolly rays. Sori apical to all over the lamina, in an ill-detıned patch, shortly spaced, supertıcial; several in a row in each soriferous areole, not confluent; 1-2 $\mathrm{mm}$ in diam.; developing from the apex downwards, when old distinct, \pm immersed in the indument. Sporangia on stalks $\pm 1 \times$ as long as the capsule, capsule $\pm 0.4 \mathrm{~mm}$ high, with 18-21 indurated annulus cells. Paraphyses not differentiated. Spores (72-)78.4-80.6($88) \times(48-) 55.0-55.8(-60) \mu \mathrm{m}$, sparsely granulate to shallowly verrucate.

Habitat: Epiphytic, in rain-forest or cloud-forest, occasionally in steppe. Altitudinal range: $1450-2100 \mathrm{~m}$. 
TANZANIA. Stolz 96 (B, P), Stolz 891 (B, BM, K, L, M, P, U, Z).

MALAWI. Chapman 86 (BM), 385 (BM).

ZAMBIA. Pawek 2214 (K), 3330 (K), 12277 (K), White 2709 (BM, K).

Notes. 1. $P$. stolzii differs from $P$. porosa only in the elongated rhizome and the characteristically whitish indument. From other African species it can be easily distinguished by the ciliate rhizome scales.

\section{Pyrrosia subfurfuracea (Hooker) Ching. Fig. 19.}

Pyrrosia subfurfuracea Ching, Bull. Chin. Bot. Soc. 1 (1935) 68; C. Chr. \& Tard., Not. Syst. 8 (1939) 206; Tard. \& C. Chr., Fl. Indo-Ch. (1941) 512; Nayar \& S. Chandra, Bull. Nat. Bot. Gard. Lucknow 117 (1965) 83 q.n.s.?; Nayar Kaur, Comp. Bedd. Handb. (1974) 80; Ching \&u, Fl. Xizang. 1 (1983) 337. - Polypodium subfurfuraceum Hooker, Sp. Fil. 5 (1863) 52; Baker in Hooker Baker, Syn. Fil. (1867) 351; C. B. Clarke, Tr. Linn. Soc. II Bot. 1 (1880) 553; Christ, Bull. Herb. Boiss. 6 (1898) 871. - Niphobolus subfurfuraceus Bedd., Ferns Brit. India (1868) pl. 259; J. Sm., Hist. Fil. (1875) 98; Bedd., Handb. ferns Brit. Ind. (1883) 329; Bedd., Suppl. Handb. (1892) 91; Diels in E. \&., Nat. Pfl. Fam. 1,4 (1899) 325; Giesenh., Niphobolus (1901) 122; Christ, Bull. Acad. int. Géogr. bot. 9 (1902) 223; Christ, Bull. Soc. Fr. 52 Mém. 1 (1905) 24.-Cyclophorus subfurfuraceus C. Chr., Ind. Fil. (1906) 201; Christ, J. Bot., Paris 21 (1908) 238; Christ, Bull. Acad. int. Géogr. bot. 20 Mém. (1909) 175; H. Lev., Fl. Kouy-Tchéou (1915) 479; Bonap., Notes Ptérid. 7 (1918) 126; C. Chr., Acta Horti Gothob. 1 (1924) 104; Dickason, Ohio J. Sc. 46 (1946) 129. - Lectotype: Griffith s.n., s.d. (holo K, iso B?, P?), India, 'Mishmee'.

Polypodium calvatum Baker, J. Bot. Lond. 17 (1879) 304; Baker, Ann. Bot., Lond. 5 (1891) 89; Dunn * Tutch., Fl. Kwangtung (1912) 352. - Niphobolus calvatus Diels, Bot. Jb. 29 (1900) 207; Christ, Bull. Soc. Fr. 52 Mém. 1 (1905) 24; Christ, Bull. Acad. int. Géogr. bot. (1906) 18. - Cyclophorus calvatus C. Chr., Ind. Fil. (1906) 198; Christ, Bull. Acad. int. Géogr. bot. 20 Mém. (1909) 175; H. Lev., Fl. Kouy-Tchéou (1915) 478; C. Chr., Acta Horti Gothob. 1 (1924) 104._Pyrrosia calvata Ching, Bull. Chin. Bot. Soc. 1 (1935) 62; C. Chr. Tard., Not. Syst. 8 (1939) 204; Tard. . C. Chr., Fl. Indo-Ch. (1941) 509, Fu, Ill. Imp. Chin. Pl. (1957) 238, fig. 321.-T y pe: native collector, Herb. Ford (K?, not found), China, 'Canton'.

Niphobolus bonii Christ ex Giesenh., Niphobolus (1901) 120. - Cyclophorus bonii C. Chr., Ind. Fil. (1906) 198; Bonap., Notes Ptérid. 7 (1918) 126.-Pyrrosia bonii Ching, Bull. Chin. Bot. Soc. 1 (1935) 67; C. Chr. Tard., Not. Syst. 8 (1939) 204; Tard. \& C. Chr., Fl. Indo-Ch. (1941) 510, fig. 60 2-4.-Syntypes: H. Bon 2820 (P, BM), Indo-china; Dr. Billet s.n., (1896) (P), IndoCiinina, "Tav Dany".

Cyclophorus esquirollii H. Lev., Fl. Kouy-Tchéou (1915) 478; C. Chr., Ind. Fil. Suppl. 2 (1917) 10.-T ype: Esquirol 2674 (E), China.

Pyrrosia subtruncata Ching, Bull. Chin. Bot. Soc. 1 (1935) 67; C. Chr. \& Tard., Not. Syst. 8 (1939) 206; Tard. C. Chr., Fl. Indo-Ch. (1941) 510.-Type: Ching 6478 (not seen), China.

Pyrrosia pseudocalvata Ching, Boufford \& Shing, J. Arn. Arb. 64 (1983) 38. - T y p e: Sino-Amer. Bot.

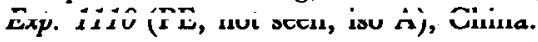

Rhizome short or occasionally shortly elongated, not grooved ventrally, 2-6.8 $\mathrm{mm}$ thick, phyllopodia contiguous or to $2.5 \mathrm{~cm}$ apart, lateral buds situated on or close behind the phyllopodia. Anatomy: ground tissue parenchymatous, sclerenchyma sheath distinct, sclerenchyma strands scattered through the inner parenchyma, many; vascular strands to \pm 12 . Scales pseudopeltate, $6.5-11 \times 0.7-1.3$ $\mathrm{mm}$; base entire to ciliate; acumen dull brown, ciliate. Fronds monomorphic, stipitate; stipes $4-31 \mathrm{~cm},\left({ }^{1} / 10^{-}\right)^{1 / 5-} \pm 1 \times$ as long as the lamina; lamina, index 3\pm 20 ; widest about the middle, $(8.5-) 15-91 \times(1-) 2-7.5 \mathrm{~cm}$, base gradually nar- 
rowed, apex more or less acuminate. Venation: secondary veins distinct, with the tertiary veins forming regular areoles; included veins frequently forked and anastomosing; free veins many, mainly excurrent. Hydathodes distinct, scattered over the lamina, \pm superficial. Anatomy: stipe with \pm 9 central and \pm 3 lateral vascular strands; lamina $0.3-0.7 \mathrm{~mm}$ thick, upper epidermis with flat cells with moderately to strongly thickened walls, hypodermis composed of a single celllayer, water-tissue absent, palissade and spongy parenchyma distinct or occasionally indistinct, lower epidermis with moderately thickened cell-walls; stomata superficial to slightly sunken, pericytic. Indument dimorphic, a thin or occasionally \pm dense mat, persistent or fugacious, dirty greyish; upper layer composed of hairs $0.8-1.3 \mathrm{~mm}$ in diam., with erecto-patent, acicular rays, \pm mixed with a lower layer composed of hairs with mainly woolly rays. Sori apical in a more or less sharply detıned patch, closely packed, supertıcial; several to many in each soriferous areole, in 1 or 2 rays or irregularly scattered, occasionally confluent; 1-2 $\mathrm{mm}$ in diam.; developing from the apex downwards, when old individually distinct, exserted from the indument. Sporangia on stalks $1-1 / 2 \times$ as long as the capsule, capsule $0.3-0.5 \mathrm{~mm}$ high, with 18-21 indurated annulus cells. Paraphyses not differentiated. Spores (64-)73.8-89.6(-96) $\times(48-) 52.4-65.0(-70)$ $\mu \mathrm{m}$, granulate.

Habitat: Epilithic, often on calcareous rocks, mostly in shade but also in full sun; occasionally epiphytic, in forest or in ravines.

Altitudinal range: $500-2000 \mathrm{~m}$ alt.

CHINA. Hupeh: 6 collections. - Szechwan: 13 collections. - Kweichow: 12 collections. Yunnan: 18 collections. - Kiangsi: S.K. Lau 4585 (GH, US, P). - Fukien: Schindler 403 b (B). -Kwangtung: Matthew s.n. (2-12-1907)(K). - Kwangsi: Ching 6182 (US), S.P. Ko 55644 (A), Steward \& Cheo 99 (A, P), 483 (P).

BHUTAN. Griffith s.n. (?B).

INDIA. Assam: 5 collections.

LAOS. Poilane 16909 (P).

VIETNAM. Tonkin: 27 collections.

Notes. 1. Variabilitv: Characteristically. the older fronds of $P$. subfurfuracea are quite glabrous or have only a thin, \pm glaucous indument left. Occasionally the indument is more persistent. Forms with fronds with a relatively short, wide lamina and a relatively long stipe have been separated as $P$. bonii (e.g., Colant 4330 , roulane $1900 \mathrm{U})$. In all characters, however, there is a gradual transition between this form and tvnical $P$. subfurfuracea. It is also somewhat similar to $P$. boothii, but generally smaller and with a thinner indument. $P$. boothii is distinct from $P$. subfurfuracea in having a wider lamina and a thick, brown, persistent, indument. 


\section{DOUBTFUL AND EXCLUDED NAMES OR SPECIES}

\section{Species dubiae}

\section{1. Niphobolus anetioides Christ}

Niphobolus anetioides Christ, Ann. Jard. bot. Buitenz. 19 (II, 4) (1904) 38.-Cyclophorus anetioides

C. Chr., Ind. Fil. 198; Alderwerelt, Malayan Ferns (1909) 682.-T y pe: $F$. \& Sarasin 2043 (holo P, not found), Celebes, Bada, $1400 \mathrm{~m}$.

Christ's description does not apply to any of the species known from Celebes. Probably it refers to an aberrant form with the lamina lobed basally. Alderwerelt gave the original description almost unchanged, and probably did not see the specimen.

\section{2. Pyrrosia fengiana Ching}

Pyrrosia fengiana Ching, Bull. Fan Mém. Inst. Biol. Bot. 11 (1941) 73. - Ty pe: K.M. Feng 7977 (not seen), China, Yunnan, 1700-1800 m.

Judging by the description this is $P$. boothii.

\section{3. Pyrrosia latifolia Ching \& Wu}

Pyrrosia latifolia Ching \& Wu, Fl. Xizang. 1 (1983) 88, fig. 88: 1-3.-Type: Qinghai-Xizang Complex Exp. 5580 (holo HP, not seen), China, Tibet, Dinggyế.

Judging by the description and the illustration this seems to be conspecific with P. boothii.

\section{4. Pyrrosia linearis Ching \& $W u$}

Pyrrosia linearis Ching \& Wu, Fl. Xizang. 1 (1983) 340, fig. 89: 1-3.-Type: Y.T. Chang \& K.Y. Lang 864 (holo HP, not seen), China, Tibet, Bomi, Tungmai.

From the description and the illustration this appears to be a narrow form of $P$. porosa, possibly $P$. porosa var. stenophylla.

\section{5. Niphobolus lingulatus Kaulf.}

Niphobolus lingulatus Kaulf., Enum. (1824) 125; Spr., Syst. 4 (1827) 44; Presl, Epim. Bot. (1851) 126. - Type: Commerson s.n., s.d. (not seen), 'Nova Brittannia'. 
Kaulfuss' description is not very clear; it may apply to $P$. foveolata, in which case 'lingulatus' would be an earlier name. Both Sprengel and Presl followed Kaulfuss' description closely, and probably did not see the material themselves.

\section{6. Pyrrosia matsudai (Hayata) Tagawa}

Pyrrosia matsudai (Hayata) Tagawa, J. Jap. Bot. 24 (1949) 119.-Cyclophorus matsudai Hayata, Ic. Pl. Formosa 10 (1921) 73, fig. 48; G. Chr., Ind. Fil. Suppl. 3 (1934) 65; DeVol, Fl. Taiwan (1975) 207 pro syn. - Ty pe: Y. Matsuda s.n., (July 1919) (not seen), Taiwan.

This species appears to be characterized mainly by the irregularly hastate lamina-outline. In view of the plasticity of the lamina-shape of $P$. polydactyla (discussed under that species) it is most likely a form of that species; alternatively, it may be an aberrant form of $P$. porosa. DeVol (1975) considered it a synonym of $P$. porosa. Somewhat similar plants are discussed on page 74 .

\section{7. Pyrrosia medogensis Ching \& Wu}

Pyrrosia medogensis Ching Wu, Fl. Xizang. 1 (1983) 335, fig. 87: 1-3. -Type: Qinghai-Xizang Complex Exp. 1789 (holo HP, not seen), China, Tibet, Medôg.

According to the description this differs from $P$. lingua var. lingua merely in the absence of hydathodes.

\section{8. Pyrrosia nipponica Beppu \& Serizawa}

Pyrrosia nipponica Beppu \& Serizawa, J. Phytog. Tax. 30 (1983) 46.-Type: Beppu 3361 (holo AICH, not seen), Japan.

This supposed hybrid is discussed in the General Part, page 74.

\section{9. Pyrrosia scolopendrina Ching}

Pyrrosia scolopendrina Ching, Bull. Fan Mém. Inst. Biol. Bot. 11 (1941) 74.-Type: R.C. Ching 24771 (not seen), China.

According to the description this does not differ from $P$. porosa.

\section{10. Pyrrosia similis Ching}

Pyrrosia similis Ching, Bull. Chin. Bot. Soc. 1 (1935) 56. - Ty pe: Y. Tsiang 6816 (not seen), China.

One of the collections cited under this species by Ching (Von Rosthorn 1707) is discussed under $P$. boothii.

\section{11. Pyrrosia transmorrisonensis (Hayata) Ching}

Pyrrosia transmorrisonensis (Hayata) Ching, Bull. Chin. Bot. Soc. 1 (1935) 7 2; Tagawa, J. Jap. Bot. 24 (1949) 118.-Cyclophorus transmorrisonensis Hayata, Ic. Pl. Formosa 4 (1914) 256; C. Chr., Ind. Fil. Suppl. 2 (1917) 11; DeVol, Fl. Taiwan (1975) 207 pro syn. - Ty pe: U. Mori 2363 (not seen), Taiwan. 
From Hayata's description this can be identified as $P$. porosa, the single differential character he gives ('fronds ... pilose on both sides') applies to all Pyrrosia species. The small size and hairy appearance of the type specimens are probably due to the high altitude at which it was collected.

A number of specimens distributed under this name differ in several characters from $P$. porosa, they are discussed on page 74 .

\section{Nomina dubia}

D 12. Niphobolus latus J. Sm.

This name is cited by Baker, in Hooker \& Baker, Syn. Fil. Ed. 2 (1874) 512, but apparently it has never been published.

D 13. Polypodium magnifolium Bory

Polypodium magnifolium Bory, Voy. 4 Iles de mers d'Afrique 3 (1804)

This name and reference were cited by Fée, Gen. Fil. (1853) 262, under Niphobolus bicolor. I have not been able to find it at the indicated place, nor in any other work by Bory.

\section{Nomina excludenda}

E 1. Polypodium americanum Hooker, Sp. Fil. 5 (1863) 54; Baker in Hooker \& Baker, Syn. Fil. (1867) 352; C. Chr., 1937, pro syn. - Niphidium americanum J. Sm., Hist. Fil. (1875) 99. - Niphobolus americanus Diels in E. \& P., Nat. Pfl. Fam. 1, 4 (1899) 325. - Cyclophorus americanus C. Chr., Ind. Fil. (1906) 198; Hieron., Hedwigia 48 (1909) 272.-Syntypes: Jameson s.n., s.d. (not seen), Ecuador, Cuenca; Spruce s.n., s.d.

This species was removed from Pyrrosia and placed in Niphidium by Morton \& Lellinger (Amer. Fern J. 61 (1971) 38) under N. longifolium (Cav.) Morton \& Lellinger.

E 2. Polypodium angustatum Sw. var. depauperata Clarke, Tr. Linn. Soc. 2 Bot. 1 (1880) 559.-Ty pe: Jenkins s.n., s.d. (not seen), India, Assam.

I have not seen any material of this variety; judging by the description it is a Lepisorus spec.

E 3. Niphobolus antillarum Spr., Syst. 4 (1827) 44.

This name is based on Polypodium hirtisorum Desv. = ? Microgramma piloselloides (L.) Copel.

E 4. Niphobolus linearis (L.) Keyserl., Polyp. Herb. Bunge (1873) 39.

Based on Polypodium lineare Thunb. = Lepisorus thunbergianus (Klf.) Ching. 
E 5. Cyclophorus longifolius C. Chr., Dansk Bot. Ark. 9 (1937) 11, nom. illeg., non Desv. $1811=$ Pyrrosia longifolia (Burm.) Morton.-Polypodium longifolium Cav., Descr. 1 (180 2) 245; Sw., Syn. (1806) 28; Spr., Syst. (1827) 47; G. Chr., Ind. Fil. (1906) 541.-Niphidium longifolium Morton - Lellinger, Amer. Fern J. 61 (1) (19 71) 38.-Type: Don Luis Née s.n., s.d. (holo MA, not seen), Ecuador, Pelileo.

See Christensen (l.c.) and Morton \& Lellinger (l.c.) for a discussion of this species.

E 6. Niphobolus lycopodioides (L.) Keyserl., Polyp. Herb. Bunge (1873) 38.

Based on Polypodium lycopodioides L. = Microgramma lycopodioides (L.) Copel.

E 7. Niphobolus neglectus (Bl.) Fée, Gen. Fil. (1853) 263.

Based on Polypodium neglectum Bl. According to Backer \& Posthumus, Varenfl. Java (1939) this is a synonym of $P$. stenophyllum Blume (=Crypsinus stenophyllus (B1.) Holttum). The type specimen, however, could not be located in $\mathrm{L}$.

E 8. Niphobolus percussus (Cav.) Keyserl., Polyp. Herb. Bunge (1873) 38.

Based on Polypodium percussum Cav. = Pleopeltis percussa (Cav.) Hooker \& Grev.

E 9. Niphobolus piloselloides (L.) Keyserl., Polyp. Herb. Bunge (1873) 38.

Based on Polypodium piloselloides L. = Microgramma piloselloides (L.) Copel. Pyrrosia piloselloides (L.) Price is based on Pteris piloselloides L.

E 10. Niphobolus polycarpus (Cav.) Spr., Syst. 4 (1827) 45.

Based on Polypodium polycarpon Cav. = Microsorum punctatum (Gav.) Copel.

E 11. Cyclophorus polycarpus Desvaux.

This name was cited by T. Moore, Ind. Fil. (1861) 276 as a synonym of Pleopeltis polycarpa. Desvaux (Mag. Ges. Naturf. Freunde Berlin 5, 1811: 300) mentioned Polypodium polycarpon as possibly belonging to Cyclophorus but did not make the necessary combination.

E 12. Niphobolus sesquipedalis Keyserl., Polyp. Herb. Bunge (1873) 39. - Type: Wallich, without further indications.

= Lepisorus spec.

E 13. Niphobolus vaccinifolius (Langsd. Fischer) Keyserl., Polyp. Herb. Bunge (1873) 38.

Based on Polypodium vaccinifolium Langsd. \& Fischer = Microgramma vaccinifolia (Langsd. \& Fischer) Copel. 


\section{IDENTIFICATION LIST}

Material used for Hovenkamp, P. H., A monograph of the fern genus Pyrrosia Mirbel (Polypodiaceae). For species treated in Ravensberg * Hennipman (1986), marked '*', see the index of collections in their separate contribution.

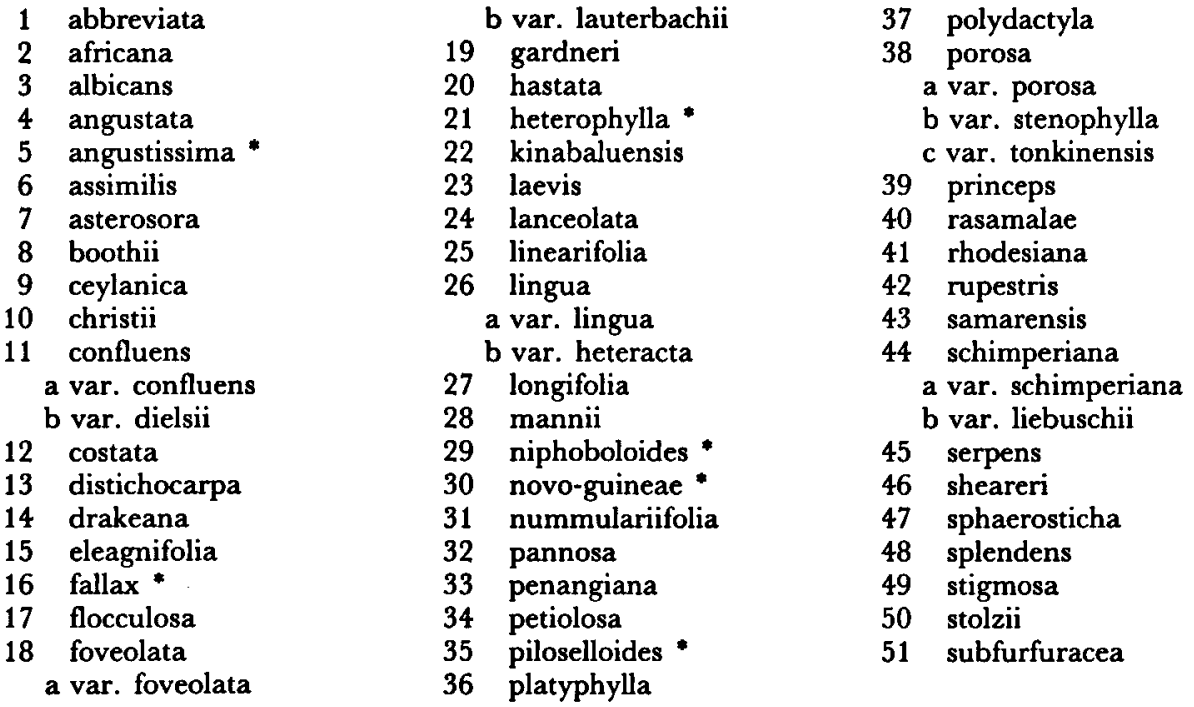

- Abbe et al. 9432: 26 b, 9626: 26 b. Adelbert 158: 3. Aet 179: 24. Aet Idjan: 39. Ah To (CCC) 3068: 26 a. Ajoeb 264: 40, 326: 40, 329: 3, 438: 40. Albrecht 1: 20. Alcasid (PNH) 1724: 24. Alcasid Edaño (PNH) 4660: 31, (PNH) 4708: 31. Allsop * Brückner 220: 2. Alston 12456: 40, 12459: 3, 12768: 3, 12869: 27, 13118: 24, 13222: 24, 13396: 27, 13578: 24, 13609: 24, 13610: 1, 13845: 40, 13846: 1, 13948: 40, 14063: 40, 14065: 7, 14080: 13, 14360: 4, 14989: 13, 15157: 40, 15183: 13, 15622: 27, 15628: 31, 15631: 47, 15657: 24, 15958: 47, 16087: 27, 16890: 39. Amdjah 38: 49, 220: 10, 239: 36, 706: 10. Amnaj 83: 49. Anang 421: 24. Anderson 7757: 24, 8974: 24, 8989: 24, 9054: 27, 9057: 27. Ando \& Suzuki 70355: 26 a. Andrews 212: 27, 252: 11 b. Angus 345: 44 a. Anon (Kew Distr. No.) 973: 26 a, 943: 26 b. Anon (herb. Kew 4195): 36. Anon. (Fukien 794): 26 a. Anon. (Fukien Exp.) 369: 26 a. Anon. (Sun Hong Fan Herb.) 9298: 24, 9316: 24. Anta 300: 27, 343: 27, 507: 27, 970: 27. Antiko 4: 24. Ash 417: 44 a, 694: 44 a. Ashton (BRUN) 8183: 24, S 17973: 24. Atasrip (Exp. Wichmann) 106: 27.-BKF-series 153321: 27, 17004: 27, 24321: 40, 24341: 26 b, 31373: 27, 36356: 4, 46603: 4, 46625: 27. BS-series (Philippine Bureau of Science) 611: 24, 657: 24 746: 27, 903: 24 972: 24 1521: 24, 1573: 24, 1580: 48, 1704: 27, 3411: 38 a, 3433 : 38 a, 3621: 24, 4842: 38 a, 4846: 38 a, 5552: 38 a, 5675: 38 a, 5902: 47, 7519: 27, 7961: 27, 10366: 26 a 10310: 31, 10311: 27, 12052: 43 13822: 48, 14789: 47, 15863: 38 a, 16190: 27, 16204: 31, 16551: 27, 19241: 40, 20872: 27, 24740: 27, 24827: 48, 26882: 24, 27949: 40, 28220: 31, 28257: 24, 28490: 24, 28804: 48, 29053: 24, 29329: 40, 29348: 47, 30259: 43, 31375: 43, 31467: 43, 31672: 38 a, 34365: 27, 34425: 48, 34851: 48, 34911: 27, 35591: 31, 40489: 38 a, 45083: 38 a, 77927: 31, 77940: 31, 77942: 24, 77960: 31, 78734: 31, 80138: 24. BSI-series (Bot. Survey India) 6350: 
35, 6365: 24, 6456: 24, 6488: 24 14767: 28, 14950: 38 b, 15714: 14, 17504: 51, 17563: 31, 19363: 12, 19773: 26 b. BSIP-series (British Solomon Island Protectorate series) 830: 27 2172: 27, 4389: 27, 6289: 24, 7269: 24, 7344: 27, 7940: 27, 13564: 27. Buwalda 6137: 24. BW-series (Boswezen Neth. New Guinea) 10274: 39, 12544: 18 a, 14965: 27. Baagøe et al. 239: 24. Bacani (BS) 15863: 38 a. Backer 52: 49, 372: 3, 722: 31, 746: 27, 841: 49, 926: 49 1229: 27, 1880: 27, 2936: 27, 2950: 27, 3607: 3, 3772: 31, 4019: 27, 4365: 27, 4572: 24, 4861: 33, 6521: 49, 8830: 27, 10882: 3, 11352: 3, 11998: 27, 12258: 3, 12356: 3, 14387: 27, 15877: 3, 16445: 27, 16600: 27, 17213: 24, 17456: 24, 18001: 27, 18013: 49, 18241: 24, 18444: 27, 18782: 31, 22421: 31, 22903: 31, 25395: 40, 26903: 27, 27967: 27, 28883: 27, 30514: 24, 31400: 27, 31481: 27, 31539: 27, 32084: 27, 32085: 27, 32086: 27. Backer Posthumus 23: 3, 75: 3, 161: 24, 165: 27, 168: 3, 254: 49, 305: 49, 315: 49, 369: 40, 414: 24, 538: 31, 637: 49. Backhouse 745: 11 a. Badré 750: 24. Bailey 11: 34, 36: 34, 45: 46 . Bakhuizen v.d. Brink 1807: 31, 1184: 24, 2887: 31, 3538: 24, 4963: 31, 5528: 3, 2586: 3, 3166: 27, 3168: 27, 3762: 27. Balakrishnan 2982: 24. Balakrishnan et al. (BSI) 6488: 24. Balansa 66: 11 a, 160: 24, 156: 38 a, 1930: 38 c, 1931: 26 a, 1932: 26 a, 1933: 26 a. Balapure et al. (LWG) 81230: 35. Van Balgooy 1552: 42, 1744: 45, 1915: 45, 2226: 49, 2343: 27, 2658: 49, 3043: 24, 3675: 24, 3821: 27, 4076: 24. Van Balgooy \&iriadinata 2916: 3. Ballard 1036: 24, 1100: 24, 1369: 38 a, 1437: 24, 1517: 19. Bally 12354: 44 a. Bamler 34: 27, $61: 18$ b, (Rosenst. Fil. Nov.-Guin) 77: 24, 130: 18 b, 134: 27. Bamps 557: 44 a, 5788: 11 a, 80: 44 a. Bamps et al. 575: 41. Banerjee et al. 3189: 17, 3393: 12. Banerji 1299: 38 a, 1514: 38 a, 1534: 28, 1535: 17, 1591: 12. Barchett 684: 46. Barclay 3324: 45, 3325: 45. Barker (LAE) 66849: 18 a. Barker Vinas (LAE) 66573: 27. Barnes 381: 38 a, 437: 38 a, (For. Bur.) 962: 24. Baron 3526: 41, 3805: 41. Bartlett 6060: 46, 6099: 26 a, 6099: 46, 6156: 37, 6721: 24, 6756: 13, 7574: 27, 7629: 24, 7932: 13 14323: 31. Bartlett La Rue 80: 1, 167: 24. Bartsch 108: 24, 169: 24, 175: 24, 362: 24, 386: 48, 393: 48, 443: 48, 450: 27. Baudouin 116: 11 a. Baumann 5826: 11 a. Beattie \& Kurihara 10830: 26 a. Beccari 112: 19, 458: 7. W. Beer's coll. (BSIP) 7269: 24. Beddome 90: 38 a, 91: 24, 92: 24, 93: 24, 102: 26 b. Beguin 37: 3. Bélanger 602: 24. Bels 259: 27, 265: 4. Bequaert 4881: 44 a. Bergeret 30: 11 a. Bernardi 12380: 15, 12865: 27, 13041: 24, 15449: 19, 15519: 38 a, 15530: 32, 15609: 32, 15692: 38 a. Bernier 498: 11 a. Best 21230: 33, 21231: 24. Beumee A 624: 40, 1537: 49, 1765: 49, 3425: 27, 3539: 27, 3569: 49, 3644: 49, 3770: 27, 3843: 49, 3906: 27, 4104: 49, 4396: 49, 4905: 49, 5024: 27. Van Beusekom Phengklai 240: 40, 388: 40, 491: 24, 574: 24, 679: 27, 680: 24, 840: 40, 855: 26 b, 1275: 38 a, 1277: 26 a, 1285: 26 a, 2498: 38 a, 2653: 24, 2653: 38 c, 2983: 38 c, 2998: 26 b. Van Beusekom Santisuk 2771: 24, 2783: 49, 2904: 24, 3213: 24. Van Beusekom et al. 432: 31, 688: 31, 3525: 49, 3648: 33, 4129: 38 c. Bhargawa et al. (BSI) 6350: 35, (BSI) 6365: 24, (BSI) 6456: 24. Biet 1612: 38 a, 1613: 38 a. Bijhouwer 264: 31. Billiet Jadin 877: 24. Bir 8: 17. Bisset 43: 26 a, 540: 25, 1942: 26 a, 1943: 26 a, 1944: 26 a. Biswas 1902: 24, 1940: 28, 1999: 26 b, 2044: 12, 3703: 26 b. Blake 23332: 27. Blanchon 1411: 11 a. Blaxell \& Coveny 3340: 11 a. Bliss 52: 38 a, 169: 38 a, 200: 38 a, 224: 38 a. Bloembergen (Kwae Noi R. Basin Exp.) 20: 31, (Kwae Noi R. Basin Exp.) 27: 24, 3509: 24, 4542: 27, 4758: 27. Boden-Kloss 10592: 24, 14495: 31, 14759: 27, 19045: 24, 19052: 10. Bodinier 1192: 26 a, 1573: 51, 1723: 34, 1743: 46, 1829 bis: 38 a, 1829: 38 a, 1841: 51, 1961: 26 a, 1973: 51, 2538: 51. Boerlage 133: 39. Bogner 446: 44 a, 507: 38 a, 518: 21. Boiteau 2538: 41, 2879: 41, 2990: 41. Boivin 822: 24. Bolster 34: 40, 348: 48. Bon 1327: 24, 1968: 17, 2655: 26 a, 2820: 51. Bor 16: 28, 45: 24, 46: 38 b, 196: 26 b. Dr. Bor's coll. 135: 28. Van Borssum Waalkes 293: 49, 349: 31, 858: 27, 1023: 24, 1623: 4, 1729: 33, 2080: 40, 2083: 1, 2247: 40, 2252: 13, 2273: 1, 2322: 40, 2425: 24, 2606: 4, 2643: 4, 3243: 27, 3297: 24, 3327: 27. Bory 601: 27. Bosser 12617: 41. Bouillod 50: 26 b. Bourne 4956: 24, 5271: 24. Bourret 66: 51, 84: 26 a, 134: 17. Boyland Gillieatt 517: 27. Bradford 371: 38 a, 372: 24. Braithwaite 66: 15, 138: 11 a, (RSNH) 2308: 24, 4135: 24. Brandin 233: 31. Brandis 249: 33, $967: 38$ a. Brass 1143: 39, 1161: 18 a, 1473: 24, 1575: 24, 2554: 27, 5244: 18 a, 5383: 18 a, 5384: 18 a, 5492: 39, 5779: 27, 5780: 24, 5800: 27, 6450: 27, 6457: 24, 6482: 24, 6872: 18 b, 6879: 18 b, 7253: 18 b, 7371: 18 b, 7577: 24, 7579: 27, 7586: 24, 7586: 24, 8492: 27, 8859: 39, 8989: 24, 11372: 18 a, 11832: 18 a, 13782: 24, 13919: 27, 18548: 27, 18659: 27, 19246: 27, 19247: 24, 19846: 27, 20219: 27, 20231: 27, 21806: 24, 21955: 24, 21960: 24, 22063: 24, 23538: 39, 23703: 39, 23857: 24, 24036 : 24, 24126: 24, 24137: 24, 24219: 27, 24335: 24, 24376: 27, 25417: 24, 25450: 24, 25943: 27, 27317 : 27, 27341: 24, 27583: 24, 27786: 24, 28364: 24, 29136: 18 a, 29360: 27, 29539: 18 a, 31095: 18 a, 31380: 18 a, 31631: 18 a, 32604: 24, 32605: 24, 32606: 18 b. Braun 736: 44b, 780: 44b. Brause 317: 24. Brenan 4391: 44 a. Breutel 268: 2. Brinkman 448: 3. Britton 368: 24. Brooke 8102: 24, 
8103: 24, 8227: 27, 8822: 27, 8904: 24, 9629: 24, 10773: 31. Brooks 13: 4, 33: 4, 69J: 3, S 193: 33, 194S: 31, 203/S: 27, S 479: 3 15833: 7, 16866: 24, 17752: 39. Broome 29: 18 a. Brousmiche 30: 11 a. Brown 65: 14, 389: 27, 955: 27. R. Brown 9: 11 a. Brownlie 1008: 24, 2183: 15. Bruggeman 664: 3. Brunt 1247: 44 a. Bryce 8: 27. Buchanan 28: 41, 101: 11 a, 119: 2. Buchholz 1309: 11 a. Bunak 384: 27 (BKF 153321): 27. Bunchuai 1633: 24. Bunchuai Nimanong 1450: 24, 1419: 38 c. Bünnemeijer 52: 24, 75: 40,1415 bis: 24,1659 bis: 27, 1659: 4, 1993: 4, 2058: 27, 2362: 27, 2388: 24, 2750: 40, 2754: 13, 3737: 40, 3775: 1, 3822: 40, 4535: 13, 4823: 40, 4825: 3, 4924: 1, 4970: 3, 5153: 7, 5608: 13, 6010: 24, 6281: 27, 6409: 24, 6802: 4, 6807: 24, 7271: 4 7635: 27, 7889: 27, 8006: 13, 8007: 40, 8010: 40, 8704: 40, 9004: 7, 9043: 7, 9316: 7, 9426: 7, 9582: 7, 10210: 7, 10215: 7, 10789: 49, 10915: 24, 11336: 47, 11757: 49. Burchard (Rosenst. Fil. Sum.) 12: 4, (Rosenst Fil. Sumatr.) 14: 27. Burck 64: 13. Burkill Haniff 15748: 27. Burkill Holttum 8470: 40, 8769: 40, 9010: 24. Burkill \&hah HMB 933: 24, HMB 1011: 4, HMB 1089: 27. Burret 197 a: 3. Buwalda 2746: 27, 3025: 27, 3269: 27, 3718: 24, 3776: 49, 4485: 24, 4925: 24, 5089: 27, 5419: 27, 6052: 27, 6277: 4, 6446: 4, 6630: 4, 6732: 4, 7213: 49, 7551: 49. Buysman 154: 40, 331: 3, 1921: 49, 2312: 40, 2823: 3, 2942: 12, 2943: 17, 2946: 38 a. -CCC-series (Canton Christian College) 1545 bis: 26 a, 1753: 24, 1969:24, 3068: 26 a, 6521:26 a, 6847: 26 a, 7683: 24, 8427: 38 c, 9427: 38 c, 9644: 24, 9725: 38 c 14687: 26 a. CP-series (Collection Peradenyia) 665: 20, 988: 19, 993: 24, 998: 19 993: 9, 1294: 32, 3104: 19, 3104: 38 a, 3104: 38 a, 3293: 9. Cadbury B 13: 24. Cadet 274: 24, 333: 24, 2551: 24, 4300: 24. Cadière 33: $26 \mathrm{~b}, 38: 17,46: 27,65: 26 \mathrm{~b}, 83$ : 26 b, 96: 17, 164: 26 a, 753: $24,927: 38$ c, $960: 26$ a, $970: 38$ c, $972: 26$ a, $981: 26$ a, $992: 26$ a 1008: 51, 1009: 46, 1016: 26 b, 1032: 51, 1033: 38 a, 1120: 46, 1130: 38 a, 1161: 26 a, 1544: 26 b. Caljon 2169: 44 a. Callens 1194: 44 a, 2645: 44 a, 3352: 44 a. Cameron 5: 41 . Campbell 13: 12. Campbell * Hope 83: 28, 99: 17. Campere 744: 44 a. Canright 1087: 4. Carisso \& Mendonça 69: 44 a. Carr 11897: 24, 11965: 27, 12194: 27, 12396: 39, 13020: 18 a, 13039: 18 a, 14682: 39, 16163: 27. Carrick Enoch JC/31: 27. Carse 24: 15. Carter 40: 42. Carvalho 14: 41. Cavalerie 563: 34, 606: 26 a, 1054: 26 a, 1209: 5, 1246: 51, 1427: 38 a, 1527: 38 a, 1807: 46, 1809: 46, 1883: 5, 1902: 51, 1906: 38 c, 1906: 51, 2603: 5, 2762: 51, 2874: 38 c, 2875: 51, 2876: 51, 3386: 38 c, 4410: 46, 4615: 38 a, 7024: 46, 7028: 5, 7299: 51, 7305: 38 a, 7649: 26 a, 7788: 38 a. Cavalerie (Rosenst. Fil. Chin.) 25: 51, 26: 38 a, 27: 34, 28: 46, 110: 26 a, 111: 38 c, 121: 5. Celestino (PNH) 2530: 40, (PNH) 2541: 24, (PNH) 2547: 47. Celestino * Ramos 114 (PNH 23009): 24. Chamlong - Tem 1149 (BKF 31373: 27. Chandra (LWG) 92448: 17. P. Chandra et al. (LWG) 77009: 38 a, (LWG) 81153: 31, (LWG) 81158: 12, (LWG) 83015: 28, (LWG) 89087: 24, (LWG) 94149: 26 b. Chanet 415: 34. Chapman 86: 50, 385: 50. Charette 1416: 26 a. Charoenphol et al. 3720: 40, 4069: 24, 4215: 26 b, 4535: 27, 4746: 26 b, 5020: 24. Chase 1038: 41, 1039: 41, 1040: 44 a, 3102: 41, 3245: 41, 3296: 41, 3297: 41, 3394: 41, 4470: 44 a, 5795: 41, 6438: 41, 6507: 41, 6567: 41, 6577: 44 a, 6612: 44 a, 6715: 41, 6722 A: 41, 6722: 41. Cheeseman 110: 15. Chen 219: 34. Cheng (C.H) 1179: 26 a. Cheng (T.S) 43: 26 a, 1136: 26 a. Cheng 223: 34, 1143: 25. Cheo 19: 26 a, 41: 6, 179: 26 a. Cheo \& Yen 279: 34. Chevalier 29483: 26 a, 29749: 51, 30676: 26 b. Chew Wee Lek 218: 4. Chew et al. 1727: 10. Chiao 1227: 38 a, 1307 (NANK 14718): 26 a, 1679: 26 a, 2695: 34, (NANK 14705): 46, (NANK) 14970: 34, 14123: 26 a, 14226: 26 a, (NANK) 18640: 26 a. Chiao * Fan 518: 14. Ching 1442: 26 a, 21941: 14, 2354: 46, 3429: 26 a, 4120 (NANK 8511): 26 a, 4404 (NANK 8786): 26 a, 6129: 46, 6182: 51, 7172: 38 a, 7316: 24, 8845: 46, 8910: 46. Chipp (SFN 5915): 4. Chow 76100: 34, 78023: 24. Christiaensen 608: 44 a. Christophersen 110: 24. Chu 2284: 26 a, 2314: 51, 2315: 38 a, 2907: 14, 3950: 14, 4068: 51. Chuang 2076: 46. Chuang Kao 2484: 38 a, 2508: 38 a. Chun \& Tso 43987: 26 b, 44076: 38 c, 44153: 38 c, 44160: 26 b. Chung 1001: 26 a, 1390: 24, 1391: 24, 2920: 26 a, 3821: 26 a. Cinatti 357: 27. Clarke 1006: 28, 1033: 24, 5814: 38 a, 5870: 28, 5925: 26 b, 6459: 12, 6459: 17, 8738C: 28, 9746: 12 10785: 38 a, 13116: 17, 13135: 17, 14968A: 31, 15492: 26 b, 15895: 28, 16317: 28, 16318: 26 b, 17762: 28, 17833: 23, 17914 B: 17, 18366: 38 a, 18514: 17, 24396: 24, 24862: 12, 25133C: 28, 25250: 26 b, 26752: 28, $27101 \mathrm{C}$ : 24, 27580: 17, 27962: 12, 36187 B: 12, 37908: 31, 38759: 28, 41215 B: 26 b, 41294: 38 b, 41419B: 38 b, 41424B: 38 b, 42074 A: 51, 42120: 26 b, 42145 B: 12, 42203: 31, 42500 A: 26 b, 43632A: 28, 43659: 28, (CP) 3104: 38 a. Clemens 118: 47, 155: 18 b, 159: 24, 273: 18 b, 503: 48. Clemens - Clemens 1950: 18 b, 2929: 18 a, 3177: 24, 3333: 24, 3334: 27 4016: 18 a, 4972: 18 a, 7679: 18 a, 20759: 24, 21015: 24, 21483: 24, 21484: 24, 21486: 31, 22040: 24, 26984: 22, 27327: 40, 27479 bis: 22, 27479: 22, 28625: 24, 29299: 25, 29628: 24, 33229: 40. Cockburn 23: 38 a (SAN) 84865: 24. Coert 644: 24, 740: 49, 1472: 26 a, 3915: 24. Colani 1563: 51, 1565: 38 c, 1566: 38 c, 1567: 
26 b, 1568: 38 a, 1669: 51, (Petelot?) 3731: 38 c, 3735: 24, 3738: 38 c, 3739: 38 c, 3740: 38 c, 3740: 38 c, 3746: 38 c, 4258: 24, 4522: 51, 4523,: 24, 4524: 51, 4526: 12, 4528: 51, 4530: 51, 4868: 17. Collarins 538: 24. Collett 109: 38 a. Compton 169: 11 a. Compton 447: 11 a. Conklin Buwaya I-843 (PNH 78679): 24, I-892 (PNH) 78728: 38 a, I-903 (PNH 78739): 24, I-917 (PNH 78753): 31. Conklin * Del Rosario 35 (PNH) 72385: 24. Conn et al. (LAE) 66321: 18 b. Conover 1299: 26 a. Constable 4297 (P 8625): 42, 5062 (P 9034): 42, P 3094: 42, P 6260: 42, P 6279: 42, P 6685: 42, P 6686: 42, P 6714: 42, P 6800: 42, P 6973: 42, P 7393: 42, P 7958: 11 a. Coode et al. (NGF) 29644: 27. Cooper (for Bulley) 4667: 26 b. Cooper 1392: 38 a. Copeland 301: 24, 660: 27, 684: 48 1303: 47, 1412: 27, 1595: 24, 1660: 47, 1816: 47, 1834 A: 38 a, 1834: 38 a, 2038: 40, (Pterid. Philipp.) 88: 48, 89: 40, 90: 47, 158: 38 a. Copland King 30: 39, 51: 39. Corner (SFN?) 24158: 27, 30136: 24, (SFN) 30574: 27, (SFN) 30575): 4. Corner \& Henderson (SING) 22808: 31, $22811:$ 49, 23057: 27, 23105: 24. Courage 51: 24. Cours 222: 41, 1169: 41, 4034: 41. Coveny 5152: 11 a, 9400: 11 a. Coveny \& Roy 9024: 42. Coveny * Hind 7122: 27. Coveny et al. 5860: 42, 6023: 11 a, 6408: 11 a, 6753: 11 a, 8459: 11 a. Cowdry 4: 24, 279: 34, 1204: 34, 1232: 34, 1595: 38 a. Cramer 42: 4. Craven Schodde 357: 24. Creech 489: 26 a. Cribs 457: 11 a. Croft 39: 18 a, $61: 24,63: 24,143: 18$ a, 427: 27, 564: 18 a, 770:30, 836B: 30, 1044: 24 (LAE) 60585: 18 a, (LAE) 61862: $18 \mathrm{a}$, (LAE) 65281: $18 \mathrm{a}$, (LAE) 65702: $18 \mathrm{a}$, (LAE) 68230: 27, (LAE) 68294: $18 \mathrm{~b}$. Croft - Akakavara (LAE) 68233: 18 a. Croft \& Lelean (NGF) 34905: 18 a, (LAE) 65408: 27. Croft a Marsh 918: 39, 931: 42. Croft \& Vinas (NGF) 34877: 18 a. Croft et al. 949: 42, 980: 11 b, (NGF) 41300: 27. Cuming 67: 24, 67: 27, 88: 40, 92: 43, 93: 24 115: 31, 127: 40, 47, 135: 4, 24, 240: 24, 43, 246: 31, 247: 4, 286: 27, 323:43, 331: 48, 372: 4. Cunningham 33: 11 a, 15. Curran (BS) 4842: 38 a, (BS) 4846: 38 a. Curran \& Merritt (BS) 16551: 27. Curran et al. (For. Bur.) 16284: 38 a. Curtis 590: 24.-Daemel 78: 42, 335: 42. Däniker 95: 11 a 95 a: 11 a, 2323: 11 a, 2394: 11 a. Dai 24137: 46, 26908: 26 a, 101568: 14, 101596: 5, 103906: 38 a, 104588: 14/46 (interm.), 104590: 51. Damask 7: 39. Danser 6369: 31. Darbyshire 389: 27, 863: 24, 986: 24. Darbyshire \& Hoogland 8225: 24, 8276: 24. Darnaedi 125: 7, 40, 162: 24, 186: 24, 251: 24, 267:36, 1761 : 47, 2112: 47. Darnton 216: 40. David 558: 38 a, 567: 34, 655: 38 a, 2261: 34, 2274: 38 a. Davidse 8102: 21, 8253: 19. Davidse \& Sumithraarachchi 8080: 32. Decary 1728: 41, 1753: 41, 6960: 41, 14671: 41, 16769: 41, 17744: 41, 18181: 41, 18317: 41. Degener 15006: 24. Degener \& Ordonez 13790: 24, 13860: 24. Deistel 520: 44 a. Delavay 34: 34, 36: 38 a, 48: 51, 280: 38 a, 1157: 38 a, 1197: 38 a, 1734: 14, 3250: 14, 4518: 14, 4954: 26 a, 4954: 46. Dennis (BSIP) 7940: 27. Deplanche 9: 27, 33: 11 a. Descoings 8175: 24, 8286: 24, 9542: 24. Dickason 557: 24, 6560: 24, 6633: 24, 6713: 26 b, 6745: 28, 6747: 17, 6951: 24, 7420: 38 a, 7845: 38 a, 7981: 24, 8261: 49, 9175: 24, 9206: 26 a. Diels 8406: 11 b. Dietrich 232: 42, 297: 11 a, 482: 11 a, 483: 11 a. Dihm 52: 35, 53: 35, 54: 35, 60: 24, 61: 24, 62: 24, 63: 4, 64: 31, 66: 33. Dilmy 990: 3. Din 168: 26 a. Dissing et al. 2343: 18 b. Dockrill 252: 11 b, 271: 11 b, 283: 42. Docters v. Leeuwen 289: 3, 290: 33, 1095: 3, 1659: 24, 2622: 40, 9293: 24, 9559: 24, 9456: 39, 9691: 24 10422: 24, 11082: 24. Docters v. Leeuwen-Reijnvaan 732: 40, 745: 31, 2110: 31, 3626: 27, 3764: 27, 4085: 27, 5059 a: 35, 5070: 27 7373: 42, 11578: 24, 11606: 49, 11783: 35, 12599: 35. Doederlein (Herb. Luerssen) 11153: 26 a, (Herb. Luerssen) 11392: 26 a. Doenitz (Herb. Luerssen) 11343: 26 a, (Herb. Luerssen) 11344: 26 a. Donk 1: 35, P 332: 3, P 368: 3, P 369: 3. Dorsett Dorsett 3049: 34. Dr. King's coll. 60: 8, 201: 4, 207: 4, 222: 24, 328: 27, 461: 33, 8090: 24, 8270: 31, 8275: 4, 8330: 24, 8361: 49, 10482: 24, 10597: 4. Dransfield 3216: 4, 3306: 27, 3822: 27, 4001: 31. Dransfield \& Saerudin 2168: 24, 2172: 31, 2214: 36. Drummond Hensley 1917: 24. DuBois-Reymond 137: 26 a. Ducloux (Herb. Bonati) 30: 38 a, 32: 38 a, (Herb. Bonati) 44: 38 a, (coll. S. Ten) 108: 14, 150: 46, 2050: 46, 2425: 38 a, 3351: 38 a, 3402: 38 a, 5051: 38 a, 5102: 46, 7221: 38 a, 7381: 38 a, 7466: 38 a. Dümmer 788: 24. Dunn (Hongkong herb.) 3822: 26 a. Dusselman 91: 27. Duthie 1303: 38 a, 2243: 12, 3696: 24, 3697: 38 a, 6294: 38 a, 15566: 38 a, 26040: 17. Dutta 79/11: 24. - Eberhardt 26; 27: 17, 39: 38 a, 40: 38 a, $42: 51,51: 38$ a, 78: 26 b, 106: 17, 112: 26 b, 119:17, 135: 38 a, 164: 38 a, 419: 17, 1341: 26 b, 9107: 38 a, 9108: 51, 9112: 38 c. Edaño 2568 (PNH 11255): 24, 9676 (PNH 40521): 43, 9717 (PNH 41294): 38 a (BS) 24740: 27, (BS) 24827: 48, (BS) 26882: 24, (BS) 77927: 31, (BS) 77940: 31, (BS) 77942: 24, (BS) 77960: 31, (BS) 78734: 31, (PNH) 482: 31, (PNH) 749: 27, (PNH) 3877: 43, (PNH) 12585: 48, (PNH) 12592: 31, (PNH) 12602: 27, (PNH) 15124: 24, (PNH) 15176: 43, (PNH) 16644: 27, (PNH) 16651: 43, (PNH) 17265: 27, (PNH) 17291: 40, (PNH) 35870: 24, (PNH) 35879: 24. Edaño \& Guttierez (PNH) 38558: 24. Edelfeldt 105: 39, 169: 39, 217: 39. Edeling 173: 27, 204: 27. Eggeling 1559: 44 a, 2024: 44 a, 2117: 44 a, 2295: 44 a, 2839: 44 a. Elbert 
1598: 33, 4621: 24. Elmer 5891: 24, 6060: 24, 6297: 38 a, 7061: 31, 7075: 24, 7649: 27, 7683: 24, 7751: 27, 7753: 27, 7767: 47, 7867: 27, 9042: 40, 9480: 24, 9512: 47, 9804: 47 10221: 24, 10766: 47, 11303: 31, 12133: 27, 13222: 27, 13597: 48, 13618: 31, 14234: 31, 15892: 48, 16872: 43, 16975: 24, 17959: 27, 17965: 27, 18174: 24, 20659: 36, 20680: 4, 20909: 31, 21334: 27, 21962: 47, 22015: 24, 22255: 40, 22325: 40. Endert 1505: 24, 1516: 27, 2163: 24, 3146: 10, 3161: 27, 4617: 24, 4617: 27, 4666: 10, 4957: 27, 5217: 36, 5384: 24, 5391: 31, 5395: 24, 5396: 24. Endlich 122: 15. Engler 382: 24, 5085: 40, 5162: 3, 5397: 26 b, 6985: 34. Equipe de Boukoko 69: 44 a, 990: 44 a, 998: 44 a, 999: 44 a, 1090: 44 a, 1199: 24. Ernst 69: 1, 179: 3, 585: 27, 658: 40, 660: 1, 710: 1, 711: 13, 836: 31, 871: 27 1025: 4, 1047: 4, 1048: 27, 1138: 27, 1160: 40, 1161: 40, 1383: 27, 1384: 27. Escritor (BS) 20872: 27, (PNH) 20865: 24. Esquirol 20: 38 c, 22: 38 a, 23: 26 a, 324: 51, 635: 46, 2037: 5, 2078: 5, 2603: 6, 2674: 51, 2696: 26 a, 3232: 34, 26 a, 3266: 26 a, 6084: 26 a. Evans 148: 40, 1532: 24, 182 8: 24, 1996: 24. Evans et al. 15118: 44 a. Everest 1066: 11 a. Evrard 340: 38 a, 1008: 26 b, 1014: 26 b, 1194: 49. Exell \&endonça 117: 44 a. Eyles 4472: 41. Eyma 1668: 47, 3705: 24, 3945: 31, 4042: 27, 4135: 24, 5110: 18 a. - Faber 47: 5, 1049: 51, 1064: 26 a, 1075: 38 a, 1076: 14, 20152: 38 c. Faden 70/306: 44b. Faden \&aden 77/52: 19, 74/378: 44b, 76/300: 9, 76/379: 38 a, 77/53: 24. Faden et al. 76/235: 38 a. Fairchild 58: 1. Fairchild a Dorsett 547: 1, 651: 13. Falconer 166: 24, 453: 17, (Kew distr.) 979: 38 a, 1297: 17, 1298: 12. Fan $\&$ Li 61: 26 a, 107: 46, 433: 46, 660: 6. Fang 38: 34, 272: 26 a, 815: 26 a, 1066: 46, 1095: 26 a, 1776: 26 a, 1814: 46, 2710: 14, 2748: 26 a, 3056: 14/46 (interm.), 3459: 51, 3490: 38 a, 3966: 14/46 (interm.), 4539: 46, 5667: 34, 5729: 46, 5840: 46, 6663: 26 a, 6666: 14, 6671: 14, 7991: 26 a, 8059: 26 a, 8284: 51, 8473: 26 a, 8600: 26 a, 9091: 34, 12848: 14/46 (interm.). Fang (?) 8824: 38 a. Farges 95: 5, 275: 14, 452: 5. Farlane 169: 24. Farlow 277: 15. Farrel 3: 38 a. Fasken 177: 24, 179: 15. Faurie 77: 25, 79: 34, 134: 20, (Rosenst. Fil. Form.) 170: 46, 218: 20, 222 (Rosenst. Fil. Form. 171): 24, 223: 26 a, 484: 46, 485: 46, 486: 37, 487: 37, 609: 37, 610: 24, 707: 34, 708: $25,847: 25,1293: 20,1563: 20,2864: 26$ a, 2868: $25,3834: 25,4572: 26$ a, 5249: 25, 5639: 25, 6607: 25, 7758: 26 a, 8097: 25, 8435: 37, 11807: 25, 11977: 26 a, 13474: 25, 15643: 26 a, 29643: 26 a, 72280: 20, 782175: 26 a. Feng 620: 14, 2490: 38 a, 3361: 38 a. Fenix (BS) 3621: 24, (BS) 12914: 38 a, (BS) 28220: 31, (BS) 28257: 24. Ferguson 173: 24, 175: 38 a, 176: 19. Ferman 32: 33. Feuilleteau de Bruyn 220: 24. Feung Kao 267: 38 a, 270: 46. Fisher 1138: 41, 1577: 41, 1635 a: 41. Fisher \&chweicherdt 222: 41, 273: 44 a 449: 41, 496: 41. Fleischer 693: 3. Fleming 5: 24, 10: 17, 78: 38 a, 120: 17, 120 A: 17, 877: 38 a, 948: 38 a, 951: 12. Flora of Thailand 7936: 27, 9727: 27. Floto 7537: 26 b. Floyd 6510: 24. Floyd \&ray (NGF) 8035: 24. Forbes 1003 bis: 3, 1036 a: 3, 1965: 40, 2547 a: 40, 2547 b: 3, 2547: 40, 3625: 24. Ford 217: 6. Foreman et al. (LAE) 60037: 18 a. Forrest 9464: 12, 9508: 12, 10108: 38 a, 11355: 38 a, 11766: 38 a, 13119: 14, 16195: 14, 16220: 38 a, 17103: 38 a, 18269: 12, 18443: 38 a, 20374: 38 a, 25022: 38 b, 25094: 26 b. Fortune 169: 24. Fosberg 30443: 15, 35339: 24, 39703: 24, 43424: 24, 43425: 24, 43841: 31. Fosberg - Moore 58202: 24. Foxworthy (BS) 611: 24. Franc 130: 11 a, 2378: 11 a, (Bonati lle Maré) 1132: 11 a, (Bonati Nov. Cal.) 11 A: 11 a, 11 B: 11 a, 671: 11 a, (Rosenst. Fil. Nov. Cal.) 107: 11 a. Franchet (Savatier, PI. Jap.) 2363: 25. Fraser 99: 11 a, 478: 11 a. Fraser Vickery P 2810: 11 a. Freeman 310: 38 a, 311: 38 a. Friedman 1948: 24. Fries 804: 44 a. Friis et al. 149: 44 a. Frodin (NGF) 26738: 24. Fung 20204: 27. Furuse 1187: 26 a, 6250: 20.-Gamble 360 E: 24, 406 A: 24, 406 D: 24, 6308: 38 a, 6327A: 28, 6331 A: $24,6332: 26$ b, 6335 A: 12,6336 A: 12, 6337 A: 24 , 6338 A: 24, 7016: 28, 7038: 24, 709A: 28, 7919: 24, 7997: 28, 8220: 17, 8350: 12, 9415: 38 a, 9885: 38 a, 9942: 17, 9943: 28, 9998: 28, $11306: 38$ a, 13269: 38 a, 14512: 38 a, 15459: 38 a, 17248: 38 a, 17434: 38 a, 21766: 24, 22524: 17, 22833: 38 a, 24250: 38 a, 27131: 17. Gammie 18284: 38 a. Gandoger 22: 3. Garbett 9164: 12. Garden P 6286: 42. Gardner 53: 19, 263: 19, 1153: 24, 1154: 19, 1226: 28. Garret 48: 45, 460: 38 a. Gaudichaud 2 a: 27, 2 b: 24, 6: 27, 15: 27, 19: 27, 23: 24. Gawi 31: 24. Geesink Phengklai 6238: 33, 6315: 27. Geesink Santisuk 5113: 40, 5255: 27, 5443: 31. Geesink et al. 5531: 49, 6616: 35, 6665: 27, 6943: 38 c, 6944: 49, 7002 A: 38 c, 8123: 38 a. Germain 3131: 44 a. Gerrard 97: 2. Van Gesker 48: 3. Gibbs 3995: 40. Gideon 22: 24, (LAE) 76149: 27. Giesenhagen 2: 40, 4: 31, 5: 31, 6: 27, 7: 27, 8: 27, 9: 27, 10:33, 12: 4, 13: 4, 14: $3,15: 1,16: 24,17: 24,18: 24,19: 24,20: 24,21: 24,22: 24,23: 24,24: 24,25: 24,26: 24,28$ : 24, 29: 24, 31:24, 32: 24, 35: 24, 36: 24, 37: 24, 38:24, 39:24, 40:24, 41: 24, 42: 38 a, 43: 27, 68: 21. Gilbert P 5091: 11 a. Gilbert \& Thulin 731: 44 a. Gill 13: 45. Gillespie 2066: 24. Gillett 13790: 44 a. Gilliland 2105: 41. Giraldi 8b: 38 a, 18(?): 38 a, 21(?): 5, 576: 34, (Herb. Biondi) 36: 5. Giraldi (?) 17: 38 a. Given \&olloy 8115: 15. Gjellerup 806: 24. Glover et al. 8: 44 a, 47: 
44 a. Glynne 238: 24, 244: 44b. Godefroy 472: 49. Goldschmid 188: 2. Gomes \& Sousa 1285: 44 a. Göring 73: 26 a, 197: 3, 280: 26 a. Gossweiler 7362: 44 a. Gough 3242 (?105): 9. Gough (Herb. Ball) 278: 34. Gould 648: 38 b. Goy 435: 11 b. Goy Smith 123: 11 a. Goy \&mith 154: 42. Graeffe 251: 24. Grant 3508: 45. Grashoff 44: 4, 51: 4. Gray * Floyd (NGF) 8030: 24. Green 1165: 11 a, 1465: 11 a. Greenway 1031: 44b, 1755: 44b, 6669: 44b. Gregory 164: 44 a. Grether 3523: 24, 3671: 24, 3696: 24, 4315: 24, 4337: 24, 4483: 24. Grether Wagner 4031: 24, 4220: 39. Grierson t Long 806: 17, 1548: $26 \mathrm{~b}, 2399: 31$. Griffith 26: 12, 880: 31, 978: 38 b 2781: 28, 2781: 38 a, 2781: 38 b, 2782: 8, 2783: 8, 2784: 24, 2787: 24. De Grijs 145: 26 a. Güntzel 79: 34. Guillaumin * Baumann 7468: 11 a, 7741: 11 a, 7786: 11 a, 9286: 11 a, 9428: 11 a, 10399: 11 a, 12072: 11 a. Guppy 75: 24. Gurung 69: 4. Guttierez et al. 423 (PNH 117404): 48, 589 (PNH 117577): 43, 660 (PNH) 117648: 27. -De Haan 1756: 24, 1799: 27. Haines 552: 24, 552 a: 24, 4049: 24, 5377: 12. Hallier 16: 24, 1933: 27. Hancock 3: 33, 8: 6, 9: 34, 16: 24, 21: 25, 23: 3, 27: 6, 32: 26 a, 33: 37, 36: 19, 46: 38 a, 47: 26 a, 48: 46, 51: 14, 52: 51, 53: 51, 68: 49, 96: 25, 165: 24. HandelMazzetti 2103: 34. Haniff (SING) 15887: 24. Haniff \& Nur 2361: 40, 3560: 31, 3969: 33, 10371: 27. Hansen \& Smitinand 12320: 24, 12933: 26 b, 12975: 24. Hansen et al. 10892: 28, 10893: 38 a, 11152: 26 b, 11376: 26 b, 12932: 28. Hara et al. 300: 17, 11309: 8. Van Hardeveld \& v.d.Werff 206: 38 a. Harland 225: 27. Hartley 9784: 27, 12316: 18 a. Hartmann 31: 24, 95: 24. Harvey 31: 24. Hattori 38: 26 a. Hay (Exp. Novara) 285: 15. Hayata 90: 17, 132: 26 b, 288: 26 b. Hellwig 355: 18 a. Hemstra Toussaint 59: 24, 209: 24. Henderson 10282: 24, 11440: 40, 18472: 24, 19447: 33, 19453: 49, 19675: 27, 20149: 24, 20362: 27, (SFN) 21378: 24, 21697: 40, (SFN) 21962: 24, (SFN) 22258: 24, 22366: 27, 25154: 24, 25239: 33, 29076: 24 (SFN) 22556: 33, (SFN) 22572: 49, (SFN) 22771: 27, (SFN?) 22780: 4, (SING) 22238: 33, (SING) 22569: 31. Hennipman 3014: 24, 3015: 49, 3102: 49, 3105: 24, 3114: 24, 3145 A: 26 a, 3145: 26 b, 3149: 38 a, 3203 a: 38 c, 3203: 49, 3243: 38 a, 3245: 26 b, 3304: 38 a, 3319: 24, 3344 A: 24, 3344: 24, 3350: 38 c, 3352: 17, 3463: 26 b, 3498: 24, 3569 A: 26 a, 3569: 26 b, 3718: 27, 3741: 24, 3750: 24, 3791: 24, 3814: 40, 3831: 26 b, 3920: 24, 3922: 31, 3944: 26 b, 4007: 27, 5006: 24, 5035: 27, 5036: 39, 5049: 24, 5085: 47, 5122 A: $47,5138: 47,5190: 31,5200: 47,5559: 31,5560: 24,5706: 35,5716: 27,5752: 27,5788$ : 24, 5792: 31, 5898: 24, 5948: 47, 5958: 27, 6114: 31. Henry 47: 5, 644: 46, 747: 24, 1075: 38 a, 1247: 26 a, 1428: 46, 1429: 26 a, 1431: 26 a, 1432: 26 a, 1993: 38 a, 2369: 46, 2813: 46, 4624: 51, 5028: 46, 5128: 26 a, 5137: 5, 5447: 5, 5486: 38 a, 5488 a: 5, 5488: 5, 5570: 51, 5810: 26 a, 9061 (A, B, C): 38 a, 9114: 46, 9114A: 46, 9116: 46, 9291: 51, 9834: 51, 10263: 34, 11816: 26 a, 12704 A: 12, 12704: 12, 12884 A: 24, 12884 B: 24, 12884: 24, 13071 (A, B, C): 38 a, 13329: 26 a. B. C. Henry 145: 26 a. Henty (NGF) 16680: 24. Hepburn 95: 44 a. Herre 1245: 27. Van Heurn (NIAS): 3, 51: 49, 52: 40, 53: 40, 54: 40, 55: 40, 57: 24, 58: 3, 59: 3. Hiepko \& SchultzeMotel 585: 24, 1444: 18 a. Hirano * Hotta 4: 24. Hochreutiner 199: 3, 3431: 24. Hodgkinson 84: 11 a. Den Hoed \& v. d. Meer 419: 24, 497: 27. Hohenacker 5: 42, 907: 38 a. Hollrung 448: 24. Holstvoogd 332: 3, 381: 1, 463: 24, 702: 24, 733: 27 743: 24, 767: 24, 859: 24. Holttum 9520: 24, 10953: 24, 14541: 13, 19054: 27, 19777: 24, 21585: 40, 25358: 40, 28113: 40, 28117: 1, 31343: 40, (SFN) 9428: 4, (SFN) 9951: 4, (SFN?) 9421: 4, (SFN?) 9938: 4, (SFN) 25304: 40, (SING) 39199: 38 a. Hombron 19: 45. Hoogland 4173: 24, 4994: 39, 5070: 24, 10035: 42, 11277: 11 a. Hoogland \&raven 10284: 27. Hoogland * Pullen 6237: 18 a. Hooker Thomson 74: 23, 77: 17. Hope 83: 28, 143: 17, 149: 17, 287: 28, 287: 38 a, 330(?): 38 a. Hope Campbell 66: 17. Hose 708: 27. Hose \&ose 5015: 24, (SFN) 4844: 4, (SFN) 5018: 4. Hosokawa 7325: 24. Hosseus 325: 24. Hotchkiss 181: 42, 366: 42. Hotta (Pterid. Jap. 594) 11760: 26 a, 12661: 27, 13086: 4, 14216: 4, 14217: 27, 14319: 27. Hou 174: 27, 751: 4. How 70505: 27. 71360: 24, 72884: 26 b, 73428: 26 a. How Chun 70188: 26 b. Hsu Kuoh 12500: 25. S. Y. Hu 1426: 26 a, 5196: 24, 5425: 24, 5547 A: 24, 6081: 24, 6709: 24, 7612: 26 a, 8152: 26 a, 8995: 24, 9518: 24, 9683: 24, 9687: 26 a, 9709: 26 a, 9710: 24, 9844: 24, 9886: 24, 10777: 26 a, 11220: 24, 11955: 24, 13576: 26 a. Huber 439: 32, 465: 38 a. Hürlimann 15: 11 a, 558: 24. Humbert Capuron 22029: 24. Humbert \& Cours 17715: 41. Hume 8393: 4, 9359: 24. Hundt 294: 44 a. Hynes 31488: 15.-Iboet 58: 27, 59: 4, 128: 4, 136: 49, 479: 27. Idjan \& Moehtar 104: 27, 180: 39, 335: 27, 350: 39. Igura 17: 25. Inayat (Herb. Hope) 25085: 17, 26040: 17, 26040A: 28. Ip 1776: 46. de l'Isle 120: 24, 564: 24. Isles \& Croft (NGF) 32231: 24. Ito 66: 26 a, 67: 20, 2059: 25. Iwatsuki 4556: 20. Iwatsuki et al. 58: 25, B 447: 4, B 705 bis: 24, B 705: 4, B 765: 4, B 794: 24, В 840: 31, В 850: 24, B 974: 36, B 2128: 22, B 2764: 31, B 2781: 24, B 2981: 24, B 3255: 10, P 1198: 40, S 168: 13, S 261: 24, S 360: 4, S 716: 24, S 1375: 13, S 1598: 40, S 1599: 1, T 8443: 26 b, T 8503: 31, T 9595: 26 
b.-Jaag 989: 33, 1003: 24, 1706: 24, 1781: 3, 1831: 3. Jacobs 4787: 27, 5132: 22, 5157: 24, 5521: 27, 5636: 31, 7791: 47, 8407: 31. Jacobson 9: 49. Jacques-Felix 4443: 44 a. Jagor 181: 3, 548: 49. Jaheri (Exp. Nieuwenhuis) 868: 10, 1369: 36. James et al. S 37492: 24. Janowsky 452: 27. Jansen 6349: 44 a. Jarrett \& Saldanha (HFP) 765: 38 a. Jayasuriya 864: 19. Jayasuriya \& Premadasa 1646: 19. Jelineck 152: 45, (Exp. Novara) 286: 15, 287: 15, 288: 15. Jeng 1934: 38 a. Jensen 153: 24, 155: 24. Jermy 13333: 31, 13334: 24, 13764: 31, 13799: 31, 14018: 10, 14201: 24, 14385: 27, 14470: 24. Jeswiet 636 a: 13, 935: 40, 979: 3, 1026: 27, 1718: 1, 1999: 27. Jochems 12: 4, 78: 1, 566: 13. Johansson 808: 44 a. Johnstone 33: 24. De Joncheere BCO 66, ETS 12: 44 a, SAC 254: 2. Jonker 322: 27. Joss 91: 27. - Kadim * Mahmood KM 55: 27. Kadim * Noor K 280: 4. Kadim * Noor K 428: 27. Kadir 18054: 27. Kairo 242: 24, (NGF) 45425: 27. Kajewski 101: 27, 714: 27, 1159: 11 b. Kalkman 4274: 18 a. Kanehira 2015: 24. Kanis 1015: 27, 1091: 24, 1153: 39. Kanis \& Karupin 54369: 24. Kao 3843: 25, 3891: 37, 3909: 38 a, 4175: 26 a, 6514: 24. Kari 10: 26 b, 20: 28, 188: 26 b. Karsten 76: 11 b. Karta 326: 24. Kassner 2644: 44 a, 2947: 44 a, 3399: 44 a. Katik (LAE) 62129: 39. Katik et al. (LAE) 70909: 30. Kato et al. B 4146: 36. Kaulbach 297: 24. Keenan et al. 797: 40, 5592: 26 b. Kehding 2903: 4. Keiske 10: 26 a, 13: 26 a. Keng 1324: 24, 8467: 40. Kern 8517: 40. Kerr 2677: 38 a, 6632: 38 a, 7302: 31, 14621 (Eryl Smith 2588): 31, 17147: 24. Kew Distr. 941: 24, 945: 49, 949: 38 a, 969: 24. Khwaunsu (Khwaunju?) 1222: 24, 1225: 38 b, 1228: 17. Kiah (SING) 35314: 33. Kingdon-Ward 4: 24, 9363: 8, 14222: 38 a, 19036: 38 a, 19198: 38 b, 19227: 26 b, 19235: 14, 20454: 40, 20455: 12, 20669: 23. Kjellberg 776: 27, 1660: 31, 1684: 24. Klein 38: 24. Kleinhoonte 551: 24, 566: 49, 567: 1, 602: 31. Klemme (BS) 5675: 38 a. Ko 55175: 38 c, 55633: 38 a, 55644: 51, 55739: 38 c, 55882: 46. Koelz 3112: 38 a, 21402: 17. Komarov (Fl. Mansh.) 47: 34. Kondo a Edaño 8893 (PNH 38690): 24, (PNH) 38673: 24, (PNH) 38706: 24. Konta (Pterid. of Japan 544) 4778: 26 a. Koorders 2722 (17010 B): 27, 300 (17101 B): 27, 15431 B: 24, 17102 B: 24, 21189 B: 49, 31435 B: 24, 35349 B: 27, 35354 B: 24, 35680 B: 49, 44103 B: 27, 44182 B: 27. Kooy 419: 27. Koper B 1021: 40. Kornaś 733: 44 a, 3451: 44 a. Kornassi 928: 24, 1216: 27. Kornicke(?) 14524 a, b: 3. Korthals 42(?): 4, 52 B: 13, 56: 4, 90: 40, 102(?): 4, 109: 4, 179 Fi: 13, 206: 4, 236(?): 3, 253: 27. Kostermans 96: 4, 138: 4, 324: 4, (Kwae Noi R. Basin Exp.) 1403: 49, 4609: 31, 5056: 27, 5147: 27, 5624: 36, 5647: 4, 5680 a: 36, 5728: 4, 6047: 36, 6455: 24, 6512: 4, 7993: 27, 8720: 4, 13308: 36, 18268: 40, 18278: 24, 18281: 40, 18545: 40, 18818: 40, 21403: 36, 22084: 27, 22122: 1, 25512 A: 19, 27114: 19, 27230 a: 21. Kostermans Anta 507: 27. Kostermans Soegeng 858 A: 18 a. Kostermans \& Wirawan 339: 27. Kostermans et al. 49: 49, 86: 40, 88: 3. Koyama 45: 25. Kramer (Savatier) 2246: 25. Kramer \& Nair 6180: 9. Kramer et al. 7667: 37, 7752: 38 a, 7817: 46, 7850: 26 a, 7962: 24, 8124: 37, 8130: 46, 8142: 38 a, 8175: 37, 8296: 26 a. Van Kregt 83: 24. Krug 321: 34, 347: 26 a, 464: 34. Kuan Wang 1366: 34, 3417: 51. Kubitzki 77-54: 19. Kuhl * Van Hasselt 132: 24. Kunstler 4935: 31, 7083: 33. Kuntze 5395: 3. Kurata Nakaike 2655: 25, 2657: 25. Kurz 3196: 31, 3200: 12. Kuswata 255: 33. Kuswata Supadmo 62: 27. -LAE 51205: 24, 51540: 27, 52508: 27, 53029: 27, 56112: 30, 58582: 27, 60037: 18 a, 60585: 18 a, 61862: 18 a, 62129: 39, 65281: 18 a, 65408: 27, 65702: 18 a, 66321: 18 b, 66573: 27, 66849: 18 a, 68230: 27, 68233: 18 a, 68294: 18 b, 70326: 27, 70909: 30, 75402: 27, 76149: 27. LWG (Lucknow Bot. Gardens) 49839: 17, 77009: 38 a, 81153: 31, 8i158: 12, 81230: 35, 83015: 28, 88772: 24, 89087: 24, 92448: 17, 94149: 26 b. Laborde * Bodinier 2117: 5. Lacaita 16593: 12. Lace 2207: 26 b, 4915: 17, 5511: 49, 6024: 38 a. Lahaie 936: 39. Lam 102 J: 3, 606: 24, 753: 24, 2476: 24, 3147: 24, 3389: 24, 3599: 27, 3756: 24, 7023: 15, 7125: 15, 7262: 11 a, 7629: 42, 7655: 42, 7660: 11 a. Lambrechtsen 10 A-B: 15. Lamont 312: 11 a, 1035: 24, 1036: 26 a. Lamoureux 3146: 15. Larsen 9747: 24, 10623: 49, 10679: 26 b. Larsen * Larsen 32702: 4. Larsen et al. 816: 24, 851: 24, 855: 49, 1184: 49, 1371: 49, 1672: 27, 1748: 24, 2012: 38 a, 2599: 12, 2678: 24, 3119: 27, 3915: 24, 30846: 26 b, 31457: 24, 31769: 27, 31770: 24. Last 392 (391?): 41. Lau 672: 26 a, 1459: 26 b, 2088: 24, 2542: 6, 3114: 26 b, 3244: 38 c, 3499: 38 c, 4169: 26 a, 4585: 51, 4781: 26 a, 5478: 38 c, 25656: 38 c, 26648: 24, 28502: 38 a, 28581: 5, 28670: 46. Lauterbach 157: 27, 519 b: 18 b. Lavarack Ridsdale (NGF) 31241: 27. Law 1259: 46. Layard 100: 11 a, 101: 11 a. Lebrun 987: 24. LeRat 205: 11 a, 419: 11 a, 810: 11 a. Leach * Katik (LAE) 56112: 30. Lecomte * Finet 484: 51, 575: 38 a. Ledermann 5642: 44 a, 6456: 44 a, 7934: 27, 8840: 30, 14027: 24, 14076: 24. Lee 3808: 14. Leeuwenberg 10246: 44 a. Legendre 1068: 34, 1091: 38 a, 1396: 38 a. Lei 813: 24. Leland et al. 32: 45, 152: 15. Lelean \& Stevens (LAE) 51205: 24. Lelean Streimann (LAE) 52508: 27. Leonard 6994: 24. Lepire 61: 45. Leschenault 149: 38 a. Letouzey 2327: 44 a, 7652: 44 a, 8568: 44 a. Levine (CCC) 1545 bis: 26 a, (CCC) 1753: 
24, (CCC) 1969: 24. Levine et al. (CCC) 6847: 26 a. Lewalle 4343: 44 a, 5323: 44 a, 6470: 44 a. Lewis 80: 4. Liang 62319: 24, 62705: 26 b, 63598: 38 c, 66099: 24. Licent 634: 38 a, 875: 34, 976: 38 a, 1948: 38 a, 2492: 34, 3558: 38 a, 3590: 34, 3615: 34, 3646: 38 a, 4934: 14, 5036: 38 a, 8254: 38 a, 8433: 34, 8582: 34, 8665: 38 a, 12175: 38 a, 13099: 34, 13111: 34, 13161: 34, 13366: 34, 13822: 38 a. Lin 304: 26 a. Linder 2538: 44 a. Linsley Gressit 280: 26 a, 337: 25, 1050: 24, 1403: 26 a. Lister 126: 51. Littke 258: 49. Liu 1933: 34. Loher 863: 38 a, 864: 47, 878: 40, 880: 48, 1180: 24, 1266: 40, 1267: 40, (BS?) 13822: 48, (BS?) 14522: 31. Lorence 536: 24, 537: 24. Lo'ŕzing 539: 3, 689: 31, 689A: 31, 699: 40, 700: 40, 993: 24, 1013: 27, 2566: 3, 4640: 31, 5010: 40, 5400: 24, 5611: 24, 5761: 13, 6045: 40, 6078: 13, 6968: 24, 7021: 1, 7128: 13, 7733: 13, 8437: 40, 8742: 1, 8756: 1, 8901: 13, 9553: 1, 11250: 49, 11921: 40, 11926: 33, 11957: 31, 12219: 24, 12734: 1, 12981: 24, 13704: 1, 13840: 13, 15321: 49, 15979: 1, 16713: 49, 16888: 27, 16937: 33 . Loveridge 74: 24. Lucas 92: 44 a. Ludlow \& Sherriff 2931: 26 b, 2966: 26 b. Ludlow et al. 12053: 14. Ludlow et al. 5362: 14, 6680: 38 b, 6683: 14, 6985: 14, 7226: 12, 12120: 26 b, 12147: 38 b, 12221: 38 b, 18610: 38 b, 18646: 8, 20543: 38 a, 20555: 8. Ludwigs 445: 24. Luh 4064: 34. Lütjeharms 4246: 24, 4694: 24, 5156: 24. Lysaght 53: 15.-Ma 237: 38 a. Maas Geesteranus 6270 a: 44 a. Mabberley Tweedie 1101: 44 a, 3960: 44 a. MacDaniels 2037: 11 a, 2261: 11 a, 2451: 11 a. MacGillivray 3: 15, (HMS Herald) 958 B: 15. Mackinnon 43: 24. Macrae 454: 19. Madulid et al. 858 (PNH 117836): 43, 1297 (PNH 18274): 27. Main 1760: 24, 1769: 27, 1878: 27, 1907: 24, 1911: 27, 1978: 27. Main Aden 699: 27, 903: 39, 1508: 27, 1508 a: 4. Maingay 901: 26 a, 1793: 4. Maire (?) 17: 24. Maire 1387: 38 a, 1483: 38 a, (Bonati) 8: 38 a, (Plantes de Chine) 6466 B: 38 a, 6548 B: 38 a, (Plantes de Yunnan) 6069 B: 38 a. Maitland 1312: 44 a. Makino 34291: 26 a. Malasse 6043: 44 a. Malhotra 112: 28, 114: 28. Man 6: 24. Manickam 81: 38 a, 502: 24, 1607: 38 a, 1659: 38 a, 1715: 38 a, 1951: 24. Manton 157: 19. Marcan 1223: 27, 1317: 24, 1380: 27. Marche 170: 24. Martellini \& Edaño (BS) 35591: 31, (BS) 35278: 43, (BS) 35626: 43. Martensz 4014: 11 a. Martin 458: 26 b. Martin \&odinier 1743: 46, 1829: 38 a, 1841: 51, 2128: 26 a. Matsumura 13: 26 a, 115: 25, 151: 25, 176: 25, 234: 26 a. Matthew 13: 45, 14: 40, 40: 26 b, 41: 49, 702: 24, 920: 1. Mauen 38055: 33. Mauriasi et al. (BSIP) 13564: 27, 15: 26 a, 16: 34, 17: 20. Maxwell 74-867: 26 b, 74-900: 24, 74-992: 24, 75-1100: 49, 75-879: 31, 76-194: 27, 80-43: 4, 81-149: 24. McClure 1299 (CCC 7683): 24, 1549 (CCC 7706): 24, 1565 (CCC 7908?): 24, 1892 (CCC 8427): 38 c, (CCC) 6521: 26 a, (CCC) 9427: 38 c, (CCC) 9644: 24, (CCC) 9725: 38 c. McGregor 254: 27, 255: 43, 496: 24, (BS) 10310: 31, (BS) 10311: 27, (BS) 1704: 27. McKee 2587 (NSW P 8649): 11 a, 2811 (NSW P 7345), 3011 (NSW) P 7346: 24, 3128 (NSW P 7348): 27, 3233 (NSW P 7581): 11 a, 6147 (NSW P 8255): 38 a, 8218 (NSW P 8213): 11 a, 19681: 11 a, 28892 bis: 11 a. Mcmullin 19: 24, 33: 24, 35: 24. Mearns 1118: 44 a, 1626: 44 a, (BS) 3411: 38 a, (BS) 3433: 38 a. Meebold 2143: 26 b, 2146: 28, 2147: 12, 3068: 42, 3612: 42, 4646: 15, 4796: 31, 5822: 15, 5876: 26 b, 7402: 12, 7581: 24, 8115: 38 a, 12625: 2, 16627: 24, 26515: 24. Ven der Meer Mohr 25: 24. Meijer 293: 24, 585: 24, 673: 22, 681: 22, 691: 24, 698: 22, 699 b: 22, 847: 22, 1111: 27, 1974: 4, 2029: 4, 2196: 4, 2220: 4, 2257: 4, 2373: 24, 2378: 4, 2403: 27, 2462: 24, 2466: 27, 2482: 4, 5581: 24, 9564: 31, 9566: 24, 10568: 3, 12176: 49, 12192: 33, (SAN) 23618: 36. Meijer * Gunatilleke 1392: 19. Melville \& Mair NSW 751: 11 a. Mendonça 3690: 44 a. Mendoza 61-103 (PNH 41943): 27, 61-644 (PNH 42474): 48, 61392: 27, (PNH) 17231: 47, (PNH) 97959: 48. Mendoza Convocar (PNH) 8626: 27. Merrill 545: 24, 902: 38 a, 903: 24, 3757: 31, 3819: 31, 3822: 24, 4016: 24, 5272: 27, 5316: 31, 5996: 43, 6360: 38 a, 11349: 34, (BS) 903: 24, (BS) 10366: 26 a, (Philipp. Plants) 902: 38 a, (Philipp. Plants) 1142: 31, (Spec. Blancoanae) 790: 24. Merritt (BS) 12052: 43. Metcalf et al. 667: 26 a, 3583: 26 a. Metzner 96: 27. Meyer 958: 34, 1037: 38 a, 1818: 14, 7939: 44 a. Meyer et al. 17160: 26 a, 17322: 26 a. Michel 43: 44 a, 94: 44 a. Millar 1172: 24, 1175: 27, (NGF) 23312: 39, (NGF) 23565: 39, (NGF) 35277: 27, (NGF) 35387: 24. Millar \& Holttum (NGF) 15764: 18 a, (NGF) 15971: 18 a. Millar Vandenberg (NGF) 37573: 27, (NGF) 40902: 24. Millar \&an Royen 15652: 39. Millburn 39: 24. Mills 280: 25. Milne (HMS Herald) 61; 62: 15, 141: 24. Milne-Redhead 3437: 44 a. Mizushima 14810: 25. Mjöberg 5: 10. Mohidin 8597: 24. Moi 140: 24. Molesworth Allen 998 a: 27, 1088: 40, 1395: 24, 1503 A: 49, 1524: 4, 2308 : 40, 2328: 49, 2413: 1, 2557: 27, 3173: 31, 3174: 24, 3202: 31, 3719: 44 a, 3912: 33, 4396: 31, 4611: 4, 4832: 49, 4840: 33, 4841: 31, 4901: 4. Von Möllendorf 145: 34. Moon 98: 19. Mooney 478: 24, 1169: 49, 1366: 24, 3080: 24. Moore 61: 45. Moore 206: 24, 252: 45, 259: 24. Moran 5525: 20. Morris 74: 41. Morrison 26: 24. Morse 69: 38 c. Morton 88: 26 b. Mossman 627: 15, 627: 42. Mousset 14: 24, 129: 24, 244: 24, 768: 40, (C. Muller herb. Jav.) 152: 3, 154: 40, 167: 49, 
484: 49, (Rosenst. Fil Jav. Or.) 81: 3, 32: 40, 22: 24, 95: 49. Muchtar 79 A: 4. Murata 9845: 26 a, 15849: 26 a, (Pterid. of Japan) 12339: 25. Murata et al. T 15 718: 26 b, T 16275: 27, T 16927: 49, T 16932: 24, T 17556: 24, T 17623: 27, T 17677: 27.-NGF 7618: 18 a, 8030: 24, 8035: 24, 8303: 18 a, 8618: 24 11722: 18 a, 12051: 27, 12081: 24, 12809: 18 a, 15764: 18 a, 15971: 18 a, 16287: 18 a, 16399: 24, 16467: 27, 16680: 24, 18059: 27, 21897: 24, 23312: 39, 23565: 39, 28603: 24, 29644: 27, 31241: 27, 32231: 24, 34101: 24, 34103: 24, 34877: 18 a, 34905: 18 a, 35277: 27, 35387: 24, 37106: 39, 37573: 27, 40902: 24, 41300: 27, 43636: 24, 45425: 27, 47714: 24. NIASseries: see Van Heurn. NSW P 2034: 42, P 6286: 42, P 6345: 24, P 7346: 24, P 7348: 27, P 8255: 38 a, P 9313: 15, P 3094: 42, P 6260: 42, P 6279: 42, P 6685: 42, P 6686: 42, P 6714: 42, P 6800: 42, P 6973: 42, P 7393: 42, P 8625: 42, P 9034: 42. Nagler 420: 1. Nakaike 49: 18 a. Nakisi (BSIP) 7344: 27. Namegata 10784: 38 a. Native coll. (BS) 746: 27, (BS) 1521: 24, (BS) 1573: 24. Nayar et al. (LWG) 49839: 17. Nayaranaswami 628: 24. Naylor Beckett 815: 32. Necker 86: 24, R 98: 24. Nedi 127: 24. Nedi 677: 27. De Nere 783: 24. Nicodemus (PNH) 22708: 24. Nicolson 2293: 28, 2535: 17. Niederlein 209: 34. Van Niel 3388: 27, 3425: 27, 3833: 24. Nielsen 291: 24, 314 : 11 a, 315: 11 a, 614: 24, 747: 27, 948: 10. De Nijs 1971: 3. Nitta 15278: 35. Noerkas 109: 27, 122: 27. Nol 99: 49. Noorudin 6750: 24. Nooteboom 1150: 31, 1226: 10, 1405 A: 22. Nur 22: 31, 69: 49, 192: 4, 11134: 40, 11805: 4, 12056: 31, 12059: 49, 12060: 4, 12071: 33, (SING) 34000: 24.-Ocampo (BS) 27949: 40. Oldham 53: 26 a, 54: 25, 145: 26 a, 239: 25, 276: 26 a, 315: 25, 1048: 25. Van Oosten 16: 49. Van Ooststroom 13151: 3. Orchard 3728: 15.-PNH 482: 31, 749: 27, 1724: 24, 2530: 40, 2541: 24, 2547: 47, 3436: 47, 3877: 43, 4521: 24, 4660: 31, 4708: 31, 8626: 27, 11255: 24, 12585: 48, 12592: 31, 12602: 27, 12642: 27, 15124: 24, 15176: 43, 15176: 43, 16644: 27, 16651: 43, 17231: 47, 17265: 27, 17921: 40, 20865: 24, 22708: 24, 23009: 24, 35870: 24, 35879: 24, 38558: 24, 38673: 24, 38706: 24, 40521: 43, 41294: 38 a, 41943: 27, 42474: 48, 72385: 24, 78679: 24, 78728: 38 a, 78739: 24, 78753: 31, 96227: 40, 97959: 48 117404: 48, 117577: 43, 117648: 27, 117836: 43, 118274: 27. Palis 5: 39. Palmer \& Bryant 72: 24, 100: 24, 711: 27, 1265: 24, 1290: 24, 1294: 31, 1298: 4 9, 1299: 27, 1300: 27, 643: 24. Pancher 1: 11 a, 22: 11 a, 116 : 11 a. Panigrahi 15137: 24, (BSI) 14767: 28, (BSI) 14950: 38 b, (BSI) 15714: 14, (BSI) 19363: 12, (BSI) 19773: 26 b. Pant 31837: 12. Parham 8: 24, 21: 24. Parish 20: 27, 56: 24, 134: 26 b, 143: 33, 160: 26 a, 180: 26 b, 243: 38 a. Parks 16300: 24, 16426: 24, 20511: 45. Parks * Parks 22098: 45, 22246: 45, 22339: 45, 22346: 45. Parris Croxall 5756: 27. Pawek 2214: 50, 3330: 50, 12277: 50. Pedro \& Pedrogăo 6063: 44 a, 6466: 41. Pei 10093: 34. Pendleton 435: 27. Perrier de la Bâthie 6156: 41, 7442: 24, 7464: 24, 7505: 41, 17394: 41. Perrotet 1480: 38 a, 1488: 38 a, 1489: 38 a. Pételot 175: 24, 176: 24, 180: $26 \mathrm{a}, 516: 26 \mathrm{a}, 516$ bis: $26 \mathrm{a}, 526: 38 \mathrm{c}, 1568: 38 \mathrm{a}, 2527: 51,3538$ : 26 b, 3727: 46, 3728: 24, 3730: 24, 3731: 24, 3732: 24, 3733: 24, 3734: 24, 3735: 24, 3736: 26 b, 3737: 26 a, 4082: 46, 4090: 24, 4257: 38 a, 4473: 51, 4474: 51, 4523: 51, (Colani?) 4526: 12, 4529: 51, 8897: 24. Peter 7979: 44b, 16845: 44b, 19887: 44b, 24633 a: 24, 24633: 24. Philipson 10085: 15, 10183: 45. Phloenchit 246: 31, 785: 31, 1382 (BKF 17004): 27. Pichi Sermolli 1835: 44 a, 1837: 44 a, 7241: 44 a. Pierre 656: 49, 5718: 49, 5719: 27. Piggott 1442: 4, 1443: 4, 1597: 4, 1598: 4, 1762: 40, 1856: 24, 1857: 24, 2085: 24, 2086: 24, 2239: 33, 2266: 24, 2287: 24, 2289: 27. V. d. Pijl 428: 49, 469: 49, 683: 27. Plant 309: 2, 351: 2. Pleyte 54: 27, 128: 24, 530: 39. Ploem 170(?): 3. Pocs 6515/A: 44b. Poilane 1245: 27, 3788: 26 b, 3831: 27, 4003: 17, 4060: 26 b, 4139: 26 b, 4784: 24, 4877: 24, 5119: 17, 5234: 27, 5542: 24, 5593: 49, 5799: 24, 5976: 26 b, 5979: 26 b, 7134: 26 b, 7820: 24, 8013: 17, 10033: 49, 10223: 17, 10673: 17, 11277: 26 b, 13362: 27, 14176: 49, 15010: 49, 15027: 49, 15110: 49, 15871: 26 a, 16074: 26 b, 16154: 26 b, 16793: 38 c, 16909: 51, 17164: 26 a, 17242: 51, 17273: 51, 19060: 51, 21954: 26 b, 22175: 26 b, 24598: 26 b, 25482: 51, 25497: 51, 25498: 38 c, 25516: 38 c, 25551: 51, 25632: 46, 25936: 38 c, 26321: 38 a, 26711: 38 c, 26891: 17, 26921: 38 c, 28373: 26 b, 28788: 26 b, 30942: 26 b, 31453: 24, 31927: 17. Polhill \& Paulo 1673: 44 a. Polunin et al. 1975: 17, 3206: 38 a. Pope \& Muller 558: 44 a. Popta 92: 3. Posthumus 51: 24, 76: 40, 209: 3, 533: 27, 588: 4, 610: 4, 781: 4, 1483: 49, 1509: 24, 1536: 40, 1628: 24, 1664: 3, 1750: 3, 1770: 3, 1807: 3, 1808: 33, 1848: 31, 2286: 27, 2411: 31, 2413: 24, 2724: 47, 2866: 38 a, 2884: 3, 3209: 40, 3216: 3, 3366: 1, 3372: 40, 3505: 49, 3543: 31, 3555: 40, 3651: 24, 3655: 40, 3693: 3, 3700: 31, 3707: 49, 3711: 3, 3744: 40, 3796: 3, 4026: 33, 4167: 31 . Powell 36: 15. Pradham * Jhapa 6466: 38 a. Preuss 193: 44 a, 195: 44 a, 284: 24, 429: 44 a. Price 56: 26 a, 20: 46, 279: 43, 1056: 26 a, 2181: 47, 2186: 43. Price \& Evans 38: 24. Pulle 128: 18 b, 244: 18 b, 1191: 18 a, 3192: 3. Pullen 6938: 24, 7616: 27, 8126: 24, 8211A: 27. Purdom 83: 5, 89: 5, 91: 34, 97: 14. Purseglove P 5100: 27, 5245: 31, 5451: 24.-Quayle 183: 45. Quintas 30: 
24.-Raap 127: 24, 554: 24, 583: 4, 742: 31. Rachmat 1: 27, 191: 27. Rahmat Si Boeea 6306: 4, 9102: 27, 11013: 13. Rahmat Si Toroes 2071: 27. Ramos (BS) 657: 24, (BS) 972: 24, 1630: 27, (BS) 1580: 48, 1876: 24, (BS) 5552: 38 a, (BS) 5902: 47, (BS) 7519: 27, (BS) 7961: 27, (BS) 14541: 31, (BS) 14789: 47, (BS) 30259: 43, (BS) 34911: 27, (BS) 42994: 31, (BS) 80138: 24, (Philipp. Pl.) 946: 43 (Philipp. Pl.) 1157: 48. Ramos a Edaño 29348: 47, (BS) 28490: 24, (BS) 28804: 48, (BS) 29053: 24, (BS) 29329: 40, (BS) 29331: 31, (BS) 30965: 31, (BS) 31375: 43, (BS) 31467: 43, (BS) 40489: 38 a, (BS) 45083: 38 a. Ramos \& Pascasio (BS) 34365: 27, (BS) 34425: 48, (BS) 34851: 48 . Rankin 77: 44 a. Rant 536: 39, 626: 27. Rao (BSI) 17504: 51, (BSI) 17563: 31. Rau 233: 24, 310: 16, 355: 27, 409: 24. Rau \& Johns 324: 16. Rauh 7139: 41. Rawson 935: 24, 943: 2, 1281: 49, 1282: 1, 1738: 19, 2329: 1, 3027: 19, 3220: 19. Rechinger Rechinger 961: 24, 1198: 24. Reillo (BS) 16190: 27, (BS) 16204: 31, (BS) 19241: 40. Reimschüssel 33: 24. Rein 2246: 25. Reinecke 19: 24. Reksodihardjo 642: 27. Rensch 128: 33, 301: 33, 319: 40, 48: 27, 666: 40, 677: 33, 1025: 27, 1525: 3. Ribourt 105: 45. Richard 110: 24, 293: 24. Richards 5447: 49, 17414: 44 a, 18178: 44b. Riddell 10: 17. Ridley 484: 27, 2952: 4, 4347: 24, 4348: 27, 6684: 27, 6919: 24, 9829: 31, 10162: 4, 10820: 4, 14758: 24, 15922: 24. Robinson 205: 38 a, 206: 32, 1377: 44 a, 1932: 24, 1979: 39, 6260: 24. Robinson \& Boden-Kloss 89: 40, 153: 24, 154: 7, 191: 7. Robyns 6983: 38 a. Rock 349: 26 b, 1508: 26 b, 6646: 38 a, 7146: 38 a, 7161: 12, 7228: 38 a, 7253: 38 a, 7462: 17, 7490: 17, 7491: 26 b, 7499: 26 b, 7544: 38 a, 7546: 26 b, 7703: 12, 7825: 24, 7847: 24, 7881: 38 a, 11535: 38 a, 11580: 38 a, 11653: 14, 12085: 5, 12139: 38 a, 14715: 38 a. Rodatz * Klonk 142: 39. Rodgers 3044: 27, 3073: 27. Rodin 572: 24, 4382: 44 a. Roemer 315: 24. Rogers 24480: 2. Del Rosario Cordero (PNH) 96227: 40. Ross 1065: 44 a. Von Rosthorn 88: 34, 721: 26 a, 1063: 26 a, 1706: 5, 1707: 8, 1708: 51, 1709: 14, 1710: 38 a, 1711: 34, 1713: 14/46 (interm.), 1714: 34, 1717: 34, 1718: $34,1721: 51,1723: 51,1725: 38$ a, 1727: 14, 3123: 14, 7105: 26 a. Van Royen 3523: 24, 4052: 27, 4315: 18 a, 4413: 18 a, 4538: 24, 4549: 27, 4662: 24, 4811:27, 5189: 39, 5458: 39, (NGF) 16287: 18 a, (NGF) 16399: 24, (NGF) 16467: 27. Van Royen \&leumer 6164: 27, 6775: 27. Rutten 79: 24, 341: 39, 1769: 39, 2008: 39, 2024: 24.-S.A.B.E. 18: 14, 428: 5, 438: 34, 519: 14, 697: 5, 805: 38 a, 852: 5, 1110: 51, 1159: 26 a, 1429: 51, 1663: 51, 1925: 46, 1929: 26 a, 2055: 46 . SAN (SANDAKAN) 23618: 36, 84865: 24, 86730: 24. SFN (Singapore Field No.) 4844: 4, 5018: 4, 5915: 4, 9428: 4, 9951: 4, 21378: 24, 21837: 24, 22258: 24, 22572: 49, 22771: 27, 25304: 40, 30574: 27, 30575: 4. SING 15887: 24. SING 22808: 31. SING 39199: 38 a. Sacleux 605: 24. Safford 10: 24, 960: 24. Safford \& Seale 1043: 24. Saldanha \& Jarrett 16978: 38 a. Sallet (Herb. Petelot) 3538: 26 a. Salsedo 328: 24, 386: 27. Samat bin Abdullah 70: 4. Sands et al. 2129: 18 a. Sangkhachand \&imanong 1265 (BKF 36356): 4. Sangster S 125: 44 a, S 166: 44 a. Santos (BS) 31672: 38 a. Sarasin 33: 31, 94: 11 a, 269: 11 a, 384: 11 a, 408: 11 a, 409: 11 a, 724: 11 a, 1032: 24. Sarasin Sarasin 27: 47, 1181: 47, 1199: 49. Saulière 424: 38 a, 434: 38 a, 436: 24, 785: 24. Savatier 755: 45, (Pl. Jap.) 1536: 26 a, 2497: 26 a. Saves 6: 11 a. De La Savinière 62: 27. Sayers (NGF) 18059: 27, (NGF) 21897: 24. Scheffer 16488: 3. Schelpe 4067: 41, 5450: 44 a, 5601: 41. Schelpe \& Leach 6922: 41. Schiffner P 124: 31, P 178: 24, P 182: 49, P 185: 7, P 186: 1, P 237: 35. Schimper 1441: 44 a. Schindler 400: 24, 403 b: 51, 403: 26 a, 415: 6. Schlagintweit 83: 26 b. Schlechter 4133: 24, 13551: 36, 14418: 18 b, 14771: 11 a, 16377: 39, 16477: 24, 17239: 18 b, 19020: 18 b. Schlieben 1600: 44 a. Schmid 999: 38 a, 1000: 24, 1119: 19, 1139: 19. Schmidt 337: 27. Schmutz F 19: 31 57: 24, 102: 40, F 135: 3, F 139: 31, 146: 1, 165: 1, 634: 24, 956: 24, 1369A: 31, 1761: 44 a, 2129B: 31, 2129C: 1, 2230: 33, 2253: 33, 2326: 40, 2336: 40, 2422: 27, 3066: 1, 3493: 44 a, 3682: 33, 5117: 1, 5413: 35, 5511: 40, 5512: 40, 5751: 1 . Schneider 1144: 34 . Schnell 5040: 44 a. Schneller 137: 44 a, 142: 44 a. Schoch 143: 38 a. Schodde 2325: 27, 3167: 42, 3242: 42. Schodde \& Craven 4086: 24. Schoenian 99: 24. Schomburgk 21: 4. Schottmüller 79: 4, 170: 26 a, 193: 34. Schram (BW) 14965: 27. Schway-Green 203: 24. Schweicherdt 2368: 44 a, 2371: 44 a, 2403: 44 a. Schweinfurdt Riva 1576: 44 a. Schweinfurth 94: 15, 403: 15, 962: 15, 1020 : 15, 1039: 15, 2003: 44 a, 3195: 44 a. Scortechini 43: 4, 231: 40, 517: 33, 844: 24. Scott Elliot 8523: 41. Sebald 2214: 44 a. Seemann 724: 24, 2382: 24. Seidenfaden 2125: 49. Seimund 1259: 24. Seku \& Bowling GC 37092: 44 a. Sen 69/15: 28, 70/37: 12, 72/38: 24. Serre 1399: 34. Setchell 4: 24. Setchell \& Parks 25: 45, 15149: 24. Shah 73: 4, 246: 27, 252: 27, 380: 4. Shah Noor MS 560: 27. Shearer 7: 26 a, 282: 46, 287: 6. Shimada 106: 25, 107: 37, 138: 26 a. Shimizu Fukuoka M 13216: 4. Shimizu Hutoh T 10207: 38 c, T 10209: 49. Shimizu \& Stone T 14353: 33. Shimizu et al. T 7743: 49. Shiota 1419: 25. Shrutra 1782: 24. Sibat ak Luang (SFN?) 21837: 24. Sidek Bin Kiah SK 413: 4. Sidney 57: 24. Sieber 94: 11 a, 95: 42. Siebold 237: 26 a, 238: 26 a, 239: 26 a, 
240: 20. Siebold * Burger 234: 20. Sillitoe 115: 44 a. Silvestri 36: 5, 3266: 34, 3424: 5. Sim TMH 644 c: 2 . Simada 4939 B: 5. Simons 275: 23, 284: 38 a. Sin Whang 438: 46. Sinclair 10000: 49, (SF) 38469: 31. Sinclair \& Edaño 9717: 38 a. Sing 34000: 24. Sita 550: 24, 691: 24, 692: 24, 728: 24. Sledge 947: 32, 1141: 24. Slooff 32: 24. Van Slooten 160: 3, 239: 24, 520: 31, 668: 24, 770: 27. Van Slooten \& Backer 35022: 24. A.C. Smith 98: 24, 1070: 24, 1172: 24, 5384: 45, 6052: 45, 6300: 24, 8110: 24, 9518: 24. Eryl Smith 611: 31, 1148: 38 c, 1150: 38 a, 1153: 24, 1155: 49, 1156: 26 a, 1287: 26 a, 1411: 38 c, 1519: 24, 1520: 24, 1521: 24, 1522: 24, 1524: 24, 1526: 38 c, 1527: 38 c, 1528: 38 c, 1529: 26 b, 1530: 26 b, 1531: 26 a, 1532: 27, 1577: 38 a, 2004 (Kerr 7200): 24, 2006: 4, 2009: 31, 2011: 24, 2012: 33, 2013: 33, 2014: 49, 2143 (Kerr 8407): 49, 2146 (Kerr 8646): 38 c, 2156 (Kerr 8707): 26 b, 2608: 26 b, 2863: 26 b, 2588: 31, 2589 (coll. Put?): 33, 2606 (Kerr 14655): 33, 2609: 40, 2804 (Kerr 11881): 49, 2860: 31, 2862: 31, 2865: 49. H. Smith 15: 34, 27 : 38 a, 1721: 38 a, 1722: 34, 1898: 26 a 1984: 14, 4610: 38 a, 4930: 14, 6743: 34, 7755: 38 a, 13012: 14, 13319: 26 a, 13335: 34, 13336: 38 a, 13377: 34. H. M. Smith 11: 45, 228: 24, 247: 24, 310 : 26 b, 377: 24, 437: 24, 475: 38 c, 388: 27, 587: 38 c. J. J. Smith 62: 27, 68: 24. L. S. Smith 10803: 11 b. Smith \& Pendley 10011: 27. Smith * Tindale P 7436: 11 a. Smitinand 203 (Flora of Thailand 9727): 27, 993: 24, 1033: 40, 1244 (Flora of Thailand 7936): 27, 6036 (BKF 24321): 40, 7165: 27, 8725: 38 a, 9699: 38 c, 10913 (BKF 46625): 27, 10914 (BKF 46603): 4, (BKF) 24341: 26 b. Smitinand et al. 1047: 38 a, 1256: 49. Snowden 98: 44 a, 787: 41, 788: 44 a, 789: 44 a. Sörensen et al. 4098: 38 a. Sohmer Was 10469: 19. Sohmer et al. (LAE) 75402: 27. Soulie 577: 14, 1610: 26 b, 1622: 38 a, 1673: 38 a, 1691: 14. Spare 1605 (SING 36008): 31. Spruce 5240: 24. Srivaslava et al. (LWG) 88772: 24. St. John 14455: 45, 16505: 45, 17182: 45. St. John \& Fosberg 14148: 45, 15154: 45, 158282: 45, 16556: 45. St John \& Maireau 15354: 45. Stainton et al. 2429: 12, 5259: 28, 5260: 12, 5417: 17, 7706: 17. Staub 10902: 24. Staudt 479: 44 a, 775: 24. Van Steenis 546: 27, 852: 24, 976: 24, 999: 4, 1158: 27, 2412: 40, 2491: 3, 3295: 24, 3884: 3, 5896: 1, 6094: 13, 7721: 27, 7726: 31, 8010: 3, 8727: 13, 8832: 49, 9297: 49, 10365: 27, 11097: 40. Stephenson 122: 15, 626: 11 b. Stevens \& Lelean (LAE) 58582: 27. Steward 2906: 34, 4649: 46, 9753: 34, 9781 : 34, 14542: 38 a. Steward \& Cheo 99: 51, 227: 26 a, 373: 38 a, 432: 5, 483: 51, 992: 26 a. Steward et al. 56: 46, 409: 26 a, 422: 46, 1009: 46. Stewart 12350: 17, 16022: 17. Stewart \& Stewart 2077: 17. Stewart \& Nasir 23751: 38 a. Stocker 756: 27. Stolz 96: 50, 891: 50, 1507: 44 a. Stone 1387: 24, 1671: 24, 2316: 27, 3786: 24, 6313: 4, 6573: 49, 9729 (LAE 53029): 27. Stone et al. (SAN) 86730: 24. Stone Sidek 12474: 27. Stone Streimann 10397: 24. Strachey Winterbottom 1: 38 a, 2: 17, 3: 12, 4: 24. Strange 1104: 11 a. Streimann \& Kairo (LAE) 51540: 27. Streimann * Kairo (NGF) 47714: 24. Streimann Katik (NGF) 28603: 24, (NGF) 34101: 24, (NGF) 34103: 24. Strey 8583: 2. Strugnell 13395: 4. Stuhlmann 8926: 24, 8997: 24. Sulit (PNH) 12642: 27. Sulit et al. (PNH) 4521: 24. Surbeck 41: 13, 42: 13, 572: 33, 582: 4, 585: 4, 623: 24, 666: 13, 775 (1244?): 27, 779: 49, 790: 33, 783: 24, 784: 24, 785: 24, 806: 24, 809: 1, 813: 13, 915: 1, 971 : 24, 972: 24, 1000: 24, 1012: 33, 1109: 24, 1245: 27, 1246: 24. Suzuki 5: 26 a. Swartz 2685: 24, 2846: 3. Swinkoe 6/70: 24. Swynnerton 425: 41, 425 a: 41 . Sykes 267/K: 15, 1434/CI: 45. Symington 22765: 24, 22929: 4. -Taam 239: 26 a, 429: 26 a, 563: 26 a, 1125: 24, 1383: 26 a, 1388: 24, 2072: 26 a. Tagawa 109: 46, 372: 26 a, 372: 38 a, 601: 26 a, 632: 26 a, 1046: 46, 1791: 24, 1875: 46, 2413: 26 a, 2904: 24, 3023: 38 a, 3305: 46, 3718: 38 a, 3730: 46, 3756: 46, 3763: 26 a, 4339: 26 a, 4821: 25, 5225: 26 a, 5768: 26 a, 5853: 20, 6609: 25, 6906: 26 a, 7322: 25, 8544: 26 a, (Pl. Formos.) 3728: 38 a. Tagawa \& Iwatsuki 716: 26 a, 1522: 25, 2550: 26 a, 4916: 26 a. Tagawa Yamada T 106: 24, T 226: 27. Tagawa et al. T 196: 31, T 379: 24, T 632: 26 b, T 1255: 38 c, T 1256: 49, T 1323: 26 b, T 2260: 24, T 4079: 49, T 4079: 12, T 4513: 31, T 4670: 26 b, T 4779: 26 b, T 5238: 40, T 6819 bis: 40, T 7510: 12, T 8582: 49, T 9221: 38 a, T 9770: 24, T 9972: 26 b. Tak 17427: 26 b. Takamatsu 1413: 24. Takeuchi 1421: 25. Tamura Koyama 23138: 38 a. Tanaka 10437: 46, 30989: 20 . Tanaka Shimada 13496: 26 a. Tang 1173: 26 a. Taquet 2480: 25, 2481: 25, 2482: 26 a, 2489: 20, 2490: 20, 2491: 20, 2492: 20, 3653: 26 a, 3657: 25, 3826: 26 a, 3827: 26 a, 3828: 20, 3829: 20, 3833: 25, 3834: 25, 3992: 25, 4780: 25, 4781: 25, 4916: 26 a, (Rosenst. Fil. Kor.) 66: 20, 68: 25. Telford 5317: 11 a, 5714: 42. Ten 170: 38 a. Teng 90059: 38 a, 90276: 46. Teona (BSIP) 6289: 24. Teysmann 11: 27, 40: 4, 43: 4, 45: 4, 75: 31, 5335: 27, 8573: 27, 10373: 27, 10679: 24, 16420 p.p.: 33. Theusz 32: 44 a. Thomas 2314: 44 a. Thompson 73: 44 a. Thomson 79: 4, 703: 39, 722: 12. Thorel 2478: 49. Thorenaar 282: 49. Thorey 50: 42, 51: 42. Thorold CP 9: 24. Thulin 1686: 44 a. Thwaites (CP) 993: 9, (CP) 998: 19, 1154: 19, (CP) 1294: 32, (CP) 3104: 38 a. Tilden 348: 45, 492: 45. Tindale (NSW) P 9313: 15. Tindale 
\& Constable P 2034: 42. Ting \& Shih 133: 26 a, 262: 26 a. Tisserant 124: 44 a, 2177: 44 a, 2471: 44 a. Titi Nagari 13: 27. Togashi 2131: 26 b, (NSM) 707: 26 a, (TNS) 1362: 20, (TNS) 1366: 25, (Pterid. of Japan) 447: 26 a, (Pterid. of Japan) 593: 25. Toppin 4410: 31, 6330: 23, 6351: 12, 6364: 38 a. Topping 268: 24, 293: 38 a, 343: 24, 480: 40, 548: 24, 749: 24, 869: 38 a, 905: 24, 990: 24, 1081: 38 a, 1089: 24, 1090: 24, 1151: 24, 1157: 38 a, 1230: 27, 1325: 27, 1376: 24, 1508: 40, 1606: 24, 1809: 22. Torre 4189 A: 24, 4577: 41. Torre \&ereira 12589: 41. Tothill 948: 24. Toxopeus 637: 24. Travancore Univ. 538: 38 a. Treutler 937: 17. Trotter 425: 17, $968: 38$ a. Tsai 5234: 51, 51126: 51, 51130: 26 a, 51203: 34, 51335: 46, 51491: 46, 51694: 38 a, 51883: 51, 52057: 34, 52218: 26 a, 52338: 46, 52371: 51, 52579: 51, 53066: 38 a, 53252: 51, 53654: 38 a, 54297: 26 b, 55174: 26 a, 55275: 26 a, 55278: 26 a, 55348: 26 a, 55355: 26 a, 55443: 38 a, 55444: 26 a, 56369: 38 a, 57140: 38 a, 57159: 14, 57283: 38 a, 57518: 38 a, 57568: 14, 57874: 14, 59579: 14, 59924: 14, 59928: 14, 59986: 14, 60124: 26 a, 60217: 26 a, 60344: 26 a, 60659: 38 a, 60665: 26 a, 60773: 38 a, 60907: 38 a, 61757: 51, 62545: 38 a, 62584: 46, 63012: 38 a. Tsang 46: 24, 217 (LU 16706): 26 a, 255: 24, 416: 24, 678 (LU 17427): 26 b, 713: 24, 861: 38 c 16535: 24, 20205: 26 a, 20710: 26 a, 20896: 6 20908: 46, 21135: 26 a, 21356: 6 21447 A: 6 21904: 38 c, 22200: 26 a, 22269: 26 a, 22413: 38 c, 22499: 26 a, 22831: 26 a, 22888: 26 a, 23483: 26 a, 23648: 6 24911: 26 a, 25790: 26 a, 25985: 26 a, 26077: 6 26119: 26 a, 26736: 24, 27287: 24, 27394: 26 b, 27401: 24, 27772: 6 27732: 26 a, 28366: 46, 28403: 26 a, 28849: 26 a, 29303: 38 c, 29307: 24, 29658: 26 a, 29676: 26 a, 30129: 24, 30143: 24, 30342: 24, 30569: 24. Tsang \& Fung 442: 24, 674 (LU 18208): 26 b. Tsang * Wong (CCC 14687) 2826: 26 a. Tsang et al. 17715: 38 c. Tschonoski 12: 25, 17: 20. Tsiang 1247: 26 a, 4523: 51, 4998: 26 a, 5049: 46, 5084: 46, 5099: 51, 6836: 5, 6843: 5, 6851: 6, 7083: 38 a, 7626: 26 a, 8401: 5, 9201: 38 c, 9202: 38 c, 9249: 51, 9485: 51. Tsui 42: 26 a, 55: 6, 61: 24, 798: 26 a. Turnau 808: 27, 809: 24, 900: 4. Tutcher (Hongkong herb.) 10802: 26 a. Tweedie 1830: 44 a, 2853: 44 a.-D'Urville 48: 45. U. S. S. Pac. Expl. Exp. 1: 15, 42, 3: 45 15, 4: 24, 6: 27. Unesco Limestone exp. 137: 24, 161: 24, 243: 33, 249: 31, 328: 24. Univ. San Carlos 58: 27, 688 A: 47, 695 A: 47, 750: 43, 751: 27, 860: 24. Uno 23891: 34.-Vanoverbergh 1571: 38 a, 1667: 38 a. Varekamp 62: 15. Vaughan 3290: 24. Vaupel 106: 24. Veldkamp 6161: 24, 7901: 4. Veldkamp \& Stevens 5509: 18 a. Vera Santos 4224: 27, 5169: 24, 5386: 38 a. Verdcourt 148: 44b, 149: 24. Verdon 106: 11 a. Verheijen 463: 31, 2241: 27, 3514 a: 24, 3703: 27. Verreaux 437: 42, 527: 11 a, 528: 42, 927: 11 b. Versteeg 1254: 18 b, 1532: 18 b, 1963: 27. Versteegh (BW) 10274: 39, (BW) 12544: 18 a. Versuchsanstalt Kamerun 445: 24. Vieillard 91: 15, 101: 24, 180: 26 a, 467: 51, 1589: 24, 1590: 11 a, 1591: 11 a. Viguier * Humbert 1122: 41. Vink (NGF) 12051: 27, (NGF) 12081: 24. Virot 1135: 11 a, 1664 bis: 11 a. De Vogel 2927: 40, 3090: 27, 3312: 24, 3680: 18 a, 4129: 18 a, 4252: 24. De Voogd 197: 3, 2024: 24. De Vriese 20: 3, 21(?): 49, 22: 47, 24: 49, 503: 24, 507: 1, 508: 27. De Vriese *eysmann 21: 24, 23: 47 171: 1.-Waas 2068: 19. Wagner 3232: 24, 3293: 24, 3585: 24, 3880: 24. Wakefield 1461: 24, 1462: 24, 1464: 39. Walker 219: 4, T 3217: 24, 4286: 15, 5119: 15, 5234: 15. T 13045: 24, T 13155: 24, T 13164: 24, T 13548: 24, T 13550: 24. Walker et al. 6 490: 26 a. Wallace 6: 27, 5918: 24. Wallich 72: 27, 76: 38 a, 85(?): 12, 121: 38 a, 265: 12, 266: 38 a, 267: 24, 270: 24, 272: 4. Wallis 44: 38 a. Walter Walter 51: 15, 2396: 42, 2428: 42. C. Wang 33397: 27. C. W. Wang 476: 24, 1993: 14, 33428: 24, 35082: 24, 35338: 38 c, 35375: 26 b, 35409: 38 c, 36110: 24, 40505: 46, 41132: 5, 62536: 38 a, 62593: 34, 62594: 38 a, 62930: 38 a, 63009: 38 a, 63032: 38 a, 63590: 14, 64110: 14, 65171: 14, 66315: 14, 66951: 26 b, 67112: 26 b, 67467: 26 b, 67587: 51, 68234: 14, 68670: 14, 69145: 14, 69233: 14, 70448: 14, 71912: 38 a, 72889: 28, 73182: 24, 73556: 24, 73616: 26 b, 73626: 26 a, 73801: 26 a, 73818: 26 b, 73862: 24, 73938: 26 b, 74123: 38 a, 74393: 26 a, 74472: 38 a, 74740: 24, 74995: 24, 76173: 24, 76951: 24, 77239: 26 b, 77254: 26 a, 77334: 38 a, 78407: 26 b, 78534: 26 b, 78734: 38 c, 79605: 24, 79881: 24. F. T. Wang 20389: 35, 21881: 14. T. P. Wang 6570: 14. Y. K. Wang 518: 26 a. Warburg 3449: 3, 3480: 3, 9526: 26 a, 9556: 26 a, 11329(?): 3, 16521: 47, 16565: 47, 17230: 1, 17353: 42, 19394: 15. Warnecke 316: 44b, 317: 24, 328: 44b. Watt 6005: 38 b, 6131: 28, 6131: 38 a, 6132: 38 b, 6665: 24, 7475: 31. Watts P 285: 11 a. Wawra 1441: 25. Weber 13: 24, 1170: 27, 1180: 24, 1181: 43, 1185: 31, 1534: 31, 1562: 31 . Weis 3846: 47. Weiss 80: 3, 401: 26 a. Welwitsch 152: 44 a. Wenger 69: 12, 70: 17, 74: 28, 145: 28, 176: 24, 177: 31, 178: 24, 179: 24. Wenzel 543: 27, 2741: 24, 2808: 27. Whistler 2821: 24, 3941: 24. White 2709: 50, 3617: 44 a. White Brass 128: 11 b. Whitford 312: 40, (BS?) 570: 24, 1577: 27. Whitmore (BSIP) 4389: 27. Whitmore \& Grubb (BSIP) 2172: 27. Whitmore \& Womersley (BSIP) 830: 27. Wiakabu \& Yefle (LAE) 70326: 27. Wight 21: 38 a, 32: 21, 56: 31, 3163: 24, 3164: 
38 a. Wild 1106: 44 a, 2007: 44 a, 2119: 41, 4500: 41. J.J.F.E. de Wilde 1247: 39, 5242: 44 a, 5805: 44 a. W.J.J.O. de Wilde c.s. 8889: 44 a, 8915: 44 a, 10105: 44 a, 10376: 44 a, 11304: 44 a, 12126: 33, 12236: 24, 12464: 1, 12526: 24, 12527: 33, 12709: 1, 13559: 24, 13561: 1, 14020: 13, 14577: 33, 14645: 24, 15120: 7, 15573: 27, 15653: 33, 15809: 13, 18562: 13, 18855: 35 . Wilder 1114: 45. Wilford 29: 26 a, 30: 24, 595: 12, (CP) 665: 20. Wilhelm 12: 15. Williams 682: 24, 1476: 40, 1495: 24, 1496: 24, 1514: 38 a, 2255: 24, 2256: 24, 2259: 31, 2260: 31, 2830: 24. Wilson 309: 46, 406: 5, 587: 11 a, 2614: 51, 2629: 14, 5323: 14/46 (interm.), 5324 a: 26 a, 5327: 51, 5328: 38 a, 5329: 38 a. C. L. Wilson 523: 42. Winckel 151 b: 3, 1287 B: 27, 1482 B: 24, 1881 B: 24. Winit 1010: 49. Winkler 251 a: 44 a, 2105: 24, 2681: 31, 2736: 36, 3468: 27, (Rosenst. Fil. Sum.) 66 a: 13, 66: 13, 196: 24. Wirawan 376: 49. Wiriadinata 696: 27. Wirosari 3425: 27. Wisse 67: 27, 79: 47, 399: 49, 623: 40. De Wit 207: 24. De Witte 78: 44 a, 3850: 44 a. Womersley 3404: 27, 3405: 24, 3406: 27, 6057: 18 a, (NGF) 11722: 18 a, (NGF) 37106: 39, (NGF) 43636: 24. Womersley Gray (NGF) 8618: 24. Womersley et al. 4793: 18 a, 7985: 27. Womersley \& Millar (NGF) 7618: 18 a, (NGF) 8303: 18 a. Womersley \& Thorne (NGF) 12809: 18 a. Wood 2011: 36. Wray 68: 40, 807: 4, 1701: 24, 3784: 4. Wright \& Ismawi S 32554: 4. Wyatt-Smith 71142: 24, 71335: 4.-Yapp 544: 31. Yates 82: 13, 715: 13, 1173: 1, 1238: 4, 1577: 13, 1710: 27, 2503: 13, 2574: 4, 3039: 24. Yongsok 8003: 26 a. Yoshida 2304: 24, 2442: 24. Young 47: 27. Yü 8237: 14, 10455: 38 a, 19960: 51, 20188: 26 a, 20530: 38 b, 20545: 26 b, 20861: 38 b, 23009: 38 a. Yuncker 9055: 24, 15497: 24, 16038: 24, 16195: 24.-Zahn 445: 24. Zahn 445: 44 a. Van Zanten 1161: 15. Zimmermann 2032: 28. Zippelius 32: 49, 33: 49, 263(?): 3. Zogg * Gassner 4196: 26 a, 4311: 26 a, 4332: 26 a, 4341: 37, 4376: 26 a, 4497: 24, 4553: 24, 4569: 26 a. Zollinger 18: 26 a, 97(?): 3, 128: 3, 33, 225: 24, 228: 3, 27, 257(?): 3, 309:27, 554: 31, 781: 24, 1225: 24, 1368: 24, 1368 a: $24,1381: 31,1505: 24,3,1747: 33,1984: 1,2015: 49,2022: 3,40,2022$ a: 40, 2068: 24, 2116: 24, 2223: 40, 2387: 27, 3, 3037: 4, 3098: 4, 3175: 24, 3177: 40, 3183: 33, 3, 3747: 40, 3761: 33. 


\section{INDEX}

Accepted names in roman type, synonyms in italic. The numbers refer to the numbers of the accepted taxa. Pyrrosia: pp. 149-257; dubious names (D): pp. 258-260, excluded names (E): pp. 260-261.

\section{Acrostichum bicolor 27}

\section{dubium 24}

hastatum 20

lanceolatum 24

lingua 26 a

longifolium 27

nummulariifolium 31

nummularifolium var. subpeltatum 31

obovatum 31

Anthrophyum niphoboloides 40

Apalophlebia: see Pyrrosia

costata 12

flocculosa 17

splendens 48

venosa 49

Candollea: see Pyrrosia

lanceolata 24

longifolia 27

Craspedaria pertusa 24

rupestris 42

serpens 45

Crypsinus stenophyllus E 7

Cyclophorus: see Pyrrosia

sect. Niphobolus: see Pyrrosia

sect. Niphopsis: see Pyrrosia

abbreviatus 1

acrocarpus 38 a

acrostichoides 27

acrostichoides fo. camosa 27

acrostichoides var. backeri 27

acrostichoides var. fissum 27

acrostichoides var. gracilis 27

adnascens 24

adnascens fo. dichotoma 24

adnascens fo. pernuda 24

adnascens var. minor 24

africanus 2

aglaophyllus 39

albicans 3

alcicomu 38 a

americanus $\mathbf{E} 1$

anetioides D 1 angustatus 4

annamensis 17

argyrolepis 43

assimilis 6

assimilis fo. lobata 6

assimilis var. mollifrons 6

asterosorus 7

asterosorus fo. subfurfuracea 7

beddomeanus 12

blepharolepis 45

blumeanus 3

bodinieri 26 a

bonii 51

boothii 8

bormeensis 40

brassii 18 a

brevipes 33

calvatus 51

ceylanicus 9

christii 10

cinnamomeus 27

confluens 11 a

confluens fo. lobatus 11 a

cornutus 24

cuneatus 42

davidii 38 a

dielsii $11 \mathrm{~b}$

dimorphus 24

dispar $18 \mathrm{~b}$

distichocarpus 13

drakeanus 14

drakeanus fo. maxima ?46

eberhardtii 26 b.

elaphoglossoides 3

esquirollii 51

flocciger 3

flocculosus 17

foveolatus 18 a

gardneri 19

giesenhageni 24

glaber 24

gralla 38 a 
grandis 13

grandissimus 46

hastatus 20

heteractis $26 \mathrm{~b}$.

heteractis var. minor $26 \mathrm{~b}$.

heterophyllus 24

inaequalis 46

induratus 27

intermedius $11 \mathrm{~b}$

laevis 23

lanceolatus 24

lancifolius 3

lanuginosus 40

lauterbachii $18 \mathrm{~b}$

liebuschii $4 \mathbf{4 b}$

linearifolius 25

lingua 26 a

lingua var. angustifrons 26 a

lingua var. attenuata 26 a

longifolius Desv. 27

longifolius C. Chr. E 5

macrocarpus 45

macropodus 27

madagascariensis 41

malacophyllus 38 a

martini 26 a

matsudai D 6

mechowii 44 a

micrester 4

mollis 33

nigropunctatus 3

nudus 24

nummulariifolius 31

nummularifolius var. obovatus 31

nummularifolius var. rufus 31

oblanceolatus 41

obovatus 31

pachydermus 24

pannosus 32

pekinensis 38 a

pekinensis fo. minor 38 a

penangianus 33

petiolosus 34

polycarpus E 11

polydactylus 37

porosus 38 a

princeps 39

pseudo-lingua 47

pustulosus 24

rasamalae $\mathbf{4 0}$

rasamalae fo. minor 40

rhodesianus 41

rhomboidalis 17

rupestris 42

samarensis 43 sarasinorum 47

schimperianus 44 a

scolopendrium 27

scytopteris 11 a

serpens 45

serpens var. normalis 45

serpens var. rupestris 42

sheareri fo. maxima 46

sheareri 46

spicatus 11 a

spissus 24

spissus var. continentalis 24

splendens 48

stellatus 24

stenophyllus $38 \mathrm{c}$

sticticus 38 a

stigmosus 49

stolzii 50

subfissus 38 a

subfurfuraceus 51

subvelutinus 8

taiwanensis 26 a

tonkinensis $38 \mathrm{~b}$

transmorrisonensis D 11

tricuspis 20

valleculosus 27

varius var. flabelliformis 24

varius 24

vittarioides Christ 38 b

vittarioides Presl 24

warburgii 47

winkleri 13

xiphioides 38 a

Drymoglossum: see Pyrrosia

carnosum 11 a

cunninghamii 11 a

martinicense 24

Drynaria angustata 4

macrosora 45

Galeoglossa: see Pyrrosia

nummulariifolia 31

obovata 31

rotundifolia 31

Gymnopteris lanceolata 24

nummularifolium 31

Gyrosorium: see Pyrrosia

africanum 2

angustatum 19

fissum 27

samarense 43

Lepisorus thunbergianus E 4 spec. E 2, E 12

Microgramma lycopodioides E 6 piloselloides E 3, E 9

vaccinifolia E 13 
Microsorum punctatum E 10

Neoniphopsis: see Pyrrosia linearifolia 25

Niphidium americanum E 1 longifolium E 1, E 5

Niphobolus: see Pyrrosia

* Caespitosae: see Pyrrosia

* Repentes: see Pyrrosia

abbreviatus 1

acrocarpus 38 a

acrostichoides Presl 11 a acrostichoides J. Sm. 47

acrostichoides Bedd. 27

adnascens 24

adnascens var. spissum 24

adnascens var. varius 24

africanus var. major 2

africanus var. minor 2

africanus 2

albicans 3

americanus E 1

anetioides D 1

angustatus 4

annamensis 17

antillarum E 3

assimilis 6

beddomeanus 12

beddomeanus fo. fallax 12

bicolor 45

blumeanus 3

bonii 51

boothii 8

calvatus 51

carnosus 24

caudatus 24

ceylanicus 9

chamissonianus 24

christii 10

confluens 11 a

costatus 12

cuneatus 42

davidii 38 a

detergibilis 17

distichocarpus 13

drakeanus 14

drakeanus fo. elongata 14

elongatus 24

fissus 27

fissus var. stenophyllus $38 \mathrm{c}$

flocciger 3

flocciger var. loriformis 3

flocculosus 17

gardneri 19

giesenhageni 24

glaber 24

gralla 38 a hastatus 20

heteractis $26 \mathrm{~b}$

heterophyllus 24

inaequalis 46

koenigii 24

laevis 23

lanceolatus 24

lanuginosus 40

latus D 12

lauterbachii 18 b

liebuschii $44 \mathrm{~b}$

linearifolius 25

linearis E 4

lingua 26 a

lingulatus D 5

longifolius 27

lycopodioides E 6

macrocarpus 45

mannii 28

martini 26 a

mechowii 44 a

mollis 33

neglectus $\mathbf{E} 7$

nudus 24

nummulariifolius 31

obovatus 31

pannosus 32

penangianus 33

percussus E 8

pertusus 24

petiolosa 34

piloselloides E 9

polycarpus E 10

polydactylon 37

porosus 38 a

princeps 39

puberulus 27

rasamalae 40

rotundifolia 31

rupestris 42

samarensis 43

sarasinorum 47

schimperianus 44 a

scolopendrium 27

scytopteris 11 a

serpens 45

sesquipedalis $\mathbf{E} 12$

sheareri 46

smithianus 47

spathulifer 24

sphaerocephalus 4

sphaerostichus 47

spissus 24

spissus var. continentalis 24

splendens 48

stenophyllus $38 \mathrm{c}$ 
sticticus 38 a

sticticus var. major 38 a

stigmosus 49

stolzii 50

subfurfuraceus 51

subvelutinus 8

tener 24

tonkinensis 38 b

tricholepis 45

tricuspis 20

vaccinifolius $\mathrm{E} 13$

varius 24

venosus 49

vittarioides 24

warburgii 47

xiphioides 38 a

Niphopsis: see Pyrrosia angustata 4

Phymatodes sphacrocephala 4

Pleopeltis angustata 4 glabra 11 a

macrosora 45

percussa $E 8$

Polycampium: see Pyrrosia hastatum 20

lingua 26 a

penangianum 33

Polypodium sect. Niphobolus: see Pyrrosia subg. Niphobolus: see Pyrrosia abbreviatum 1

acrostichoides 27

adnascens 24

africanum 2

albicans 3

americanum E 1

angustatum 4

angustatum var. depauperata E 2

assimile 6

asterosorum 7

bicolor 45

boothii 8

breve 23

calvatum 51

carnosum 24

carnosum var. elongatum 24

caudatum 24

confluens 11 a

confluens var. Lobatum 11 a

coriaceum 4

costatum 12

davidii 38 a

detergibile 17

distichocarpum 13

drakeanum 14

dubium 24 eleagnifolium 15

fissum var. floccigerum 3

floccigerum 3

floccigerum var. latifolium 3

floccigerum var. loriforme 3

flocculosum 17

gardneri 19

glabrum 11 a

heteractis $26 \mathrm{~b}$.

jaintense 23

koenigii 24

laeve 23

linearifolium 25

lingua 26 a

macropodum 27

magnifolium D 13

molle 33

mollissimum 38 a

nitens 48

nummulariaefolium var. obovatum 31

nummulariifolium 31

obovatum 31

pachydermum 24

pannosum 32

penangianum 33

pertusum 24

petiolosum 34

polydactylon 37

porosum 38 a

princeps 39

rasamalae 40

rupestre 42

samarense 43

schimperianum 44 a

serpens 45

sheareri 46

sphacrocephalum 4

sphaerosticha 47

spissum 24

splendens 48

sticticum 38 a

stigmosum 49

stoloniferum 45

subfurfuraceum 51

taiwanense 26 a

tomentosum 17

tricholepis 45

tricuspe 20

varium 24

vittarioides 24

Pteropsis: see Pyrrosia

martinicense 24

Pyrrosia p. 139

ser. costatae: see Pyrrosia

sect. Dichlamys: see Pyrrosia

ser. drakeanae: see Pyrrosia 
ser. Heteractides: see Pyrrosia subg. Niphopsis: see Pyrrosia abbreviata 1

acrostichoides 27

adnascens 24

africana 2

albicans 3

angustata 4

angustissima 5

assimilis 6

assimilis fo. lobata 6

assimilis var. longissima 6

asterosora 7

beddomeana 12

bicolor 45

blepharolepis 45

bonii 51

boothii 8

borneensis 40

brassii 18 a

calvata 51

caudata 24

caudifrons 26 a

chinensis 49

christii 10

coccideisquamata 27

confluens 11

confluens ssp. scytopteris 11 a

confluens var. confluens 11 a

confluens var. dielsii $11 \mathrm{~b}$

cornuta 24

costata 12

davidii 38 a

dielsii $11 \mathrm{~b}$

dimorpha 24

dispar $18 \mathrm{~b}$

distichocarpa 13

drakeana 14

eberhardti 26 b.

eleagnifolia 15

fallax 16

fengiana D 2

fissa 27

floccigera 3

flocculosa 17

foveolata 18

foveolata var. foveolata 18 a

foveolata var. lauterbachii $18 \mathrm{~b}$

gardneri 19

gralla 38 a

grandissima 46

hastata 20

heteractis var. minor $26 \mathrm{~b}$.

heteractis 26 b.

heterophylla 21

intermedia $11 \mathrm{~b}$ jaintensis 23

kinabaluensis 22

laevis 23

lanceolata 24

lanuginosa 40

latifolia D 3

lauterbachii 18 b

liebuschii 44 b

linearifolia 25

linearifolia var. heterolepis 25

linearis D 4

lingua 26

lingua var. heteractis $26 \mathrm{~b}$.

lingua var. lingua 26 a

longifolia 27

macrocarpa 45

macropoda 27

madagascariensis 41

mannii 28

martini 26 a

matsudai D 6

mechowii 44 a

medogensis D 7

micraster 4

mollis 33

mollis fo. alcicornu 38 a

mollis var. mollissima 38 a

mollis fo. rhomboidalis 17

nanchuanensis 46

nayariana 38 a

niphoboloides 29

nipponica D 8

novo-guineae 30

nuda 24

nudicaulis 38 a

nummulariifolia 31

nummulariifolia var. rufa 31

oblanceolata 41

oblonga $26 \mathrm{~b}$.

obovata 31

pachyderma 24

pannosa 32

pekinensis 38 a

penangiana 33

petiolosa 34

philippinensis 43

piloselloides 35

platyphylla 36

polydactyla 37

porosa 38

porosa var. porosa 38 a

porosa var. stenophylla $38 \mathrm{c}$

porosa var. tonkinensis $38 \mathrm{~b}$

princeps 39

pseudocalvata 51

pseudopolydactylis 37 
rasamalae 40

rhodesiana 41

rhomboidala 17

rupestris 42

samarensis 43

schimperiana 44

schimperiana var. liebuschii $44 \mathrm{~b}$

schimperiana var. mechowii 44 a

schimperiana var. schimperiana 44 a

scolopendrina D 9

serpens 45

sheareri 46

similis D 10

sphaerosticha 47

splendens 48

stellata 24

stenophylla 38 c

stictica 38 a

stigmosa 49

stolzii 50 subfissa 38 a

subfurfuracea 51

subtruncata 51

subvelutina 8

tibetica $38 \mathrm{c}$

tibetica var. angustata $38 \mathrm{c}$

tonkinensis $38 \mathrm{~b}$

transmorrisonensis D 11

tricholepis 45

tricuspis $\mathbf{2 0}$

varia 24

Saxiglossum: see Pyrrosia

Scytopteris: see Pyrrosia acrostichoides 11 a

acrostichoides var. brevipes 11 a

Sphacrostichum: see Pyrrosia

abbreviatum 1

acrostichoides 47

Taenitis niphoboloides T. Moore 40 niphoboloides Luerss. 29 